Portland State University

PDXScholar

$11-30-2020$

\title{
Aryne-Guided C-H Functionalization of Benzenoid Rings Using Diaryliodonium Salts
}

Aleksandra Nilova

Portland State University

Follow this and additional works at: https://pdxscholar.library.pdx.edu/open_access_etds

Part of the Organic Chemistry Commons

Let us know how access to this document benefits you.

\section{Recommended Citation}

Nilova, Aleksandra, "Aryne-Guided C-H Functionalization of Benzenoid Rings Using Diaryliodonium Salts" (2020). Dissertations and Theses. Paper 5602.

https://doi.org/10.15760/etd.7474

This Dissertation is brought to you for free and open access. It has been accepted for inclusion in Dissertations and Theses by an authorized administrator of PDXScholar. Please contact us if we can make this document more accessible: pdxscholar@pdx.edu. 
Aryne-Guided C-H Functionalization of Benzenoid Rings Using Diaryliodonium Salts

by

Aleksandra Nilova

A dissertation submitted in partial fulfillment of the requirements for the degree of

Doctor of Philosophy

in

Chemistry

\section{Dissertation Committee: \\ David R. Stuart, Chair \\ Robert M. Strongin \\ Andrea M. Goforth \\ Kenneth M. Stedman}

Portland State University

2020 
(C) 2020 Aleksandra Nilova 
Abstract

The benzenoid core is a frequent and irreplaceable component of biologically active molecules. Structure function relationship of these compounds has been broadly analyzed and presented in numerous literature reports. Herein, we augmented existing knowledge by a broad analysis of the benzenoid substitution patterns in small molecule active pharmaceutical ingredients approved by the FDA. Our findings reveal a strong correlation that the most represented substitution patterns are those achieved via $S_{E} A r$. Despite the rapid development of methods to functionalize benzenoid rings, the lack of synthetic methodologies to access sterically and electronically unfavorable positions is highlighted. We sought to establish a protocol to fulfill the synthetic gap to inaccessible benzenoids. The realization of this goal was achieved through aryne enabled $\mathrm{C}-\mathrm{H}$ functionalization.

Disubstituted aryl(mesityl)iodonium tosylates were demonstrated to undergo aryne formation upon ortho-deprotonation under basic conditions. Functionalization of these intermediates with a broad scope of arynophiles resulted in a variety of sterically congested tetra-substituted benzenoids. The practicality of the established protocol was supported by a successful performance of a gram scale reaction. The compatibility with halogen substituents on the aryne precursor provided an opportunity for sequential functionalization of the coupling products in transition metal catalyzed reactions.

With our focus on the application of diaryliodonium salts, the diverse mechanistic possibilities of aryl(2,4,6-trimethoxyphenyl)iodonium tosylates in arylation reactions 
were expanded and incorporated access to aryne intermediates. The choice of the reaction conditions depends on the electronic nature of the substituents. The exceptionally mild conditions for aryne formation via deprotonation of the corresponding aryl iodides are viable in a telescoped reaction through iodonium intermediate. 
Dedication

To my beautiful and strong mother.

Thank you for always believing in me. 


\section{Acknowledgements}

I would like to express my deepest appreciation to my advisor, Prof. David Stuart, for his support and guidance through my graduate studies. Your mentoring and profound belief in my ability helped me to develop as an independent scientist. Thank you for letting me be a part of your group and learn from you.

I would like to extend my gratitude to my committee, Profs. Andrea Goforth, Robert Strongin, and Kenneth Stedman, for their availability and valuable feedback on the work presented herein. I would also like to thank a former member of my committee, Prof. Theresa McCormick, for the support during annual meetings.

I would like to thank our collaborators for invaluable contribution to this work: Prof. Edward Valente, University of Portland, for performing X-ray crystallography of the synthesized compounds; Drs. Louis-Charles Campeau and Edward Sherer, Merck Research Laboratories, Merck \& Co., Inc., for the analysis of medicinal chemistry properties of small molecule drugs approved by the FDA; Prof. Paul Cheong, Oregon State University, for performing DFT calculations.

I am grateful to Prof. Gary Molander for an opportunity to perform research in his laboratory that increased my skillset as a synthetic chemist and led me to joining the doctoral program at Portland State University.

I want to thank my coworkers, colleagues, and friends in the Chemistry Department. I am thankful to have been a part of this helpful, inspiring, and enjoyable 
community. I value greatly the competences I acquired working with talented chemists throughout these years.

I am thankful to my friends, those who sent me on this journey and supported throughout, and those who joined along the way. I deeply appreciate the devotion and care of the amazing families I have met who made me feel home away from home.

Most importantly, I thank my family for their continuing support. Their faith in me has been the source of motivation when I did not believe in myself. I would not have accomplished so much if it were not for you. 
Table of Contents

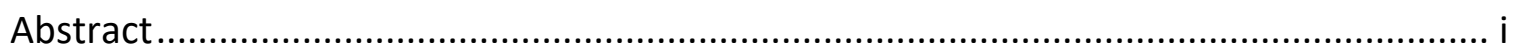

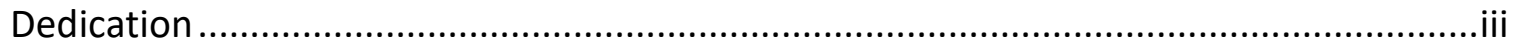

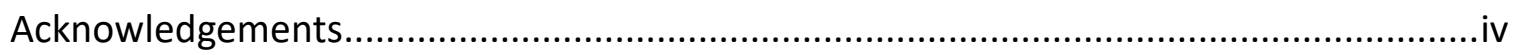

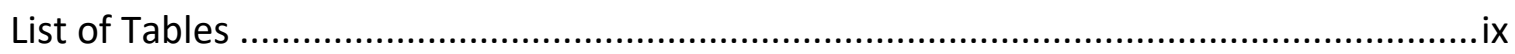

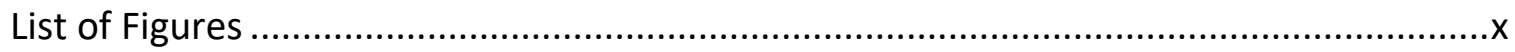

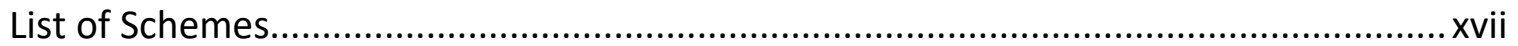

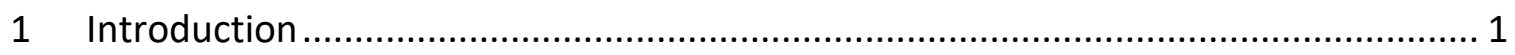

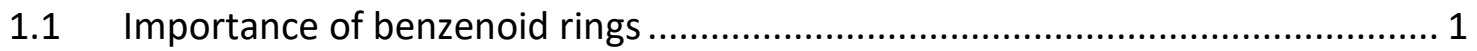

1.2 Substitution patterns: existing analyses, identifying a gap ............................ 2

1.3 Functionalization of benzenoid rings .......................................................... 3

1.3.1 Electrophilic aromatic substitution ...................................................... 4

1.3.2 Nucleophilic aromatic substitution .......................................................... 5

1.3.3 Transition metal catalyzed reactions ...................................................... 6

1.3.4 Aryne enabled functionalization .......................................................... 7

1.4 Application of aryne intermediate ............................................................... 8

1.4.1 Recent advances in aryne formation reactions .................................... 9

1.4.2 Current synthetic challenges in aryne formation .................................. 11

1.5 Diaryliodonium salts as aryne precursor: from the first evidence ................... 12

1.6 Synthesis of unsymmetrical diaryliodonium salts........................................... 14

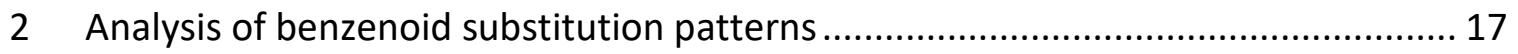

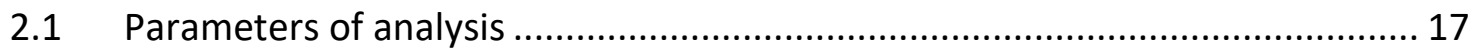

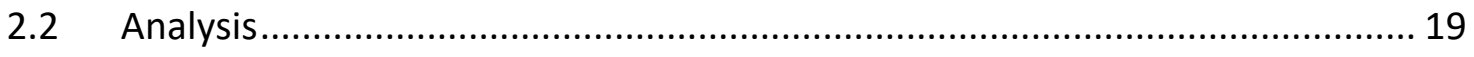

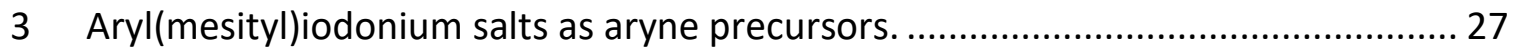

3.1 Modern synthetic approach to aryne formation from diaryliodonium salts .... 27

3.2 Synthesis of sterically congested benzenoid rings........................................ 28

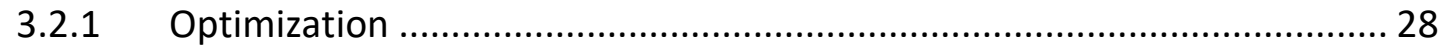

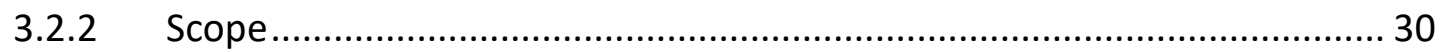

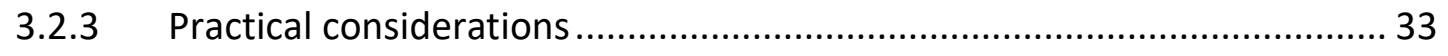

3.2.4 Derivatization via transition metal catalysis .......................................... 34 
3.2.5 Sequential dual C-H functionalization of disubstituted arenes .................. 35

3.2.6 Unexpected aryne reactivity in the reaction with cyclic ureas................... 36

3.2.7 Dimerization of aryl(mesityl)iodonium salts.......................................... 39

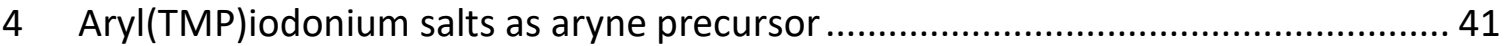

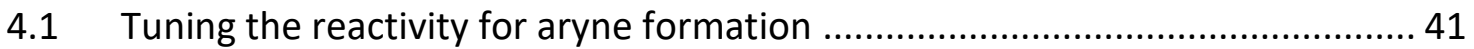

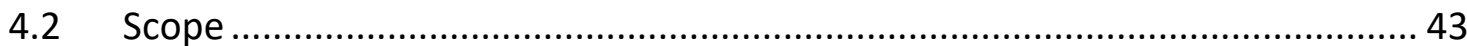

4.3 Multistep one-pot functionalization of aryl iodides ..................................... 44

4.4 Formal synthesis of bioactive compound .................................................. 45

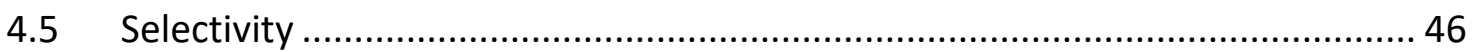

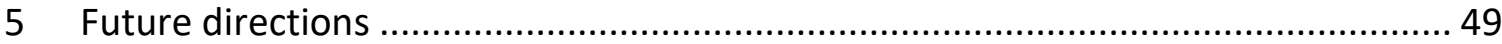

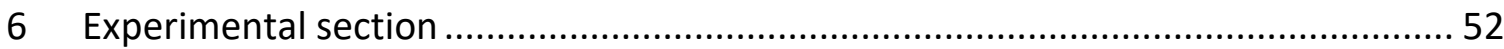

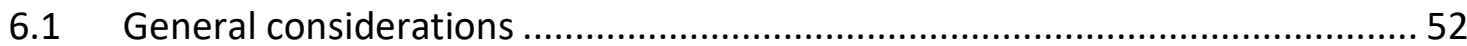

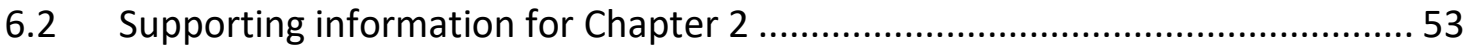

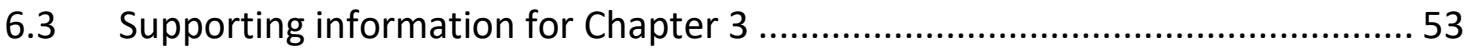

6.3.1 Preparation of hydroxy(tosyloxy)iodomesitylene ................................ 53

6.3.2 Preparation of aryl(Mes)iodonium tosylates........................................ 54

6.3.3 Characterization of aryl(Mes)iodonium tosylates ................................. 56

6.3.4 Synthesis and characterization of 1,2,3,4-substituted arenes with

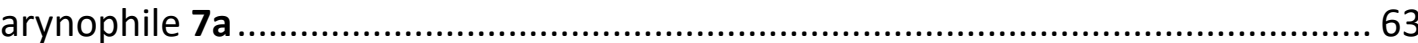

6.3.5 Synthesis and characterization of 1,2,3,4-substituted arenes with other

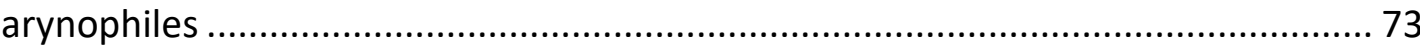

6.3.6 Derivatization of aryne coupling product by transition metal catalysis..... 81

6.3.7 Unexpected aryne reactivity in reactions with tertiary amines ................. 84

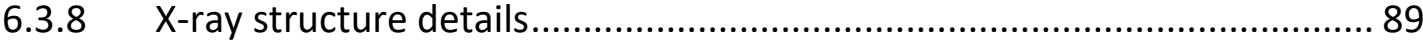

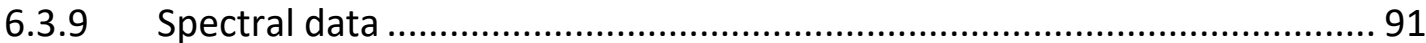

6.4 Supporting information for Chapter 4 ............................................... 151

6.4.1 Preparration of aryl(TMP)iodonium tosylates................................... 151

6.4.2 Characterization of aryl(TMP)iodonium tosylates................................ 152

6.4.3 Synthesis and characterization of aryne trapping products.................... 160

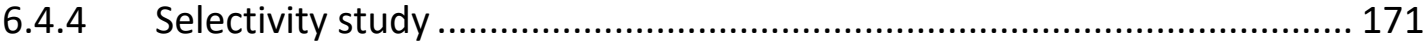

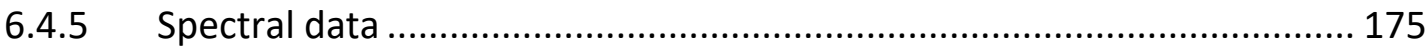




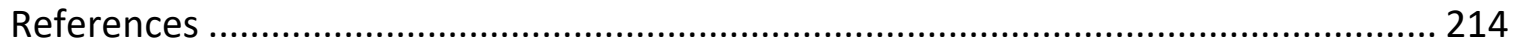


List of Tables

Table 1. Representative examples of aryl(Mes)iodonium tosylates as aryne precursors.

Table 2. Scope of 1,2,3,4-substituted arenes via aryne and cyclic ureas. ...................... 31

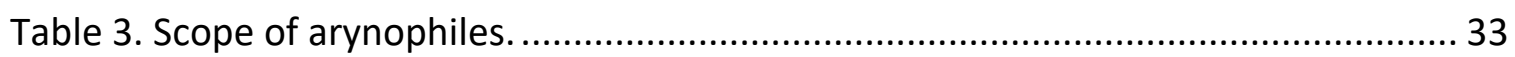

Table 4. Scope of aryne trapping products............................................................... 44

Table 5. Main ${ }^{1} \mathrm{H}-{ }^{1} \mathrm{H}$ and ${ }^{1} \mathrm{H}-{ }^{13} \mathrm{C}$ correlations for major isomer (N.D. - not determined). 86 Table 6. Selected crystallographic information for structures $6 \mathrm{~g}, \mathbf{8 m a}$, 9c. Esteemated

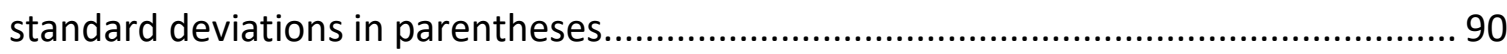


Figure 1. Examples of benzenoid-containing molecules with benzenoid rings highlighted in blue.

Figure 2. Electrophilic aromatic substitution reaction: A. Mechanism; B. Example of

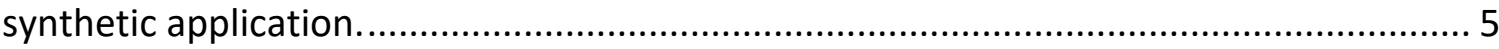

Figure 3. Mechanism of nucleophilic aromatic substitution reaction........................... 6

Figure 4. General mechanism of metal catalyzed cross-coupling reaction...................... 7

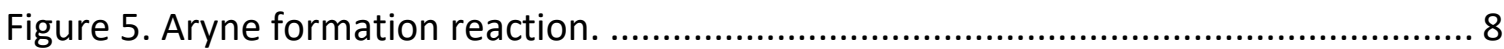

Figure 6. Methods to generate benzyne and required conditions. $\mathrm{Hal}=$ halogen........... 10

Figure 7. First evidence for aryne formation from diaryliodonium salt. ....................... 13

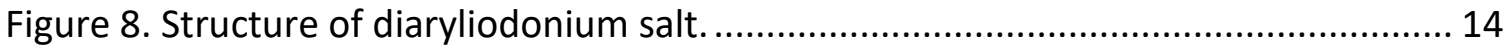

Figure 9. Possible benzenoid substitution patterns. ................................................... 19

Figure 10. Distribution of the number of benzenoid rings in a given API. ..................... 19

Figure 11. Distribution of benzenoid substitution patterns in APIs. ............................. 21

Figure 12. Historical insight in distribution of benzenoid rings in a given API. ............... 22

Figure 13. Distribution of benzenoid substitution patterns in historical perspective...... 23

Figure 14. Percent of "druglike" molecules based on rule-of-five and rule-of-six.......... 24

Figure 15. Average complexity and standard deviation of substitution patterns............ 25

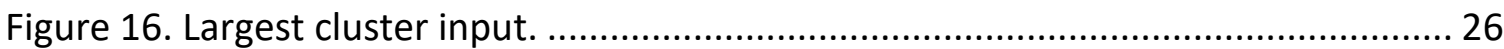

Figure 17. A. X-ray structure of $\mathbf{6 a}$ and $\mathbf{6 i}$. B. Stack of ${ }^{1} \mathrm{H}$ NMR spectra of concentrations (bottom to top) $0.1 \mathrm{M}, 0.01 \mathrm{M}, 0.001 \mathrm{M}$ in $\mathrm{CDCl}_{3}$

Figure 18. A. Literature precedent for alkyl aryl ether formation. B. Effect of substituents on mechanistic outcome.

Figure 19. Effect of base and substituent on aryne formation; circles represent yields. 43 Figure 20. A. Predicted distortion angles and selectivity. B. Observed selectivity of nucleophilic attack.

Figure 21. Aryne coupling reaction on $5 \mathrm{mmol}$ scale: A. Slurry of iodonium salt in MTBE and DMI; B. Appearance of the reaction mixture after addition of $\mathrm{NaOt-Bu;} \mathrm{C.}$ Appearance of the reaction mixture after $1 \mathrm{~min}$ at stirring. ....................................... 64

Figure 22. ${ }^{1} \mathrm{H}$ NMR of hydroxy(tosyloxy)iodomesitylene in $\mathrm{CD}_{3} \mathrm{OD}$ at $400 \mathrm{MHz}$............. 91 Figure $23 .{ }^{13} \mathrm{C}\left\{{ }^{1} \mathrm{H}\right\}$ NMR of hydroxy(tosyloxy)iodomesitylene in $\mathrm{CD}_{3} \mathrm{OD}$ at $101 \mathrm{MHz} \ldots . .91$

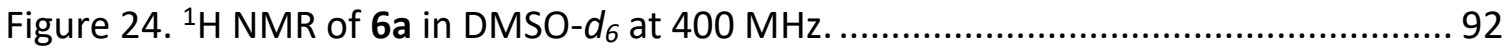

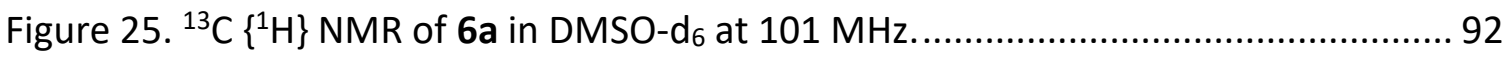

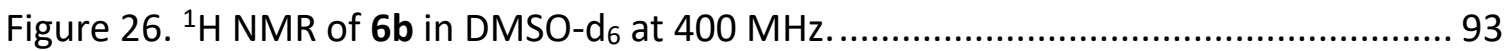

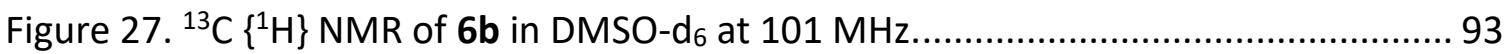

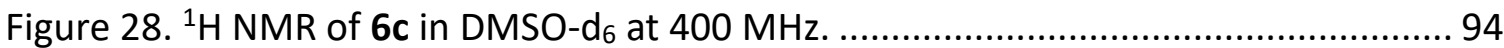

Figure 29. ${ }^{13} \mathrm{C}\left\{{ }^{1} \mathrm{H}\right\}$ NMR of $6 \mathrm{c}$ in DMSO-d 6 at $101 \mathrm{MHz}$............................................. 94

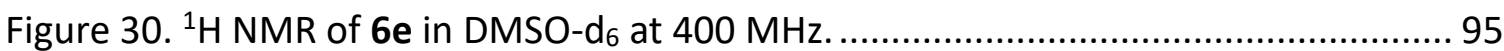

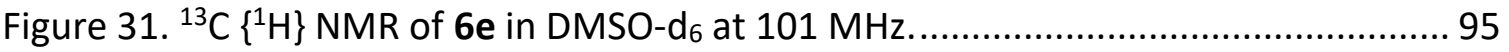




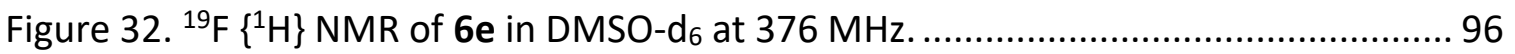

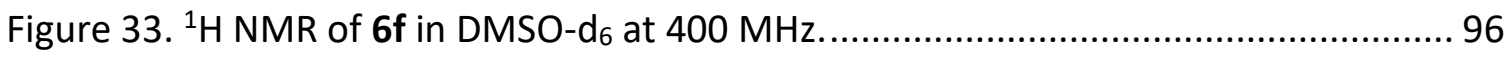

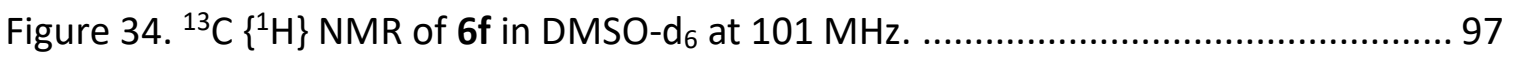

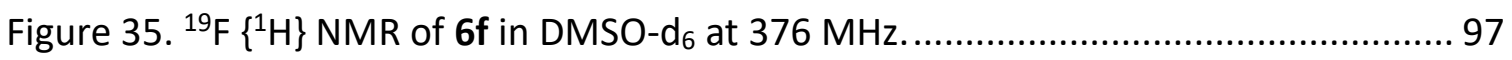

Figure 36. ${ }^{1} \mathrm{H}$ NMR of $6 \mathrm{~g}$ in DMSO-d 6 with $0.05 \%$ v/v TMS at $400 \mathrm{MHz}$........................ 98

Figure $37 .{ }^{13} \mathrm{C}\left\{{ }^{1} \mathrm{H}\right\}$ NMR of $6 \mathrm{~g}$ in DMSO-d 6 with $0.05 \% \mathrm{v} / \mathrm{v}$ TMS at $101 \mathrm{MHz} . \ldots \ldots \ldots \ldots . . . . . . . .98$

Figure 38. ${ }^{19} \mathrm{~F}\left\{{ }^{1} \mathrm{H}\right\}$ NMR of $6 \mathrm{~g}$ in DMSO- $\mathrm{d}_{6}$ with $0.05 \% \mathrm{v} / \mathrm{v} \mathrm{TMS}$ at $376 \mathrm{MHz}$................. 99

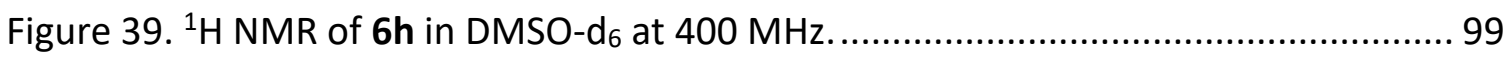

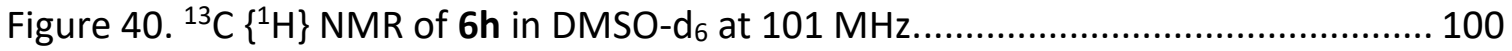

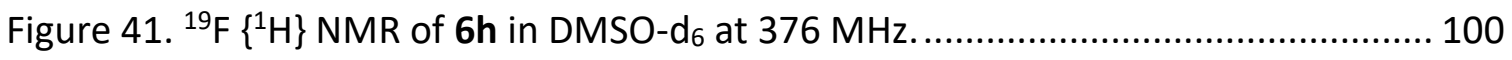

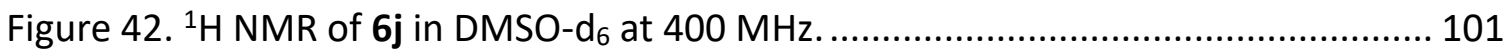

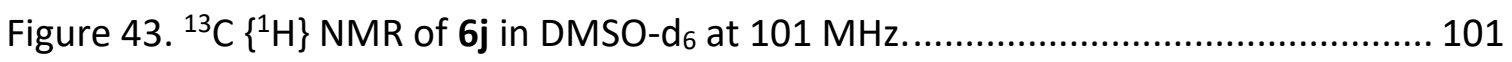

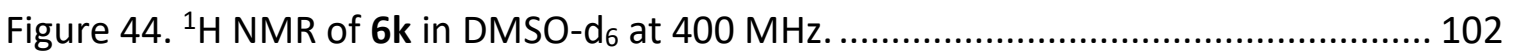

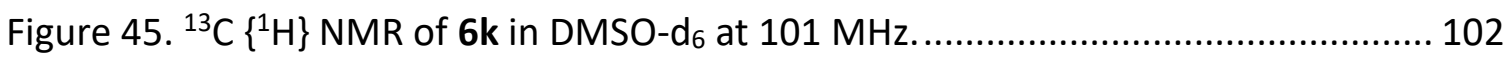

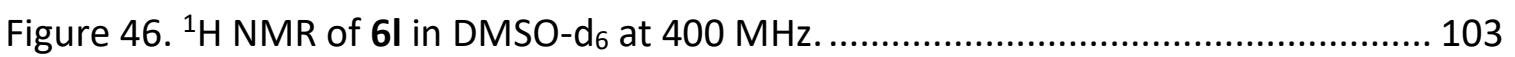

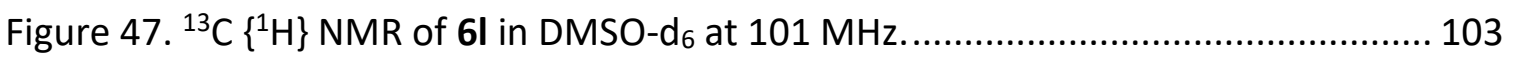

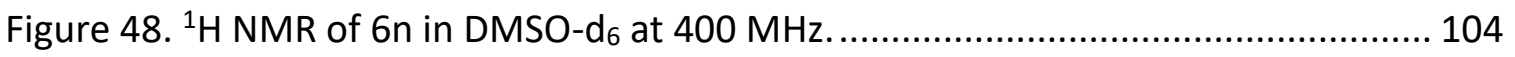

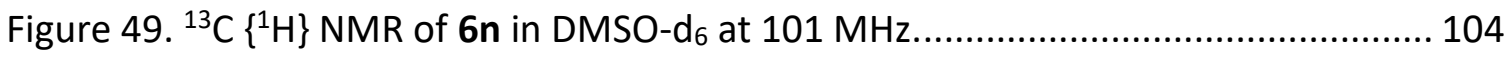

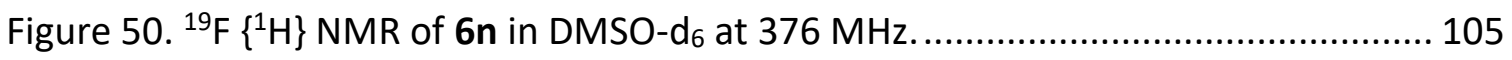

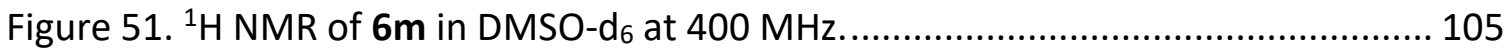

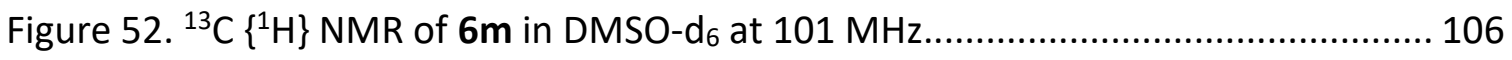

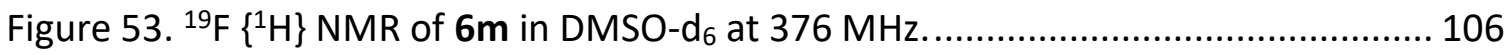

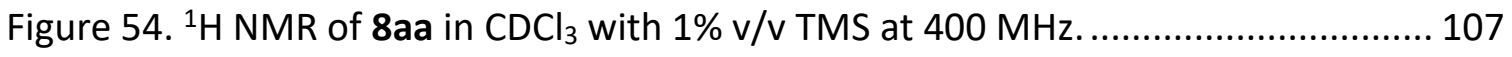

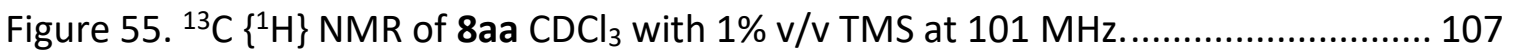

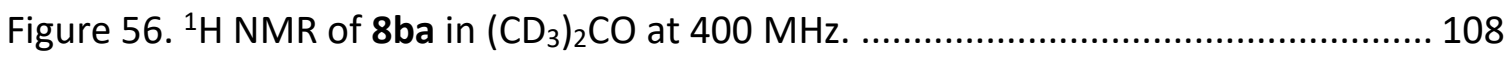

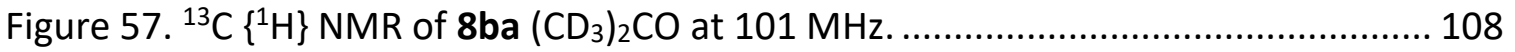

Figure 58. ${ }^{1} \mathrm{H}$ NMR of $8 \mathrm{ca}$ in $\mathrm{CDCl}_{3}$ with $1 \% \mathrm{v} / \mathrm{v}$ TMS at $400 \mathrm{MHz}$.............................. 109

Figure 59. ${ }^{13} \mathrm{C}\left\{{ }^{1} \mathrm{H}\right\} \mathrm{NMR}$ of $8 \mathrm{ca} \mathrm{CDCl} 3$ with $1 \% \mathrm{v} / \mathrm{v} \mathrm{TMS}$ at $101 \mathrm{MHz}$............................ 109

Figure 60. ${ }^{1} \mathrm{H}$ NMR of 8da in $\mathrm{CDCl}_{3}$ with $1 \% \mathrm{v} / \mathrm{v}$ TMS at $400 \mathrm{MHz}$............................... 110

Figure $61 .{ }^{13} \mathrm{C}\left\{{ }^{1} \mathrm{H}\right\} \mathrm{NMR}$ of 8 da $\mathrm{CDCl}_{3}$ with $1 \% \mathrm{v} / \mathrm{v}$ TMS at $101 \mathrm{MHz}$........................... 110

Figure $62 .{ }^{19} \mathrm{~F}\left\{{ }^{1} \mathrm{H}\right\}$ NMR of 8da in $\mathrm{CDCl}_{3}$ with $1 \% \mathrm{v} / \mathrm{v}$ TMS at $376 \mathrm{MHz}^{2 . . . . . . . . . . . . . . . . . . . . . . . ~} 111$

Figure 63. ${ }^{1} \mathrm{H}$ NMR of 8 ea in $\mathrm{CDCl}_{3}$ with $1 \% \mathrm{v} / \mathrm{v}$ TMS at $400 \mathrm{MHz}$.............................. 111

Figure $64 .{ }^{13} \mathrm{C}\left\{{ }^{1} \mathrm{H}\right\} \mathrm{NMR}$ of 8 ea $\mathrm{CDCl}_{3}$ with $1 \% \mathrm{v} / \mathrm{v}$ TMS at $101 \mathrm{MHz}$............................ 112

Figure 65. ${ }^{19} \mathrm{~F}\left\{{ }^{1} \mathrm{H}\right\} \mathrm{NMR}$ of $8 \mathrm{ea}$ in $\mathrm{CDCl}_{3}$ with $1 \% \mathrm{v} / \mathrm{v}$ TMS at $376 \mathrm{MHz}$........................ 112

Figure 66. ${ }^{1} \mathrm{H}$ NMR of $8 \mathrm{fa}$ in $\mathrm{CDCl}_{3}$ with $1 \% \mathrm{v} / \mathrm{v}$ TMS at $400 \mathrm{MHz}$............................... 113

Figure 67. ${ }^{13} \mathrm{C}\left\{{ }^{1} \mathrm{H}\right\} \mathrm{NMR}$ of $8 \mathrm{fa} \mathrm{CDCl}_{3}$ with $1 \% \mathrm{v} / \mathrm{v}$ TMS at $101 \mathrm{MHz}$............................ 113

Figure 68. ${ }^{19} \mathrm{~F}\left\{{ }^{1} \mathrm{H}\right\} \mathrm{NMR}$ of $8 \mathrm{fa}$ in $\mathrm{CDCl}_{3}$ with $1 \% \mathrm{v} / \mathrm{v} \mathrm{TMS}$ at $376 \mathrm{MHz}$.......................... 114

Figure 69. ${ }^{1} \mathrm{H}$ NMR of 8ga in $\mathrm{CDCl}_{3}$ with $1 \% \mathrm{v} / \mathrm{v}$ TMS at $400 \mathrm{MHz}$............................. 114

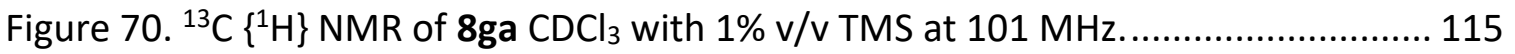

Figure $71 .{ }^{19} \mathrm{~F}\left\{{ }^{1} \mathrm{H}\right\} \mathrm{NMR}$ of $8 \mathrm{ga}$ in $\mathrm{CDCl}_{3}$ with $1 \% \mathrm{v} / \mathrm{v}$ TMS at $376 \mathrm{MHz} \ldots \ldots \ldots \ldots \ldots \ldots \ldots . . . . . . . . . .115$ 


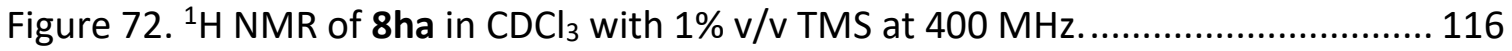

Figure $73 .{ }^{13} \mathrm{C}\left\{{ }^{1} \mathrm{H}\right\} \mathrm{NMR}$ of 8 ha $\mathrm{CDCl}_{3}$ with $1 \% \mathrm{v} / \mathrm{v}$ TMS at $101 \mathrm{MHz}$.......................... 116

Figure 74. ${ }^{19} \mathrm{~F}\left\{{ }^{1} \mathrm{H}\right\} \mathrm{NMR}$ of 8 ha in $\mathrm{CDCl}_{3}$ with $1 \% \mathrm{v} / \mathrm{v}$ TMS at $376 \mathrm{MHz} \ldots \ldots \ldots \ldots \ldots \ldots . . . . . . . . . . . .117$

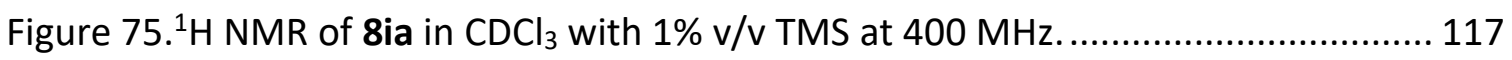

Figure 76. ${ }^{13} \mathrm{C}\left\{{ }^{1} \mathrm{H}\right\} \mathrm{NMR}$ of 8 ia $\mathrm{CDCl}_{3}$ with $1 \%$ v/v TMS at $101 \mathrm{MHz} \ldots \ldots \ldots \ldots \ldots \ldots \ldots \ldots . . . . . . . . . . . . . .118$

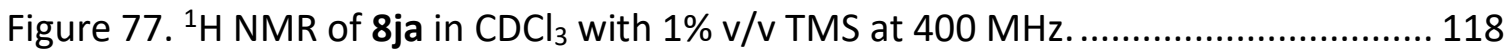

Figure 78. ${ }^{13} \mathrm{C}\left\{{ }^{1} \mathrm{H}\right\} \mathrm{NMR}$ of $8 \mathrm{ja} \mathrm{CDCl}_{3}$ with $1 \% \mathrm{v} / \mathrm{v}$ TMS at $101 \mathrm{MHz} \ldots \ldots \ldots \ldots \ldots \ldots \ldots \ldots . . . . . . . . . . . . . . .119$

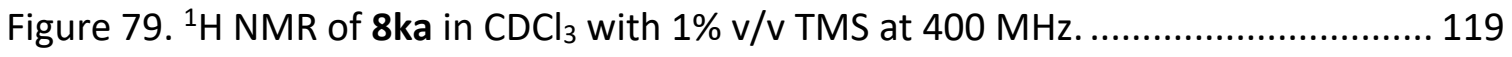

Figure $80 .{ }^{13} \mathrm{C}\left\{{ }^{1} \mathrm{H}\right\}$ NMR of 8ka in $\mathrm{CDCl}_{3}$ with 1\% v/v TMS at $101 \mathrm{MHz} \ldots \ldots \ldots \ldots \ldots \ldots . . . . . . . . . . .120$

Figure 81. ${ }^{1} \mathrm{H}$ NMR of 8la in $\mathrm{CDCl}_{3}$ with $1 \% \mathrm{v} / \mathrm{v}$ TMS at $400 \mathrm{MHz}$.............................. 120

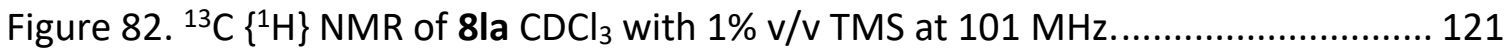

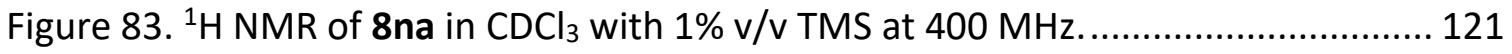

Figure $84 .{ }^{13} \mathrm{C}\left\{{ }^{1} \mathrm{H}\right\} \mathrm{NMR}$ of 8na $\mathrm{CDCl}_{3}$ with $1 \% \mathrm{v} / \mathrm{v}$ TMS at $101 \mathrm{MHz} . \ldots \ldots \ldots \ldots \ldots \ldots \ldots . . . . . . . . . . . . . . .122$

Figure 85. ${ }^{19} \mathrm{~F}\left\{{ }^{1} \mathrm{H}\right\} \mathrm{NMR}$ of 8 na in $\mathrm{CDCl}_{3}$ with $1 \% \mathrm{v} / \mathrm{v}$ TMS at $376 \mathrm{MHz}$........................ 122

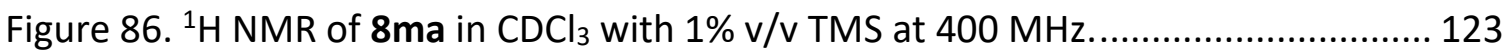

Figure 87. ${ }^{13} \mathrm{C}\left\{{ }^{1} \mathrm{H}\right\} \mathrm{NMR}$ of $8 \mathrm{ma} \mathrm{CDCl} 3$ with $1 \% \mathrm{v} / \mathrm{v}$ TMS at $101 \mathrm{MHz}$.......................... 123

Figure 88. ${ }^{19} \mathrm{~F}\left\{{ }^{1} \mathrm{H}\right\} \mathrm{NMR}$ of $8 \mathrm{ma}$ in $\mathrm{CDCl}_{3}$ with $1 \% \mathrm{v} / \mathrm{v}$ TMS at $376 \mathrm{MHz}^{2 . . . . . . . . . . . . . . . . . . . . . . . ~} 124$

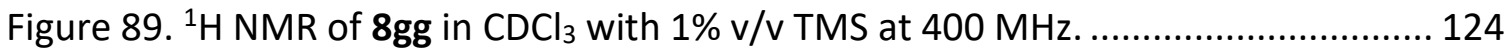

Figure $90 .{ }^{13} \mathrm{C}\left\{{ }^{1} \mathrm{H}\right\} \mathrm{NMR}$ of 8gg $\mathrm{CDCl}_{3}$ with $1 \% \mathrm{v} / \mathrm{v}$ TMS at $101 \mathrm{MHz}$........................... 125

Figure 91. ${ }^{19} \mathrm{~F}\left\{{ }^{1} \mathrm{H}\right\} \mathrm{NMR}$ of $8 \mathrm{gg}$ in $\mathrm{CDCl}_{3}$ with $1 \% \mathrm{v} / \mathrm{v}$ TMS at $376 \mathrm{MHz}$........................ 125

Figure 92. ${ }^{1} \mathrm{H}$ NMR of 8vg in $\mathrm{CDCl}_{3}$ with $1 \% \mathrm{v} / \mathrm{v}$ TMS at $400 \mathrm{MHz}$............................... 126

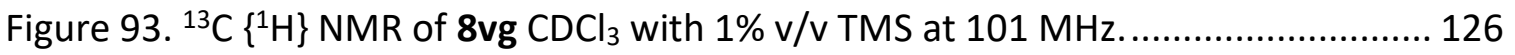

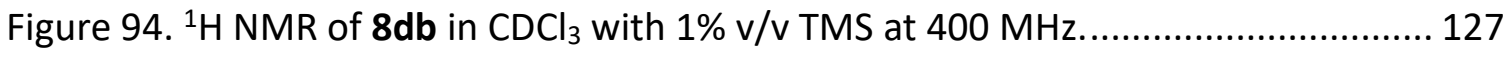

Figure $95 .{ }^{13} \mathrm{C}\left\{{ }^{1} \mathrm{H}\right\} \mathrm{NMR}$ of $8 \mathrm{db} \mathrm{CDCl}_{3}$ with 1\% v/v TMS at $101 \mathrm{MHz} . \ldots \ldots \ldots \ldots \ldots \ldots \ldots . . . . . . . . . . . . .127$

Figure 96. ${ }^{19} \mathrm{~F}\left\{{ }^{1} \mathrm{H}\right\} \mathrm{NMR}$ of $8 \mathrm{db}$ in $\mathrm{CDCl}_{3}$ with $1 \% \mathrm{v} / \mathrm{v}$ TMS at $376 \mathrm{MHz} \ldots \ldots \ldots \ldots \ldots \ldots \ldots . . . . . . . . . . .128$

Figure 97. ${ }^{1} \mathrm{H}$ NMR of $8 \mathrm{ac}$ in $\mathrm{CDCl}_{3}$ with $1 \% \mathrm{v} / \mathrm{v}$ TMS at $400 \mathrm{MHz}$............................. 128

Figure $98 .{ }^{13} \mathrm{C}\left\{{ }^{1} \mathrm{H}\right\} \mathrm{NMR}$ of 8 ac $\mathrm{CDCl}_{3}$ with $1 \%$ v/v TMS at $101 \mathrm{MHz}$.......................... 129

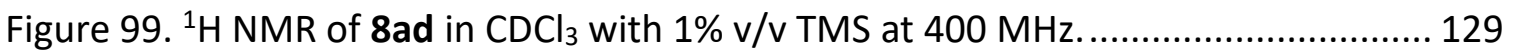

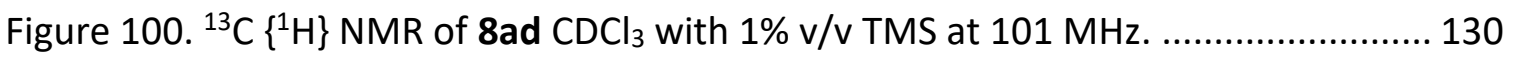

Figure 101. ${ }^{1} \mathrm{H}$ NMR of 8gd in $\mathrm{CDCl}_{3}$ with $1 \% \mathrm{v} / \mathrm{v} \mathrm{TMS}$ at $400 \mathrm{MHz}$............................. 130

Figure 102. ${ }^{13} \mathrm{C}\left\{{ }^{1} \mathrm{H}\right\}$ NMR of 8gd $\mathrm{CDCl}_{3}$ with $1 \% \mathrm{v} / \mathrm{v}$ TMS at $101 \mathrm{MHz} \ldots \ldots \ldots \ldots \ldots \ldots \ldots . . . . . . . . . . . . . . .131$

Figure 103. ${ }^{19} \mathrm{~F}\left\{{ }^{1} \mathrm{H}\right\} \mathrm{NMR}$ of $8 \mathrm{gd}$ in $\mathrm{CDCl}_{3}$ with $1 \% \mathrm{v} / \mathrm{v}$ TMS at $376 \mathrm{MHz} \ldots \ldots \ldots \ldots \ldots \ldots . . . . . . . . .131$

Figure 104. ${ }^{1} \mathrm{H}$ NMR of 8ge in $\mathrm{CDCl}_{3}$ with $1 \% \mathrm{v} / \mathrm{v}$ TMS at $400 \mathrm{MHz}$............................ 132

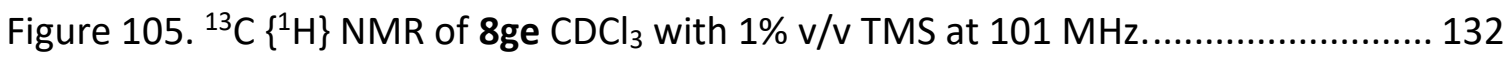

Figure 106. ${ }^{19} \mathrm{~F}\left\{{ }^{1} \mathrm{H}\right\} \mathrm{NMR}$ of 8ge in $\mathrm{CDCl}_{3}$ with $1 \% \mathrm{v} / \mathrm{v}$ TMS at $376 \mathrm{MHz}$...................... 133

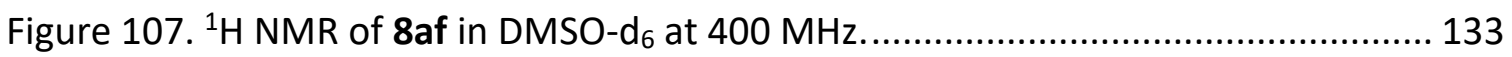

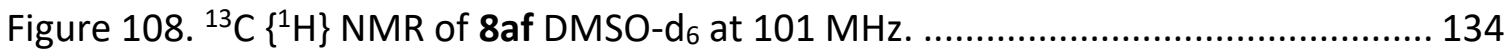

Figure 109. ${ }^{1} \mathrm{H}$ NMR of $8 \mathrm{dg}$ in $\mathrm{CDCl}_{3}$ with $1 \% \mathrm{v} / \mathrm{v} \mathrm{TMS}$ at $400 \mathrm{MHz}$............................ 134

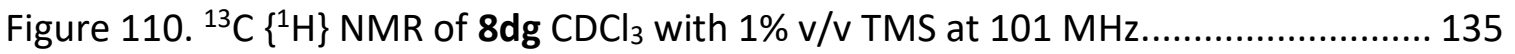

Figure 111. ${ }^{19} \mathrm{~F}\left\{{ }^{1} \mathrm{H}\right\} \mathrm{NMR}$ of $8 \mathrm{dg}$ in $\mathrm{CDCl}_{3}$ with $1 \% \mathrm{v} / \mathrm{v}$ TMS at $376 \mathrm{MHz} \ldots \ldots \ldots \ldots \ldots \ldots . . . . . . . . . .135$ 


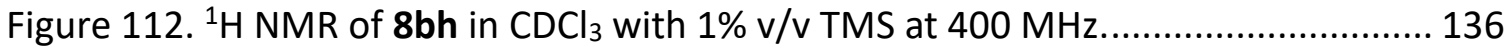

Figure 113. ${ }^{13} \mathrm{C}\left\{{ }^{1} \mathrm{H}\right\}$ NMR of 8 bh $\mathrm{CDCl}_{3}$ with $1 \%$ v/v TMS at $101 \mathrm{MHz}$........................ 136

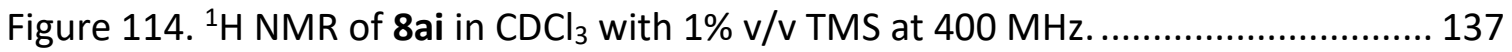

Figure 115. ${ }^{13} \mathrm{C}\left\{{ }^{1} \mathrm{H}\right\}$ NMR of 8ai $\mathrm{CDCl}_{3}$ with $1 \%$ v/v TMS at $101 \mathrm{MHz}$.......................... 137

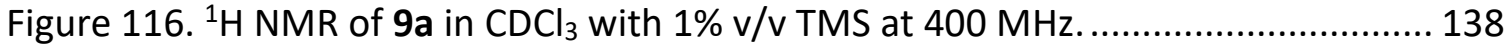

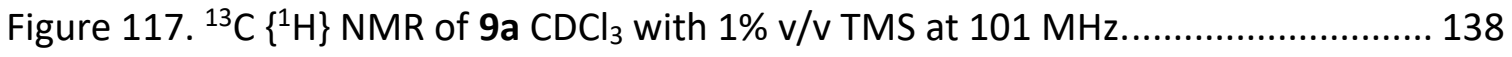

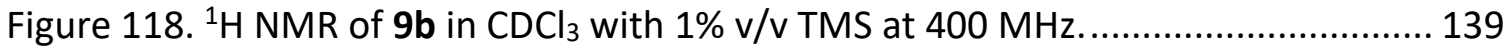

Figure 119. ${ }^{13} \mathrm{C}\left\{{ }^{1} \mathrm{H}\right\}$ NMR of $9 \mathrm{~b} \mathrm{CDCl} 3$ with $1 \%$ v/v TMS at $101 \mathrm{MHz}$........................... 139

Figure 120. ${ }^{19} \mathrm{~F}\left\{{ }^{1} \mathrm{H}\right\}$ NMR of $9 \mathrm{~b}$ in $\mathrm{CDCl}_{3}$ with $1 \% \mathrm{v} / \mathrm{v}$ TMS at $376 \mathrm{MHz} \ldots \ldots \ldots \ldots \ldots \ldots . . . . . . . . . . . .140$

Figure 121. ${ }^{1} \mathrm{H}$ NMR of $9 \mathrm{c}$ in $\mathrm{CDCl}_{3}$ with $1 \% \mathrm{v} / \mathrm{v}$ TMS at $400 \mathrm{MHz}$............................. 140

Figure 122. ${ }^{13} \mathrm{C}\left\{{ }^{1} \mathrm{H}\right\}$ NMR of $9 \mathrm{C} \mathrm{CDCl}_{3}$ with $1 \% \mathrm{v} / \mathrm{v}$ TMS at $101 \mathrm{MHz}$.......................... 141

Figure 123. ${ }^{1} \mathrm{H}$ NMR of $10 \mathrm{a}$ and $10 \mathrm{~b}$ in $\mathrm{CDCl}_{3}$ with $1 \% \mathrm{v} / \mathrm{v}$ TMS at $400 \mathrm{MHz} \ldots \ldots \ldots \ldots . . . . . . .141$

Figure $124 .{ }^{13} \mathrm{C}\left\{{ }^{1} \mathrm{H}\right\}$ NMR of $10 \mathrm{a}$ and $10 \mathrm{~b} \mathrm{CDCl} 3$ with $1 \%$ v/v TMS at $101 \mathrm{MHz} . \ldots \ldots \ldots . . . .142$

Figure 125. COSY of 10a and $10 \mathrm{~b}$ in $\mathrm{CDCl}_{3}$ with $1 \% \mathrm{v} / \mathrm{v} \mathrm{TMS}$ at $400 \mathrm{MHz}$.................... 142

Figure 126. NOESY of 10a and 10b in $\mathrm{CDCl}_{3}$ with $1 \% \mathrm{v} / \mathrm{v}$ TMS at $400 \mathrm{MHz} \ldots \ldots \ldots \ldots \ldots . . . . . . . . .143$

Figure 127. Stacked ${ }^{13} \mathrm{C}$ NMR spectra of 10a and 10b............................................. 143

Figure 128. HSQC of $10 \mathrm{a}$ and $10 \mathrm{~b}$ in $\mathrm{CDCl}_{3}$ with $1 \% \mathrm{v} / \mathrm{v}$ TMS at $400 \mathrm{MHz} . . . \ldots \ldots \ldots . . . . . . . . .144$

Figure 129. $\mathrm{HMBC}$ of $10 \mathrm{a}$ and $10 \mathrm{~b}$ in $\mathrm{CDCl}_{3}$ with $1 \% \mathrm{v} / \mathrm{v}$ TMS at $400 \mathrm{MHz}$ (unambiguous

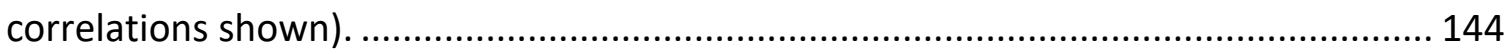

Figure 130. ${ }^{1} \mathrm{H}$ NMR of $10 \mathrm{c}$ and $10 \mathrm{~d}$ in $\mathrm{CDCl}_{3}$ with $1 \% \mathrm{v} / \mathrm{v} \mathrm{TMS}$ at $600 \mathrm{MHz}$................. 145

Figure 131. ${ }^{13} \mathrm{C}\left\{{ }^{1} \mathrm{H}\right\}$ NMR of $10 \mathrm{c}$ and $10 \mathrm{~d} \mathrm{CDCl}$ with $1 \% \mathrm{v} / \mathrm{v}$ TMS at $101 \mathrm{MHz}$............. 145

Figure 132. ${ }^{19} \mathrm{~F}\left\{{ }^{1} \mathrm{H}\right\} \mathrm{NMR}$ of $10 \mathrm{c}$ and $10 \mathrm{~d}$ in $\mathrm{CDCl}_{3}$ with $1 \% \mathrm{v} / \mathrm{v} \mathrm{TMS}$ at $376 \mathrm{MHz} . \ldots \ldots . . .146$

Figure 133. ${ }^{1} \mathrm{H}$ NMR of 10e and 10f in $\mathrm{CDCl}_{3}$ with $1 \% \mathrm{v} / \mathrm{v} \mathrm{TMS}$ at $400 \mathrm{MHz} \ldots \ldots \ldots \ldots . . . . . . . .146$

Figure 134. ${ }^{13} \mathrm{C}\left\{{ }^{1} \mathrm{H}\right\}$ NMR of 10e and $10 \mathrm{CDCl}_{3}$ with 1\% v/v TMS at $101 \mathrm{MHz}$............. 147

Figure 135. ${ }^{19} \mathrm{~F}\left\{{ }^{1} \mathrm{H}\right\}$ NMR of $10 \mathrm{e}$ and $10 \mathrm{f}$ in acetone- $\mathrm{d}_{6}$ with $1 \% \mathrm{v} / \mathrm{v} \mathrm{TMS}$ at $376 \mathrm{MHz} . .147$

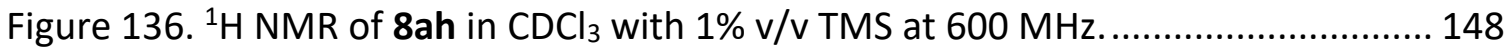

Figure 137. ${ }^{13} \mathrm{C}\left\{{ }^{1} \mathrm{H}\right\}$ NMR of 8 ah $\mathrm{CDCl}_{3}$ with $1 \% \mathrm{v} / \mathrm{v}$ TMS at $151 \mathrm{MHz}$........................ 148

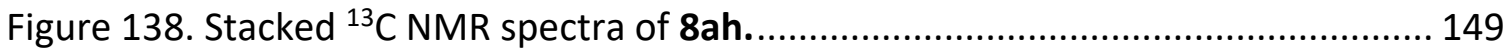

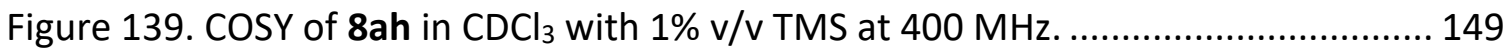

Figure 140. NOESY of 8ah in $\mathrm{CDCl}_{3}$ with $1 \% \mathrm{v} / \mathrm{v}$ TMS at $400 \mathrm{MHz}$............................... 150

Figure 141. A. ${ }^{1} \mathrm{H}$ NMR spectrum of crude reaction mixture of $11 \mathbf{w}$ with morpholine recorded at $400 \mathrm{MHz}$ in $\mathrm{CDCl}_{3} ; \mathrm{B} .{ }^{1} \mathrm{H} \mathrm{NMR}$ spectrum of the major product recorded at $400 \mathrm{MHz}$ in $\mathrm{CDCl}_{3} ; \mathrm{C}^{1}{ }^{1} \mathrm{H} \mathrm{NMR}$ spectrum of the minor product recorded at $400 \mathrm{MHz}$ in $\mathrm{CDCl}_{3}$

Figure 142. A. ${ }^{1} \mathrm{H}$ NMR spectrum of crude reaction mixture of $11 \mathbf{x}$ with piperidine recorded at $400 \mathrm{MHz}$ in $\mathrm{CDCl}_{3} ; \mathrm{B} .{ }^{1} \mathrm{H}$ NMR spectrum of the major product recorded at $400 \mathrm{MHz}$ in $\mathrm{CDCl}_{3}$; C. ${ }^{1} \mathrm{H}$ NMR spectrum of the minor product recorded at $400 \mathrm{MHz}$ in $\mathrm{CDCl}_{3}$

Figure 143. ${ }^{1} \mathrm{H}$ NMR spectrum of crude reaction mixture of $\mathbf{1 1 y}$ with morpholine recorded at $400 \mathrm{MHz}$ in $\mathrm{CDCl}_{3}$. 
Figure 144. ${ }^{1} \mathrm{H}$ NMR spectrum of crude reaction mixture of $\mathbf{1 1 z}$ with morpholine recorded at $400 \mathrm{MHz}$ in $\mathrm{CDCl}_{3}$. 173

Figure 145. ${ }^{1} \mathrm{H}$ NMR spectrum of crude reaction mixture of 11 aa with morpholine recorded at $400 \mathrm{MHz}$ in $\mathrm{CDCl}_{3}$. 174

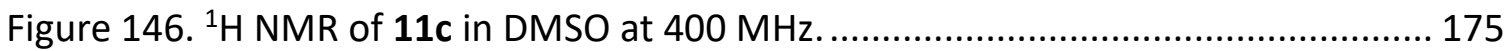

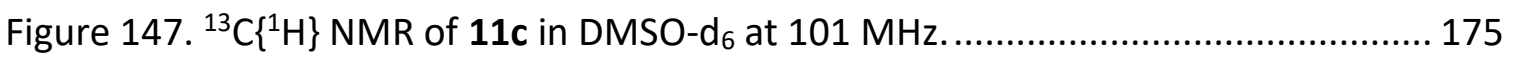

Figure 148. ${ }^{1} \mathrm{H}$ NMR of $\mathbf{1 1} \mathrm{g}$ in DMSO-d 6 with 1\% v/v TMS at $400 \mathrm{MHz} \ldots \ldots \ldots \ldots \ldots \ldots . . . . . . . . . . . . .176$

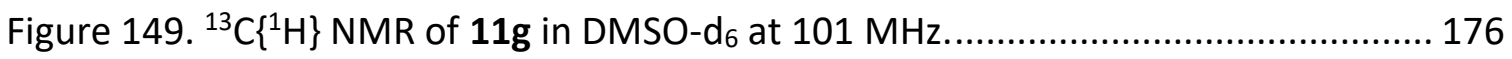

Figure 150. ${ }^{1} \mathrm{H}$ NMR of $11 \mathrm{l}$ in DMSO-d $\mathrm{d}_{6}$ with 1\% v/v TMS at $400 \mathrm{MHz} \ldots \ldots \ldots \ldots \ldots \ldots . . . . . . . . . . . . .177$

Figure 151. ${ }^{13} \mathrm{C}\left\{{ }^{1} \mathrm{H}\right\}$ NMR of 11c in DMSO-d $\mathrm{d}_{6}$ with $1 \% \mathrm{v} / \mathrm{v}$ TMS at $101 \mathrm{MHz} \ldots \ldots \ldots \ldots \ldots . . . . . . .177$

Figure 152. ${ }^{19} \mathrm{~F}\left\{{ }^{1} \mathrm{H}\right\}$ NMR of $11 \mathrm{c}$ in DMSO-d $\mathrm{d}_{6}$ with $1 \% \mathrm{v} / \mathrm{v}$ TMS at $376 \mathrm{MHz} \ldots \ldots \ldots \ldots \ldots . . . . . . .178$

Figure 153. ${ }^{1} \mathrm{H}$ NMR of 110 in DMSO-d 6 with $1 \% \mathrm{v} / \mathrm{v}$ TMS at $400 \mathrm{MHz}$........................ 178

Figure 154. ${ }^{13} \mathrm{C}\left\{{ }^{1} \mathrm{H}\right\}$ NMR of $\mathbf{1 1 0}$ in DMSO-d 6 with $1 \% \mathrm{v} / \mathrm{v}$ TMS at $101 \mathrm{MHz}$................. 179

Figure 155. ${ }^{1} \mathrm{H}$ NMR of $11 \mathrm{p}$ in DMSO-d $\mathrm{d}_{6}$ with $1 \% \mathrm{v} / \mathrm{v}$ TMS at $400 \mathrm{MHz}$........................ 179

Figure 156. ${ }^{13} \mathrm{C}\left\{{ }^{1} \mathrm{H}\right\}$ NMR of 11p in DMSO-d 6 with $1 \% \mathrm{v} / \mathrm{v}$ TMS at $101 \mathrm{MHz}$................. 180

Figure 157. ${ }^{19} \mathrm{~F}\left\{{ }^{1} \mathrm{H}\right\}$ NMR of $11 \mathrm{p}$ in DMSO-d $\mathrm{d}_{6}$ with $1 \% \mathrm{v} / \mathrm{v}$ TMS at $376 \mathrm{MHz} \ldots \ldots \ldots \ldots \ldots . . . . . . . .180$

Figure 158. ${ }^{1} \mathrm{H}$ NMR of $11 \mathrm{r}$ in DMSO-d 6 with $1 \% \mathrm{v} / \mathrm{v}$ TMS at $400 \mathrm{MHz}$........................ 181

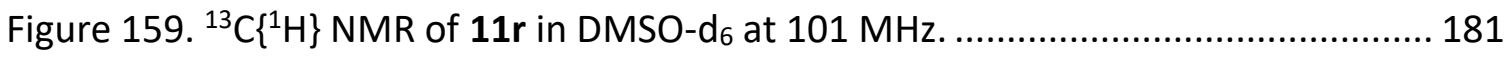

Figure 160. ${ }^{1} \mathrm{H}$ NMR of 11s in DMSO-d 6 with $1 \%$ v/v TMS at $400 \mathrm{MHz}$........................ 182

Figure 161. ${ }^{13} \mathrm{C}\left\{{ }^{1} \mathrm{H}\right\}$ NMR of 11s in DMSO- $\mathrm{d}_{6}$ with $1 \% \mathrm{v} / \mathrm{v}$ TMS at $101 \mathrm{MHz} . \ldots \ldots \ldots \ldots \ldots . . . . . . . .182$

Figure 162. ${ }^{19} \mathrm{~F}\left\{{ }^{1} \mathrm{H}\right\}$ NMR of 11s in DMSO- $\mathrm{d}_{6}$ with $1 \% \mathrm{v} / \mathrm{v}$ TMS at $376 \mathrm{MHz}$.................. 183

Figure 163. ${ }^{1} \mathrm{H}$ NMR of $11 w$ in DMSO-d $\mathrm{d}_{6}$ with $1 \% \mathrm{v} / \mathrm{v}$ TMS at $400 \mathrm{MHz}$....................... 183

Figure 164. ${ }^{13} \mathrm{C}\left\{{ }^{1} \mathrm{H}\right\}$ NMR of $11 w$ in DMSO-d 6 with $1 \%$ v/v TMS at $101 \mathrm{MHz} \ldots \ldots \ldots \ldots . . . . . . .184$

Figure 165. ${ }^{1} \mathrm{H}$ NMR of $11 w^{\prime}$ in DMSO-d 6 with 1\% v/v TMS at $400 \mathrm{MHz} \ldots \ldots \ldots \ldots \ldots . . . . . . . . . . . .184$

Figure 166. ${ }^{13} \mathrm{C}\left\{{ }^{1} \mathrm{H}\right\}$ NMR of $11 w^{\prime}$ in DMSO-d 6 with $1 \%$ v/v TMS at $101 \mathrm{MHz} . \ldots \ldots \ldots . . . . . . .185$

Figure 167. ${ }^{1} \mathrm{H}$ NMR of 11x in DMSO-d 6 with $1 \% \mathrm{v} / \mathrm{v}$ TMS at $400 \mathrm{MHz}$........................ 185

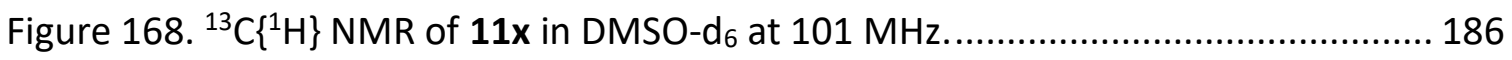

Figure 169. ${ }^{19} \mathrm{~F}\left\{{ }^{1} \mathrm{H}\right\}$ NMR of $11 \mathrm{x}$ in DMSO-d 6 with $1 \% \mathrm{v} / \mathrm{v}$ TMS at $376 \mathrm{MHz} \ldots \ldots \ldots \ldots \ldots . . . . . . . . .186$

Figure 170. ${ }^{1} \mathrm{H}$ NMR of $11 x^{\prime}$ in DMSO-d 6 with $1 \% \mathrm{v} / \mathrm{v}$ TMS at $400 \mathrm{MHz}$........................ 187

Figure $171 .{ }^{13} \mathrm{C}\left\{{ }^{1} \mathrm{H}\right\}$ NMR of $11 x^{\prime}$ in DMSO-d $\mathrm{d}_{6}$ with $1 \% \mathrm{v} / \mathrm{v}$ TMS at $101 \mathrm{MHz}$................. 187

Figure 172. ${ }^{19} \mathrm{~F}\left\{{ }^{1} \mathrm{H}\right\}$ NMR of $11 x^{\prime}$ in DMSO-d 6 with $1 \%$ v/v TMS at $376 \mathrm{MHz}$................. 188

Figure 173. ${ }^{1} \mathrm{H}$ NMR of 11y in DMSO-d 6 with $1 \% \mathrm{v} / \mathrm{v}$ TMS at $400 \mathrm{MHz}$........................ 188

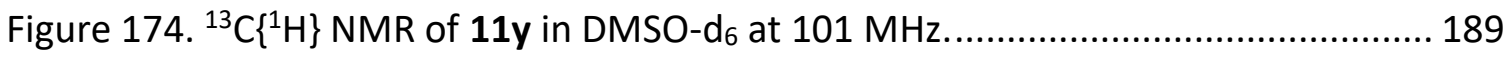

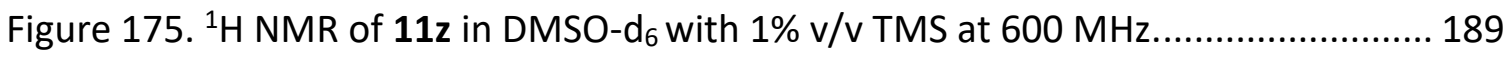

Figure 176. ${ }^{13} \mathrm{C}\left\{{ }^{1} \mathrm{H}\right\}$ NMR of $\mathbf{1 1 z}$ in DMSO-d $\mathrm{d}_{6}$ at $101 \mathrm{MHz}$........................................ 190

Figure 177. ${ }^{1} \mathrm{H}$ NMR of 11aa in DMSO-d 6 with $1 \% \mathrm{v} / \mathrm{v}$ TMS at $600 \mathrm{MHz}$....................... 190

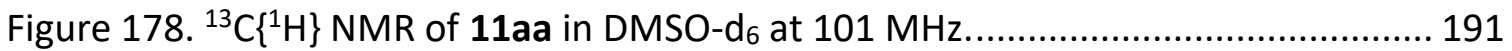

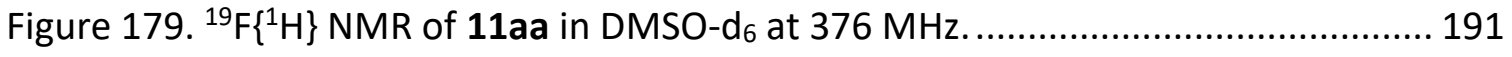

Figure 180. ${ }^{1} \mathrm{H}$ NMR of $12 \mathrm{ag}$ in $\mathrm{CDCl}_{3}$ with $1 \% \mathrm{v} / \mathrm{v} \mathrm{TMS}$ at $400 \mathrm{MHz}$........................... 192

Figure 181. ${ }^{13} \mathrm{C}\left\{{ }^{1} \mathrm{H}\right\}$ NMR of 12ag in $\mathrm{CDCl}_{3}$ with 1\% v/v TMS at $101 \mathrm{MHz}$.................... 192 
Figure 182. ${ }^{1} \mathrm{H}$ NMR of $12 \mathrm{cg}$ in $\mathrm{CDCl}_{3}$ with $1 \% \mathrm{v} / \mathrm{v} \mathrm{TMS}$ at $400 \mathrm{MHz} . \ldots \ldots \ldots \ldots \ldots \ldots . . . . . . . . . . . . . . .193$

Figure 183. ${ }^{13} \mathrm{C}\left\{{ }^{1} \mathrm{H}\right\}$ NMR of $12 \mathrm{cg}$ in $\mathrm{CDCl}_{3}$ with $1 \% \mathrm{v} / \mathrm{v}$ TMS at $101 \mathrm{MHz}$..................... 193

Figure 184. ${ }^{1} \mathrm{H}$ NMR of $12 \mathrm{eg}$ in $\mathrm{CDCl}_{3}$ with $1 \% \mathrm{v} / \mathrm{v}$ TMS at $400 \mathrm{MHz}$........................... 194

Figure 185. ${ }^{13} \mathrm{C}\left\{{ }^{1} \mathrm{H}\right\}$ NMR of 12eg in $\mathrm{CDCl}_{3}$ with $1 \% \mathrm{v} / \mathrm{v}$ TMS at $101 \mathrm{MHz}$...................... 194

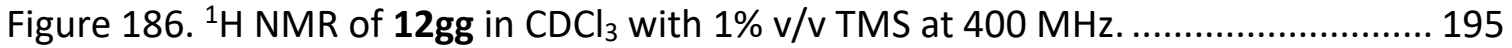

Figure 187. ${ }^{13} \mathrm{C}\left\{{ }^{1} \mathrm{H}\right\}$ NMR of 12gg in $\mathrm{CDCl}_{3}$ with $1 \%$ v/v TMS at $101 \mathrm{MHz}$...................... 195

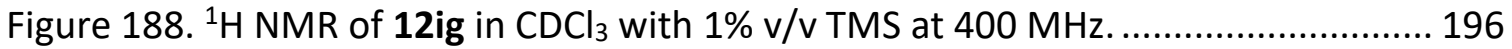

Figure 189. ${ }^{13} \mathrm{C}\left\{{ }^{1} \mathrm{H}\right\}$ NMR of 12ig in $\mathrm{CDCl}_{3}$ with $1 \%$ v/v TMS at $101 \mathrm{MHz} \ldots \ldots \ldots \ldots \ldots \ldots . . . . . . . . . . . .196$

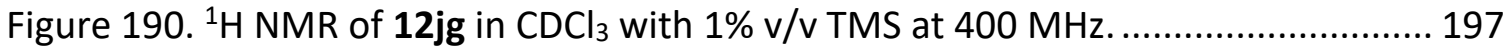

Figure 191. ${ }^{13} \mathrm{C}\left\{{ }^{1} \mathrm{H}\right\}$ NMR of 12jg in $\mathrm{CDCl}_{3}$ with 1\% v/v TMS at $101 \mathrm{MHz}$...................... 197

Figure 192. ${ }^{1} \mathrm{H}$ NMR of $12 \mathrm{~kg}$ in $\mathrm{CDCl}_{3}$ with $1 \% \mathrm{v} / \mathrm{v}$ TMS at $400 \mathrm{MHz}$.......................... 198

Figure 193. ${ }^{13} \mathrm{C}\left\{{ }^{1} \mathrm{H}\right\}$ NMR of $12 \mathrm{~kg}$ in $\mathrm{CDCl}_{3}$ with $1 \% \mathrm{v} / \mathrm{v}$ TMS at $101 \mathrm{MHz}$..................... 198

Figure 194. ${ }^{1} \mathrm{H}$ NMR of $12 \mathrm{mg}$ in $\mathrm{CDCl}_{3}$ with $1 \% \mathrm{v} / \mathrm{v} \mathrm{TMS}$ at $400 \mathrm{MHz}$........................... 199

Figure 195. ${ }^{13} \mathrm{C}\left\{{ }^{1} \mathrm{H}\right\}$ NMR of $\mathbf{1 2 m g}$ in $\mathrm{CDCl}_{3}$ with $1 \% \mathrm{v} / \mathrm{v}$ TMS at $101 \mathrm{MHz}$..................... 199

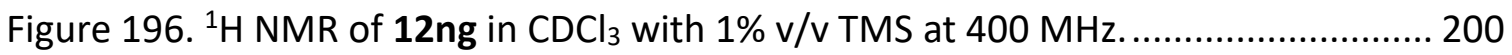

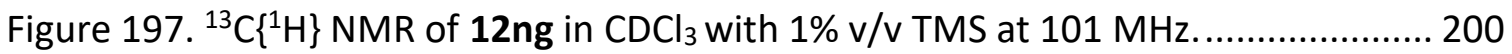

Figure 198. ${ }^{19} \mathrm{~F}\left\{{ }^{1} \mathrm{H}\right\}$ NMR of 12ng in $\mathrm{CDCl}_{3}$ with $1 \% \mathrm{v} / \mathrm{v}$ TMS at $376 \mathrm{MHz}$..................... 201

Figure 199. ${ }^{1} \mathrm{H}$ NMR of $120 \mathrm{~g}$ in $\mathrm{CDCl}_{3}$ with $1 \% \mathrm{v} / \mathrm{v}$ TMS at $400 \mathrm{MHz}$........................... 201

Figure 200. ${ }^{13} \mathrm{C}\left\{{ }^{1} \mathrm{H}\right\}$ NMR of $12 \mathrm{og}$ in $\mathrm{CDCl}_{3}$ with $1 \% \mathrm{v} / \mathrm{v}$ TMS at $101 \mathrm{MHz} \ldots \ldots \ldots \ldots \ldots \ldots . . . . . . . . . . .202$

Figure 201. ${ }^{1} \mathrm{H}$ NMR of $12 \mathrm{pg}$ in $\mathrm{CDCl}_{3}$ with $1 \% \mathrm{v} / \mathrm{v}$ TMS at $400 \mathrm{MHz}$........................... 202

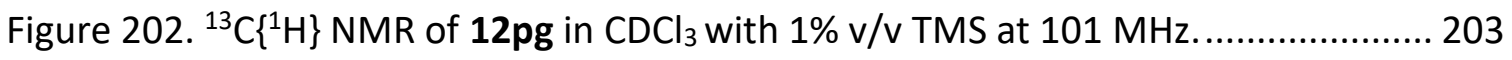

Figure 203. ${ }^{19} \mathrm{~F}\left\{{ }^{1} \mathrm{H}\right\}$ NMR of 12pg in $\mathrm{CDCl}_{3}$ with $1 \% \mathrm{v} / \mathrm{v}$ TMS at $376 \mathrm{MHz}$..................... 203

Figure 204. ${ }^{1} \mathrm{H}$ NMR of 12qg in $\mathrm{CDCl}_{3}$ with $1 \% \mathrm{v} / \mathrm{v}$ TMS at $400 \mathrm{MHz}$........................... 204

Figure 205. ${ }^{13} \mathrm{C}\left\{{ }^{1} \mathrm{H}\right\}$ NMR of 12qg in $\mathrm{CDCl}_{3}$ with 1\% v/v TMS at $101 \mathrm{MHz}$..................... 204

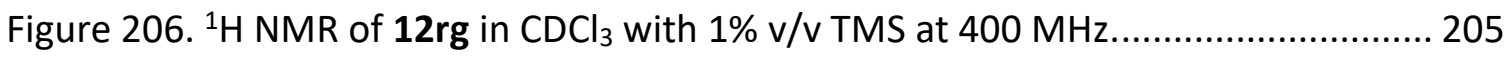

Figure 207. ${ }^{13} \mathrm{C}\left\{{ }^{1} \mathrm{H}\right\}$ NMR of 12rg in $\mathrm{CDCl}_{3}$ with 1\% v/v TMS at $101 \mathrm{MHz}$...................... 205

Figure 208. ${ }^{1} \mathrm{H}$ NMR of 12sg in $\mathrm{CDCl}_{3}$ with $1 \% \mathrm{v} / \mathrm{v} \mathrm{TMS}$ at $400 \mathrm{MHz}$.......................... 206

Figure 209. ${ }^{13} \mathrm{C}\left\{{ }^{1} \mathrm{H}\right\}$ NMR of 12sg in $\mathrm{CDCl}_{3}$ with $1 \% \mathrm{v} / \mathrm{v}$ TMS at $101 \mathrm{MHz}$...................... 206

Figure 210. ${ }^{19} \mathrm{~F}\left\{{ }^{1} \mathrm{H}\right\}$ NMR of 12sg in $\mathrm{CDCl}_{3}$ with $1 \% \mathrm{v} / \mathrm{v}$ TMS at $376 \mathrm{MHz}$....................... 207

Figure 211. ${ }^{1} \mathrm{H}$ NMR of $12 \mathrm{tg}$ in $\mathrm{CDCl}_{3}$ with $1 \% \mathrm{v} / \mathrm{v}$ TMS at $400 \mathrm{MHz}$.............................. 207

Figure 212. ${ }^{13} \mathrm{C}\left\{{ }^{1} \mathrm{H}\right\}$ NMR of 12tg in $\mathrm{CDCl}_{3}$ with $1 \% \mathrm{v} / \mathrm{v}$ TMS at $101 \mathrm{MHz}$....................... 208

Figure 213. ${ }^{1} \mathrm{H}$ NMR of 12 de in $\mathrm{CDCl}_{3}$ with $1 \% \mathrm{v} / \mathrm{v}$ TMS at $400 \mathrm{MHz}$........................... 208

Figure 214. ${ }^{13} \mathrm{C}\left\{{ }^{1} \mathrm{H}\right\}$ NMR of 12de in $\mathrm{CDCl}_{3}$ with 1\% v/v TMS at $101 \mathrm{MHz} \ldots \ldots \ldots \ldots \ldots \ldots . . . . . . . . . . .209$

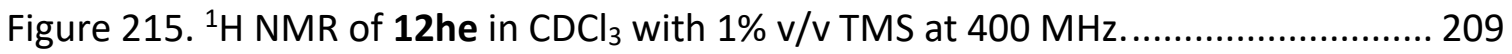

Figure 216. ${ }^{13} \mathrm{C}\left\{{ }^{1} \mathrm{H}\right\}$ NMR of $12 \mathrm{he}$ in $\mathrm{CDCl}_{3}$ with $1 \% \mathrm{v} / \mathrm{v}$ TMS at $101 \mathrm{MHz} \ldots \ldots \ldots \ldots \ldots \ldots . . . . . . . . . . .210$

Figure 217. ${ }^{19} \mathrm{~F}\left\{{ }^{1} \mathrm{H}\right\}$ NMR of $12 \mathrm{he}$ in $\mathrm{CDCl}_{3}$ with $1 \% \mathrm{v} / \mathrm{v}$ TMS at $376 \mathrm{MHz}$...................... 210

Figure 218. ${ }^{1} \mathrm{H}$ NMR of $12 \mathrm{le}$ in $\mathrm{CDCl}_{3}$ with $1 \% \mathrm{v} / \mathrm{v}$ TMS at $400 \mathrm{MHz} \ldots \ldots \ldots \ldots \ldots \ldots \ldots . . . . . . . . . . . . . . . . .211$

Figure 219. ${ }^{13} \mathrm{C}\left\{{ }^{1} \mathrm{H}\right\}$ NMR of 12le in $\mathrm{CDCl}_{3}$ with $1 \% \mathrm{v} / \mathrm{v}$ TMS at $101 \mathrm{MHz} \ldots \ldots \ldots \ldots \ldots \ldots . . . . . . . . . . .211$

Figure 220. ${ }^{19} \mathrm{~F}\left\{{ }^{1} \mathrm{H}\right\}$ NMR of 12 le in $\mathrm{CDCl}_{3}$ with $1 \% \mathrm{v} / \mathrm{v}$ TMS at $376 \mathrm{MHz}$..................... 212

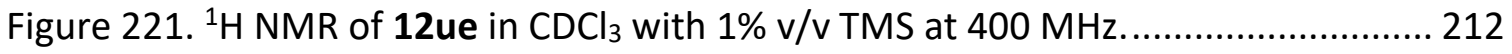


Figure 222. ${ }^{13} \mathrm{C}\left\{{ }^{1} \mathrm{H}\right\} \mathrm{NMR}$ of 12 ue in $\mathrm{CDCl}_{3}$ with $1 \% \mathrm{v} / \mathrm{v}$ TMS at $101 \mathrm{MHz} \ldots \ldots \ldots \ldots \ldots \ldots . . . . . . . . . . . . .213$

Figure 223. ${ }^{19} \mathrm{~F}\left\{{ }^{1} \mathrm{H}\right\} \mathrm{NMR}$ of 12 ue in $\mathrm{CDCl}_{3}$ with $1 \% \mathrm{v} / \mathrm{v}$ TMS at $376 \mathrm{MHz}$.................... 213 


\section{List of Schemes}

Scheme 1. A. Representative reactions of benzyne. B. Influence of substituent on attack

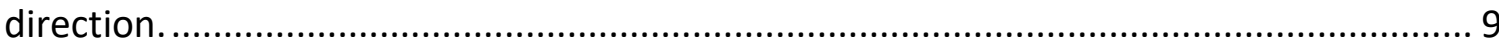

Scheme 2. Synthesis of 3-chlorobenzyne precursor..................................................... 11

Scheme 3. Aryl halides in aryne formation reactions............................................... 12

Scheme 4. Synthetic routes to aryl(Mes)iodonium tosylates (left) and aryl(TMP)iodonium tosylates (right) 15

Scheme 5. Synthetic possibilities of aryl(TMP)iodonium salts via various mechanistic

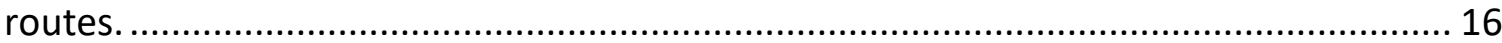

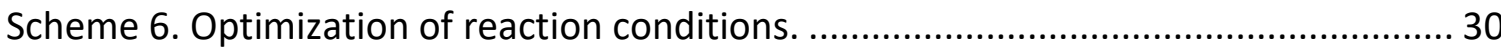

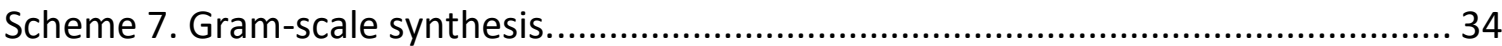

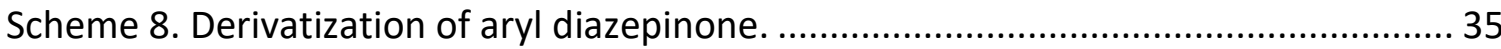

Scheme 9. Functionalization of two adjacent $\mathrm{C}-\mathrm{H}$ bonds via iodonium salts formation. 36

Scheme 10. Discovery of unexpected side products. ................................................ 37

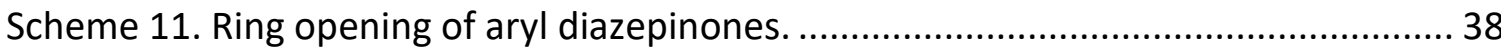

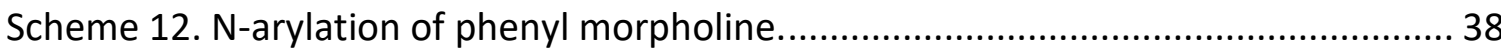

Scheme 13. Telescoped approach to aryne from aryl iodides. ................................... 45

Scheme 14. Application of telescoped reaction in formal synthesis of bioactive compound.

Scheme 15. Access to underrepresented substitution patterns via aryne intermediate. 50

Scheme 16. Phosphate promoted aryne formation. ...................................................... 51

Scheme 17. Synthesis of hydroxy(tosyloxy)iodomesitylene........................................ 53

Scheme 18. Synthesis of aryl(Mes)iodonium salts from iodides.................................... 54

Scheme 19. Synthesis of aryl(Mes)iodonium tosylates from aryl boronic acids............. 55

Scheme 20. Synthesis of aryl(Mes)iodonium tosylates from simple arenes...................56

Scheme 21. Dual C-H functionalization of 2-fluoroanisole.......................................... 74

Scheme 22. Functionalization via Suzuki-Miyaura coupling........................................... 81

Scheme 23. Functionalization via Buchwald-Hartwig amination. ............................... 82

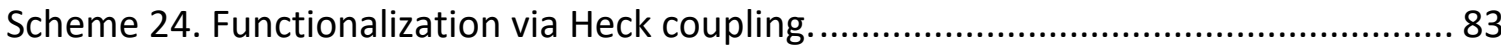

Scheme 25. Synthesis of aryl(TMP)iodonium salts from aryl iodides. ......................... 151

Scheme 26. Regioselectivity of trapping aryne formed from $11 \mathbf{w} . . . \ldots \ldots \ldots \ldots \ldots \ldots \ldots . . . . . . . . . . . . . .171$

Scheme 27. Regioselectivity of trapping aryne formed from 11x............................. 172

Scheme 28. Regioselectivity of trapping aryne formed from 11y............................... 172

Scheme 29. Regioselectivity of trapping aryne formed from 11z............................... 173

Scheme 30 . Regioselectivity of trapping aryne formed from 11aa............................... 174 
1 Introduction

\subsection{Importance of benzenoid rings}

The importance of benzenoid rings is hard to overstate due to their abundance in various societally important industries. Applications of benzenoid containing compounds range from plastics and dyes to vital medicines and agrochemicals. Figure 1 shows several examples that include the biologically active natural product morphine, synthetic drugs cobimetinib and meclofenamic acid, as well as the herbicide tembotrione, petroleumderived dye Sunset Yellow, and thermoplastic polymer polycarbonate. The ability of synthetic chemists to form new bonds to aromatic rings, and in a desired position is of the utmost importance to the discovery of new compounds that may have important societal applications.
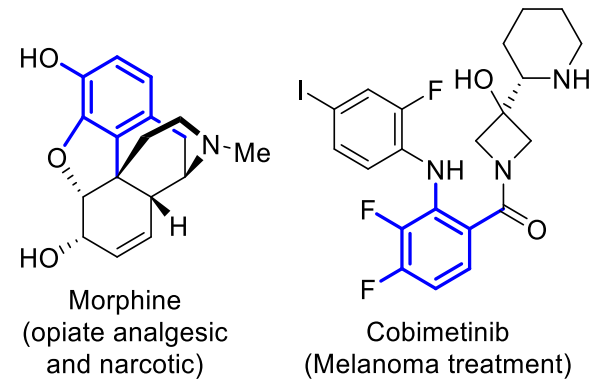

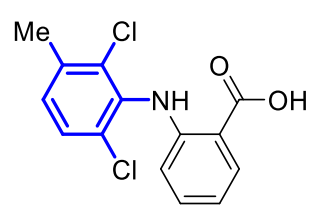

Meclofenamic acid (non-steroidal anti-inflammatory agent)

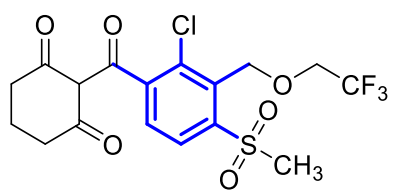

Tembotrione "Laudis" (Herbicide)

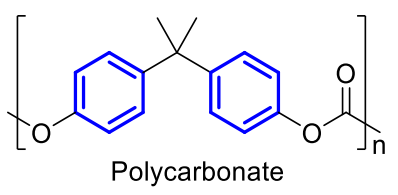<smiles>O=S(=O)(O[Na])c1ccc(N=Nc2c(O)ccc3cc(S(=O)(=O)O[Na])ccc23)cc1</smiles>

Figure 1. Examples of benzenoid-containing molecules with benzenoid rings highlighted in blue. 


\subsection{Substitution patterns: existing analyses, identifying a gap}

Aromatic rings are a prevalent motif in drug molecules. ${ }^{1}$ Benzenoid rings in particular are the most common ring type in drug candidates ${ }^{2}$ and small molecule new molecular entities (NME) approved by the U.S. FDA. ${ }^{3}$ The structure-function relationship of active pharmaceutical ingredients (API) is a strong tool for predicting druglikeness and guides synthesis of drug candidates. Previous analyses of APIs by both academic and industrial medicinal chemistry groups have focused on physiological properties ${ }^{1,4,5}$, common frameworks ${ }^{3,6}$, and the reagents ${ }^{7}$ and reactions ${ }^{2,8,9}$ to synthesize them. For instance, Ritchie and Macdonald looked at the connection between aromatic ring count in oral drug candidates and lipophilicity and solubility as properties reflecting the binding ability of a potential drug and its availability for interaction with a biological target. ${ }^{1}$ They concluded that molecules with three or fewer aromatic rings correlate with higher success in developability and reaching the market. Taylor et al. analyzed marketed drugs approved by the FDA and found that 1175 ring containing molecules are represented by only 351 ring systems. ${ }^{3}$ Considering the timeline associated with the introduction of drugs to the market the authors noticed that from year to year most of new drugs repeat previously introduced ring systems. Meanwhile, the overall number of drug candidates has been continuously increasing for several decades..$^{10}$ As medicinal chemists rely on previously present ring systems in new drug development, the synthesis of new drug candidates is based on functional group modification reactions that stand up among other types of reactions. ${ }^{2,9}$ Comparison of the most favorable reactions for medicinal chemists between 1984 and 2014 revealed that nucleophilic aromatic substitution $\left(\mathrm{S}_{N} \mathrm{Ar}\right)$, reaction 
of aryl lithium, and Sonogashira coupling were preferred for aromatic ring functionalization in both analyzed periods. With the further development of Pd catalysis, Suzuki-Miyaura coupling and Buchwald-Hartwig amination became irreplaceable in derivatization of haloarenes.

Among substituted benzenoid ring-containing starting materials used for synthesis of drug candidates the preference for para-substituted rings over other substitution patterns is discerned. ${ }^{9}$ Specifically, Brown et al. noted that para-chloro substituted benzenoid is prevalent in various screening collections and known drugs over its meta- and ortho- analogs. ${ }^{7}$ Moreover, further analysis of chemical databases revealed similar trend for other groups and their similarly substituted analogs (e.g., di-Cl, di-F, diOMe). In an attempt to determine the origin of this event, the ease of accessing the para position through electrophilic aromatic substitution $\left(S_{E} A r\right)$ reactions was seen as the most plausible explanation (historical synthetic route). However, a broader analysis of benzenoid substitution patterns in APIs has not been previously reported in literature.

\subsection{Functionalization of benzenoid rings}

Substituted benzenoids can be produced through various general ways, including electrophilic and nucleophilic aromatic substitution, transition metal catalyzed reactions, and aryne reactions. In contrast to $S_{E} A r$ and more recent transition metal catalyzed reactions, the other methods require a leaving group to proceed. Thus, reaction in which the leaving group is replaced by a new group are synthetically useful, but do not create a new substitution pattern. 


\subsubsection{Electrophilic aromatic substitution}

Discovered in the late $19^{\text {th }}$ century, electrophilic aromatic substitution $\left(S_{E} A r\right)$ reactions represent one of the most important and well-studied transformations for arene functionalization. It is widely utilized to access valuable intermediates and products in various industries. ${ }^{11} \mathrm{An}$ important aspect of this approach is an ability to install a new functionality in place of a hydrogen substituent and, therefore, increase the number of substituents on a benzenoid ring. The general pathway of $S_{E} A r$ involves two important intermediates: 1) the formation of a $\pi$-complex between the $\pi$-system of an arene and an electrophile represented by either cationic or dipolar species, 2) the formation of a $\sigma$ complex (arenium ion or Wheland complex) between a ring carbon and the electrophile (Figure 2, A). Rearomatization occurs as a result of a removal of the ipso proton with base. The nature of substituents on the aromatic ring dictates the direction of the electrophilic attack and the resulting substitution pattern of the benzenoid ring. Electron donating groups (such as $\mathrm{R}, \mathrm{OR}, \mathrm{NR}_{2}$ ) that are capable of resonance donation, including halogen substituents, direct the attack in positions 2 or 4 relative to the substituent, thus, resulting in 1,2-, 1,4-, and/or 1,2,4-substituted benzenoids. Further functionalization of trisubstituted benzenoids relies not only on the electronic effect of substituents but also on a steric accessibility of the functionalized position. In this case an installation of the fourth substituent generally produces 1,2,4,5-substituted arene (Figure 2, B). Presence of strong electronegative substituents $\left(\mathrm{NO}_{2}, \mathrm{CF}_{3}, \mathrm{COOR}, \mathrm{CN}\right)$ causes destabilization of a $\sigma$ complex, and electrophilic aromatic substitution is feasible only at the position 3. As a 
result, 1,3-substituted benzenoids are produced in some cases, though these reactions are more rare.

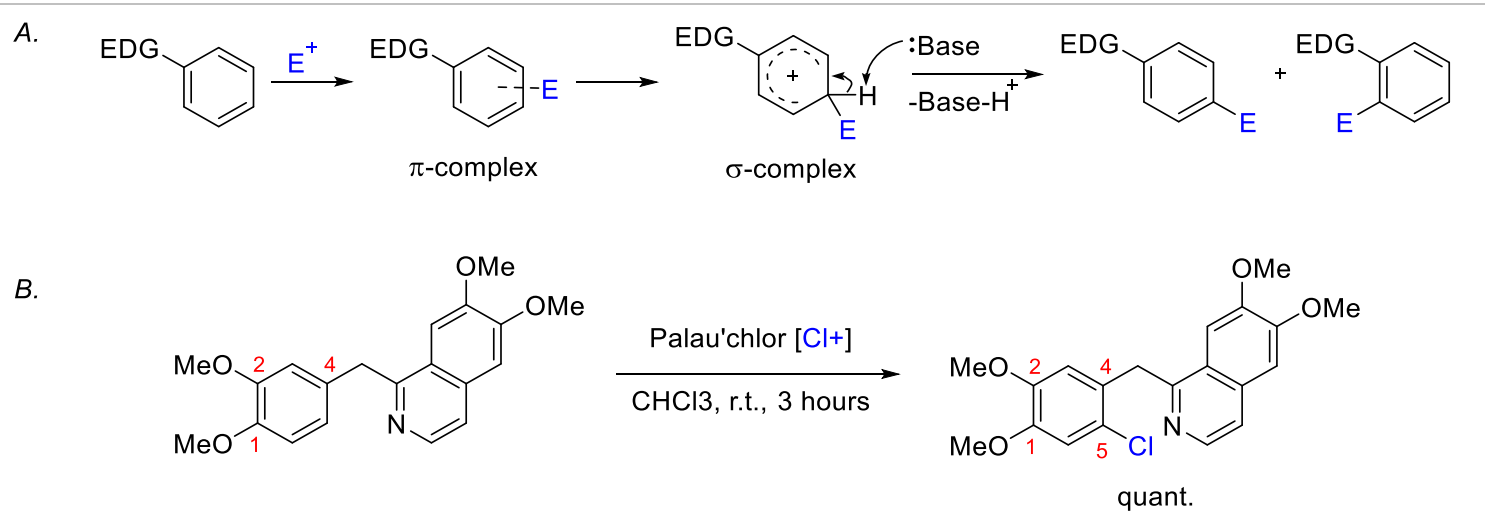

Figure 2. Electrophilic aromatic substitution reaction: A. Mechanism; B. Example of synthetic application. ${ }^{12}$

\subsubsection{Nucleophilic aromatic substitution}

The presence of a strong electron-withdrawing group (EWG) on a benzenoid ring opens an opportunity for nucleophilic aromatic substitution $\left(\mathrm{S}_{N} \mathrm{Ar}\right)$ when an appropriate leaving group is present (typically a halide). ${ }^{13}$ Additionally, the leaving group must be positioned ortho or para to the EWG. The mechanism of this transformation has been intensely studied since the $19^{\text {th }}$ century, and the most favored addition-elimination mechanism was proposed by J. Meisenheimer..$^{14,15}$ In this process the $\sigma$-complex (Meisehheimer complex) is formed upon addition of a nucleophile and stabilized by the EWG. Leaving group expulsion results in a new functionality installed in its place (Figure 3). $\mathrm{C}-\mathrm{H}$ functionalization is rather uncommon for $\mathrm{S}_{N} \mathrm{Ar}$ and the transformation conserves the substitution pattern of a starting material. 

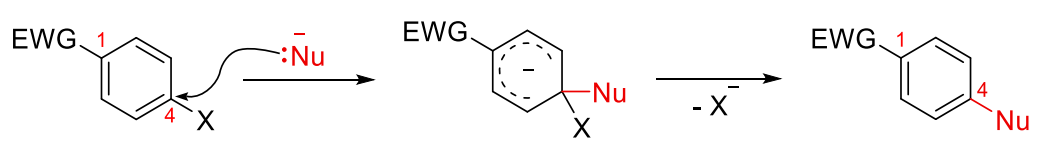

$\sigma$-complex

Figure 3. Mechanism of nucleophilic aromatic substitution reaction.

\subsubsection{Transition metal catalyzed reactions}

A century after the discovery of $S_{E} A r$ and $S_{N} A r$ reactions, aryl halides became a prominent element of novel transformations facilitated by the transition metals. Since then, transition metal catalyzed reactions, and $\mathrm{Pd}$ catalyzed reactions in particular, have proven to be a reliable method for synthesis of various biologically active molecules. ${ }^{2,16}$ This approach allows previously challenging carbon-carbon and carbon-heteroatom bonds formation to occur. Transition metal catalysis obviates the formation of charge intermediates and, therefore, does not rely on the electron deficiency of an aromatic ring in comparison to the $S_{N} A r$. The general steps of a metal catalyzed cross-coupling reaction include oxidative addition of aryl halide to a metal complex, transmetalation of a nucleophile on a transition metal, and reductive elimination (Figure 4). The overall outcome is a replacement of a leaving group with a nucleophile. Similar to $S_{N} A r$ reactions, the retention of substitution pattern in the final product is observed. 


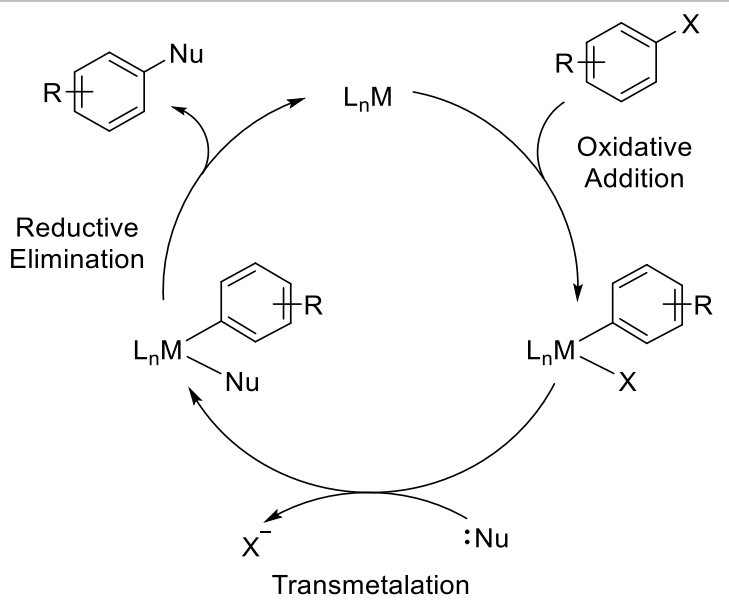

Figure 4. General mechanism of metal catalyzed cross-coupling reaction.

\subsubsection{Aryne enabled functionalization}

Arynes are recognized as useful intermediates to functionalize aromatic rings. The traditional approach to aryne formation includes deprotonation of the benzenoid ring under basic conditions followed by the loss of a leaving group in an adjacent position (Figure 5). This process results in the formation of a highly strained cycloalkyne. ${ }^{17}$ Although the observation of aryne reactivity had originated in early $20^{\text {th }}$ century, ${ }^{18}$ the first structural assignment of an aryne intermediate was revealed in 1953 by Roberts et al. ${ }^{19}$ Strain caused by the direction of orbitals of the triple bond makes it highly reactive electrophile. Aryne intermediates can be used for building multiple new carbon-carbon and carbon-heteroatom bonds in a single step. ${ }^{20}$ Attack by charged and uncharged nucleophiles leads to a direct approach to 1,2-difunctionalization of aromatic rings. ${ }^{21}$ 


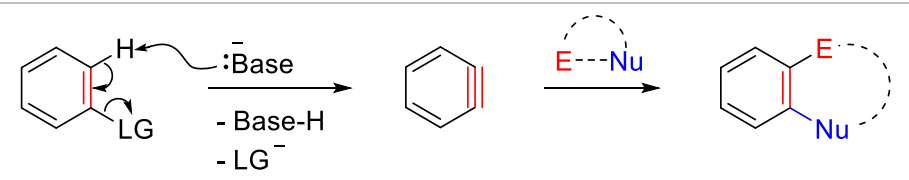

$\mathrm{LG}=\mathrm{Cl}, \mathrm{Br}$, I

Figure 5. Aryne formation reaction.

\subsection{Application of aryne intermediate}

Aryne formation reactions (Scheme 1. A.) have found a broad application in the pericyclic reactions such as [4+2] cycloaddition reaction with dienes ${ }^{22},[2+2]$ cycloaddition with alkenes ${ }^{23}$, and [3+2] cycloaddition with dipolar substrates ${ }^{24}$ (i.e. azides). In addition, arynes can insert in the element-element bond of a polar $\sigma$-bond where one of the components serves as a nucleophile and the other as an electrophile. ${ }^{25-28}$ Similar to the insertion reaction, 1,2-disubstituted products are formed in the process of the multicomponent reactions. ${ }^{29}$ However, in this case a nucleophile and an electrophile are represented by distinct molecules. Multicomponent and bond insertion reactions may lead not only to vicinal difunctionalization of aromatic ring, but also to ipso or cine substitution in the case where a proton plays a role of an electrophile. ${ }^{30,31}$ The substituents on an aryne intermediate have a significant influence on the direction of nucleophilic attack. Thus, $\sigma$-withdrawing groups (including halides and alkoxides) direct nucleophilic attack to the distal carbon of the triple bond in highly selective manner (Scheme 1. B.). The released pair of electrons attacks an electrophile producing 1,2,3substituted pattern. 
A.
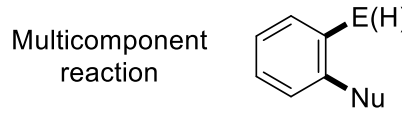

reaction<smiles>CCCCC</smiles>
insertion
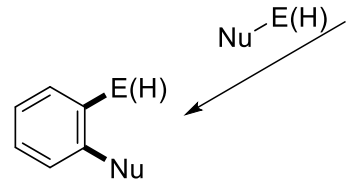

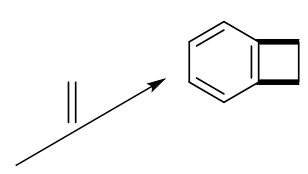

Cycloaddititon

Cycloaddititon
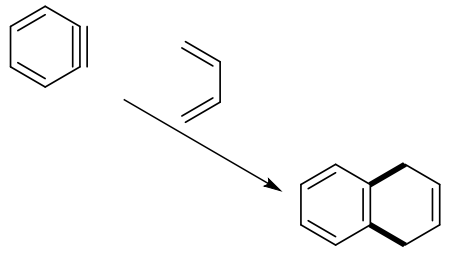

$[4+2]$

Cycloaddititon

B.

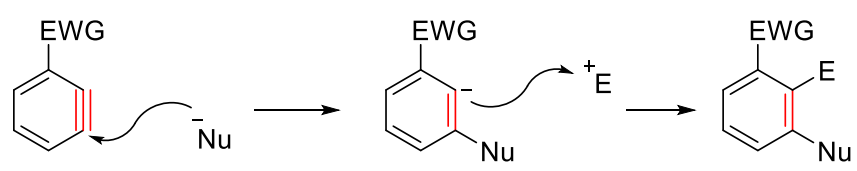

Scheme 1. A. Representative reactions of benzyne. B. Influence of substituent on attack direction.

\subsubsection{Recent advances in aryne formation reactions}

A number of aromatic ring containing compounds can serve as starting materials for generating highly reactive benzyne intermediate (Figure 6). Aryl monohalides were the first precursors for generating aryne intermediates. ${ }^{19,32}$ Treating the substrate with alkali metal amide in boiling ammonia leads to $\mathrm{C}-\mathrm{H}$ deprotonation followed by halogen elimination to form benzyne. However, the presence of multiple halogens results in unselective elimination of the leaving group in some cases. ${ }^{33}$ The reaction conditions also preclude this method with base-sensitive substituents. In addition, the strong base required for deprotonation may act as a competitive nucleophile for attack on the aryne. Nevertheless, the availability of aryl halides makes this type of precursors highly attractive for application as aryne precursor. Significant improvements to the classical approach were presented by the groups of Olafs Daugulis and Qiu Wang over the last few years. ${ }^{25,30,34-36}$ Aryl chlorides, bromides, and triflates are shown to undergo aryne 
formation reaction with a broad range of arynophiles resulting in carbon-carbon and carbon-heteroatom bonds formation. Additionally, selective elimination of a triflate group over chloride is achieved under the reaction conditions.

An approach to synthesize benzyne intermediate from ortho-dihalobenzenes and pseudohalocontaining analogs has been proposed by multiple groups. This type of the transformation is enabled by metalation reaction with lithium containing compounds followed by the elimination of a leaving group (halide) and generally requires cryogenic temperatures. ${ }^{37-40}$ Benzenediazonium-2-carboxylates can alternatively generate an aryne intermediate upon thermolysis. ${ }^{41}$ Although this approach does not require chemical facilitation, it is limited due to the explosive nature of diazotized anthranilic acid. ${ }^{42}$ Among other precursors ortho-(trimethylsilyl)aryl triflates remain one of the most widely used starting materials. This method was developed by Kobayashi in 1983 and has received considerable attention from the scientific community due to moderately basic conditions used for the formation of aryne. ${ }^{43}$ Under similar reaction conditions phenyl[2(trimethylsilyl)aryl]iodonium triflates generate aryne intermediates. Proposed by Kitamura in 1995, this transformation is advanced by the higher nucleofugality of iodonium group relative to triflate. ${ }^{44}$

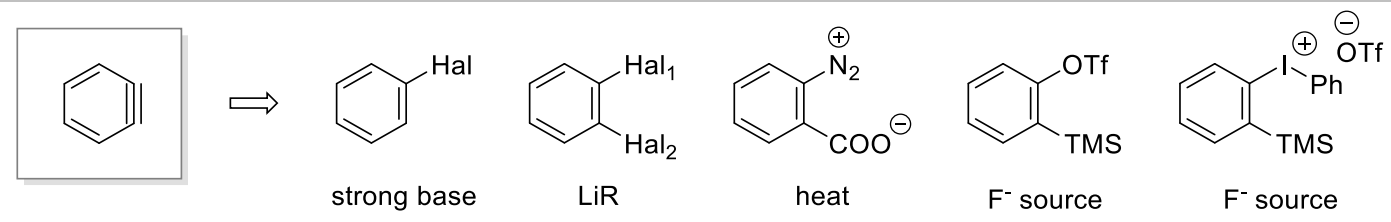

Figure 6. Methods to generate benzyne and required conditions. $\mathrm{Hal}=$ halogen. 


\subsubsection{Current synthetic challenges in aryne formation}

The ability of aryne intermediates to form multiple new bonds in one step has amplified an interest in these species. Its profound capability for rapid construction of diverse molecular frameworks has been demonstrated for synthesis of pharmaceutically and biologically relevant small molecules and natural products. ${ }^{20,45}$ The method developed by Kobayashi is greatly appealing for this purpose. Along with the use of a mild base to generate aryne, the rate of reaction can be controlled by the choice of solvent, fluoride source, and combination of thereof. ${ }^{46}$ However, this method is not free of disadvantages. The relatively high price and lack of commercially available substituted benzyne precursors bring the need for an on-site synthesis. Installation of the required substituents in adjacent positions takes 3-5 steps along with multiple distillations or column chromatography purifications. ${ }^{43,47-49}$ For example, 3-chlorobenzyne precursor can be obtained from 2-chlorophenol in $68 \%$ yield (Scheme 2). Total synthesis of this precursor takes 20 hours of reaction time and includes three chromatography purifications. $^{48}$

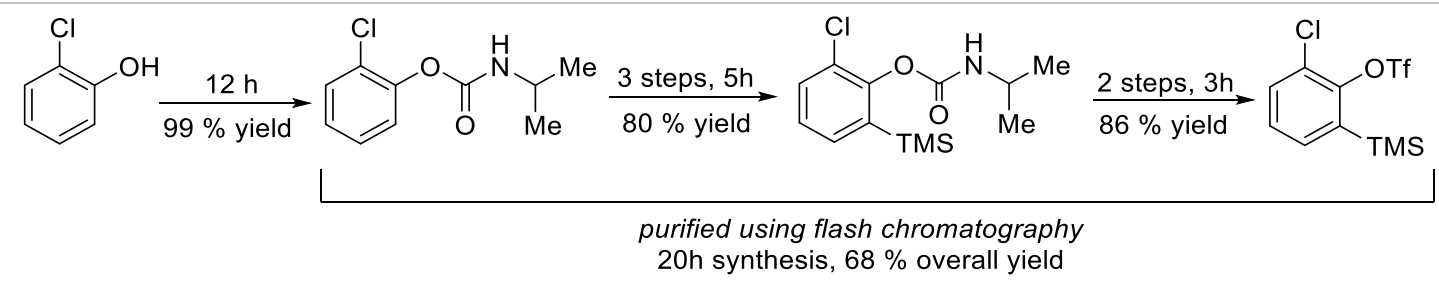

Scheme 2. Synthesis of 3-chlorobenzyne precursor.

On the other hand, a large variety of substituted aryl(pseudo)halides is commercially available. The requirement to have a single substituent (halide or 
pseudohalide) and available C-H bond in adjacent position for aryne formation gives an opportunity for introducing additional functionality. The conversion of aryl(pseudo)halides to aryne intermediates has been successfully used as a key transformation in natural product syntheses. ${ }^{45,50-52}$ Despite the recent advances, the use of lithium containing bases and need of cryogenic temperatures are a practical limitation. The discovery of a new base lithium diadamantylamide (LDAM) allows for a reaction to proceed at $0{ }^{\circ} \mathrm{C} .{ }^{25}$ The hindrance of this amide base suppresses its nucleophilic property and consequently results in an enhanced selectivity of aryne coupling (Scheme 3, top). Nevertheless, LDAM promoted aryne formation has only been reported in air-free atmosphere. A milder base $\mathrm{NaOt}$-Bu has been shown to successfully convert aryl chlorides to aryne intermediates for 0 -arylation of phenols (Scheme 3, bottom). This transformation is facilitated by high temperature $\left(135-155^{\circ} \mathrm{C}\right)$ and usually requires $\mathrm{AgOAC}$ as an additive. ${ }^{30}$

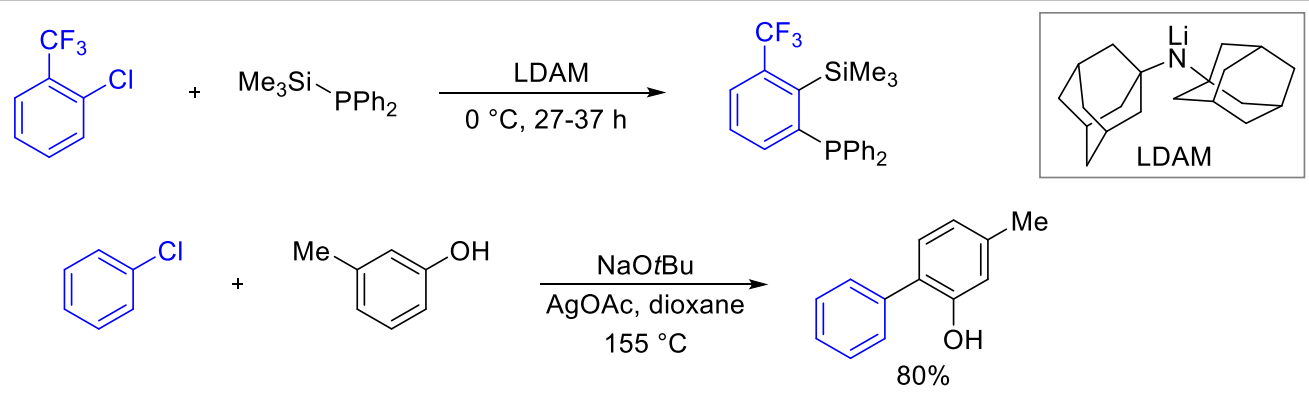

Scheme 3. Aryl halides in aryne formation reactions.

\subsection{Diaryliodonium salts as aryne precursor: from the first evidence}

The application of diaryliodonium salts for aryne synthesis was initially demonstrated in $1974 .{ }^{53}$ The symmetrical diaryliodonium halide $\mathbf{1}$ was utilized as an 
arylation agent in the reaction with phenyltetrazolide $\mathbf{2}$ (Figure 7). Refluxing of the reaction mixture for 24 hours in tert-butanol resulted in the formation of three pairs of products consisted of meta and para-substituted structural isomers 3-5 consistent with aryne reactivity. The authors confirmed their hypothesis of aryne formation by treating the same iodonium salt with $\mathrm{NaO} t$-Bu in $t$ - $\mathrm{BuOH}$ where a mixture of $p$-tolyl and $m$-tolyl $t$ butyl ethers was obtained in 1:1 ratio and overall yield of $27 \%$. A year later Cadogan et.al. synthesized arynes through thermolysis of diaryliodonium acetate and its substituted derivatives prepared by admixing of corresponding iodonium halides with KOAc. ${ }^{54}$ Trapping of an intermediate with tetraphenylcyclopentadienone gave corresponding 1,2,3,4-tetraphenylnaphthalenes in 3-12\% yield. Since these initial reports the formation of arynes from diaryliodonium salts via deprotonation is sparse in the recent literature and have typically been noted as a minor by-product when reductive elimination is desired.${ }^{55}$ Despite the observation of aryne formation in the reactions of diaryliodonium salts this approach continued to remain undeveloped until our discovery in $2016 .{ }^{56}$ This approach will be introduced in Chapter 3.

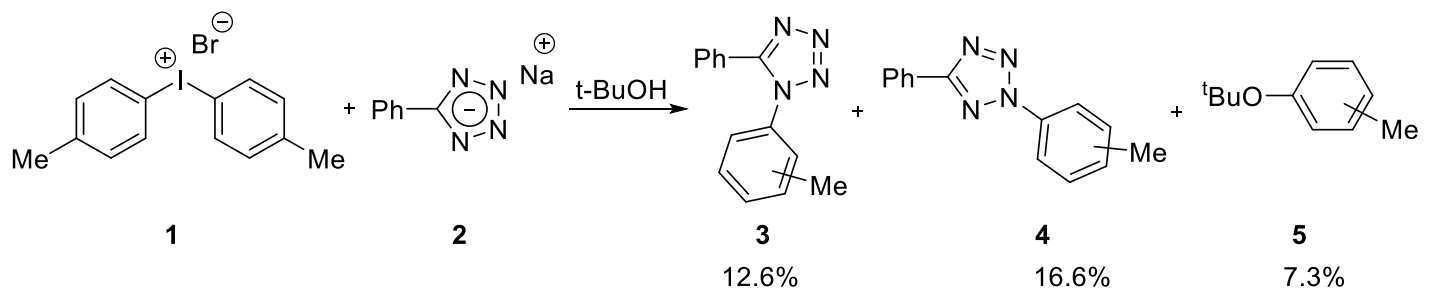

Figure 7. First evidence for aryne formation from diaryliodonium salt. 


\subsection{Synthesis of unsymmetrical diaryliodonium salts}

In addition to their ability to act as aryne precursors, hypervalent iodine compounds are of high interest in contemporary organic synthesis as aryl transfer reagents and an alternative to transition metal catalysis; they are known to be nontoxic and relatively bench-stable materials. ${ }^{57-59}$ Diaryliodanes, commonly known as diaryliodonium salts, are represented by structure shown in Figure 8 where $\lambda^{3}$-iodane center is covalently bound to two (hetero)aromatic rings and associated with anionic ligand. It was experimentally determined that in the solid state substituents of diaryliodonium salts favor a T-shape orientation with an Ar-I-Ar

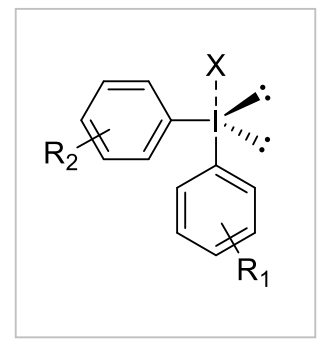

Figure 8. Structure of diaryliodonium salt. angle close to $90^{\circ}$.

Unsymmetrical diaryliodonium salts are especially advantageous when one aryl group can be transferred selectively. Aryl(mesityl)iodonium tosylates represent a valuable group of hypervalent iodine compounds. The arylation properties of these substrates are conveniently complemented by an access via multiple synthetic routes and in one-pot (Scheme 4). Boronic acid of the functionalized arene of interest can be introduced into the reaction with an auxiliary containing aryl- $\lambda^{3}$-iodane to produce corresponding aryl(mesityl)iodonium salt in the presence of Lewis acid. The application of simple arenes was demonstrated by several research groups. Electron-rich arenes are used in the reaction with aryl- $\lambda^{3}$-iodane electrophiles such as hydroxy(tosyloxy)iodomesitylene. The scope of shown substrates is limited to $1,3,5$ - 
trimethoxybenzene $(\mathrm{TMB})$, anisole, and thiophen and its derivatives. ${ }^{60} \mathrm{~A}$ broader scope of possible electron-rich substrates was demonstrated when fluorinated solvents were utilized. ${ }^{61}$ The oxidation of aryliodides with $m$-chloroperbenzoic acid ( $m$-CPBA) in the presence of $p$-toluenesulfonic acid (HOTs) followed by addition of mesitylene affords aryl(mesityl)iodonium tosylate in under 4 hours. ${ }^{59}$ The ubiquity of Suzuki cross-coupling has made aryl iodides and aryl boronic acids widely commercially available.

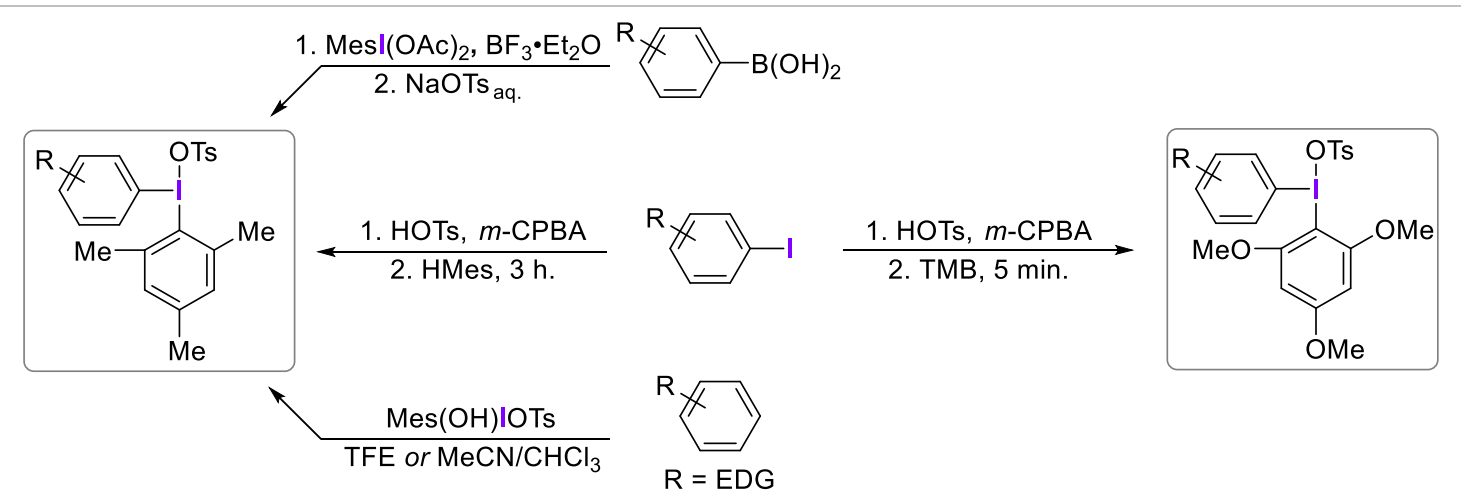

Scheme 4. Synthetic routes to aryl(Mes)iodonium tosylates (left) and aryl(TMP)iodonium tosylates (right).

The examples of synthetic application of 2,4,6-trimethoxyphenyl (TMP) containing iodonium salts had been sparse from literature due to a lack of a convenient method of preparation. A robust one-pot protocol was reported only in 2016 and provided a routine access to these substrates in under an hour (Scheme 4, right)..$^{59}$ This discovery accelerated the reaction development methods focused on aryl(TMP)iodonium salts (Scheme 5). Thus, the ability of these compounds to undergo metal-free ipso-substitution reactions has been demonstrated with various nucleophiles. They have been shown to selectively react with $\mathrm{N}$ - and $\mathrm{O}$-nucleophiles as well as undergo radiofluorination in this type of transformation. ${ }^{59,62-66}$ Likewise, the reports of transition metal catalyzed arylation of 
amides and imines with TMP salts have been recently presented in the literature. ${ }^{67,68}$ Additionally, aryl(TMP)iodonium salts can undergo transformations via radical mechanism, and the methods for arylation of $\mathrm{N}$-heteroaromatics and a rapid access to 3arylsulfonylquinolines have been established. ${ }^{69,70}$ The work described in Chapter 4 reveals new synthetic possibilities of aryl(TMP)iodonium tosylates as an aryne precursor. Thus, this specific ability of TMP containing iodonium reagents to undergo various types of transformations selectively on an aryl group rather than the auxiliary makes these substrates highly attractive and prospective universal iodonium substrates as an arylating agent.

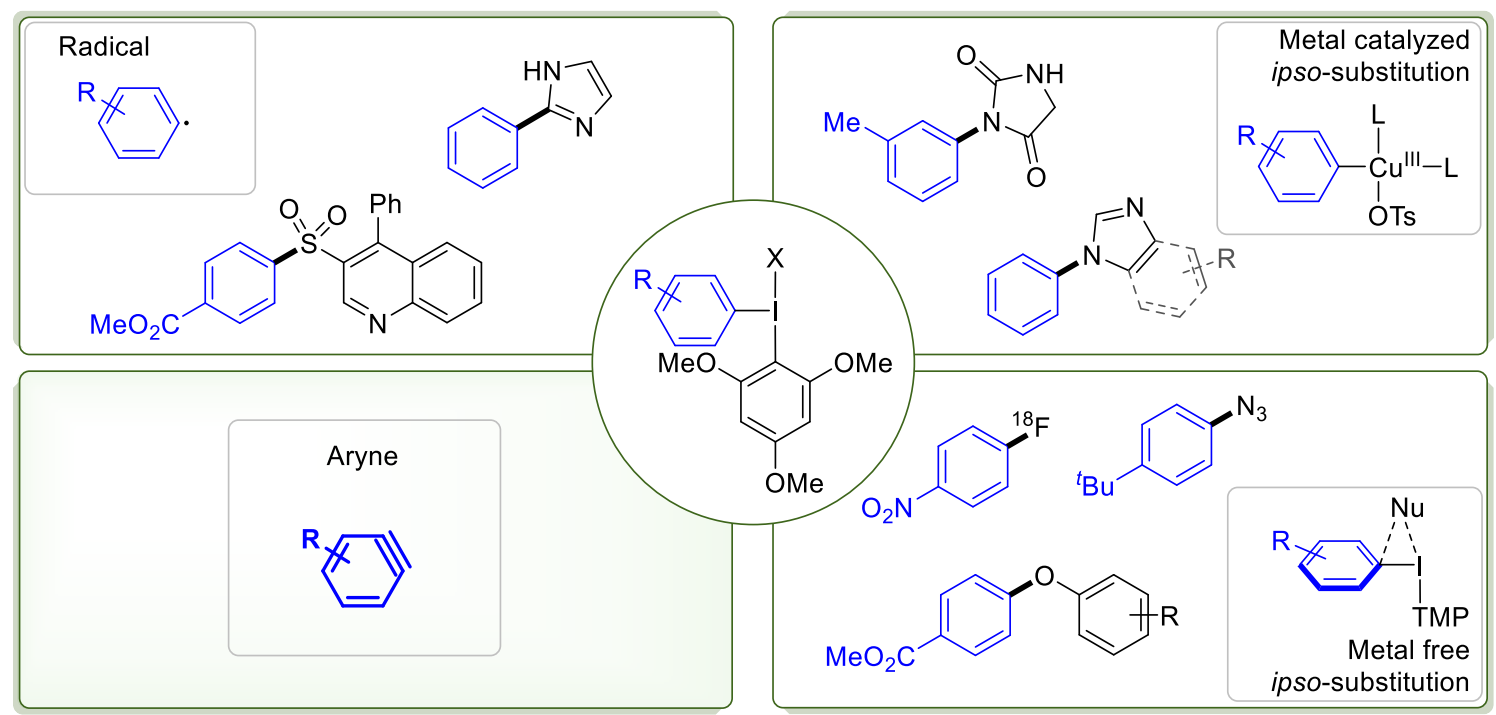

Scheme 5. Synthetic possibilities of aryl(TMP)iodonium salts via various mechanistic routes. 


\subsection{Parameters of analysis}

An overview of synthetic methods to functionalize aromatic rings was presented in Chapter 1 and was proposed to influence the substitution patterns of aromatic rings in a variety of industries. The pharmaceutical industry has been particularly proactive in assessing structure-function relationships of API, though a broad analysis of aromatic ring substitution patterns has not previously appeared in the literature. Our analysis of benzenoid substitution patterns in APIs is focused on small molecule drugs approved by the FDA up to the end of 2019. We used the database publicly available on DrugBank (drugbank.ca) ${ }^{71}$ with the following filters applied: "small molecule drugs", "approved", and "US". The original search was performed on January 31, 2019 and revealed 1793 approved small molecule drugs, and the NMEs approved during 2019 were obtained from a list of novel drug approvals for 2019 published by the FDA. ${ }^{72}$ Benzenoid containing small molecule drugs were manually extracted, excluding benzenoid rings fused to other (hetero)aromatic systems (i.e., naphthalene, (iso)quinoline, indole, etc.) previously identified as distinct ring systems. ${ }^{3}$ The dataset was narrowed to 904 APIs. Our analysis included the number of benzenoid rings in each API and the substitution pattern for each ring; we also included time as an additional dimension of our analysis. Substitution patterns were assigned based on the position of substituents on the benzenoid ring, but neglecting the substituents identity, and, therefore the chemical space of benzenoid rings consists of twelve different substitution patterns shown in Figure 9 (1-; 1,2-; 1,3-; 1,4-; 1,2,3-; 1,2,4-; 1,3,5-; 1,2,4,5-; 1,2,3,5-; 1,2,3,4-; 1,2,3,4,5-; 1,2,3,4,5,6-). Our analysis 
across time employed the FDA drug approval reports by month; the search was performed based on submission classification only including drugs classified as "Type 1 New Molecular Entity". The chemical structures of the NMEs identified from the FDA were retrieved from DrugBank ${ }^{71}$ and PubChem ${ }^{73}$. The druglikeness, complexity, and similarity of the APIs within each substitution pattern were calculated for a slightly reduced dataset where multi-component and metal containing entries were excluded from the database along with several compounds that failed the data processing protocols of our collaborators at Merck. This modification reduced the dataset to 864 molecules. The complexity of small molecule drugs was estimated by the use of software developed inhouse at Merck and reflects a correlation with synthetic tractability and process mass intensity. ${ }^{74}$ According to this approach the complexity ranges from 1 to 5 , where 1 is the least complex and 5 is the most complex molecule. The druglikeness of the elements in the dataset was quantified using Lipinski's rule-of-five ${ }^{75}$ and a rule-of-six model $^{76}$ developed at Merck. Similarity was calculated using Dice similarity based on 2dimensional atom pair descriptor. According to this method a cluster centroid is determined and its pairwise combination of atom pairs is compared to those of other molecules. ${ }^{77}$ Based on a magnitude of the match the molecules are clustered, and the similarity ranges from 0 (nothing in common) to 1 (identical). Similarity of the molecules was measured separately for the individual groups of substitution patterns with Dice similarity cutoff of 0.5 and 0.6 . 


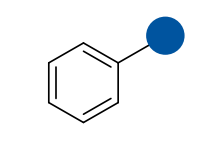

$1-$

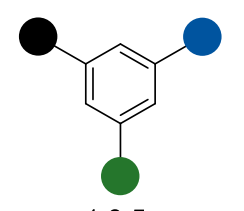

$1,3,5-$

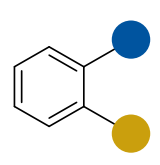

$1,2-$

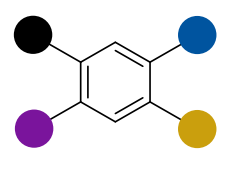

$1,2,4,5-$

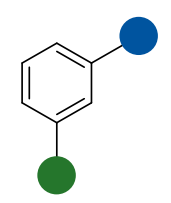

$1,3-$

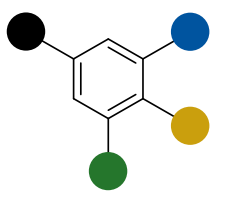

$1,2,3,5-$

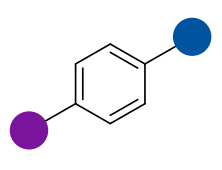

$1,4-$

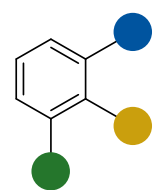

$1,2,3-$

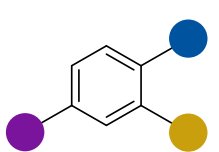

$1,2,4-$

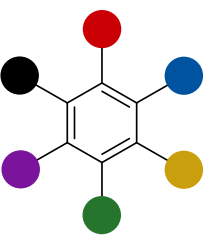

$1,2,3,4,5,6-$

Figure 9. Possible benzenoid substitution patterns.

\subsection{Analysis}

We began our analysis by looking at the distribution of benzenoid rings in a given API for a dataset of 904 small molecule drugs. It was found that about $60 \%$ (539 molecules) of the APIs contain only one benzenoid ring, $34 \%$ (307 molecules) contain two benzenoid rings, and only $5 \%$ contain 3 benzenoid rings (Figure 10). This result aligns with the previously reported correlation of the number of aromatic rings with the developability of molecules where it was noticed that molecules with less than three aromatic rings were more developable. ${ }^{1}$

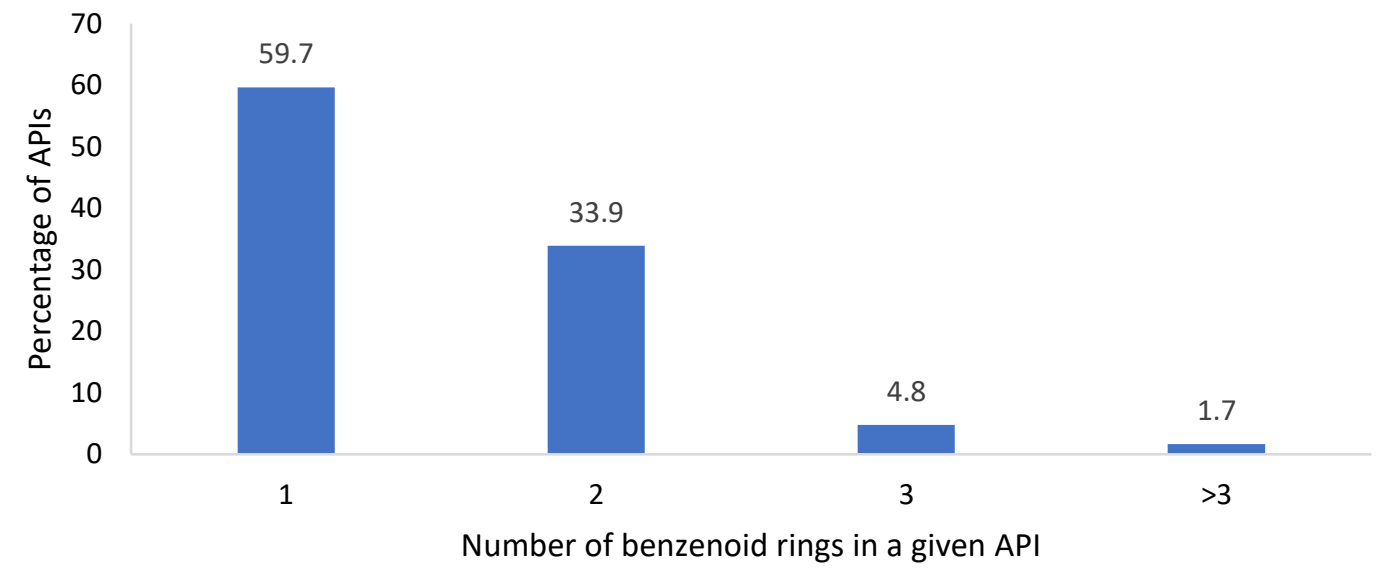

Figure 10. Distribution of the number of benzenoid rings in a given API. 
The total number of benzenoid rings in the dataset of 904 molecules was 1364, and the substitution pattern of every ring was visually identified (Figure 11). The most abundant substitution patterns are 1,4-, 1-, 1,2,4-, and 1,2-substituted arenes. These four substitution patterns represent $76 \%$ of benzenoid rings and are the most synthetically accessible via $S_{E} A r$ and correlate with those purchased by medicinal chemists as starting materials. ${ }^{9}$ The remaining eight substitution patterns represent only $24 \%$ of benzenoid rings and their individual appearance is attributed to not more than $5 \%$. This sparse representation may be explained by a lack of synthetic pathways and low commercial availability of starting materials. As mentioned in Chapter 1.2, among the most prevalent synthetic methodologies, those used for benzenoid ring functionalization are nucleophilic aromatic substitution $\left(\mathrm{S}_{N} \mathrm{Ar}\right)$, reaction with aryl lithium, Sonogashira coupling, SuzukiMiyaura coupling, and Buchwald-Hartwig amination. ${ }^{2,8}$ However, these reactions replace an existing substituent with a new one, but do not create a new substitution pattern. The relative position of individual substituents in the underrepresented benzenoid rings are categorized as contra-electronic by means of $S_{E} A r(1,3-$ and 1,3,5-) and sterically congested (1,2,3-, 1,2,3,5-, 1,2,4,5-, 1,2,3,4-, 1,2,3,4,5,6-, and ,1,2,3,4,5-). 


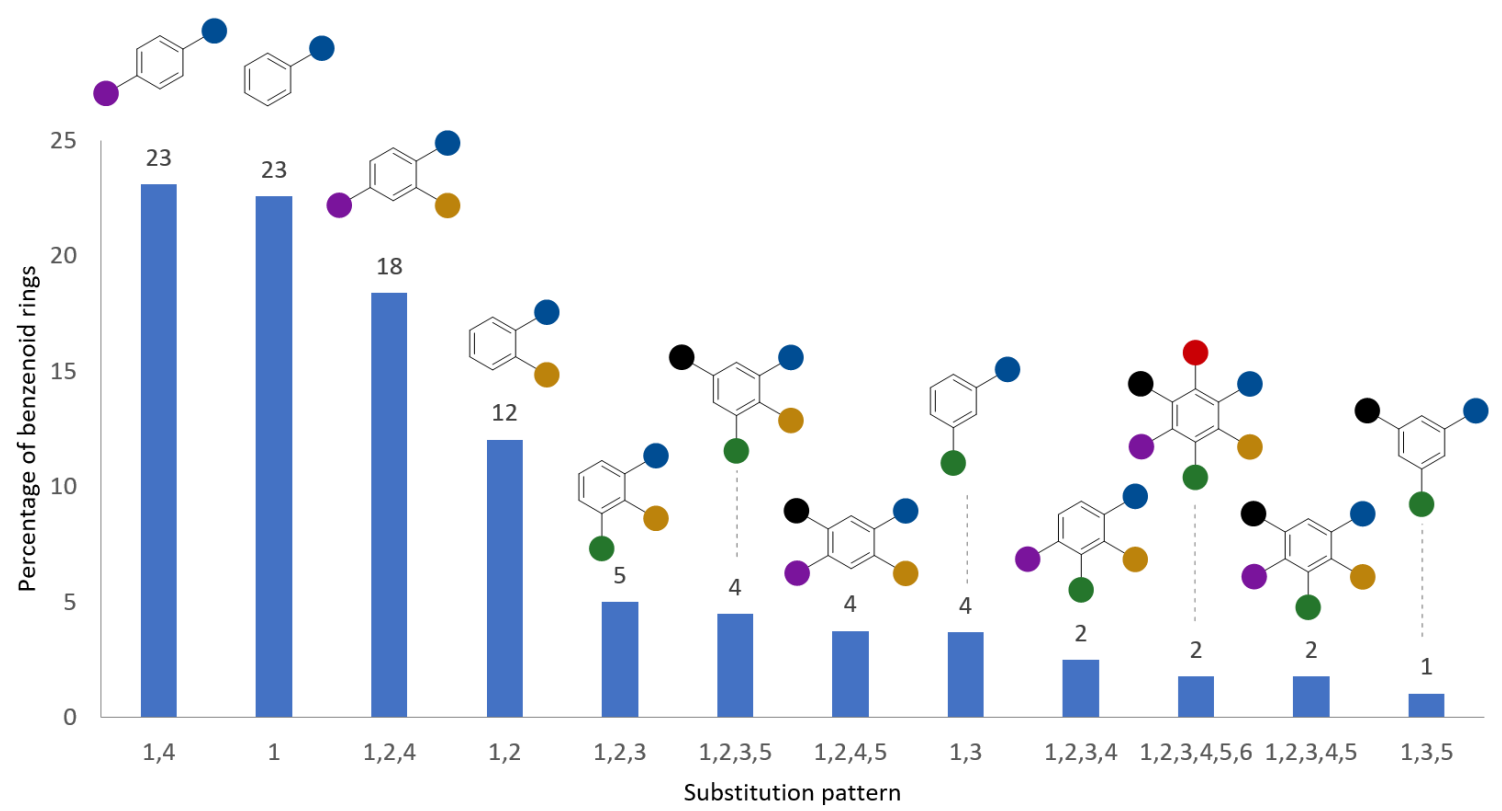

Figure 11. Distribution of benzenoid substitution patterns in APIs.

I further analyzed both the number of benzenoid rings in a given API and the substitution patterns over time. The discovery of palladium-catalyzed reactions has had a dramatic impact on synthetic chemistry, especially coupling reaction of aromatic rings. Developed at the end of the $20^{\text {th }}$ century Sonogashira, Suzuki-Miyaura, and BuchwaldHartwig Pd-catalyzed cross-coupling reactions became a prominent and reliable tool to incorporate benzenoid rings in drug candidates. In this analysis we compared two time periods roughly separated by the "named reactions" described above. The first period includes NMEs for the period of 1959-1979, at the end of which aryl-alkyne and aryl-aryl coupling reactions were reported. For the second period we chose two decades of postcross-coupling 1999-2019. We first looked at the distribution of the number of benzenoid rings in a given API in each time-period in comparison to the distribution of approved drug molecules. It can be seen in Figure 12 that the overall trend remains the same, and the 
drug molecules containing only one benzenoid ring are still prevalent and attributed to more than $50 \%$ of all molecules. However, a slight change in distribution between two time periods is evident. The number of compounds incorporating one benzenoid ring decreases from $58 \%$ in the pre-palladium catalysis era (1959-1979) to $53 \%$ in the postpalladium catalysis era (1999-2019). This moderate change results in an increase in the number of those APIs with two or more benzenoid rings in comparison to the previous time period. Although this difference may seem insignificant, it reflects analogous changes observed in screening libraries over the last two decades. ${ }^{8}$

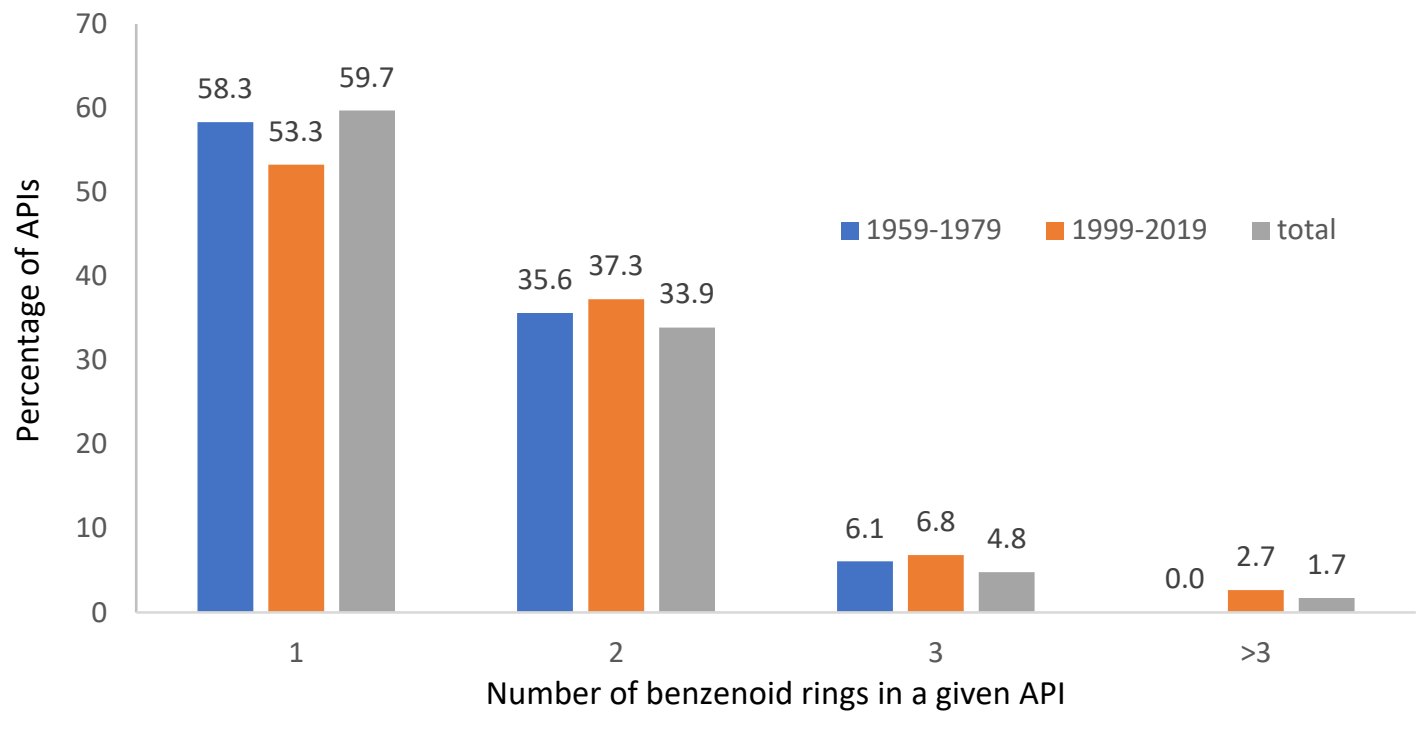

Figure 12. Historical insight in distribution of benzenoid rings in a given API.

We considered the influence of transition-metal catalysis on distribution of benzenoid substitution patterns. Over the two time periods described above the distribution of substitution patterns did not significantly change in comparison to the complete dataset. The most prevalent substitution patterns in both time periods were 1,4-, 1-, 1,2,4-, and 1,2-substituted benzenoids comprising 78\% in $1959-1979$ and $74 \%$ in 
1999-2019 (Figure 13). Meanwhile, a number of NMEs approved in a later time period, and a number of benzenoid rings accordingly, increased drastically from 100 molecules (150 benzenoid rings) to 333 molecules (536 rings). Despite an impressive synthetic reliability and applicability of Sonogashira, Suzuki-Miyaura, and Buchwald-Hartwig crosscoupling reactions, these strategies mostly rely on previously installed substitution pattern of starting materials and, thus, do not have a significant influence on synthesis of sterically congested and contra-electronic benzenoids.

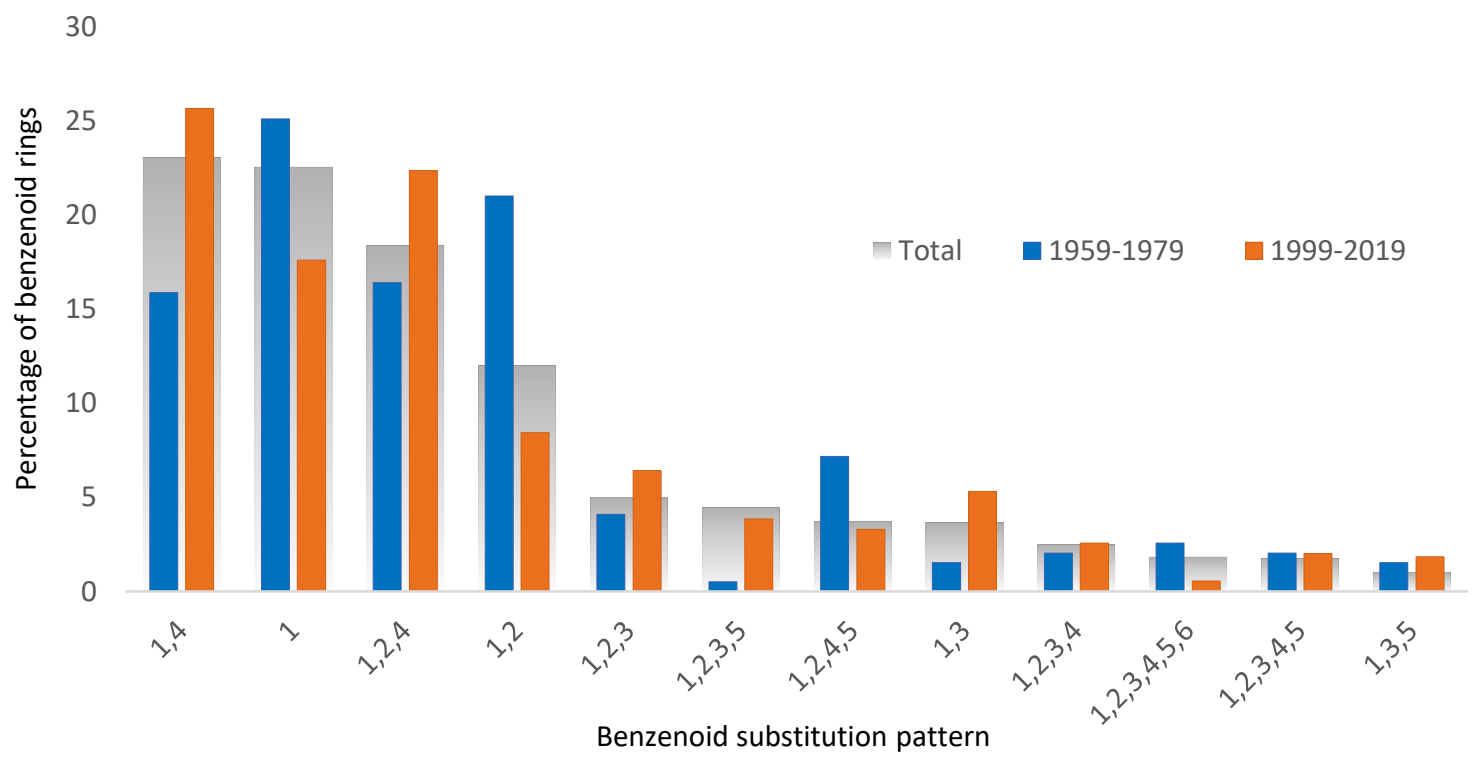

Figure 13. Distribution of benzenoid substitution patterns in historical perspective.

Although the dataset is comprised of small molecule NMEs approved by the FDA, we wanted to estimate the druglikeness of molecules across the substitution patterns to evaluate if there is a difference in druglikeness based on substitution pattern. It was done by applying the parameters of Lipinski's rule-of-five (RO5) and Merck's rule-of-six (RO6). Analysis demonstrated there was not substantial difference among substitution patterns and between the models applied. The distribution of druglikeness among substitution 
patterns can be seen in Figure 14. The vast majority of the molecules meet the requirements of druglikeness and are quantified on average as $85 \%$ for Lipinski's rule and $72 \%$ of NMEs when RO6 is applied. Both approaches allow for only a single rule violation to "pass". Overall, $96 \%$ of the molecules that did not pass RO5 or RO6 exceeded the molecular weight limit of 500 Da for RO5. Noticeably, over $60 \%$ of $1,2,3,4,5,6$-substituted benzenoid containing molecules violate both RO5 and RO6. This group represents the most substituted benzenoids and has the highest average molecular weight in comparison to others, that causes the first violation. Additionally, most of these molecules have a prohibited excess of hydrogen bond acceptors $(\geq 10)$ and donors $(\geq 5)$. Despite failure to meet theoretical requirements, these APIs include important classes of drugs, such as anthracyclins (e.g. epirubicin and daunorubicin) and iodinated contrast agents (e.g. iopromide and iohexol).

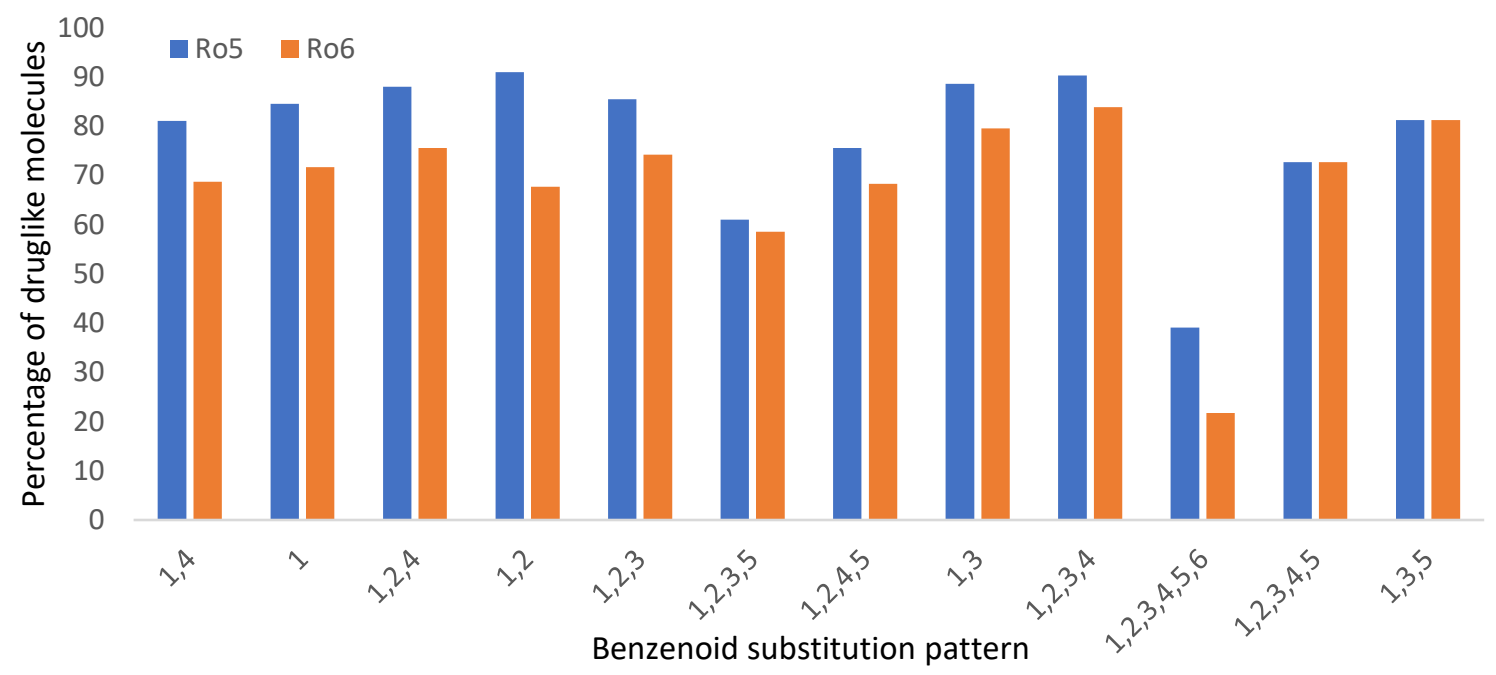

Figure 14. Percent of "druglike" molecules based on rule-of-five and rule-of-six.

The complexity of small molecule NMEs was assessed for every group of benzenoid substitution pattern and the standard deviation was calculated. A moderate 
increase in complexity from more abundant substitution patterns towards underrepresented benzenoids can be seen on Figure 15. As complexity in this analysis correlates with synthetic difficulty, these data support our hypothesis that underrepresented patterns are harder to obtain via synthetic methodologies favored by medicinal chemists.

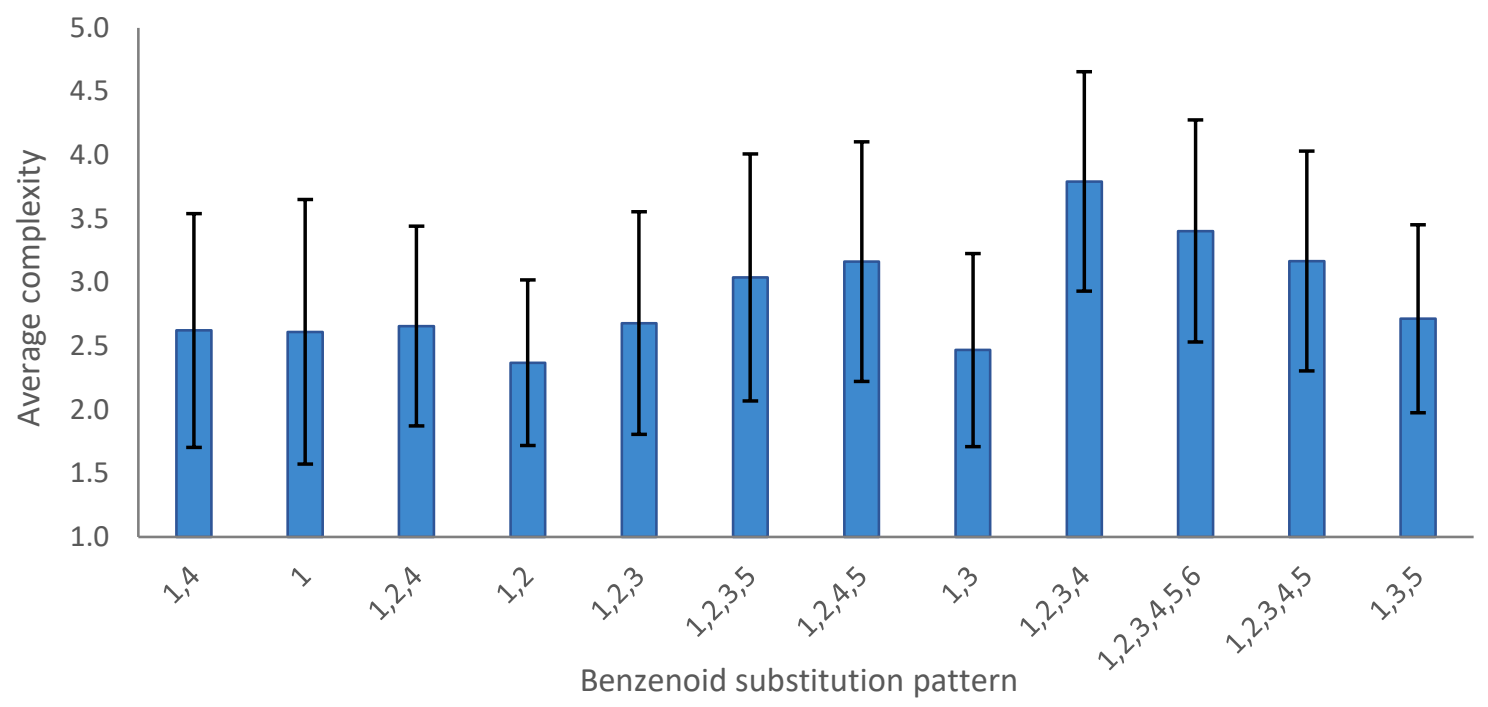

Figure 15. Average complexity and standard deviation of substitution patterns.

To connect the complexity of approved drugs to structural appearance, we decided to gain an insight on the similarity of the molecules within every substitution pattern. Additionally, this analysis would provide an estimate of structural diversity. For this analysis we chose the largest cluster of each benzenoid substitution pattern and calculated an input in a total number of molecules in every group. It appeared that most of the substitution patterns are represented by very diverse structures and the size of the largest cluster is accounted to not more than $15 \%$ of the total substitution pattern with a similarity cutoff of 0.5 and $10 \%$ when similarity is set to 0.6 (Figure 16). However, NMEs 
of 4 out of 12 substitution patterns are represented by less diverse chemical structures, and the contribution of the largest cluster varies from $21 \%$ to $45 \%$. Interestingly, these benzenoid substitution patterns are synthetically challenging: 1,3,5- (21\%, 3-molecule cluster), 1,2,3,4,5,6- (21\%, 5-molecule cluster), 1,2,3,4,5- (27-32\%), and 1,2,3,4substituted benzenoids (39-45\%). Noticeably, the least structurally diverse is $1,2,3,4-$ substituted pattern; that is also the most complex with average complexity of 3.8 and highly druglike ( $88 \%$ of druglike molecules based on RO5) pattern. An explanation for this relationship arises from the nature (structural appearance) of the largest cluster. Almost half of the small molecules NMEs of this substitution pattern are represented by natural product morphine and its derivatives. These molecules are synthetically challenging with calculated complexity above 4 and pass both RO5 and RO6. The subsequent chapters describe the development of synthetic methods that address the limited access to contraelectronic and sterically congested benzenoid rings.

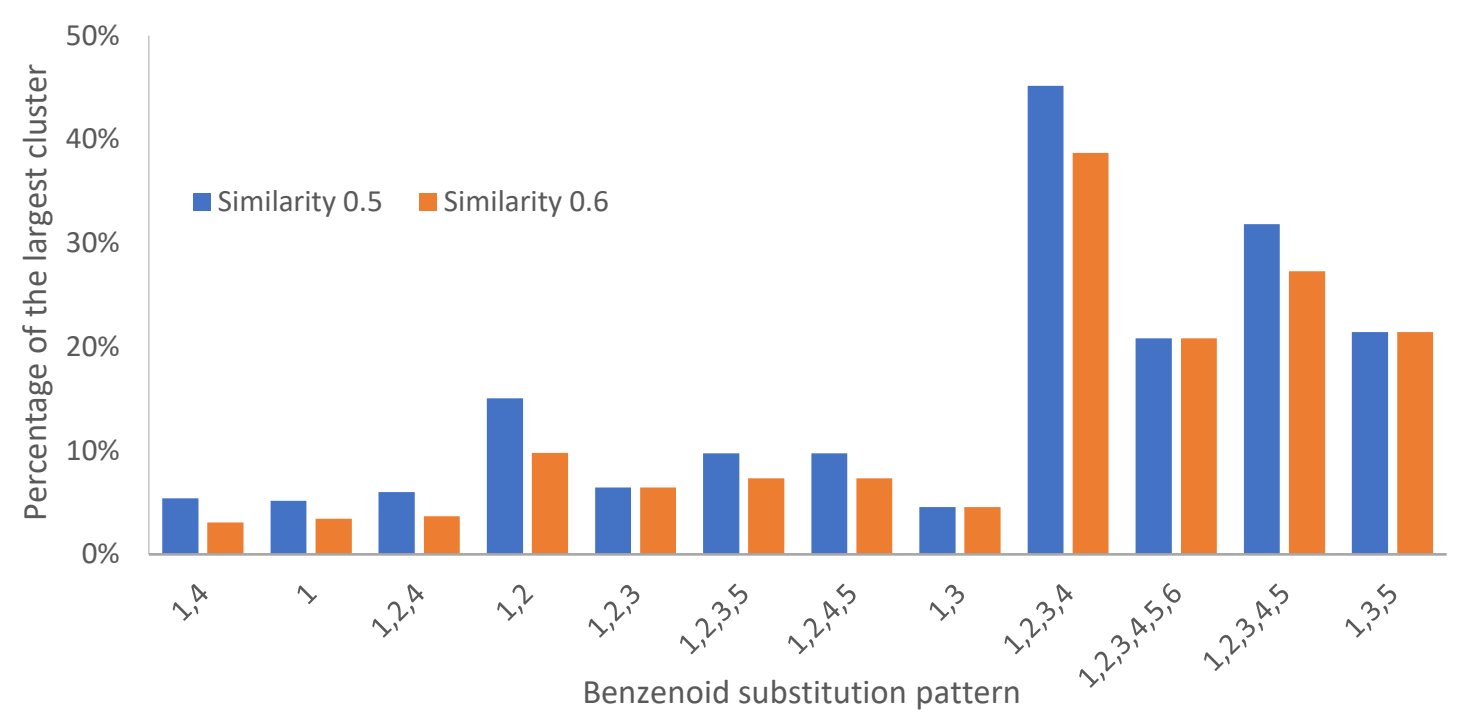

Figure 16. Largest cluster input. 


\section{Aryl(mesityl)iodonium salts as aryne precursors.}

\subsection{Modern synthetic approach to aryne formation from diaryliodonium salts}

The approach to aryne formation from diaryliodonium salts via $\mathrm{C}-\mathrm{H}$ deprotonation remained underdeveloped since the first observation in 1974 in which an aryne was trapped in low-yield. ${ }^{53}$ In 2016, two high-yielding methods to access arynes from diaryliodonium salts with strong base were described. First, the Stuart research group ${ }^{56}$ demonstrated the formation of aryne intermediates from aryl(mesityl)iodonium tosylates using LiHMDS as a base, and the highly reactive intermediate was trapped with furan. The method was applied to more than 20 distinct aryl(mesityl)iodonium tosylates as substituted aryne precursors (Table 1). Soon after, the Wang research group demonstrated $\mathrm{N}$-phenylation of various amides using symmetrical diphenyliodonium triflates as the benzyne precursor and $\mathrm{KOt}$-Bu as base, followed by insertion into $\mathrm{N}-\mathrm{H}$ bond. ${ }^{31}$ Later, the aryne reactivity of aryl(Mes)iodonium tosylates was expanded with Naryl pyrroles and tertiary amines. ${ }^{78,79}$

Table 1. Representative examples of aryl(Mes)iodonium tosylates as aryne precursors.
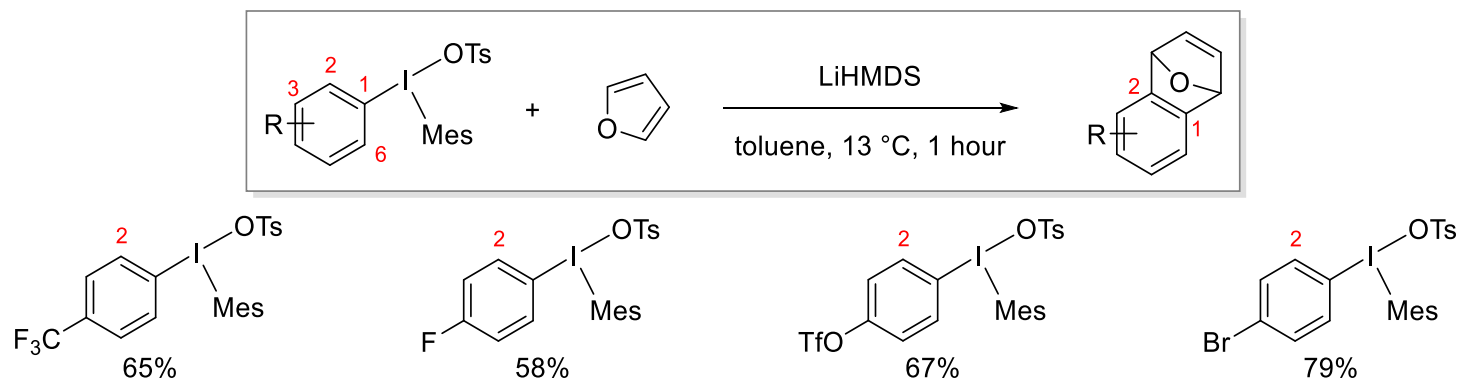

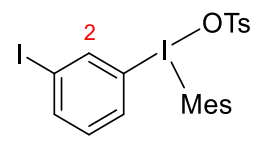

$89 \%$

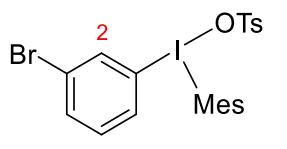

$84 \%$

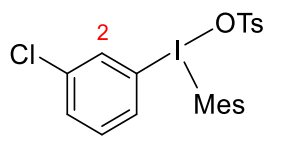

$69 \%$

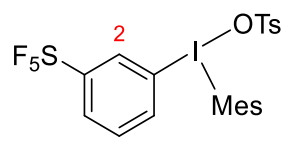

$50 \%$ 


\subsection{Synthesis of sterically congested benzenoid rings}

We became particularly interested in the development of a synthetic methodology that would provide an easy access to the underrepresented benzenoids described in Chapter 2. The precedent for the functionalization of a sterically congested C-H position (position 2, Table 1) using iodonium salts inspired us to apply this approach in building densely functionalized benzenoid rings. Therefore, we aimed to establish a protocol to synthesize 1,2,3,4-substituted benzenoids from disubstituted aryl(Mes)iodonium tosylates which are readily available from the corresponding 1,2,4substituted arenes, which are common starting materials.

\subsubsection{Optimization}

As a starting point, 3-chloro-4-methylphenyl(Mes)iodonium tosylate 6a was chosen as a disubstituted aryne precursor. Dimethylimidazolidinone (DMI) has been shown to act as an arynophile that provides an access to aryl diazepinone analogs via $\sigma$ bond insertion into a C-N bond of urea. ${ }^{80}$ The coupling of these two substrates under the previously developed reaction conditions provided the expected compound in $64 \%$ yield. Switching the base to $\mathrm{NaOt}-\mathrm{Bu}$, that was previously shown to enable aryne formation, increased the reaction outcome to $72 \%$. Reducing the amount of DMI from 5.5 to 3 equivalents drastically reduced the yield of this reaction with LiHMDS (29\%) but had less significant effect when $\mathrm{NaOt}$-Bu was used (56\%). Based on these preliminary results, the interaction effects of equivalents of $\mathrm{NaOt}$-Bu and arynophile and temperature was explored by applying the design of experiments. A $2^{3}$ full factorial design consisted of eight experiments revealed that the optimal reaction conditions consist of 1.5 equivalents of 
$\mathrm{NaOt}$-Bu, 3 equivalents of $\mathrm{DMI}$, and $25{ }^{\circ} \mathrm{C}$ reaction temperature, resulting in $69 \%$ yield of product (Scheme 6). The consumption of the iodonium salt as the limiting reagent was assessed based on the formation of mesityl iodide as the main by-product in this transformation and was found to be $95 \%$. An immediate color change was observed in the reaction and therefore the reaction time was also tested. Indeed, an identical yield was observed after 15 minutes, and the yield was slightly reduced to $55 \%$ within 5 minutes of reaction time. Toluene was found to be a suitable solvent for this transformation not only with LiHMDS as a base but also with $\mathrm{NaOt}-\mathrm{Bu}$ (66\% yield). The use of acetonitrile led to a reduced reaction yield of $45 \%$. The iodonium moiety is crucial for aryne formation under the developed conditions, and the product formation was not observed when the corresponding iodide was used instead. Even a significant increase in temperature to 135 ${ }^{\circ} \mathrm{C}$ and time to 24 hours $^{30}$ did not provide useful reactivity of the aryl iodide (Scheme 6, Entry 7). 


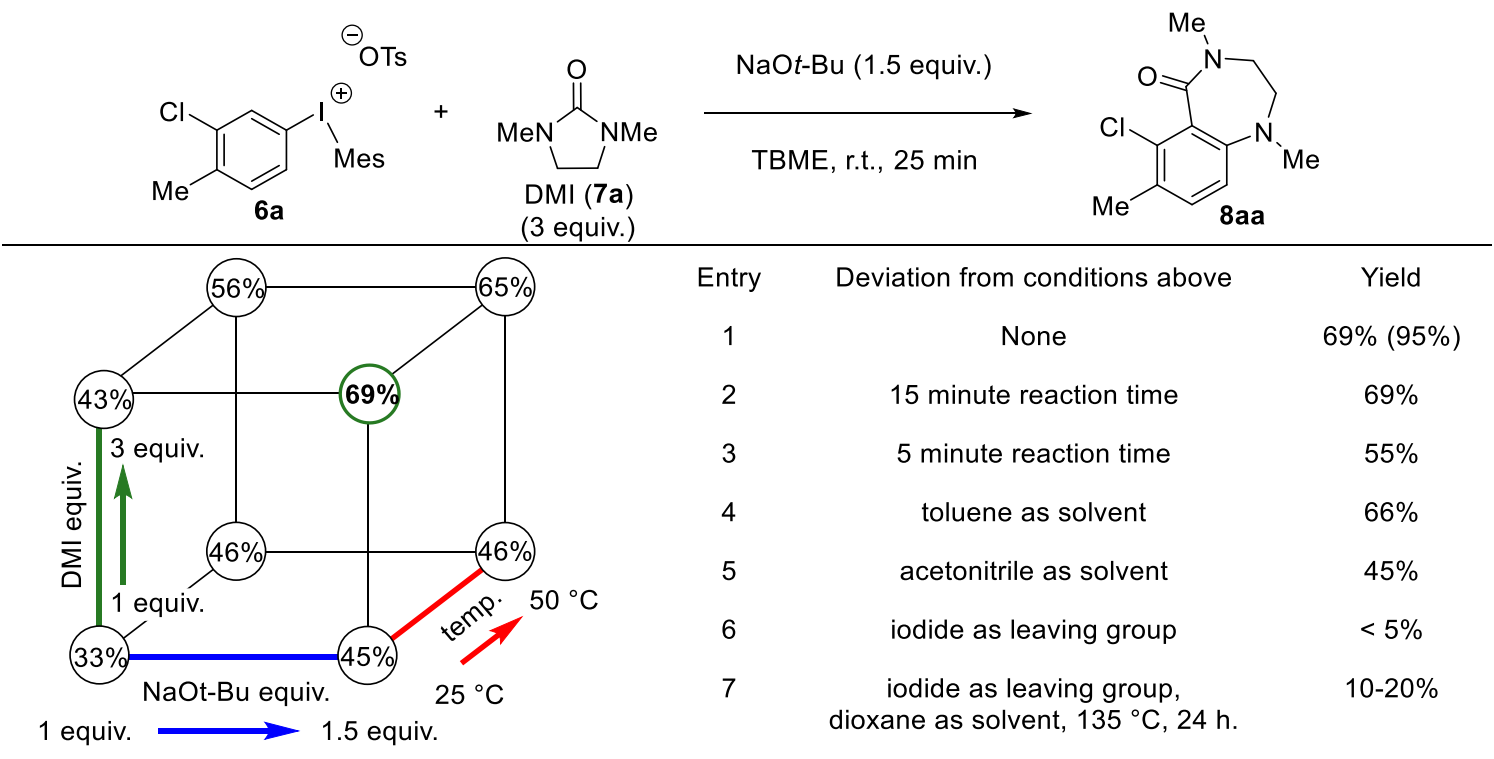

Scheme 6. Optimization of reaction conditions.

\subsubsection{Scope}

\subsubsection{Scope of iodonium salts as aryne precursor}

The scope of disubstituted aryl(Mes)iodonium tosylates compatible in the transformation with DMI is shown in Table 2. The reaction was conducted under the conditions indicated in Scheme 6, entry 1. To ensure the complete conversion of the iodonium salts, the reaction time was increased to $40 \mathrm{~min}$ for most substrates. The yield ranged between $41-71 \%$ with the average yield $55 \%$. A wide range of substituents is well tolerated including halogen substituents $(\mathrm{F}, \mathrm{Cl}, \mathrm{Br})$ known to form aryne intermediates as described in Chapter 1.4. Fluorinated groups prevalent in biologically active compounds are not impacted in this transformation. The attempt of aryne insertion in an amide bond of 6-membered urea, $\mathrm{N}, \mathrm{N}^{\prime}$-dimethylpropylene urea, did not lead to the formation of the desired product under the optimized condition despite the structural similarity. 
Surprisingly, the formation of coupling product was observed only when LiHMDS was used as a base and the reaction was performed in toluene yielding $37 \%$ of 8 -membered insertion product $\mathbf{8 d a}$.

Table 2. Scope of 1,2,3,4-substituted arenes via aryne and cyclic ureas.
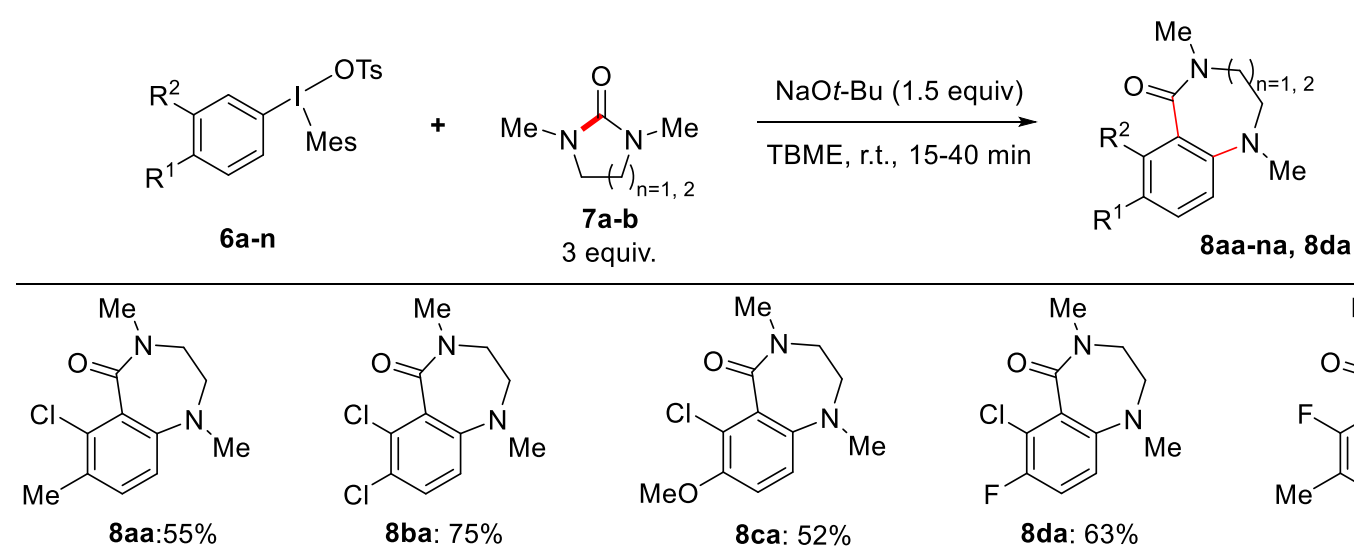

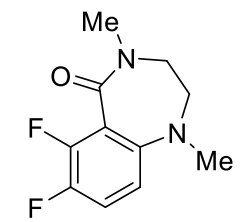

8fa: $53 \%$

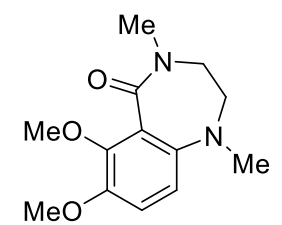

8ka: $43 \%$

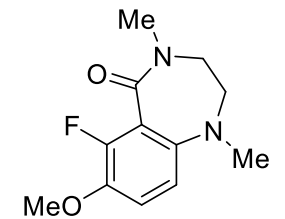

8 ga: $50 \%$

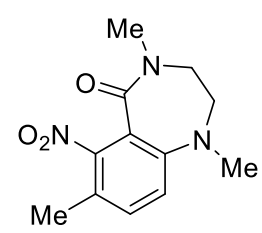

8la: $41 \%$

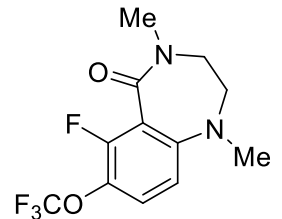

8ha: $53 \%$

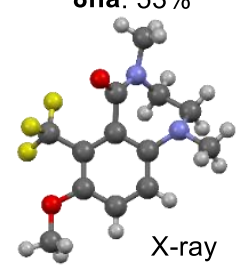

8ma: $60 \%$
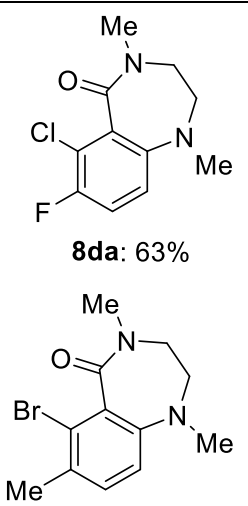

8ia: $51 \%$

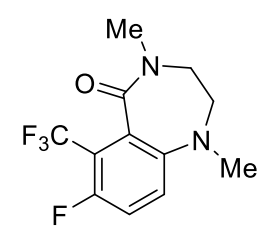

8na: $71 \%$
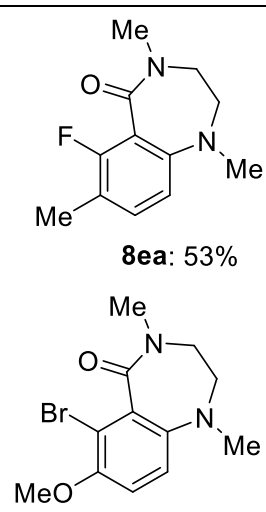

8ja: $46 \%$

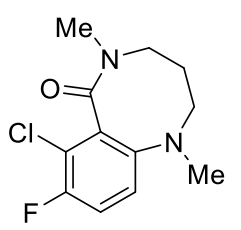

8da: $37 \%$

\subsubsection{Scope of arynophiles}

The difunctionalization of arynes to access sterically congested benzenoid rings was further assessed by the scope of arynophiles. TMS protected 2-hydroxyfuran 7c, similar to its unsubstituted analog, participates in [4+2] cycloaddition reaction, followed by deprotection under acidic conditions and oxidation under exposure to air yield the naphthoquinone in $47 \%$ yield (Table 3 , entry 1 ). Phenyl $\mathrm{N}$-tert-butylnitrone $\mathbf{7 d}$ underwent 
[3+2] cycloaddition with 3-chloro-4-methylbenzyene intermediate resulting in an excellent $92 \%$ yield (Table 3, entry 2). However, in this case an 11:1 mixture of sterically congested regioisomers was isolated. Coupling with benzyl azide 7e gave the cycloaddition product in $47 \%$ yield (Table 3, entry 3 ). The formation of pyridyl substituted phenol in $29 \%$ yield was enabled in the reaction with pyridine $\mathrm{N}$-oxide $\mathbf{7 f}$ accompanied with rearrangement (Table 3, entry 4). The insertion in an amide bond of cyclic ureas was extended to N-heteroatom bond insertion reactions. This type of reaction of 3-chloro-4fluorobenzyne with $\mathrm{N}$-trimethylsilyl morpholine $7 \mathrm{~g}$ resulted in the formation of new $\mathrm{C}-\mathrm{N}$ and C-Si bonds. Similarly, the use of $\mathrm{N}$-chloromorpoholine $\mathbf{7 h}$ provided a tri-chlorinated benzenoid from the corresponding aryne in $56 \%$ yield. Although the previous examples demonstrated the selective formation of 1,2,3,4-substituted aryne coupling products from 3-chloro-4-fluoro(Mes)iodonium tosylate, 1,2,4,5-substituted benzenoid was produced as a minor isomer in the reaction with chloroazepane 7i. Nevertheless, the expected sterically congested benzenoid was obtained in $47 \%$ yield (Table 3 , entry 6 ). 
Table 3. Scope of arynophiles.

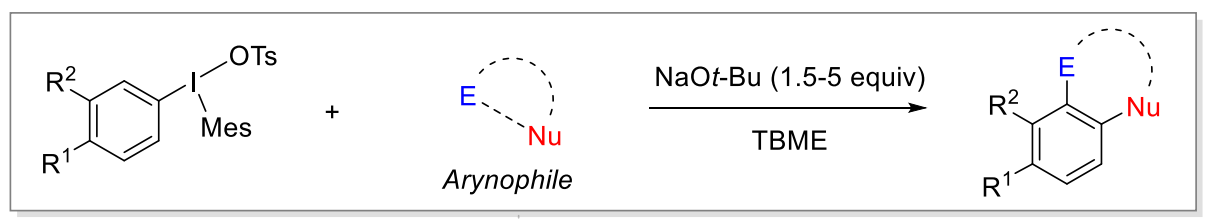

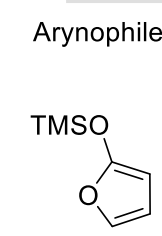

7c

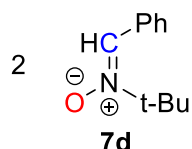

$7 d$

$3 \quad N_{\substack{1 \\ N}}^{\mathrm{N}} \mathrm{Ph}$

7 e

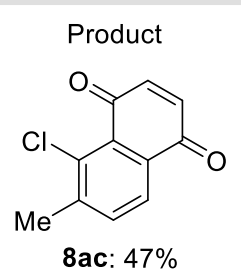

8ac: $47 \%$

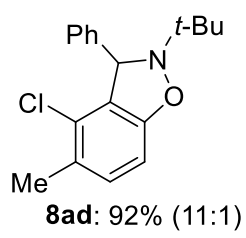

8ad: $92 \%(11: 1)$

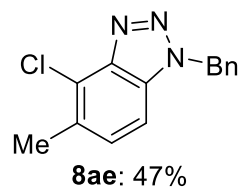

4

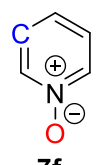

$7 f$

5

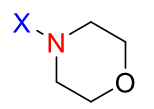

7g: $X=\mathrm{SiMe}_{3}$

7h: $\mathrm{X}=\mathrm{Cl}$

6
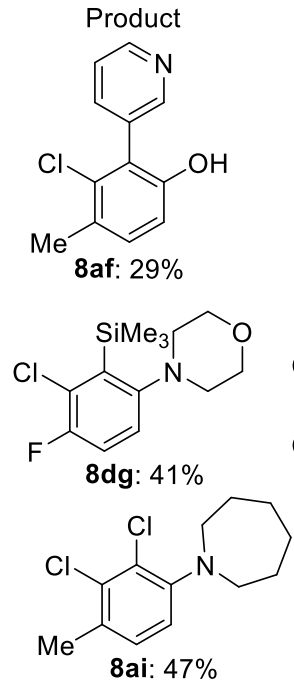

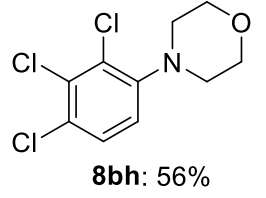

8bh: $56 \%$

\subsubsection{Practical considerations}

Reaction development typically focuses on mg-scale quantities of starting materials and scaling up a process can often be problematic. ${ }^{81}$ While our standard protocol is designed for $0.5 \mathrm{mmol}$ of the limiting reagent, we applied it in a tenfold scale reaction $(5 \mathrm{mmol})$, which would correspond to gram-scale quantities of product. The reaction was conducted in a flask open to air and the final aryl diazepinone 8na was isolated in slightly reduced $62 \%$ yield (compared to $71 \%$ ). No visible changes, including a dramatic temperature change, were observed upon increasing the scale of the reaction. 

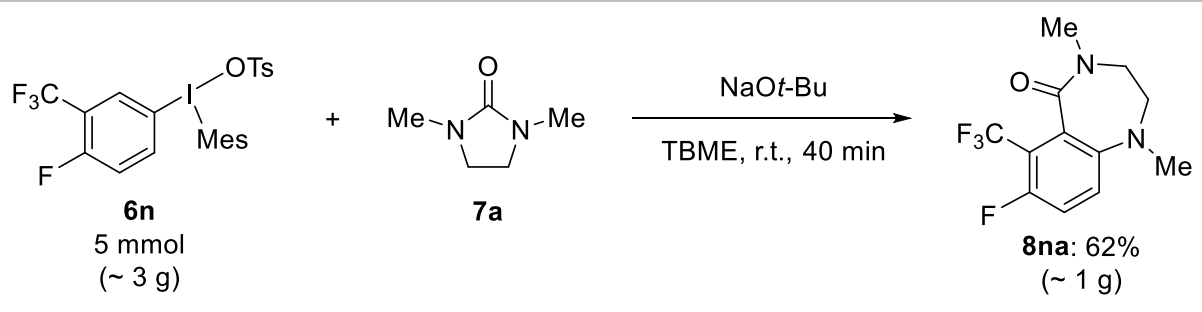

Scheme 7. Gram-scale synthesis.

\subsubsection{Derivatization via transition metal catalysis}

The development of transition metal catalyzed reactions has enabled previously challenging synthetic transformations, and these methods have become irreplaceable in medicinal chemists' toolbox. The compatibility of halides in the formation of arynes demonstrated here allows for further derivatization of the aryne coupling products via transition metal catalyzed reactions. Bromo-substituted aryl diazepinone was chosen for further derivatization based on known high reactivity of this substituent. The conditions of Suzuki-Miyaura coupling, Buchwald-Hartwig amination and Heck coupling reactions were successfully applied and the products of these transformations were isolated in excellent yield. Although Heck reaction with methyl acrylate yielded 99\%, the coupling product was isolated as a mixture of $E$ and $Z$ isomers with the useful ratio of 9.6:1. Overall, despite the steric hindrance of the aryne coupling compound, it demonstrated high reactivity in the transition metal catalyzed reactions. 


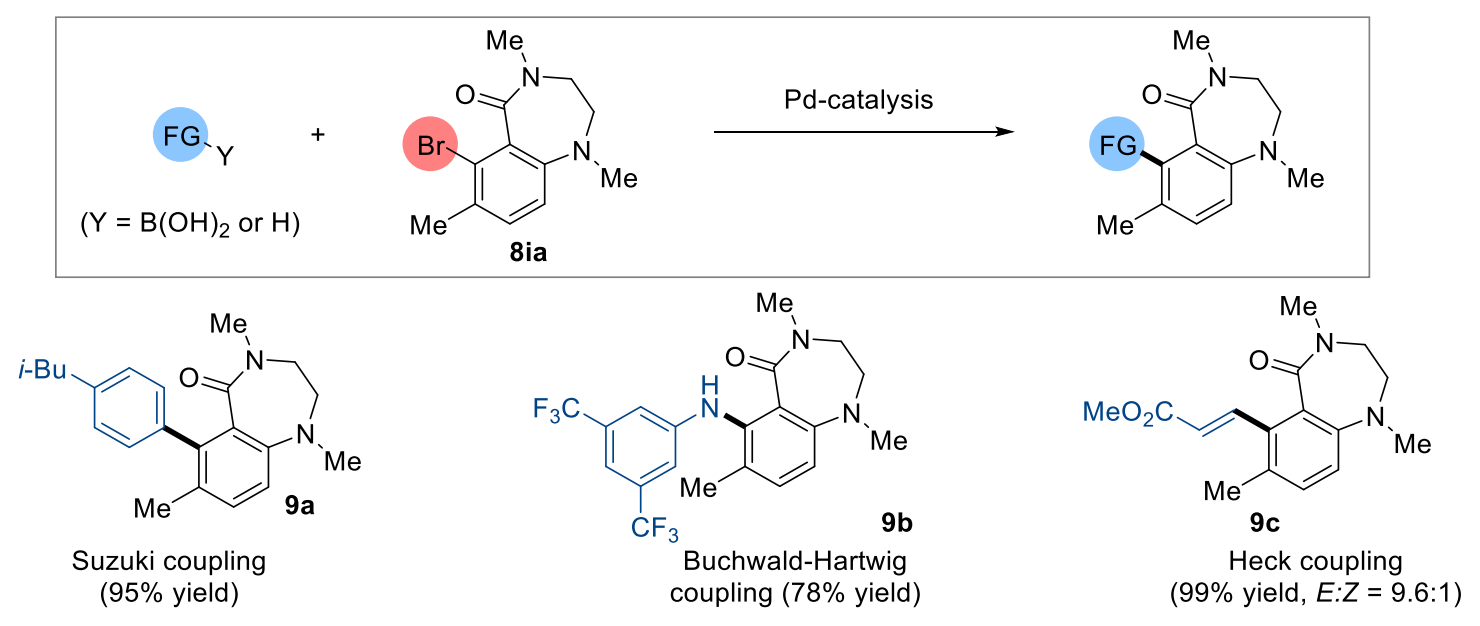

Scheme 8. Derivatization of aryl diazepinone.

\subsubsection{Sequential dual C-H functionalization of disubstituted arenes}

The ability of arenes to participate in diaryliodonium salt formation from Koser's type reagents was envisioned as an opportunity to functionalize two adjacent $\mathrm{C}-\mathrm{H}$ bonds. In this way an electron-rich 1,2-substituted arene may be converted into a 1,2,3,4substituted arene. Ultimately, first $\mathrm{C}-\mathrm{H}$ bond is cleaved in the iodonium salt formation step, where electron donating group dictates the regioselectivity of a $S_{E} A r-t y p e$ reaction. The second $\mathrm{C}-\mathrm{H}$ bond is cleaved by deprotonation of the most sterically congested position and results in aryne formation followed by trapping with an arynophile. This approach was successfully applied for the functionalization of o-fluoroanisole in two step synthetic sequence (Scheme 9). First, the corresponding iodonium salt was produced under acidic conditions in $74 \%$ isolated yield. Then, coupling of 3-fluoro-4methoxybenzyne with nitrone yielded substituted benzoisoxazoline in $85 \%$; the yield over two steps is $63 \%$ and corresponds to cleavage of two $\mathrm{C}-\mathrm{H}$ bonds and formation of $\mathrm{C}-\mathrm{O}$ and C-C bonds. The same substrate underwent dual C-H functionalization, however, in one- 
pot protocol. To minimize the conflict of reaction media used in the two sequential steps, a catalytic amount of tosic acid was used to facilitate aryl(Mes)iodonium tosylate formation. The aryne intermediate formed under basic conditions was trapped with furan and isolated in $38 \%$ yield. It is important to note that the reactivity of every step was not assessed individually, and the overall yield has potential for improvement.

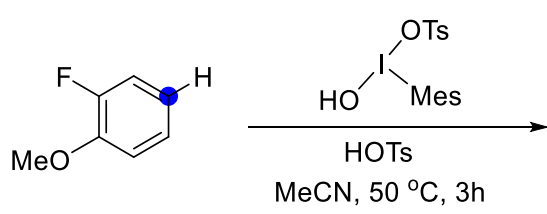

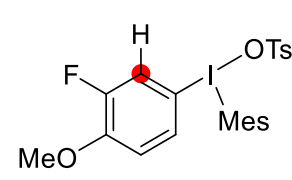

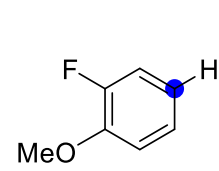

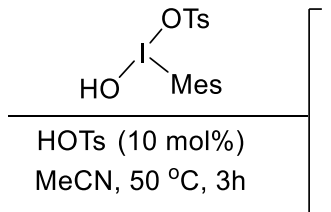

$\mathrm{MeCN}, 50^{\circ} \mathrm{C}, 3 \mathrm{~h}$ 6g: $74 \%$

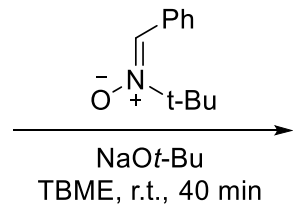

TBME, r.t., $40 \mathrm{~min}$
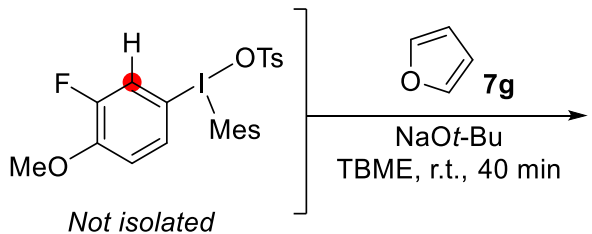

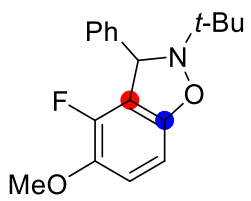

8gd: $85 \%$ (63\% over two steps)

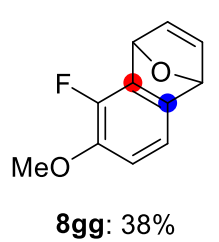

Scheme 9. Functionalization of two adjacent $\mathrm{C}-\mathrm{H}$ bonds via iodonium salts formation.

\subsubsection{Unexpected aryne reactivity in the reaction with cyclic ureas}

As it has been noted, the consumption of aryl(Mes)iodonium tosylates was assessed based on the formation of Mes-I. In the optimization process we observed the complete consumption of the aryne precursor based on the $95 \%$ yield of this by-product (Mes-I), while the formation of the desired product was $69 \%$. Analysis of the crude reaction mixture by GC-MS revealed an unexpected discovery: a peak with a mass corresponding to the addition of two aryne intermediates with DMI $(m / z=363)$ accounted for $5-10 \%$, which corresponds to $10-20 \%$ of the aryne precursor. Our initial hypothesis was that an aryne inserted into each of the urea C-N bonds to yield a symmetrical 9-membered ring product (Scheme 10). However, further analysis of this side 
product using NMR spectroscopy demonstrated that the aryl groups were in fact inequivalent and that the ethylene unit had been modified. Indeed, the presence of a single $\mathrm{CH}_{2}$ group with $\mathrm{H}$ resonances at $\sim 4.5 \mathrm{ppm}$ and a $\mathrm{CH}$ group with a downfield resonance of $\sim 6.5 \mathrm{ppm}$ was determined from ${ }^{1} \mathrm{H}, \mathrm{DEPT}$, and HSQC NMR experiments. The literature precedent for arylation of tertiary amines with aryne intermediate via dealkylation ${ }^{78}$ along with obtained data resulted in a new hypothesis. A mixture of plausible structural isomers was proposed as an outcome of the nucleophilic attack by either nitrogen atom of the aryl diazepinone 8aa followed by the ring opening.
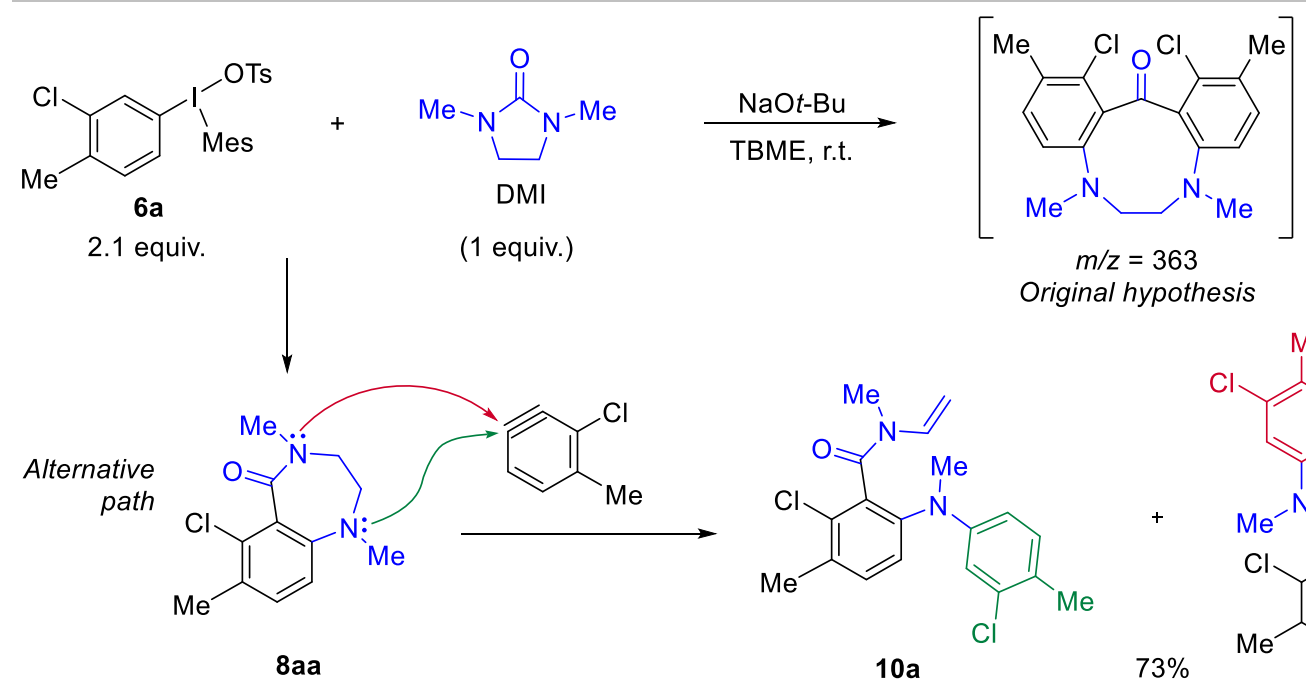

Scheme 10. Discovery of unexpected side products.

The formation of aryl diazepinone as an intermediate was confirmed when it was successfully reacted with iodonium salt upon treatment with $\mathrm{NaOt}$ - $\mathrm{Bu}$. The aryne coupling product 8aa underwent ring opening in the presence of 3-fluorotrifluoromethylphenyl(TMP)iodonium tosylate $\mathbf{6 d}$ under basic conditions and yielded a mixture of structural isomers $10 \mathrm{c}$ and $\mathbf{1 0 d}$ in $80 \%$ (Scheme 11). Additionally, the substituted starting materials were switched; the ring opening of aryl diazepinone 8ma 
produced corresponding compounds $\mathbf{1 0 e}$ and $\mathbf{1 0 f}$ in $50 \%$ isolated yield. In both cases, the ratio of products is approximately 2-3: 1 , though the identity of the major and minor isomers was hampered by overlapping signals in the NMR spectra.
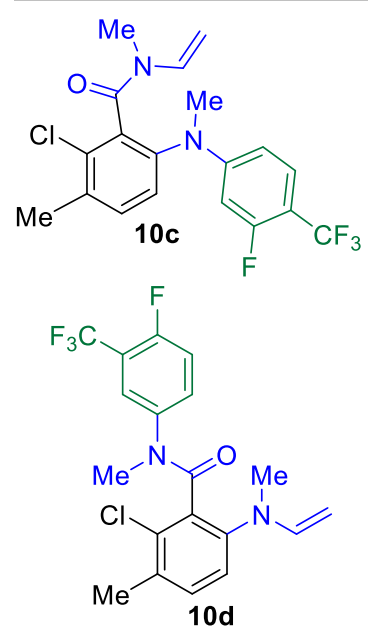

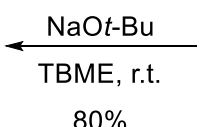

$80 \%$

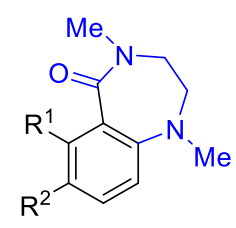

$+$

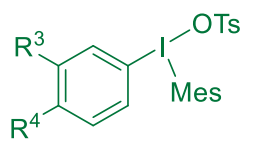

1.1 equiv.

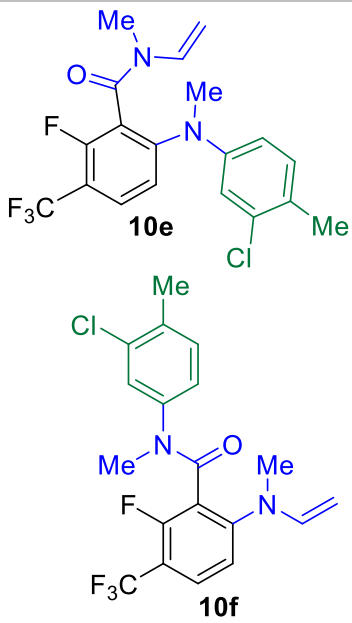

Scheme 11. Ring opening of aryl diazepinones.

To validate the $\mathrm{C}-\mathrm{N}$ bond cleavage in the ring opening process, phenyl morpholine was reacted under the demonstrated conditions (Scheme 12). As expected, $\mathrm{N}$-arylation took place in the reaction with iodonium salt 6 a producing the corresponding diarylamine 8 ah in $63 \%$ yield. Similarly, a strong downfield resonance at $~ 6.4 \mathrm{ppm}$ of the vinyl proton of the $\mathrm{CH}$ group was found in the ${ }^{1} \mathrm{H}$ NMR experiment characteristic for this functional group.

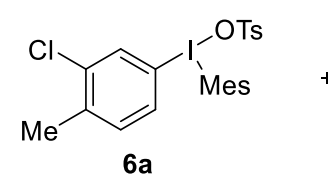

1.1 equiv.

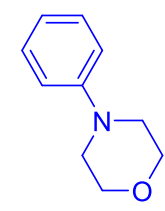

$7 \mathrm{~h}$

1 equiv.

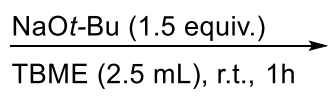

TBME (2.5 mL), r.t., $1 \mathrm{~h}$

TBME
$50 \%$

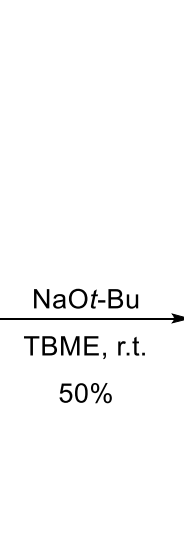

$10 f$

.




\subsubsection{Dimerization of aryl(mesityl)iodonium salts}

The X-ray analysis of aryl(mesityl)iodonium tosylates used in the reactions presented in this chapter revealed the formation of centrosymmetric dimer with bridging tosylate groups (Figure 17, A). It was questioned whether similar behavior is observed in solution. To probe this, an experiment using ${ }^{1} \mathrm{H}$ NMR spectroscopy in which spectra of solutions of different concentrations are recorded and the change in chemical shift of signals demonstrates an interaction between molecules present in solution was performed. As the solubility of diaryliodonium salts is known to be extremely low in many common solvents, their characterization by ${ }^{1} \mathrm{H}$ NMR is typically performed in deuterated dimethyl sulfoxide (DMSO- $d_{6}$ ). In the initial experiment three samples of 3-chloro-4methylphenyl(mesityl)iodonium tosylate $\mathbf{6 a}$ of three different concentrations were prepared by dilution. We observed no shift for any of the signals. This may be explained by the coordinating nature of DMSO and competitive association of DMSO to break up the dimer. ${ }^{82}$ When the experiment was repeated using deuterated chloroform $\left(\mathrm{CDCl}_{3}\right)$ as a solvent, considerable shifts can be seen for all signals of aromatic protons indicating dynamic intermolecular interaction dependent on concentration. Similar tendency was observed when phenyl(mesityl)iodonium tosylate was analyzed as an unsubstituted analogue under the same conditions (Figure 17, B). With the increase of concentration of iodonium salt in solution, the upfield shift of aromatic protons can be observed with an exception for signals for hydrogen atoms located in ortho-position to iodonium. However, X-ray analysis also demonstrated that some iodonium salts do not dimerize in solid state. 2-chloro-4-methoxyphenyl(mesityl)iodonium tosylate is one of the examples of this 
group. Nonetheless, when the experiment described above was performed using this compound the same trend in shifts of signals was revealed. Thus, the formation of dimer can be hypothesized and does not necessarily correlates with data obtained from X-ray analysis.

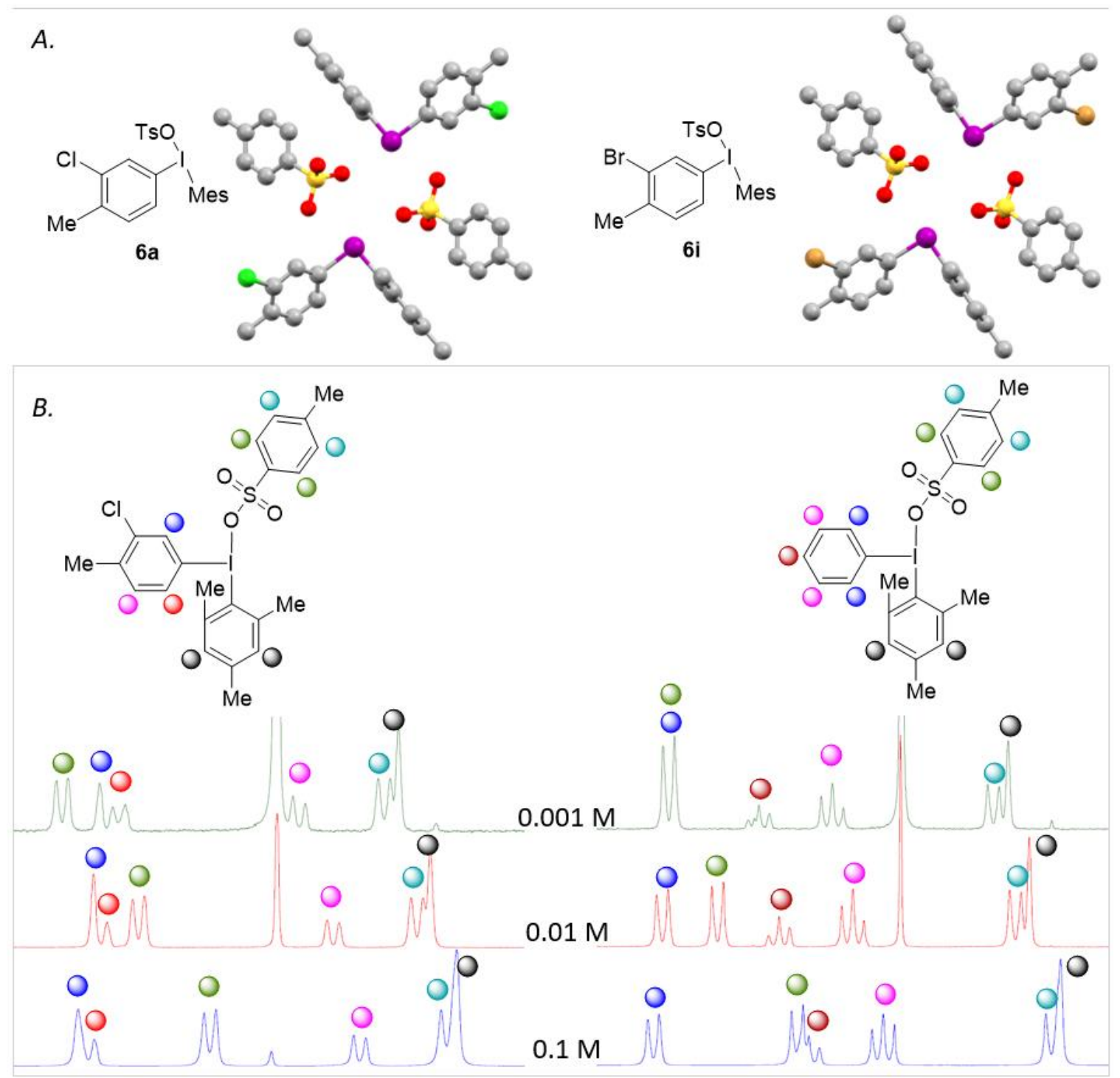

Figure 17. A. X-ray structure of $6 \mathbf{a}$ and $6 \mathbf{6}$. B. Stack of ${ }^{1} \mathrm{H}$ NMR spectra of concentrations (bottom to top) $0.1 \mathrm{M}, 0.01 \mathrm{M}, 0.001 \mathrm{M}$ in $\mathrm{CDCl}_{3}$. 
The diverse synthetic possibilities of aryl(TMP)iodonium salts have been discussed in Chapter 1. Herein, we describe the development of a complimentary mechanistic pathway for these substrates as an arylating agent. In particular, the ability of these substrates to form arynes is demonstrated.

\subsection{Tuning the reactivity for aryne formation}

We envisioned the formation of aryne intermediates from aryl(TMP)iodonium salts to be feasible under the reaction conditions similar to those described in Chapter 3. However, the use of $\mathrm{NaOt}$-Bu has been previously reported to facilitate the formation of alkyl aryl ethers from diaryliodonium salts and alcohols. Moreover, tert-butoxide anion was shown to form tert-butyl aryl ether with highly electron-poor diaryliodonium salts; particularly, para-nitrophenyl tert-butyl ether was obtained upon treatment with

aforementioned base (Figure 18, A). ${ }^{83,84}$ Thus, overriding ipso-substitution became a priority in order to achieve the formation of aryne from aryl(TMP)iodonium salts.

In order to assess the effect of aryl substituent electronic effects on the competing mechanisms of ipso-substitution and aryne formation several para-substituted aryne precursors were selected (Figure 18, B). The substrates ranged from highly electronwithdrawing nitro substituent $\left(\sigma^{-}=1.27\right)$ to electron-donating methoxy substituent $\left(\sigma^{+}=\right.$ -0.78). It was found that the formation of a significant amount of the ipso-substitution product was observed for electron-poor aryne precursors with $\pi$-EWG (i.e., $\mathrm{NO}_{2}, \mathrm{CN}$, $\mathrm{CO}_{2} \mathrm{Me}$, and $\left.\mathrm{CF}_{3}\right)$. A very small amount of ipso-substitution product was observed for 
mildly electron-withdrawing $\mathrm{Cl}$ substituent, and only aryne formation was observed for those substrates with electron-donating substituents.

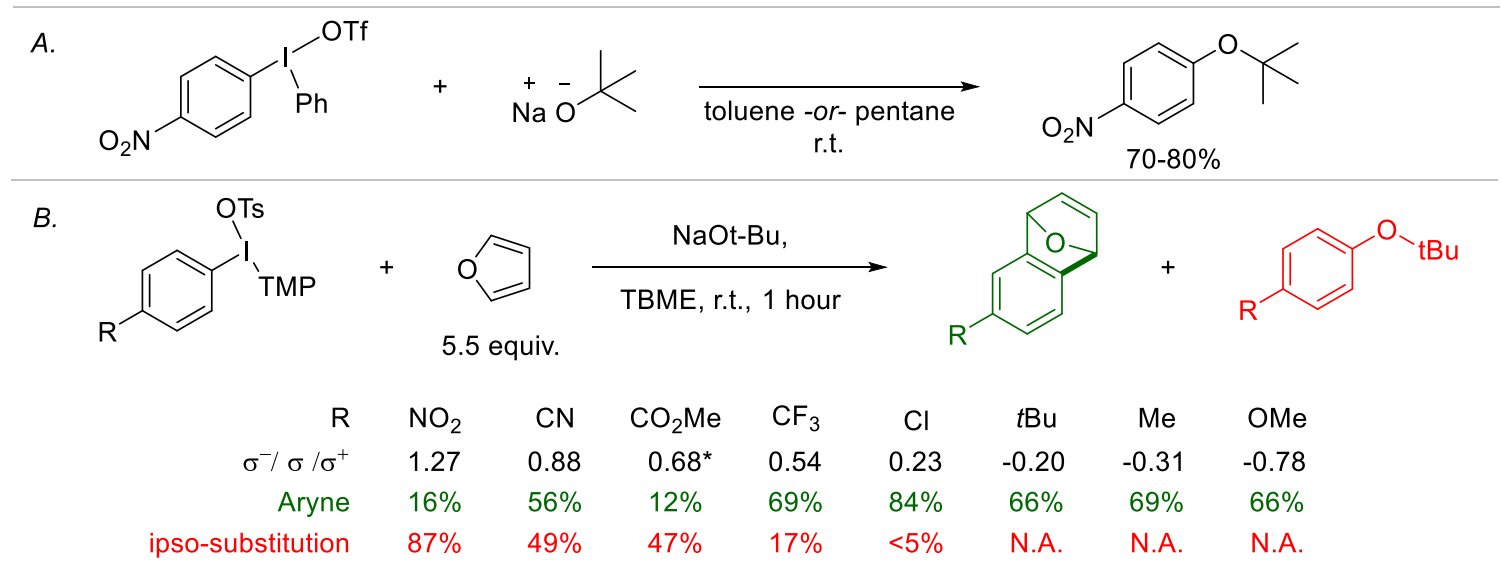

Figure 18. A. Literature precedent for alkyl aryl ether formation. B. Effect of substituents on mechanistic outcome.

The undesirable reactivity of the electron-poor aryne precursors was envisioned to be restrained by the use of less nucleophilic base LiHMDS, that has demonstrated to be effective in this type of transformation. ${ }^{56}$ The combination of the effect of base, nature of the substituent, and its relative position on aryne formation and trapping with furan was more broadly assessed (Figure 19). To our delight, the electron-poor aryl group of iodonium salt was successfully converted into aryne intermediate when LiHMDS was used as base. This observation is valid for both meta and para-substituted aryl(TMP)iodonium salts. On the other hand, the reactivity of methoxy-substituted aryne precursor was not dramatically affected by the identity of base. These feasibility experiments demonstrated milder NaOt-Bu to be a suitable base for the majority of the substrates and LiHMDS needed for select examples. 


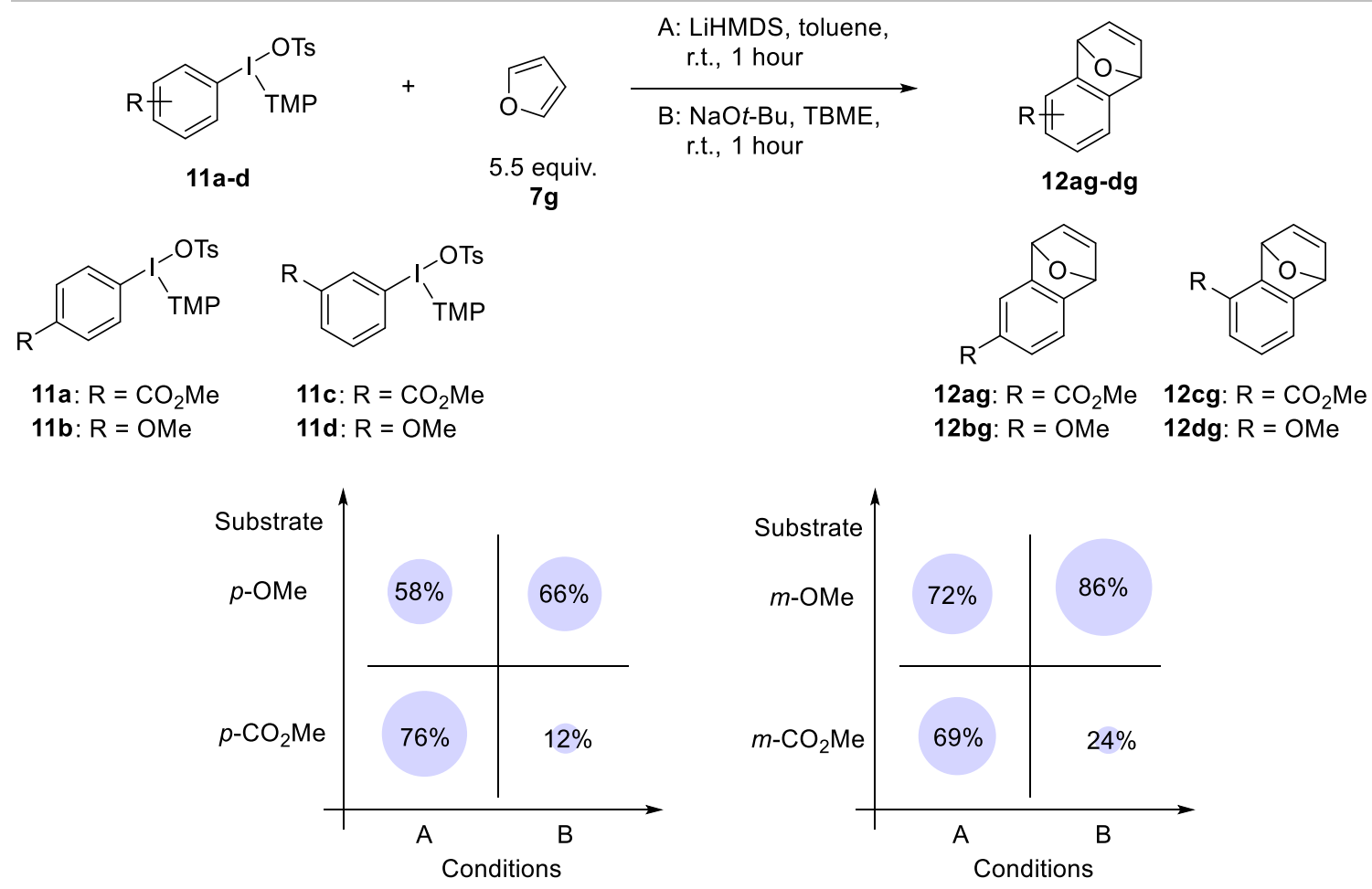

Figure 19. Effect of base and substituent on aryne formation; circles represent yields.

\subsection{Scope}

The scope of the aryne trapping products from compatible aryl(TMP)iodonium salts is shown in Table 4. In the cycloaddition reaction with furan or benzyl azide the yield ranged from $54 \%$ to $97 \%$. The presence of a meta-substituent on the aryl group of iodonium salts allowed the use of $\mathrm{NaOt}$-Bu as a base to facilitate aryne formation. Various functional groups are tolerated in this strategy, including such strong EWG as $\mathrm{NO}_{2}$ and $\mathrm{CN}$. However, in case of 2-methyl-5-nitrophenyl(TMP)iodonium tosylate the use of LiHMDS was necessary for aryne formation. Moreover, $\mathrm{CO}_{2} \mathrm{Me}$ functional group is reactive under the reaction conditions and likely undergoes transesterification with tertbutoxide; this results in the formation of a mixture of aryne products. As it has been highlighted previously, a significant increase in yield of the aryne adduct was observed for 
this substrate in the presence of LiHMDS. The use of this base also promoted the formation of aryne intermediate with para-nitro and para-cyanophenyl(TMP)iodonium tosylates. Furthermore, various benzenoid substitution patterns were accessed via this route and included 1,2,3-, 1,2,4-, 1,2,3,4-, 1,2,3,5-, and 1,2,3,4,5-substituted benzenoids. Table 4. Scope of aryne trapping products.

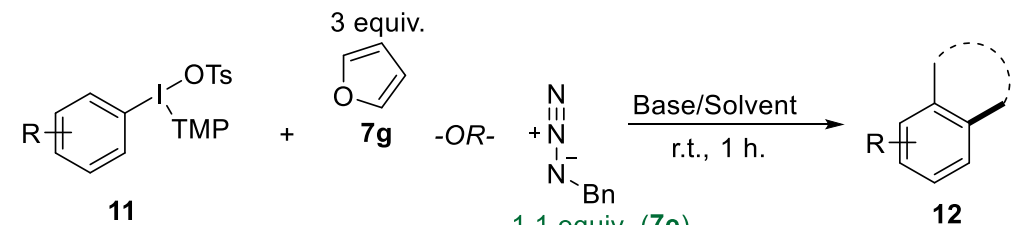

Conditions:

A. LiHMDS (1 equiv.), Toluene

B. NaOt-Bu (3 equiv.), TBME

C. $\mathrm{NaO} t-\mathrm{Bu}(1.5$ equiv.),

TBME, $0{ }^{\circ} \mathrm{C}$<smiles>CC(=O)c1ccc2c(c1)C1C=CC2O1</smiles>

12ag: $69 \%$
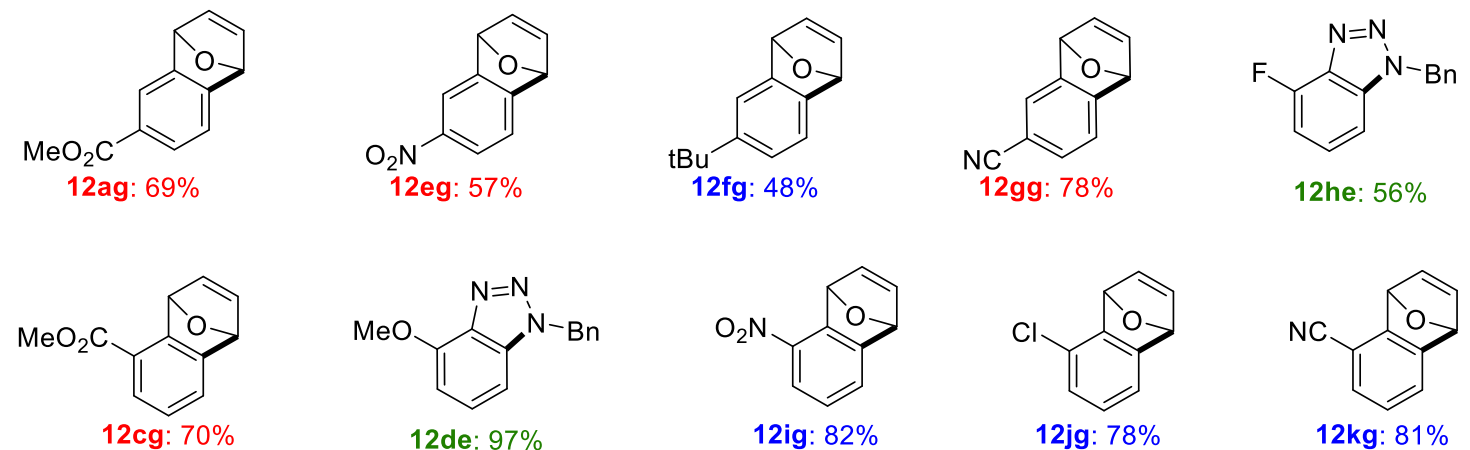

12ig: $82 \%$

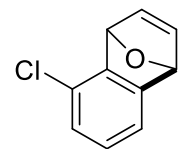

12jg: $78 \%$

12he: $56 \%$<smiles>FC(F)(F)Oc1cccc2c1nnn2Cc1ccccc1</smiles>

12le: $66 \%$

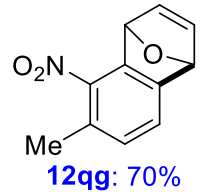<smiles>Clc1cc(Cl)c2c(c1)C1C=CC2O1</smiles>

12mg: $87 \%$

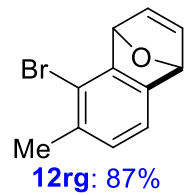

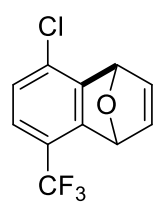

12ng: $54 \%$

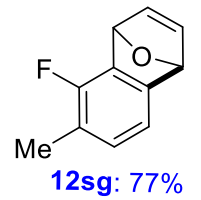

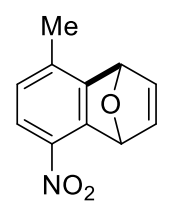

12og: $72 \%$

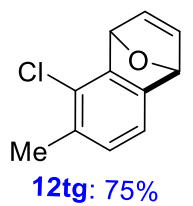<smiles>N#Cc1cccc2c1C1C=CC2O1</smiles>

12kg: $81 \%$<smiles>Cc1c(F)cc(Br)c2c1C1C=CC2O1</smiles>

12pg: $76 \%$<smiles>FC(F)(F)c1ccc2c(nnn2Cc2ccccc2)c1C(F)(F)F</smiles>

\subsection{Multistep one-pot functionalization of aryl iodides}

The developed aryne formation approach was successfully adjoined to the iodonium salt synthesis mentioned in Chapter 1 . However, these two processes occur in fundamentally different surroundings: synthesis of aryl(TMP)iodonium salts is conducted 
in acidic media, while the presence of base is required for aryne formation. The insolubility of iodonium salts in TBME was exploited to merge the two steps in a solvent switch, which resulted in the removal of meta-chlorobenzoic acid, the reduction product of $m$-CPBA, and potential impurities with a minimal loss of the aryne precursor (Scheme 13). The main advantage of this one-pot protocol is the depletion of the quantity of solvent required for the trituration of iodonium salts as a purification method. The synthesis of aryne coupling adduct from corresponding aryl iodide is conveniently accomplished in a timeframe of 2 hours. These examples demonstrate an improvement of our previously developed approach to the same substrates from aryl(Mes)iodonium tosylates. ${ }^{56}$ For comparison, the formation of $\mathbf{1 2} \mathrm{jg}$ was reported in analogous $69 \%$ isolated yield, however, this result did not account for the yield of iodonium salt. Similarly, the yield of $12 \mathrm{vg}$ is slightly reduced in the developed protocol to $78 \%$ from previously reported $84 \%$.

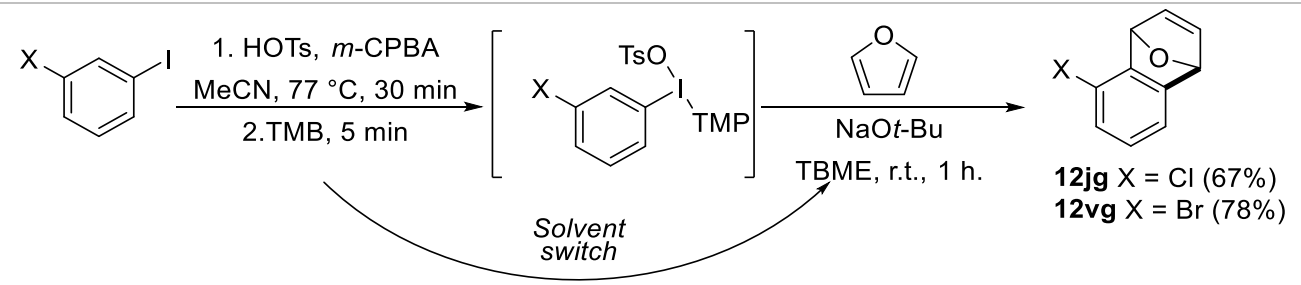

Scheme 13. Telescoped approach to aryne from aryl iodides.

\subsection{Formal synthesis of bioactive compound}

The practicality of the one-pot protocol was evaluated by the efficient synthesis of a bioactive compound. Anaplastic Lymphoma Kinase (ALK) and tyrosine-protein kinase Met (c-Met) inhibitor is a potential cancer treatment. The synthesis of this bioactive 
compound has been patented and includes the formation of an aryl diazepinone intermediate. ${ }^{85}$ The previously reported route to this intermediate required six steps and resulted in an overall yield of 3\% from 2,6-dinitrotoluene. The telescoped approach from 3-nitrophenyl iodide with a solvent switch shown in the previous section was successfully applied to synthesize the required aryl diazepinone. m-Nitrophenyl(TMP)iodonium tosylate formation followed by the aryne insertion in the amide bond of DMI 7a resulted in $55 \%$ yield of the desired substrate 12ia (Scheme 14). Although the purification by column chromatography provided a solution of this compound in excess of DMI, it was effectively crystallized out of this solution.

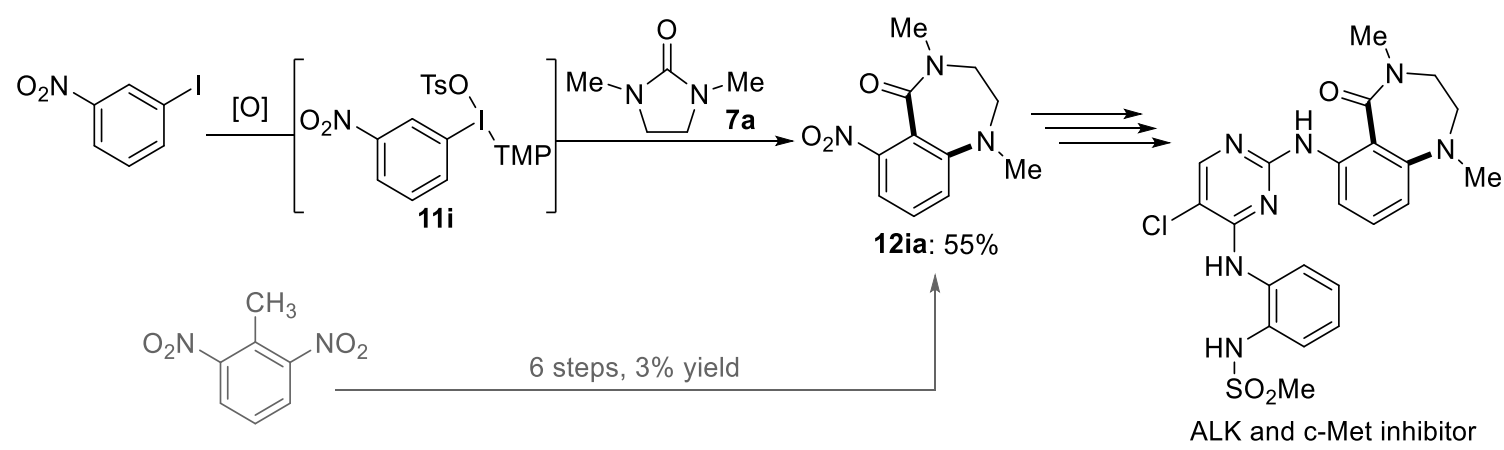

Scheme 14. Application of telescoped reaction in formal synthesis of bioactive compound.

\subsection{Selectivity}

The nature of substituents on an aryne intermediate is known to dictate the site of the nucleophilic attack on it. The regioselectivity of the attack by a nucleophile is described by the aryne distortion model, according to which the attack occurs at the more linear site of aryne triple bond. The distortion model for arynes bearing two substituents adjacent to triple bond has been proposed by Garg et al. based on density functional 
theory (DFT) study in 2014 (Figure 20, A). ${ }^{86}$ The degree of distortion is assessed as a difference in internal angles, where a $4^{\circ}$ angle or greater results in useful regioselectivity. Among the tested substrates the periodic trend of decreasing electronegativity of halides is interrupted by the methoxy substituent that is the second strongest $\sigma$-EWG after fluoride in this sequence. The authors noted that these computational predictions relied exclusively on the optimized geometry of the arynes and did not consider the steric effect of the substituents. To date experimental verification of these predictions has been limited by the synthesis of suitable aryne precursors.

However, in this case the aforementioned type of aryne intermediate is successfully generated from the corresponding aryl(TMP)iodonium tosylates and trapped with furan (Table 4). To test the selectivity of nucleophilic attack the representative examples of aryne precursors were chosen based on the commercial availability. With calculated distortion of $5^{\circ}$, 3-chloro-6-methoxybenzyne demonstrated extreme selectivity (18:1) in the reaction with morpholine (Figure 20). One can suggest this result to be caused by ipso-substitution process. However, both regioisomers of aryl(TMP)iodonium tosylate showed the preference for nucleophilic attack is distal to the methoxy group. The distortion of 3-bromo-6-fluorobenzyne is reported to be $10^{\circ}$. The same set of experiments was performed on the corresponding iodonium salts. Despite the high predicted selectivity, the mixture of regioisomers was obtained in less than 2:1 ratio, yet with the major isomer as predicted. 
High selectivity was observed in the reaction of 5-halotolyl(TMP)iodonium tosylates with morpholine. Although no computational data were provided for these substrates, the $\sigma$-donating nature of methyl group can be expected to lead the nucleophilic attack to the adjacent position. However, the control experiment to evaluate the competing pathway of ipso-substitution failed, resulting in less than $10 \%$ yield for each substrate. Consequently, the nature of the intermediate cannot be confirmed for this group of aryne precursors.

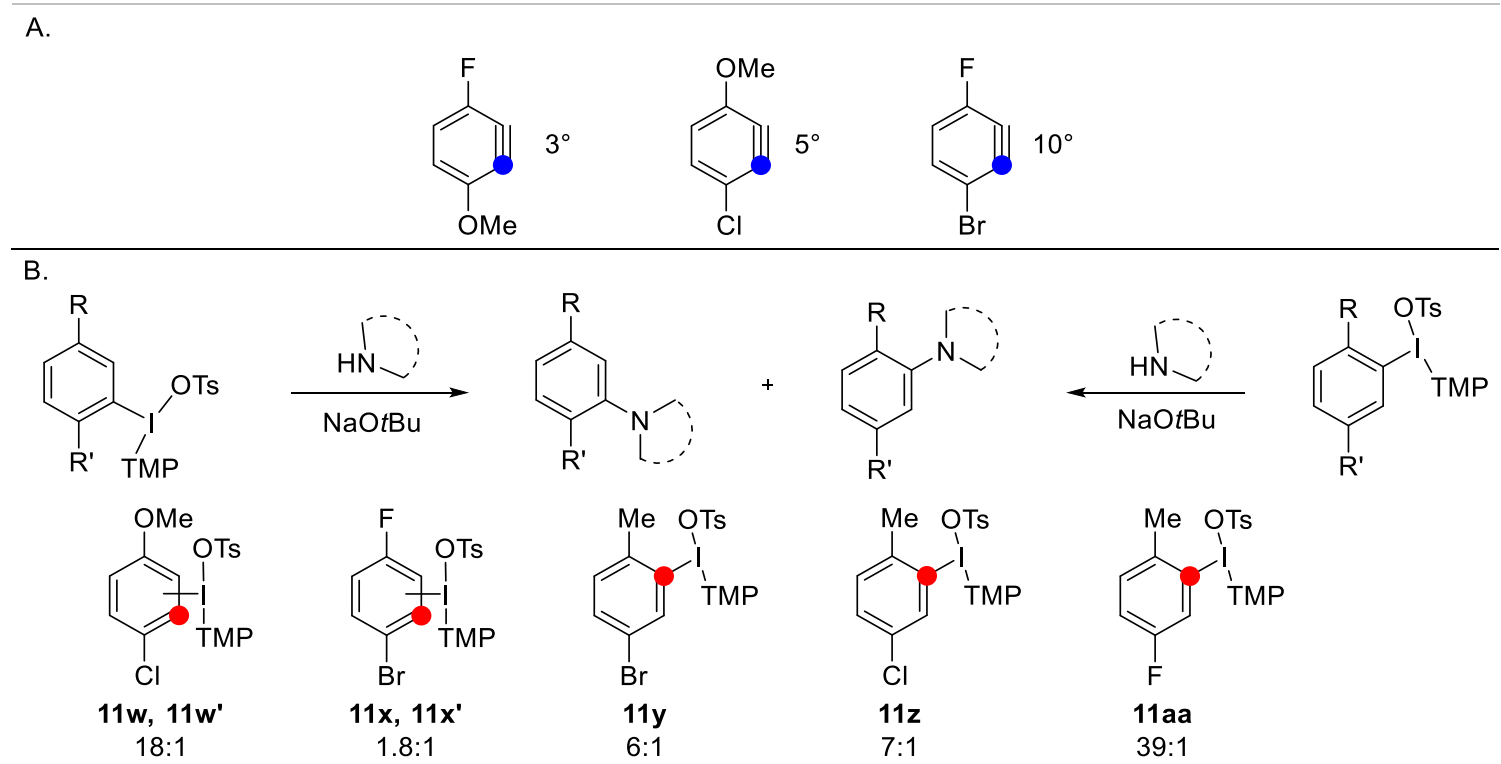

Figure 20. A. Predicted distortion angles and selectivity. B. Observed selectivity of nucleophilic attack. 


\section{Future directions}

Uneven distribution of the benzenoid substitution patterns within small molecule active pharmaceutical ingredients motivated us to provide an access to challenging examples via new synthetic routes. We see the potential of diaryliodonium salts in achieving this goal. Comparably mild conditions for aryne formation via $\mathrm{C}-\mathrm{H}$ deprotonation (a combination of relatively moderate base and room temperature) open an opportunity for diverse functionalization in a timely manner. Our preliminary data demonstrate several examples of underrepresented substitution patterns. Although 1,3substituted benzenoids are underrepresented, the available feedstock of these iodides can provide formal ipso-substitution product via aryne intermediate. Thus, arylation of piperidine was observed in the presence of $\mathrm{NaOt}$-Bu in $77 \%$ (Scheme 15, top left). Difunctionalization of the same aryne intermediate in the reaction with furan resulted in 1,2,3-substituted benzenoid under the same conditions (Scheme 15, top right). New possibilities of readily available 1,2,4-substituted benzenoids are recognized when the leaving group (iodonium) is located in position 1. Substitutive ortho-transposition (or cinesubstitution) with a nucleophile is directed towards the formation of a contra-electronic substitution pattern. As an example, deprotonation of the single available position ortho to the iodonium of 4-bromo-2-fluorophenyl(TMP)iodonium tosylate followed by a nucleophilic attack resulted in 1,3,5-substitution pattern (Scheme 15, bottom left). On the other hand, difunctionalization of the same aryne intermediate provides results in a new 
steric cluster. Trapping the aforementioned aryne intermediate with phenyl $\mathrm{N}$-tert-butyl nitrone yielded a 1,2,3,5-substituted benzenoid (Scheme 15, top right).
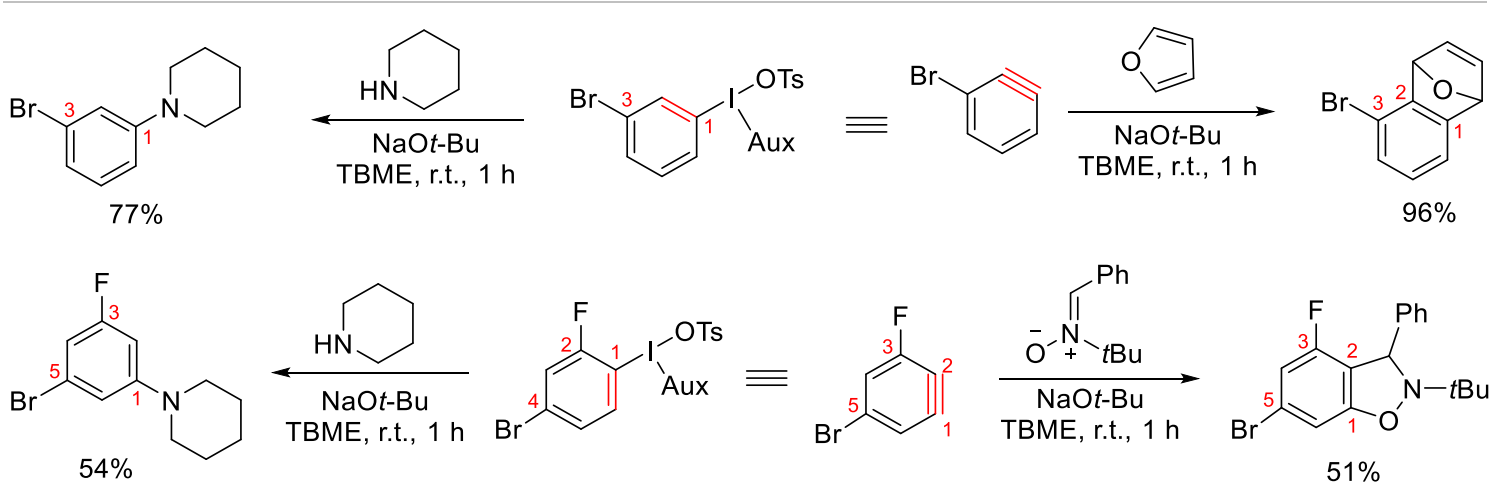

Scheme 15. Access to underrepresented substitution patterns via aryne intermediate.

The development of a telescoped approach from readily commercially available aryl iodides is highly appealing and anticipated to dramatically reduce solvent consumption required for iodonium salt isolation as well as overall time to achieve the final arylation product. A solvent switch method has been briefly introduced in this manuscript. Alternatively, the neutralization of acid can be performed with base. However, a careful choice is necessary due to the exothermicity of this interaction and a successful result was not achieved with NaOt-Bu. A recent additional screen of bases revealed an unexpected result. Use of $\mathrm{K}_{3} \mathrm{PO}_{4}$ facilitates the formation of aryne intermediate from diaryliodonium tosylates (Scheme 16), and good yield of aryne trapping products was observed independently of the auxiliary. Thus, 3trifluoromethoxyphenyl(Mes)iodonium tosylate in the reaction with furan yielded the product in 56\%. Trapping of 3-fluoro-4-methylbenzyne from the corresponding 
aryl(TMP)iodonium salt resulted in $65 \%$ yield. These results are the subject of intense future investigation in the Stuart group.
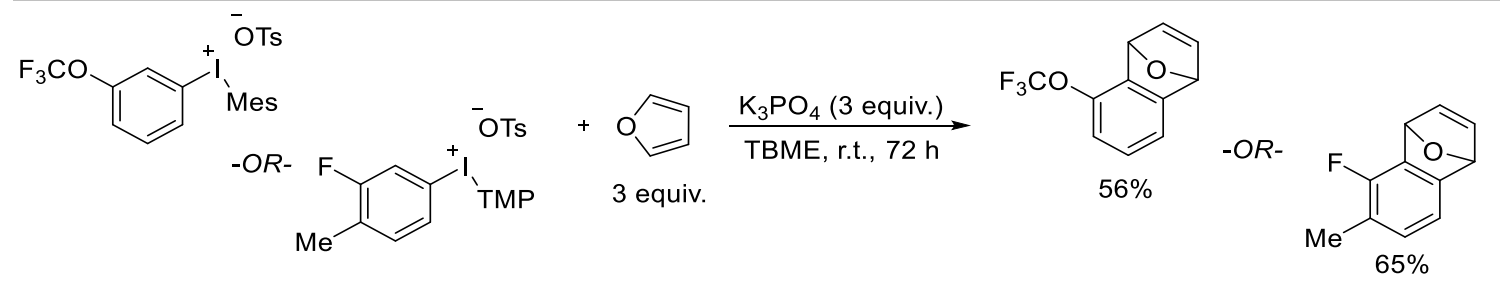

Scheme 16. Phosphate promoted aryne formation. 


\section{Experimental section}

\subsection{General considerations}

Commercially available reagents and solvents were used without further purification. m-CPBA was assayed by iodometric titration and determined to contain 71$74 \%$ active oxidant. Compounds $6 \mathrm{~d}, \mathbf{6 i}, \mathbf{1 1 a}, \mathbf{1 1 d - f ,} 11 \mathrm{i}-\mathbf{k}, \mathbf{1 1} \mathrm{m}, \mathbf{1 1} \mathrm{n}, \mathbf{1 1 q}$, and $11 \mathrm{u}$ were prepared according to a literature procedure. ${ }^{56,65,87} \mathrm{~N}$-chloroamines $\mathbf{7 h}$ and $\mathbf{7 i}$ were prepared according to a literature procedure ${ }^{88}$ using sodium hypochlorite solution (10$15 \%$ available chlorine) and the spectral data were consistent with those previously reported. ${ }^{88,89}$ All other materials were prepared as described in detail below.

Crude reaction mixtures were analyzed by ${ }^{1} \mathrm{H}$ NMR spectroscopy, GC-MS, and/or thin-layer chromatography (TLC) on silica gel plates (60 Å F-254) or basic alumina plates (F-254) and visualized by UV irradiation and/or iodine stain. Crude material was purified by flash column chromatography on silica gel unless otherwise stated. Proton $\left({ }^{1} \mathrm{H}\right)$, carbon $\left({ }^{13} \mathrm{C}\left\{{ }^{1} \mathrm{H}\right\}\right)$, and fluorine $\left({ }^{19} \mathrm{~F}\left\{{ }^{1} \mathrm{H}\right\}\right)$ neclear magnetic resonance (NMR) spectra were obtained at $298 \mathrm{~K}$ in $\mathrm{CDCl}_{3}$, DMSO- $d_{6}$, or $\left(\mathrm{CD}_{3}\right)_{2} \mathrm{CO}$ on a Bruker Avance $\mathrm{II}+400 \mathrm{MHz}$ spectrometer or Bruker Avance III $600 \mathrm{MHz}$ spectrometers and referenced to residual solvent peaks ${ }^{90}$ or tetramethylsilane when applicable. The following notation is used: s singlet, $d$ - doublet, $d d-$ doublet of doublets, ddd - doublet of doublet of doublets, $t-$ triplet, $\mathrm{q}$ - quartet, $\mathrm{n}$ - nonet, $\mathrm{br}$ - broad signal. Molecular weight was determined on

Thermo Scientific Q-exactive high resolution mass spectrometer with electrospray ionization (ESI). Infrared spectra were recorded on Thermo Scientific Nicolet iS5 FTIR 
spectrometer in transmission mode. Melting points $\left({ }^{\circ} \mathrm{C}\right)$ were recorded on Melt-Temp (Thermo Scientific ${ }^{\mathrm{TM}}$ ) and are uncorrected.

\subsection{Supporting information for Chapter 2}

Database of benzenoid rings in FDA approved small molecule drugs is available online as a searchable $\underline{\text { Excel }}^{\mathrm{TM}}$ spreadsheet with ChemDraw $^{\circledR}$ extension enabled. The database includes the following sheets: FDA approved, Sub1 through Sub123456, and Approval by year. FDA approved and Sub1 through Sub123456 sheets consist of small molecule APIs organized by alphabetical order and contain the specific information for each molecule that was included in our analysis. Sub1 is monosubstituted, Sub12 is 1,2substituted, Sub13 is 1,3-substituted and so on. A user-guide to the database is available as $\underline{P D F}$.

\subsection{Supporting information for Chapter 3}

\subsubsection{Preparation of hydroxy(tosyloxy)iodomesitylene}
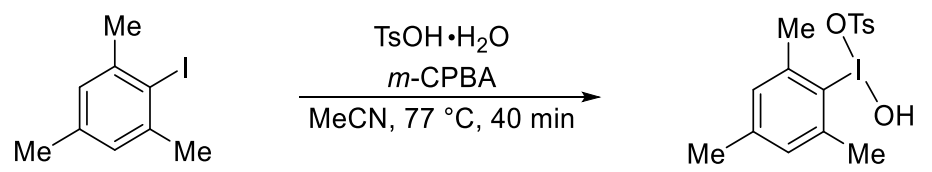

Scheme 17. Synthesis of hydroxy(tosyloxy)iodomesitylene.

Mesityl iodide $(0.738 \mathrm{~g}, 3 \mathrm{mmol})$, acetonitrile $(3 \mathrm{~mL})$, and toluenesulfonic acid monohydrate $(0.651 \mathrm{~g}, 3.03 \mathrm{mmol}, 1.01$ equiv.) were added to a round bottom flask equipped with a magnetic stir bar. $m$-CPBA (0.706 g, $3.03 \mathrm{mmol}, 1.01$ equiv.) was added in one portion at room temperature and the flask was placed into an oil bath set to $77^{\circ} \mathrm{C}$. After 40 min reaction was removed from heat, the contents were allowed to reach 
ambient room temperature, and the crude residue was triturated with diethyl ether. The precipitate was isolated by vacuum filtration and washed by slurry filtration with diethyl ether to provide analytically pure product in $85 \%$ yield $(1.11 \mathrm{~g}, 2.6 \mathrm{mmol})$ as white powder. Spectral data are consistent with those previously reported. ${ }^{91,92}$

${ }^{1} \mathrm{H}$ NMR (CD $\left.30 \mathrm{OD}, 400 \mathrm{MHz}\right) \delta=7.61(\mathrm{~d}, J=7.9 \mathrm{~Hz}, 2 \mathrm{H}), 7.28(\mathrm{~s}, 2 \mathrm{H}), 7.20(\mathrm{~d}, J=8.0 \mathrm{~Hz}, 2 \mathrm{H})$, $2.72(\mathrm{~s}, 6 \mathrm{H}), 2.41(\mathrm{~s}, 3 \mathrm{H}), 2.36(\mathrm{~s}, 3 \mathrm{H})$.

${ }^{13} \mathrm{C}$ NMR (CD ${ }_{3}$ OD, $\left.101 \mathrm{MHz}\right) \delta=147.4,144.2,142.9,141.9,130.6,129.8,126.9,26.7$, 21.3(4), 21.3(0).

\subsubsection{Preparation of aryl(Mes)iodonium tosylates}

\subsubsection{General procedure A}

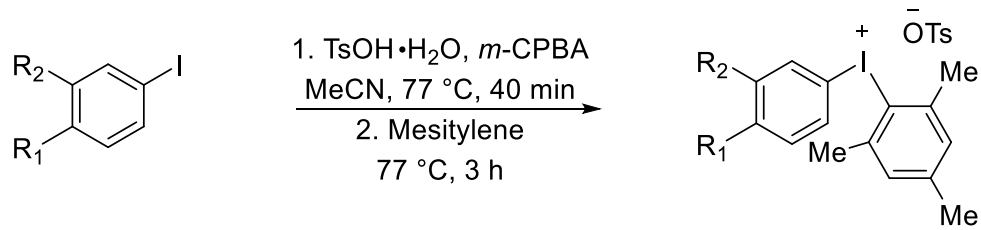

Scheme 18. Synthesis of aryl(Mes)iodonium salts from iodides.

Prepared according to the literature procedure. ${ }^{59}$ Aryl iodide (1.0 equiv.) and acetonitrile $(1 \mathrm{~mL} / \mathrm{mmol})$ were added to a round bottom flask, equipped with a magnetic stir bar. Toluenesulfonic acid monohydrate (1.01 equiv.) was added in one portion, followed by one portion of m-CPBA (1.01 equiv.). The flask was lowered into an oil bath set to $77^{\circ} \mathrm{C}$ and stirred vigorously. After $30 \mathrm{~min}$ 1,3,5-trimethylbenzene (1.01 equiv.) was added in one portion and stirring was continued at $77^{\circ} \mathrm{C}$ for 3 hours. The reaction was removed from heat and concentrated under reduced pressure. The resulting crude residue was triturated with diethyl ether. The precipitate was isolated by vacuum 
filtration and washed by slurry filtration with diethyl ether to give analytically pure $\operatorname{aryl}($ mesityl)iodonium tosylate.

\subsubsection{General procedure B}

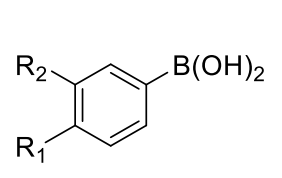

$$
\begin{aligned}
& \text { 1. } \mathrm{DCM}, 0{ }^{\circ} \mathrm{C}, \mathrm{N}_{2} \text { atm } \\
& \frac{\mathrm{BF}_{3} \cdot \mathrm{Et}_{2} \mathrm{O}, 10 \mathrm{~min}}{2 . \mathrm{Mesl}_{(\mathrm{OAc})_{2} \text { in } \mathrm{DCM}}} \\
& 0{ }^{\circ} \mathrm{C} \text { to r.t., r.t., overnight } \\
& \text { 3. } \mathrm{NaOTs}_{\mathrm{aq}}, 30 \mathrm{~min}
\end{aligned}
$$

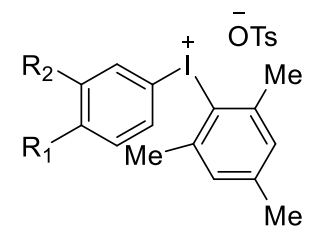

Scheme 19. Synthesis of aryl(Mes)iodonium tosylates from aryl boronic acids.

Prepared according to the literature procedure. ${ }^{93}$ Arylboronic acid $(5.0 \mathrm{mmol}, 1.0$ equiv.) was weighed and transferred to a round bottom flask equipped with a magnetic stir bar. The flask was sealed with a rubber septum, flushed with nitrogen, and left under a static nitrogen atmosphere. DCM $(30 \mathrm{~mL})$ was added via syringe to the aryl boronic acid and the solution was cooled to $0{ }^{\circ} \mathrm{C}$ in an ice-water bath with stirring. $\mathrm{BF}_{3} \cdot \mathrm{OEt}_{2}(1.1 \mathrm{~mL}$, $9.0 \mathrm{mmol}, 3.0$ equiv.) was added via syringe to the aryl boronic acid solution and the reaction mixture was stirred for $10 \mathrm{~min}$ at $0{ }^{\circ} \mathrm{C}$. Mesitylene iododiacetate $(1.20 \mathrm{~g}, 3.3$ mmol, 1.1 equiv.) was weighed and transferred to a separate pear-shaped flask. The flask was sealed with a rubber septum, flushed with nitrogen, and left under a static nitrogen atmosphere. DCM $(9 \mathrm{~mL})$ was added to the mesitylene iododiacetate via syringe. The mesitylene iododiacetate solution was added to the aryl boronic acid/BF $3 \cdot \mathrm{OEt}_{2}$ solution dropwise via syringe at $0{ }^{\circ} \mathrm{C}$. The reaction mixture was allowed to warm to ambient room temperature and stirred overnight. The septum was removed, and an aqueous solution of NaOTs (60 mmol, 20 equiv. in $30 \mathrm{~mL}$ of water) was added with vigorous stirring for $\sim 30$ min. The biphasic mixture was added to a separatory funnel, and the DCM/water layers 
were separated. The water layer was extracted with DCM $(3 \times 30 \mathrm{~mL})$. The combined DCM layers were dried over $\mathrm{MgSO}_{4}$, filtered, and solvent was removed under reduced pressure. The resulting crude residue was triturated with diethyl ether. The precipitate was isolated by vacuum filtration and washed by slurry filtration with diethyl ether to give analytically pure aryl(mesityl)iodonium tosylate. See below for the specific scale of reactions and characterization data of individual compounds.

\subsubsection{General procedure C}

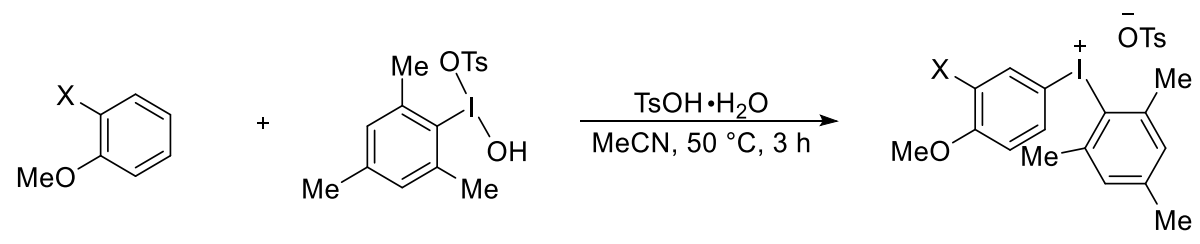

Scheme 20. Synthesis of aryl(Mes)iodonium tosylates from simple arenes.

Hydroxy(tosyloxy)iodomesitylene $(0.434 \mathrm{~g}, 1 \mathrm{mmol})$, acetonitrile $(1 \mathrm{~mL}), 2$ haloanisole (1.01 equiv.), and toluenesulfonic acid monohydrate ( $0.190 \mathrm{~g} ., 1$ equiv.) were added to a round bottom flask equipped with a magnetic stir bar. The flask was placed into an oil bath set to $50{ }^{\circ} \mathrm{C}$ and the mixture was stirred at this temperature for 3 hours. The flask was removed from heat and brought to room temperature. The crude mixture was triturated with diethyl ether. The precipitate was isolated by vacuum filtration and washed by slurry filtration with diethyl ether to give analytically pure aryl(mesityl)iodonium tosylate.

\subsubsection{Characterization of aryl(Mes)iodonium tosylates}

\section{Compound 6a}




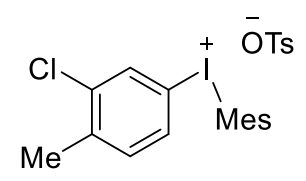

Prepared according to the general procedure A on $15.0 \mathrm{mmol}$ scale of 2-chloro-4iodotoluene and obtained in $63 \%$ yield $(5.12 \mathrm{~g}, 9.1 \mathrm{mmol}$ ) as white powder.

${ }^{1} \mathrm{H}$ NMR (DMSO-d $\left.{ }_{6}, 400 \mathrm{MHz}\right) \delta=8.13(\mathrm{~s}, 1 \mathrm{H}), \delta 7.78(\mathrm{~d}, J=8.2 \mathrm{~Hz}, 1 \mathrm{H}), \delta 7.48-7.46(\mathrm{~m}$, $3 \mathrm{H}), \delta 7.22(\mathrm{~s}, 2 \mathrm{H}), \delta 7.11(\mathrm{~d}, J=7.6,2 \mathrm{H}), \delta 2.60(\mathrm{~s}, 6 \mathrm{H}), \delta 2.36(\mathrm{~s}, 3 \mathrm{H}), 2.30-2.29(\mathrm{~m}, 6 \mathrm{H})$.

${ }^{13} \mathrm{C}$ NMR (DMSO- $\left.d_{6}, 101 \mathrm{MHz}\right) \delta=145.7,143.2,141.6,140.1,137.6,135.3,134.0,133.9$, $133.0,129.8,128.0,125.5,122.8,111.2,26.3,20.8,20.5,19.5$.

FT-IR: $2976,1574,1466,1218,1150,1005,810 \mathrm{~cm}^{-1}$.

HRMS: Calculated for $\mathrm{C}_{16} \mathrm{H}_{17} \mathrm{ClI}^{+}[\mathrm{M}-\mathrm{OTs}]^{+}$: 371.0058; Found 371.0057.

Melting point: $187-189^{\circ} \mathrm{C}$.

Compound 6b<smiles>C[I+]([O-])([O-])c1ccc(Cl)c(Cl)c1</smiles>

Prepared according to the general procedure B on $5.0 \mathrm{mmol}$ scale of 3,4-dichlorophenyl boronic acid and obtained in $84 \%$ yield $(2.36 \mathrm{~g}, 4.2 \mathrm{mmol}$ ) as white powder.

${ }^{1} \mathrm{H}$ NMR (DMSO- $\left.d_{6}, 400 \mathrm{MHz}\right) \delta=8.35(\mathrm{~s}, 1 \mathrm{H}), 7.83(\mathrm{~d}, J=8.6 \mathrm{~Hz}, 1 \mathrm{H}), 7.74(\mathrm{~d}, J=8.6 \mathrm{~Hz}$, $1 \mathrm{H}), 7.45(\mathrm{~d}, J=7.3 \mathrm{~Hz}, 2 \mathrm{H}), 7.23(\mathrm{~s}, 2 \mathrm{H}), 7.10(\mathrm{~d}, J=7.5 \mathrm{~Hz}, 2 \mathrm{H}), 2.59(\mathrm{~s}, 6 \mathrm{H}), 2.30(\mathrm{~s}, 3 \mathrm{H})$, $2.28(\mathrm{~s}, 3 \mathrm{H})$.

${ }^{13} \mathrm{C}$ NMR (DMSO- $\left.d_{6}, 101 \mathrm{MHz}\right) \delta .=145.5,143.4,141.8,137.7,135.6,135.3,134.3,133.4$, $133.3,129.9,128.1,125.5,122.9,112.5,26.3,20.8,20.5$.

FT-IR: 2982, 1449, 1215, 1170, 1008, $865 \mathrm{~cm}^{-1}$.

HRMS: Calculated for $\mathrm{C}_{15} \mathrm{H}_{14} \mathrm{Cl}_{2} \mathrm{I}^{+}[\mathrm{M}-\mathrm{OTs}]^{+}:$390.9512; found 390.9531.

Melting point: $192-193^{\circ} \mathrm{C}$.

Compound 6c 
<smiles>COc1ccc([I+][Na-]c2ccccc2)cc1Cl</smiles>

Prepared according to the general procedure A with the following modification: the reaction was conducted on $5.0 \mathrm{mmol}$ scale of mesityl iodide. After $30 \mathrm{~min} 2$-chloroanisole was added in one portion. After standard workup the resulting solid was recrystallized from $\mathrm{MeOH} / \mathrm{MeCN}$ mixture to provide the product in $45 \%$ yield $(1.162 \mathrm{~g}, 2.3 \mathrm{mmol})$ as off-white to light brown powder. Spectral data are consistent with those previously reported. ${ }^{56}$

${ }^{1} \mathrm{H}$ NMR (DMSO- $\left.d_{6}, 400 \mathrm{MHz}\right) \delta=8.16(\mathrm{~d}, J=2.2 \mathrm{~Hz}, 1 \mathrm{H}$ ), 7.89 (dd, $J=8.9,2.2 \mathrm{~Hz}, 1 \mathrm{H}$ ), 7.45 $(\mathrm{d}, J=8.0 \mathrm{~Hz}, 2 \mathrm{H}), 7.23-7.20(\mathrm{~m}, 3 \mathrm{H}), 7.10(\mathrm{~d}, J=7.9 \mathrm{~Hz}, 2 \mathrm{H}), 3.88(\mathrm{~s}, 3 \mathrm{H}), 2.60(\mathrm{~s}, 6 \mathrm{H}), 2.29-$ $2.28(\mathrm{~m}, 6 \mathrm{H})$.

${ }^{13}$ C NMR (DMSO-d $\left.d_{6}, 101 \mathrm{MHz}\right) \delta=157.2,145.7,143.0,141.5,137.6,135.3,129.7,128.0$, $125.5,123.3,123.1,115.7,102.9,56.7,26.3,20.8,20.5$.

Compound 6e<smiles></smiles>

Prepared according to the general procedure A on $5.0 \mathrm{mmol}$ scale of methyl 2-fluoro-4iodotoluene and obtained in $60 \%$ yield $(1.59 \mathrm{~g}, 3.0 \mathrm{mmol})$ as white powder.

${ }^{1} \mathrm{H}$ NMR (DMSO- $\left.d_{6}, 400 \mathrm{MHz}\right) \delta=7.93(\mathrm{~m}, 1 \mathrm{H}), 7.68(\mathrm{~m}, 1 \mathrm{H}), 7.48-7.41(\mathrm{~m}, 3 \mathrm{H}), 7.22(\mathrm{~s}$, $2 \mathrm{H}), 7.11(\mathrm{~d}, J=7.9,2 \mathrm{H}), 2.60(\mathrm{~s}, 6 \mathrm{H}), 2.29(\mathrm{~s}, 3 \mathrm{H}), 2.28(\mathrm{~s}, 3 \mathrm{H}), 2.26(\mathrm{~s}, 3 \mathrm{H})$.

${ }^{13} \mathrm{C}$ NMR (DMSO- $\left.d_{6}, 101 \mathrm{MHz}\right) \delta=160.6$ (d, $J_{\mathrm{C}-\mathrm{F}}=251.2$ ), 145.7, 143.1, 141.6, 137.6, 134.5 $\left(d, J_{C-F}=4.9\right), 130.5\left(d, J_{C-F}=3.7\right), 129.8,129.2\left(d, J_{C-F}=16.9\right), 128.0,125.5,122.9,121.2$ $\left(d, J_{C-F}=25.7\right), 110.5\left(d, J_{C-F}=8.1\right), 26.3,20.8,20.5,14.1\left(d, J_{C-F}=3.0\right)$.

${ }^{19} \mathrm{~F}\left\{{ }^{1} \mathrm{H}\right\}$ NMR (DMSO-d $\left.6,376 \mathrm{MHz}\right) \delta=-111.6$.

FT-IR: 3092, 2921, 1573, 1481, 1212, 1165, 1118, $852 \mathrm{~cm}^{-1}$.

HRMS: Calculated for $\mathrm{C}_{16} \mathrm{H}_{17} \mathrm{FI}^{+}[\mathrm{M}-\mathrm{OTs}]^{+}$: 355.0356; found 355.0371.

Melting point: $172-173^{\circ} \mathrm{C}$.

Compound $6 f$ 
<smiles>C[I+]c1ccc(F)c(F)c1</smiles>

Prepared according to the general procedure B on $5.0 \mathrm{mmol}$ scale of 3,4-difluorophenyl boronic acid and obtained in $86 \%$ yield $(2.28 \mathrm{~g}, 4.3 \mathrm{mmol}$ ) as white powder.

${ }^{1} \mathrm{H}$ NMR (DMSO- $\left.\boldsymbol{d}_{6}, 400 \mathrm{MHz}\right) \delta=8.26(\mathrm{~m}, 1 \mathrm{H}), 7.82(\mathrm{~m}, 1 \mathrm{H}), 7.61(\mathrm{~m}, 1 \mathrm{H}), 7.46(\mathrm{~d}, J=7.2$ $\mathrm{Hz}, 2 \mathrm{H}), 7.23(\mathrm{~s}, 2 \mathrm{H}), 7.11(\mathrm{~d}, J=7.5,2 \mathrm{H}), 2.61(\mathrm{~s}, 6 \mathrm{H}), 2.31(\mathrm{~s}, 3 \mathrm{H}), 2.29(\mathrm{~s}, 3 \mathrm{H})$.

${ }^{13} \mathrm{C}$ NMR (DMSO- $\left.d_{6}, 101 \mathrm{MHz}\right) \delta=151.7\left(\mathrm{dd}, J_{\mathrm{C}-\mathrm{F}}=251.2,10.5\right), 150.0\left(\mathrm{dd}, J_{\mathrm{C}-\mathrm{F}}=253.6\right.$, 12.6), 145.5, 143.3, 141.7, 137.7, 132.3 (dd, $\left.J_{C-F}=7.2,4.0\right), 129.8,128.1,125.5,124.3$ (d, $\left.J_{C-F}=20.1\right), 123.2,120.8\left(d, J_{C-F}=18.3\right), 107.7\left(d d, J_{C-F}=5.7,4.0\right), 26.3,20.8,20.5$.

${ }^{19} \mathrm{~F}\left\{{ }^{1} \mathrm{H}\right\}$ NMR (DMSO- $\left.d_{6}, 376 \mathrm{MHz}\right) \delta=-132.19(\mathrm{~d}, J=21.8),-132.75(\mathrm{~d}, J=21.7)$.

FT-IR: $2979,1496,1272,1162,1116,1030,812 \mathrm{~cm}^{-1}$.

HRMS: Calculated for $\mathrm{C}_{15} \mathrm{H}_{14} \mathrm{~F}_{2} \mathrm{I}^{+}[\mathrm{M}-\mathrm{OTs}]^{+}$: 359.0103; found 359.0121.

Melting point: $192-193^{\circ} \mathrm{C}$.

Compound 6g<smiles></smiles>

Prepared according to the general procedure $\mathrm{C}$ on $1.0 \mathrm{mmol}$ scale using 2-fluoroanisole ( $0.113 \mathrm{~mL}, 1.01$ equiv.) and obtained in $74 \%$ yield $(0.404 \mathrm{~g}, 0.7 \mathrm{mmol}$ ) as white powder.

${ }^{1} \mathrm{H}$ NMR (DMSO- $d_{6}$ with 1\% v/v TMS, $400 \mathrm{MHz}$ ) $\delta=8.01$ (dd, $J=10.2,2.1,1 \mathrm{H}$ ), 7.77-7.76 $(\mathrm{m}, 1 \mathrm{H}), 7.46(\mathrm{~d}, J=8.0,2 \mathrm{H}), 7.27(\mathrm{dd}$, appears as triplet, $J=8.8 \mathrm{~Hz}, 1 \mathrm{H}), 7.20(\mathrm{~s}, 2 \mathrm{H}), 7.10$ $(\mathrm{d}, J=7.9,2 \mathrm{H}), 3.87(\mathrm{~s}, 3 \mathrm{H}), 2.60(\mathrm{~s}, 6 \mathrm{H}), 2.29-2.28(\mathrm{~m}, 6 \mathrm{H})$.

${ }^{13} \mathrm{C}$ NMR (DMSO- $\left.d_{6}, 101 \mathrm{MHz}\right) \delta=151.56\left(\mathrm{~d}, J_{\mathrm{C}-\mathrm{F}}=261.8 \mathrm{~Hz}\right.$ ), 150.4, 145.4, 143.1, 141.5, $137.9,132.3\left(\mathrm{~d}, J_{\mathrm{C}-\mathrm{F}}=3.7 \mathrm{~Hz}\right), 129.8,128.2,125.6,123.3,122.4\left(\mathrm{~d}, J_{\mathrm{C}-\mathrm{F}}=21.3 \mathrm{~Hz}\right), 116.6$, $101.8\left(\mathrm{~d}, J_{\mathrm{C}-\mathrm{F}}=6.9 \mathrm{~Hz}\right), 56.5,26.3,20.8,20.6$.

${ }^{19} \mathrm{~F}\left\{{ }^{1} \mathrm{H}\right\}$ NMR (DMSO-d, $\left.376 \mathrm{MHz}\right) \delta=-130.2$.

FT-IR: 2980, 2842, 1592, 1496, 1208, 1171, 1031, 1009, 815, $680 \mathrm{~cm}^{-1}$. 
HRMS: Calculated for $\mathrm{C}_{16} \mathrm{H}_{17} \mathrm{FIO}^{+}[\mathrm{M}-\mathrm{OTs}]^{+}:$371.0303; found 371.0295.

Melting point: $179.7-180.8^{\circ} \mathrm{C}$.

Compound $6 \mathrm{~h}$<smiles>C[I+]c1ccc(OC(F)(F)F)c(F)c1</smiles>

Prepared according to the general procedure B on $2.0 \mathrm{mmol}$ scale of 3-fluoro-4trifluoromethoxyphenyl boronic acid and obtained in $74 \%$ yield $(0.879 \mathrm{~g}, 1.5 \mathrm{mmol})$ as white powder.

${ }^{1} \mathrm{H}$ NMR (DMSO-d $\left.6,400 \mathrm{MHz}\right) \delta=8.29$ (dd, $J=9.2,2.0 \mathrm{~Hz}, 1 \mathrm{H}, 7.86-7.84(\mathrm{~m}, 1 \mathrm{H}), 7.75-$ $7.71(\mathrm{~m}, 1 \mathrm{H}), 7.46(\mathrm{~d}, J=8.0 \mathrm{~Hz}, 2 \mathrm{H}), 7.25(\mathrm{~s}, 2 \mathrm{H}), 7.10(\mathrm{~d}, J=7.9 \mathrm{~Hz}, 2 \mathrm{H}), 2.60(\mathrm{~s}, 3 \mathrm{H}), 2.31$ $(\mathrm{s}, 3 \mathrm{H}), 2.28(\mathrm{~s}, 2 \mathrm{H})$.

${ }^{13} \mathrm{C}$ NMR (DMSO- $\left.d_{6}, 101 \mathrm{MHz}\right) \delta=153.7\left(\mathrm{~d}, J_{\mathrm{C}-\mathrm{F}}=258.3 \mathrm{~Hz}\right.$ ), 145.4, 143.4, 141.8, 137.8137.7 (m, two overlapping signals), $131.9\left(\mathrm{~d}, J_{\mathrm{C}-\mathrm{F}}=4.1 \mathrm{~Hz}\right), 129.8,128.0,126.6,125.4$, $124.0\left(d, J_{C-F}=21.9 \mathrm{~Hz}\right), 123.0,119.8\left(q, J_{C-F}=259.4 \mathrm{~Hz}\right), 112.3\left(d, J_{C-F}=6.5 \mathrm{~Hz}\right), 26.3,20.7$, 20.5 .

${ }^{19} \mathrm{~F}\left\{{ }^{1} \mathrm{H}\right\}$ NMR (DMSO- $\left.d_{6}, 376 \mathrm{MHz}\right) \delta=-57.8(\mathrm{~d}, J=5.2 \mathrm{~Hz}),-124.3(\mathrm{q}, J=5.2 \mathrm{~Hz})$.

FT-IR: 2981, 1491, 1255, 1164, 1118, 1008, $813 \mathrm{~cm}^{-1}$.

HRMS: Calculated for $\mathrm{C}_{16} \mathrm{H}_{14} \mathrm{~F}_{4} \mathrm{IO}^{+}[\mathrm{M}-\mathrm{OTs}]^{+}$: 425.0020; found 425.0011.

Melting point: $186.3-186.7^{\circ} \mathrm{C}$.

Compound $\mathbf{6 j}$<smiles>COc1ccc([I+][O-])cc1Br</smiles>

Prepared according to the literature procedure ${ }^{61}$ overnight on $1.0 \mathrm{mmol}$ scale of hydroxy(mesityl)iodonium tosylate and 2-bromoanisole and obtained in $52 \%$ yield $(0.313$ $\mathrm{g}, 0.52 \mathrm{mmol}$ ) as off-white powder.

${ }^{1} \mathrm{H}$ NMR (DMSO- $\left.d_{6}, 400 \mathrm{MHz}\right) \delta=8.29(\mathrm{~d}, J=2.1,1 \mathrm{H}), 7.93(\mathrm{~d}, J=8.9,2.1,1 \mathrm{H}), 7.47(\mathrm{~d}, J$ $=8.0,2 \mathrm{H}), 7.21-7.18(\mathrm{~m}, 3 \mathrm{H}), 7.11(\mathrm{~d}, J=7.8,2 \mathrm{H}), 3.89(\mathrm{~s}, 3 \mathrm{H}), 2.61(\mathrm{~s}, 6 \mathrm{H}), 2.30(\mathrm{~m}, 6 \mathrm{H})$. 
${ }^{13} \mathrm{C}$ NMR (DMSO- $\left.d_{6}, 101 \mathrm{MHz}\right) \delta=158.3,145.3,143.3,141.7,138.2(2), 138.1(8), 136.0$, 130.0, 128.3, 125.7, 123.3, 115.7, 112.9, 103.5, 57.0, 26.4, 21.0, 20.7.

FT-IR: 2978, 2842, 1473, 1439, 1219, 1046, 1030, 814, $679 \mathrm{~cm}^{-1}$.

HRMS: Calculated for $\mathrm{C}_{16} \mathrm{H}_{17} \mathrm{BrIO}^{+}[\mathrm{M}-\mathrm{OTs}]^{+}$: 430.9502 ; found 430.9495.

Melting point: $183.8-186.4^{\circ} \mathrm{C}$.

Compound $\mathbf{6 k}$<smiles></smiles>

Prepared according to the general procedure B on $3.0 \mathrm{mmol}$ scale of 3,4dimethoxybenzene boronic acid with the following modification: the reaction was performed with $0.4 \mathrm{~mL}$ (1.1 equiv.) of $\mathrm{BF}_{3} \cdot \mathrm{Et}_{2} \mathrm{O}$. and resulted in $65 \%$ yield $(1.09 \mathrm{~g}, 2.0$ $\mathrm{mmol}$ ) as light brown powder.

${ }^{1}$ H NMR (DMSO-d $\left.{ }_{6}, 400 \mathrm{MHz}\right) \delta=7.58(\mathrm{~d}, J=2.0 \mathrm{~Hz}, 1 \mathrm{H}), 7.47-7.45(\mathrm{~m}, 3 \mathrm{H}), 7.19(\mathrm{~s}, 3 \mathrm{H})$, $7.10(\mathrm{~d}, J=7.9 \mathrm{~Hz}, 2 \mathrm{H}), 7.02(\mathrm{~d}, J=8.7 \mathrm{~Hz}, 1 \mathrm{H}), 3.77(5)-3.77(0)(\mathrm{m}, 6 \mathrm{H}), 2.62(\mathrm{~s}, 6 \mathrm{H}), 2.28$ $(\mathrm{s}, 6 \mathrm{H})$.

${ }^{13} \mathrm{C}$ NMR (DMSO-d $\left.101 \mathrm{MHz}\right) \delta=151.6,150.1,145.6,142.8,141.4,137.6,129.6$, 128.0(3), 128.0(0), 125.5, 123.1, 117.7, 114.2, 102.8, 56.2, 55.8, 26.3, 20.8, 20.5.

FT-IR: 2982, 2920, 1502, 1143, 100, 794, $677 \mathrm{~cm}^{-1}$.

HRMS: Calculated for $\mathrm{C}_{17} \mathrm{H}_{20} \mathrm{IO}_{2}{ }^{+}[\mathrm{M}-\mathrm{OTs}]^{+}$: 383.0502 ; found 383.0493.

Melting point: $186.1-187.3^{\circ} \mathrm{C}$.

Compound 6I<smiles>Cc1ccc([I+][Na-])cc1[N+](=O)[O-]</smiles>

Prepared according to the general procedure A on $3.0 \mathrm{mmol}$ scale of 4-iodo-2nitrotoluene and obtained in $78 \%$ yield $(1.29 \mathrm{~g}, 2.3 \mathrm{mmol})$ as off-white powder. Spectral data are consistent with those previously reported. ${ }^{56}$

${ }^{1} \mathrm{H}$ NMR (DMSO-d $\left.{ }_{6}, 400 \mathrm{MHz}\right) \delta=8.60(\mathrm{~d}, J=1.7 \mathrm{~Hz}, 1 \mathrm{H}), 8.05(\mathrm{dd}, J=8.3,1.8 \mathrm{~Hz}, 1 \mathrm{H}$ ), $7.58(\mathrm{~d}, J=8.4 \mathrm{~Hz}, 1 \mathrm{H}), 7.45(\mathrm{~d}, J=8.0 \mathrm{~Hz}, 2 \mathrm{H}), 7.22(\mathrm{~s}, 2 \mathrm{H}), 7.10$ (d, J = 7.9, 2H), 2.59 (s, $6 \mathrm{H}), 2.51$ (c, 3H, overlapped with DMSO), $2.30(\mathrm{~s}, 3 \mathrm{H}), 2.28(\mathrm{~s}, 3 \mathrm{H})$. 
${ }^{13} \mathrm{C}$ NMR (DMSO-d $\left.d_{6}, 101 \mathrm{MHz}\right) \delta=149.7,145.5,143.4,141.7,138.2,137.7,136.7,135.7$, $130.0,129.9,128.1,125.5,123.0,111.0,26.4,20.8,20.6,19.3$.

Compound $6 \mathrm{~m}$<smiles></smiles>

Prepared according to the general procedure B on $2.0 \mathrm{mmol}$ scale of 4-methoxy-3trifluoromethylphenyl boronic acid and obtained in $98 \%$ yield $(1.16 \mathrm{~g}, 1.96 \mathrm{mmol})$ as white powder.

${ }^{1} \mathrm{H}$ NMR (DMSO-d $\left.6,400 \mathrm{MHz}\right) \delta=8.28(\mathrm{~d}, J=1.9 \mathrm{~Hz}, 1 \mathrm{H}), 8.11(\mathrm{dd}, J=9.0,2.1 \mathrm{~Hz}, 1 \mathrm{H})$, $7.46(\mathrm{~d}, J=8.0 \mathrm{~Hz}, 2 \mathrm{H}), 7.34(\mathrm{~d}, J=9.0 \mathrm{~Hz}, 1 \mathrm{H}), 7.21(\mathrm{~s}, 1 \mathrm{H}), 7.10(\mathrm{~d}, J=7.9,2 \mathrm{H}), 3.92(\mathrm{~s}$, $3 \mathrm{H}), 2.60(\mathrm{~s}, 6 \mathrm{H}), 2.30(\mathrm{~s}, 3 \mathrm{H}), 2.28(\mathrm{~s}, 3 \mathrm{H})$.

${ }^{13} \mathrm{C}$ NMR (DMSO- $\left.d_{6}, 101 \mathrm{MHz}\right) \delta=159.4,145.5,143.2,141.6,140.7,137.8,133.1$ (q, $J_{C-F}$ $=5.2 \mathrm{~Hz}$ ), 129.8, 128.1, 125.5, 123.2, 122.6 (q, $\left.J_{\mathrm{C}-\mathrm{F}}=261.5 \mathrm{~Hz}\right), 119.2\left(\mathrm{q}, J_{\mathrm{C}-\mathrm{F}}=31.5 \mathrm{~Hz}\right.$ ), $116.5,102.8,56.9,26.3,20.8,20.5$.

${ }^{19} \mathrm{~F}\left\{{ }^{1} \mathrm{H}\right\}$ NMR (DMSO-d $\left.6,376 \mathrm{MHz}\right) \delta=-61.44$.

FT-IR: 2979, 1599, 1485, 1119, 1008, $829 \mathrm{~cm}^{-1}$.

HRMS: Calculated for $\mathrm{C}_{17} \mathrm{H}_{17} \mathrm{~F}_{3} \mathrm{IO}^{+}[\mathrm{M}-\mathrm{OTs}]^{+}:$421.0276; Found 421.0286.

Melting point: $215-216^{\circ} \mathrm{C}$.

Compound 6n<smiles>C[I+]([O-])c1ccc(F)c(C(F)(F)F)c1</smiles>

Prepared according to the general procedure A on $5.0 \mathrm{mmol}$ scale of 1-fluoro-4-iodo-2trifluoromethylbenzene and obtained in $67 \%$ yield $(1.96 \mathrm{~g}, 3.4 \mathrm{mmol})$ as white powder.

${ }^{1} \mathrm{H}$ NMR (DMSO- $\left.\boldsymbol{d}_{6}, 400 \mathrm{MHz}\right) \delta=8.50-8.48(\mathrm{~m}, 1 \mathrm{H}), 8.19-8.15(\mathrm{~m}, 1 \mathrm{H}), 7.64(\mathrm{dd}$, appears as triplet, $J=9.8 \mathrm{~Hz}, 1 \mathrm{H}), 7.45(\mathrm{~d}, J=8.1 \mathrm{~Hz}, 2 \mathrm{H}), 7.24(\mathrm{~s}, 2 \mathrm{H}), 7.10(\mathrm{~d}, J=7.9 \mathrm{~Hz}, 2 \mathrm{H}), 2.59$ (s, $6 \mathrm{H}), 2.31(\mathrm{~s}, 3 \mathrm{H}), 2.28(\mathrm{~s}, 3 \mathrm{H})$.

${ }^{13} \mathrm{C}$ NMR (DMSO-d $\left.d_{6}, 101 \mathrm{MHz}\right) \delta=160.5$ (d, $J_{\mathrm{C}-\mathrm{F}}=260.1 \mathrm{~Hz}$ ), 145.4, 143.4, 141.8, 141.3 (d, $\left.J_{C-F}=9.7 \mathrm{~Hz}\right), 137.8,133.6\left(\mathrm{~d}, J_{\mathrm{C}-\mathrm{F}}=4.0 \mathrm{~Hz}\right), 129.9,128.1,125.5,123.0,121.3\left(\mathrm{q}, J_{\mathrm{C}-\mathrm{F}}=261.0\right.$ $\mathrm{Hz}), 121.0\left(\mathrm{~d}, J_{\mathrm{C}-\mathrm{F}}=21.8 \mathrm{~Hz}\right), 119.1\left(\mathrm{dq}, J_{\mathrm{C}-\mathrm{F}}=33.3,13.2 \mathrm{~Hz}\right), 108.8\left(\mathrm{~d}, J_{\mathrm{C}-\mathrm{F}}=3.6 \mathrm{~Hz}\right), 26.3$, $20.8,20.5$.

${ }^{19} \mathrm{~F}\left\{{ }^{1} \mathrm{H}\right\}$ NMR (DMSO-d, $\left.376 \mathrm{MHz}\right) \delta=-55.53(\mathrm{~d}, J=12.3 \mathrm{~Hz}),-105.51(\mathrm{q}, J=12.5 \mathrm{~Hz}$ ). 
FT-IR: 3059, 1575, 1282, 1127, 1030, 1004, 812, $679 \mathrm{~cm}^{-1}$.

HRMS: Calculated for $\left.\mathrm{C}_{16} \mathrm{H}_{14} \mathrm{~F}_{4}\right|^{+}[\mathrm{M}-\mathrm{OTs}]^{+}$: 409.0071; found 409.0072.

Melting point: $178-180^{\circ} \mathrm{C}$.

\subsubsection{Synthesis and characterization of 1,2,3,4-substituted arenes with arynophile 7a}

\subsubsection{General procedure D}

The iodonium salt ( $0.5 \mathrm{mmol}, 1$ equiv.) was weighed out and placed in a $12 \mathrm{~mL}$ vial containing a magnetic stir bar. TBME $(2.5 \mathrm{~mL})$ and $7 \mathrm{a}(0.16 \mathrm{~mL}, 1.5 \mathrm{mmol}, 3$ equiv.) were added sequentially forming slurry. Ground to fine powder $\mathrm{NaOt}$-Bu $(0.0721 \mathrm{~g}, 0.75 \mathrm{mmol}$, 1.5 equiv. or as indicated) was weighed out in air and added to the vial with stirring in one portion. The vial was sealed with a cap, and the reaction mixture was vigorously stirred at the room temperature for 40 minutes or as indicated. The reaction was quenched with saline solution $(7 \mathrm{~mL})$ and extracted with EtOAc $(3 \times 3 \mathrm{~mL})$. The combined organic phases were dried with $\mathrm{MgSO}_{4}$, drying agent was removed by vacuum filtration, and solvent was removed on rotary evaporator. The crude residue was purified by column chromatography on silica gel with acetone/hexanes mixture as eluent.

\subsubsection{Gram scale reaction}

The iodonium salt $6 \mathrm{n}(2.9019 \mathrm{~g}, 5 \mathrm{mmol})$ was weight out and placed in $100 \mathrm{~mL}$ round bottom flask containing a magnetic stir bar. MTBE $(25 \mathrm{~mL})$ and 1,2-dimethyl-2imidazolidinone (DMI, $1.62 \mathrm{~mL}, 15 \mathrm{mmol}, 3$ equiv.) were added sequentially forming white slurry (Figure 21, A). Ground to fine powder NaOt-Bu (0.7208 g, $7.5 \mathrm{mmol}, 1.5$ equiv.) was weighed out in air and added to the round bottom flask with stirring in one portion with a powder funnel (Figure 1, B), and the reaction mixture turned yellow within 1 min (Figure 
1, C). The contents were vigorously stirred for $40 \mathrm{~min}$. at room temperature without further change in color. The reaction was quenched with saline solution and extracted with EtOAc $(3 \times 10 \mathrm{~mL})$. The combined organic phases were dried with $\mathrm{MgSO}_{4}$, drying agent was removed by vacuum filtration, and solvent was removed on rotary evaporator. The crude residue was purified by column chromatography on silica gel with acetone/hexanes mixture as eluent to provide the product in $62 \%$ yield $(0.8570 \mathrm{~g}, 3.1 \mathrm{mmol})$ as a white solid.
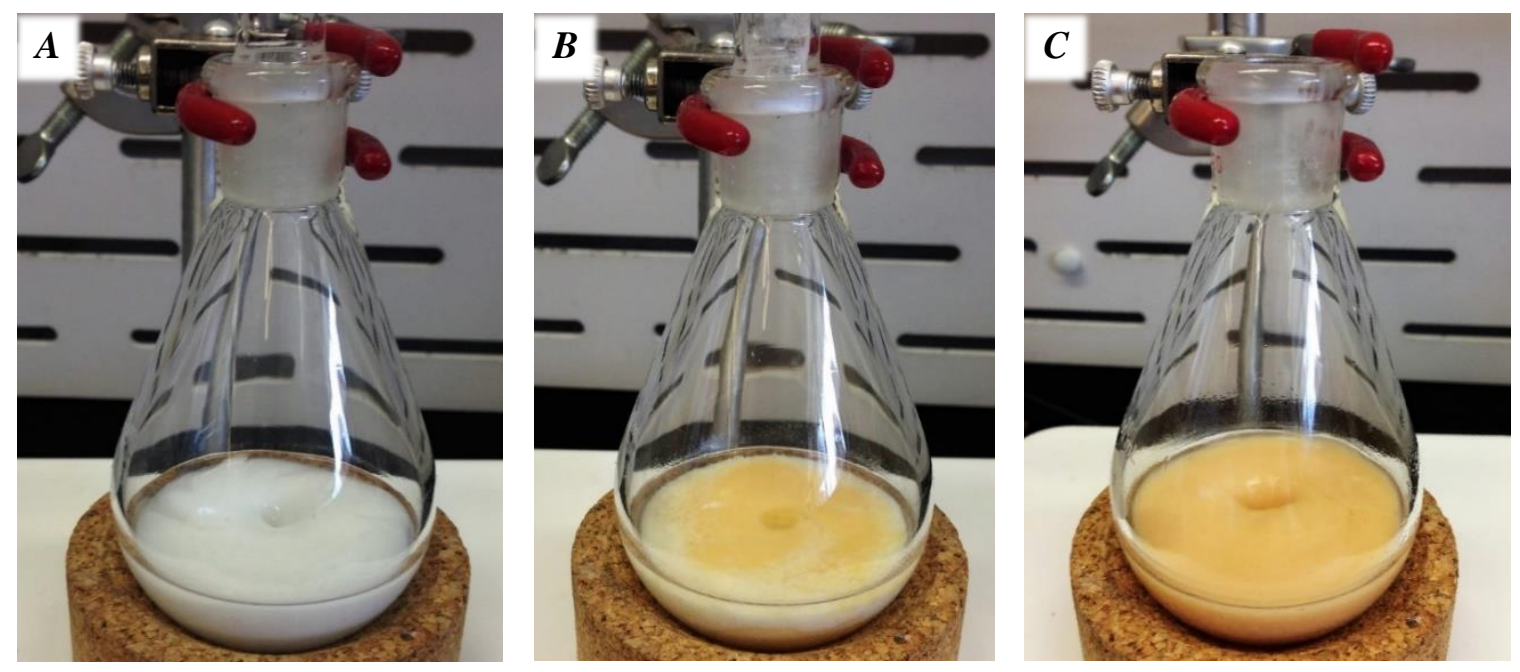

Figure 21. Aryne coupling reaction on $5 \mathrm{mmol}$ scale: A. Slurry of iodonium salt in MTBE and DMI; B. Appearance of the reaction mixture after addition of $\mathrm{NaOt}-\mathrm{Bu} ; \mathrm{C}$. Appearance of the reaction mixture after 1 min at stirring.

\section{Compound 8aa}<smiles>Cc1ccc2c(c1Cl)C(=O)N(C)CCN2C</smiles>

Prepared from 6a according to the general procedure D for $15 \mathrm{~min}$. and obtained in 55\% yield (0.0666 $\mathrm{g}, 0.28 \mathrm{mmol})$ as a white solid.

$\mathrm{R}_{f}=0.34$ in $35 \%$ acetone/hexane. 
${ }^{1} \mathrm{H}$ NMR (CDCl 3 with $1 \%$ v/v TMS, $400 \mathrm{MHz} \delta=7.18(\mathrm{~d}, J=8.1 \mathrm{~Hz}, 1 \mathrm{H}), 6.74(\mathrm{~d}, J=8.1 \mathrm{~Hz}$, $1 \mathrm{H}), 3.87-3.33(\mathrm{br}, 2 \mathrm{H}), 3.21(\mathrm{~s}, 3 \mathrm{H}), 2.76(\mathrm{~s}, 3 \mathrm{H}), 2.33(\mathrm{~s}, 3 \mathrm{H})$.

Note: two H's of ethelene group are not reported as they appear as broad signals between $\sim$ 4-2 ppm, consistent with previous reports on related compounds. ${ }^{80}$

${ }^{13} \mathrm{C}$ NMR ( $\mathrm{CDCl}_{3}$ with 1\% v/v TMS, $\left.101 \mathrm{MHz}\right) \delta=167.7,145.8,132.4,132.2,131.0,129.3$, 116.0, 57.0, 47.9, 40.1, 33.3, 19.8 .

FT-IR: 2944, 1647, 1596, 1482, 1446, 1425, $826 \mathrm{~cm}^{-1}$.

HRMS (ESI ${ }^{+}$): calculated for $\mathrm{C}_{12} \mathrm{H}_{16} \mathrm{ClN}_{2} \mathrm{O}^{+}[\mathrm{M}+\mathrm{H}]^{+}$239.0948; found 239.0942.

Melting point: $110-111^{\circ} \mathrm{C}$.

Compound 8 ba<smiles>CN1CCN(C)c2ccc(Cl)c(Cl)c2C1=O</smiles>

Prepared from $\mathbf{6 b}$ according to the general procedure D and obtained in $75 \%$ yield $(0.0980$ $\mathrm{g}, 0.38 \mathrm{mmol}$ ) as an off-white solid.

$\mathrm{R}_{f}=0.22$ in $30 \%$ acetone/hexane

${ }^{1} \mathrm{H}$ NMR $\left(\left(\mathrm{CD}_{3}\right)_{2} \mathrm{CO}, 400 \mathrm{MHz}\right) \delta=7.51(\mathrm{~d}, J=8.8 \mathrm{~Hz}, 1 \mathrm{H}), 6.98(\mathrm{~d}, J=8.8 \mathrm{~Hz}, 1 \mathrm{H}), 3.50(\mathrm{br}$, $2 \mathrm{H}), 3.14(\mathrm{~s}, 3 \mathrm{H}), 2.80(\mathrm{~s}, 3 \mathrm{H})$.

Note: two $\mathrm{H}^{\prime} \mathrm{s}$ of ethelene group are not reported as they appear as a broad signal between $\sim 4-2$ ppm, consistent with previous reports on related compounds. ${ }^{80}$

${ }^{13} \mathrm{C}$ NMR $\left(\left(\mathrm{CD}_{3}\right)_{2} \mathrm{CO}, 101 \mathrm{MHz}\right) \delta=166.3,147.8,132.2,132.1,131.0,126.5,118.7,57.6$, 48.0, 40.3, 33.1.

FT-IR: 2942, 2812, 1642, 1579, 1450, 1405, 1255, 1172, 1060, 822, $731 \mathrm{~cm}^{-1}$.

HRMS (ESI ${ }^{+}$): calculated for $\mathrm{C}_{11} \mathrm{H}_{13} \mathrm{Cl}_{2} \mathrm{~N}_{2} \mathrm{O}^{+}[\mathrm{M}+\mathrm{H}]^{+} 259.0399$; found 259.0412 .

Melting point: $90.6-91.6^{\circ} \mathrm{C}$.

Compound 8ca 
<smiles>COc1ccc2c(c1Cl)C(=O)N(C)CCN2C</smiles>

Prepared from $\mathbf{6 c}$ according to the general procedure $\mathrm{D}$. The product was isolated by column chromatography with diethyl ether as eluent and obtained in $52 \%$ yield $(0.0664$ $\mathrm{g}, 0.26 \mathrm{mmol}$ ) as a yellow oil.

$\mathrm{R}_{f}=0.08$ in $100 \%$ ethyl ether.

${ }^{1} \mathrm{H} \mathrm{NMR}\left(\mathrm{CDCl}_{3}\right.$ with $1 \% \mathrm{v} / \mathrm{v}$ TMS, $\left.400 \mathrm{MHz}\right) \delta=6.93(\mathrm{~d}, J=8.8 \mathrm{~Hz}, 1 \mathrm{H}), 6.80(\mathrm{~d}, J=8.8 \mathrm{~Hz}$, $1 \mathrm{H}), 3.86(\mathrm{~s}, 3 \mathrm{H}), 3.76-3.30(\mathrm{br}, 2 \mathrm{H}) 3.21(\mathrm{~s}, 3 \mathrm{H}), 2.75(\mathrm{~s}, 3 \mathrm{H})$.

Note: two H's of ethelene group are not reported as they appear as broad signals between $\sim$ 4-2 ppm, consistent with previous reports on related compounds. ${ }^{80}$

${ }^{13} \mathrm{C}$ NMR $\left(\mathrm{CDCl}_{3}\right.$ with $1 \%$ v/v TMS, $\left.101 \mathrm{MHz}\right) \delta=167.0,151.4,141.0,130.9,121.3,116.5$, $113.8,57.1,56.7,48.0,40.2,33.3$.

FT-IR: 2937, 2843, 1645, 1456, 1433, 1269, 1048, 812, $686 \mathrm{~cm}^{-1}$.

HRMS (ESI ${ }^{+}$): calculated for $\mathrm{C}_{12} \mathrm{H}_{15} \mathrm{ClN}_{2} \mathrm{NaO}_{2}{ }^{+}[\mathrm{M}+\mathrm{Na}]^{+}$277.0714; found 277.0708.

\section{Compound 8da}<smiles>CN1CCN(C)c2ccc(F)c(Cl)c2C1=O</smiles>

Prepared from $6 \mathbf{d}$ according to the general procedure D for $25 \mathrm{~min}$. and obtained in $63 \%$ yield $(0.0761 \mathrm{~g}, 0.31 \mathrm{mmol})$ as an off-white solid.

$\mathrm{R}_{f}=0.3130 \%$ acetone/hexanes

${ }^{1} \mathrm{H}_{\mathrm{NMR}}\left(\mathrm{CDCl}_{3}\right.$ with $1 \%$ v/v TMS, $\left.400 \mathrm{MHz}\right) \delta=7.11$ (dd, appears as triplet, $J=8.7 \mathrm{~Hz}$, $1 \mathrm{H}), 6.79$ (dd, $J=8.9,4.2 \mathrm{~Hz}, 1 \mathrm{H}), 3.53-3.31(\mathrm{br}, 2 \mathrm{H}), 3.21(\mathrm{~s}, 3 \mathrm{H}), 2.77(\mathrm{~s}, 3 \mathrm{H})$.

Note: : two $\mathrm{H}^{\prime}$ s of ethelene group are not reported as they appear as broad signals between $\sim 4-2 \mathrm{ppm}$, consistent with previous reports on related compounds. ${ }^{80}$ 
${ }^{13} \mathrm{C}$ NMR (CDCl 3 with 1\% v/v TMS, $\left.101 \mathrm{MHz}\right) \delta=166.1$ (d, $\left.J_{\mathrm{C}-\mathrm{F}}=2.6 \mathrm{~Hz}\right), 154.3\left(\mathrm{~d}, J_{\mathrm{C}-\mathrm{F}}=\right.$ $243.5 \mathrm{~Hz}), 143.7\left(\mathrm{~d}, J_{\mathrm{C}-\mathrm{F}}=2.7 \mathrm{~Hz}\right), 130.5,119.9\left(\mathrm{~d}, J_{\mathrm{C}-\mathrm{F}}=19.6 \mathrm{~Hz}\right), 117.6\left(\mathrm{~d}, J_{\mathrm{C}-\mathrm{F}}=22.1 \mathrm{~Hz}\right)$, $117.0\left(\mathrm{~d}, J_{\mathrm{C}-\mathrm{F}}=6.8 \mathrm{~Hz}\right), 57.1,47.8,40.2,33.4$.

${ }^{19} \mathrm{~F}\left\{{ }^{1} \mathrm{H}\right\}$ NMR $\left(\mathrm{CDCl}_{3}\right.$ with $1 \%$ v/v TMS, $\left.376 \mathrm{MHz},\right) \delta=-121.9$.

FT-IR: 2949, 2863, 1650, 1482, 1459,1428, 1258, 826, $759 \mathrm{~cm}^{-1}$.

HRMS (ESI ${ }^{+}$): calculated for $\mathrm{C}_{11} \mathrm{H}_{13} \mathrm{ClFN}_{2} \mathrm{O}^{+}[\mathrm{M}+\mathrm{H}]^{+}$243.0695; found 243.0706.

Melting point: $113.4-113.7^{\circ} \mathrm{C}$.

Compound 8ea<smiles>Cc1ccc2c(c1F)C(=O)N(C)CCN2C</smiles>

Prepared from 6 e according to the general procedure $D$ and obtained in $53 \%$ yield $(0.0587$ g, $0.26 \mathrm{mmol}$ ) as a white solid.

$\mathrm{R}_{f}=0.13$ in $30 \%$ acetone/hexane

${ }^{1} \mathbf{H}$ NMR $\left(\mathrm{CDCl}_{3}\right.$ with $1 \%$ v/v TMS, $\left.400 \mathrm{MHz}\right) \delta=7.13$ (dd, appears as triplet, $J=8.3 \mathrm{~Hz}$, $1 \mathrm{H}), 6.57(\mathrm{~d}, J=8.2 \mathrm{~Hz}, 1 \mathrm{H}), 3.43(\mathrm{t}, J=5.7 \mathrm{~Hz}, 2 \mathrm{H}), 3.19-3.18(\mathrm{~m}, 5 \mathrm{H}), 2.77(\mathrm{~s}, 3 \mathrm{H}), 2.21(\mathrm{~s}$, $3 \mathrm{H})$.

${ }^{13} \mathrm{C}$ NMR ( $\mathrm{CDCl}_{3}$ with $1 \% \mathrm{v} / \mathrm{v}$ TMS, $\left.101 \mathrm{MHz}\right) \delta=166.1,158.8\left(\mathrm{~d}, J_{\mathrm{C}-\mathrm{F}}=251.1 \mathrm{~Hz}\right), 146.1(\mathrm{~d}$, $\left.J_{\mathrm{C}-\mathrm{F}}=5.2 \mathrm{~Hz}\right), 133.1\left(\mathrm{~d}, J_{\mathrm{C}-\mathrm{F}}=7.5 \mathrm{~Hz}\right), 118.8\left(\mathrm{~d}, J_{\mathrm{C}-\mathrm{F}}=18.1 \mathrm{~Hz}\right), 117.6\left(\mathrm{~d}, J_{\mathrm{C}-\mathrm{F}}=14.8 \mathrm{~Hz}\right), 112.8$ $\left(d, J_{C-F}=3.4 \mathrm{~Hz}\right), 57.4,47.8,40.2,33.5,14.1\left(d, J_{C-F}=3.8 \mathrm{~Hz}\right)$.

${ }^{19} \mathrm{~F}\left\{{ }^{1} \mathrm{H}\right\}$ NMR $\left(\mathrm{CDCl}_{3}\right.$ with $1 \% \mathrm{v} / \mathrm{v}$ TMS, $\left.376 \mathrm{MHz}\right) \delta=-116.9$.

FT-IR: 2945, 2811, 1639, 1491, 1261, 1170, $826 \mathrm{~cm}^{-1}$.

HRMS (ESI ${ }^{+}$): calculated for $\mathrm{C}_{12} \mathrm{H}_{15} \mathrm{FN}_{2} \mathrm{NaO}^{+}[\mathrm{M}+\mathrm{Na}]^{+} 245.1061$; found 245.1055.

Melting point: $107.9-109.1^{\circ} \mathrm{C}$.

Compound $8 \mathrm{fa}$ 
<smiles>CN1CCN(C)c2ccc(F)c(F)c2C1=O</smiles>

Prepared from $6 f$ according to the general procedure $D$ and obtained in $53 \%$ yield $(0.0602$ $\mathrm{g}, 0.27 \mathrm{mmol}$ ) as a colorless oil.

$\mathrm{R}_{f}=0.18$ in $30 \%$ acetone/hexane.

${ }^{1} \mathrm{H}$ NMR $\left(\mathrm{CDCl}_{3}\right.$ with $1 \%$ v/v TMS, $\left.400 \mathrm{MHz}\right) \delta=7.13(\mathrm{~m}, 1 \mathrm{H}), 6.61-6.57(\mathrm{~m}, 1 \mathrm{H}), 3.44(\mathrm{t}, J$ $=5.8 \mathrm{~Hz}, 2 \mathrm{H}), 3.22-3.20(\mathrm{~m}, 5 \mathrm{H}), 2.78(\mathrm{~s}, 3 \mathrm{H})$.

${ }^{13} \mathrm{C} \mathrm{NMR}\left(\mathrm{CDCl}_{3}\right.$ with 1\% v/v TMS, $\left.101 \mathrm{MHz}\right) \delta=164.7\left(\mathrm{~d}, \mathrm{~J}_{\mathrm{C}-\mathrm{F}}=2.7 \mathrm{~Hz}\right), 148.5$ (dd, $J_{\mathrm{C}-\mathrm{F}}=$ 254.6, 14.2 Hz), $146.2\left(\mathrm{dd}, J_{\mathrm{C}-\mathrm{F}}=243.0,13.2 \mathrm{~Hz}\right.$ ), $143.5(\mathrm{~m}), 119.8\left(\mathrm{~d}, J_{\mathrm{C}-\mathrm{F}}=10.7 \mathrm{~Hz}\right), 118.6$ $\left(d d, J_{C-F}=17.7,2.0 \mathrm{~Hz}\right), 112.9\left(\mathrm{dd}, J_{\mathrm{C}-\mathrm{F}}=5.9,3.7 \mathrm{~Hz}\right), 57.4,47.8,40.3,33.6$.

${ }^{19} \mathrm{~F}\left\{{ }^{1} \mathrm{H}\right\}$ NMR $\left(\mathrm{CDCl}_{3}\right.$ with $1 \% \mathrm{v} / \mathrm{v}$ TMS, $\left.376 \mathrm{MHz}\right) \delta=-137.26(\mathrm{~d}, J=21.8 \mathrm{~Hz}),-145.5(\mathrm{~d}, J=$ $21.8 \mathrm{~Hz}$ ).

FT-IR: 2944, 1645, 1492, 1396, 1262, 1173, $685 \mathrm{~cm}^{-1}$.

HRMS (ESI ${ }^{+}$): calculated for $\mathrm{C}_{11} \mathrm{H}_{13} \mathrm{~F}_{2} \mathrm{~N}_{2} \mathrm{O}^{+}[\mathrm{M}+\mathrm{H}]^{+} 227.0991$; found 227.1002 .

Compound 8ga<smiles>COc1ccc2c(c1F)C(=O)N(C)CCN2C</smiles>

Prepared from $6 \mathrm{~g}$ according to the general procedure $\mathrm{D}$ and obtained in $50 \%$ yield $(0.0599$ $\mathrm{g}, 0.25 \mathrm{mmol}$ ) as a white solid.

$\mathrm{R}_{f}=0.14$ in $30 \%$ acetone/hexane

${ }^{1} \mathrm{H}$ NMR ( $\mathrm{CDCl}_{3}$ with 1\% v/v TMS, $\left.400 \mathrm{MHz}\right) \delta=6.96$ (dd, appears as triplet, $J=9.0 \mathrm{~Hz}$, $1 \mathrm{H}), 6.59$ (dd, J = 8.8, 1.5 Hz, 1H), $3.85(\mathrm{~s}, 3 \mathrm{H}), 3.41(\mathrm{t}, J=5.8 \mathrm{~Hz}, 2 \mathrm{H}), 3.20(\mathrm{~s}, 3 \mathrm{H}), 3.14(\mathrm{t}$, $J=5.7 \mathrm{~Hz}, 3 \mathrm{H}), 2.76(\mathrm{~s}, 3 \mathrm{H})$.

${ }^{13} \mathrm{C} \mathrm{NMR}\left(\mathrm{CDCl}_{3}\right.$ with 1\% v/v TMS, $\left.101 \mathrm{MHz}\right) \delta=165.5,150.5\left(\mathrm{~d}, J_{\mathrm{C}-\mathrm{F}}=253.7 \mathrm{~Hz}\right), 143.5$ (d, $J_{C-F}=11.2 \mathrm{~Hz}$ ), $140.9\left(\mathrm{~d}, J_{\mathrm{C}-\mathrm{F}}=4.3 \mathrm{~Hz}\right.$ ), $119.6\left(\mathrm{~d}, J_{\mathrm{C}-\mathrm{F}}=11.4 \mathrm{~Hz}\right), 115.9\left(\mathrm{~d}, J_{\mathrm{C}-\mathrm{F}}=3.6 \mathrm{~Hz}\right), 112.6$ $\left(d, J_{C-F}=3.6 \mathrm{~Hz}\right), 57.4,57.0,47.9,40.3,33.5$. 


\section{${ }^{19} \mathrm{~F}\left\{{ }^{1} \mathrm{H}\right\}$ NMR $\left(\mathrm{CDCl}_{3}\right.$ with $1 \% \mathrm{v} / \mathrm{v}$ TMS, $\left.376 \mathrm{MHz}\right) \delta=-134.1$.}

FT-IR: 2953, 2817,1636, 1494,1457, 1267,1059, 814, $695 \mathrm{~cm}^{-1}$.

HRMS (ESI ${ }^{+}$): calculated for $\mathrm{C}_{12} \mathrm{H}_{15} \mathrm{FN}_{2} \mathrm{NaO}_{2}{ }^{+}[\mathrm{M}+\mathrm{Na}]^{+}$261.1010; found 261.1005.

Melting point: $106.5-108.9^{\circ} \mathrm{C}$.

Compound 8ha<smiles>CN1CCN(C)c2ccc(OC(F)(F)F)c(F)c2C1=O</smiles>

Prepared from $6 \mathrm{~h}$ according to the general procedure D and obtained in $53 \%$ yield $(0.0778$ $\mathrm{g}, 0.27 \mathrm{mmol}$ ) as a pale-yellow solid.

$\mathrm{R}_{f}=0.27$ in $30 \%$ acetone/hexane

${ }^{1} \mathbf{H}$ NMR $\left(\mathrm{CDCl}_{3}\right.$ with $1 \% \mathrm{v} / \mathbf{v}$ TMS, $\left.400 \mathrm{MHz}\right) \delta=7.28-7.23(\mathrm{~m}, 1 \mathrm{H}), 6.64(\mathrm{dd}, J=9.0,1.6$ $\mathrm{Hz}, 1 \mathrm{H}), 3.47(\mathrm{t}, J=5.7 \mathrm{~Hz}, 2 \mathrm{H}), 3.27(\mathrm{t}, J=5.7 \mathrm{~Hz}, 2 \mathrm{H}), 3.20(\mathrm{~s}, 3 \mathrm{H}), 2.81(\mathrm{~s}, 3 \mathrm{H})$.

${ }^{13} \mathrm{C}$ NMR ( $\mathrm{CDCl}_{3}$ with 1\% v/v TMS, $\left.101 \mathrm{MHz}\right) \delta=164.5,152.9$ (d, $J_{\mathrm{C}-\mathrm{F}}=258.4 \mathrm{~Hz}$ ), 146.8 (d, $\left.J_{\mathrm{C}-\mathrm{F}}=4.7 \mathrm{~Hz}\right), 131.1-131.0(\mathrm{~m}), 125.6,120.6\left(\mathrm{q}, J_{\mathrm{C}-\mathrm{F}}=258.3 \mathrm{~Hz}\right), 118.9\left(\mathrm{~d}, J_{\mathrm{C}-\mathrm{F}}=12.0\right), 113.1$ $\left(d, J_{C-F}=3.5 \mathrm{~Hz}\right), 57.2,47.6,40.2,33.6$.

${ }^{19} \mathrm{~F}\left\{{ }^{1} \mathrm{H}\right\}$ NMR $\left(\mathrm{CDCl}_{3}\right.$ with $1 \% \mathrm{v} / \mathrm{v}$ TMS, $\left.376 \mathrm{MHz}\right) \delta=-59.1(\mathrm{~d}, J=4.2 \mathrm{~Hz}),-128.2(\mathrm{q}, J=4.8$ $\mathrm{Hz}$ ).

FT-IR: 3060, 2964, 2821, 1643, 1617, 1495, 1256, 1209, 1158, $827 \mathrm{~cm}^{-1}$.

HRMS (ESI ${ }^{+}$): calculated for $\mathrm{C}_{12} \mathrm{H}_{12} \mathrm{~F}_{4} \mathrm{~N}_{2} \mathrm{NaO}_{2}{ }^{+}[\mathrm{M}+\mathrm{Na}]^{+}$315.0727; found 315.0720.

Melting point: $120.5-121.0^{\circ} \mathrm{C}$.

Compound 8ia<smiles>Cc1ccc2c(c1Br)C(=O)N(C)CCN2C</smiles> 
Prepared from $6 \mathbf{i}$ according to the general procedure D using NaOt-Bu $(0.1441,1.5 \mathrm{mmol}$, 3.0 equiv.) for $20 \mathrm{~min}$. and obtained in $51 \%$ yield $(0.0720 \mathrm{~g}, 0.25 \mathrm{mmol})$ yield; on $2 \mathrm{mmol}$ scale for $40 \mathrm{~min}$ and obtained in $55 \%$ yield (average of 3 trials) as a white solid.

$\mathrm{R}_{f}=0.22$ in $30 \%$ acetone/hexane.

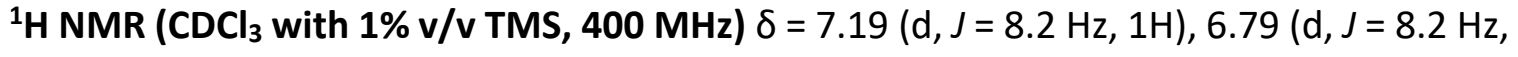
$1 \mathrm{H}), 3.88-3.40(\mathrm{br}, 2 \mathrm{H}), 3.27-3.02(\mathrm{br}, 1 \mathrm{H}$, overlaps with singlet at $3.21 \mathrm{ppm}), 3.21(\mathrm{~s}, 3 \mathrm{H}$, overlaps with broad signal), 2.88-2.56 (br, $1 \mathrm{H}$, overlaps with singlet at $2.75 \mathrm{ppm}$ ), 2.75 (s, $3 \mathrm{H}$, overlaps with broad signal), $2.37(\mathrm{~s}, 3 \mathrm{H})$.

Note: the protons of the ethelene group appear as broad signals at $\delta=3.88-3.40,3.27$ 3.02, and 2.88-2.56 ppm.

${ }^{13} \mathrm{C} \mathrm{NMR}\left(\mathrm{CDCl}_{3}\right.$ with 1\% v/v TMS, $\left.101 \mathrm{MHz}\right) \delta=168.5,145.7,133.0,132.0,131.5,123.2$, 116.7, 56.9, 48.0, 40.1, 33.3, 22.9.

FT-IR: $2942,1648,1591,1415,1424,827,729 \mathrm{~cm}^{-1}$.

HRMS (ESI ${ }^{+}$): calculated for $\mathrm{C}_{12} \mathrm{H}_{16} \mathrm{BrN}_{2} \mathrm{O}^{+}[\mathrm{M}+\mathrm{H}]^{+}$283.0441; found 283.0452 .

Melting point: $119.0-120.0^{\circ} \mathrm{C}$.

Compound 8ja<smiles>COc1ccc2c(c1Br)C(=O)N(C)CCN2C</smiles>

Prepared from $\mathbf{6 j}$ according to the general procedure $\mathrm{D}$. The product was isolated by column chromatography with diethyl ether as eluent and obtained in $46 \%$ yield $(0.0684$ $\mathrm{g}, 0.23 \mathrm{mmol}$ ) as an off-white solid.

$\mathrm{R}_{f}=0.16$ in $30 \%$ acetone/hexane

${ }^{1} \mathrm{H} \mathrm{NMR}\left(\mathrm{CDCl}_{3}\right.$ with $1 \% \mathrm{v} / \mathrm{v}$ TMS, $\left.400 \mathrm{MHz}\right) \delta=6.90(\mathrm{~d}, J=8.8 \mathrm{~Hz}, 1 \mathrm{H}), 6.85(\mathrm{~d}, J=8.8 \mathrm{~Hz}$, $1 \mathrm{H}), 3.87(\mathrm{~s}, 3 \mathrm{H}), 3.68-3.40(\mathrm{br}, 2 \mathrm{H}), 3.25-3.06(\mathrm{br}, 1 \mathrm{H}$, overlaps with singlet at $3.22 \mathrm{ppm})$, $3.22(\mathrm{~s}, 3 \mathrm{H}$, overlaps with broad signal), $2.76(\mathrm{~s}, 3 \mathrm{H}), 2.72-2.50(\mathrm{br}, 1 \mathrm{H})$.

Note: the H's of the ethelene group appear as broad signals between 4-2 ppm.

${ }^{13} \mathrm{C} \mathrm{NMR}\left(\mathrm{CDCl}_{3}\right.$ with 1\% v/v TMS, $\left.101 \mathrm{MHz}\right) \delta=167.8,152.4,141.2,133.2,117.3,113.6$, $111.1,57.0,56.9,48.1,40.2,33.4$. 
FT-IR: 2937, 2800, 1648, 1436, 1266, 1049, 808, $683 \mathrm{~cm}^{-1}$.

HRMS (ESI $)$ : calculated for $\mathrm{C}_{12} \mathrm{H}_{15} \mathrm{BrN}_{2} \mathrm{NaO}_{2}{ }^{+}[\mathrm{M}+\mathrm{Na}]^{+} 321.0209$; found 321.0203 .

Melting point: $143.1-143.8^{\circ} \mathrm{C}$.

Compound 8ka<smiles>COc1ccc2c(c1OC)C(=O)N(C)CCN2C</smiles>

Prepared from 6k according to the general procedure D using $\mathrm{NaOt}$ - $\mathrm{Bu}(0.144 \mathrm{~g}, 1.5 \mathrm{mmol}$, 3 equiv.). The crude mixture was filtered through a pad of celite eluting with EtOAc. The product was obtained in $43 \%$ yield $(0.0540 \mathrm{~g}, 0.22 \mathrm{mmol})$ as an orange solid.

$\mathrm{R}_{f}=0.014$ in $30 \%$ acetone/hexane

${ }^{1}{ }_{\mathrm{H}} \mathrm{NMR}\left(\mathrm{CDCl}_{3}\right.$ with $1 \% \mathrm{v} / \mathrm{v}$ TMS, $\left.400 \mathrm{MHz}\right) \delta=6.90(\mathrm{~d}, J=8.8 \mathrm{~Hz}, 1 \mathrm{H}), 6.59(1 \mathrm{H}, J=8.8$ $\mathrm{Hz}, 1 \mathrm{H}), 3.96(\mathrm{~s}, 3 \mathrm{H}), 3.84(\mathrm{~s}, 3 \mathrm{H}), 3.53-3.27(\mathrm{br}, 2 \mathrm{H}), 3.19(\mathrm{~s}, 3 \mathrm{H}), 2.74(\mathrm{~s}, 3 \mathrm{H})$.

Note: two H's of ethelene group are not reported as they appear as broad signals between 4-2 ppm, consistent with previous reports on related compounds. ${ }^{80}$

${ }^{13} \mathrm{C}$ NMR $\left(\mathrm{CDCl}_{3}\right.$ with $1 \% \mathrm{v} / \mathrm{v}$ TMS, $\left.101 \mathrm{MHz}\right) \delta=167.6,148.8,147.6,140.6,125.7,114.4$, $112.5,61.8,57.2,56.2,48.1,40.3,33.4$.

FT-IR: 2937, 2810, 1641, 1411, 1432, 1261, 1044, 1011, $827 \mathrm{~cm}^{-1}$.

HRMS (ESI ): calculated for $\mathrm{C}_{13} \mathrm{H}_{18} \mathrm{~N}_{2} \mathrm{NaO}_{3}{ }^{+}[\mathrm{M}+\mathrm{Na}]^{+}$273.1210; found 273.1205.

Melting point: $117.5-118.5^{\circ} \mathrm{C}$.

Compound 8la<smiles>Cc1ccc2c(c1[N+](=O)[O-])C(=O)N(C)CCN2C</smiles>

Prepared from 6I according to the general procedure D using $\mathrm{NaOt}$ - $\mathrm{Bu}(0.144 \mathrm{~g}, 1.5 \mathrm{mmol}$, 3.0 equiv.) for $25 \mathrm{~min}$. and obtained in $41 \%$ yield $(0.0517 \mathrm{~g}, 0.21 \mathrm{mmol}$ ) as a yellow solid. $\mathrm{R}_{f}=0.17$ in $30 \%$ acetone/hexane. 
${ }^{1} \mathrm{H}$ NMR (CDCl 3 with 1\% v/v TMS, $\left.400 \mathrm{MHz}\right) \delta=7.23$ (d, J=8.4 Hz, 1H), 6.92 (d, J = $8.4 \mathrm{~Hz}$, $1 \mathrm{H}), 3.54(\mathrm{t}, J=5.7 \mathrm{~Hz}, 2 \mathrm{H}), 3.29(\mathrm{t}, J=5.7 \mathrm{~Hz}, 2 \mathrm{H}), 3.17(\mathrm{~s}, 3 \mathrm{H}), 2.82(\mathrm{~s}, 3 \mathrm{H}), 2.29(\mathrm{~s}, 3 \mathrm{H})$.

${ }^{13} \mathrm{C}$ NMR ( $\mathrm{CDCl}_{3}$ with $1 \%$ v/v TMS, $\left.101 \mathrm{MHz}\right) \delta=166.3,150.5,145.2,133.8,123.5,123.2$, $120.2,57.1,47.8,40.1,33.8,17.2$.

FT-IR: 2942, 1639, 1524, 1493, 1434, 1367, $836 \mathrm{~cm}^{-1}$.

HRMS (ESI ${ }^{+}$): calculated for $\mathrm{C}_{12} \mathrm{H}_{16} \mathrm{~N}_{3} \mathrm{O}_{3}{ }^{+}[\mathrm{M}+\mathrm{H}]^{+}$250.1186; found 250.1195.

Melting point: $199^{\circ} \mathrm{C}$.

Compound 8ma<smiles>COc1ccc2c(c1C(F)(F)F)C(=O)N(C)CCN2C</smiles>

Prepared from $6 \mathrm{~m}$ according to the general procedure $\mathrm{D}$ and obtained in $60 \%$ yield (0.0867 $\mathrm{g}, 0.30 \mathrm{mmol}$ ) as a white solid.

$\mathrm{R}_{f}=0.11$ in $30 \%$ acetone/hexane

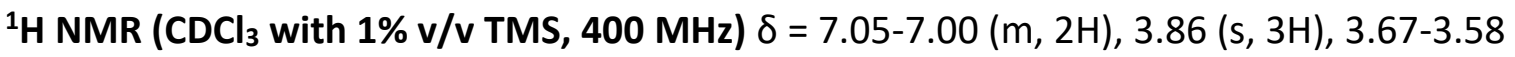
$(\mathrm{m}, 1 \mathrm{H}), 3.53-3.46(\mathrm{~m}, 1 \mathrm{H}), 3.23-3.18(\mathrm{~m}, 4 \mathrm{H}), 2.77(\mathrm{~s}, 3 \mathrm{H}), 2.67-2.64(\mathrm{~m}, 1 \mathrm{H})$.

${ }^{13} \mathrm{C}$ NMR (CDCl 3 with 1\% v/v TMS, $\left.101 \mathrm{MHz}\right) \delta=168.1,154.0(\mathrm{~m}), 139.2,131.7$ (q, $J_{\mathrm{C}-\mathrm{F}}=$ $2.6 \mathrm{~Hz}$ ), $123.3\left(q, J_{C-F}=274.7 \mathrm{~Hz}\right), 121.8,117.0\left(q, J_{C-F}=30.7 \mathrm{~Hz}\right), 114.9,56.8,56.4,48.3$, $40.3,33.1$.

${ }^{19} \mathrm{~F}\left\{{ }^{1} \mathrm{H}\right\}$ NMR $\left(\mathrm{CDCl}_{3}\right.$ with $1 \%$ v/v TMS, $\left.376 \mathrm{MHz}\right) \delta=-57.4$.

FT-IR: 2937, 2817, 1643, 1485, 1301, 1274, 1120, 1050, $712 \mathrm{~cm}^{-1}$.

HRMS (ESI ${ }^{+}$): calculated for $\mathrm{C}_{13} \mathrm{H}_{16} \mathrm{~F}_{3} \mathrm{~N}_{2} \mathrm{O}_{2}{ }^{+}[\mathrm{M}+\mathrm{H}]^{+}$289.1158; found 289.1167.

Melting point: $197-199{ }^{\circ} \mathrm{C}$.

Compound 8na<smiles>CN1CCN(C)c2ccc(F)c(C(F)(F)F)c2C1=O</smiles> 
Prepared from $6 \mathbf{n}$ according to the general procedure $D$ and obtained in $71 \%$ yield $(0.0983$ $\mathrm{g}, 0.36 \mathrm{mmol}$ ) as a white solid.

$\mathrm{R}_{f}=0.22$ in $30 \%$ acetone/hexane.

${ }^{1} \mathbf{H}$ NMR $\left(\mathrm{CDCl}_{3}\right.$ with $1 \%$ v/v TMS, $400 \mathrm{MHz} \delta=7.15$ (dd, appears as triplet, $J=9.6 \mathrm{~Hz}$, $1 \mathrm{H}), 7.07-7.04(\mathrm{~m}, 1 \mathrm{H}), 3.67-3.50(\mathrm{~m}, 2 \mathrm{H}), 3.24(\mathrm{dd}, J=14.5,3.7 \mathrm{~Hz}, 1 \mathrm{H}), 3.18(\mathrm{~m}, 3 \mathrm{H})$, $2.79-2.73(\mathrm{~m}, 4 \mathrm{H})$.

${ }^{13} \mathrm{C}$ NMR (CDCl 3 with $1 \%$ v/v TMS, $\left.101 \mathrm{MHz}\right) \delta=166.9\left(\mathrm{~d}, J_{\mathrm{C}-\mathrm{F}}=2.4 \mathrm{~Hz}\right), 155.8\left(\mathrm{~d}, J_{\mathrm{C}-\mathrm{F}}=\right.$ $252.3 \mathrm{~Hz}$ ), 142.4 (d, J J-F $=2.7 \mathrm{~Hz}$ ), 130.8 (d, J J-F $=2.1 \mathrm{~Hz}$ ), 122.6 (d, J J-F $=8.5 \mathrm{~Hz}$ ), 122.4 (dq, $\left.J_{C-F}=274.5,1.8 \mathrm{~Hz}\right), 118.7\left(\mathrm{~d}, J_{\mathrm{C}-\mathrm{F}}=23.0 \mathrm{~Hz}\right), 116.6\left(\mathrm{dq}, J_{\mathrm{C}-\mathrm{F}}=32.7,13.4 \mathrm{~Hz}\right), 56.4,40.1$, 40.2 , 33.2 .

${ }^{19} \mathrm{~F}\left\{{ }^{1} \mathrm{H}\right\}$ NMR (CDCl 3 with 1\% v/v TMS, $\left.376 \mathrm{MHz}\right) \delta=-56.8(\mathrm{~d}, J=20.5 \mathrm{~Hz}),-120.6(\mathrm{q}, J=$ $20.5 \mathrm{~Hz}$ ).

FT-IR: $2876,16.48,1489,13.94,1288,1124,694 \mathrm{~cm}^{-1}$.

HRMS (ESI $)$ : calculated for $\mathrm{C}_{12} \mathrm{H}_{13} \mathrm{~F}_{4} \mathrm{~N}_{2} \mathrm{O}^{+}[\mathrm{M}+\mathrm{H}]^{+}$277.0959; found 277.0973.

Melting point: $105.0-106.0^{\circ} \mathrm{C}$.

6.3.5 Synthesis and characterization of 1,2,3,4-substituted arenes with other arynophiles

\subsubsection{General procedure E}

The iodonium salt ( $0.5 \mathrm{mmol}, 1$ equiv.) was weighed out and placed in a $12 \mathrm{~mL}$ vial containing a magnetic stir bar. TBME $(2.5 \mathrm{~mL})$ and arynophile (1.1 - 3 equiv.) were added sequentially forming a slurry. Ground to fine powder $\mathrm{NaOt}-\mathrm{Bu}(0.1442 \mathrm{~g}, 1.5 \mathrm{mmol}, 3$ equiv. or as indicated) was weighed out in air and added to the vial with stirring in one portion. The vial was sealed with a cap, and the reaction mixture was vigorously stirred at the indicated temperature for 40 minutes to 3 hours. The reaction was quenched with saline solution $(7 \mathrm{~mL})$ and extracted with EtOAc $(3 \times 3 \mathrm{~mL})$. The combined organic phases were dried with $\mathrm{MgSO}_{4}$, drying agent was removed by vacuum filtration, and solvent was 
removed on rotary evaporator. The crude residue was purified by column chromatography on silica gel with acetone/hexanes mixture as eluent.

\subsubsection{Dual C-H functionalization of 2-fluoroanisole}

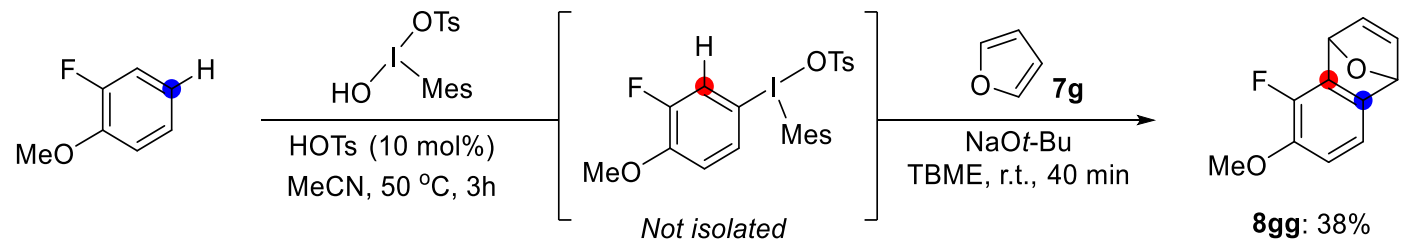

Scheme 21. Dual C-H functionalization of 2-fluoroanisole.

Hydroxy(tosyloxy)iodomesitylene $(0.217 \mathrm{~g}, 0.5 \mathrm{mmol}, 1$ equiv.) and 2fluoroanisole ( $0.57 \mathrm{~mL}, 0.5 \mathrm{mmol}, 1$ equiv.) were added to a $12 \mathrm{~mL}$ vial containing a stir bar. Acetonitrile $(0.5 \mathrm{~mL})$ was added to the vial followed by $p$-toluenesulfonic acid monohydrate $(0.0095 \mathrm{~g}, 10 \mathrm{~mol} \%)$. The vial was placed in an aluminum block set to $50^{\circ} \mathrm{C}$, and the mixture was stirred at this temperature for 3 hours. The vial was removed from heat and allowed to cool to room temperature. TBME $(2.5 \mathrm{~mL})$ was added at stirring, followed by arynophile $7 \mathrm{~g}(0.11 \mathrm{~mL}, 0.75 \mathrm{mmol}, 3$ equiv.) and $\mathrm{NaOt}-\mathrm{Bu}(0.144 \mathrm{~g}, 0.75$ mmol, 3 equiv.), and the mixture was allowed to react for $40 \mathrm{~min}$. The reaction was quenched with saline solution $(7 \mathrm{~mL})$ and extracted with EtOAc $(3 \times 3 \mathrm{~mL})$. The combined organic phases were dried with $\mathrm{MgSO}_{4}$, drying agent was removed by vacuum filtration, and solvent was removed on rotary evaporator. The crude residue was purified by column chromatography on silica gel. Compound $\mathbf{8 g g}$ was obtained in $38 \%$ yield as a white solid.

\section{Compound 8gg}

$\mathrm{R}_{f}=0.31$ in $20 \% \mathrm{Et}_{2} \mathrm{O} /$ hexane

${ }^{1} \mathrm{H}$ NMR $\left(\mathrm{CDCl}_{3}\right.$ with 1\% v/v TMS, $\left.400 \mathrm{MHz}\right) \delta=7.03-6.98(2 \mathrm{H}, \mathrm{m}), 6.91(1 \mathrm{H}, \mathrm{d}, J=7.6 \mathrm{~Hz})$, $6.47(1 \mathrm{H}, \mathrm{dd}$, appears as triplet, $J=7.5 \mathrm{~Hz}), 5.94(1 \mathrm{H}, \mathrm{s}), 5.68(1 \mathrm{H}, \mathrm{s}), 3.82(3 \mathrm{H}, \mathrm{s})$. 
${ }^{13} \mathrm{C} \mathrm{NMR}\left(\mathrm{CDCl}_{3}\right.$ with $1 \% \mathrm{v} / \mathrm{v}$ TMS,101 MHz) $\delta=146.6\left(\mathrm{~d}, J_{\mathrm{C}-\mathrm{F}}=248.5 \mathrm{~Hz}\right), 146.5\left(\mathrm{~d}, J_{\mathrm{C}-\mathrm{F}}=\right.$ $11.4 \mathrm{~Hz}$ ), 143.4, $142.4\left(\mathrm{~d}, J_{\mathrm{C}-\mathrm{F}}=2.9 \mathrm{~Hz}\right), 141.7,134.6\left(\mathrm{~d}, J_{\mathrm{C}-\mathrm{F}}=17.7 \mathrm{~Hz}\right), 115.5\left(\mathrm{~d}, J_{\mathrm{C}-\mathrm{F}}=3.5\right.$ $\mathrm{Hz}), 108.6,82.2,79.6,56.5$.

${ }^{19} \mathrm{~F}\left\{{ }^{1} \mathrm{H}\right\}$ NMR $\left(\mathrm{CDCl}_{3}\right.$ with $1 \% \mathrm{v} / \mathrm{v}$ TMS, $\left.376 \mathrm{MHz}\right) \delta=-141.4$.

FT-IR: 3091, 3036, 2949, 1488, 1460, 1279, 1265, 1056, 821, $723 \mathrm{~cm}^{-1}$.

HRMS (ESI ${ }^{+}$): calculated for $\mathrm{C}_{11} \mathrm{H}_{9} \mathrm{FO}_{2}{ }^{+}[\mathrm{M}+\mathrm{H}]^{+}$193.0659; found 193.0656.

Melting point: $62.9-63.9^{\circ} \mathrm{C}$.

Compound $\mathbf{8 d b}$<smiles>CN1CCCN(C)c2ccc(F)c(Cl)c2C1=O</smiles>

Prepared from $6 \mathrm{~d}$ and obtained in $37 \%$ yield $(0.0473 \mathrm{~g}, 0.18 \mathrm{mmol})$ as an off-white solid according to the general procedure $E$ with the following modification: the reaction was conducted at room temperature in toluene $(2.5 \mathrm{~mL})$ using $N, N^{\prime}$-dimethylpropylene urea ( $0.181 \mathrm{~mL}, 3$ equiv.) and LiHMDS (1 $\mathrm{M}$ in toluene, $0.5 \mathrm{~mL}, 1$ equiv.) for $40 \mathrm{~min}$.

$\mathrm{R}_{f}=0.18$ in $25 \%$ Acetone/hexane

${ }^{1} \mathbf{H}$ NMR $\left(\mathrm{CDCl}_{3}\right.$ with $1 \% \mathrm{v} / \mathrm{v}$ TMS, $\left.400 \mathrm{MHz}\right) \delta=7.02(1 \mathrm{H}, \mathrm{dd}, J=9.2,8.2 \mathrm{~Hz}), 6.70(1 \mathrm{H}, \mathrm{dd}$, $J=9.3,4.2 \mathrm{~Hz}), 3.60-3.52(1 \mathrm{H}, \mathrm{m}), 3.48-3.41(1 \mathrm{H}, \mathrm{m}), 3.22-3.16(1 \mathrm{H}, \mathrm{m}), 3.07(3 \mathrm{H}, \mathrm{s}), 2.99-$ $2.92(4 \mathrm{H}, \mathrm{m}), 1.98-1.87(1 \mathrm{H}, \mathrm{m}), 1.77-1.69(1 \mathrm{H}, \mathrm{m})$.

${ }^{13} \mathrm{C}$ NMR $\left(\mathrm{CDCl}_{3}\right.$ with $1 \% \mathrm{v} / \mathrm{v}$ TMS,101 MHz) $\delta=168.8\left(\mathrm{~d}, J_{\mathrm{C}-\mathrm{F}}=2.0 \mathrm{~Hz}\right), 152.1\left(\mathrm{~d}, J_{\mathrm{C}-\mathrm{F}}=\right.$ $240.8 \mathrm{~Hz}$ ), 146.1 (d, $\left.J_{C-F}=2.4 \mathrm{~Hz}\right), 125.9,119.5\left(\mathrm{~d}, J_{\mathrm{C}-\mathrm{F}}=19.1 \mathrm{~Hz}\right), 116.9\left(\mathrm{~d}, J_{\mathrm{C}-\mathrm{F}}=22.1 \mathrm{~Hz}\right)$, $115.8\left(\mathrm{~d}, J_{\mathrm{C}-\mathrm{F}}=6.7 \mathrm{~Hz}\right), 50.8,48.2,43.1,33.5,26.7$.

${ }^{19} \mathrm{~F}\left\{{ }^{1} \mathrm{H}\right\}$ NMR (CDCl 3 with $1 \%$ v/v TMS, $\left.376 \mathrm{MHz}\right) \delta=-125.6$.

FT-IR: 2961, 2921, 1634, 1496, 1463, 1431,1404, 1267, 1202, 941, $788 \mathrm{~cm}^{-1}$.

HRMS (ESI ${ }^{+}$): calculated for $\mathrm{C}_{12} \mathrm{H}_{14} \mathrm{ClFN}_{2} \mathrm{NaO}^{+}[\mathrm{M}+\mathrm{Na}]^{+} 279.0671$; found 279.0667 .

Melting point: $103.6-105.4{ }^{\circ} \mathrm{C}$.

Compound 8ac 
<smiles>Cc1ccc2c(c1Cl)C(=O)C=CC2=O</smiles>

Prepared from 6a according to the general procedure E with the following modification: the reaction was conducted at room temperature using 2-(trimethylsiloxy)furan $(0.126$ $\mathrm{mL}, 1.5$ equiv.) for $40 \mathrm{~min}$. The reaction mixture was quenched with $0.1 \mathrm{M} \mathrm{HCl}$, extracted with EtOAc $(3 \times 3 \mathrm{~mL})$, and combined organic layers were washed with brine. The product was obtained in $47 \%$ yield $(0.0489 \mathrm{~g}, 0.24 \mathrm{mmol})$ as a yellow to brown solid.

$\mathrm{R}_{f}=0.52$ (20\% acetone:hexanes)

${ }^{1} \mathrm{H} \mathrm{NMR}\left(\mathrm{CDCl}_{3}\right.$ with $1 \%$ v/v TMS, $\left.400 \mathrm{MHz}\right) \delta=7.96(\mathrm{~d}, J=7.9 \mathrm{~Hz}, 1 \mathrm{H}), 7.61(\mathrm{~d}, J=7.8 \mathrm{~Hz}$, $1 \mathrm{H})$, 6.95-6.89 (m, 2H), $2.53(\mathrm{~s}, 3 \mathrm{H})$.

${ }^{13} \mathrm{C}$ NMR ( $\mathrm{CDCl}_{3}$ with $1 \%$ v/v TMS, $\left.101 \mathrm{MHz}\right) \delta=184.0,183.8,145.5,140.4,136.5,135.2$, $134.3,132.5,128.0,125.3,21.5$.

FT-IR: 3053, 2923, 1661, 1610, 1579, 1310, 1272, 1089, 1067, 845, 818, $802 \mathrm{~cm}^{-1}$.

HRMS (ESI ${ }^{+}$): calculated for $\mathrm{C}_{11} \mathrm{H}_{8} \mathrm{ClO}_{2}{ }^{+}[\mathrm{M}+\mathrm{H}]^{+}$207.0207; found 207.0208.

Melting point: $134.5-135.7^{\circ} \mathrm{C}$.

Compound 8ad
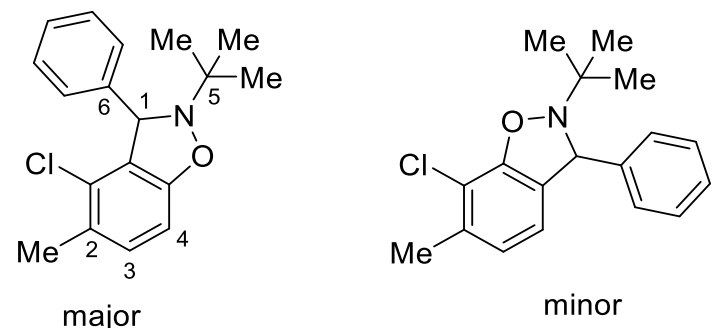

Prepared from 6a according to the general procedure $E$ under the following conditions: the reaction was conducted at room temperature using $N$-tert-Butyl- $\alpha$-phenylnitrone ( $0.266 \mathrm{~g}, 3$ equiv.) for 1 hour. The crude product was purified by column chromatography with ethyl acetate/hexanes mixture as eluent and obtained in $92 \%$ yield $(0.139 \mathrm{~g}, 0.46$ mmol, mixture of regioisomers, 11.1:1 ratio) as a yellow oil. Characterization for major isomer is provided below.

$\mathrm{R}_{f}=0.7110 \%$ ethyl acetate/hexane 
${ }^{1} \mathrm{H}$ NMR $\left(\mathrm{CDCl}_{3}\right.$ with $1 \%$ v/v TMS, $\left.400 \mathrm{MHz}\right) \delta=7.32-7.22(\mathrm{~m}, 5 \mathrm{H}, \mathrm{Ph} 6$, overlaps with minor isomer), $7.05(\mathrm{~d}, 1 \mathrm{H}, J=8.2 \mathrm{~Hz}, \mathrm{H} 3), 6.66(\mathrm{~d}, 1 \mathrm{H}, J=8.1 \mathrm{~Hz}, \mathrm{H} 4$, overlaps with minor isomer), $5.57(\mathrm{~s}, 1 \mathrm{H}, \mathrm{H} 1), 2.22\left(\mathrm{~s}, 3 \mathrm{H}, \mathrm{CH}_{3} 2\right), 1.17$ (s, 9H, $t$-Bu5).

${ }^{13} \mathrm{C} \mathrm{NMR}\left(\mathrm{CDCl}_{3}\right.$ with 1\% v/v TMS, $\left.101 \mathrm{MHz}\right) \delta=156.7,141.9,131.1,129.2,128.4,128.2$, $128.0,127.7,127.5,104.8,67.0,61.5,25.3,18.8$.

FT-IR: 2971, 2866, 1601, 1465, 1364, 1298, 804, $695 \mathrm{~cm}^{-1}$.

HRMS (ESI ${ }^{+}$): calculated for $\mathrm{C}_{18} \mathrm{H}_{20} \mathrm{CINNaO}^{+}[\mathrm{M}+\mathrm{Na}]^{+} 324.1126$; found 324.1118 .

\section{Compound 8gd}<smiles>COc1ccc2c(c1F)C(c1ccccc1)N(CC(C)(C)C)C2</smiles>

Prepared from $6 \mathrm{~g}$ according to the general procedure $\mathrm{E}$ under the following conditions: the reaction was conducted at room temperature using $N$-tert-Butyl- $\alpha$-phenylnitrone ( 0.266 g, 3 equiv.) for 1 hour. The crude product was purified by column chromatography with ethyl acetate/hexanes mixture as eluent and obtained in $85 \%$ yield $(0.128 \mathrm{~g}, 0.43$ $\mathrm{mmol}$ ) as a red solid.

$\mathrm{R}_{f}=0.4710 \%$ ethyl acetate:hexane

${ }^{1} \mathrm{H}$ NMR ( $\mathrm{CDCl}_{3}$ with 1\% v/v TMS, $\left.400 \mathrm{MHz}\right) \delta=7.41$ (d, $\left.J=7.5, \mathrm{~Hz}, 2 \mathrm{H}\right), 7.31$ (dd, appears as triplet, $J=7.5 \mathrm{~Hz}, 2 \mathrm{H}), 7.26-7.22(\mathrm{~m}, 1 \mathrm{H}), 6.79(\mathrm{dd}$, appears as triplet, $J=8.4,8.4 \mathrm{~Hz}$, $1 \mathrm{H}), 6.49(\mathrm{~d}, J=8.6 \mathrm{~Hz}, 1 \mathrm{H}), 5.71(\mathrm{~s}, 1 \mathrm{H}), 3.77(\mathrm{~s}, 3 \mathrm{H}), 1.17(\mathrm{~s}, 9 \mathrm{H})$.

${ }^{13} \mathrm{C}$ NMR (CDCl 3 with $1 \%$ v/v TMS, $\left.101 \mathrm{MHz}\right) \delta=152.9$ (d, $J_{\mathrm{C}-\mathrm{F}}=6.2 \mathrm{~Hz}$ ), 147.8 (d, $J_{\mathrm{C}-\mathrm{F}}=$ $249.3 \mathrm{~Hz}$ ), 142.1 (d, J $\left.J_{\mathrm{C}-\mathrm{F}}=10.3 \mathrm{~Hz}\right), 142.0,128.6,127.6,127.2,118.0\left(\mathrm{~d}, J_{\mathrm{C}-\mathrm{F}}=17.4 \mathrm{~Hz}\right)$, $115.1\left(\mathrm{~d}, J_{\mathrm{C}-\mathrm{F}}=1.5 \mathrm{~Hz}\right), 101.0\left(\mathrm{~d}, J_{\mathrm{C}-\mathrm{F}}=4.3 \mathrm{~Hz}\right), 64.7\left(\mathrm{~d}, J_{\mathrm{C}-\mathrm{F}}=2.1 \mathrm{~Hz}\right), 61.4,57.5,25.4$.

${ }^{19} \mathrm{~F}\left\{{ }^{1} \mathrm{H}\right\}$ NMR $\left(\mathrm{CDCl}_{3}\right.$ with $1 \%$ v/v TMS, $\left.376 \mathrm{MHz}\right) \delta=-138.0$.

FT-IR: 2972, 2937, 1423, 1364, 1262, 1021, 804, 718, $696 \mathrm{~cm}^{-1}$.

HRMS (ESI ${ }^{+}$): calculated for $\mathrm{C}_{18} \mathrm{H}_{20} \mathrm{FNNaO}_{2}{ }^{+}[\mathrm{M}+\mathrm{Na}]^{+}$324.1370; found 324.1366.

Melting point: $77.9-79.7^{\circ} \mathrm{C}$.

\section{Compound 8ge}


<smiles>COc1ccc2c(nnn2Cc2ccccc2)c1F</smiles>

Prepared from $6 \mathrm{~g}$ according to the general procedure $\mathrm{E}$ under the following conditions: the reaction was conducted using benzyl azide $(0.069 \mathrm{~mL}, 1.1$ equiv.); $\mathrm{NaOt}-\mathrm{Bu}(0.0721 \mathrm{~g}$, 1.5 equiv.) was added at $0{ }^{\circ} \mathrm{C}$ and the mixture was allowed to react at this temperature for $40 \mathrm{~min}$. The crude product was purified by column chromatography with ethyl acetate/hexanes mixture as eluent and obtained in $44 \%$ yield $(0.0560 \mathrm{~g}, 0.22 \mathrm{mmol})$ as a white solid.

$\mathrm{R}_{f}=0.29$ in $25 \%$ ethyl acetate/hexane

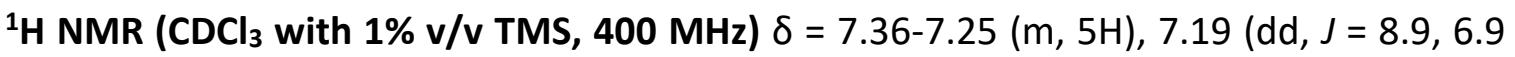
$\mathrm{Hz}, 1 \mathrm{H}), 7.02$ (dd, J = 8.9, $1.1 \mathrm{~Hz}, 1 \mathrm{H}), 5.81(\mathrm{~s}, 3 \mathrm{H}), 3.96(\mathrm{~s}, 3 \mathrm{H})$.

${ }^{13} \mathrm{C}$ NMR (CDCl 3 with $1 \%$ v/v TMS, $\left.101 \mathrm{MHz}\right) \delta=142.8\left(\mathrm{~d}, J_{\mathrm{C}-\mathrm{F}}=7.4 \mathrm{~Hz}\right.$ ), 142.5 (d, $J_{\mathrm{C}-\mathrm{F}}=$ $257.6 \mathrm{~Hz}$ ), $137.9\left(\mathrm{~d}, J_{\mathrm{C}-\mathrm{F}}=16.1 \mathrm{~Hz}\right), 134.3,130.5\left(\mathrm{~d}, J_{\mathrm{C}-\mathrm{F}}=5.1 \mathrm{~Hz}\right), 129.1,128.6,127.6,119.2$, $104.9\left(d, J_{C-F}=5.6 \mathrm{~Hz}\right), 59.1\left(\mathrm{~d}, J_{C-F}=2.0 \mathrm{~Hz}\right), 52.5$.

\section{${ }^{19} \mathrm{~F}\left\{{ }^{1} \mathrm{H}\right\}$ NMR (CDCl 3 with $1 \%$ v/v TMS, $\left.376 \mathrm{MHz}\right) \delta=-145.8$.}

FT-IR: 3021, 2939, 1524, 1455, 1288, 1234, 1089, 1071, 1032, 800, 708, 692, $681 \mathrm{~cm}^{-1}$.

HRMS (ESI ${ }^{+}$): calculated for $\mathrm{C}_{14} \mathrm{H}_{12} \mathrm{FN}_{3} \mathrm{NaO}^{+}[\mathrm{M}+\mathrm{Na}]^{+}$280.0857; found 280.0850.

Melting point: decomposed at $118.9^{\circ} \mathrm{C}$.

\section{Compound 8af}<smiles>Cc1ccc(O)c(-c2cccnc2)c1Cl</smiles>

Prepared from 6a according to the general procedure $\mathrm{E}$ under the following conditions: the reaction was conducted at room temperature using pyridine $N$-oxide $(0.143 \mathrm{~g}, 3$ equiv.) and $\mathrm{NaOt}$-Bu (0.0721 g, 1.5 equiv.) for $40 \mathrm{~min}$. The product was obtained in $29 \%$ yield ( $0.0324 \mathrm{~g}, 0.15 \mathrm{mmol})$ as an orange solid.

$\mathrm{R}_{f}=0.0720 \%$ acetone:hexane 
${ }^{1} \mathrm{H}$ NMR (DMSO- $\left.d_{6}, 400 \mathrm{MHz}\right) \delta=9.73(\mathrm{br}, 1 \mathrm{H}), 8.53(\mathrm{dd}, J=4.8,1.5 \mathrm{~Hz}, 1 \mathrm{H}), 8.41(\mathrm{~d}, J=$ $1.6 \mathrm{~Hz}, 1 \mathrm{H}$ ), 7.66 (ddd, appears as doublet of triplet, $J=7.8,1.9,1.9 \mathrm{~Hz}, 1 \mathrm{H}), 7.45$ (dd, $J=$ $7.8,4.8 \mathrm{~Hz}, 1 \mathrm{H}), 7.19(\mathrm{~d}, J=8.3 \mathrm{~Hz}, 1 \mathrm{H}), 6.86(\mathrm{~d}, J=8.3 \mathrm{~Hz}, 1 \mathrm{H}), 2.27(\mathrm{~s}, 3 \mathrm{H})$.

${ }^{13} \mathrm{C}$ NMR (DMSO-d $\left.d_{6}, 101 \mathrm{MHz}\right) \delta=154.2,150.6,148.1$, 138.0, 133.0, 132.2, 130.9, 126.0, 124.4, 123.2, 114.2, 19.7.

FT-IR: 3051, 2922, 2818, 1591, 1394, 1374, 1290, 1183, 1045, 914, 913, 799, 706, $\mathrm{cm}^{-1}$.

HRMS (ESI ${ }^{+}$): calculated for $\mathrm{C}_{12} \mathrm{H}_{11} \mathrm{CINO}^{+}[\mathrm{M}+\mathrm{H}]^{+} 220.0524$; found 220.0520 .

Melting point: decomposed at $233^{\circ} \mathrm{C}$.

\section{Compound 8dg}<smiles>CS(=O)(=O)c1c(N2CCOCC2)ccc(F)c1Cl</smiles>

Prepared from $\mathbf{6 d}$ according to the general procedure $\mathrm{E}$ under the following conditions: the reaction was conducted using 4-(trimethylsilyl)morpholine $(0.133 \mathrm{~mL}, 1.5$ equiv.) at $0{ }^{\circ} \mathrm{C}$ for $40 \mathrm{~min}$. The crude product was purified by column chromatography with ethyl acetate/hexanes mixture as eluent and obtained in $41 \%$ yield $(0.0584 \mathrm{~g}, 0.2 \mathrm{mmol})$ as a white solid.

$\mathrm{R}_{f}=0.43$ in $16 \%$ ethyl acetate/hexane

${ }^{1} \mathrm{H}$ NMR (CDCl 3 with 1\% v/v TMS, $\left.400 \mathrm{MHz}\right) \delta=7.20$ (dd, $J=8.8,4.4 \mathrm{~Hz}, 1 \mathrm{H}$ ), 7.13 (dd, appears as triplet, $J=8.4 \mathrm{~Hz}, 1 \mathrm{H}), 3.89-3.86(\mathrm{~m}, 2 \mathrm{H}), 3.81-3.75(\mathrm{~m}, 2 \mathrm{H}), 2.96-2.90(\mathrm{~m}, 2 \mathrm{H})$, 2.72-2.69 (m, 2H), $0.45(\mathrm{~s}, 9 \mathrm{H})$.

${ }^{13} \mathrm{C} \mathrm{NMR}\left(\mathrm{CDCl}_{3}\right.$ with 1\% v/v TMS, $\left.101 \mathrm{MHz}\right) \delta=156.1$ (d, $\left.J_{\mathrm{C}-\mathrm{F}}=3.6 \mathrm{~Hz}\right), 156.0$ (d, $J_{\mathrm{C}-\mathrm{F}}=$ $247.7 \mathrm{~Hz}$ ), 139.4 (d, $J_{\mathrm{C}-\mathrm{F}}=3.4 \mathrm{~Hz}$ ), 127.2 (d, $\left.J_{\mathrm{C}-\mathrm{F}}=16.1 \mathrm{~Hz}\right), 122.3\left(\mathrm{~d}, J_{\mathrm{C}-\mathrm{F}}=6.9 \mathrm{~Hz}\right), 117.5$ (d, $\left.J_{C-F}=23.3 \mathrm{~Hz}\right), 66.7,54.8,3.2$.

${ }^{19} \mathrm{~F}\left\{{ }^{1} \mathrm{H}\right\}$ NMR $\left(\mathrm{CDCl}_{3}\right.$ with $1 \% \mathrm{v} / \mathrm{v}$ TMS, $\left.376 \mathrm{MHz}\right) \delta=-115.0$.

FT-IR: 2952, 2860, 2815, 1436, 1260, 1245, 1111, 839, 820, $729 \mathrm{~cm}^{-1}$.

HRMS (ESI ${ }^{+}$): calculated for $\mathrm{C}_{13} \mathrm{H}_{20} \mathrm{ClFNOSi}^{+}[\mathrm{M}+\mathrm{H}]^{+} 288.0981$; found 288.0978 .

Melting point: $91.3-92.5^{\circ} \mathrm{C}$.

\section{Compound $\mathbf{8 b h}$}


<smiles>Clc1ccc(N2CCOCC2)c(Cl)c1Cl</smiles>

Prepared from $\mathbf{6 b}$ according to the general procedure $\mathrm{E}$ under the following conditions: the reaction was conducted using 4-chloromorpholine ( $0.182 \mathrm{~g}$, 3 equiv.); $\mathrm{NaOt}$ - $\mathrm{Bu}(0.240$ g, 5 equiv.) was added at $0{ }^{\circ} \mathrm{C}$ and the mixture was allowed to react at this temperature for $80 \mathrm{~min}$. The crude product was purified by column chromatography with ethyl acetate/hexanes mixture as eluent and obtained in $56 \%$ yield $(0.0750 \mathrm{~g}, 0.28 \mathrm{mmol})$ as a white solid.

$\mathrm{R}_{f}=0.3920 \%$ ethyl acetate:hexane

${ }^{1} \mathrm{H} \mathrm{NMR}\left(\mathrm{CDCl}_{3}\right.$ with 1\% v/v TMS, $\left.400 \mathrm{MHz}\right) \delta=7.34(\mathrm{~d}, J=8.8 \mathrm{~Hz}, 1 \mathrm{H}), 6.91$ (d, $J=8.8 \mathrm{~Hz}$, $1 \mathrm{H})$, 3.88-3.86 (m, $4 \mathrm{H}), 3.04-3.01(\mathrm{~m}, 4 \mathrm{H})$.

${ }^{13} \mathrm{C}$ NMR ( $\mathrm{CDCl}_{3}$ with $1 \%$ v/v TMS, $\left.101 \mathrm{MHz}\right) \delta=149.4,132.7,129.2,128.3,128.1,118.8$, 67.0, 51.7 .

FT-IR: 2969, 2865, 2824, 1440, 1372, 1236, 1114, 958, 810, $695 \mathrm{~cm}^{-1}$.

HRMS (ESI ${ }^{+}$): calculated for $\mathrm{C}_{10} \mathrm{H}_{11} \mathrm{Cl}_{3} \mathrm{NO}^{+}[\mathrm{M}+\mathrm{H}]^{+} 265.9901$; found 265.9901 .

Melting point: $90.1-91.9^{\circ} \mathrm{C}$.

\section{Compound 8ai}<smiles>Cc1ccc(N2CCCCCC2)c(Cl)c1Cl</smiles>

Prepared from 6a according to the general procedure E under the following conditions: the reaction was conducted using 1-chloroazepane ( $0.200 \mathrm{~g}, 3$ equiv.); $\mathrm{NaOt}$ - $\mathrm{Bu}(0.240 \mathrm{~g}$, 5 equiv.) was added at $0{ }^{\circ} \mathrm{C}$ and the mixture was allowed to react at this temperature for $3 \mathrm{~h}$. The crude product was purified by column chromatography with petroleum ether as eluent and obtained in $47 \%$ yield $(0.0610 \mathrm{~g}, 0.24 \mathrm{mmol}$, mixture of regioisomers, 22:1 ratio) as a red oil. Characterization for major isomer is provided below.

$\mathrm{R}_{f}=0.50$ in petroleum ether

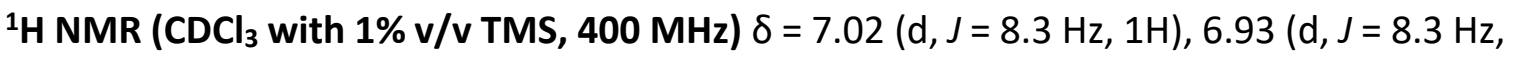
$1 \mathrm{H}), 3.17-3.14(\mathrm{~m}, 4 \mathrm{H}), 2.34(\mathrm{~s}, 3 \mathrm{H}), 1.85-1.76(\mathrm{~m}, 4 \mathrm{H}), 1.72-1.69(\mathrm{~m}, 4 \mathrm{H})$. 
${ }^{13} \mathrm{C}$ NMR $\left(\mathrm{CDCl}_{3}\right.$ with $1 \%$ v/v TMS, $\left.101 \mathrm{MHz}\right) \delta=151.7,133.6,131.1,128.2,127.9,119.8$, 55.2, 29.2, 27.1, 20.6.

FT-IR: 2922, 2853, 1592, 1464, 1444, 1032, $808 \mathrm{~cm}^{-1}$.

HRMS (ESI ${ }^{+}$): calculated for $\mathrm{C}_{13} \mathrm{H}_{18} \mathrm{Cl}_{2} \mathrm{~N}^{+}[\mathrm{M}+\mathrm{H}]^{+} 258.0811$; found 258.0809.

\subsubsection{Derivatization of aryne coupling product by transition metal catalysis}

\subsubsection{Suzuki-Miyaura Coupling}

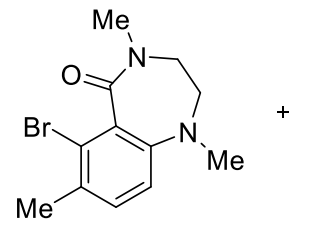

$6 \mathbf{i}$

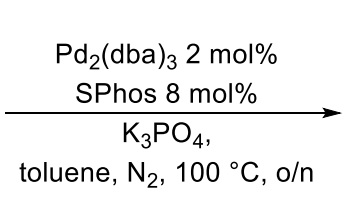

toluene, $\mathrm{N}_{2}, 100^{\circ} \mathrm{C}, \mathrm{o} / \mathrm{n}$

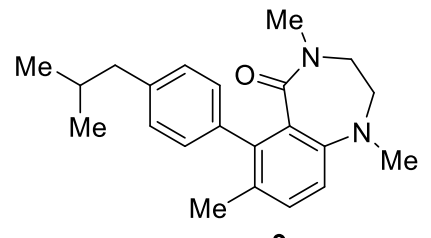

9a

Scheme 22. Functionalization via Suzuki-Miyaura coupling.

Prepared according to the literature procedure ${ }^{94}$. An oven-dried vial was charged with $\mathrm{Pd}_{2}(\mathrm{dba})_{3}(0.0090 \mathrm{~g}, 4 \mathrm{~mol} \% \mathrm{Pd})$, SPhos (0.0164 g, 8 mol\%), (4-isobutylphenyl)boronic acid ( 0.1335 g, 1.5 equiv.), $6 \mathbf{i}\left(0.1416\right.$ g, 0.5 mmol, 1 equiv.), and $\mathrm{K}_{3} \mathrm{PO}_{4}(0.3180$ g, 3 equiv.) and equipped with a magnetic stir bar. The vial was capped with a rubber septum, flushed with nitrogen and left under static nitrogen atmosphere. Toluene $(1 \mathrm{~mL})$ was added via syringe through the septum and the septum was replaced with a screwcap. The resulting mixture was heated at $100{ }^{\circ} \mathrm{C}$ under stirring overnight then allowed to cool to room temperature, diluted with diethyl ether, filtered through a thin pad of celite eluting with diethyl ether, and concentrated under reduced pressure. The crude material was purified by column chromatography on silica gel with acetone/hexane mixture and the product was obtained in $95 \%$ yield $(0.1605 \mathrm{~g}, 0.48 \mathrm{mmol})$ as a white solid.

\section{Compound 9a}


$\mathrm{R}_{f}=0.39$ (30\% acetone/hexane)

${ }^{1} \mathrm{H} \mathrm{NMR}\left(\mathrm{CDCl}_{3}\right.$ with $1 \%$ v/v TMS, $\left.400 \mathrm{MHz}\right) \delta=7.22-7.20(\mathrm{~m}, 1 \mathrm{H}), 7.17-6.89(\mathrm{br}, 4 \mathrm{H}), 6.81$ (d, J=8.2 Hz, 1H), $3.00(\mathrm{~s}, 3 \mathrm{H}), 2.79(\mathrm{~s}, 3 \mathrm{H}), 2.47(\mathrm{~d}, J=7.2 \mathrm{~Hz}, 2 \mathrm{H}), 2.06(\mathrm{~s}, 3 \mathrm{H}), 1.89(\mathrm{n}, J$ $=6.7 \mathrm{~Hz}, 1 \mathrm{H}), 0.92(\mathrm{~d}, J=6.6 \mathrm{~Hz}, 3 \mathrm{H})$.

${ }^{13} \mathrm{C}_{\text {NMR }}\left(\mathrm{CDCl}_{3}\right.$ with $1 \%$ v/v TMS, $\left.101 \mathrm{MHz}\right) \delta=169.7,144.3,141.1,139.9,137.3,131.8$, 131.0, 130.8, 128.5 (two overlapping signals), 116.2, 57.1, 48.1, 45.4, 40.2, 33.2, 30.1, 22.5, 19.9 .

FT-IR: 2953, 2865, 2802, 1651, 1449, 1443, 1384, 1177, 1093, 817.

HRMS (ESI ${ }^{+}$): calculated for $\mathrm{C}_{22} \mathrm{H}_{28} \mathrm{~N}_{2} \mathrm{NaO}^{+}[\mathrm{M}+\mathrm{Na}]^{+}$359.2088; found 359.2094.

Melting point: $157.1-158.3^{\circ} \mathrm{C}$.

\subsubsection{Buckwald-Hartwig coupling}

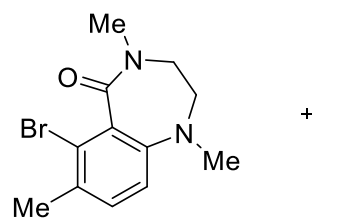

$6 \mathbf{i}$

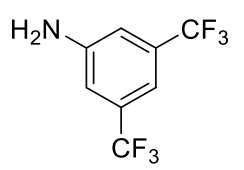

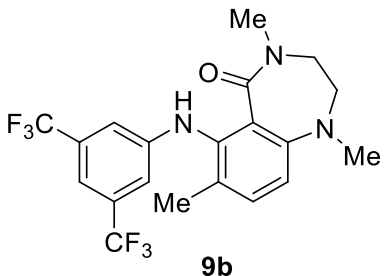

Scheme 23. Functionalization via Buchwald-Hartwig amination.

Prepared according to the modified literature procedure. ${ }^{95}$ An oven-dried vial was charged with $\mathrm{Pd}_{2}(\mathrm{dba})_{3}(6.9 \mathrm{mg}, 5 \mathrm{~mol} \% \mathrm{Pd})$, BrettPhos (0.0161 g, $\left.5 \mathrm{~mol} \%\right), 6 \mathbf{i}(0.0850 \mathrm{~g}$, $0.3 \mathrm{mmol})$, and $\mathrm{K}_{2} \mathrm{CO}_{3}(0.0995 \mathrm{~g}, 0.72 \mathrm{mmol}, 2.4$ equiv.) and equipped with a magnetic stir bar. The vial was capped with a rubber septum, purged with nitrogen and left under static nitrogen atmosphere. Toluene $(0.6 \mathrm{~mL})$ followed by 3,5-bis(trifluoromethyl)aniline $(0.056$ $\mathrm{mL}, 0.36 \mathrm{mmol}, 1.2$ equiv.) were added via syringe. The resulting mixture was heated at $110{ }^{\circ} \mathrm{C}$ under stirring for 4.5 hours, then a mixture of $\mathrm{Pd}_{2}(\mathrm{dba})_{3}(6.9 \mathrm{mg}, 5 \mathrm{~mol} \% \mathrm{Pd})$ and BrettPhos (0.0161 g, 5 mol\%) was added to the reaction mixture, and the reaction was left at $110{ }^{\circ} \mathrm{C}$ under stirring for 17.5 hours. The reaction mixture was cooled to room 
temperature, diluted with ethyl acetate, filtered through a thin pad celite eluting with ethyl acetate, and concentrated under reduced pressure. The crude material was purified by column chromatography on silica gel with acetone/hexane mixture as eluent and obtained in $78 \%$ yield $(0.1014 \mathrm{~g}, 0.24 \mathrm{mmol})$ as a white solid.

\section{Compound 9b}

$\mathrm{R}_{f}=0.3020 \%$ acetone:hexane

${ }^{1} \mathrm{H}$ NMR (CDCl 3 with $1 \%$ v/v TMS, $\left.400 \mathrm{MHz}\right) \delta=8.06(\mathrm{~s}, 1 \mathrm{H}), 7.24(\mathrm{~d}, J=8.4 \mathrm{~Hz}, 1 \mathrm{H}), 7.20$ $(\mathrm{s}, 1 \mathrm{H}), 6.91(\mathrm{~s}, 2 \mathrm{H}), 6.77(\mathrm{~d}, J=8.3 \mathrm{~Hz}, 1 \mathrm{H}), 3.37-3.36(\mathrm{~m}, 2 \mathrm{H}), 2.27-3.16(\mathrm{br}, 2 \mathrm{H}), 3.11(\mathrm{~s}$, $3 \mathrm{H}), 2.82(\mathrm{~s}, 3 \mathrm{H}), 2.05(\mathrm{~s}, 3 \mathrm{H})$.

${ }^{13} \mathrm{C}$ NMR (CDCl 3 with 1\% v/v TMS, $101 \mathrm{MHz}$ ) $\delta=169.2,146.6,146.2,138.0,133.8,132.2$ $\left(q, J_{C-F}=32.8 \mathrm{~Hz}\right), 128.1,124.5,123.5\left(q, J_{\mathrm{C}-\mathrm{F}}=272.7 \mathrm{~Hz}\right), 115.3,114.4(\mathrm{~m}), 111.5-111.4$ (m), 57.7, 48.2, 40.5, 33.8, 18.1 .

${ }^{19} \mathrm{~F}\left\{{ }^{1} \mathrm{H}\right\}$ NMR ( $\mathrm{CDCl}_{3}$ with $1 \% \mathrm{v} / \mathrm{v}$ TMS, $\left.376 \mathrm{MHz}\right) \delta=-63.1$.

FT-IR: 3231, 3073, 2946, 2805, 1630, 1620, 1480, 1392, 1272, 1161, 1119, 856, 679.

HRMS (ESI ${ }^{+}$): calculated for $\mathrm{C}_{20} \mathrm{H}_{19} \mathrm{~F}_{6} \mathrm{~N}_{3} \mathrm{NaO}^{+}[\mathrm{M}+\mathrm{Na}]^{+} 454.1324$; found 454.1317 .

Melting point: $232.1-233.9^{\circ} \mathrm{C}$.

\subsubsection{Heck coupling}

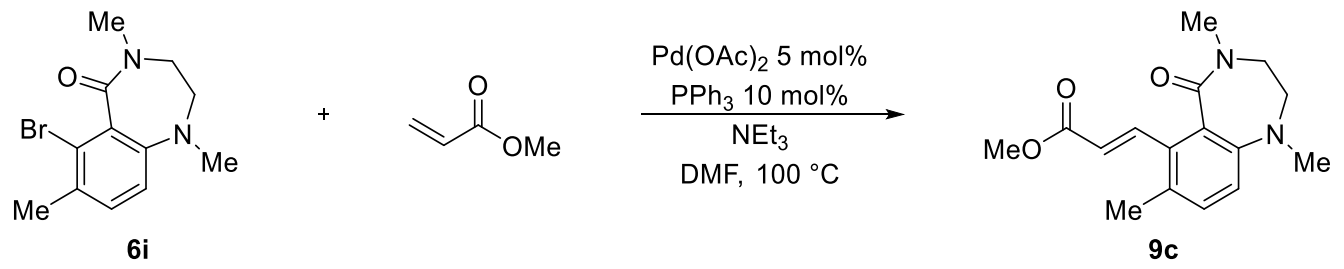

Scheme 24. Functionalization via Heck coupling.

Palladium diacetate $(0.0034 \mathrm{~g}, 5 \mathrm{~mol} \%)$, triphenylphosphine (0.0079 g, $10 \mathrm{~mol} \%)$, and $6 \mathbf{i}(0.0850 \mathrm{~g}, 0.3 \mathrm{mmol})$ were placed into an oven-dried vial equipped with a magnetic stir bar. The vial was capped with a rubber septum, purged with nitrogen, and left under 
static nitrogen atmosphere. DMF $(0.6 \mathrm{~mL})$ followed by triethylamine $(0.084 \mathrm{~mL}, 1 \mathrm{mmol}$, 2 equiv.) and methyl acrylate ( $0.052 \mathrm{~mL}, 1 \mathrm{mmol}, 2$ equiv.) were added via syringe. The resulting mixture was heated at $100{ }^{\circ} \mathrm{C}$ under stirring overnight, then cooled to room temperature and subjected to column chromatography on basic alumina with acetone/hexane mixture as eluent. Mixture of $E / Z$ isomers was isolated in $99 \%$ yield $(0.0856 \mathrm{~g}, 0.3 \mathrm{mmol}, E: Z=9.6: 1)$ as a bright yellow solid. Characterization for $E$ isomer is provided below.

Compound 9c

$\mathrm{R}_{f}=0.3930 \%$ acetone:hexane

${ }^{1} \mathbf{H}$ NMR (CDCl 3 with $1 \%$ v/v TMS, $\left.400 \mathrm{MHz}\right) \delta=7.93(\mathrm{~d}, J=16.2 \mathrm{~Hz}, 1 \mathrm{H}), 7.16(\mathrm{~d}, J=8.2$ $\mathrm{Hz}, 1 \mathrm{H}), 6.80(\mathrm{~d}, J=8.2 \mathrm{~Hz}, 1 \mathrm{H}), 5.95(\mathrm{~d}, J=16.2 \mathrm{~Hz}, 1 \mathrm{H}), 3.77(\mathrm{~s}, 3 \mathrm{H}), 3.48-3.45(\mathrm{~m}, 2 \mathrm{H})$, $3.18(\mathrm{~s}, 3 \mathrm{H}), 3.16-3.12(\mathrm{~m}, 2 \mathrm{H}), 2.77(\mathrm{~s}, 3 \mathrm{H}), 2.29(\mathrm{~s}, 3 \mathrm{H})$.

${ }^{13} \mathrm{C} \mathrm{NMR}\left(\mathrm{CDCl}_{3}\right.$ with $1 \% \mathrm{v} / \mathrm{v}$ TMS, $101 \mathrm{MHz}$ ) $\delta=169.7,166.7,144.6,143.9,134.1,132.6$, $130.9,130.3,122.9,118.0,56.8,51.6,48.2,40.1,33.4,20.0$.

FT-IR: 2947, 2813, 1710, 1634, 1434, 1396, 1300, 1190, 1166, 987, 839.

HRMS (ESI ${ }^{+}$): calculated for $\mathrm{C}_{16} \mathrm{H}_{20} \mathrm{~N}_{2} \mathrm{NaO}_{3}{ }^{+}[\mathrm{M}+\mathrm{Na}]^{+} 311.1366$; found 311.1361.

Melting point: $137.4-138.9^{\circ} \mathrm{C}$.

\subsubsection{Unexpected aryne reactivity in reactions with tertiary amines}

\subsubsection{Sequential ring expansion and ring opening of DMI}

The iodonium salt $6 a(0.285 \mathrm{~g}, 0.525 \mathrm{mmol}, 2.1$ equiv.) was weighed out and placed in a $12 \mathrm{~mL}$ vial containing a magnetic stir bar. TBME $(2.5 \mathrm{~mL})$ and 7 a $(0.027 \mathrm{~mL}$, $0.25 \mathrm{mmol}, 1$ equiv.) were added sequentially forming slurry. Ground to fine powder NaOt-Bu $(0.151 \mathrm{~g}, 1.575 \mathrm{mmol}, 6.3$ equiv. $)$ was weighed out in air and added to the vial 
with stirring in one portion. The vial was sealed with a cap, and the reaction mixture was vigorously stirred at the room temperature for 40 minutes. The reaction was quenched with saline solution $(7 \mathrm{~mL})$ and extracted with EtOAc $(3 \times 3 \mathrm{~mL})$. The combined organic phases were dried with $\mathrm{MgSO}_{4}$, drying agent was removed by vacuum filtration, and solvent was removed on rotary evaporator. The crude residue was purified by column chromatography on silica gel with $\mathrm{Et}_{2} \mathrm{O} /$ hexanes mixture as eluent. The mixture of $10 \mathrm{a}$ and $10 \mathrm{~b}$ was isolated in $73 \%$ yield as a yellow oil.

Compounds $10 \mathrm{a}$ and $10 \mathrm{~b}$
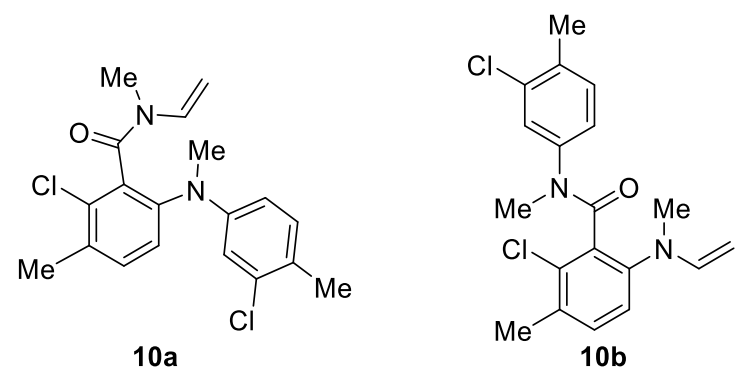

$\mathrm{R}_{f}=0.2814 \% \mathrm{Et}_{2} \mathrm{O}:$ hexane

Major isomer:

${ }^{1} \mathrm{H} \mathrm{NMR} \mathrm{CDCl}_{3}$ with $1 \% \mathrm{v} / \mathrm{v}$ TMS, $400 \mathrm{MHz}$ ) $\delta=7.29$ (d, overlaps with minor isomer, $J=$ $8.2 \mathrm{~Hz}, 1 \mathrm{H}$ ), $7.03(\mathrm{~d}, J=8.2 \mathrm{~Hz}, 1 \mathrm{H}), 6.97$ (d, overlaps with minor isomer, $J=8.2 \mathrm{~Hz}, 1 \mathrm{H}$ ), 6.65 (d, overlaps with minor isomer, $J=2.4 \mathrm{~Hz}, 1 \mathrm{H}), 6.49$ (dd, overlaps with minor isomer, $J=15.4,9.1 \mathrm{~Hz}, 1 \mathrm{H}), 6.44$ (dd, overlaps with minor isomer, $J=8.4,2.6 \mathrm{~Hz}, 1 \mathrm{H}), 4.40$ (dd, $J$ $=15.3,1.1 \mathrm{~Hz}, 1 \mathrm{H}), 4.22(\mathrm{dd}, J=9.1,1.1 \mathrm{~Hz}, 1 \mathrm{H}), 3.10(\mathrm{~s}, 3 \mathrm{H}), 3.09(\mathrm{~s}, 3 \mathrm{H}), 2.40(9)(\mathrm{s}$, overlaps with minor isomer, $3 \mathrm{H}$ ), 2.23 (s, overlaps with minor isomer, $3 \mathrm{H}$ ).

Minor isomer:

${ }^{1} \mathrm{H}$ NMR ( $\mathrm{CDCl}_{3}$ with $1 \% \mathrm{v} / \mathrm{v}$ TMS, $\left.400 \mathrm{MHz}\right) \delta=7.55(\mathrm{dd}, J=16.0,9.3 \mathrm{~Hz}, 1 \mathrm{H}), 7.29$ (overlaps with major isomer, $1 \mathrm{H}$ ), $7.05(\mathrm{~d}, J=8.2 \mathrm{~Hz}, 1 \mathrm{H}$ ), 6.99 (overlaps with major isomer, $1 \mathrm{H}$ ), 6.65 (overlaps with major isomer, $1 \mathrm{H}$ ), 6.53-6.43 (overlaps with major isomer, $1 \mathrm{H}), 4.49(\mathrm{~d}, J=2.6 \mathrm{~Hz}, 1 \mathrm{H}), 4.46(\mathrm{~d}, J=9.5 \mathrm{~Hz}, 1 \mathrm{H}), 3.12(\mathrm{~s}, 3 \mathrm{H}), 2.88(\mathrm{~s}, 3 \mathrm{H})$, $2.41(5)$ (s, overlaps with major isomer, $3 \mathrm{H}), 2.24$ (s, overlaps with major isomer, $3 \mathrm{H}$ ). 
${ }^{13} \mathrm{C}$ NMR ( $\mathrm{CDCl}_{3}$ with 1\% v/v TMS, $\left.101 \mathrm{MHz}\right) \delta=166.1,165.7,148.4,148.3,145.4,145.0$, 135.4, 135.0(3), 135.0(1), 134.9(9), 134.4(3), 134.3(7), 132.5, 132.3, 131.7, 131.6, 131.5, $130.9,130.8,126.9,126.8,125.8,125.7,115.7,115.4,114.1,113.6,95.3,93.8,40.7(4)$, $40.6(9), 32.7,28.4,28.1,19.9,18.9,18.8$.

Table 5. Main ${ }^{1} \mathrm{H}-{ }^{1} \mathrm{H}$ and ${ }^{1} \mathrm{H}_{-}^{13} \mathrm{C}$ correlations for major isomer (N.D. - not determined).

\begin{tabular}{|c|c|c|c|c|c|c|c|c|c|c|c|c|}
\hline & \multicolumn{12}{|c|}{ Chemical shift, ppm } \\
\hline${ }^{1} \mathrm{H}$ & 7.29 & 7.03 & 6.97 & 6.65 & 6.49 & 6.44 & 4.40 & 4.22 & 3.10 & 3.09 & $2.41(9)$ & 2.23 \\
\hline cosY & 7.03 & 7.03 & 6.44 & NO & $\begin{array}{l}4.40 \\
4.22\end{array}$ & 6.97 & 6.49 & 6.49 & NO & NO & NO & NO \\
\hline NOESY & 2.41 & 3.09 & 2.23 & N.D. & 3.09 & 3.10 & 3.10 & NO & 4.4 & 7.03 & 7.29 & 6.97 \\
\hline HSQC & 132.5 & 126.8 & 130.8 & 115.7 & 134.37 & 114.1 & 93.8 & 93.8 & 28.1 & 40.69 & 19.9 & 18.8 \\
\hline HMBC & $\begin{array}{c}145.4 \\
19.9\end{array}$ & 135.03 & $\begin{array}{c}148.4 \\
18.9\end{array}$ & $\begin{array}{l}114.1, \\
125.8\end{array}$ & $\begin{array}{c}166.1 \\
28.4\end{array}$ & $\begin{array}{l}115.7 \\
125.8\end{array}$ & N.D. & N.D. & 134.37 & $\begin{array}{l}145.4, \\
148.4\end{array}$ & N.D. & N.D. \\
\hline
\end{tabular}

FT-IR: 2921, 1662, 1624, 1499, 1477, 1086, 1037, 730.

HRMS (ESI ${ }^{+}$): calculated for $\mathrm{C}_{19} \mathrm{H}_{20} \mathrm{Cl}_{2} \mathrm{~N}_{2} \mathrm{O}^{+}[\mathrm{M}+\mathrm{H}]^{+} 363.1025$; found 363.1018.

\subsubsection{General procedure F}

Amine ( $0.5 \mathrm{mmol}, 1.0$ equiv.) was placed in a $12 \mathrm{~mL}$ vial containing a magnetic stir bar. TBME (2.5 mL) and iodonium salt ( $0.55 \mathrm{mmol}, 1.1$ equiv.) were added sequentially forming slurry. Ground to fine powder NaOt-Bu (0.0721 g, $0.75 \mathrm{mmol}, 1.5$ equiv.) was weighed out in air and added to the vial with stirring in one portion. The vial was sealed with a cap, and the reaction mixture was vigorously stirred at the room temperature for 1 hour. The reaction was quenched with saline solution $(7 \mathrm{~mL})$ and extracted with EtOAc $(3 \times 3 \mathrm{~mL})$. The combined organic phases were dried with $\mathrm{MgSO}_{4}$, drying agent was removed by vacuum filtration, and solvent was removed on rotary evaporator. The crude residue was purified by column chromatography on silica gel with $\mathrm{Et}_{2} \mathrm{O} /$ hexanes mixture as eluent. 
Compounds $10 \mathrm{c}$ and $10 \mathrm{~d}$
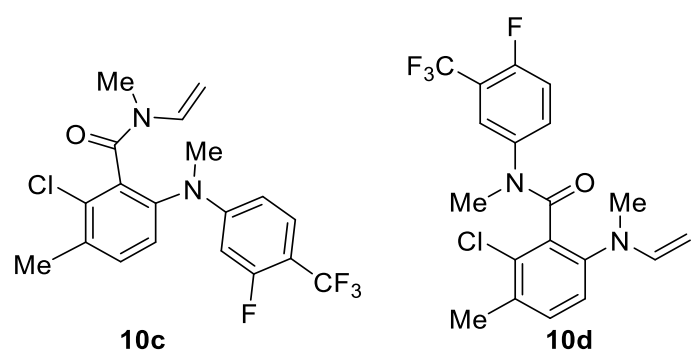

Prepared from $8 \mathrm{aa}$ and $\mathbf{6 n}$ according to the general procedure $\mathrm{F}$ and obtained in $80 \%$ yield $(0.159 \mathrm{~g}, 0.40 \mathrm{mmol})$ as a yellow oil.

$\mathrm{R}_{f}=0.2814 \% \mathrm{Et}_{2} \mathrm{O}:$ hexane

Major isomer:

${ }^{1} \mathrm{H} \mathrm{NMR}\left(\mathrm{CDCl}_{3}\right.$ with $\left.1 \% \mathrm{v} / \mathrm{v} \mathrm{TMS}, 600 \mathrm{MHz}\right) \delta=7.33$ (d, overlaps with minor isomer, $J=$ $8.1 \mathrm{~Hz}, 1 \mathrm{H}), 7.03(\mathrm{~d}, J=8.1 \mathrm{~Hz}, 1 \mathrm{H}), 6.96$ (dd, appears as triplet, overlaps with minor isomer, $J=9.6 \mathrm{~Hz}, 1 \mathrm{H}), 6.81-6.73(\mathrm{~m}$, overlaps with minor isomer, $2 \mathrm{H}), 6.44(\mathrm{dd}, J=15.3$, $9.1 \mathrm{~Hz}, 1 \mathrm{H}), 4.42(\mathrm{dd}, J=15.3,0.8 \mathrm{~Hz}, 1 \mathrm{H}), 4.22(\mathrm{dd}, J=9.0,0.9 \mathrm{~Hz}, 1 \mathrm{H}), 3.13(\mathrm{~s}, 3 \mathrm{H}), 3.08$ $(\mathrm{s}, 3 \mathrm{H}), 2.43$ (s, overlaps with minor isomer, $3 \mathrm{H})$.

${ }^{19} \mathrm{~F}\left\{{ }^{1} \mathrm{H}\right\}$ NMR (Acetone- $d_{6}$ with $1 \%$ v/v TMS, $\left.376 \mathrm{MHz}\right) \delta=-61.4(3)(\mathrm{d}, J=13.5 \mathrm{~Hz}$ ), $128.7(1)(q, J=12.7 \mathrm{~Hz})$.

Minor isomer:

${ }^{1} \mathrm{H}$ NMR $\left(\mathrm{CDCl}_{3}\right.$ with $1 \% \mathrm{v} / \mathrm{v}$ TMS, $\left.400 \mathrm{MHz}\right) \delta=7.53(\mathrm{dd}, J=16.0,9.3 \mathrm{~Hz}, 1 \mathrm{H}), 7.33$ (overlaps with major isomer, $1 \mathrm{H}$ ), $7.05(\mathrm{~d}$, overlaps with major isomer, $J=8.3 \mathrm{~Hz}, 1 \mathrm{H}$ ), 7.00-6.95 (overlaps with major isomer, $1 \mathrm{H}$ ), 6.81-6.73 (overlaps with major isomer, $2 \mathrm{H}$ ), 4.51-4.47 (m, 2H), $3.16(\mathrm{~s}, 3 \mathrm{H}), 2.43$ (overlaps with major isomer, $3 \mathrm{H}$ ).

${ }^{19} \mathrm{~F}\left\{{ }^{1} \mathrm{H}\right\}$ NMR (Acetone- $d_{6}$ with $1 \%$ v/v TMS, $\left.376 \mathrm{MHz}\right) \delta=-61.4(1)(\mathrm{d}, J=12.3 \mathrm{~Hz}$ ), $128.7(0)(q, J=13.1 \mathrm{~Hz})$.

${ }^{13} \mathrm{C}_{\text {NMR }}\left(\mathrm{CDCl}_{3}\right.$ with 1\% v/v TMS, $\left.101 \mathrm{MHz}\right) \delta=165.9,165.4,154.2(\mathrm{~m}), 151.7(\mathrm{~m}), 145.6$ $\left(d, J_{C-F}=2.1 \mathrm{~Hz}\right), 145.5\left(\mathrm{~d}, J_{\mathrm{C}-\mathrm{F}}=2.2 \mathrm{~Hz}\right), 144.9,144.6,135.7,135.5,135.1,134.1,132.8$, 132.6, 131.8, 131.7, 131.6, 126.9, 122.7 (dq, $\left.J_{C-F}=272.9,1.6 \mathrm{~Hz}\right), 120.0\left(\mathrm{~d}, J_{\mathrm{C}-\mathrm{F}}=7.5 \mathrm{~Hz}\right)$, $119.7\left(\mathrm{~d}, J_{\mathrm{C}-\mathrm{F}}=7.3 \mathrm{~Hz}\right), 118.6-117.4(\mathrm{~m}), 117.2\left(\mathrm{~d}, J_{\mathrm{C}-\mathrm{F}}=22.0 \mathrm{~Hz}\right), 117.1\left(\mathrm{~d}, J_{\mathrm{C}-\mathrm{F}}=21.7 \mathrm{~Hz}\right)$, $112.6\left(q, J_{C-F}=4.8 \mathrm{~Hz}\right), 112.3\left(q, J_{C-F}=5.1 \mathrm{~Hz}\right), 95.6,94.3,41.1,41.0,32.6,28.1,20.0$.

FT-IR: 2925, 1664, 1625, 1505, 1314, 1235, 1123, 1077, 1046, 815. 
HRMS (ESI ${ }^{+}$): calculated for $\mathrm{C}_{19} \mathrm{H}_{17} \mathrm{ClF}_{4} \mathrm{~N}_{2} \mathrm{O}^{+}[\mathrm{M}+\mathrm{H}]^{+} 401.1038$; found 401.1027 .

Compounds $10 \mathrm{e}$ and $10 \mathrm{f}$
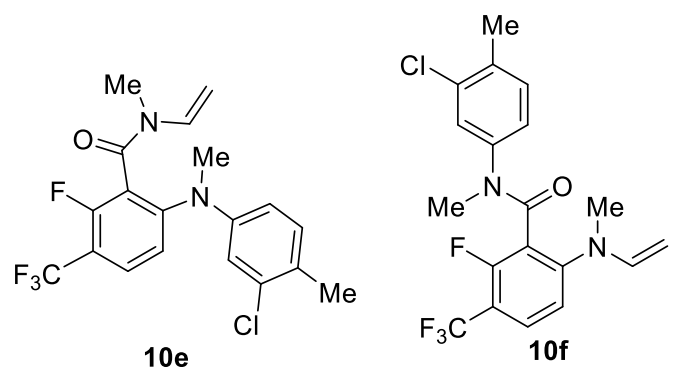

Prepared from 8na and $6 \mathrm{a}$ according to the general procedure $\mathrm{F}$ and obtained in $50 \%$ yield ( $0.0995 \mathrm{~g}, 0.45 \mathrm{mmol}$ ) as a yellow oil.

$\mathrm{R}_{f}=0.5730 \%$ acetone:hexane

Major isomer:

${ }^{1} \mathrm{H}$ NMR (CDCl 3 with 1\% v/v TMS, $\left.400 \mathrm{MHz}\right) \delta=7.39$ (dd, $\left.J=8.8,4.5 \mathrm{~Hz}, 1 \mathrm{H}\right), 7.29$ (dd, appears as triplet, overlaps with minor isomer, $J=9.4 \mathrm{~Hz}, 1 \mathrm{H}), 6.98(\mathrm{~d}$, overlaps with minor isomer, $J=7.9 \mathrm{~Hz}, 1 \mathrm{H}$ ), 6.63 (d, overlaps with minor isomer, $1 \mathrm{H}$ ), 6.44 (dd, overlaps with minor isomer, $J=15.3,9.1 \mathrm{~Hz}, 1 \mathrm{H}), 6.40$ (dd, overlaps with minor isomer, $J=8.4,2.5 \mathrm{~Hz}$, $1 \mathrm{H}), 4.42$ (dd, J = 15.2, $1.4 \mathrm{~Hz}, 1 \mathrm{H}$ ), 4.24 (dd, $J=9.1,1.5 \mathrm{~Hz}, 1 \mathrm{H}), 3.11(\mathrm{~s}, 3 \mathrm{H}), 3.06(\mathrm{~s}, 3 \mathrm{H})$, $2.24(\mathrm{~s}, 3 \mathrm{H})$.

${ }^{19} \mathrm{~F}\left\{{ }^{1} \mathrm{H}\right\}$ NMR (Acetone- $d_{6}$ with 1\% v/v TMS, $376 \mathrm{MHz}$ ) $\delta=-58.9$ (d, $J=17.7 \mathrm{~Hz}$ ), -114.7(5) (q, $J=17.7 \mathrm{~Hz}$ ).

Minor isomer:

${ }^{1} \mathrm{H}$ NMR $\left(\mathrm{CDCl}_{3}\right.$ with $1 \%$ v/v TMS, $\left.400 \mathrm{MHz}\right) \delta=7.51$ (dd, $\left.J=16.0,9.3 \mathrm{~Hz}, 1 \mathrm{H}\right), 7.43$ (dd, $J$ $=8.9,4.5 \mathrm{~Hz} 1 \mathrm{H}$ ), 7.30-7.26 (overlaps with major isomer, $1 \mathrm{H}$ ), 7.00 (d, overlaps with major isomer, $J=8.6 \mathrm{~Hz}, 1 \mathrm{H}$ ), 6.63 (overlaps with major isomer, $1 \mathrm{H}$ ), 6.46-6.39 (overlaps with major isomer, $1 \mathrm{H}), 4.50(\mathrm{dd}, J=9.3,1.1 \mathrm{~Hz}, 1 \mathrm{H}), 4.47(\mathrm{dd}, J=16.0,1.1 \mathrm{~Hz}, 1 \mathrm{H}), 3.09(\mathrm{~s}, 3 \mathrm{H})$, $2.85(\mathrm{~s}, 3 \mathrm{H}), 2.25(3 \mathrm{H})$.

${ }^{19} \mathrm{~F}\left\{{ }^{1} \mathrm{H}\right\}$ NMR (Acetone- $d_{6}$ with $1 \% \mathrm{v} / \mathrm{v}$ TMS, $\left.376 \mathrm{MHz}\right) \delta=-58.8(\mathrm{~d}, J=17.7),-114.7(4)(\mathrm{q}$, $J=17.7)$.

${ }^{13} \mathrm{C}$ NMR $\left(\mathrm{CDCl}_{3}\right.$ with $1 \% \mathrm{v} / \mathrm{v}$ TMS, $\left.101 \mathrm{MHz}\right) \delta=164.8\left(\mathrm{~d}, J_{\mathrm{C}-\mathrm{F}}=2.6 \mathrm{~Hz}\right), 164.3\left(\mathrm{~d}, J_{\mathrm{C}-\mathrm{F}}=3.2\right.$ $\mathrm{Hz}), 159.7(\mathrm{~m}), 157.1(\mathrm{~m}), 148.3,148.2,143.0\left(\mathrm{~d}, J_{\mathrm{C}-\mathrm{F}}=3.7 \mathrm{~Hz}\right), 142.5\left(\mathrm{~d}, J_{\mathrm{C}-\mathrm{F}}=3.8 \mathrm{~Hz}\right)$, 
$136.1,135.8,135.2,135.1,135.0,134.7,134.6,134.0,131.5,131.1,130.9,126.4,126.2$, $121.9\left(\mathrm{dq}, J_{\mathrm{C}-\mathrm{F}}=273.7,1.7 \mathrm{~Hz}\right), 121.8\left(\mathrm{dq}, J_{\mathrm{C}-\mathrm{F}}=275.5,1.5 \mathrm{~Hz}\right), 119.4\left(\mathrm{~d}, J_{\mathrm{C}-\mathrm{F}}=22.7 \mathrm{~Hz}\right)$, 117.4-116.3 (m), 115.5, 115.1, 113.9, 113.4, 95.7, 94.3, 40.8, 33.4, 28.5, 18.9.

FT-IR: 3035, 2923, 1664, 1624, 1502, 1484, 1269, 1140, 1119, 832.

HRMS (ESI ${ }^{+}$): calculated for $\mathrm{C}_{19} \mathrm{H}_{17} \mathrm{ClF}_{4} \mathrm{~N}_{2} \mathrm{ONa}^{+}[\mathrm{M}+\mathrm{Na}]^{+} 423.0858$; found 423.0850 .

\section{Compound 8ah}

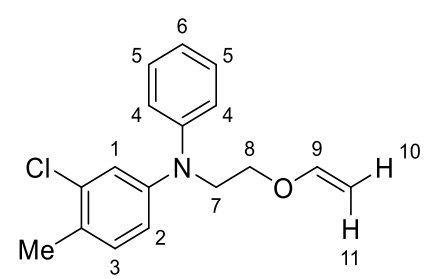

Prepared from $6 \mathrm{a}$ and $7 \mathrm{~h}$ according to the general procedure $\mathrm{F}$ and obtained in $63 \%$ yield (0.0995 g, $0.45 \mathrm{mmol}$ ) as a colorless oil.

$\mathrm{R}_{f}=0.27$ in hexane

${ }^{1} \mathrm{H}$ NMR ( $\mathrm{CDCl}_{3}$ with 1\% v/v TMS, $\left.600 \mathrm{MHz}\right) \delta=7.26(\mathrm{H} 5, \mathrm{dd}, J=8.5,7.4 \mathrm{~Hz}, 2 \mathrm{H}), 7.07(\mathrm{H} 3$, $\mathrm{d}, J=8.3 \mathrm{~Hz}, 1 \mathrm{H}), 7.02-7.01(\mathrm{H} 1, \mathrm{H} 4, \mathrm{~m}, 3 \mathrm{H}), 6.97(\mathrm{H} 6, \mathrm{dd}$, appears as triplet, $J=7.3 \mathrm{~Hz}$, $1 \mathrm{H}), 6.80(\mathrm{H} 2, \mathrm{dd}, J=8.3,2.4 \mathrm{~Hz}, 1 \mathrm{H}), 6.43(\mathrm{H} 9, \mathrm{dd}, J=14.3,6.8 \mathrm{~Hz}, 1 \mathrm{H}), 4.15(\mathrm{H} 11, \mathrm{dd}, J=$ 14.3, $2.1 \mathrm{~Hz}, 1 \mathrm{H}), 3.98(\mathrm{H} 10, \mathrm{dd}, J=6.8,2.1 \mathrm{~Hz}, 1 \mathrm{H}), 3.96(\mathrm{H7}, \mathrm{t}, J=6.1 \mathrm{~Hz}, 2 \mathrm{H}), 3.86(\mathrm{H} 8$, $\mathrm{t}, J=6.1 \mathrm{~Hz}, 2 \mathrm{H}), 2.29(\mathrm{~s}, 3 \mathrm{H})$.

${ }^{13} \mathrm{C} \mathrm{NMR}$ (CDCl 3 with 1\% v/v TMS, $\left.101 \mathrm{MHz}\right) \delta=151.5,147.3,146.8,134.8,131.3,129.4$, $128.6,122.0,121.4,121.0,119.1,86.9,64.8,51.0,19.2$.

FT-IR: 3025, 2921, 2875, 1598, 1492, 1195, 1040, 814.

HRMS (ESI ${ }^{+}$): calculated for $\mathrm{C}_{17} \mathrm{H}_{18} \mathrm{CINO}^{+}[\mathrm{M}+\mathrm{H}]^{+} 288.1150$; found 288.1142.

\subsubsection{X-ray structure details}

X-ray crystallographic analysis was performed by Dr. Edward Valente at the University of Portland. 
Crystals of $6 \mathrm{~g}$ were obtained by the use of vapor diffusion of diethyl ether into methanol solution at room temperature. Crystals of $8 \mathrm{ma}$ and $9 \mathrm{c}$ were obtained by slow evaporation of acetone solution at room temperature. Single crystals of $\mathbf{6 g}, \mathbf{8 m a}$, and $9 \mathrm{c}$ were chosen for crystallographic study with Mo K $\alpha$ radiation $(\lambda=0.71073 \AA)$ or Cu K $\alpha(\lambda$ = $1.5418 \AA$ A radiation. Data were collected on an Oxford Gemini system. Relevant details of the crystallographic experiments are given in Table 6. The structures were solved with SHELXS-86 and refined with SHELXL-97. ${ }^{96}$ All non-H atoms were found in initial E-maps, and their positions were refined with attendant anisotropic librational parameters. $\mathrm{H}$ atoms on carbons were assigned locations riding on the heavier atoms and given isotropic librational parameters equal to $150 \%$ of the equivalent isotropic librational parameter of the attached atom.

Table 6. Selected crystallographic information for structures $\mathbf{6 g}, \mathbf{8 m a}, 9 \mathrm{c}$. Esteemated standard deviations in parentheses.

\begin{tabular}{|c|c|c|c|}
\hline & Compound 6g & Compound 8ma & Compound 9c \\
\hline Formula & $\mathrm{C}_{23} \mathrm{H}_{24} \mathrm{FIO}_{4} \mathrm{~S}$ & $\mathrm{C}_{13} \mathrm{H}_{15} \mathrm{~F}_{3} \mathrm{~N}_{2} \mathrm{O}_{2}$ & $\mathrm{C}_{16} \mathrm{H}_{20} \mathrm{~N}_{2} \mathrm{O}_{3}$ \\
\hline System & monoclinic & monoclinic & triclinic \\
\hline Space Group & $\mathrm{P} 2(1) / n(\# 14)$ & $\mathrm{P} 2(1) / n(\# 14)$ & $P-1(\# 2)$ \\
\hline \multicolumn{4}{|l|}{ Cell constants } \\
\hline $\mathrm{a}(\AA \AA)$ & $8.5731(2)$ & $8.6744(3)$ & $9.1953(8)$ \\
\hline b (Å) & $11.0903(3)$ & $14.6490(4)$ & $10.6663(7)$ \\
\hline$c(\AA)$ & $23.6152(6)$ & $10.4584(3)$ & $15.3224(9)$ \\
\hline$\alpha\left({ }^{\circ}\right)$ & 90 & 90 & $91.639(5)$ \\
\hline$\beta\left({ }^{\circ}\right)$ & $92.859(2)$ & $103.035(3)$ & $101.895(7)$ \\
\hline$\gamma\left({ }^{\circ}\right)$ & 90 & 90 & $90.755(6)$ \\
\hline Data, parameters & 7372,271 & 4263,181 & 7253,380 \\
\hline$R_{1}(\mid>4 \sigma l)$ & 0.053 & 0.037 & 0.052 \\
\hline CCDC & 1916592 & 1916589 & 1916591 \\
\hline
\end{tabular}




\subsubsection{Spectral data}

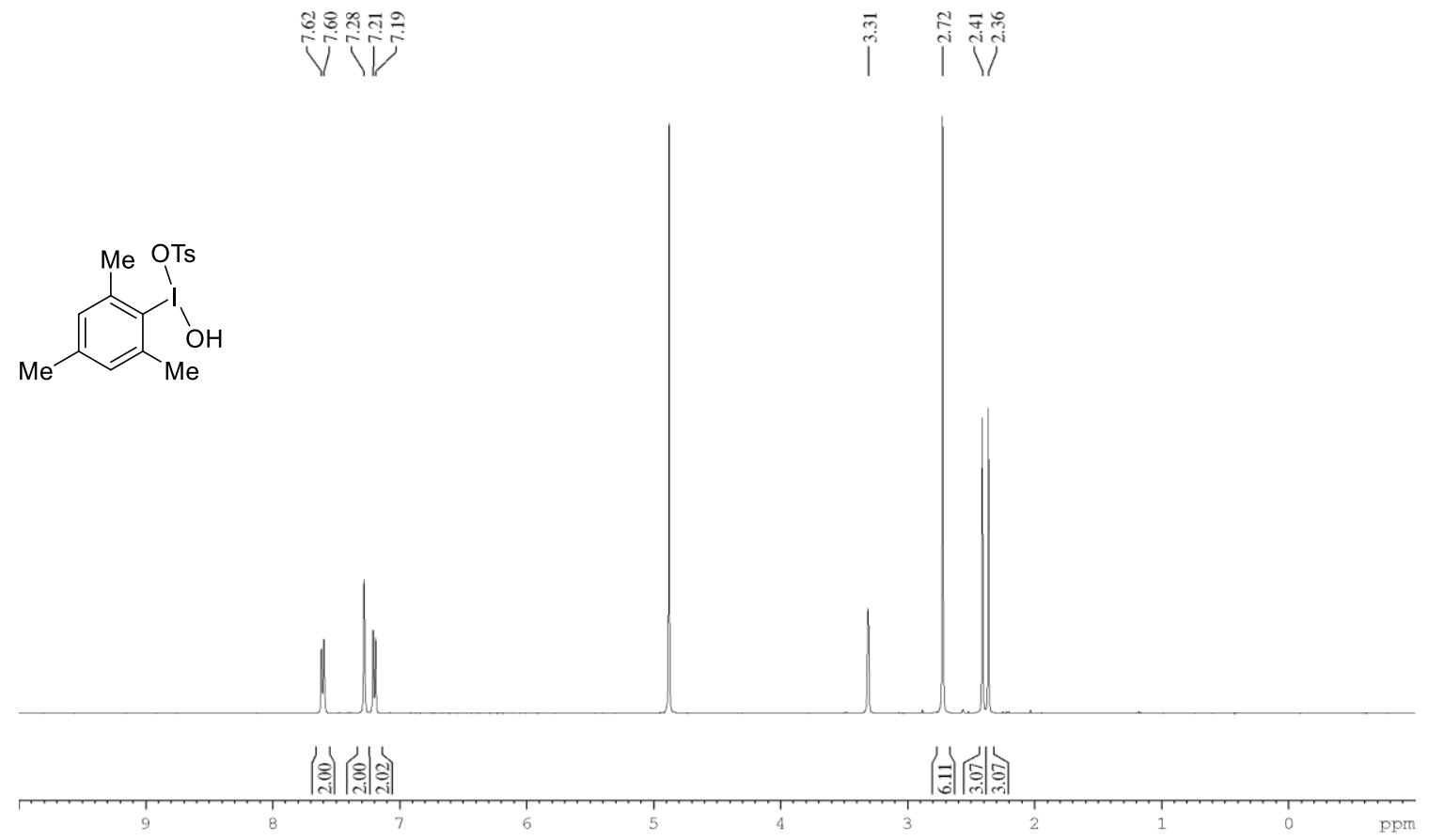

Figure 22. ${ }^{1} \mathrm{H}$ NMR of hydroxy(tosyloxy)iodomesitylene in $\mathrm{CD}_{3} \mathrm{OD}$ at $400 \mathrm{MHz}$.
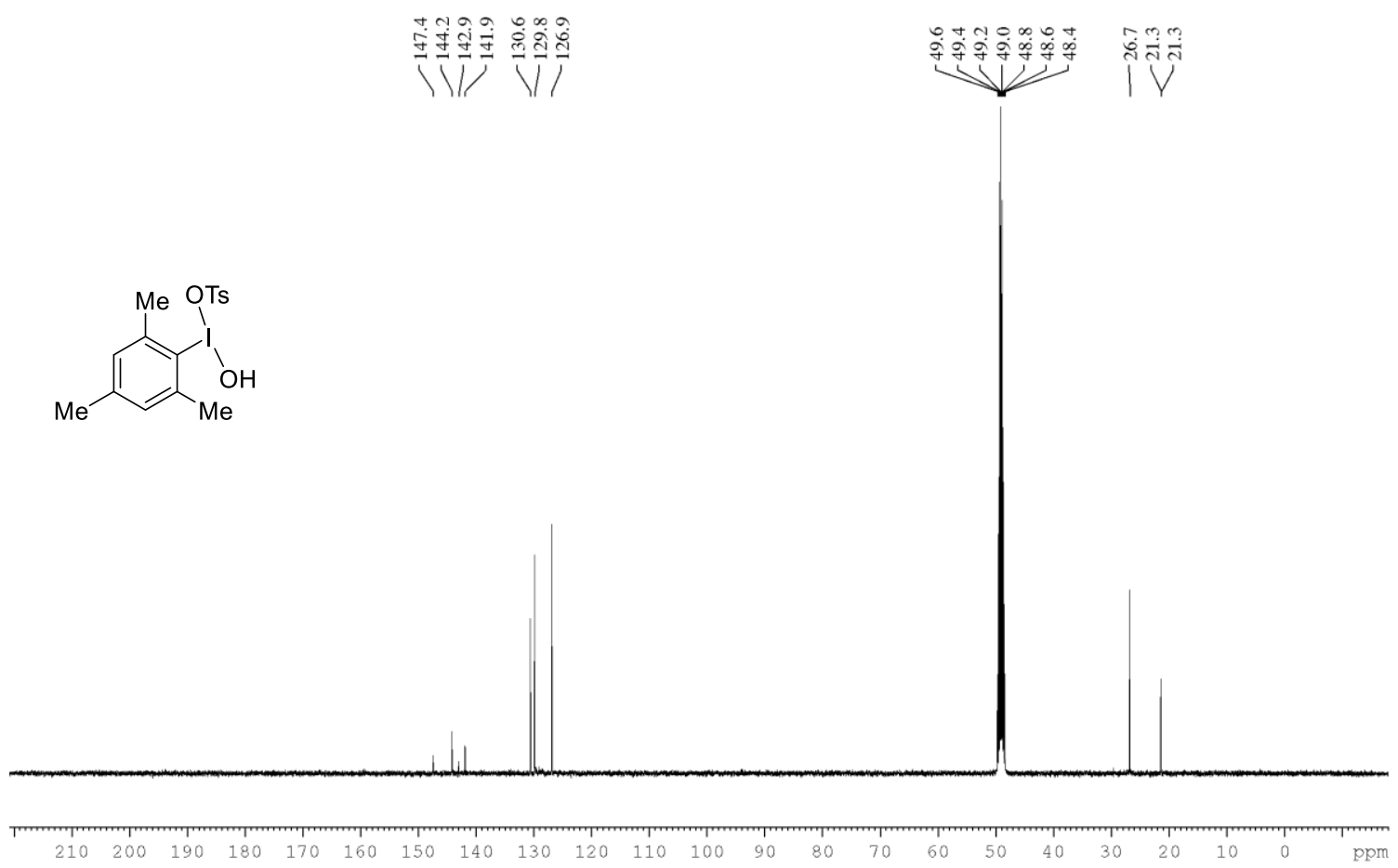

Figure 23. ${ }^{13} \mathrm{C}\left\{{ }^{1} \mathrm{H}\right\} \mathrm{NMR}$ of hydroxy(tosyloxy)iodomesitylene in $\mathrm{CD}_{3} \mathrm{OD}$ at $101 \mathrm{MHz}$. 


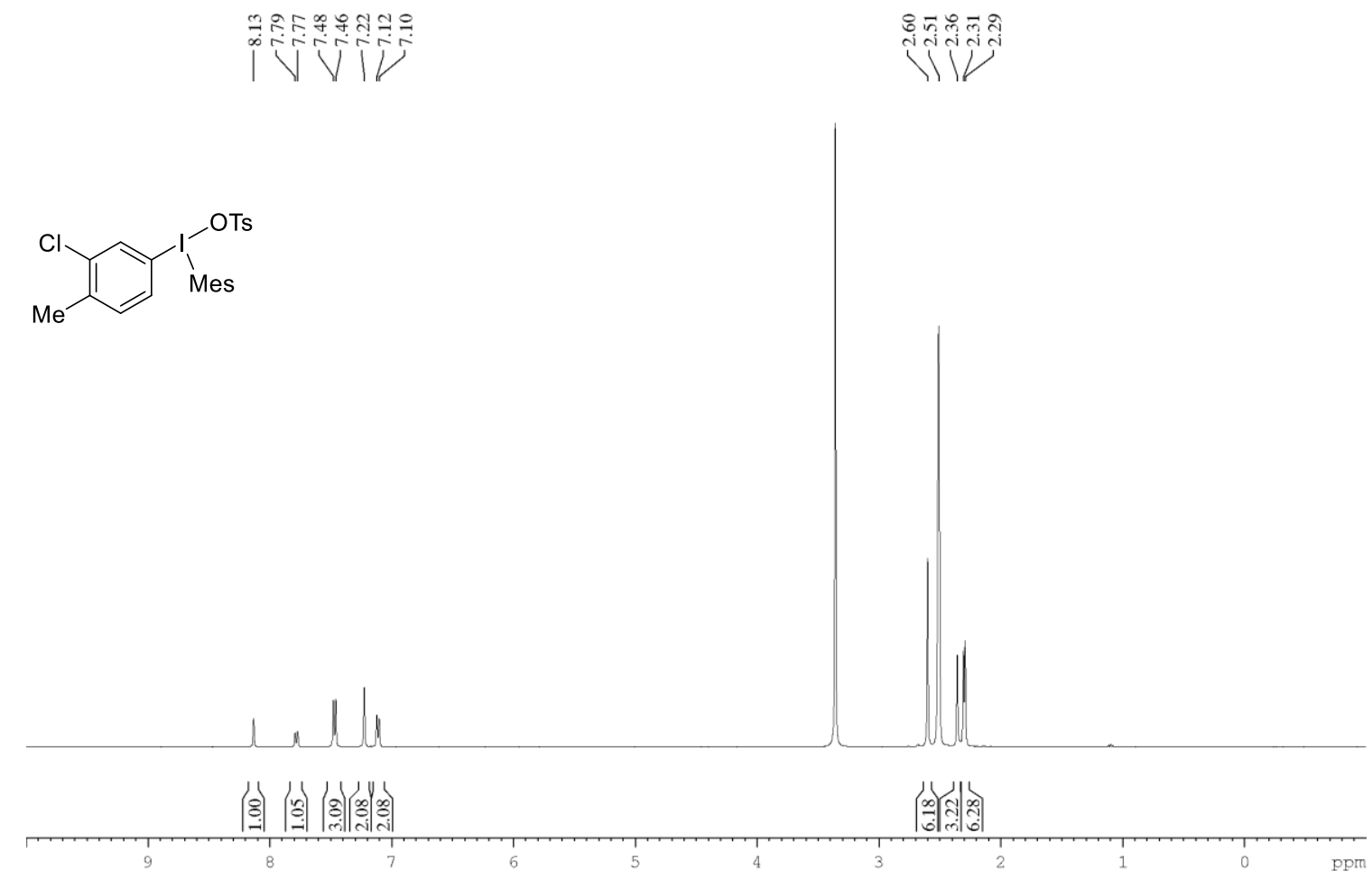

Figure 24. ${ }^{1} \mathrm{H}$ NMR of 6 a in DMSO- $d_{6}$ at $400 \mathrm{MHz}$.

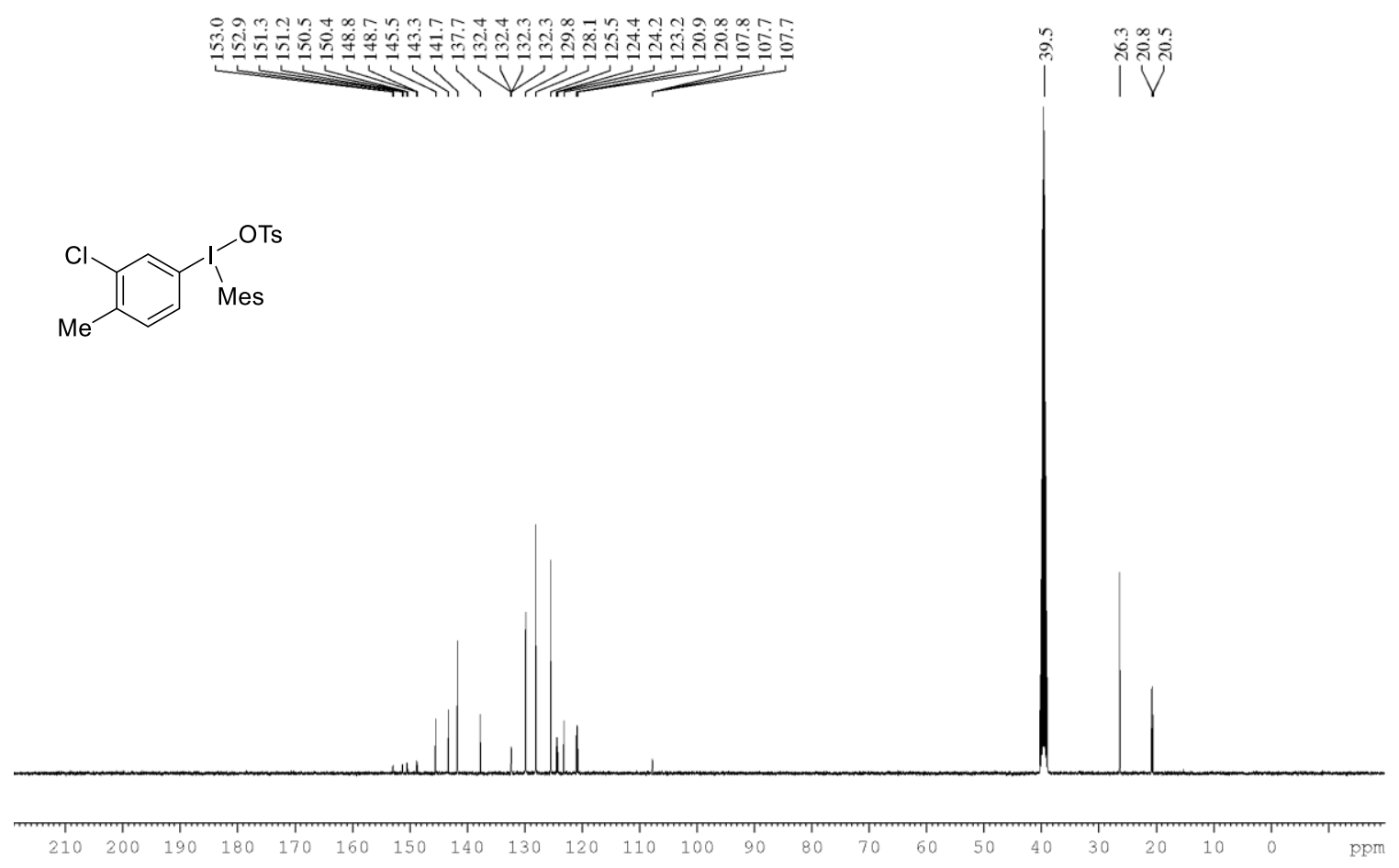

Figure $25 .{ }^{13} \mathrm{C}\left\{{ }^{1} \mathrm{H}\right\}$ NMR of 6 a in DMSO- $\mathrm{d}_{6}$ at $101 \mathrm{MHz}$. 


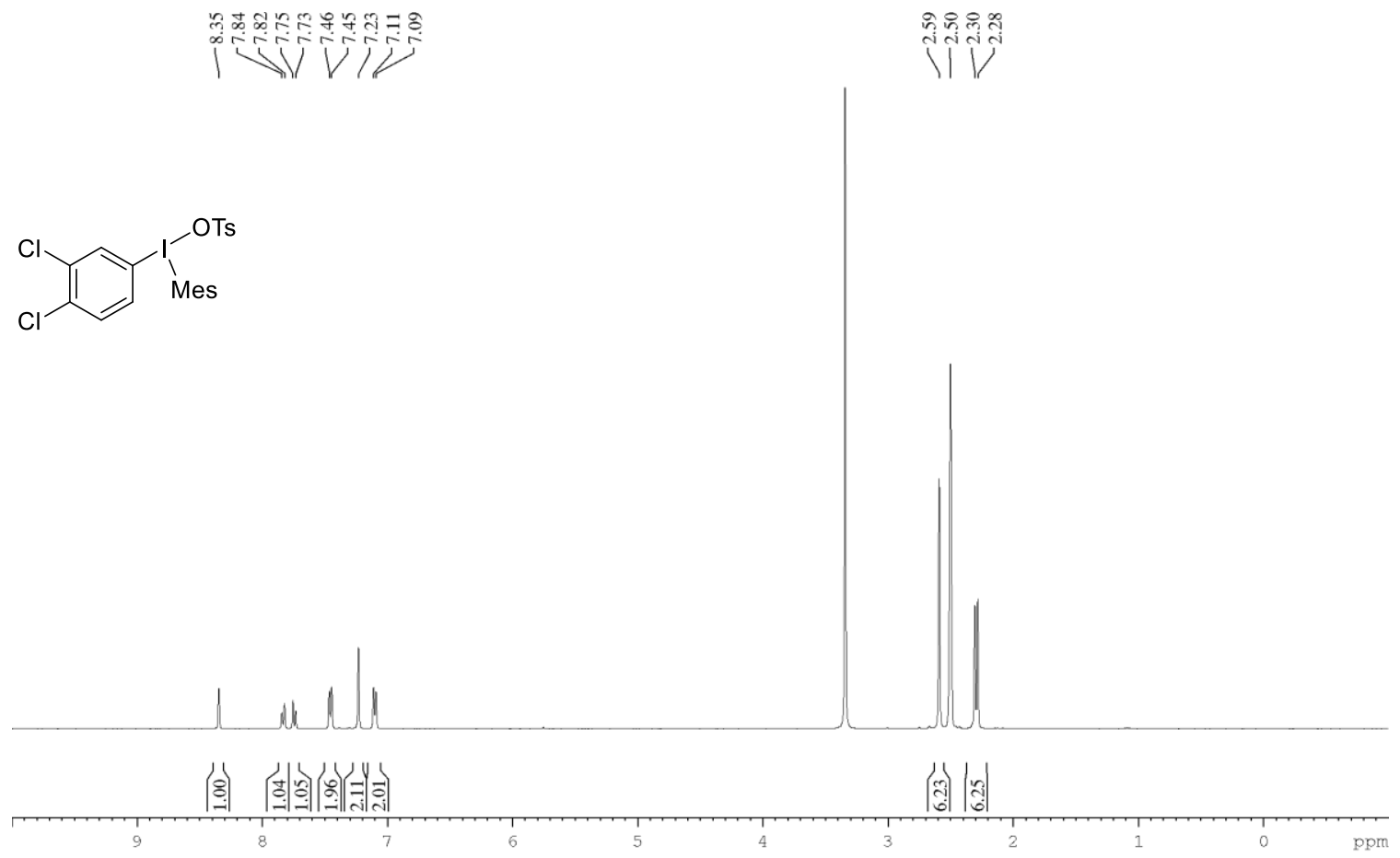

Figure $26 .{ }^{1} \mathrm{H}$ NMR of $6 b$ in DMSO- $\mathrm{d}_{6}$ at $400 \mathrm{MHz}$.
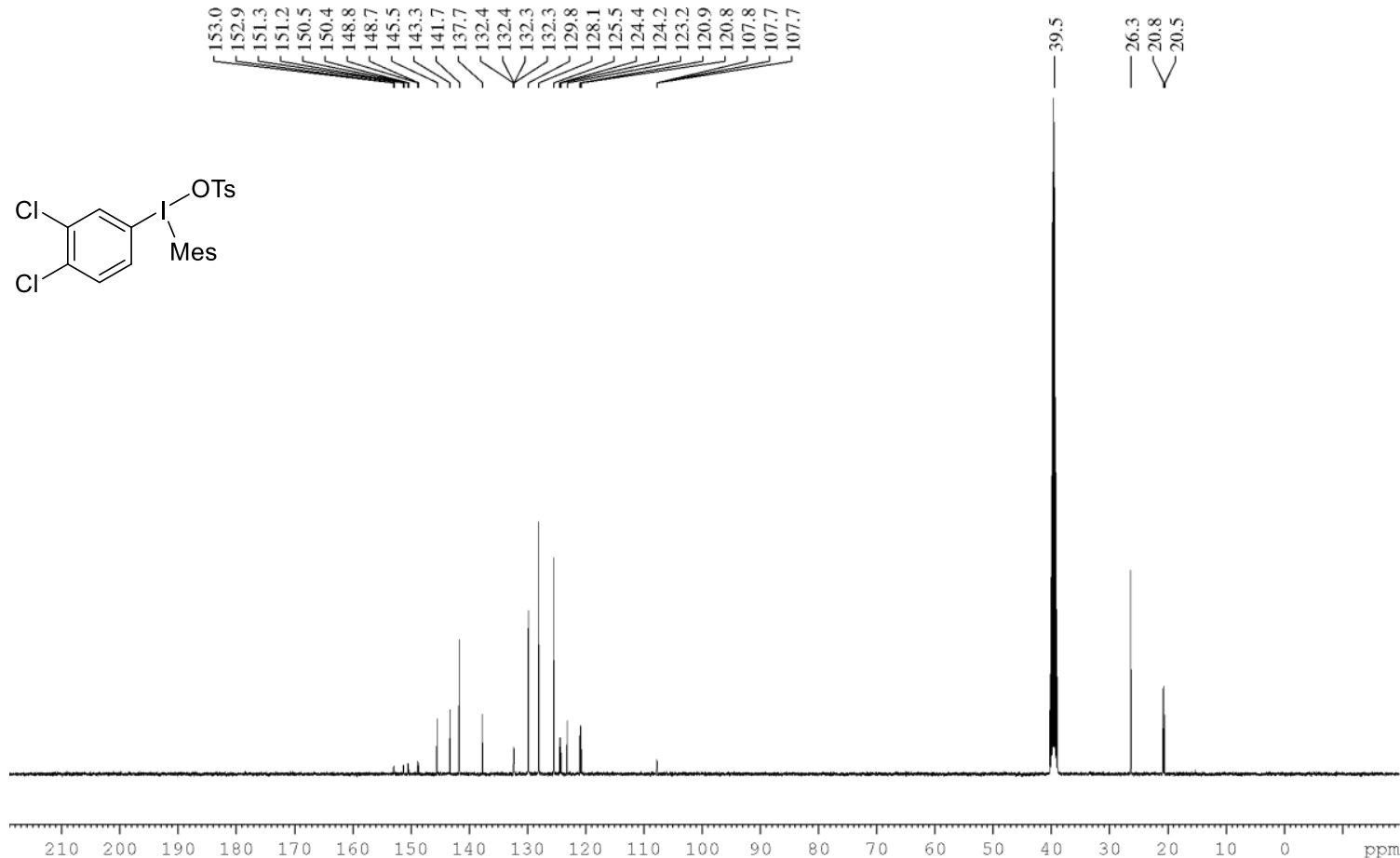

Figure 27. ${ }^{13} \mathrm{C}\left\{{ }^{1} \mathrm{H}\right\}$ NMR of $\mathbf{6 b}$ in DMSO-d 6 at $101 \mathrm{MHz}$. 

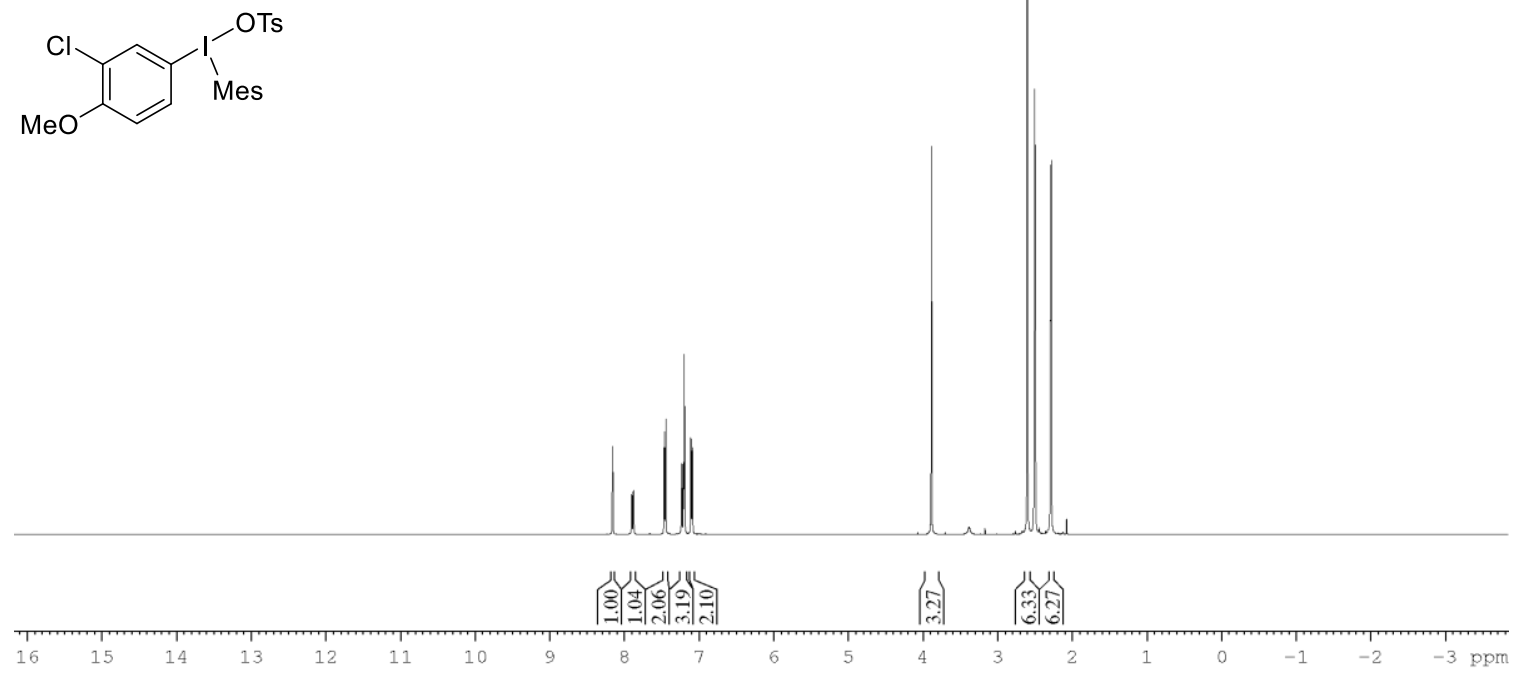

Figure $28 .{ }^{1} \mathrm{H}$ NMR of $6 \mathrm{c}$ in DMSO- $\mathrm{d}_{6}$ at $400 \mathrm{MHz}$.
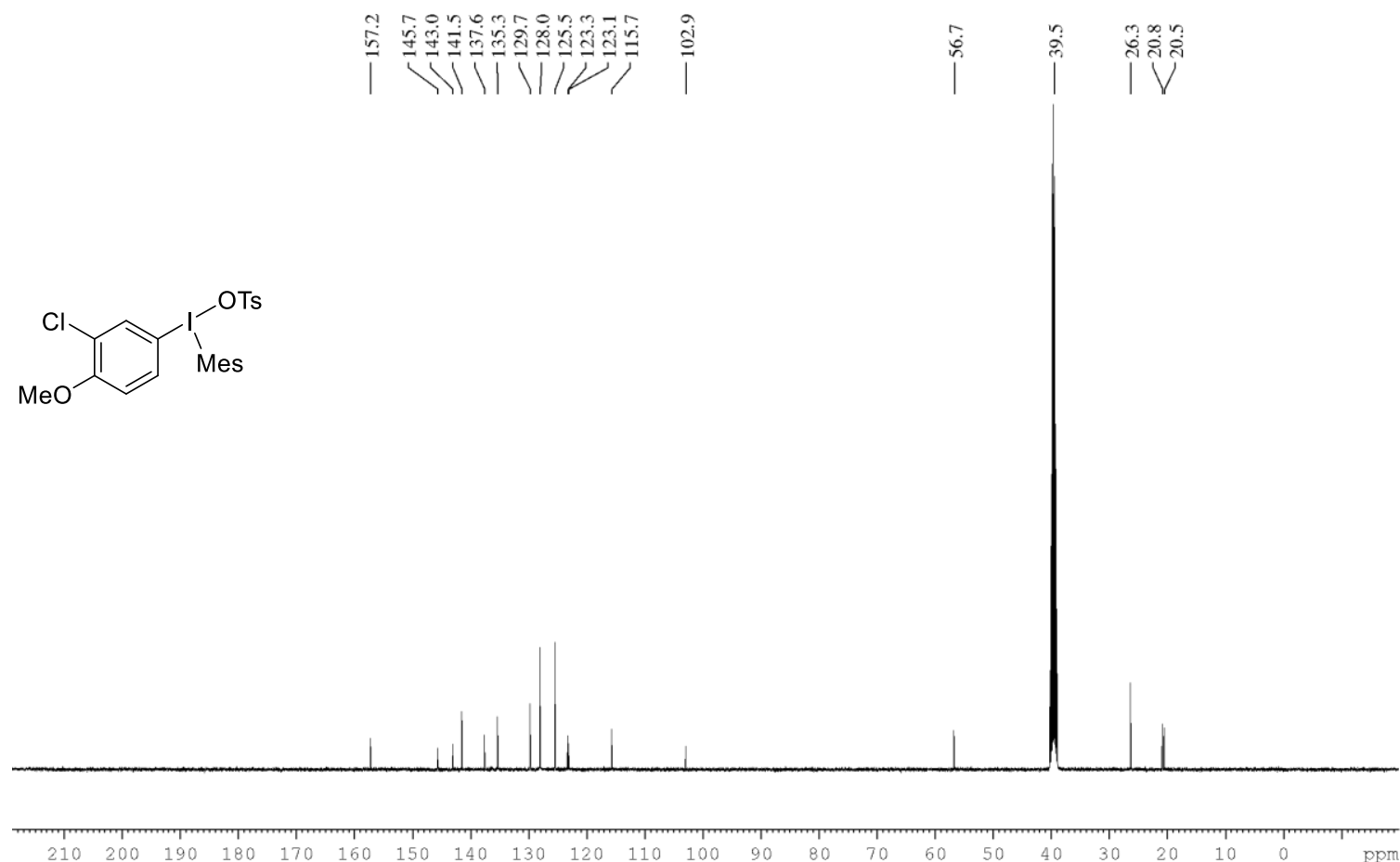

Figure $29 .{ }^{13} \mathrm{C}\left\{{ }^{1} \mathrm{H}\right\}$ NMR of $6 \mathrm{c}$ in DMSO-d 6 at $101 \mathrm{MHz}$. 


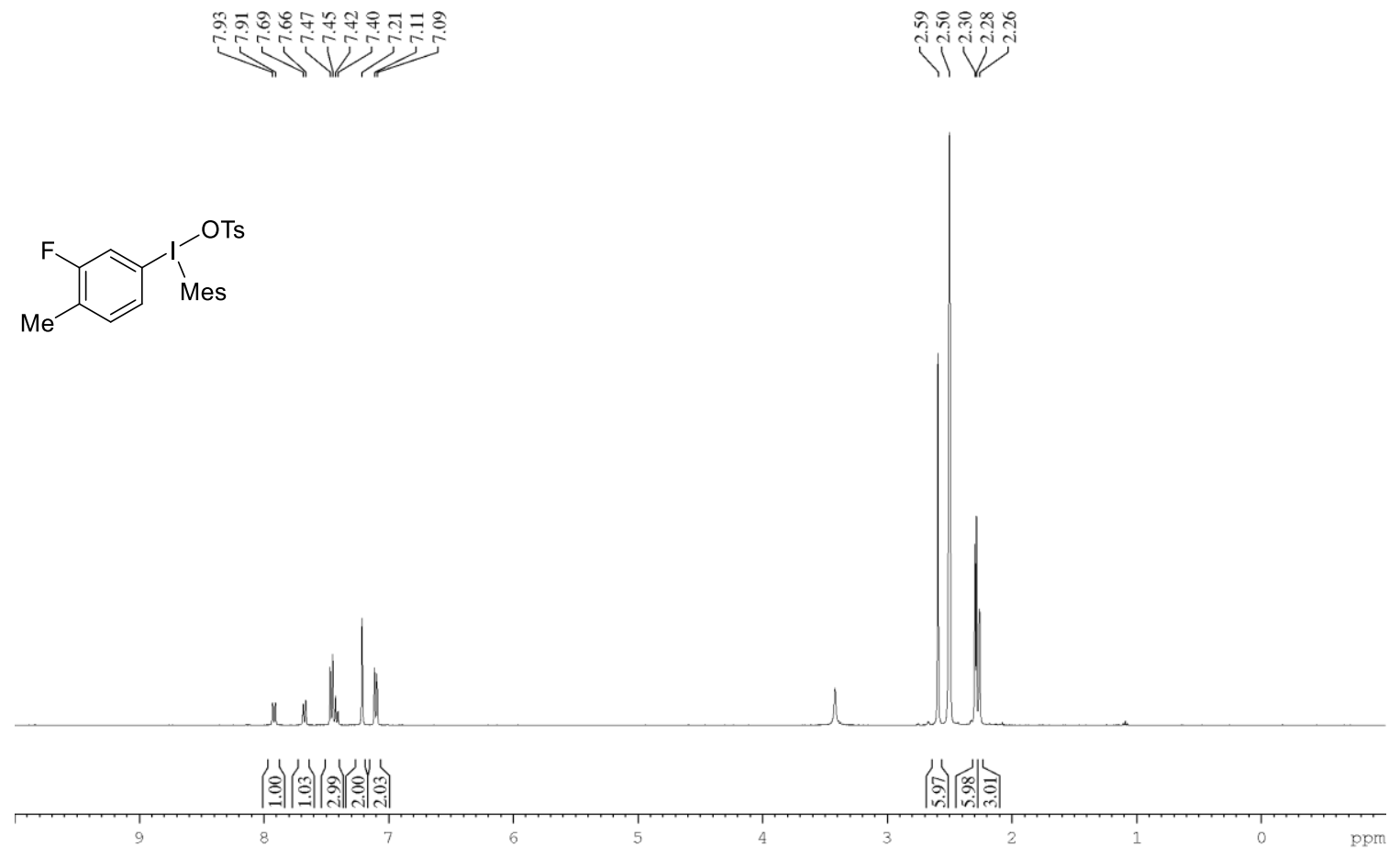

Figure $30 .{ }^{1} \mathrm{H}$ NMR of $6 e$ in DMSO-d $\mathrm{d}_{6}$ at $400 \mathrm{MHz}$.
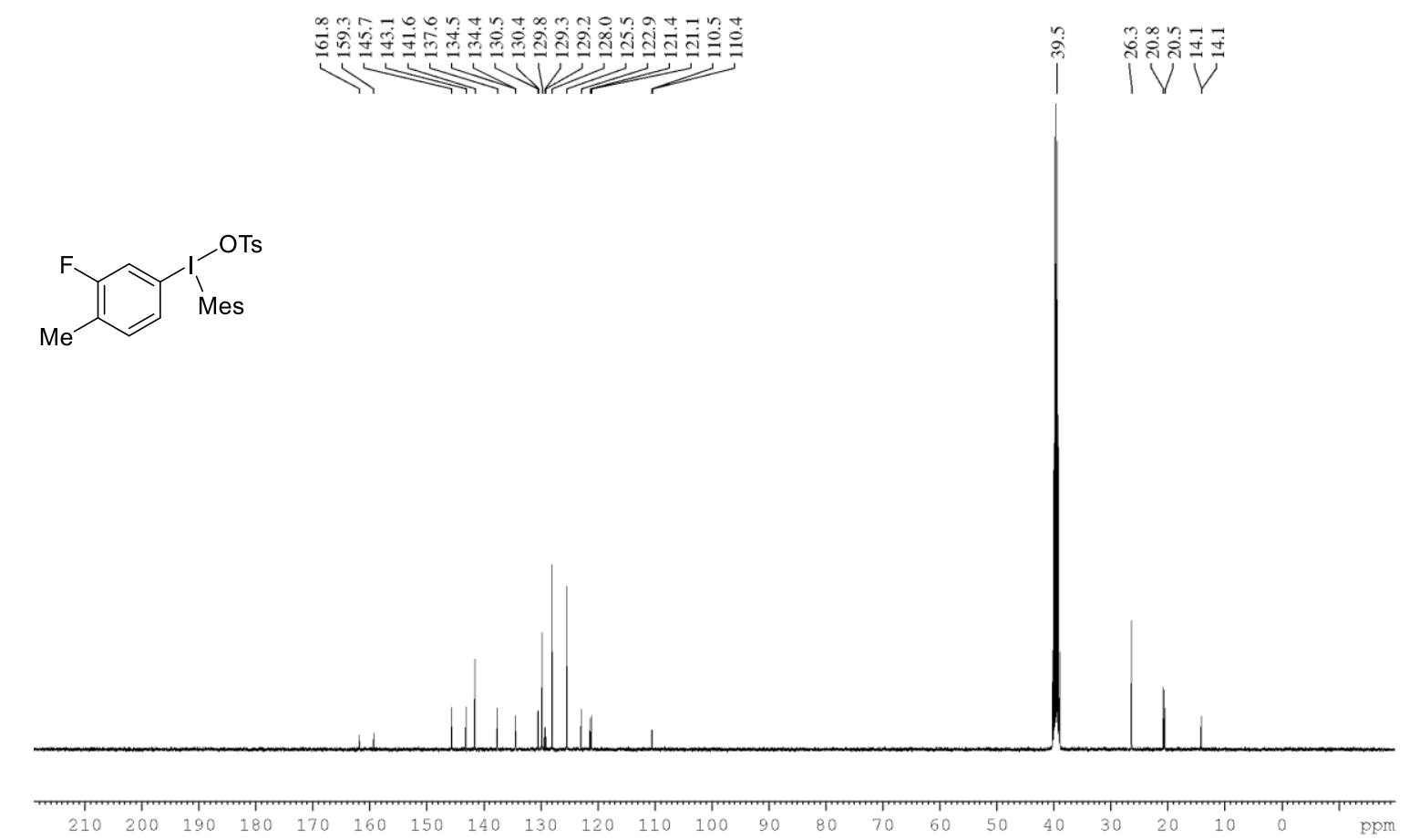

Figure $31 .{ }^{13} \mathrm{C}\left\{{ }^{1} \mathrm{H}\right\}$ NMR of $6 e$ in DMSO-d 6 at $101 \mathrm{MHz}$. 


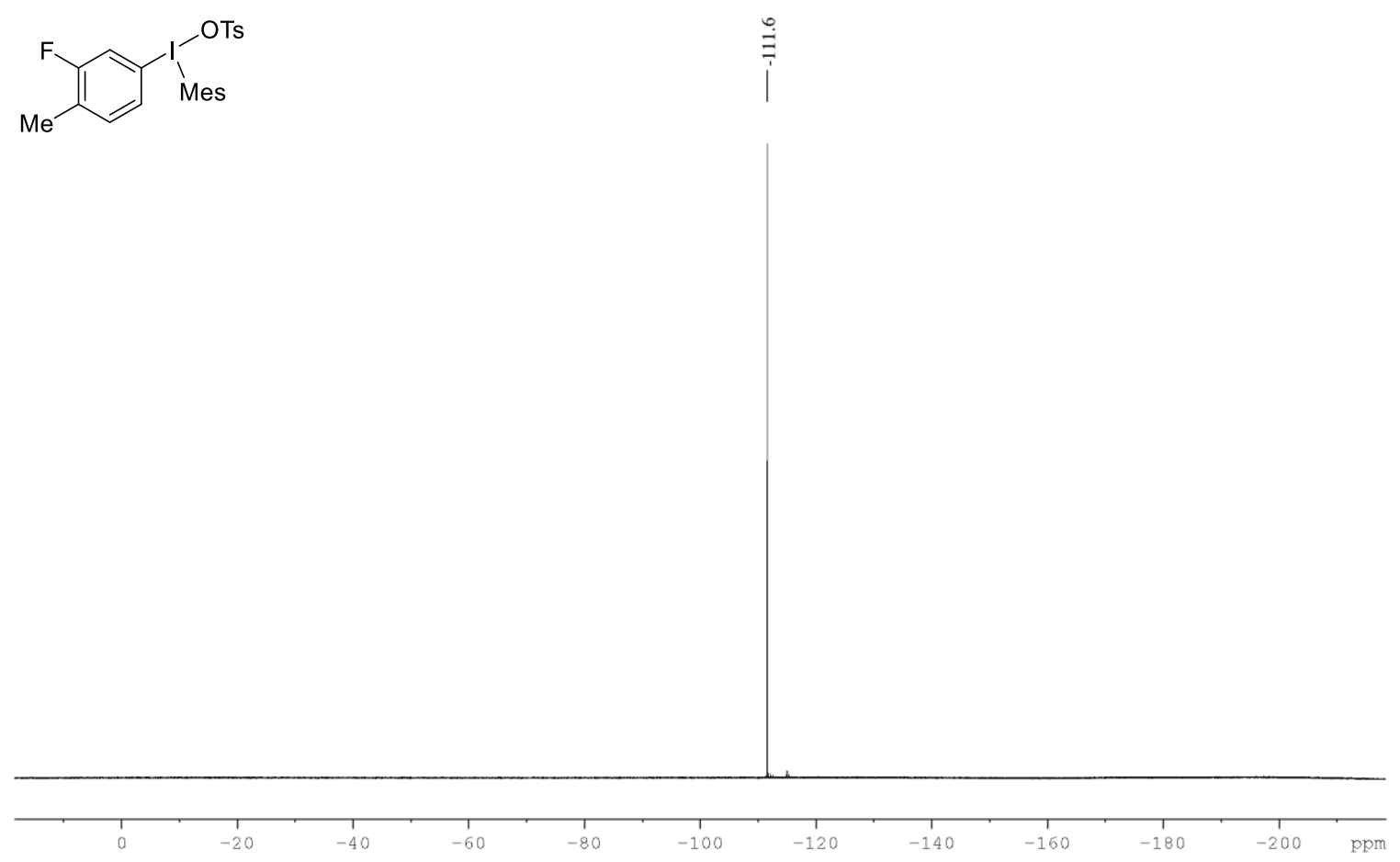

Figure 32. ${ }^{19} \mathrm{~F}\left\{{ }^{1} \mathrm{H}\right\}$ NMR of $6 e$ in DMSO- $\mathrm{d}_{6}$ at $376 \mathrm{MHz}$.

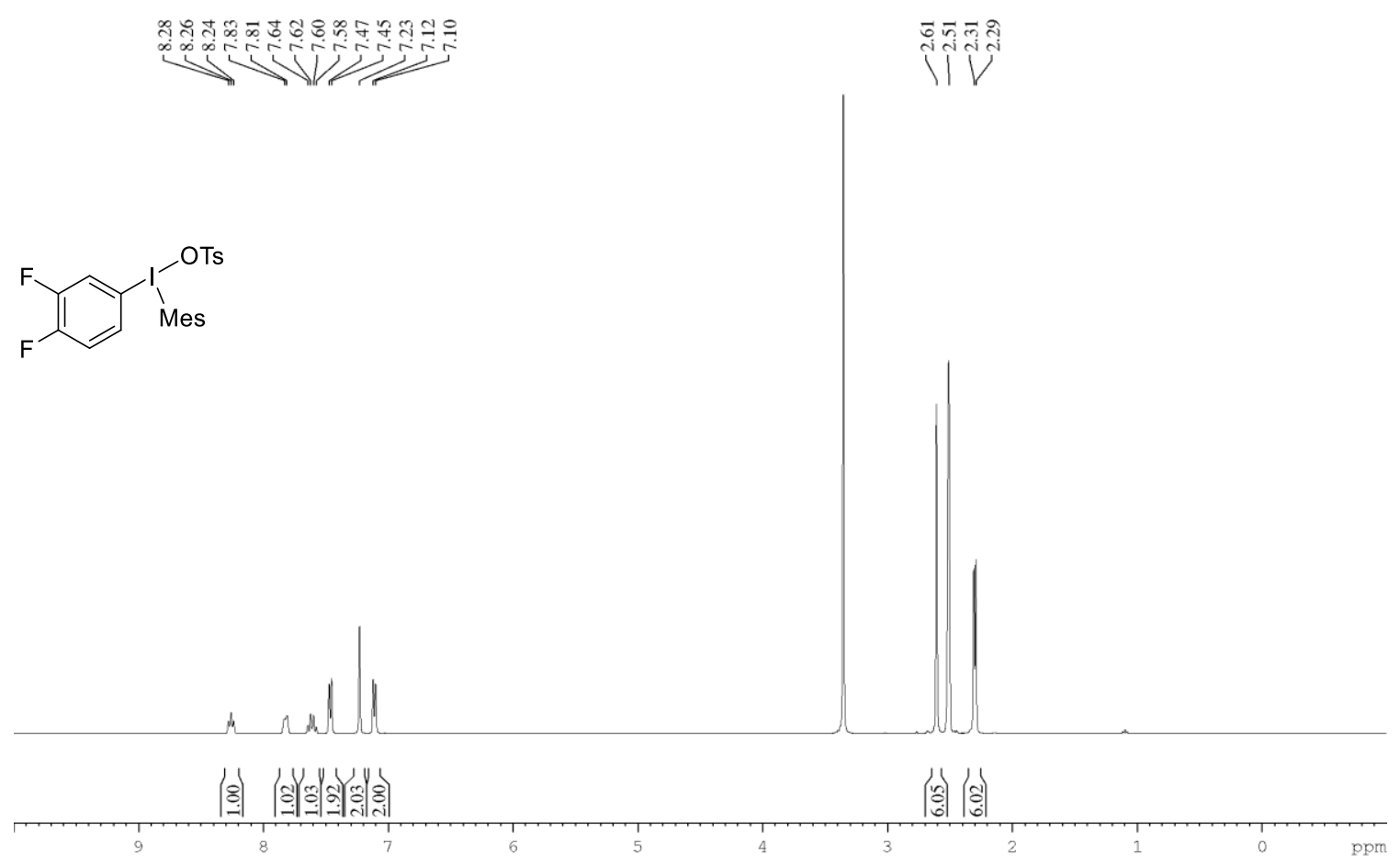

Figure $33 .{ }^{1} \mathrm{H}$ NMR of $6 \mathrm{f}$ in DMSO- $\mathrm{d}_{6}$ at $400 \mathrm{MHz}$. 


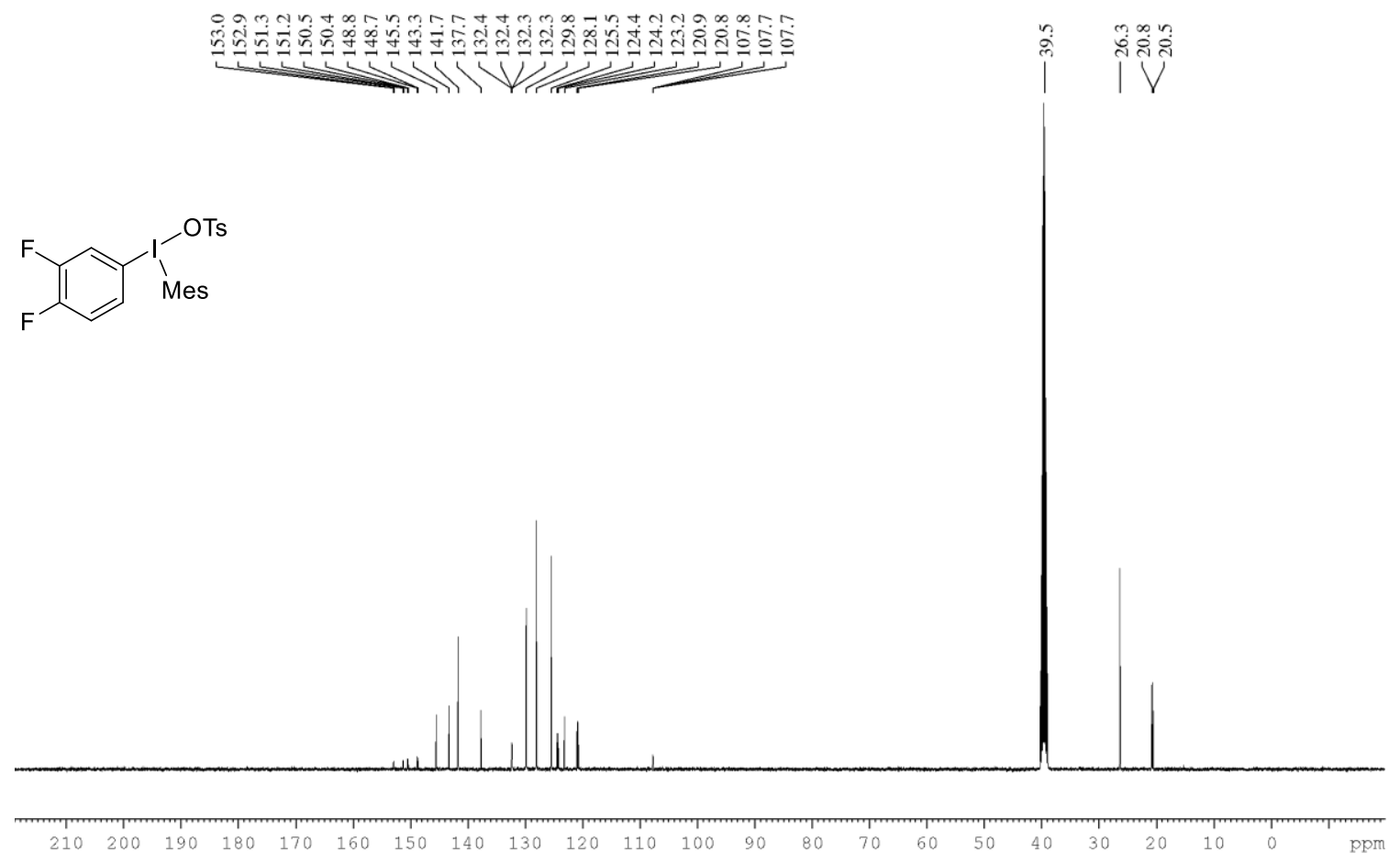

Figure $34 .{ }^{13} \mathrm{C}\left\{{ }^{1} \mathrm{H}\right\}$ NMR of $6 \mathbf{f}$ in DMSO- $\mathrm{d}_{6}$ at $101 \mathrm{MHz}$.
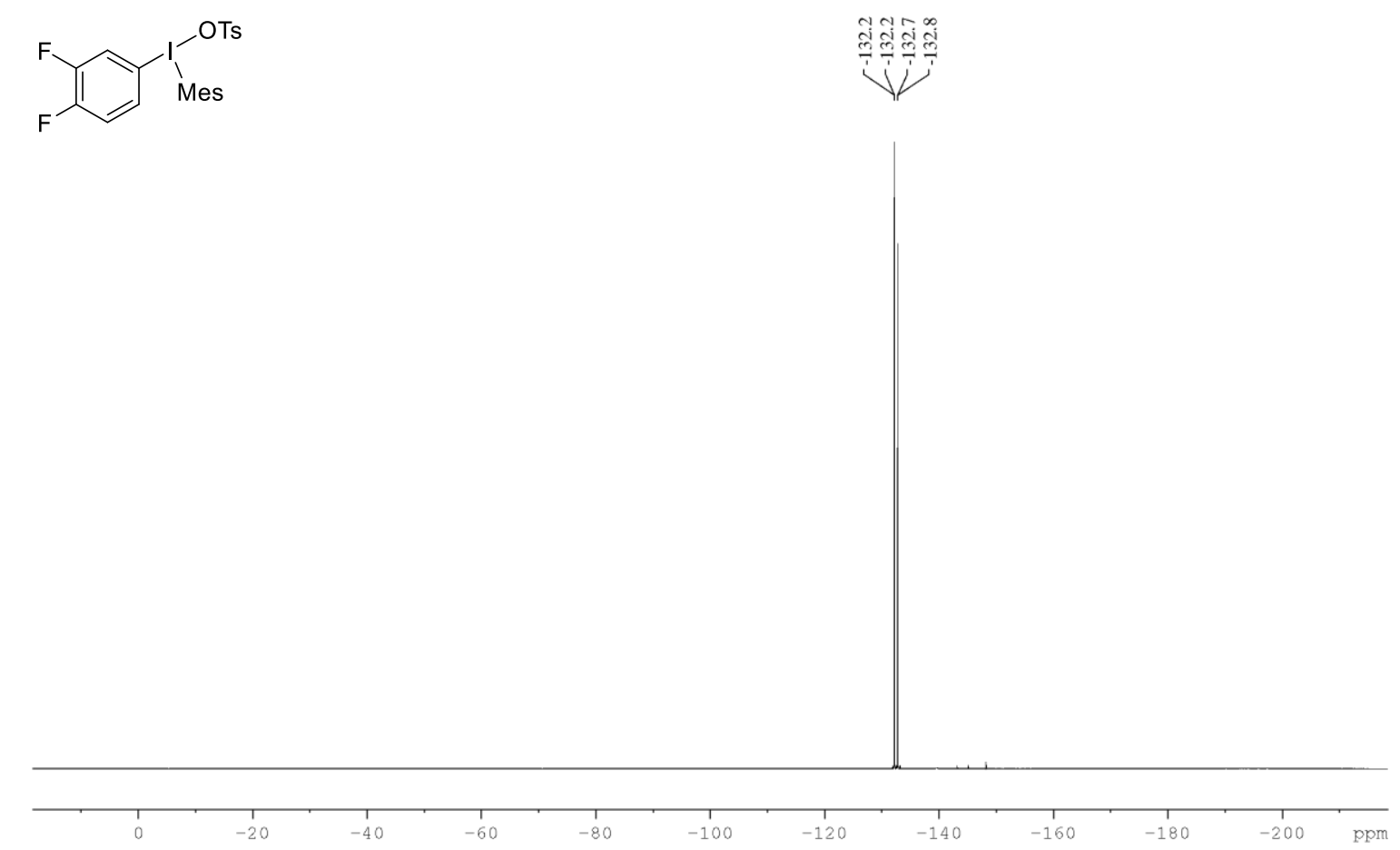

Figure 35. ${ }^{19} \mathrm{~F}\left\{{ }^{1} \mathrm{H}\right\}$ NMR of 6 in DMSO-d 6 at $376 \mathrm{MHz}$. 


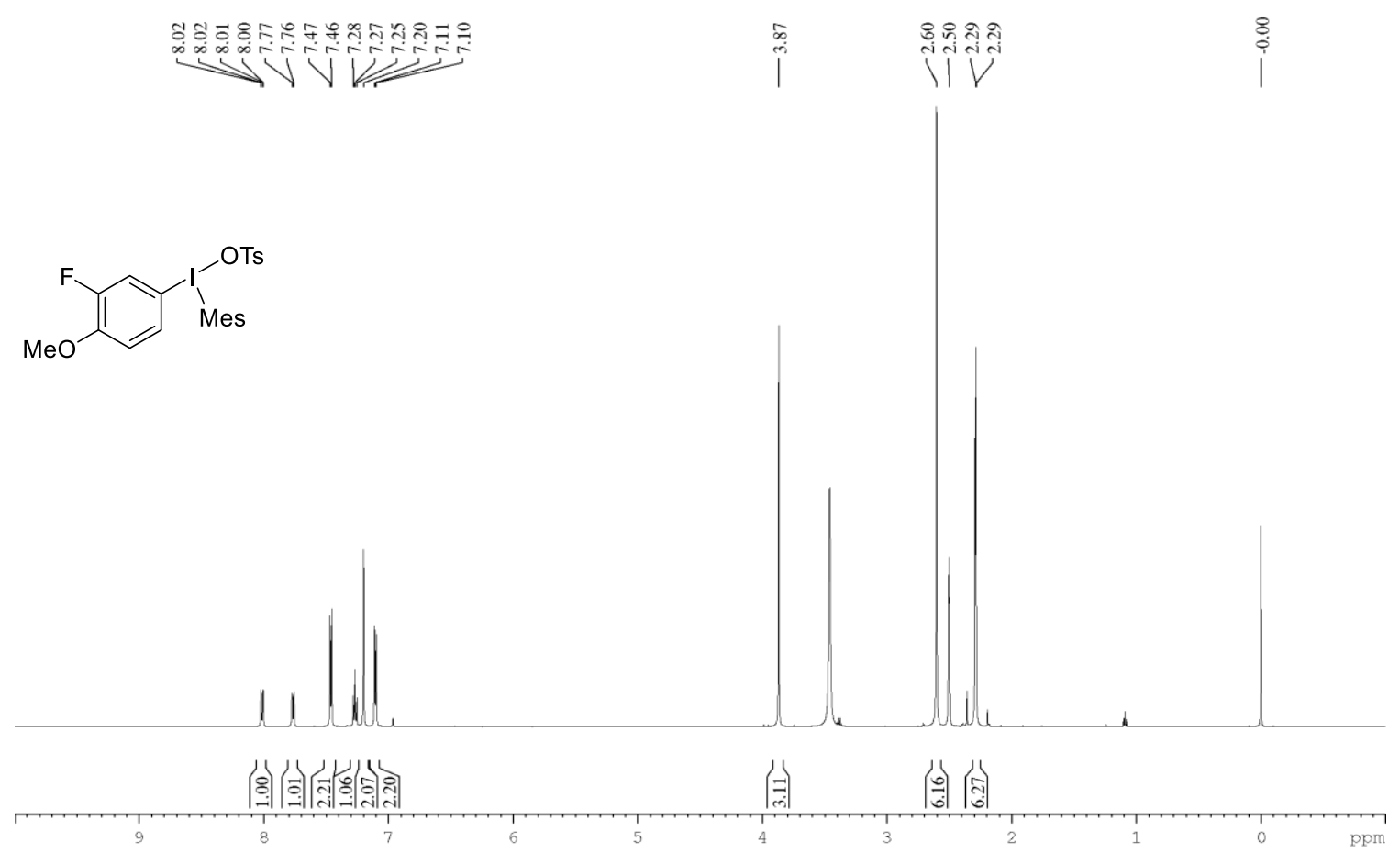

Figure $36 .{ }^{1} \mathrm{H}$ NMR of $6 \mathrm{~g}$ in DMSO- $\mathrm{d}_{6}$ with $0.05 \% \mathrm{v} / \mathrm{v}$ TMS at $400 \mathrm{MHz}$.

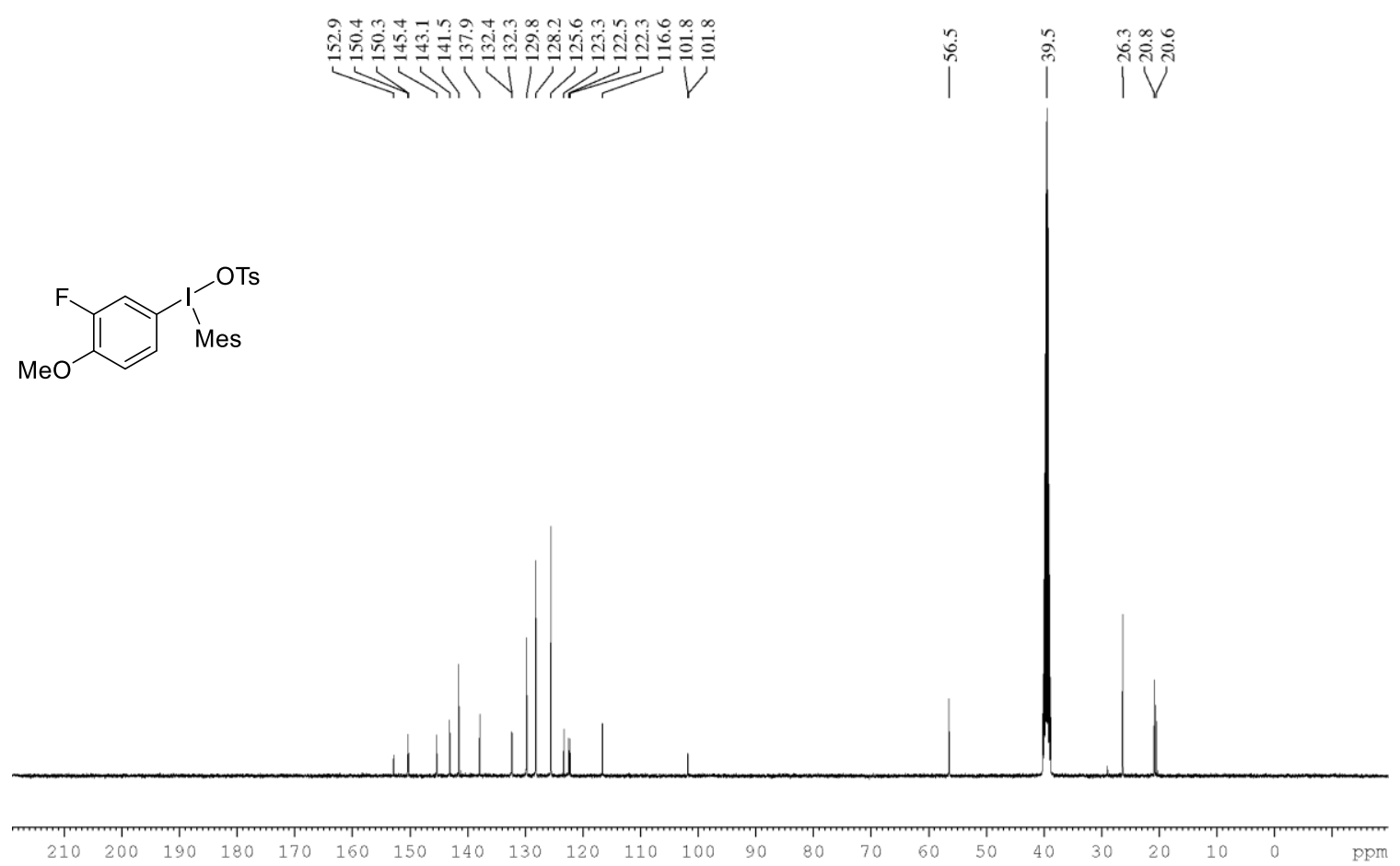

Figure 37. ${ }^{13} \mathrm{C}\left\{{ }^{1} \mathrm{H}\right\}$ NMR of $6 \mathrm{~g}$ in DMSO-d $\mathrm{d}_{6}$ with $0.05 \% \mathrm{v} / \mathrm{v}$ TMS at $101 \mathrm{MHz}$. 

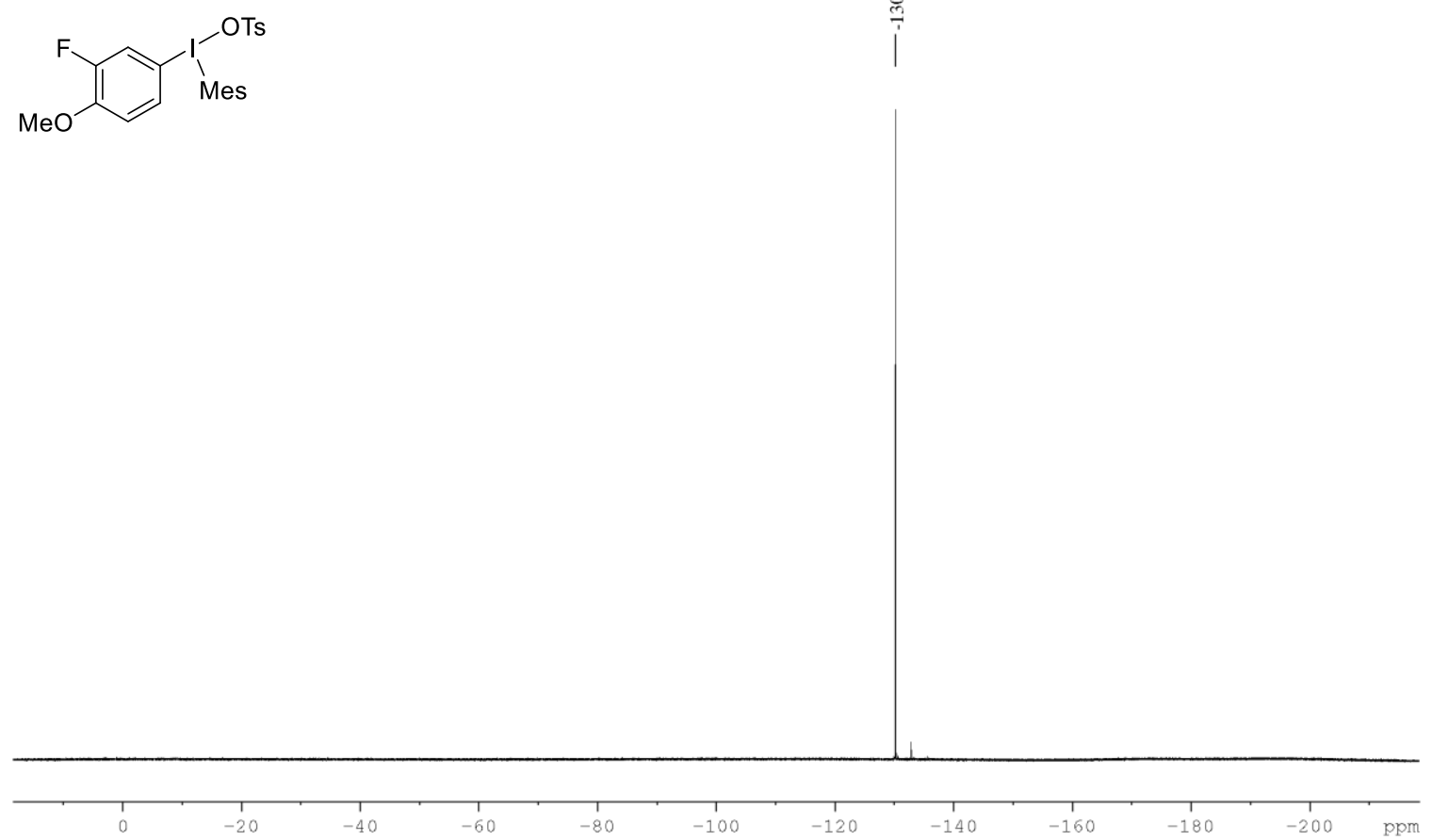

Figure 38. ${ }^{19} \mathrm{~F}\left\{{ }^{1} \mathrm{H}\right\}$ NMR of $6 \mathrm{~g}$ in DMSO- $\mathrm{d}_{6}$ with $0.05 \% \mathrm{v} / \mathrm{v}$ TMS at $376 \mathrm{MHz}$.

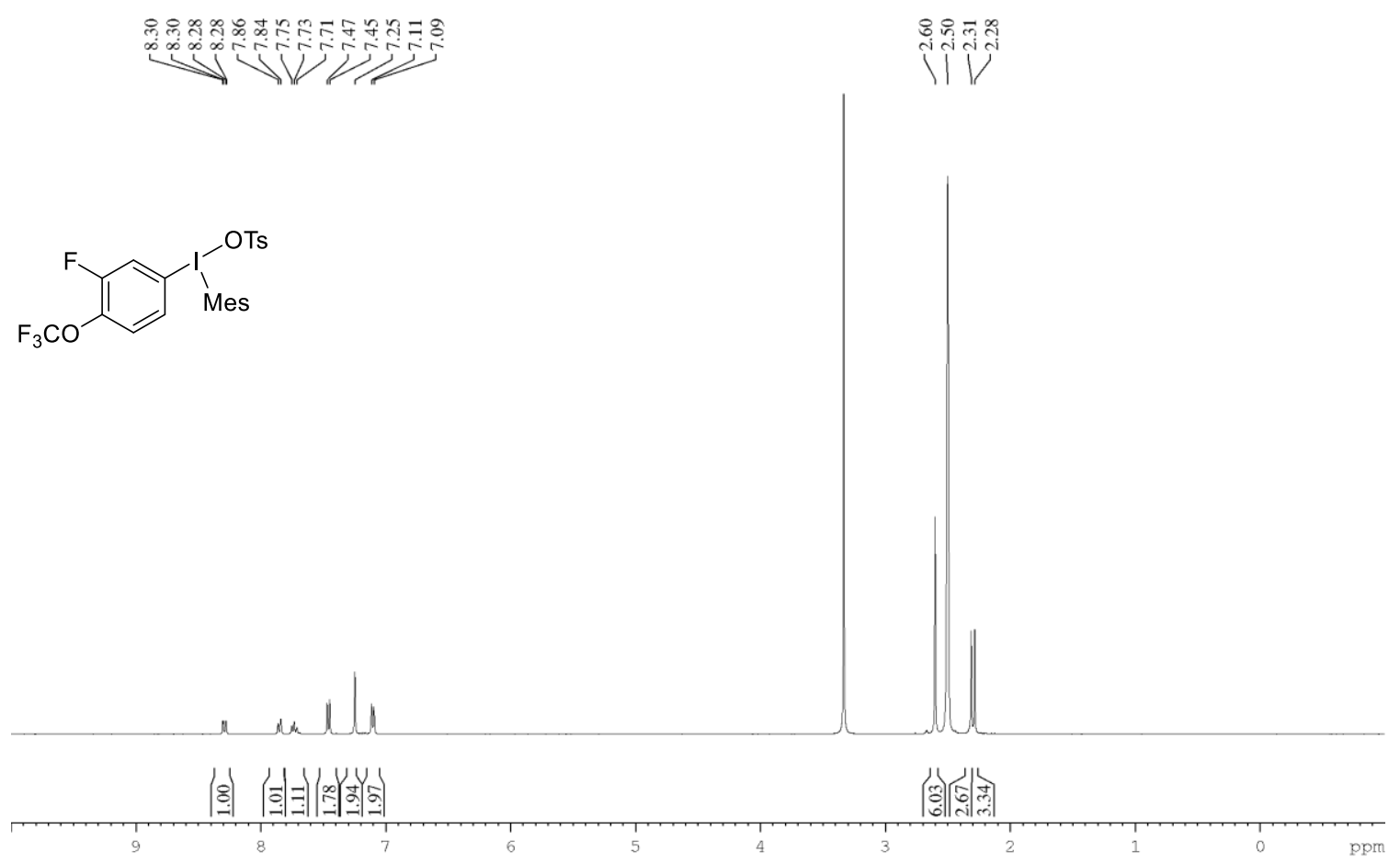

Figure 39. ${ }^{1} \mathrm{H}$ NMR of $6 \mathrm{~h}$ in DMSO- $\mathrm{d}_{6}$ at $400 \mathrm{MHz}$. 


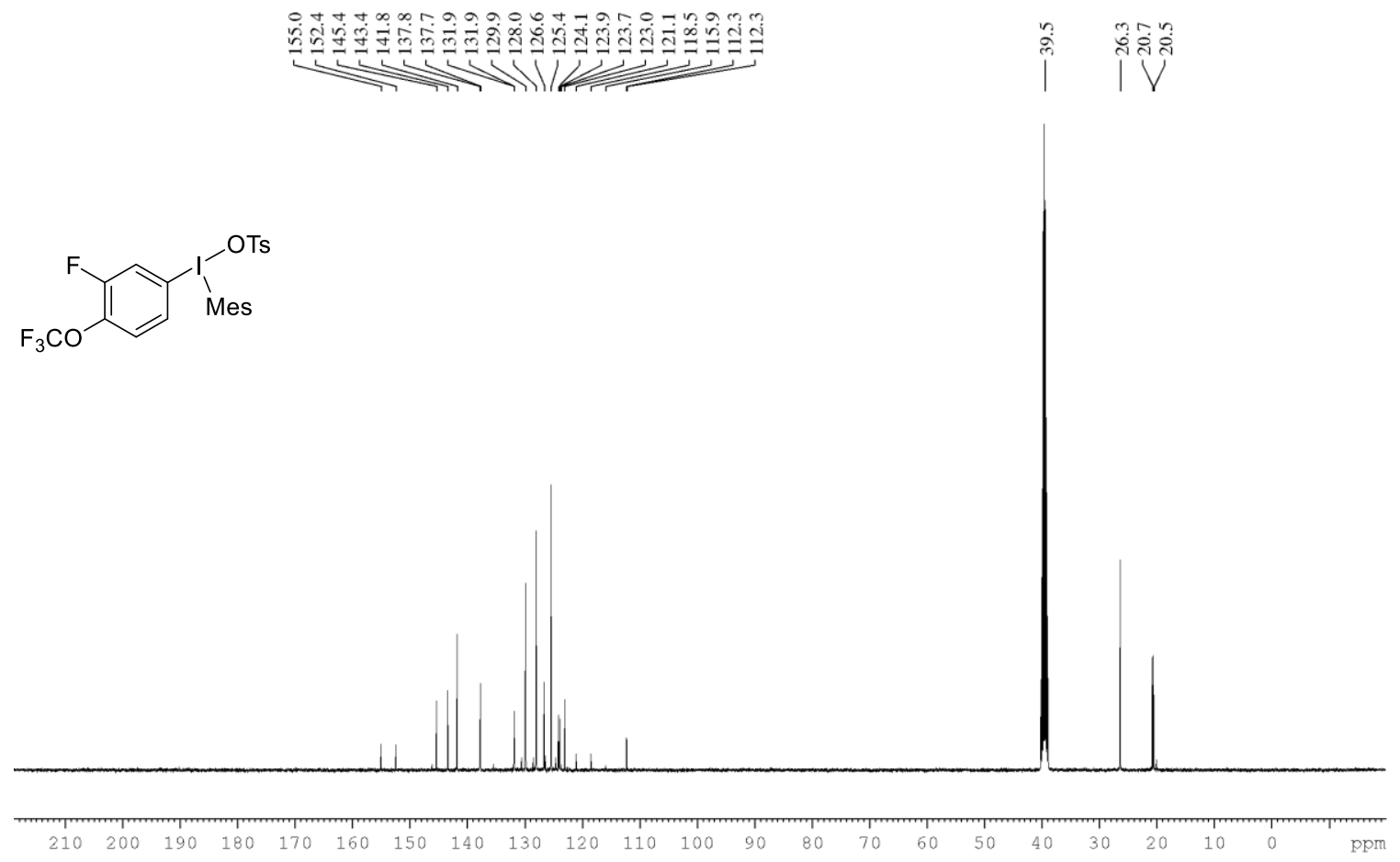

Figure $40 .{ }^{13} \mathrm{C}\left\{{ }^{1} \mathrm{H}\right\}$ NMR of $6 \mathrm{~h}$ in DMSO- $\mathrm{d}_{6}$ at $101 \mathrm{MHz}$.
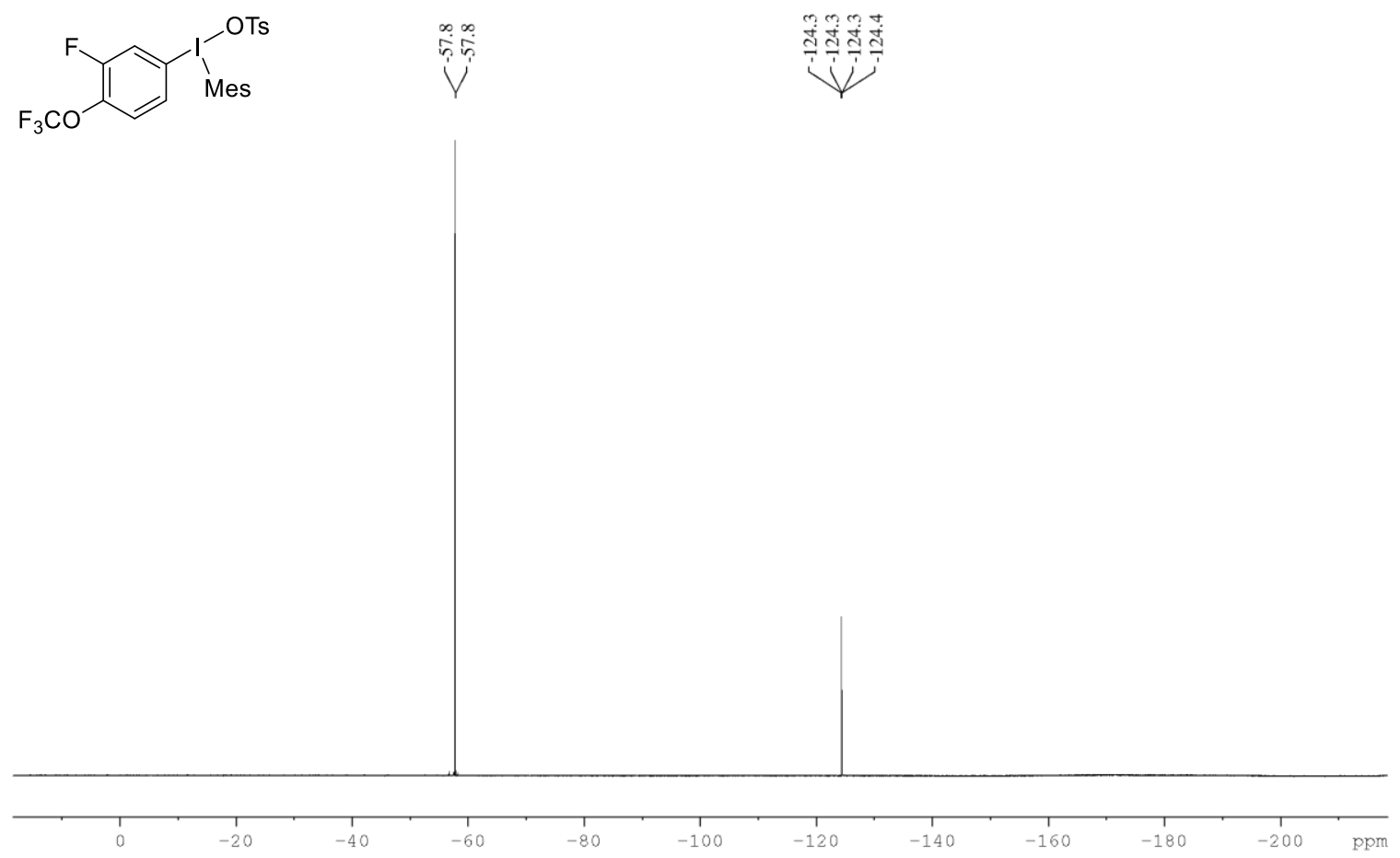

Figure $41 .{ }^{19} \mathrm{~F}\left\{{ }^{1} \mathrm{H}\right\}$ NMR of $6 \mathrm{~h}$ in DMSO- $\mathrm{d}_{6}$ at $376 \mathrm{MHz}$. 


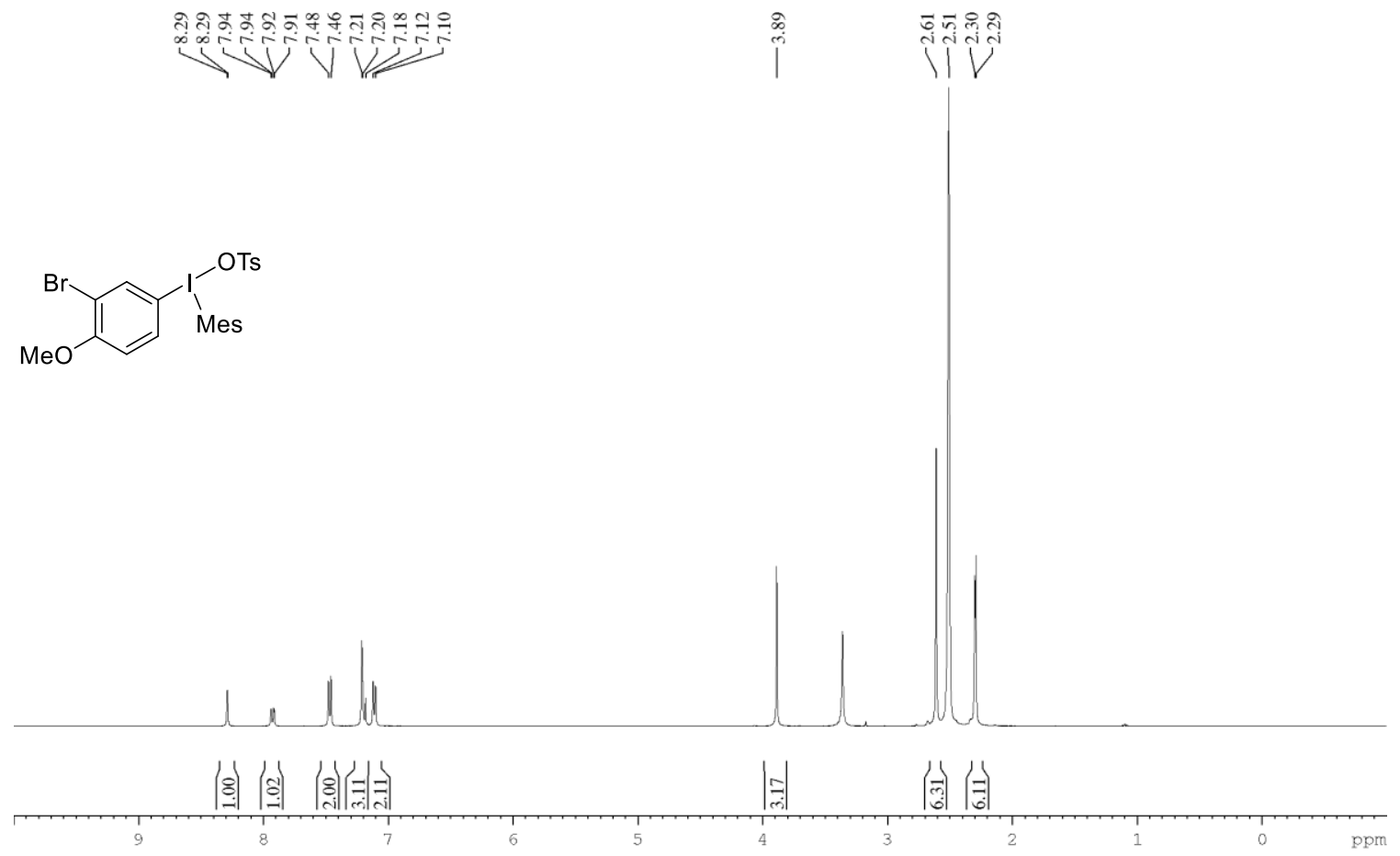

Figure $42 .{ }^{1} \mathrm{H}$ NMR of $\mathbf{6 j}$ in DMSO- $\mathrm{d}_{6}$ at $400 \mathrm{MHz}$.

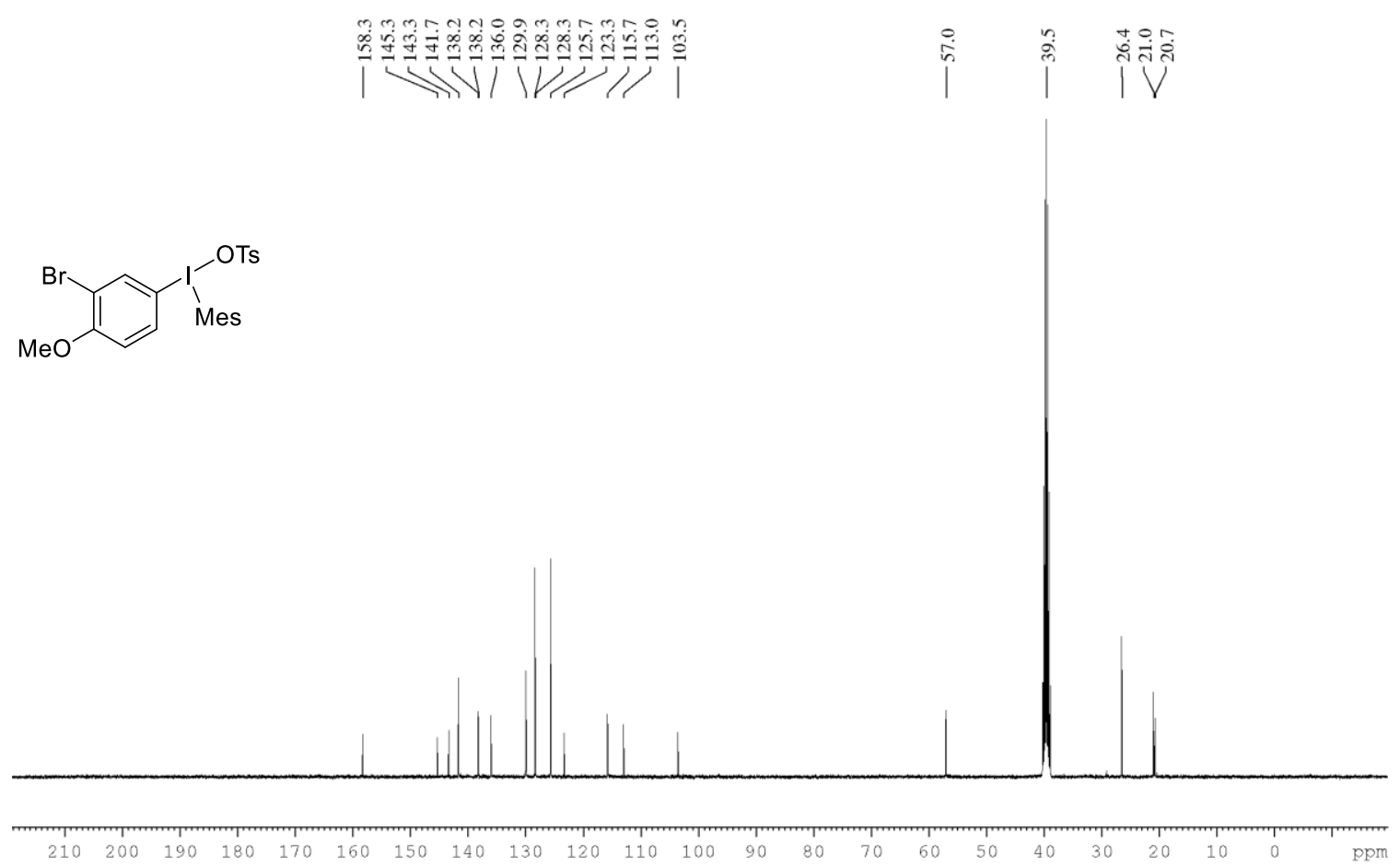

Figure $43 .{ }^{13} \mathrm{C}\left\{{ }^{1} \mathrm{H}\right\}$ NMR of $6 \mathbf{j}$ in DMSO-d 6 at $101 \mathrm{MHz}$. 


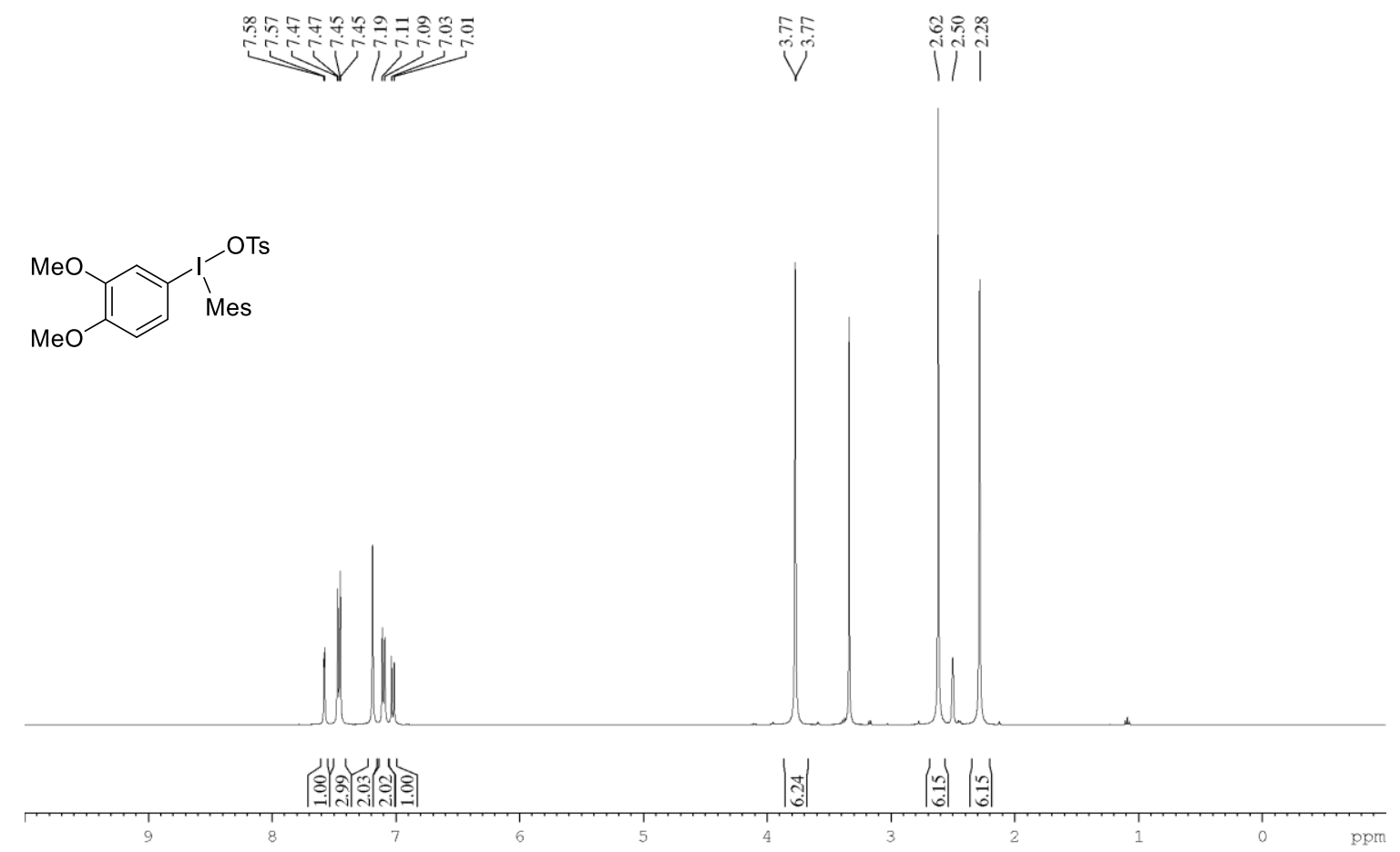

Figure $44 .{ }^{1} \mathrm{H}$ NMR of $6 \mathbf{k}$ in DMSO- $\mathrm{d}_{6}$ at $400 \mathrm{MHz}$.

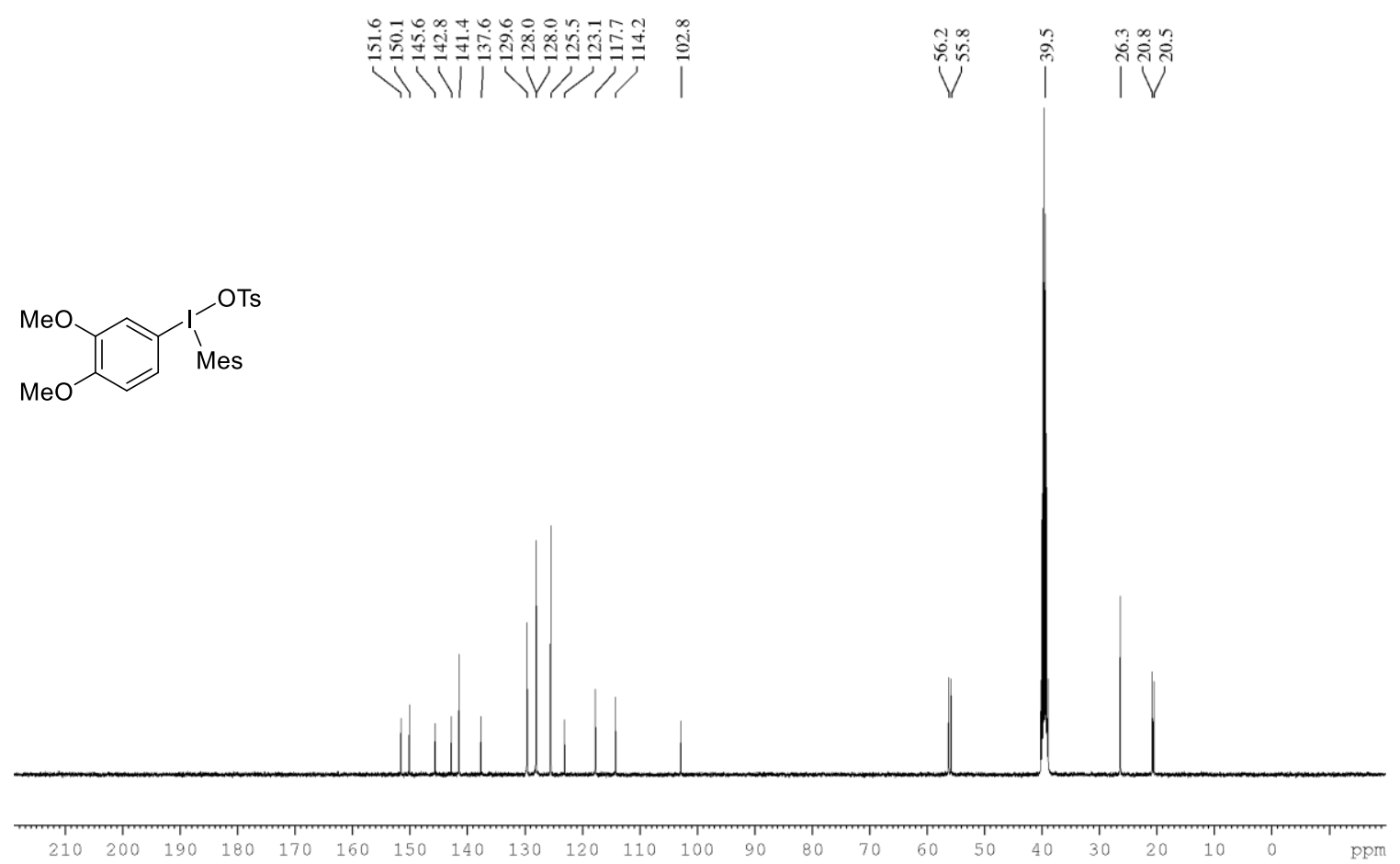

Figure $45 .{ }^{13} \mathrm{C}\left\{{ }^{1} \mathrm{H}\right\}$ NMR of $6 \mathbf{k}$ in DMSO- $\mathrm{d}_{6}$ at $101 \mathrm{MHz}$. 


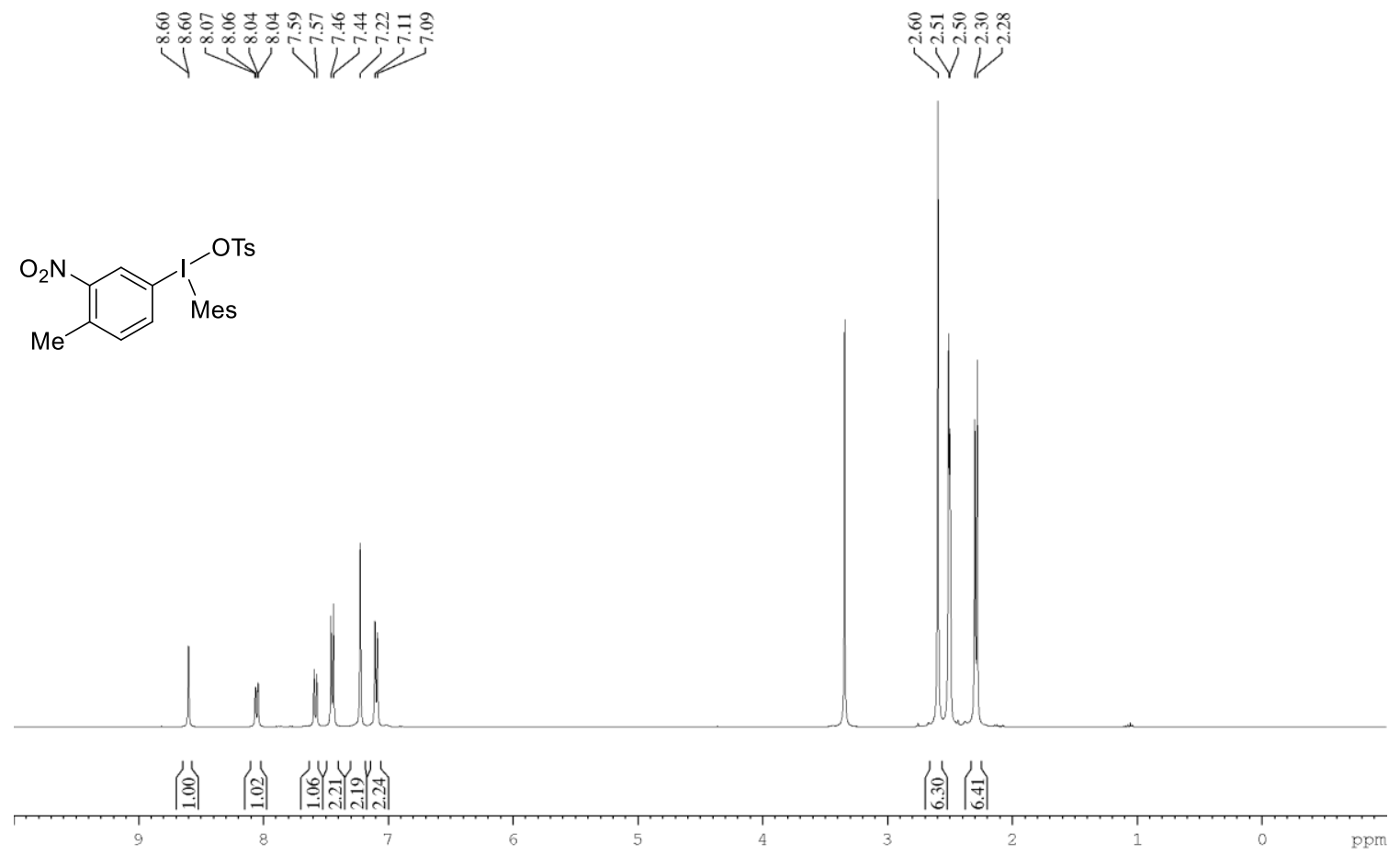

Figure $46 .{ }^{1} \mathrm{H}$ NMR of 61 in DMSO-d 6 at $400 \mathrm{MHz}$.

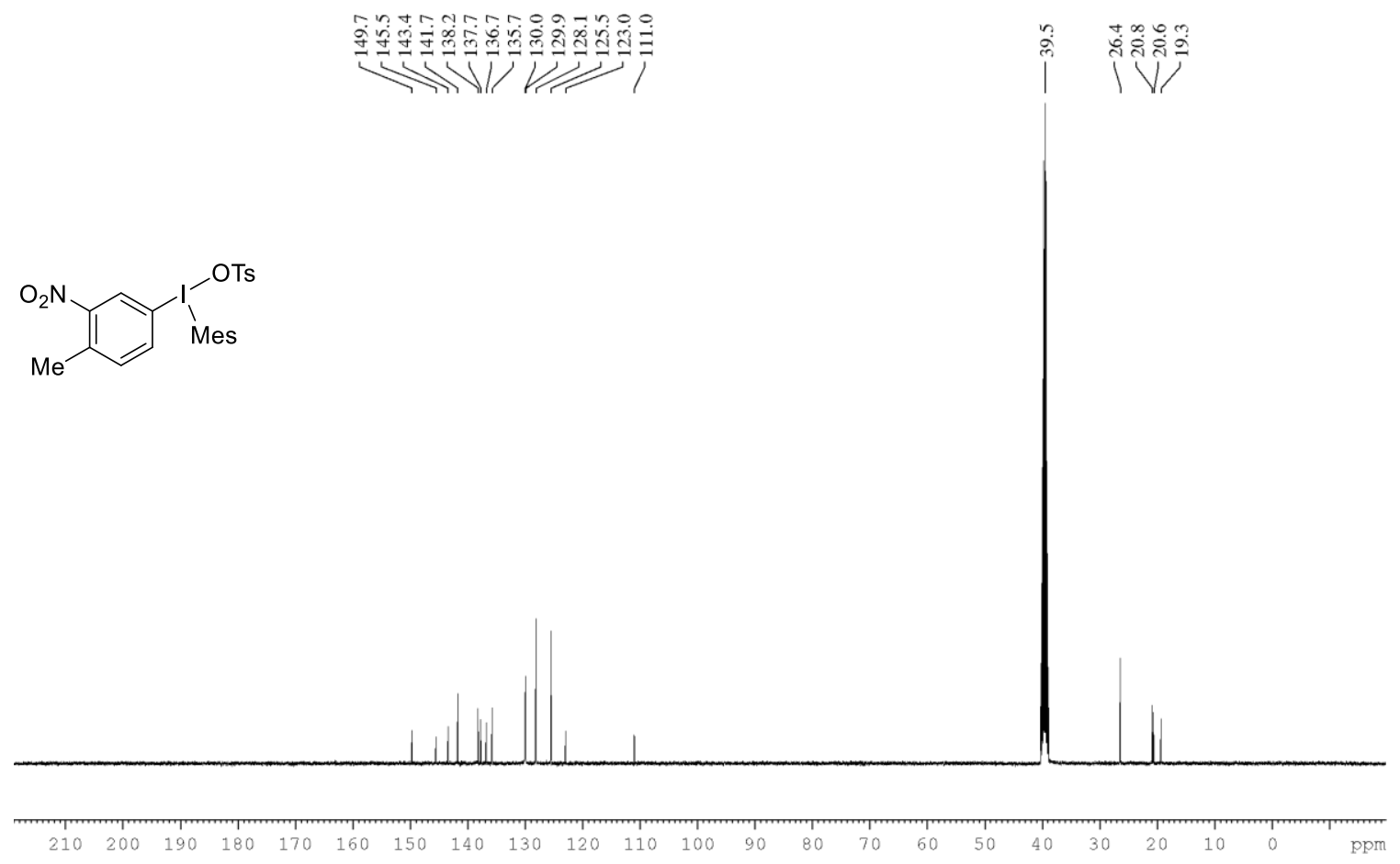

Figure $47 .{ }^{13} \mathrm{C}\left\{{ }^{1} \mathrm{H}\right\}$ NMR of $6 \mathrm{I}$ in DMSO-d 6 at $101 \mathrm{MHz}$. 


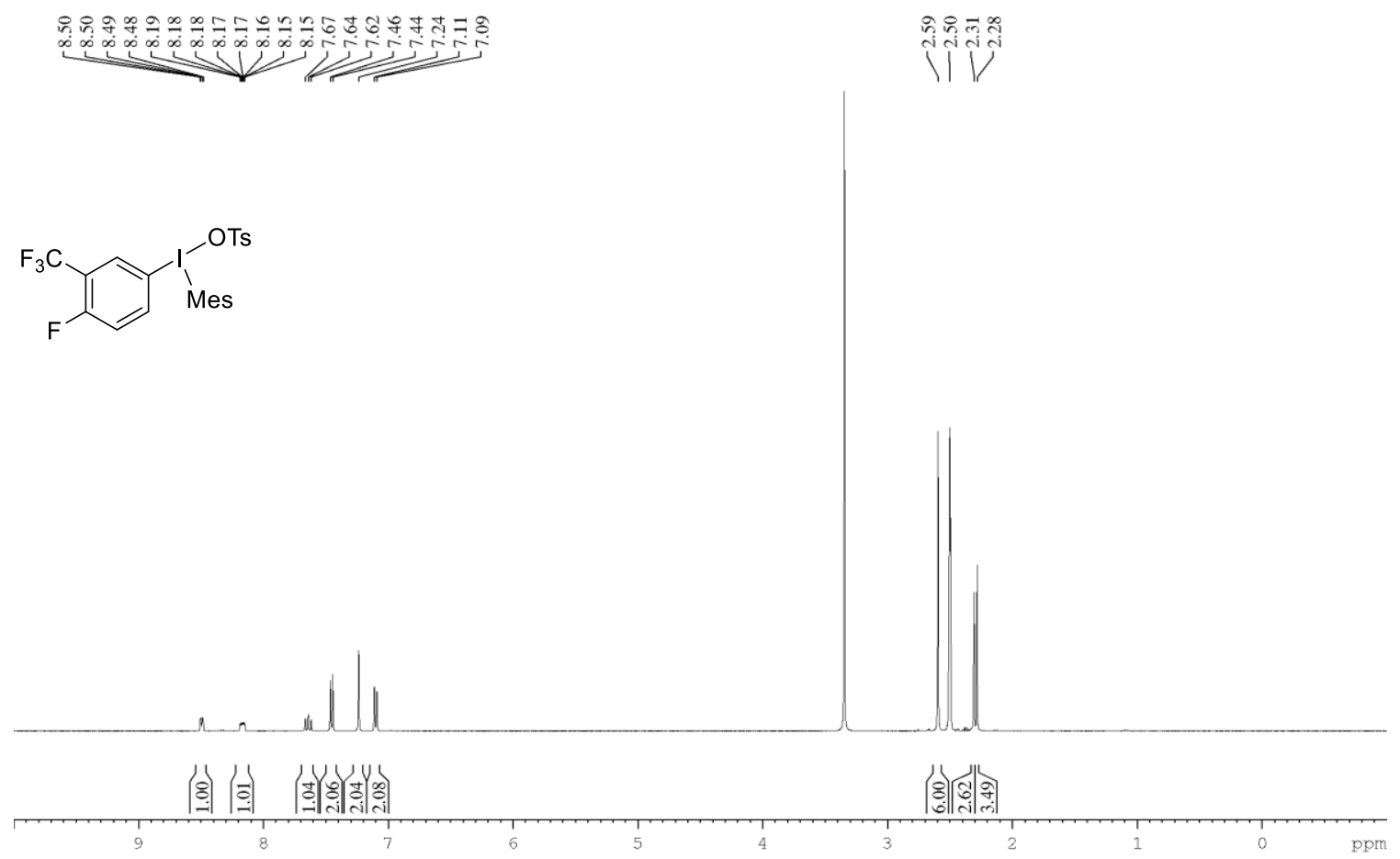

Figure $48 .{ }^{1} \mathrm{H}$ NMR of $6 \mathrm{n}$ in DMSO- $\mathrm{d}_{6}$ at $400 \mathrm{MHz}$.

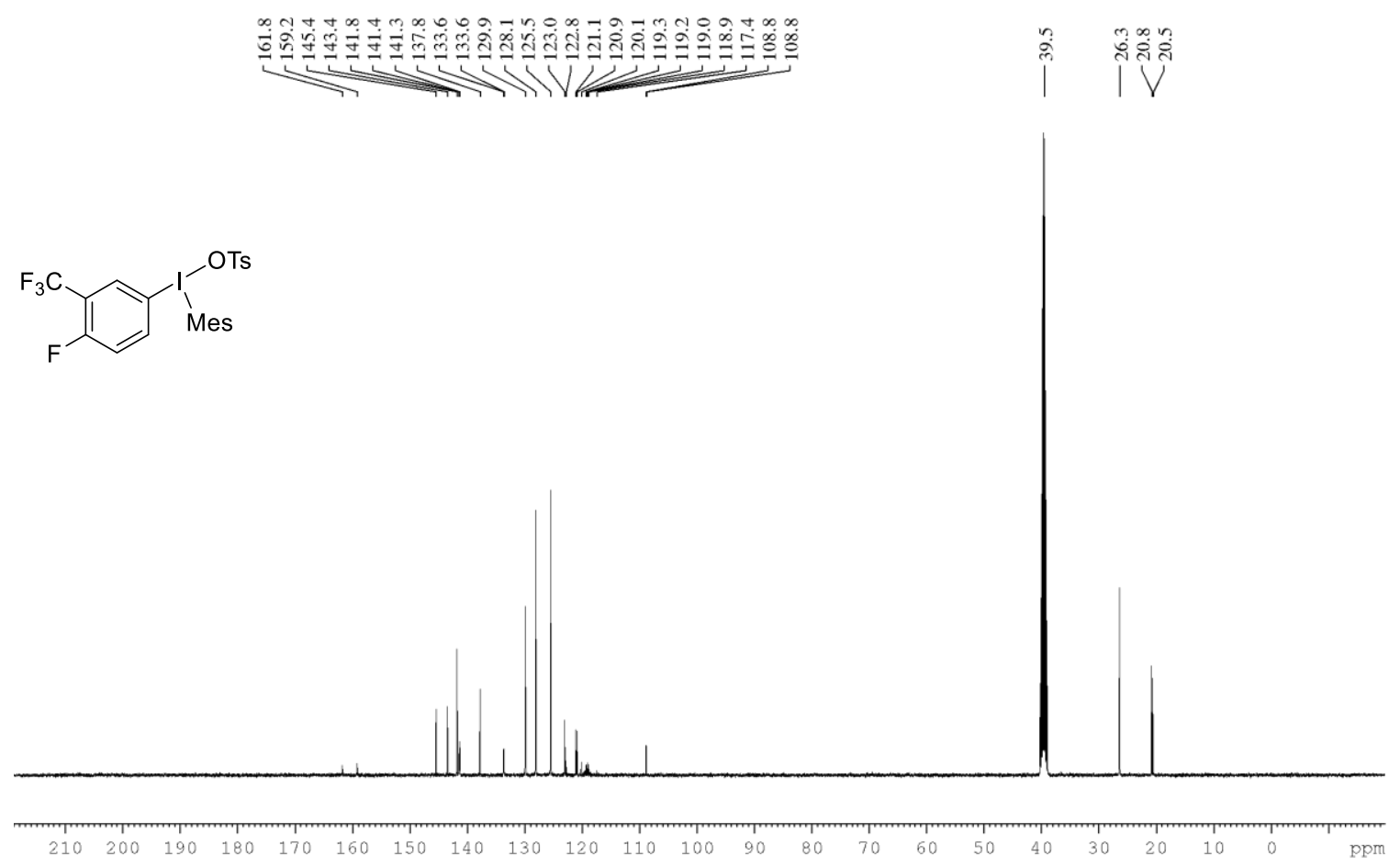

Figure 49. ${ }^{13} \mathrm{C}\left\{{ }^{1} \mathrm{H}\right\}$ NMR of $6 \mathbf{n}$ in DMSO- $\mathrm{d}_{6}$ at $101 \mathrm{MHz}$. 


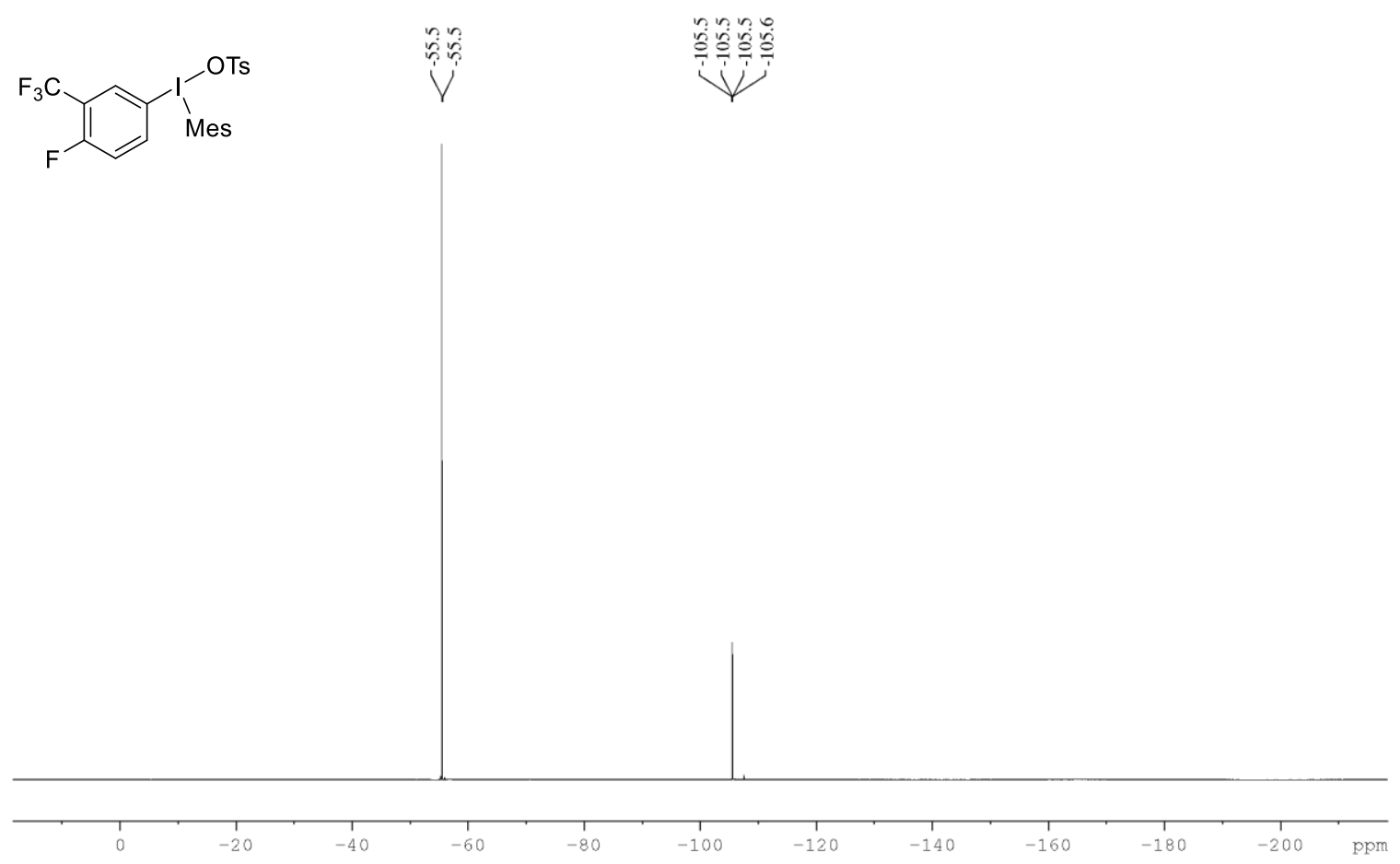

Figure $50 .{ }^{19} \mathrm{~F}\left\{{ }^{1} \mathrm{H}\right\}$ NMR of $6 \mathrm{n}$ in DMSO-d 6 at $376 \mathrm{MHz}$.

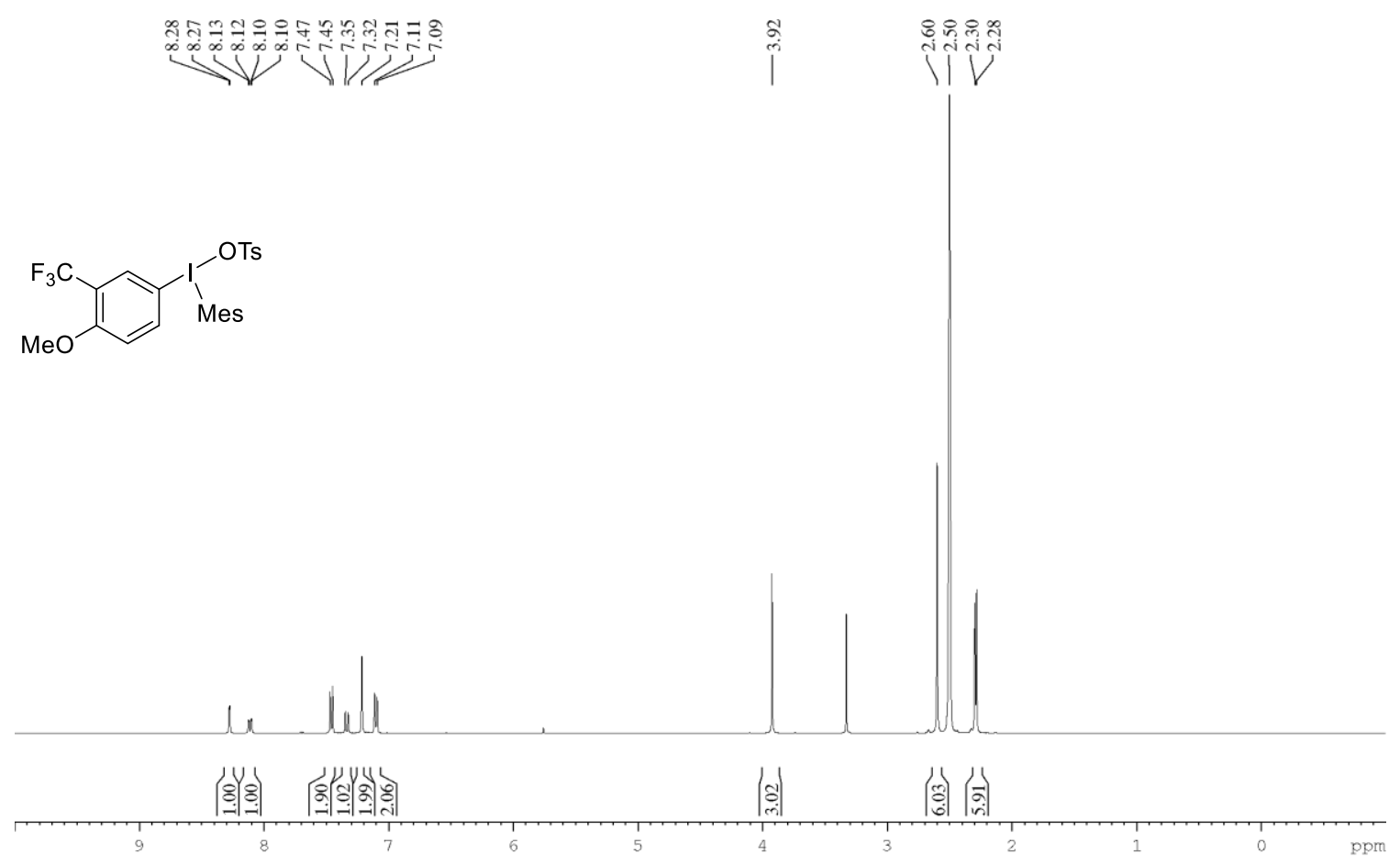

Figure $51 .{ }^{1} \mathrm{H}$ NMR of $6 \mathrm{~m}$ in DMSO-d 6 at $400 \mathrm{MHz}$. 


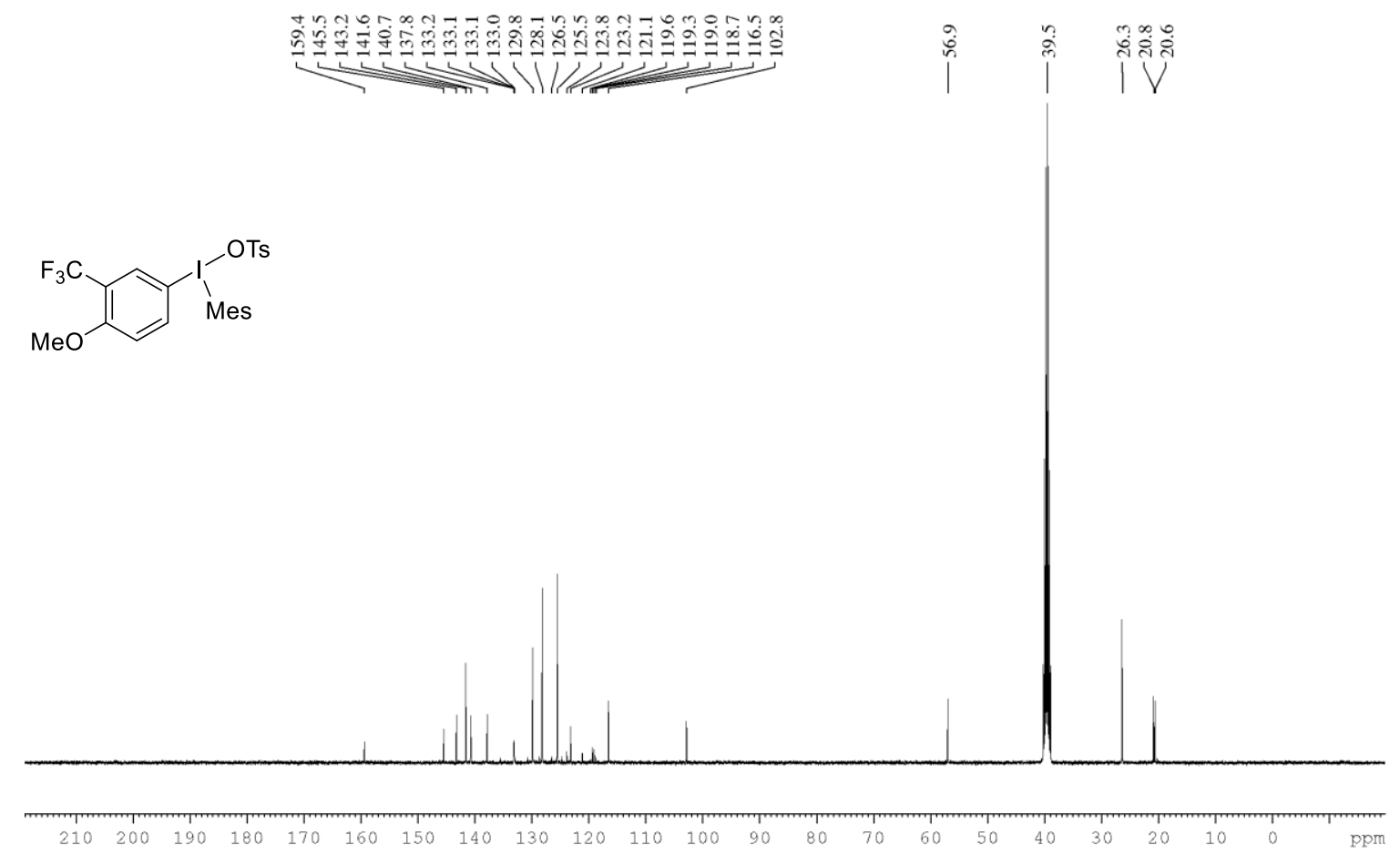

Figure $52 .{ }^{13} \mathrm{C}\left\{{ }^{1} \mathrm{H}\right\}$ NMR of $6 \mathrm{~m}$ in DMSO- $\mathrm{d}_{6}$ at $101 \mathrm{MHz}$.

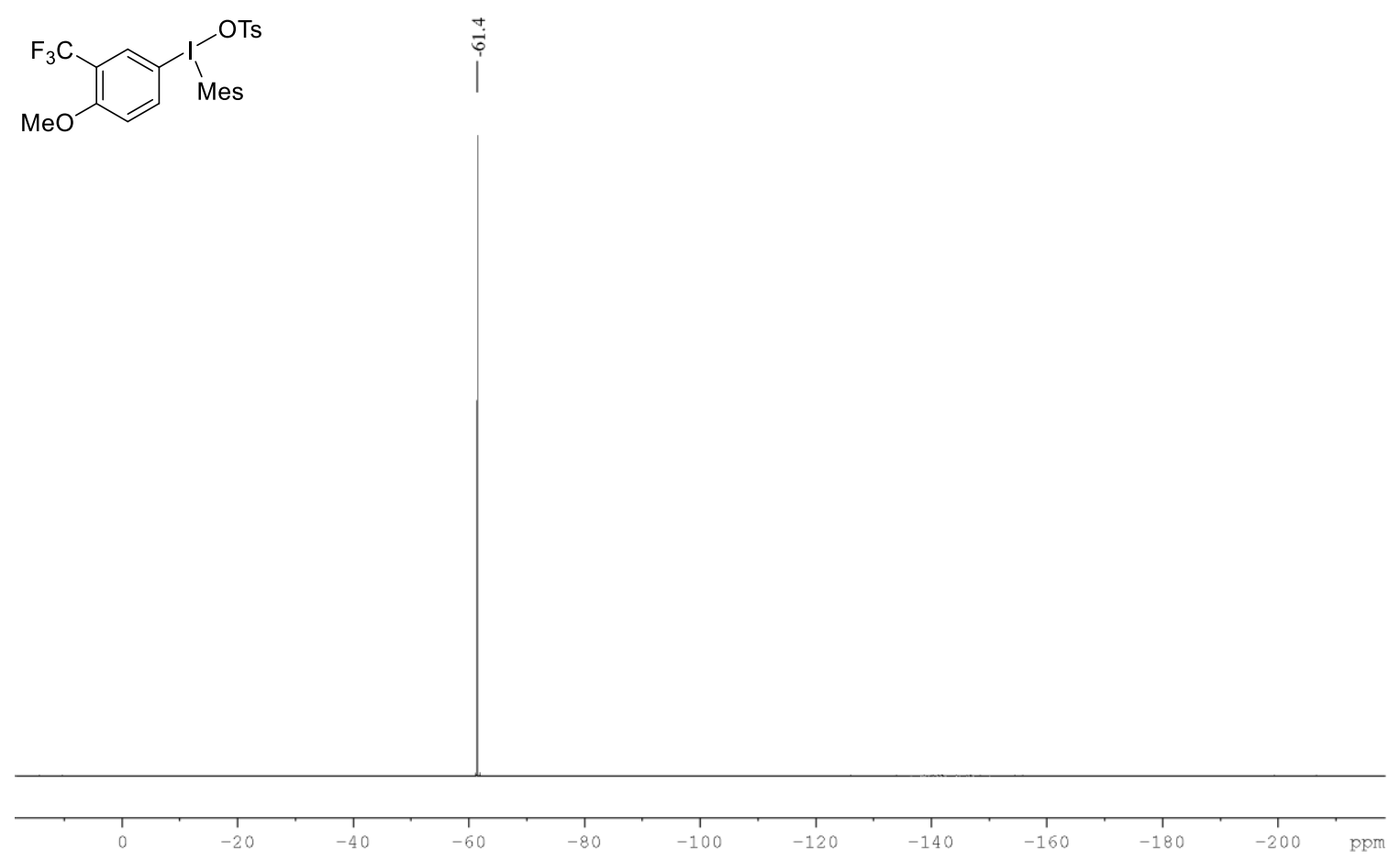

Figure 53. ${ }^{19} \mathrm{~F}\left\{{ }^{1} \mathrm{H}\right\}$ NMR of $6 \mathrm{~m}$ in DMSO- $\mathrm{d}_{6}$ at $376 \mathrm{MHz}$. 


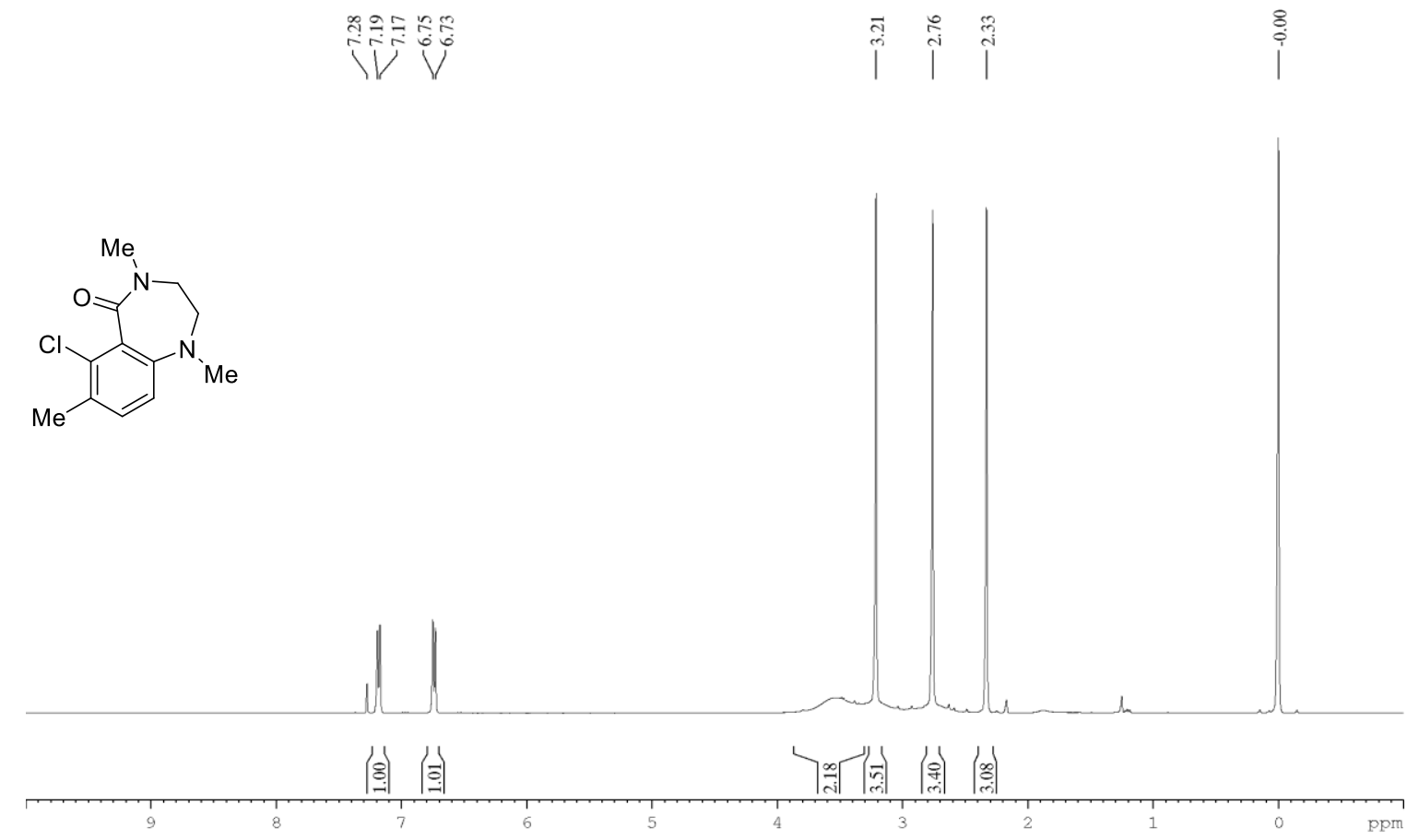

Figure $54 .{ }^{1} \mathrm{H}$ NMR of 8 aa in $\mathrm{CDCl}_{3}$ with $1 \% \mathrm{v} / \mathrm{v}$ TMS at $400 \mathrm{MHz}$.
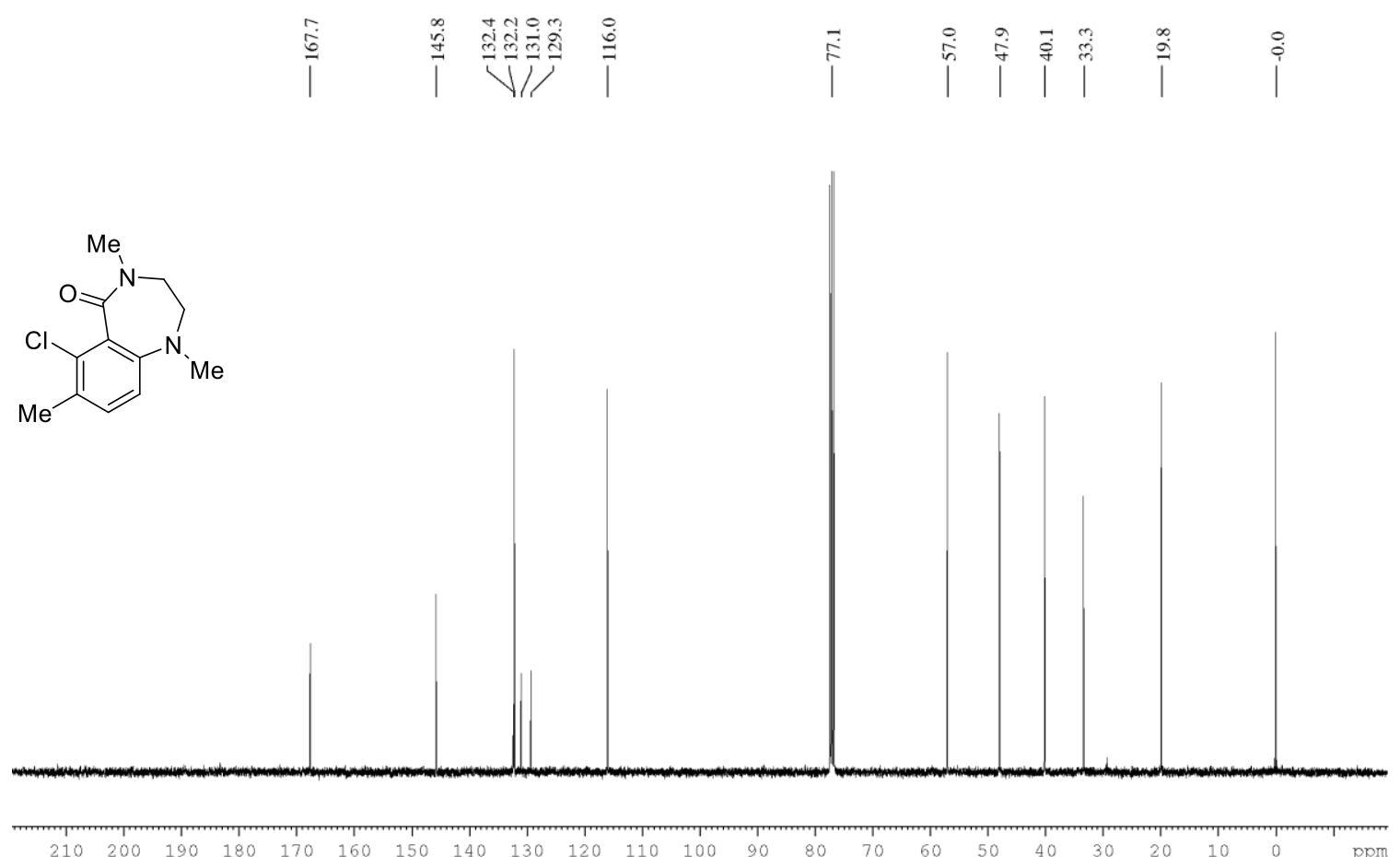

Figure $55 .{ }^{13} \mathrm{C}\left\{{ }^{1} \mathrm{H}\right\} \mathrm{NMR}$ of 8 aa $\mathrm{CDCl}_{3}$ with $1 \% \mathrm{v} / \mathrm{v}$ TMS at $101 \mathrm{MHz}$. 


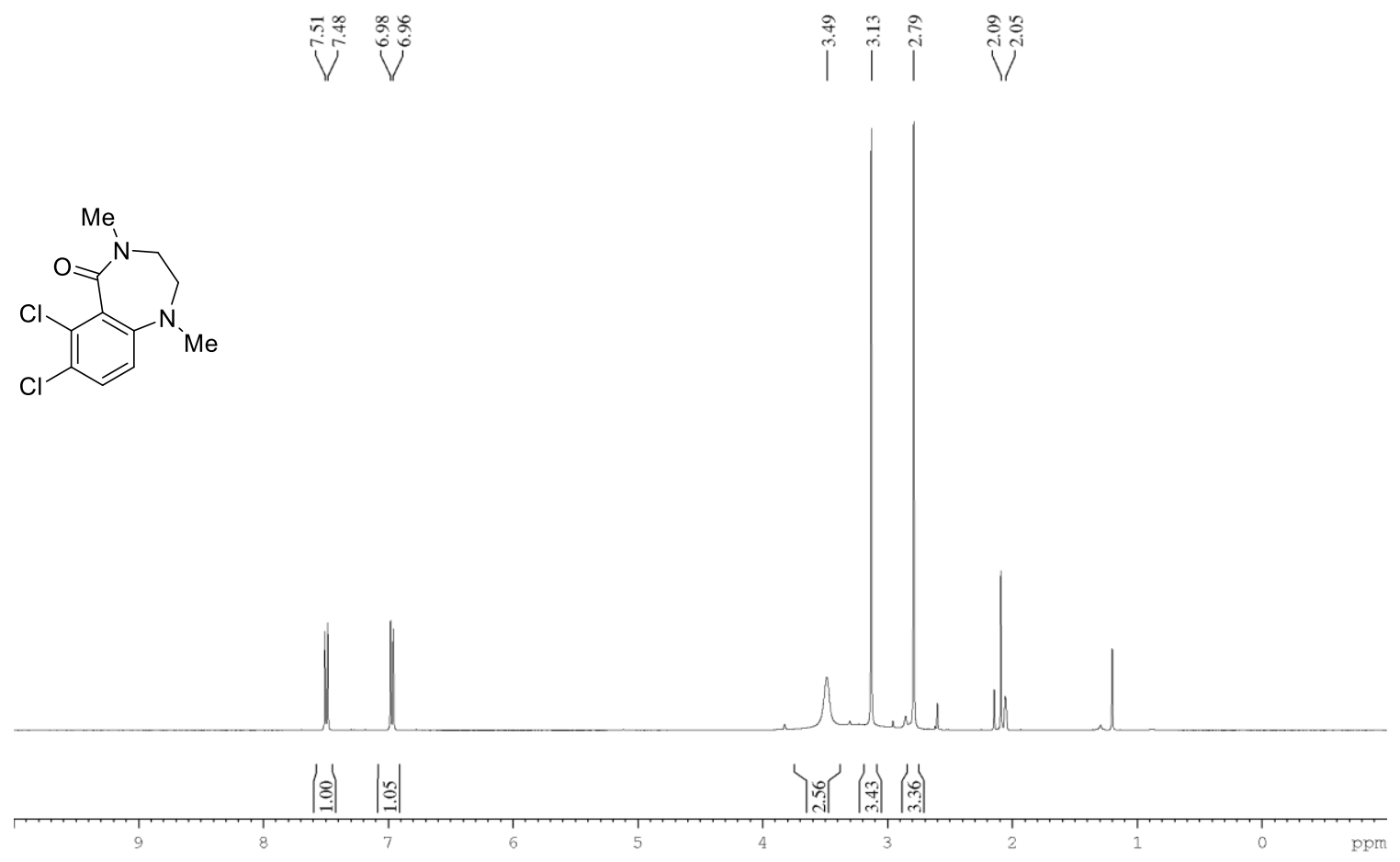

Figure 56. ${ }^{1} \mathrm{H} \mathrm{NMR}$ of 8 ba in $\left(\mathrm{CD}_{3}\right)_{2} \mathrm{CO}$ at $400 \mathrm{MHz}$.

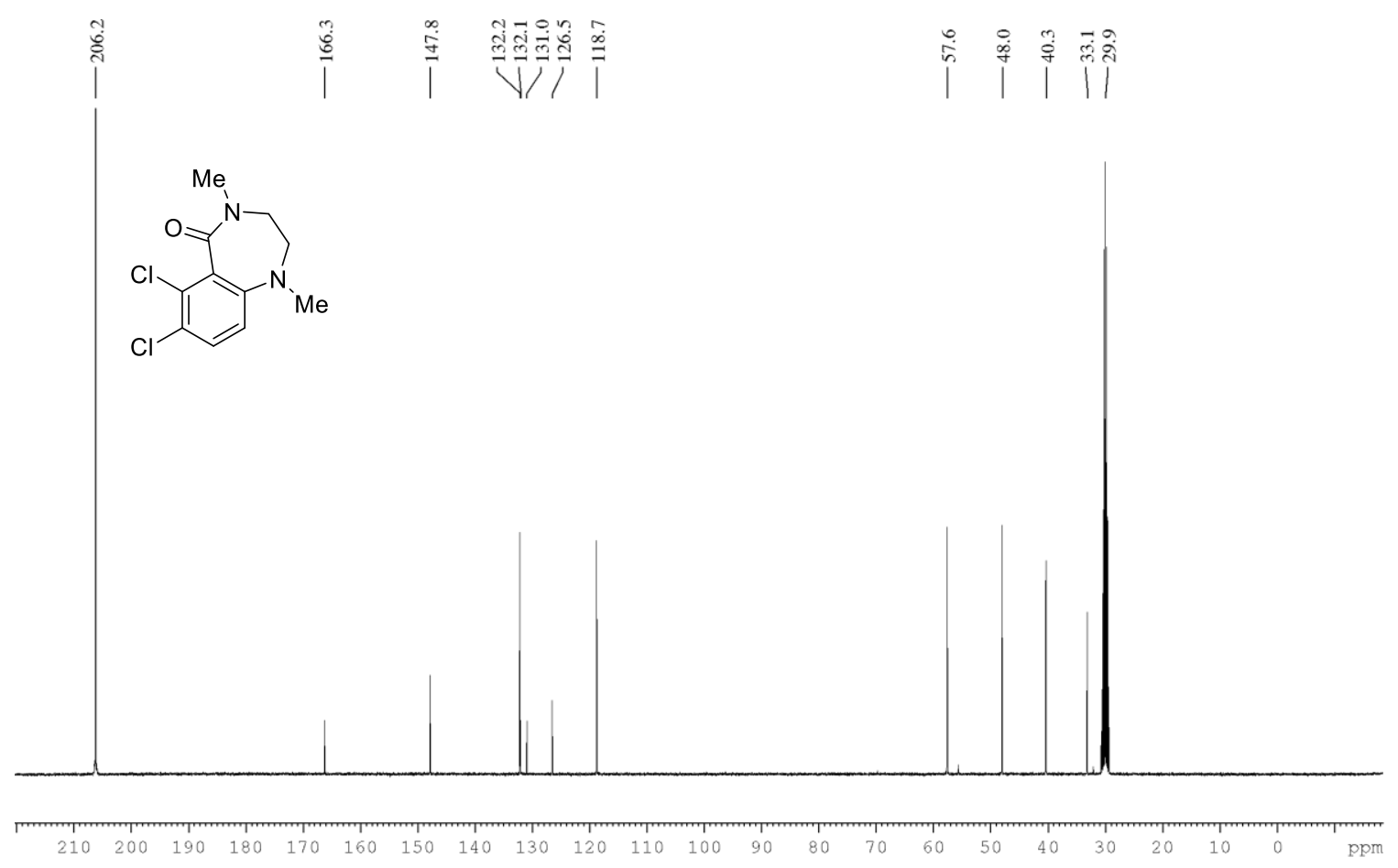

Figure 57. ${ }^{13} \mathrm{C}\left\{{ }^{1} \mathrm{H}\right\} \mathrm{NMR}$ of 8 ba $\left(\mathrm{CD}_{3}\right)_{2} \mathrm{CO}$ at $101 \mathrm{MHz}$. 


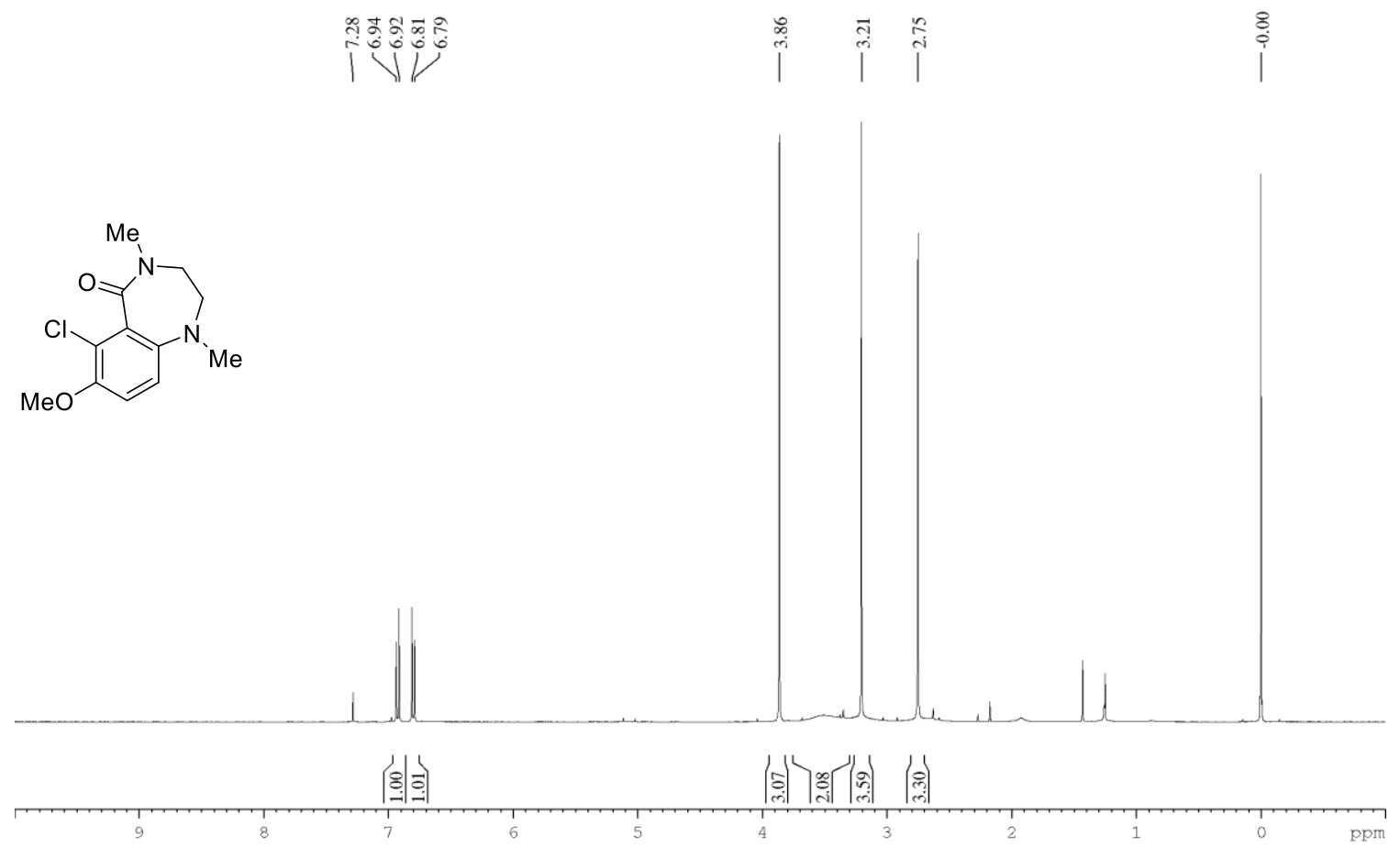

Figure $58 .{ }^{1} \mathrm{H} \mathrm{NMR}$ of $8 \mathrm{ca}$ in $\mathrm{CDCl}_{3}$ with $1 \% \mathrm{v} / \mathrm{v}$ TMS at $400 \mathrm{MHz}$.

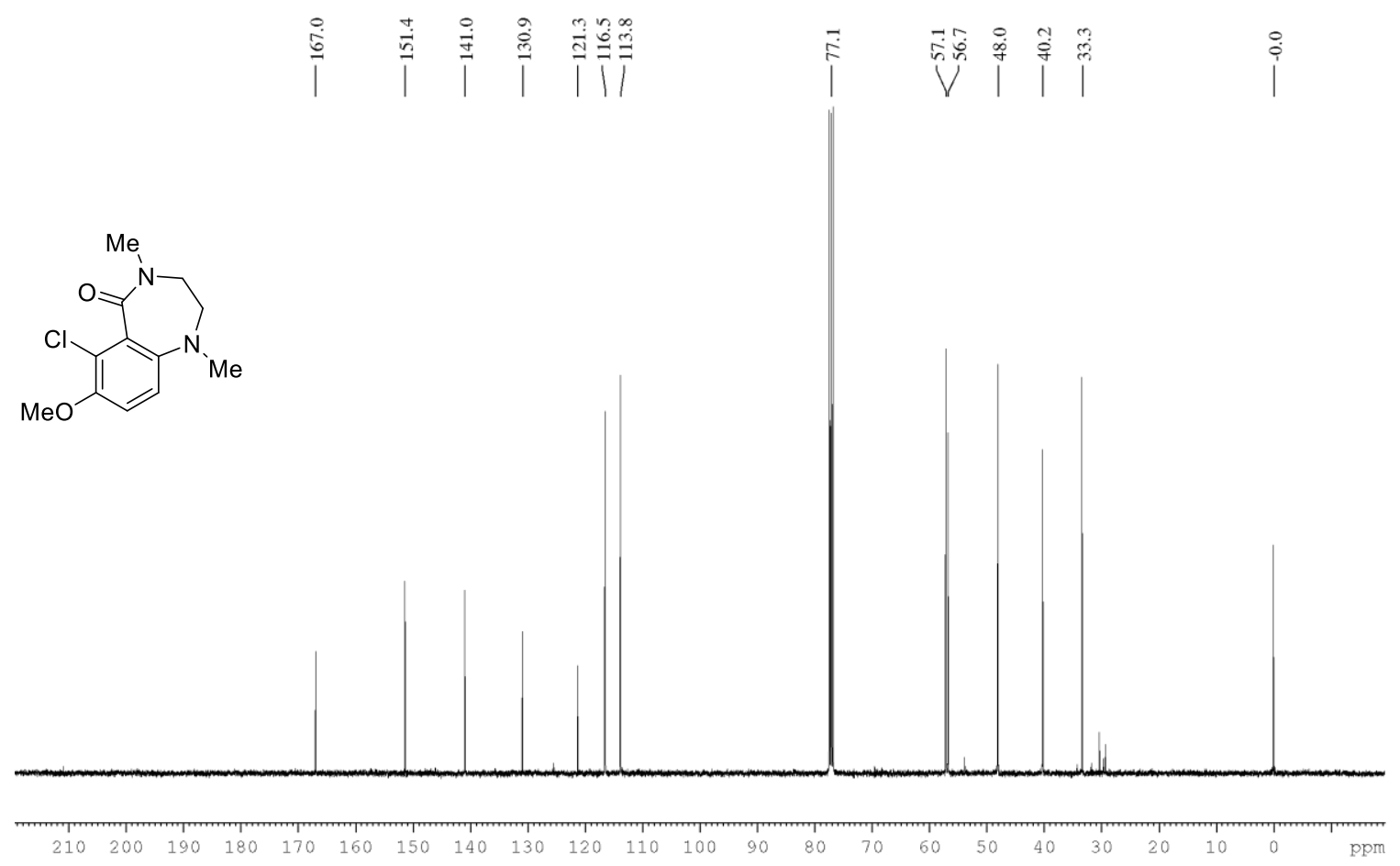

Figure 59. ${ }^{13} \mathrm{C}\left\{{ }^{1} \mathrm{H}\right\}$ NMR of $8 \mathrm{ca} \mathrm{CDCl} 3$ with $1 \% \mathrm{v} / \mathrm{v}$ TMS at $101 \mathrm{MHz}$. 


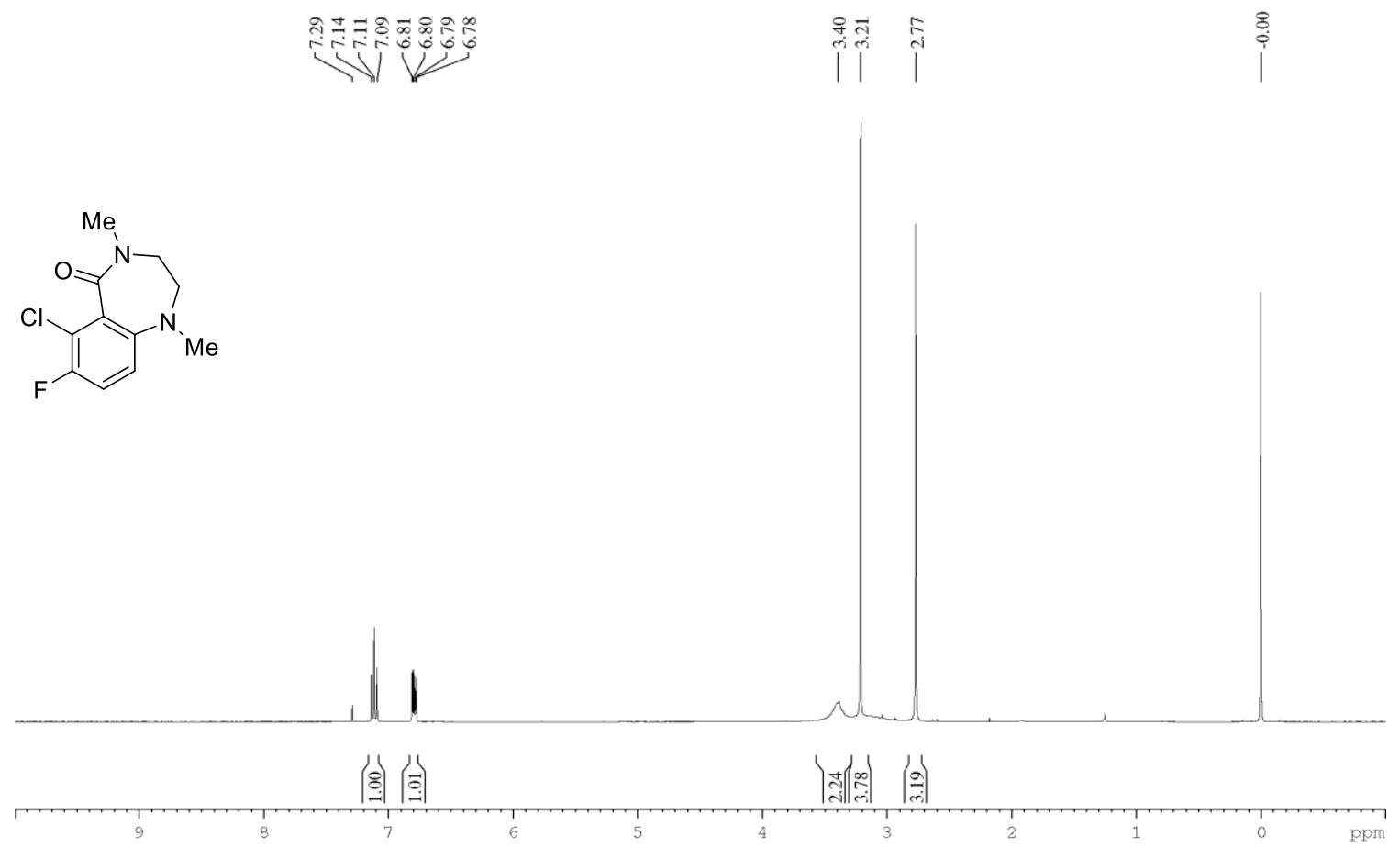

Figure $60 .{ }^{1} \mathrm{H} \mathrm{NMR}$ of $8 \mathrm{da}$ in $\mathrm{CDCl}_{3}$ with $1 \% \mathrm{v} / \mathrm{v} \mathrm{TMS}$ at $400 \mathrm{MHz}$.
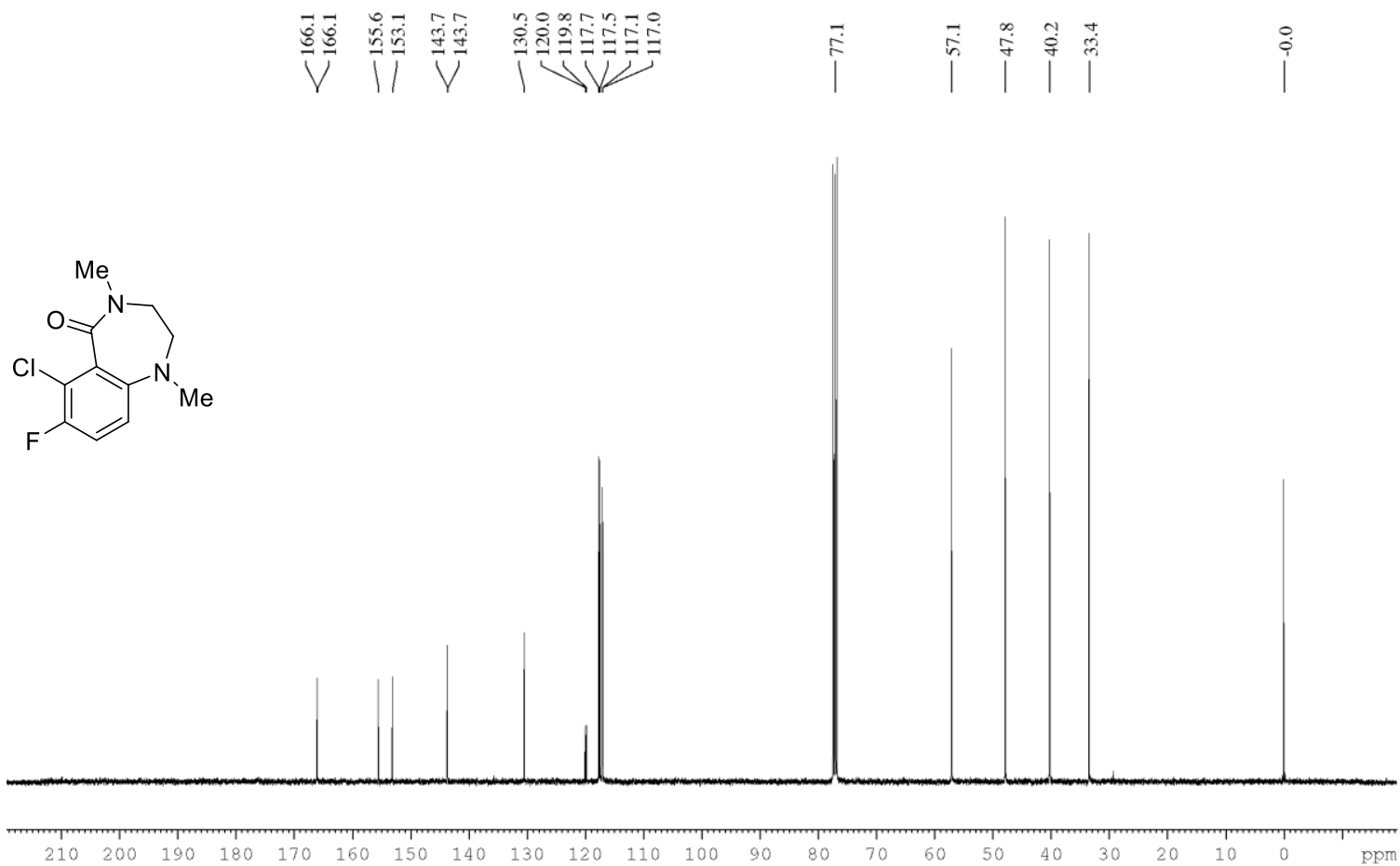

Figure $61 .{ }^{13} \mathrm{C}\left\{{ }^{1} \mathrm{H}\right\} \mathrm{NMR}$ of $8 \mathrm{da} \mathrm{CDCl}_{3}$ with $1 \% \mathrm{v} / \mathrm{v}$ TMS at $101 \mathrm{MHz}$. 


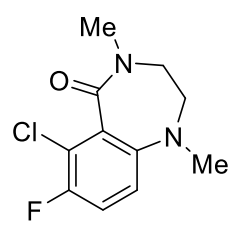

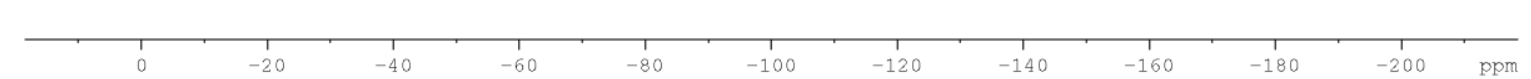

Figure $62 .{ }^{19} \mathrm{~F}\left\{{ }^{1} \mathrm{H}\right\} \mathrm{NMR}$ of $8 \mathrm{da}$ in $\mathrm{CDCl}_{3}$ with $1 \% \mathrm{v} / \mathrm{v}$ TMS at $376 \mathrm{MHz}$.

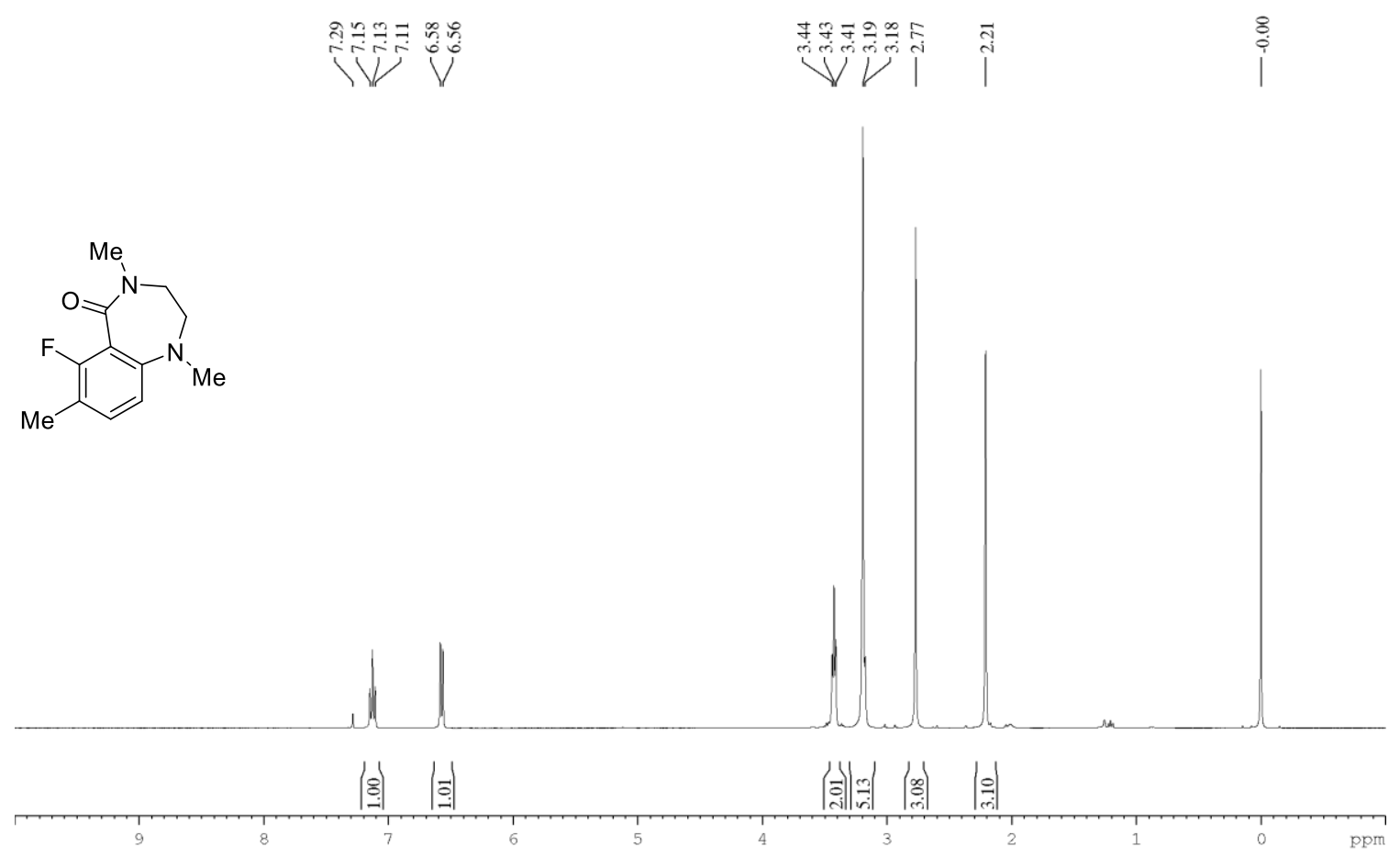

Figure 63. ${ }^{1} \mathrm{H}$ NMR of 8 ea in $\mathrm{CDCl}_{3}$ with $1 \% \mathrm{v} / \mathrm{v} \mathrm{TMS}$ at $400 \mathrm{MHz}$. 


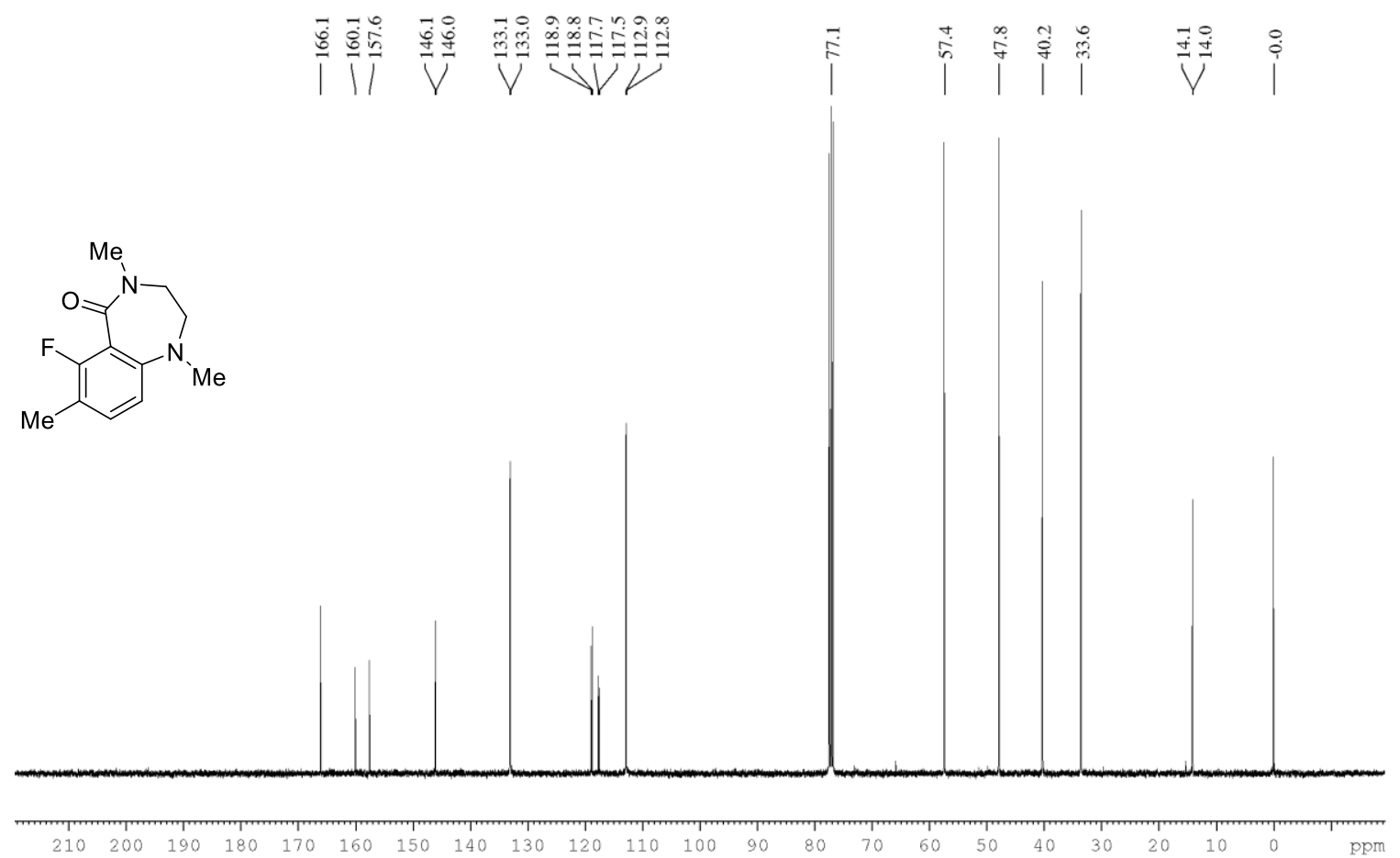

Figure $64 .{ }^{13} \mathrm{C}\left\{{ }^{1} \mathrm{H}\right\}$ NMR of 8 ea $\mathrm{CDCl}_{3}$ with $1 \% \mathrm{v} / \mathrm{v}$ TMS at $101 \mathrm{MHz}$.
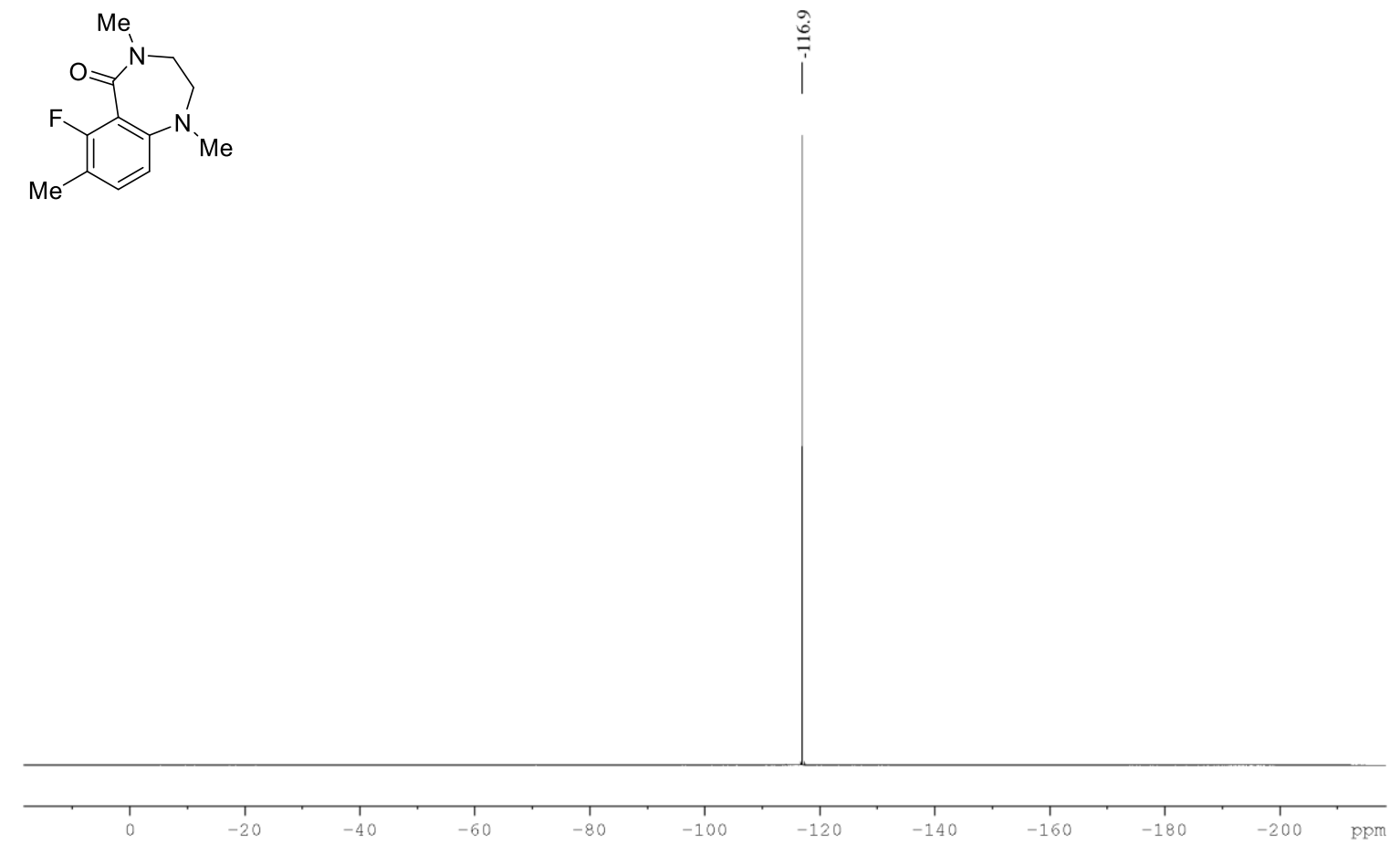

Figure $65 .{ }^{19} \mathrm{~F}\left\{{ }^{1} \mathrm{H}\right\}$ NMR of 8 ea in $\mathrm{CDCl}_{3}$ with $1 \% \mathrm{v} / \mathrm{v}$ TMS at $376 \mathrm{MHz}$. 


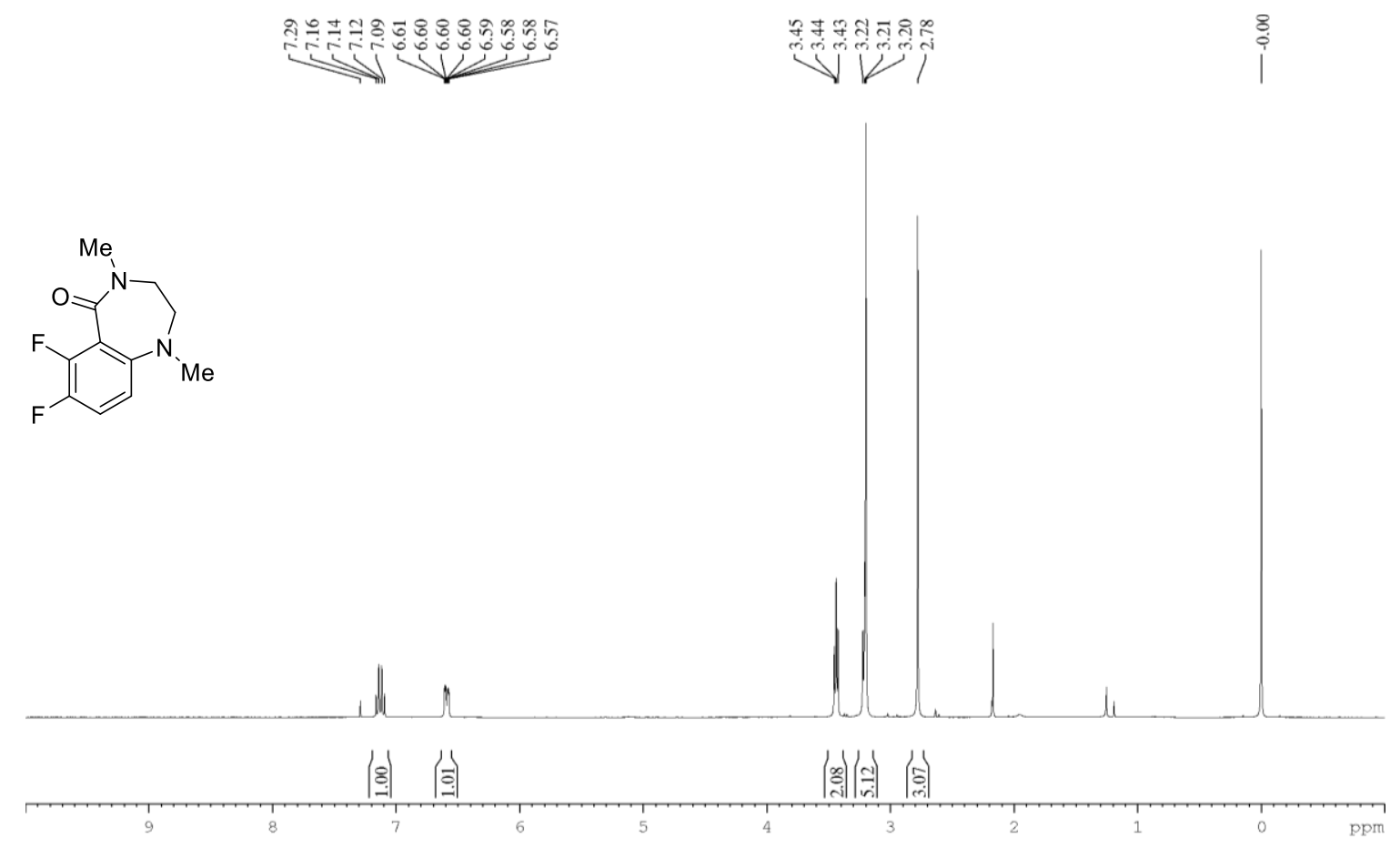

Figure $66 .{ }^{1} \mathrm{H}$ NMR of $8 \mathrm{fa}$ in $\mathrm{CDCl}_{3}$ with $1 \% \mathrm{v} / \mathrm{v}$ TMS at $400 \mathrm{MHz}$.
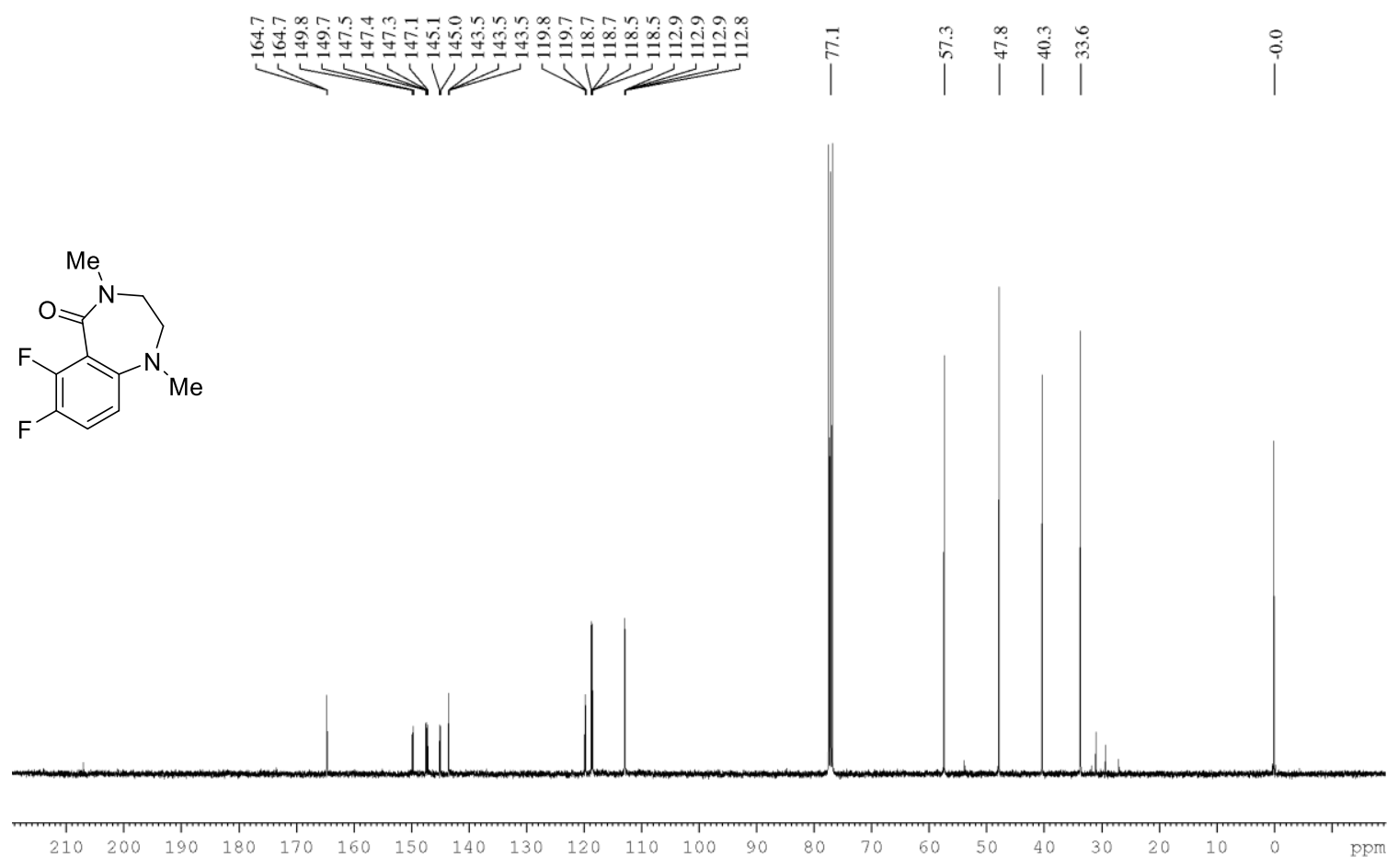

Figure $67 .{ }^{13} \mathrm{C}\left\{{ }^{1} \mathrm{H}\right\}$ NMR of $8 f a \mathrm{CDCl}_{3}$ with $1 \% \mathrm{v} / \mathrm{v}$ TMS at $101 \mathrm{MHz}$. 

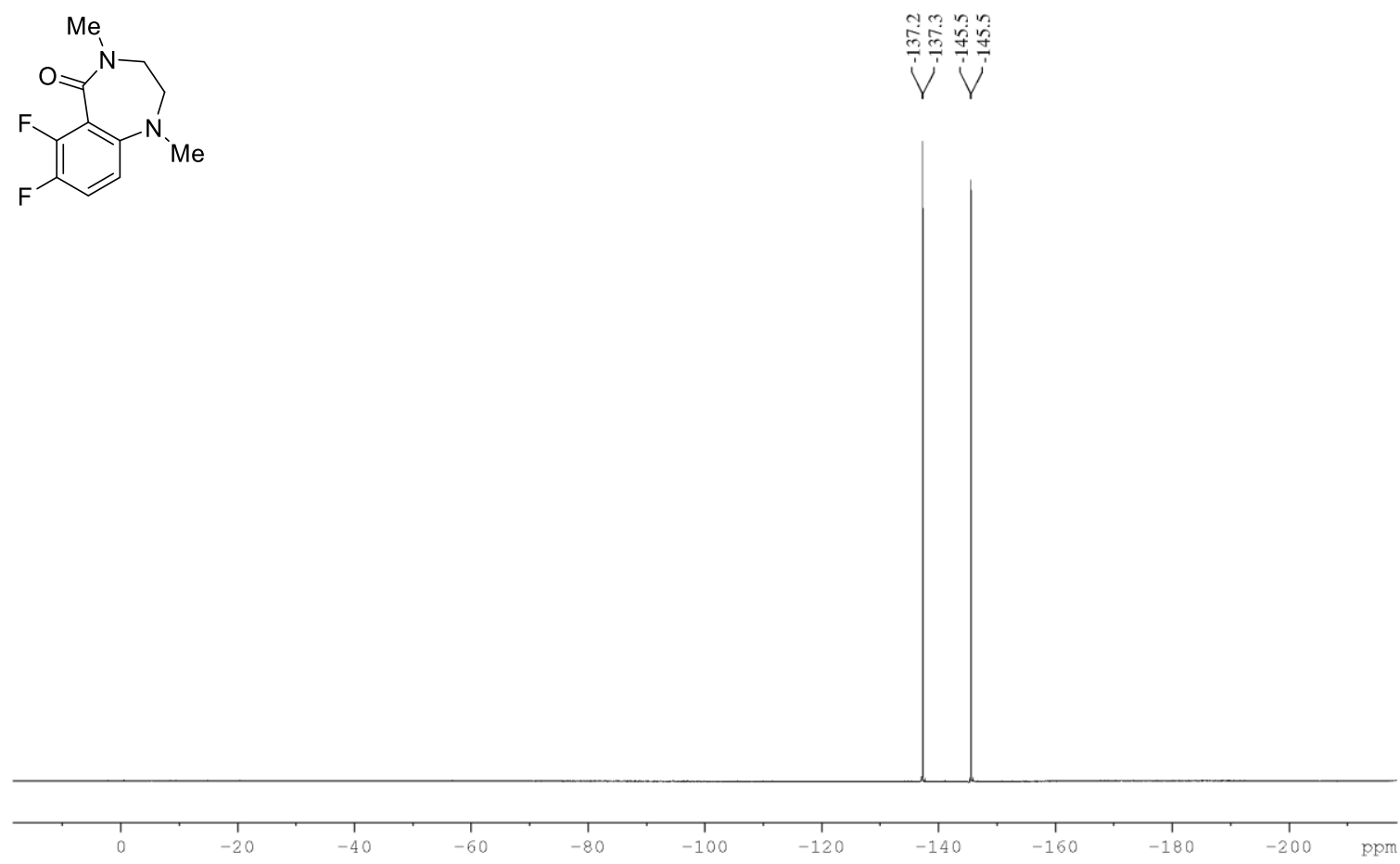

Figure $68 .{ }^{19} \mathrm{~F}\left\{{ }^{1} \mathrm{H}\right\} \mathrm{NMR}$ of $8 \mathrm{fa}$ in $\mathrm{CDCl}_{3}$ with $1 \% \mathrm{v} / \mathrm{v}$ TMS at $376 \mathrm{MHz}$.

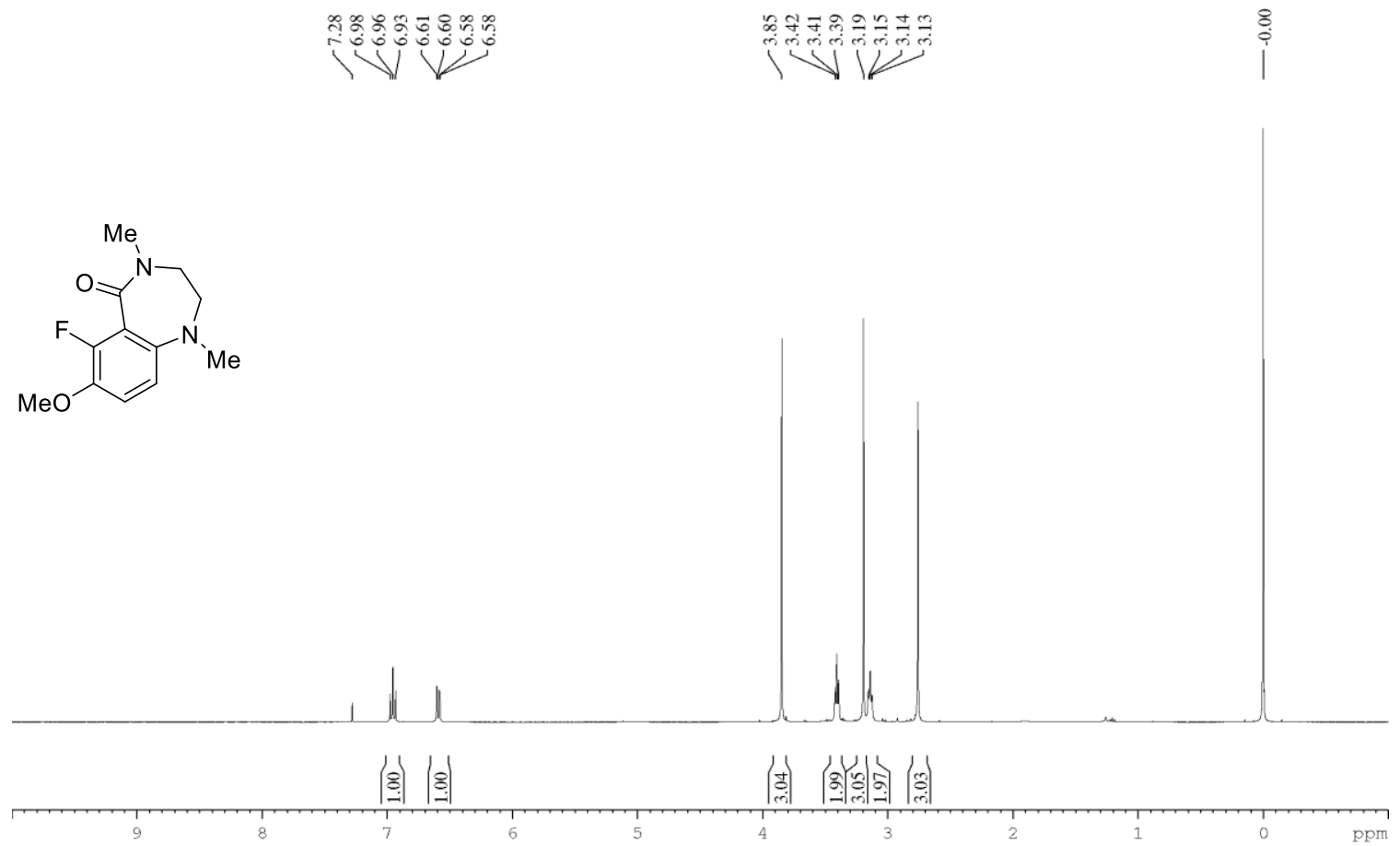

Figure 69. ${ }^{1} \mathrm{H}$ NMR of $8 g a$ in $\mathrm{CDCl}_{3}$ with $1 \% \mathrm{v} / \mathrm{v}$ TMS at $400 \mathrm{MHz}$. 


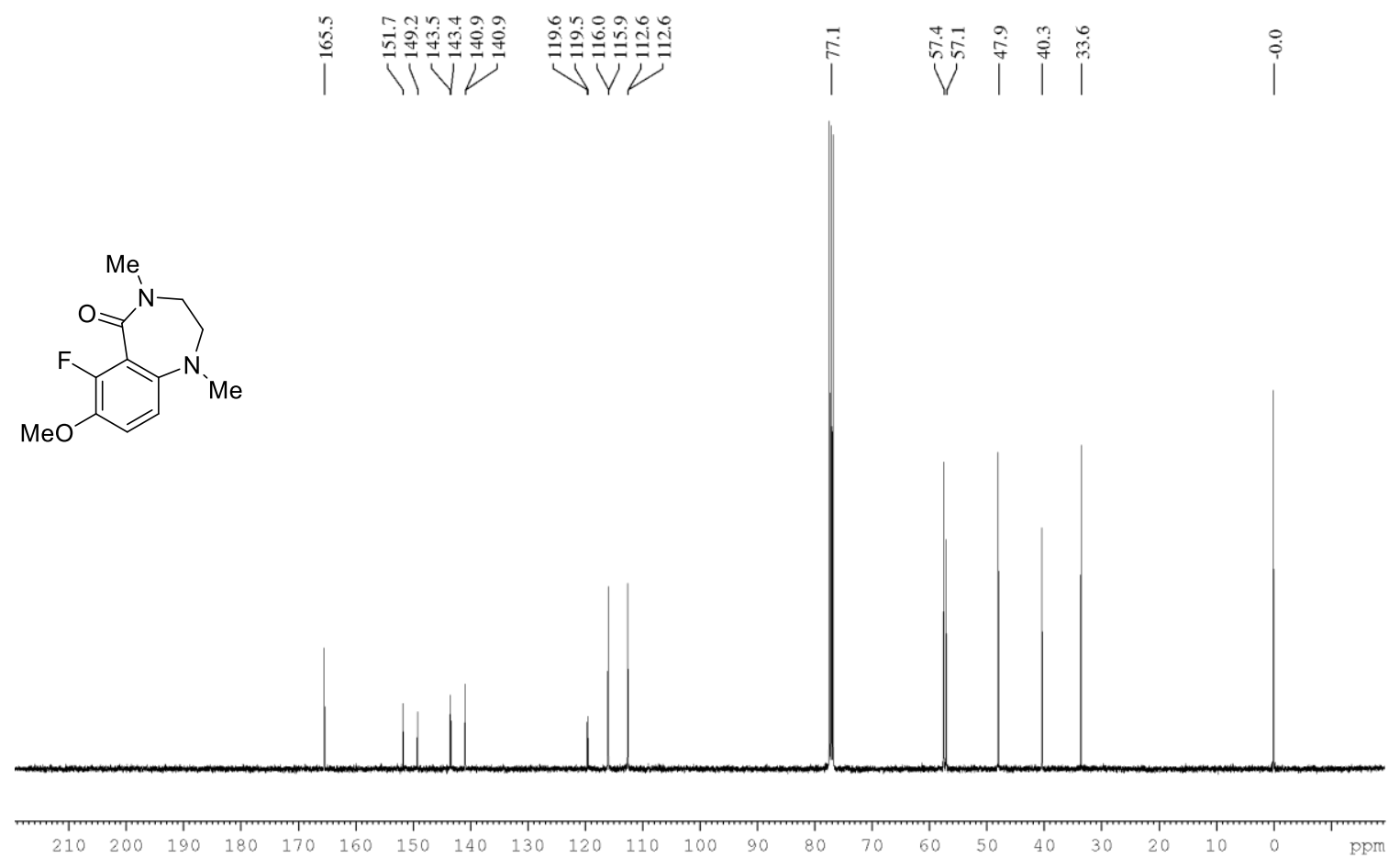

Figure $70 .{ }^{13} \mathrm{C}\left\{{ }^{1} \mathrm{H}\right\}$ NMR of 8 ga CDCl 3 with $1 \% \mathrm{v} / \mathrm{v}$ TMS at $101 \mathrm{MHz}$.

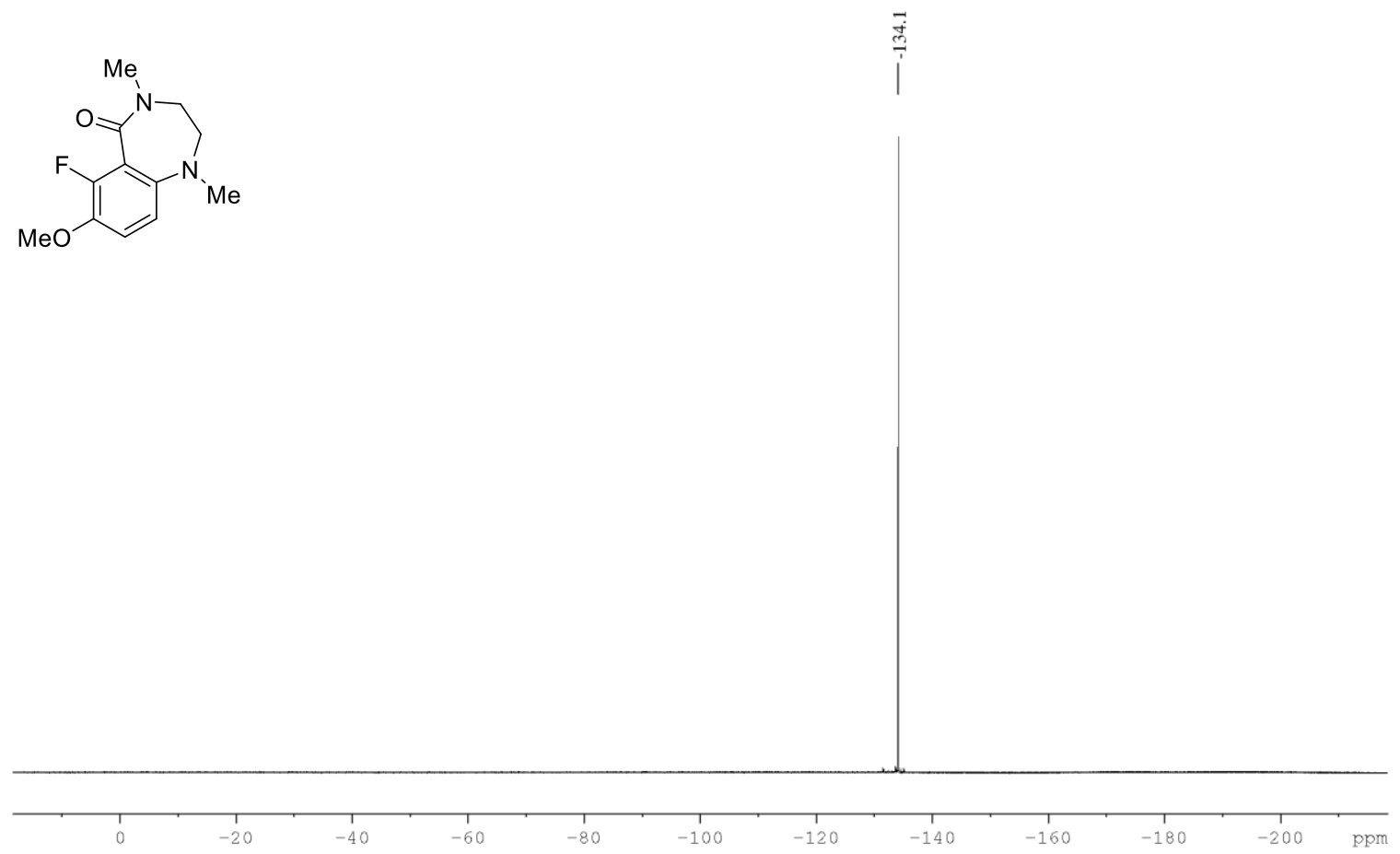

Figure $71 .{ }^{19} \mathrm{~F}\left\{{ }^{1} \mathrm{H}\right\} \mathrm{NMR}$ of $8 \mathrm{ga}$ in $\mathrm{CDCl}_{3}$ with $1 \% \mathrm{v} / \mathrm{v}$ TMS at $376 \mathrm{MHz}$. 


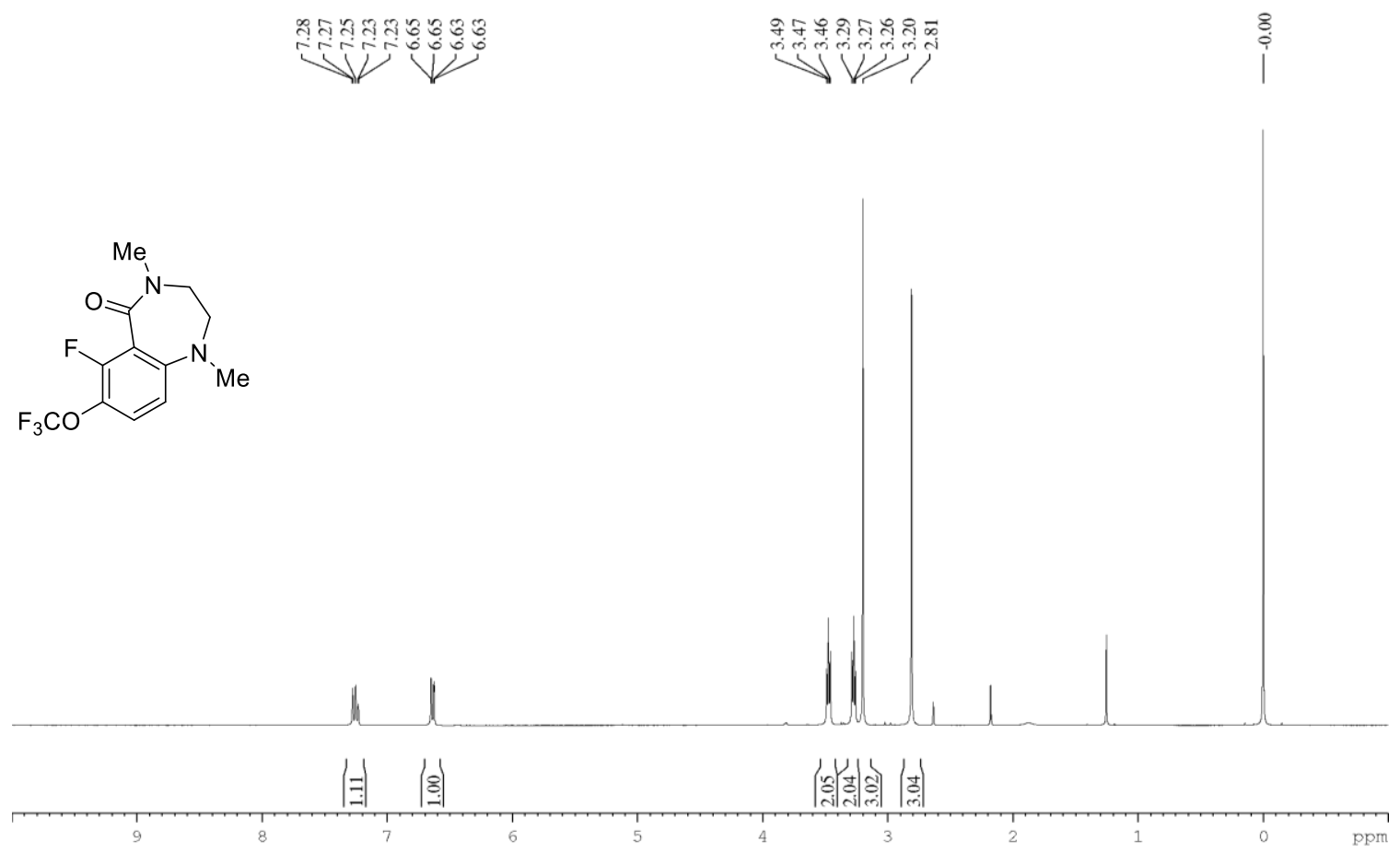

Figure $72 .{ }^{1} \mathrm{H} \mathrm{NMR}$ of 8 ha in $\mathrm{CDCl}_{3}$ with $1 \% \mathrm{v} / \mathrm{v}$ TMS at $400 \mathrm{MHz}$.

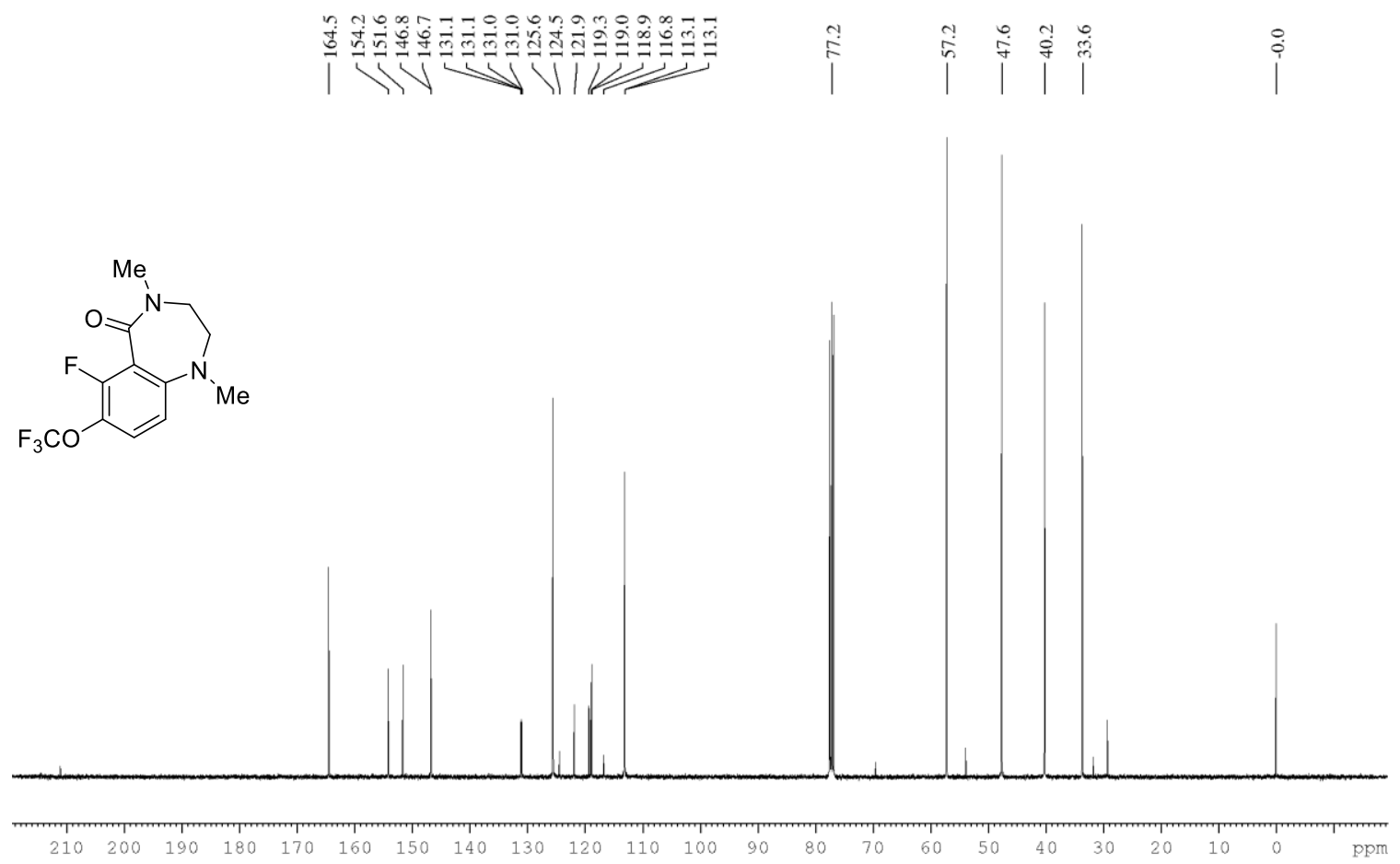

Figure $73 .{ }^{13} \mathrm{C}\left\{{ }^{1} \mathrm{H}\right\} \mathrm{NMR}$ of 8 ha $\mathrm{CDCl}_{3}$ with $1 \% \mathrm{v} / \mathrm{v}$ TMS at $101 \mathrm{MHz}$. 


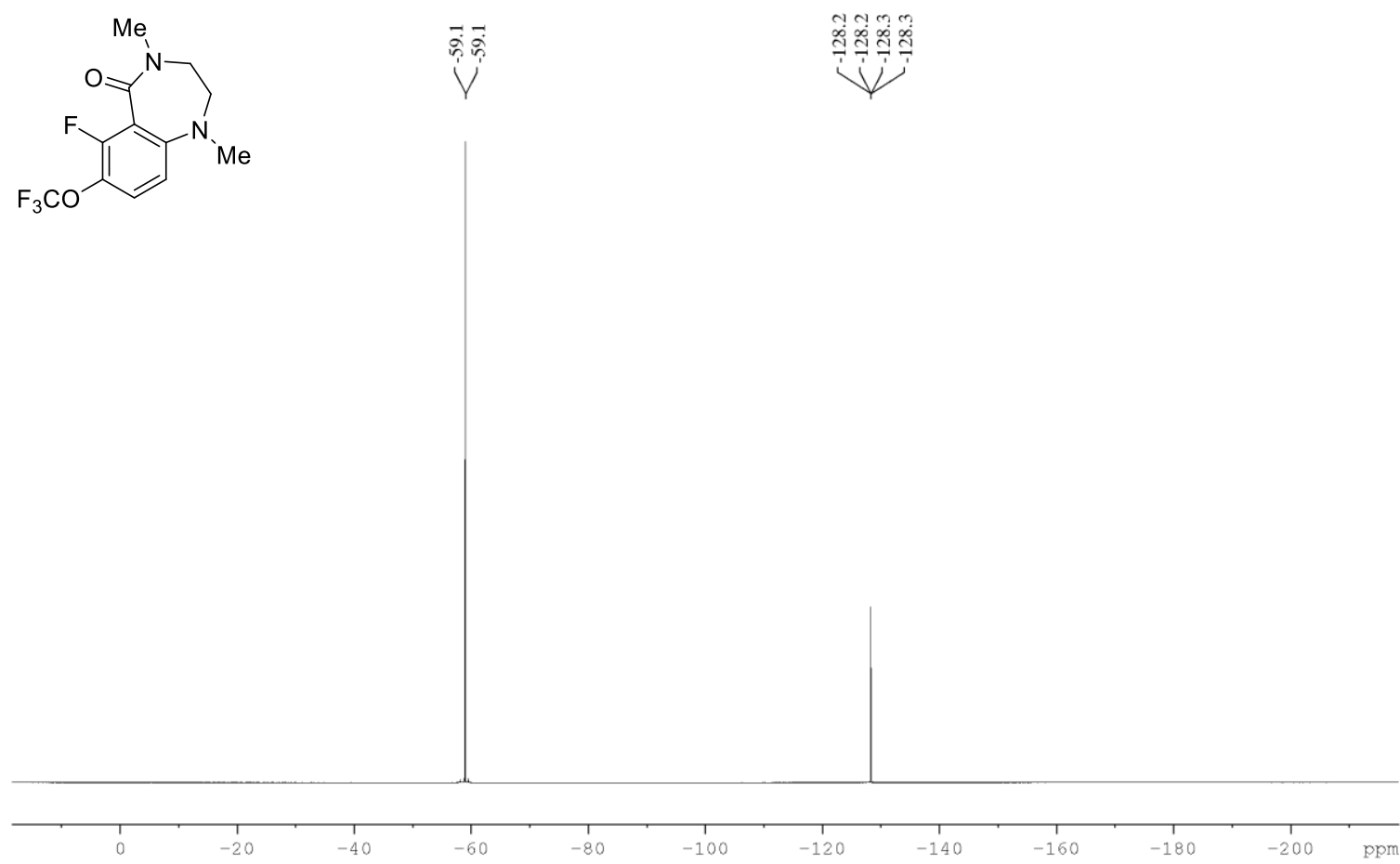

Figure $74 .{ }^{19} \mathrm{~F}\left\{{ }^{1} \mathrm{H}\right\} \mathrm{NMR}$ of 8 ha in $\mathrm{CDCl}_{3}$ with $1 \% \mathrm{v} / \mathrm{v}$ TMS at $376 \mathrm{MHz}$.

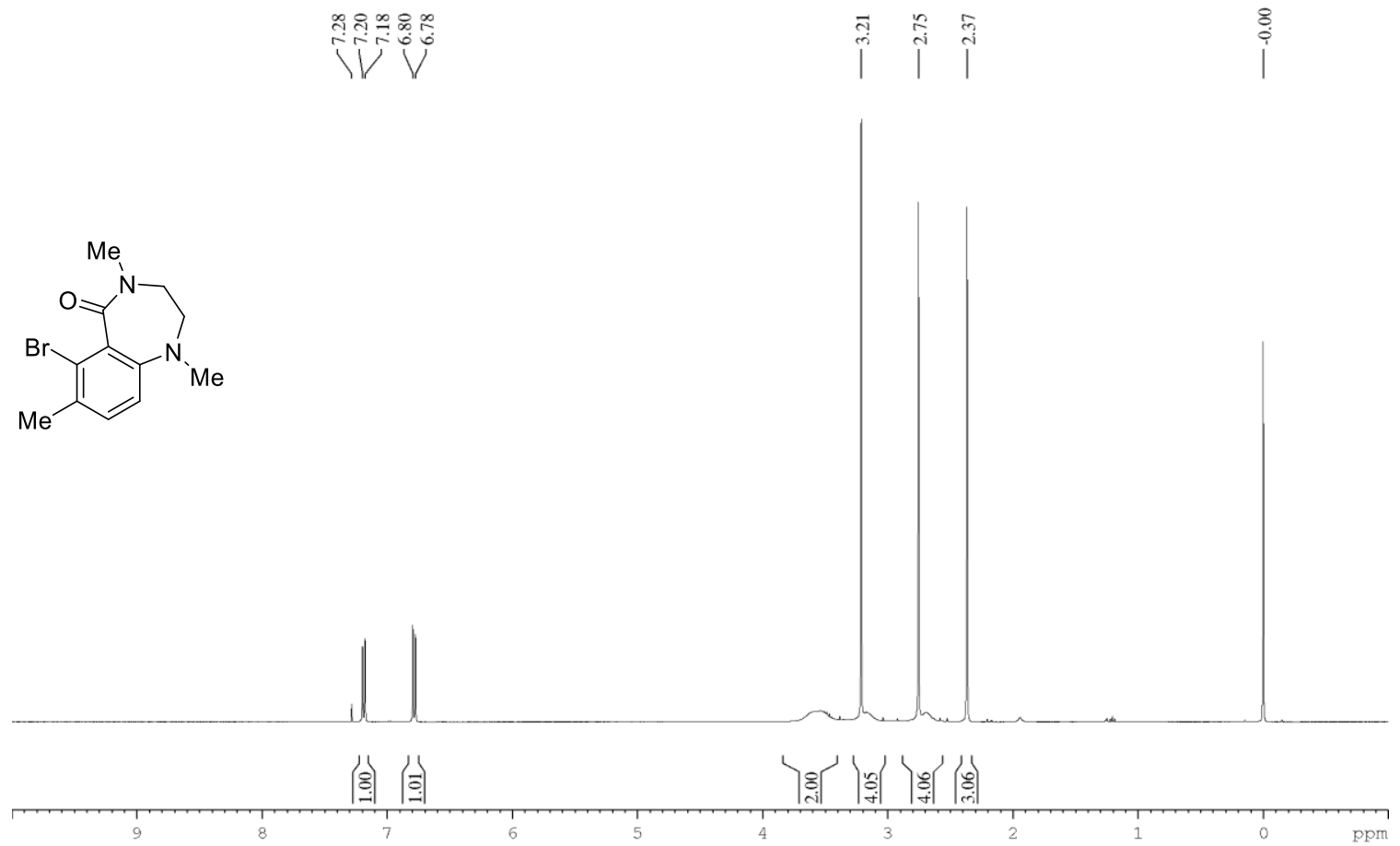

Figure $75 .{ }^{1} \mathrm{H} \mathrm{NMR}$ of 8 ia in $\mathrm{CDCl}_{3}$ with $1 \% \mathrm{v} / \mathrm{v}$ TMS at $400 \mathrm{MHz}$. 


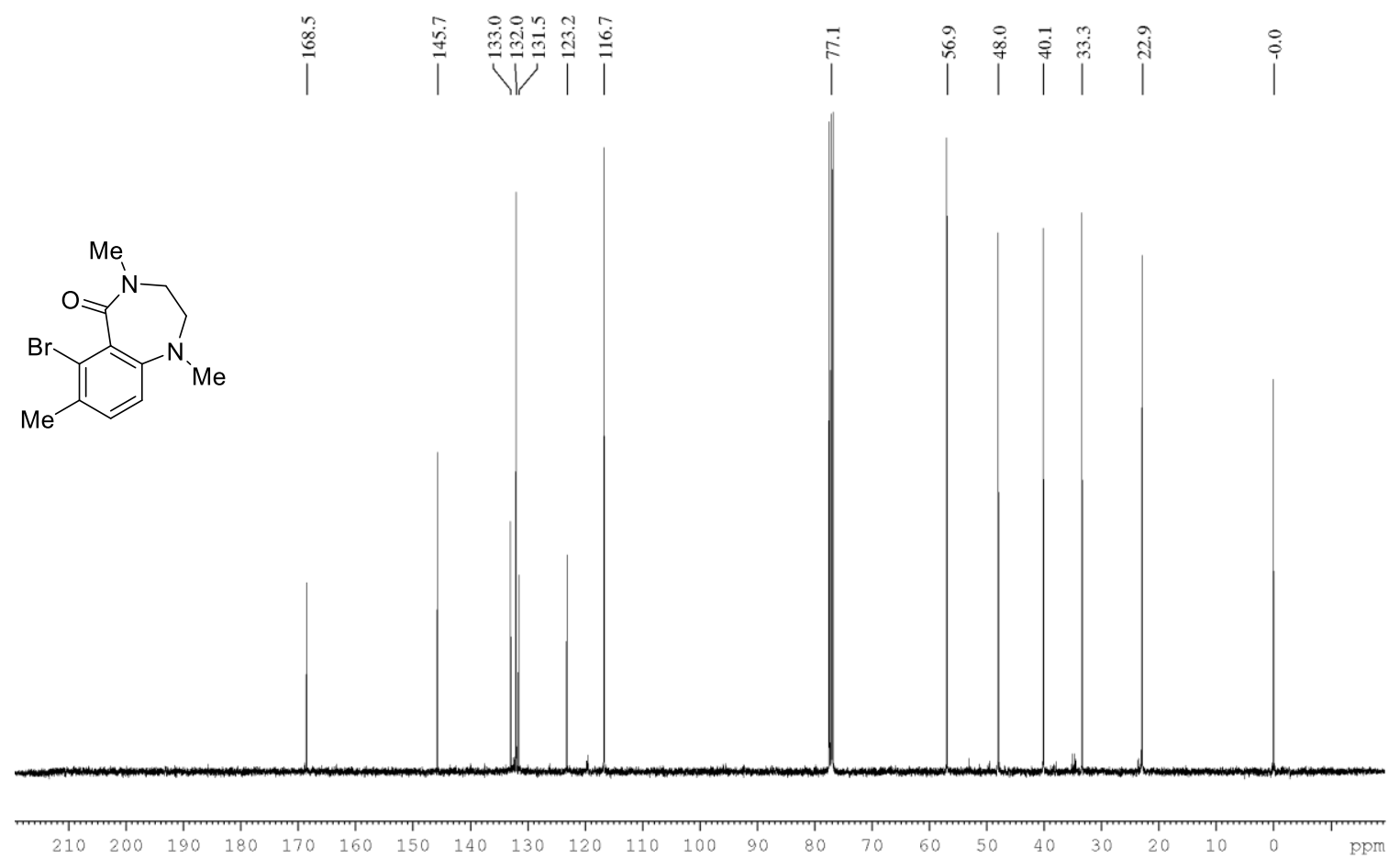

Figure 76. ${ }^{13} \mathrm{C}\left\{{ }^{1} \mathrm{H}\right\}$ NMR of 8 ia $\mathrm{CDCl}_{3}$ with $1 \% \mathrm{v} / \mathrm{v}$ TMS at $101 \mathrm{MHz}$.

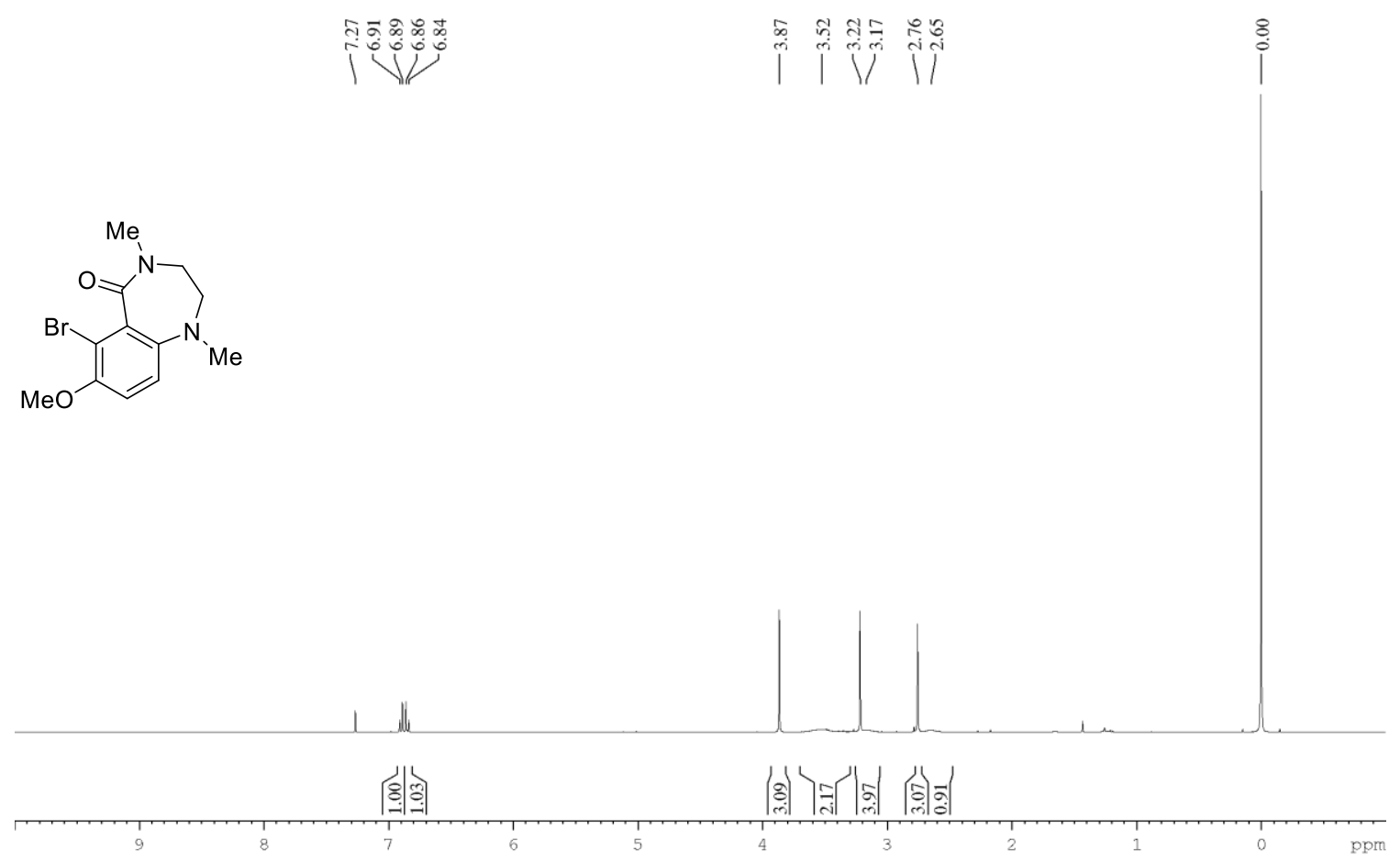

Figure $77 .{ }^{1} \mathrm{H} \mathrm{NMR}$ of $8 \mathrm{ja}$ in $\mathrm{CDCl}_{3}$ with $1 \% \mathrm{v} / \mathrm{v}$ TMS at $400 \mathrm{MHz}$. 


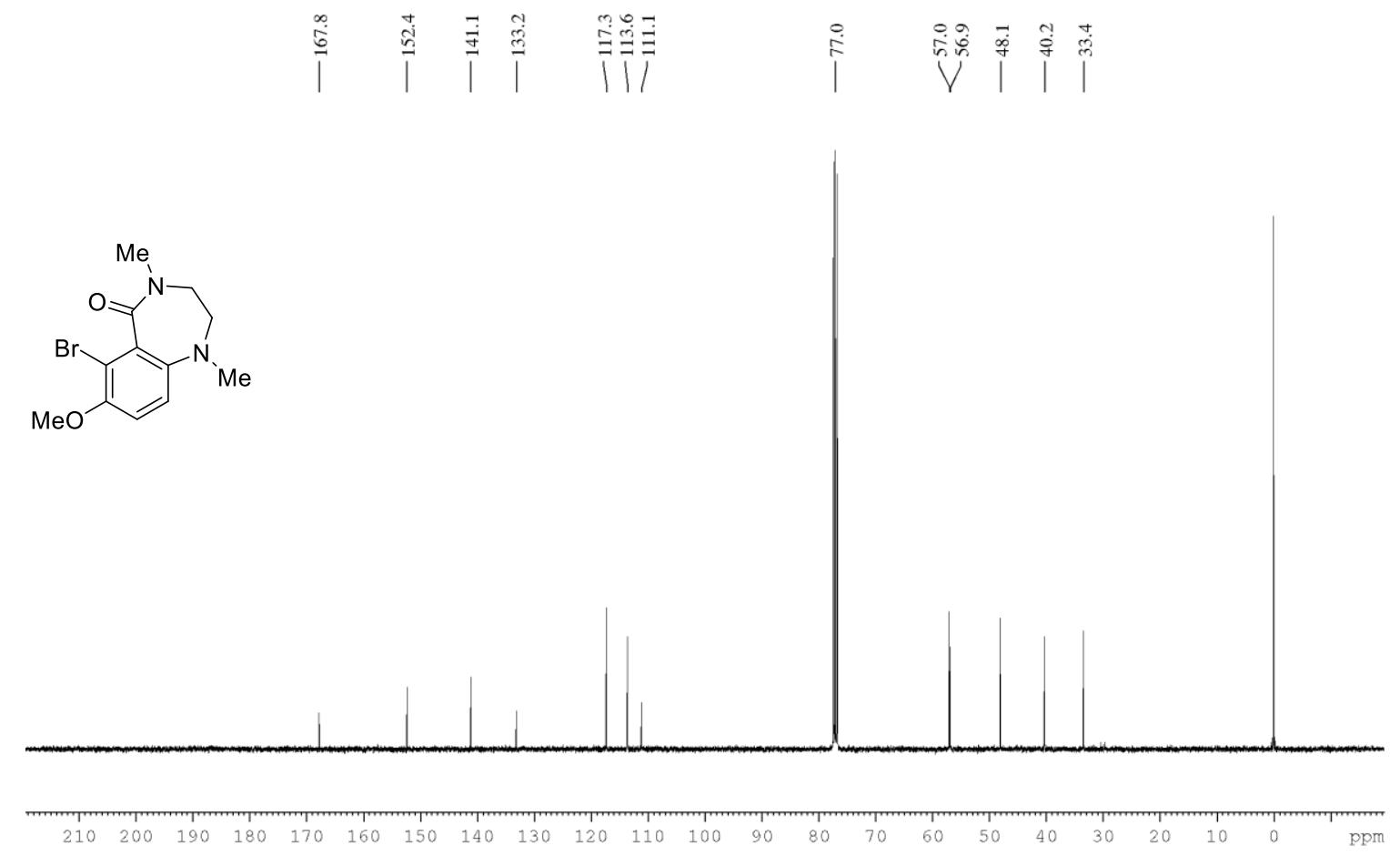

Figure $78 .{ }^{13} \mathrm{C}\left\{{ }^{1} \mathrm{H}\right\}$ NMR of $8 \mathrm{ja} \mathrm{CDCl} 3$ with $1 \% \mathrm{v} / \mathrm{v}$ TMS at $101 \mathrm{MHz}$.

|
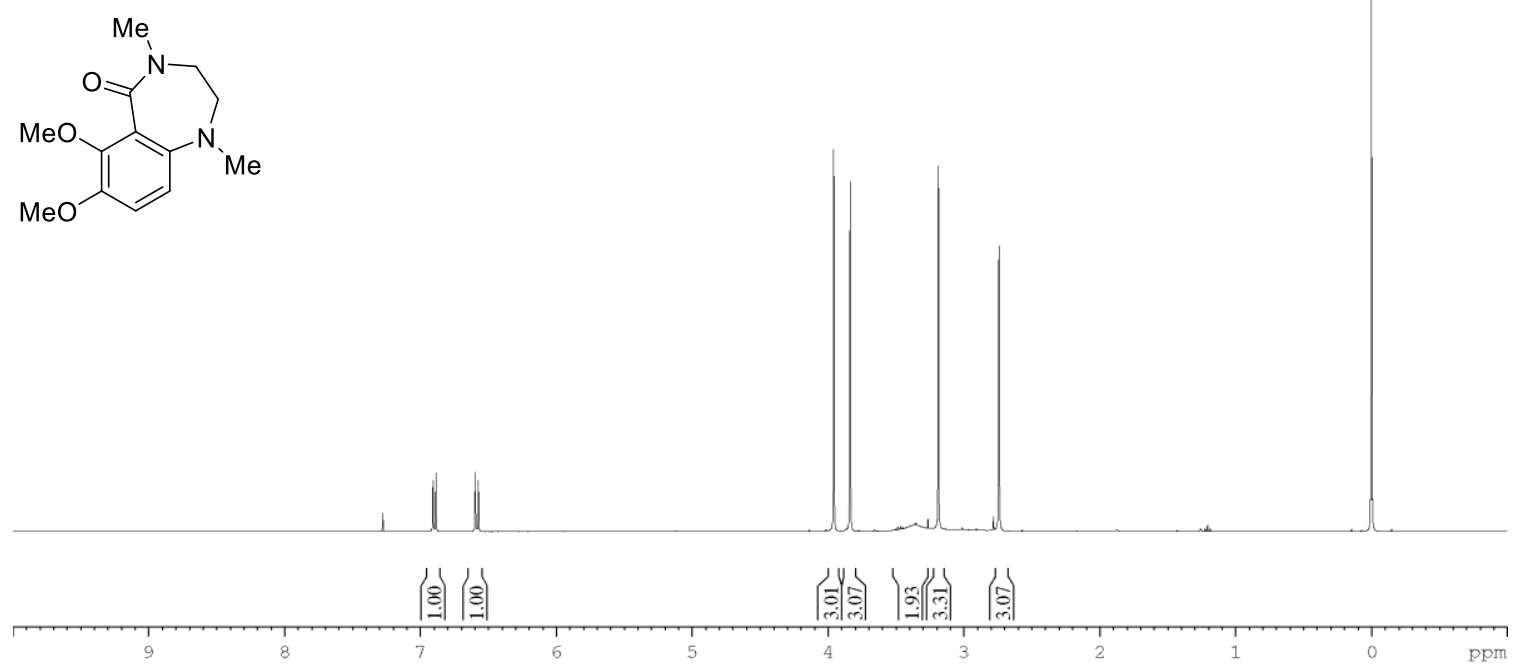

Figure 79. ${ }^{1} \mathrm{H} \mathrm{NMR}$ of $8 \mathbf{k a}$ in $\mathrm{CDCl}_{3}$ with $1 \% \mathrm{v} / \mathrm{v} \mathrm{TMS}$ at $400 \mathrm{MHz}$. 


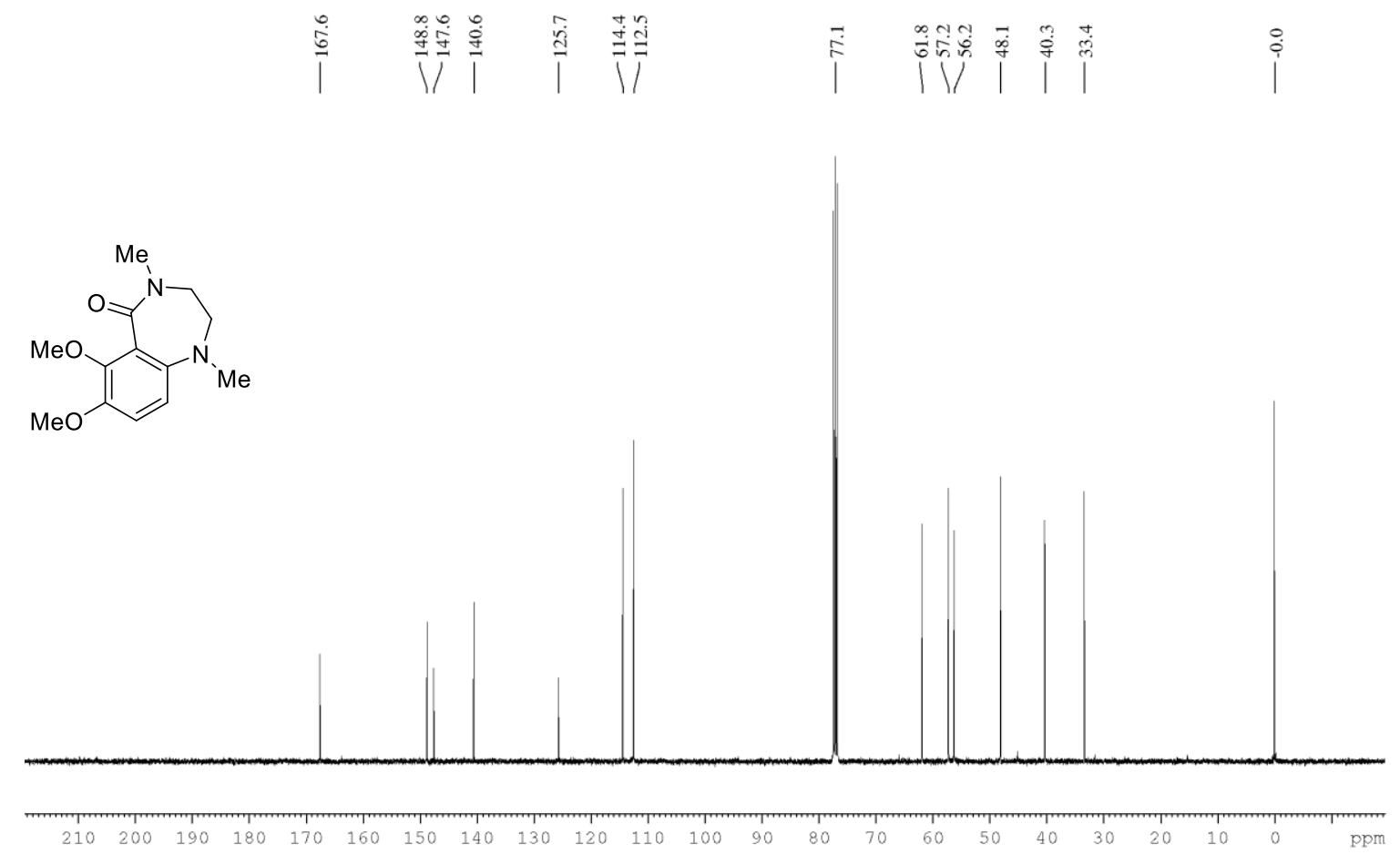

Figure $80 .{ }^{13} \mathrm{C}\left\{{ }^{1} \mathrm{H}\right\}$ NMR of $8 \mathrm{ka}$ in $\mathrm{CDCl}_{3}$ with $1 \% \mathrm{v} / \mathrm{v}$ TMS at $101 \mathrm{MHz}$.

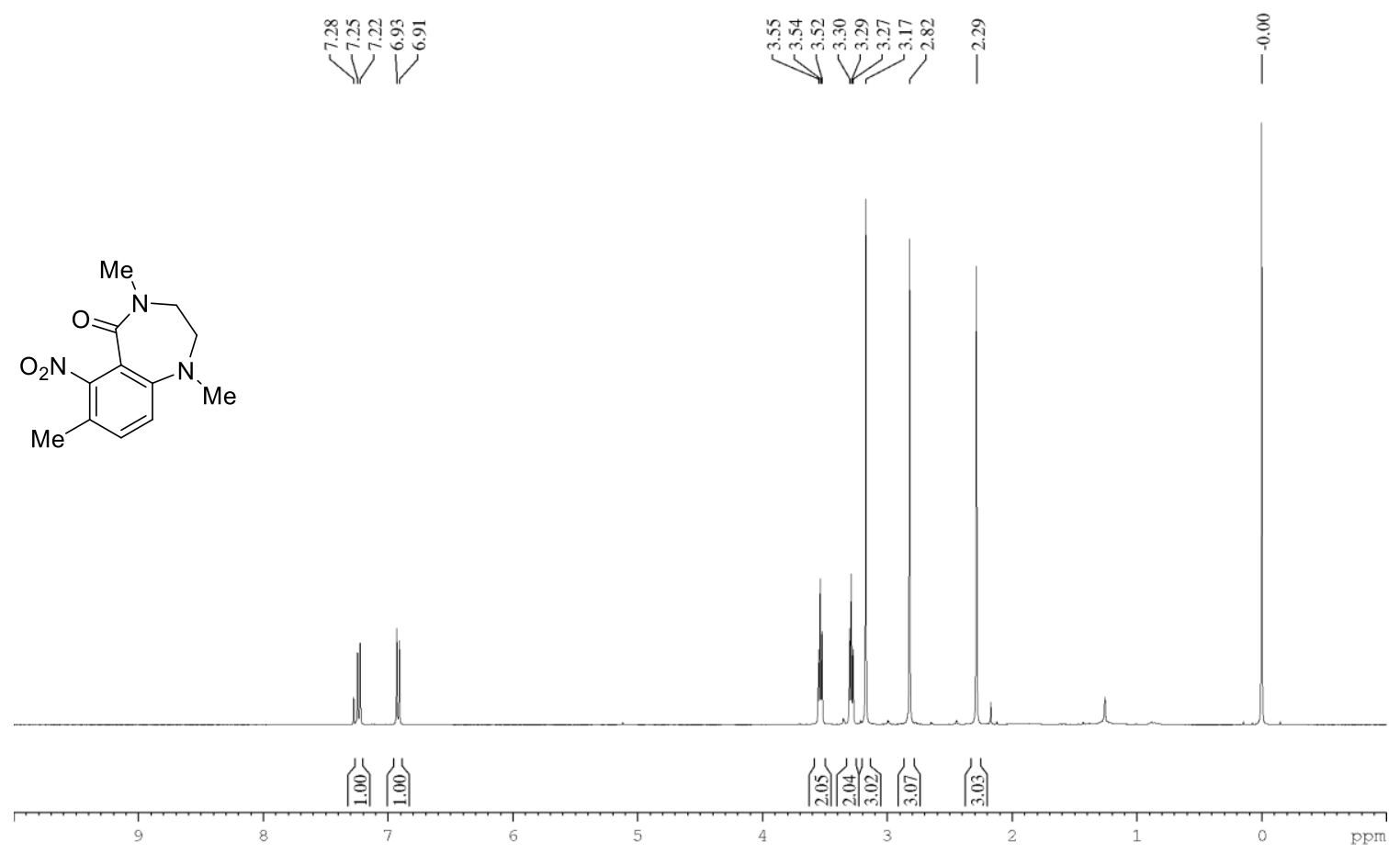

Figure 81. ${ }^{1} \mathrm{H}$ NMR of 8 la in $\mathrm{CDCl}_{3}$ with $1 \% \mathrm{v} / \mathrm{v}$ TMS at $400 \mathrm{MHz}$. 


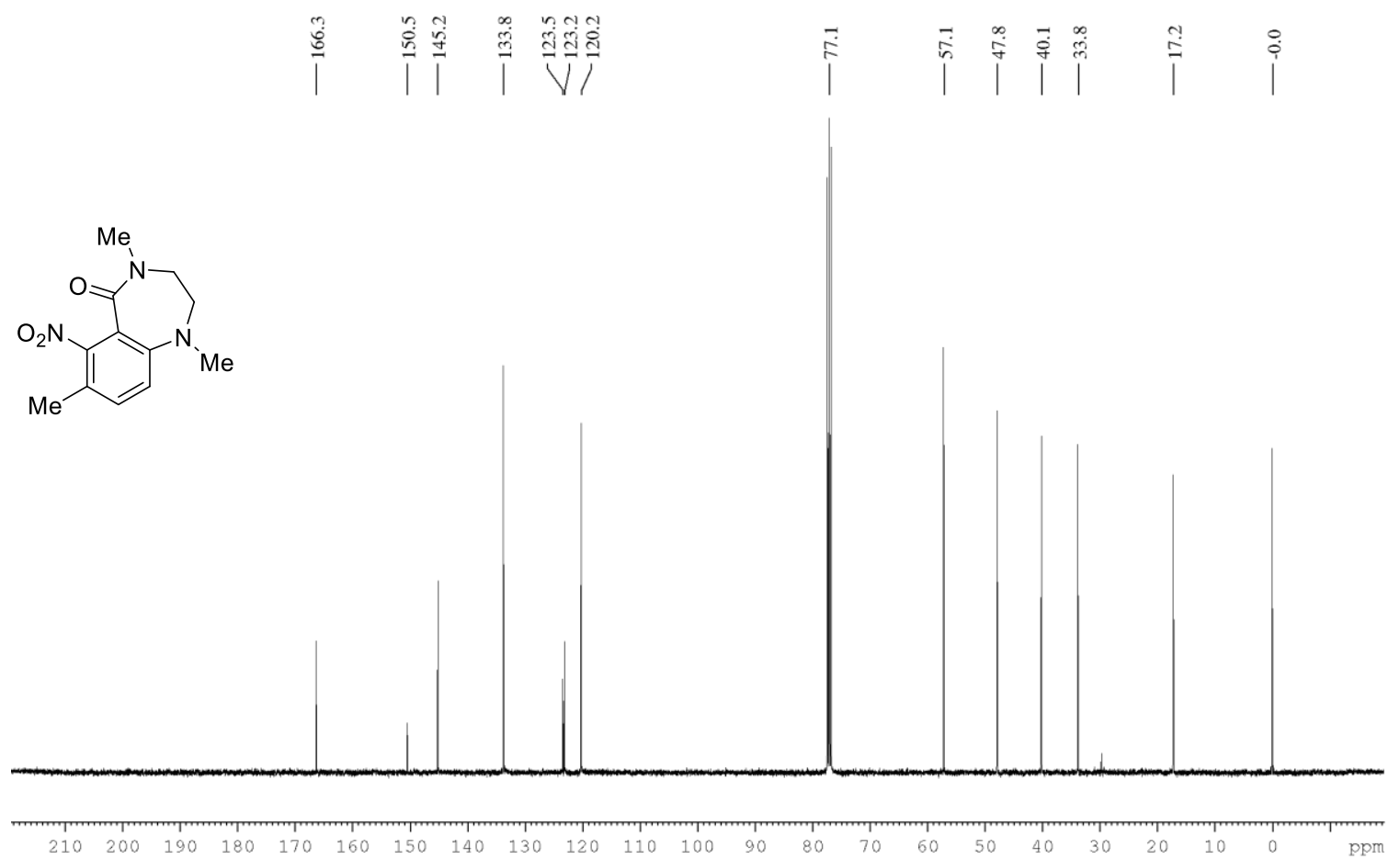

Figure $82 .{ }^{13} \mathrm{C}\left\{{ }^{1} \mathrm{H}\right\}$ NMR of 8la $\mathrm{CDCl}_{3}$ with $1 \% \mathrm{v} / \mathrm{v}$ TMS at $101 \mathrm{MHz}$.

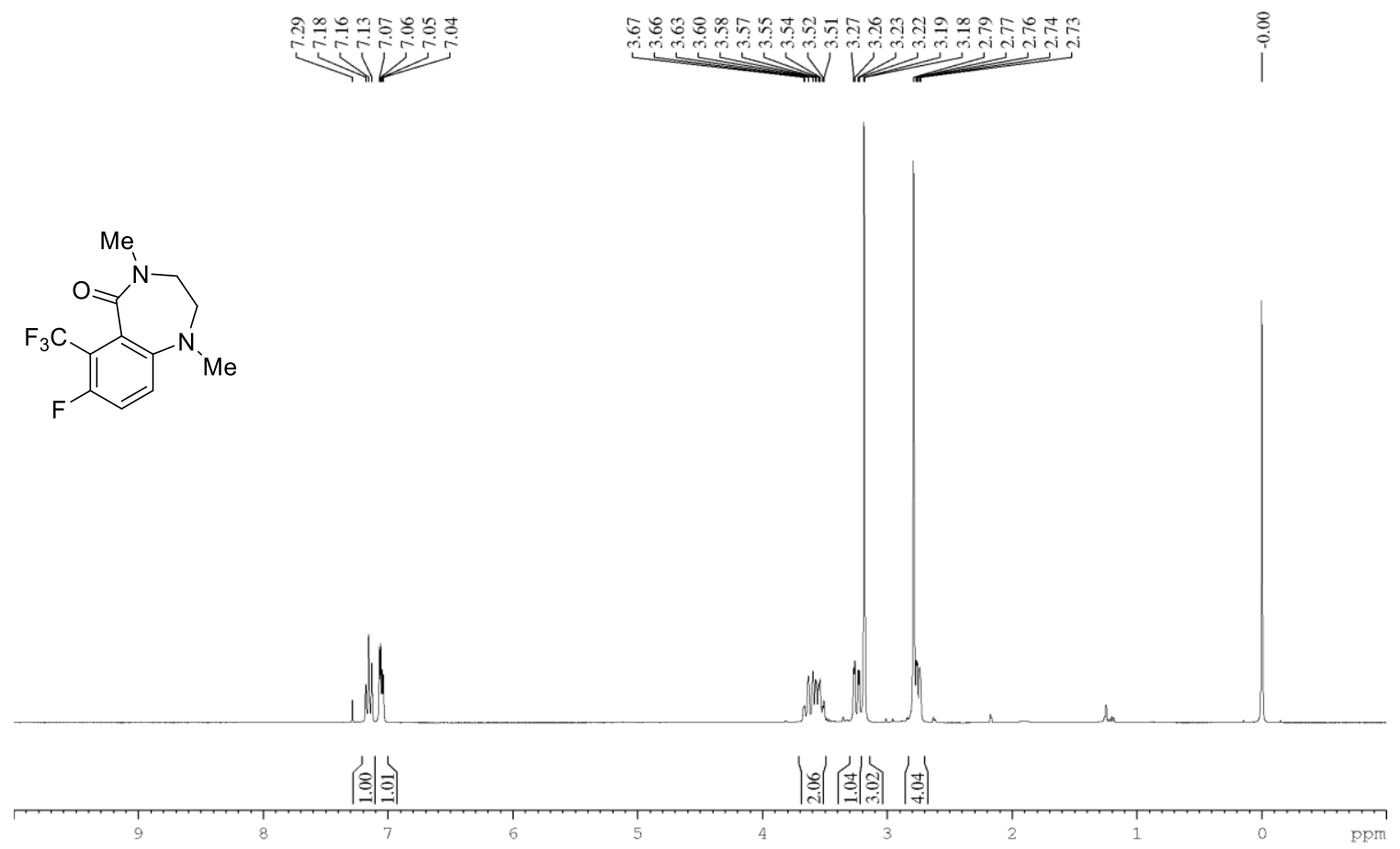

Figure $83 .{ }^{1} \mathrm{H} \mathrm{NMR}$ of 8 na in $\mathrm{CDCl}_{3}$ with $1 \% \mathrm{v} / \mathrm{v}$ TMS at $400 \mathrm{MHz}$. 


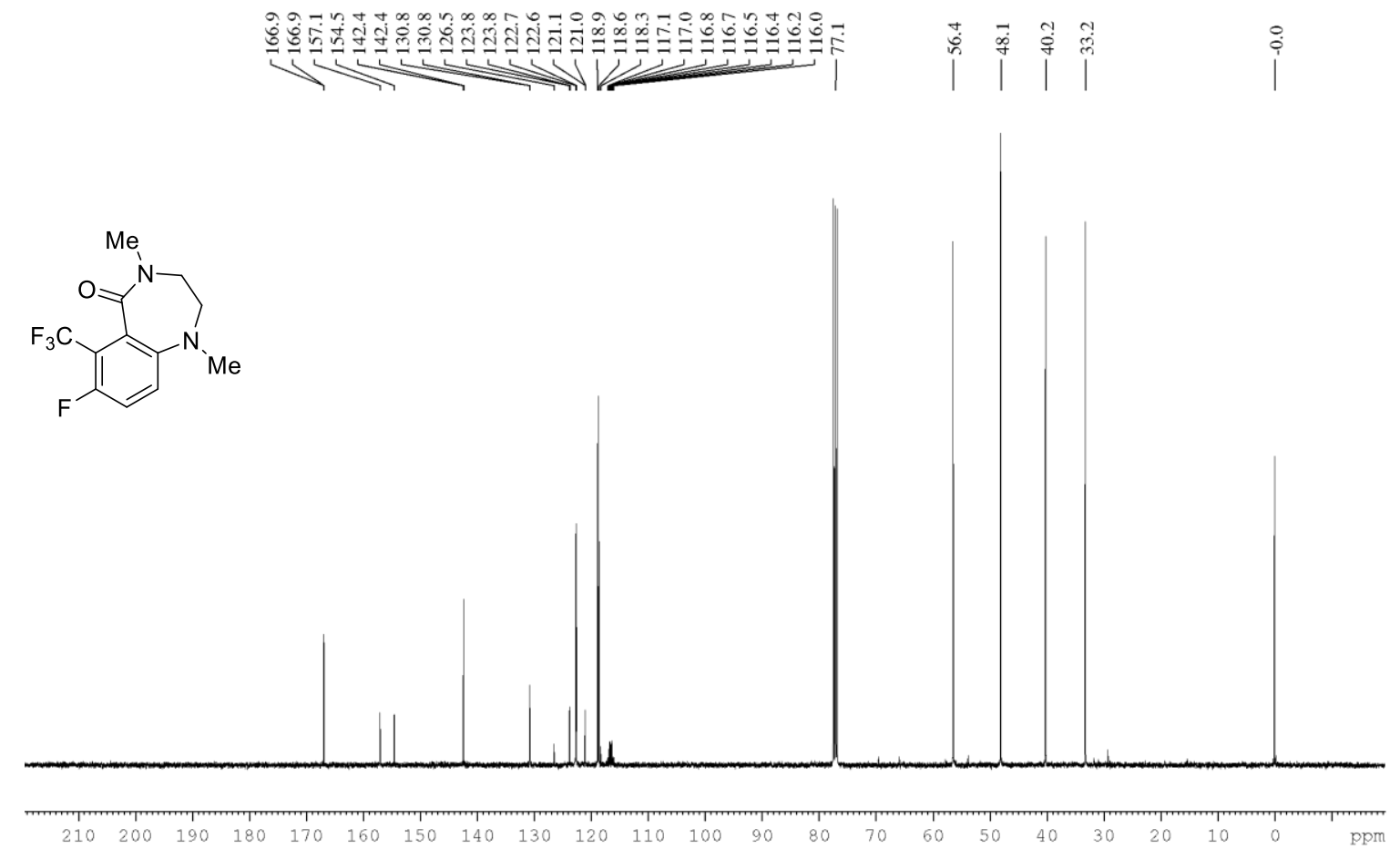

Figure $84 .{ }^{13} \mathrm{C}\left\{{ }^{1} \mathrm{H}\right\}$ NMR of 8 na $\mathrm{CDCl}_{3}$ with $1 \% \mathrm{v} / \mathrm{v}$ TMS at $101 \mathrm{MHz}$.

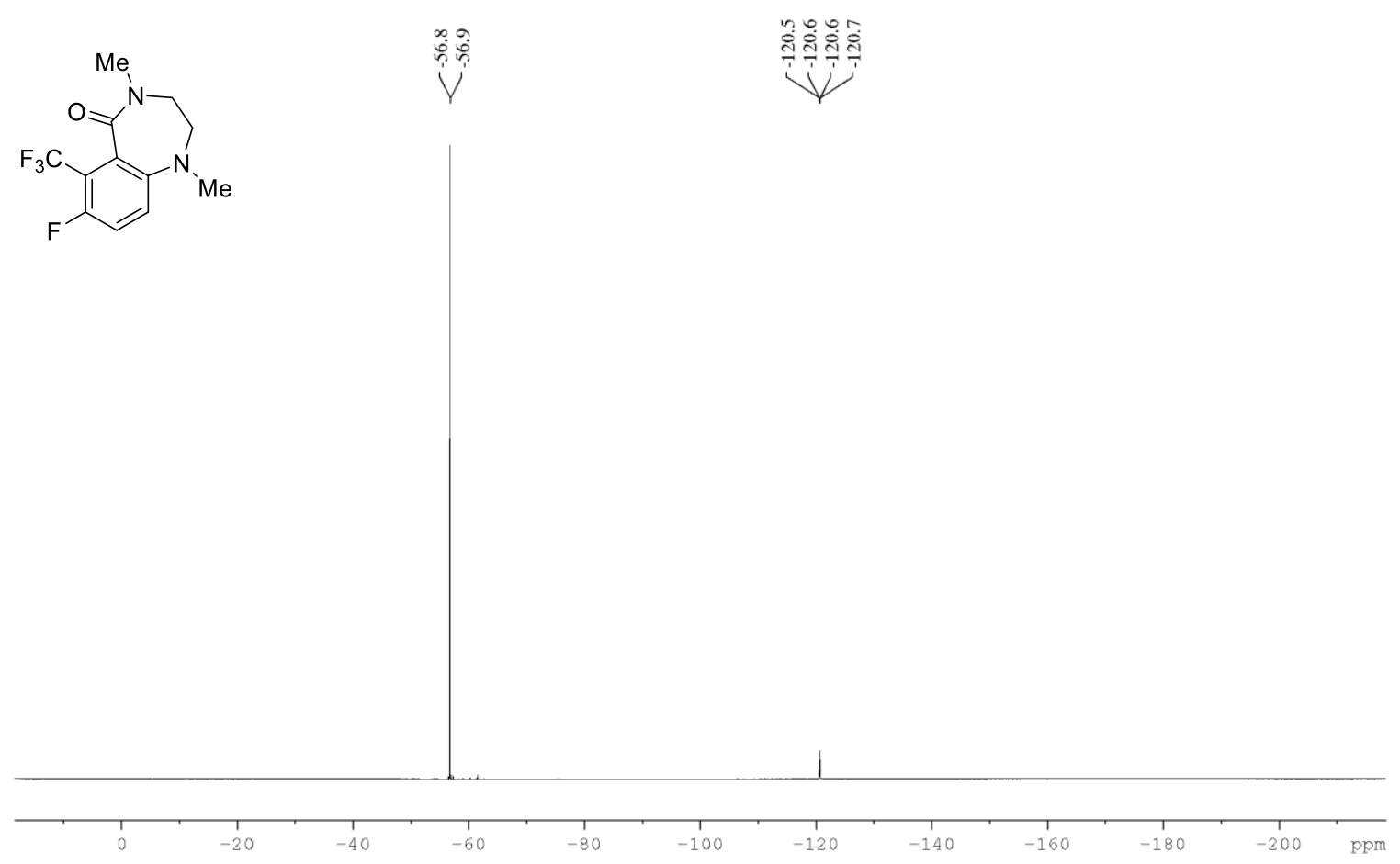

Figure $85 .{ }^{19} \mathrm{~F}\left\{{ }^{1} \mathrm{H}\right\}$ NMR of 8 na in $\mathrm{CDCl}_{3}$ with $1 \% \mathrm{v} / \mathrm{v}$ TMS at $376 \mathrm{MHz}$. 


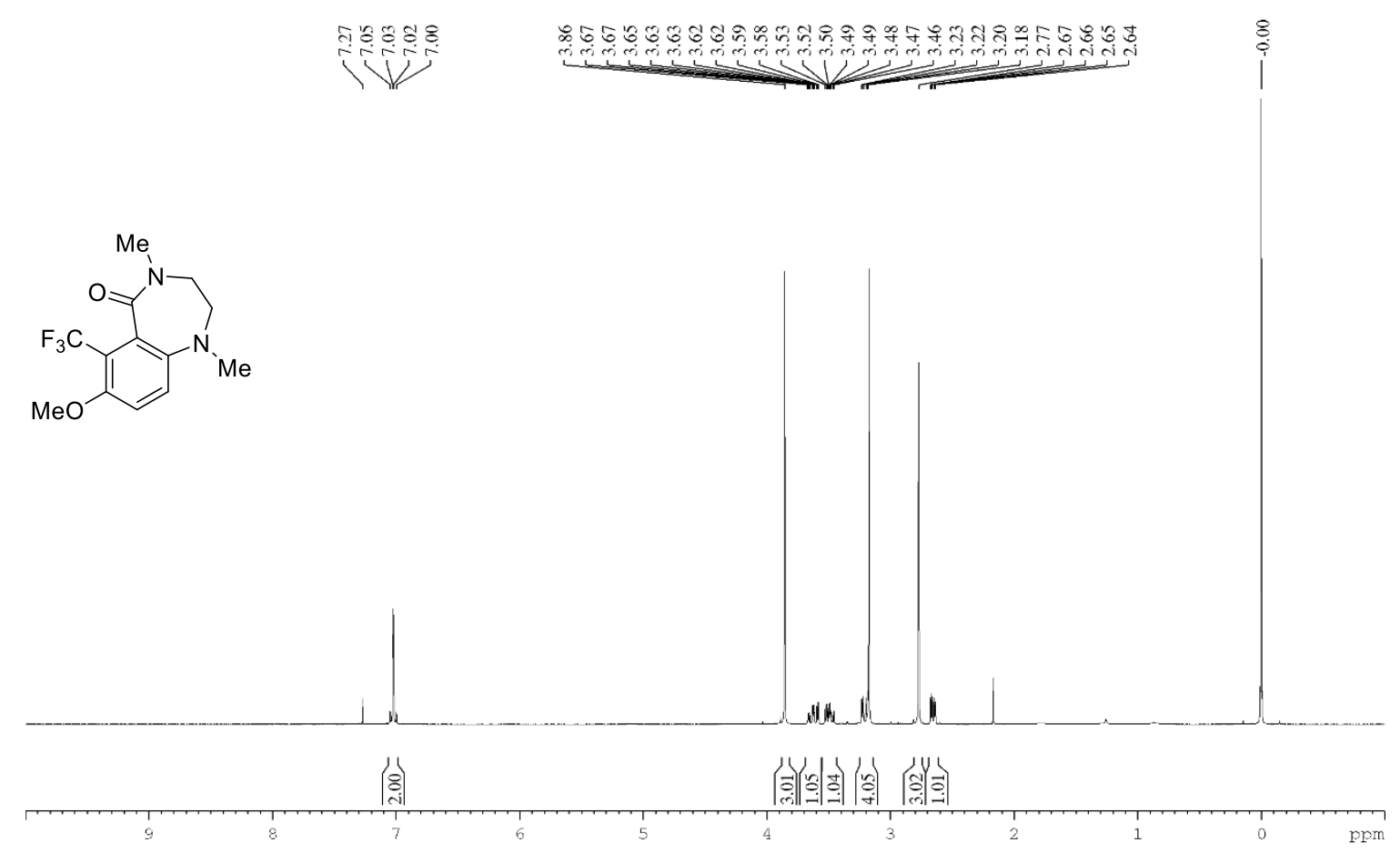

Figure 86. ${ }^{1} \mathrm{H} \mathrm{NMR}$ of $8 \mathrm{ma}$ in $\mathrm{CDCl}_{3}$ with $1 \% \mathrm{v} / \mathrm{v} \mathrm{TMS}$ at $400 \mathrm{MHz}$.

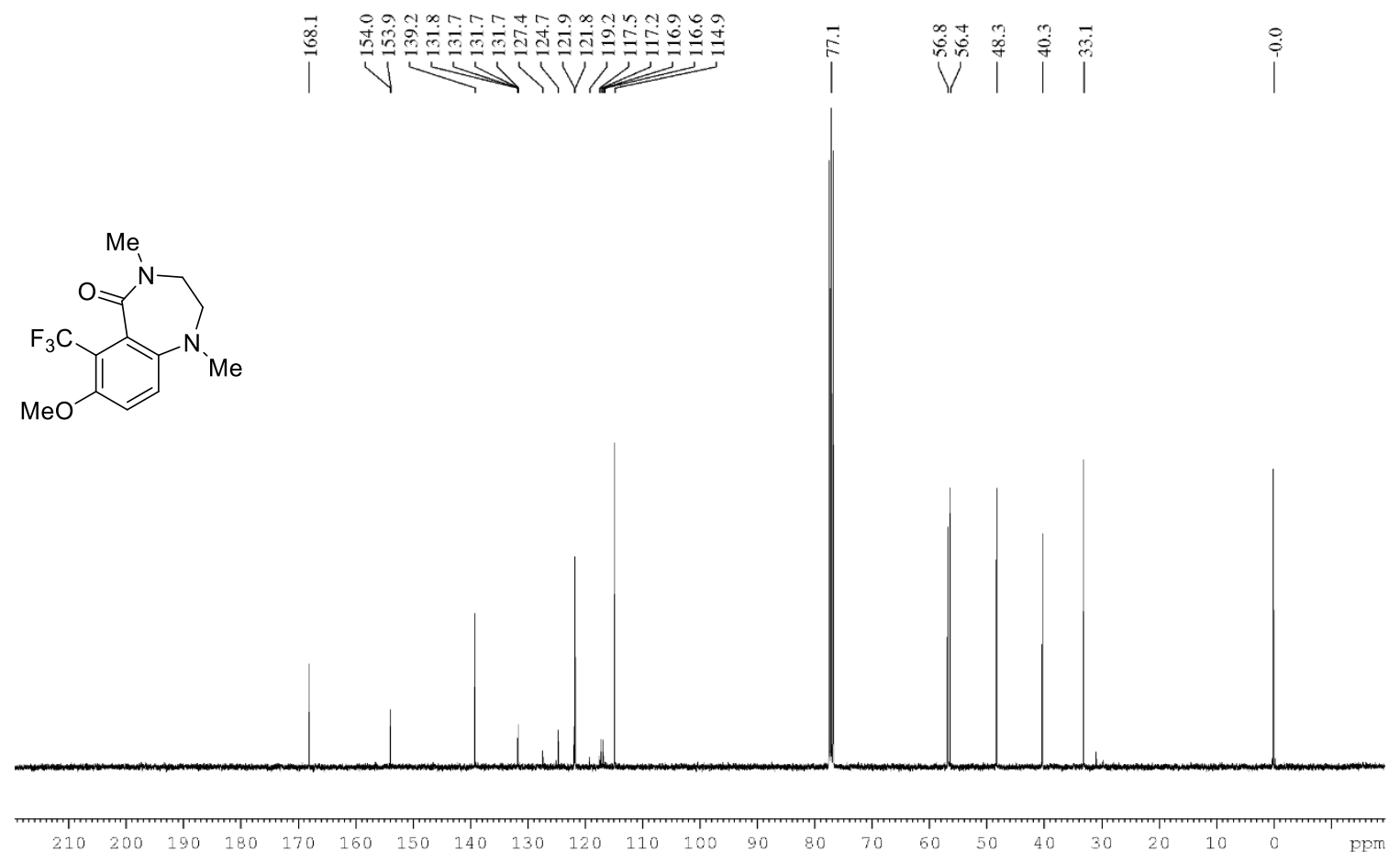

Figure 87. ${ }^{13} \mathrm{C}\left\{{ }^{1} \mathrm{H}\right\}$ NMR of $8 \mathrm{ma} \mathrm{CDCl} 3$ with $1 \% \mathrm{v} / \mathrm{v}$ TMS at $101 \mathrm{MHz}$. 


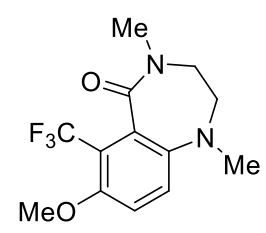

$$
\text { i }
$$

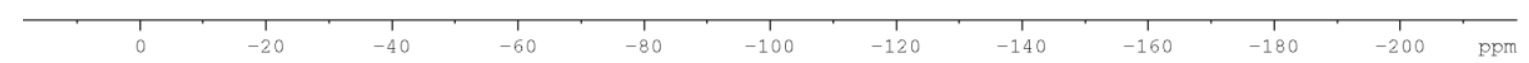

Figure $88 .{ }^{19} \mathrm{~F}\left\{{ }^{1} \mathrm{H}\right\} \mathrm{NMR}$ of $8 \mathrm{ma}$ in $\mathrm{CDCl}_{3}$ with $1 \% \mathrm{v} / \mathrm{v}$ TMS at $376 \mathrm{MHz}$.

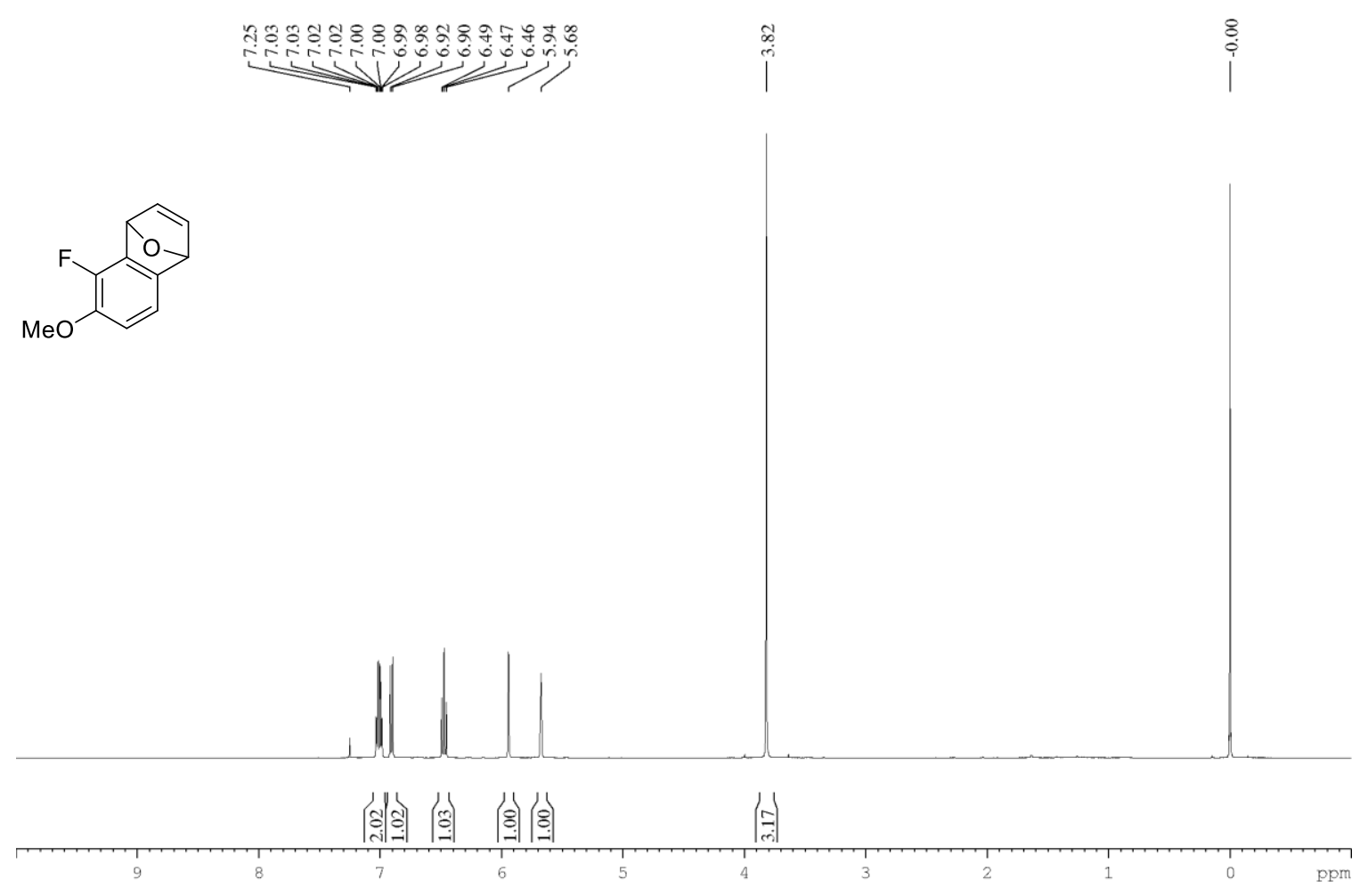

Figure 89. ${ }^{1} \mathrm{H}$ NMR of $8 \mathrm{gg}$ in $\mathrm{CDCl}_{3}$ with $1 \% \mathrm{v} / \mathrm{v}$ TMS at $400 \mathrm{MHz}$. 


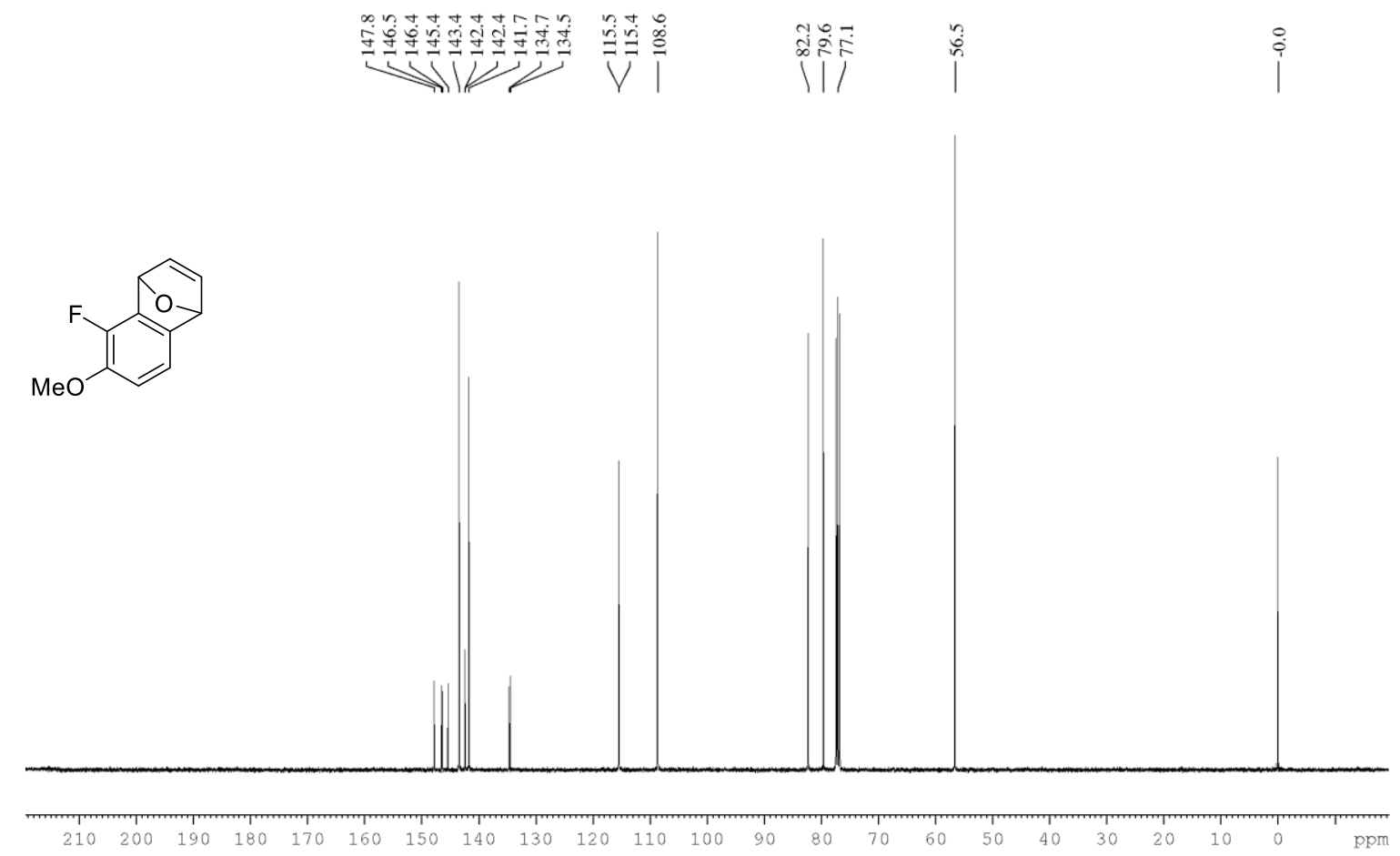

Figure 90. ${ }^{13} \mathrm{C}\left\{{ }^{1} \mathrm{H}\right\} \mathrm{NMR}$ of $8 \mathrm{gg} \mathrm{CDCl} 3$ with $1 \% \mathrm{v} / \mathrm{v}$ TMS at $101 \mathrm{MHz}$.

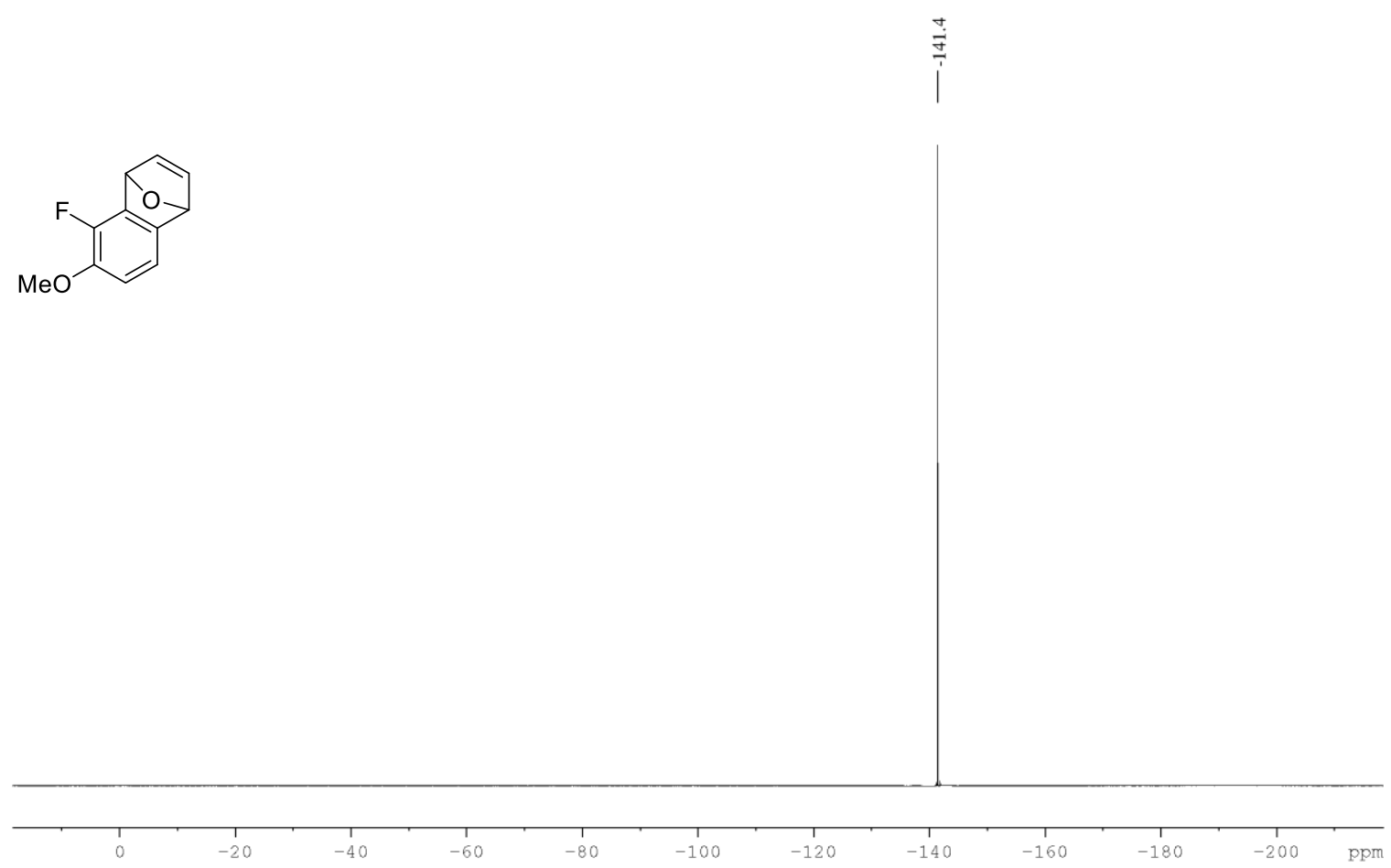

Figure $91 .{ }^{19} \mathrm{~F}\left\{{ }^{1} \mathrm{H}\right\} \mathrm{NMR}$ of $8 \mathrm{gg}$ in $\mathrm{CDCl}_{3}$ with $1 \% \mathrm{v} / \mathrm{v}$ TMS at $376 \mathrm{MHz}$. 


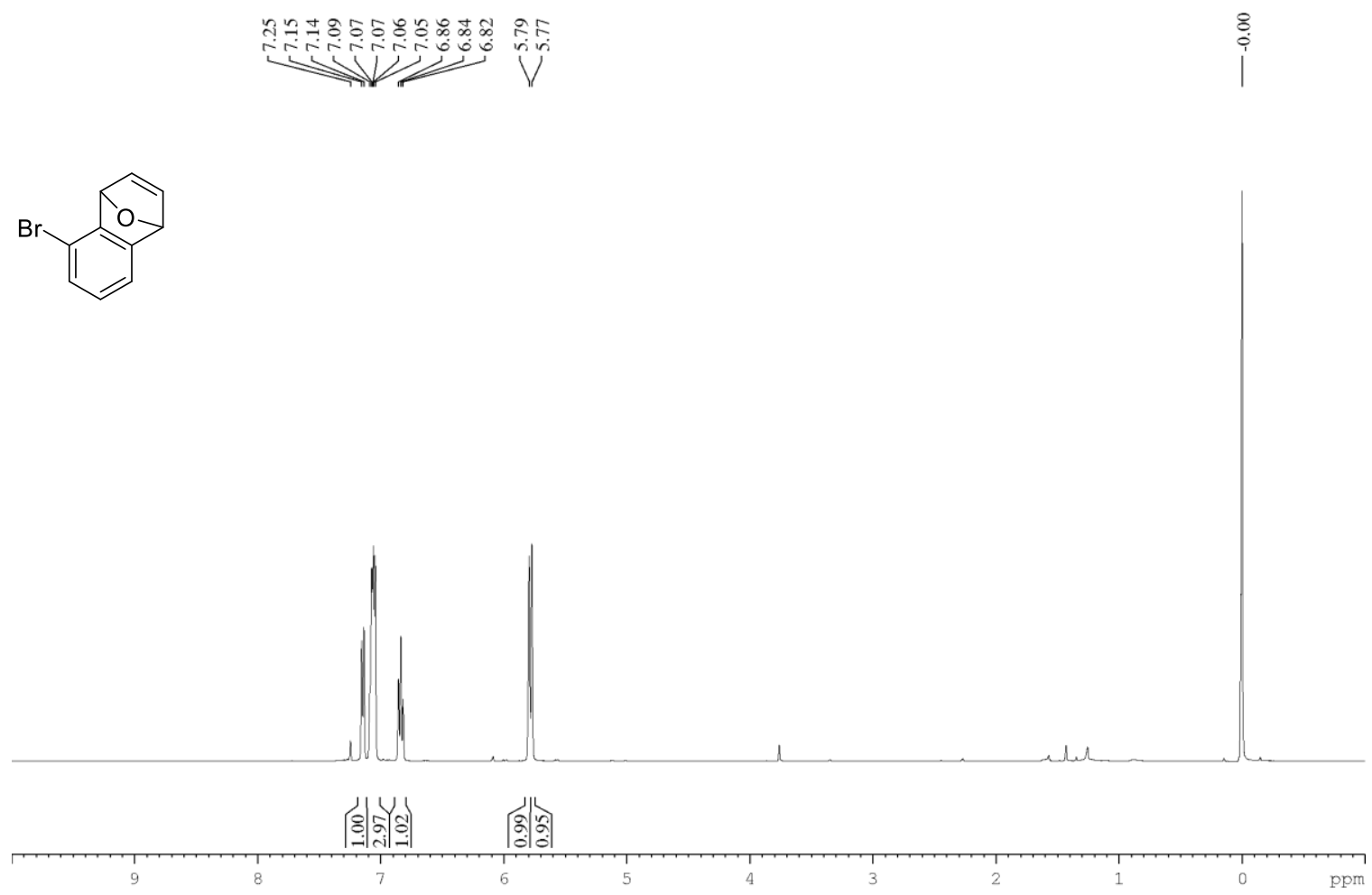

Figure 92. ${ }^{1} \mathrm{H}$ NMR of $8 \mathrm{vg}$ in $\mathrm{CDCl}_{3}$ with $1 \% \mathrm{v} / \mathrm{v}$ TMS at $400 \mathrm{MHz}$.

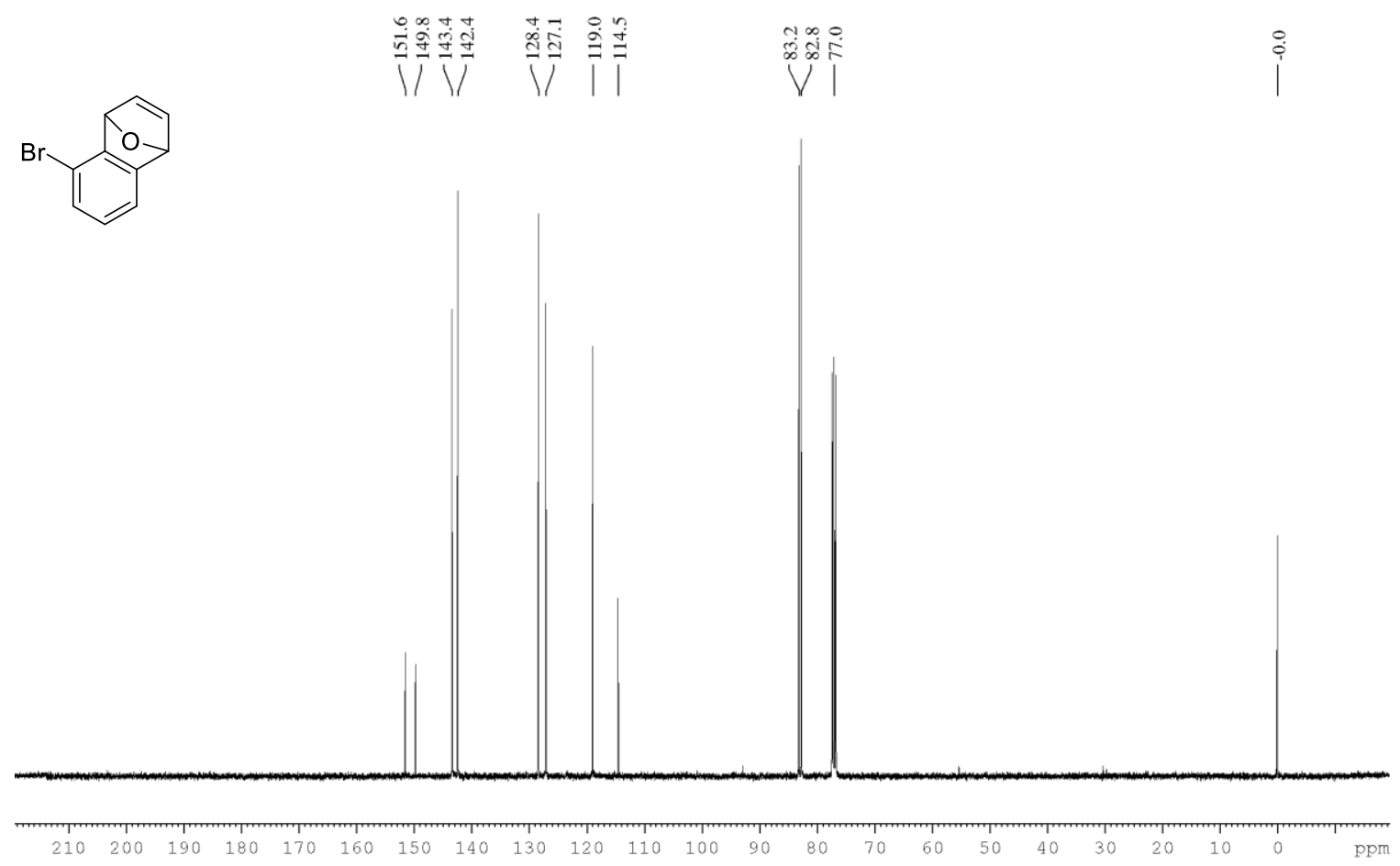

Figure 93. ${ }^{13} \mathrm{C}\left\{{ }^{1} \mathrm{H}\right\} \mathrm{NMR}$ of $8 \mathrm{vg} \mathrm{CDCl} 3$ with $1 \% \mathrm{v} / \mathrm{v}$ TMS at $101 \mathrm{MHz}$. 

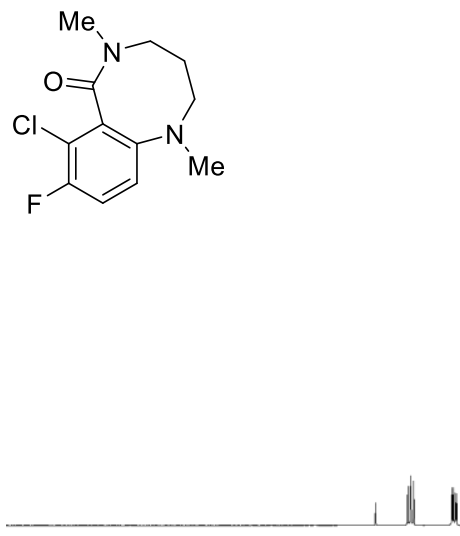

(8)

9

8

7

Figure 94. ${ }^{1} \mathrm{H}$ NMR of $8 \mathbf{d b}$ in $\mathrm{CDCl}_{3}$ with $1 \% \mathrm{v} / \mathrm{v}$ TMS at $400 \mathrm{MHz}$.
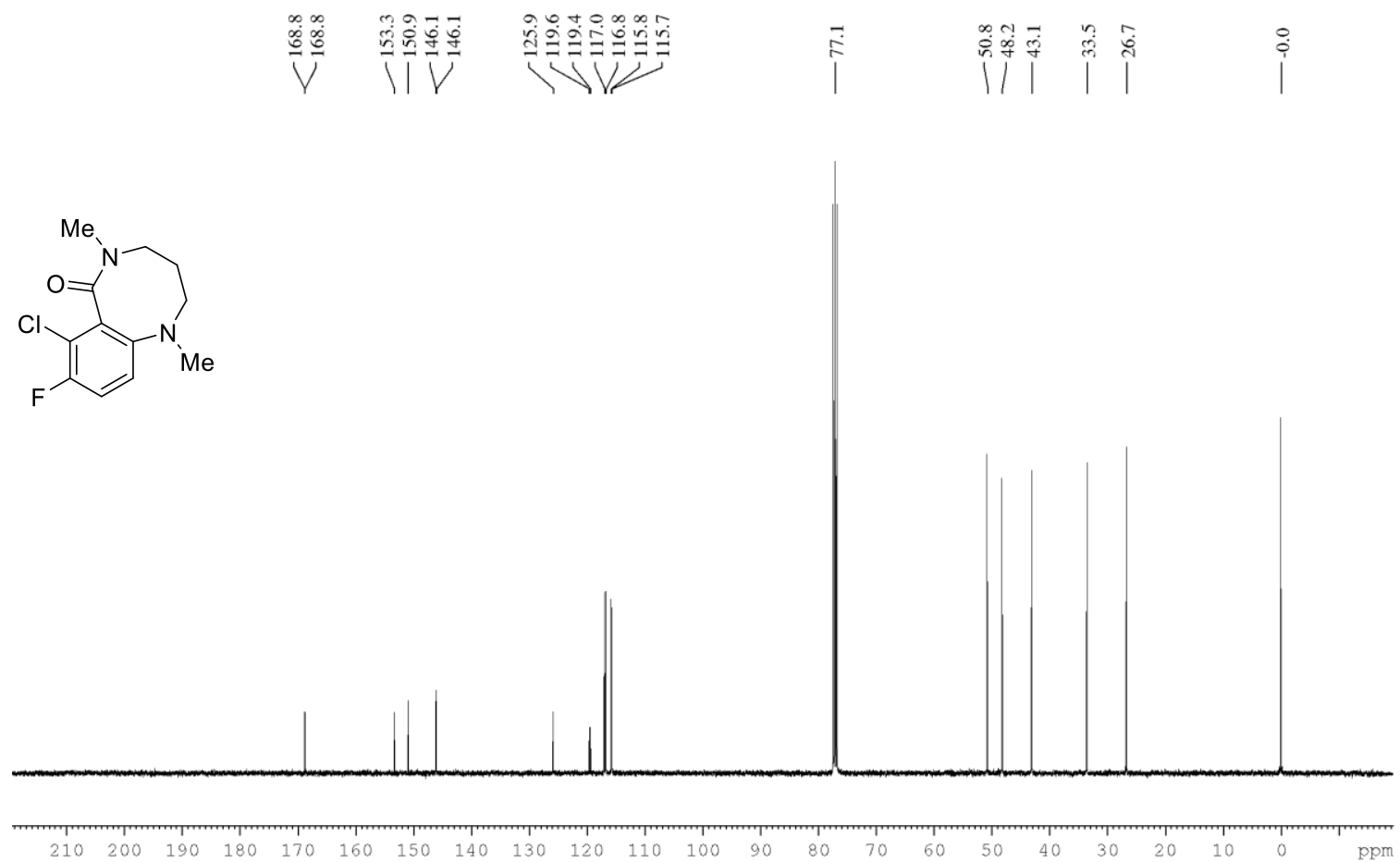

Figure 95. ${ }^{13} \mathrm{C}\left\{{ }^{1} \mathrm{H}\right\}$ NMR of $8 \mathrm{db} \mathrm{CDCl}_{3}$ with $1 \% \mathrm{v} / \mathrm{v}$ TMS at $101 \mathrm{MHz}$. 


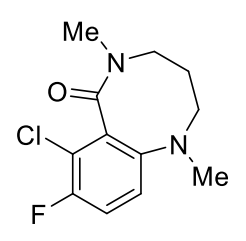

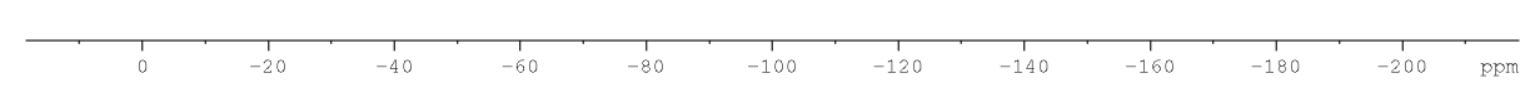

Figure 96. ${ }^{19} \mathrm{~F}\left\{{ }^{1} \mathrm{H}\right\} \mathrm{NMR}$ of $\mathbf{8 d b}$ in $\mathrm{CDCl}_{3}$ with $1 \% \mathrm{v} / \mathrm{v}$ TMS at $376 \mathrm{MHz}$.

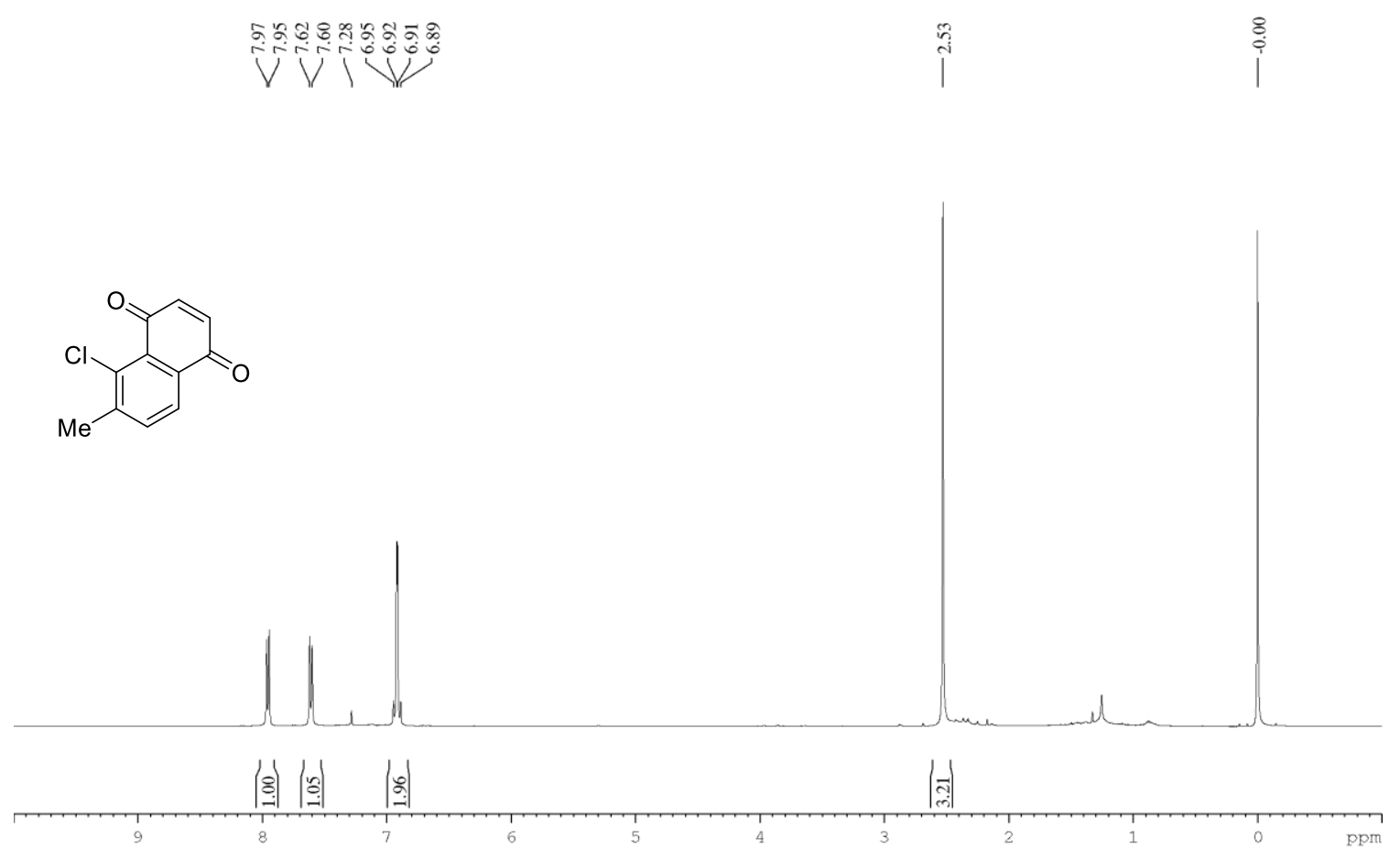

Figure 97. ${ }^{1} \mathrm{H}$ NMR of 8 ac in $\mathrm{CDCl}_{3}$ with $1 \% \mathrm{v} / \mathrm{v}$ TMS at $400 \mathrm{MHz}$. 


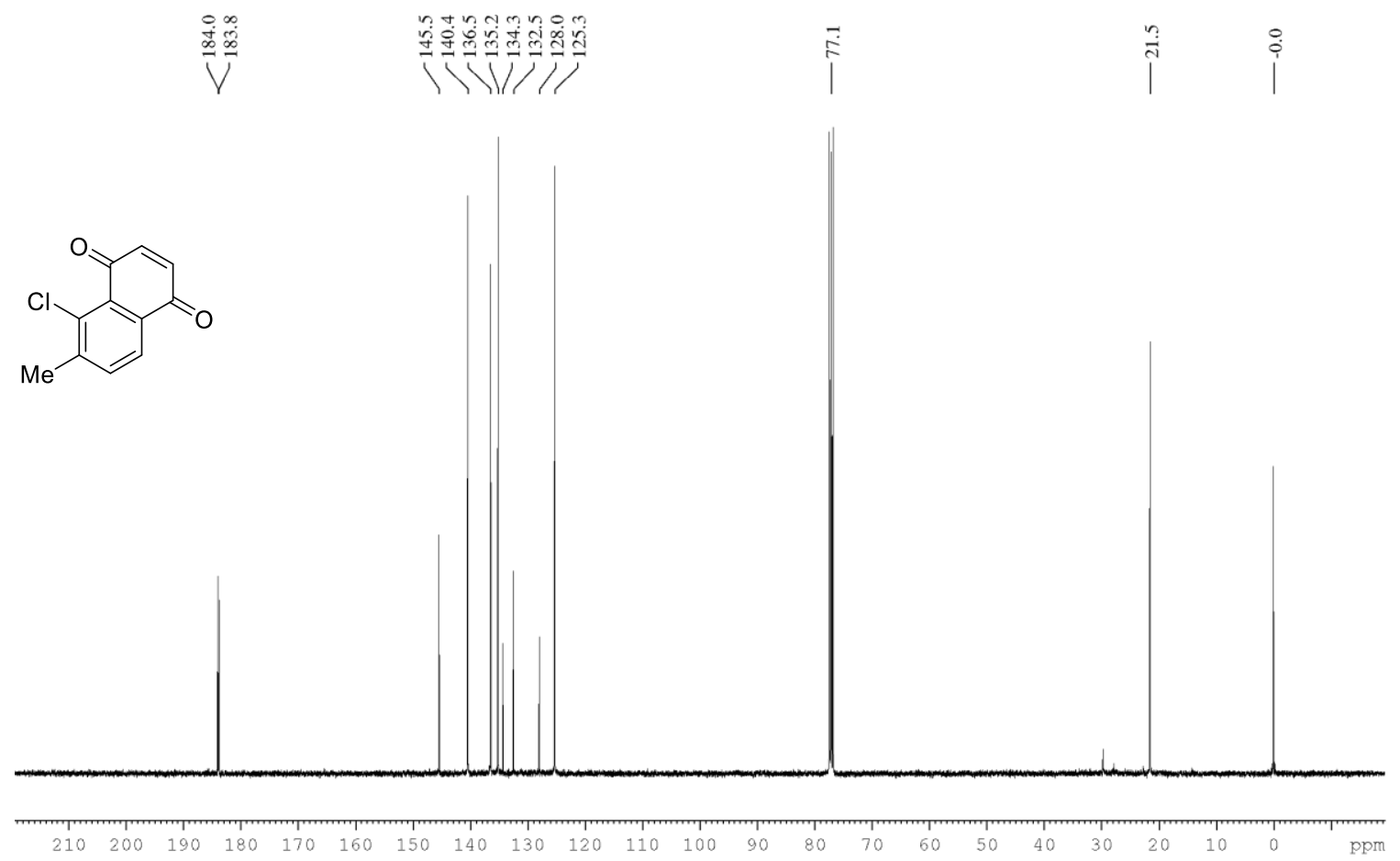

Figure 98. ${ }^{13} \mathrm{C}\left\{{ }^{1} \mathrm{H}\right\} \mathrm{NMR}$ of $8 \mathrm{ac} \mathrm{CDCl}_{3}$ with $1 \% \mathrm{v} / \mathrm{v}$ TMS at $101 \mathrm{MHz}$.

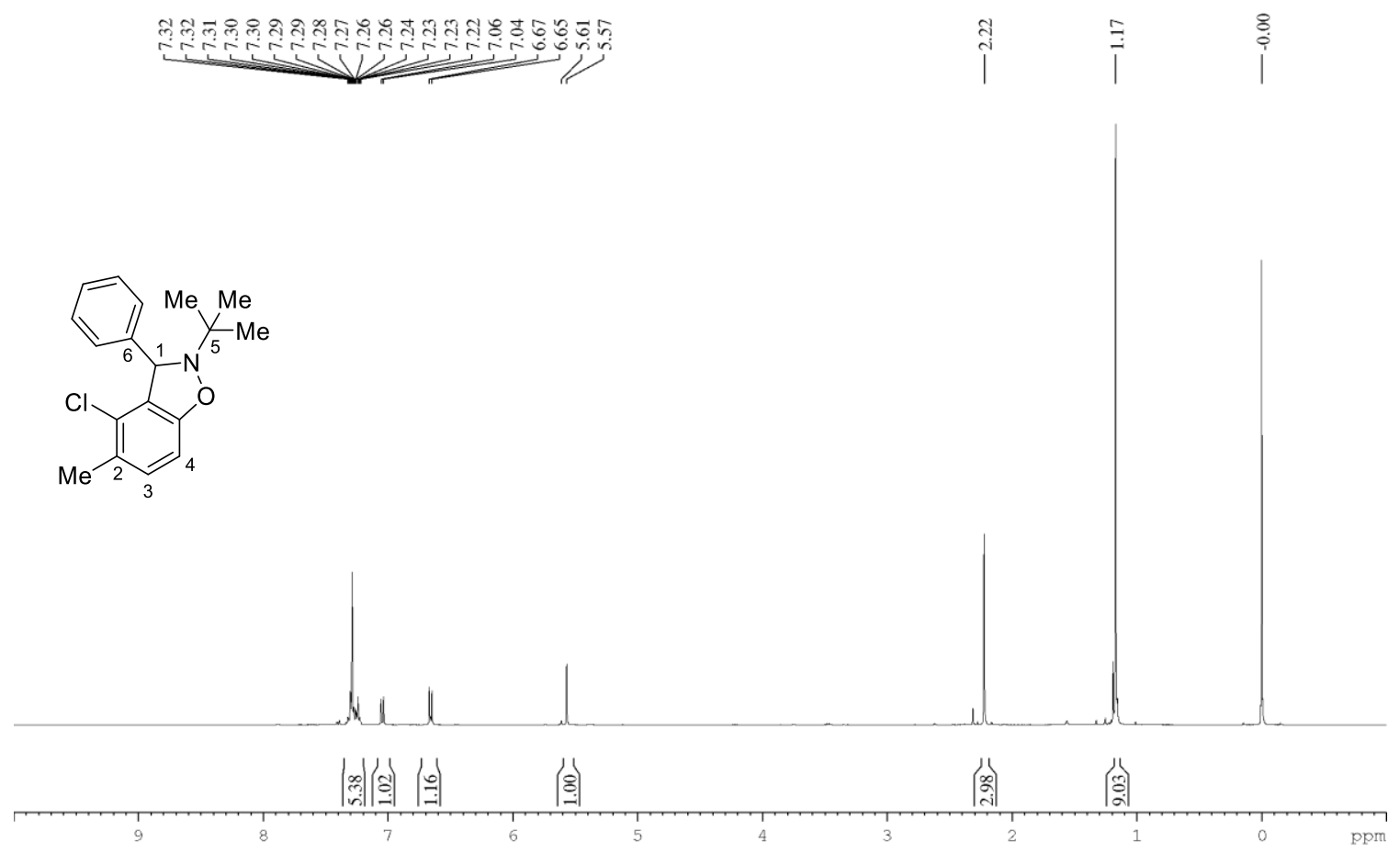

Figure 99. ${ }^{1} \mathrm{H} \mathrm{NMR}$ of 8 ad in $\mathrm{CDCl}_{3}$ with $1 \% \mathrm{v} / \mathrm{v}$ TMS at $400 \mathrm{MHz}$. 


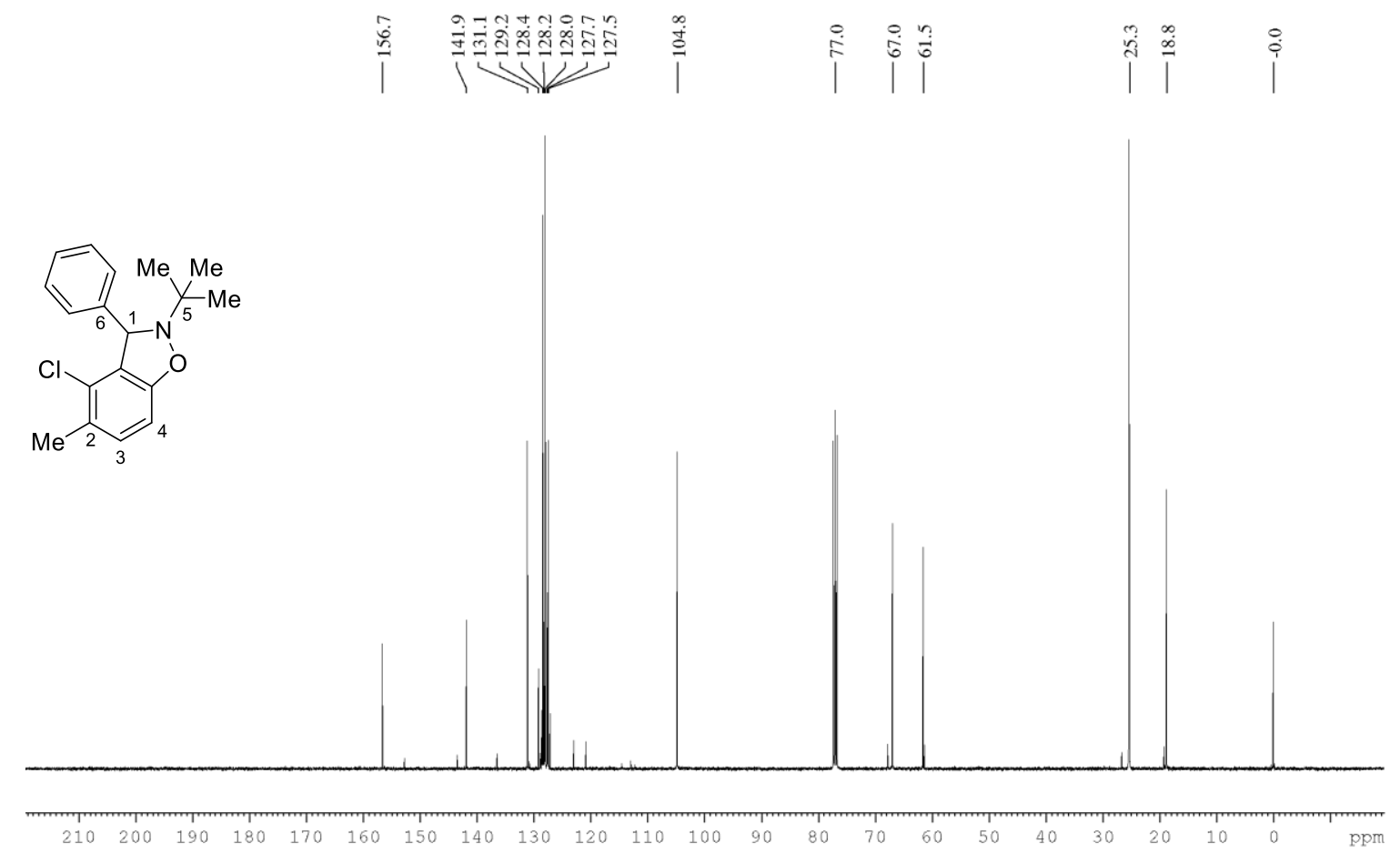

Figure $100 .{ }^{13} \mathrm{C}\left\{{ }^{1} \mathrm{H}\right\} \mathrm{NMR}$ of $8 \mathrm{ad} \mathrm{CDCl}_{3}$ with $1 \% \mathrm{v} / \mathrm{v}$ TMS at $101 \mathrm{MHz}$.

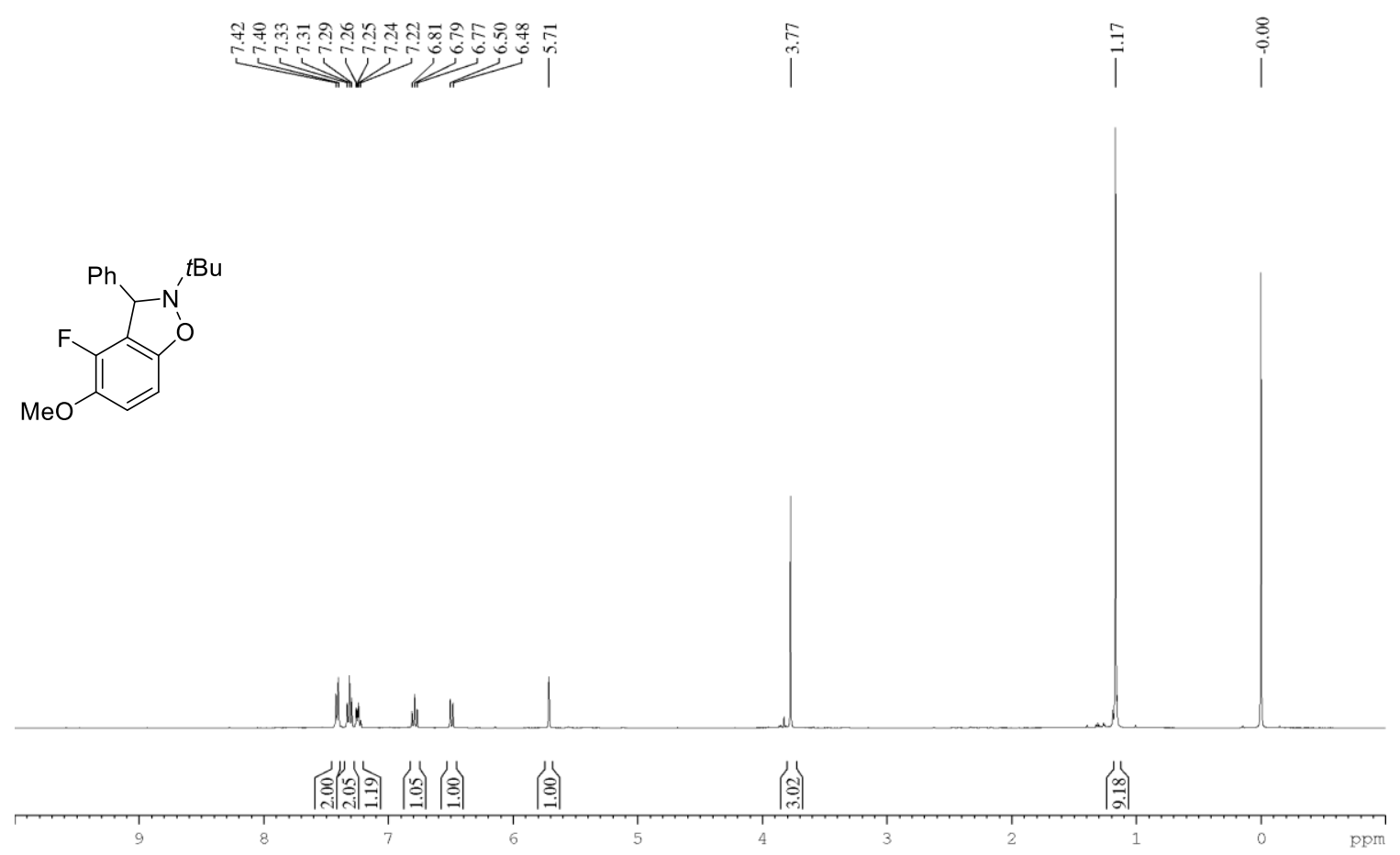

Figure 101. ${ }^{1} \mathrm{H} \mathrm{NMR}$ of $8 \mathrm{gd}$ in $\mathrm{CDCl}_{3}$ with $1 \% \mathrm{v} / \mathrm{v}$ TMS at $400 \mathrm{MHz}$. 


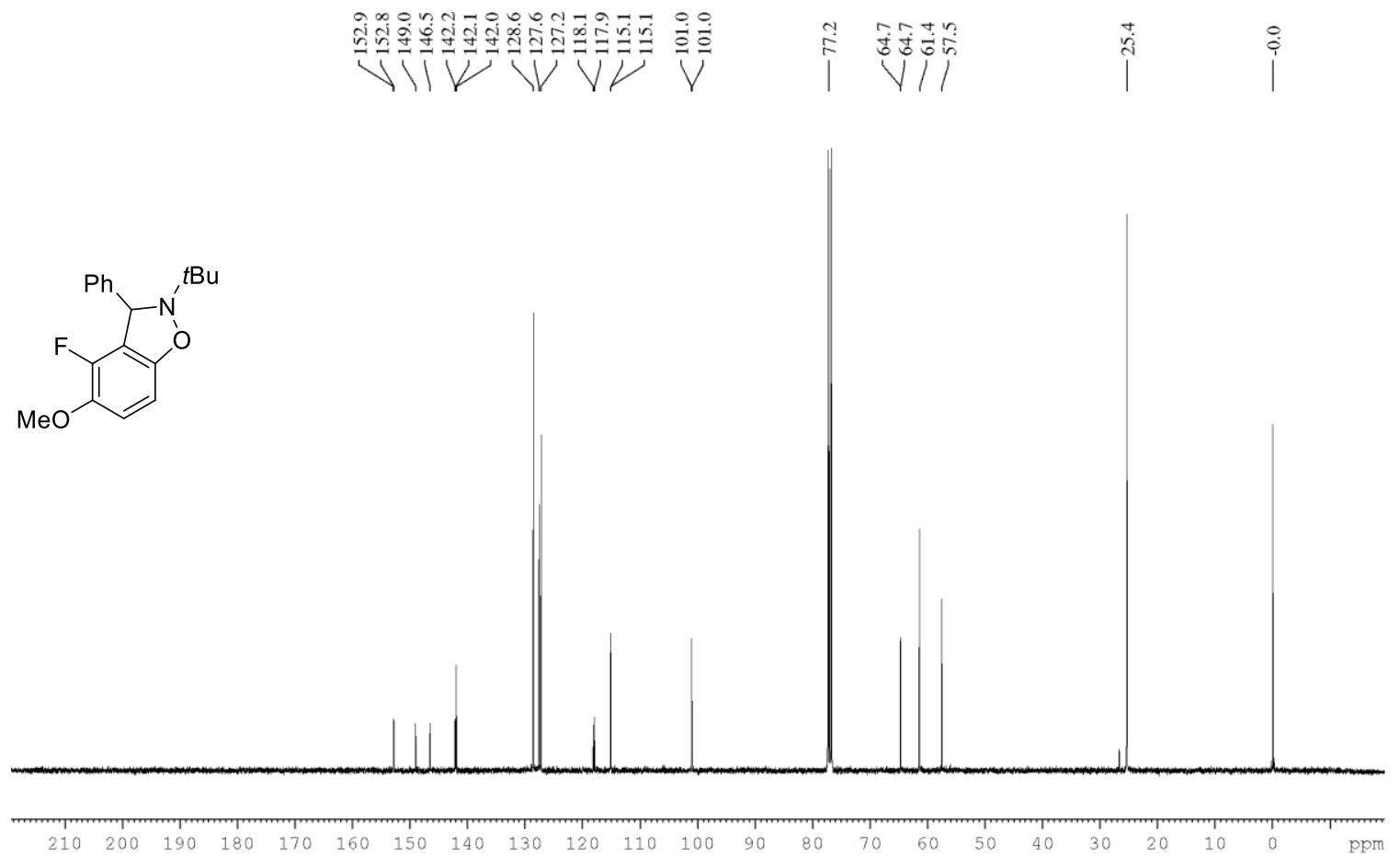

Figure 102. ${ }^{13} \mathrm{C}\left\{{ }^{1} \mathrm{H}\right\} \mathrm{NMR}$ of $8 \mathrm{gd} \mathrm{CDCl} \mathrm{Cl}_{3}$ with $1 \% \mathrm{v} / \mathrm{v}$ TMS at $101 \mathrm{MHz}$.

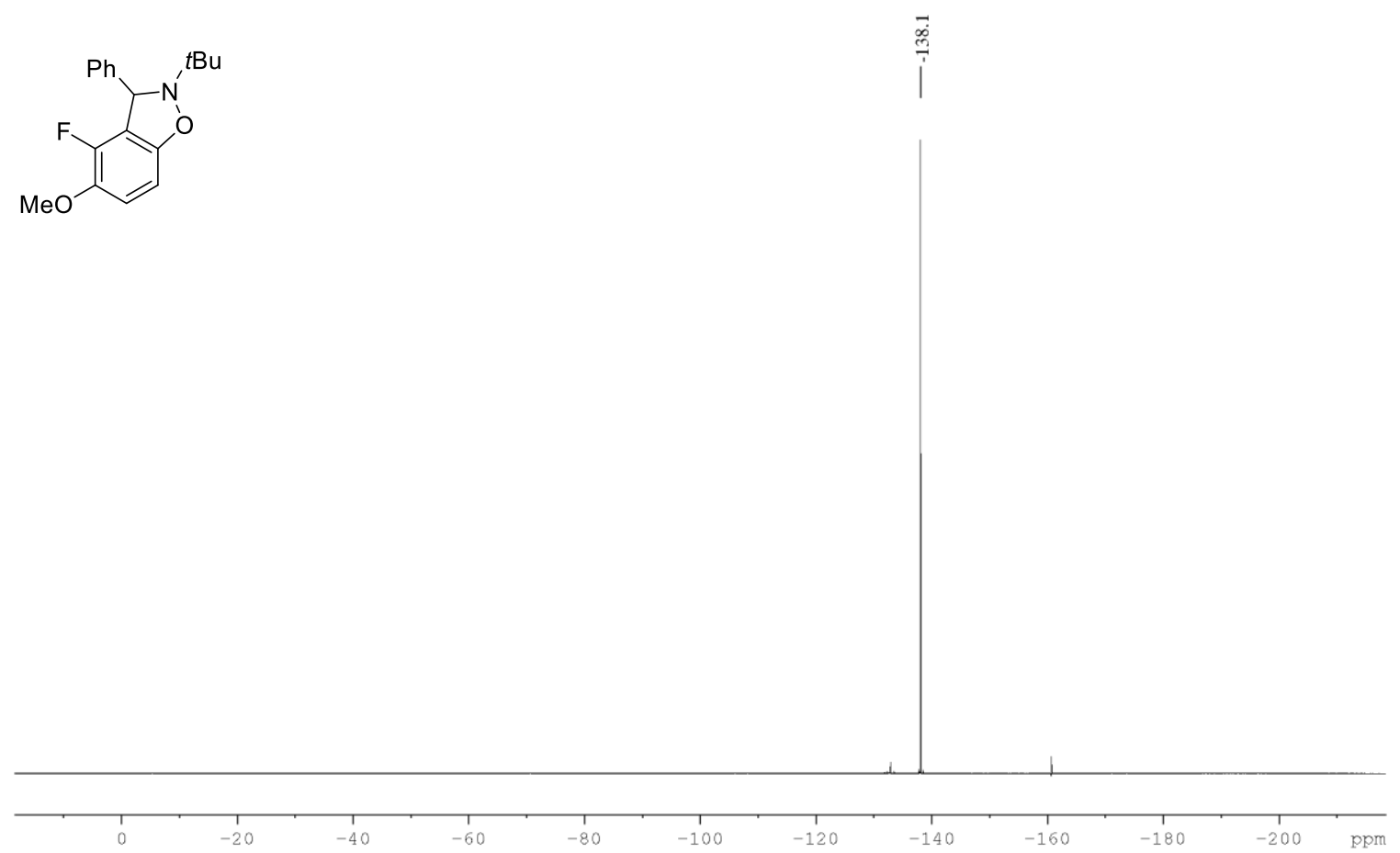

Figure 103. ${ }^{19} \mathrm{~F}\left\{{ }^{1} \mathrm{H}\right\} \mathrm{NMR}$ of $8 \mathrm{gd}$ in $\mathrm{CDCl}_{3}$ with $1 \% \mathrm{v} / \mathrm{v}$ TMS at $376 \mathrm{MHz}$. 

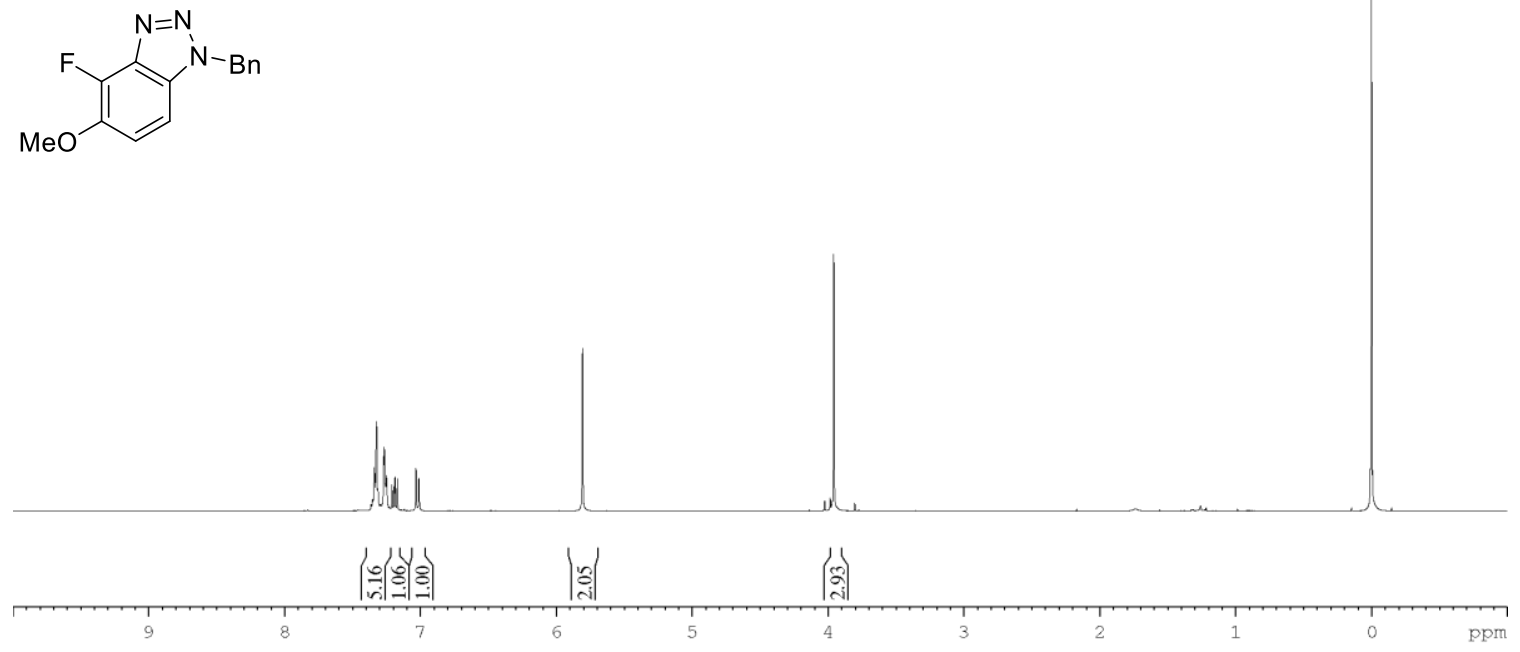

Figure 104. ${ }^{1} \mathrm{H}$ NMR of 8 ge in $\mathrm{CDCl}_{3}$ with $1 \% \mathrm{v} / \mathrm{v}$ TMS at $400 \mathrm{MHz}$.

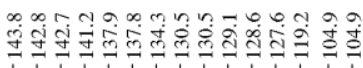

긴.

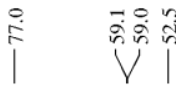

$\stackrel{\circ}{i}$
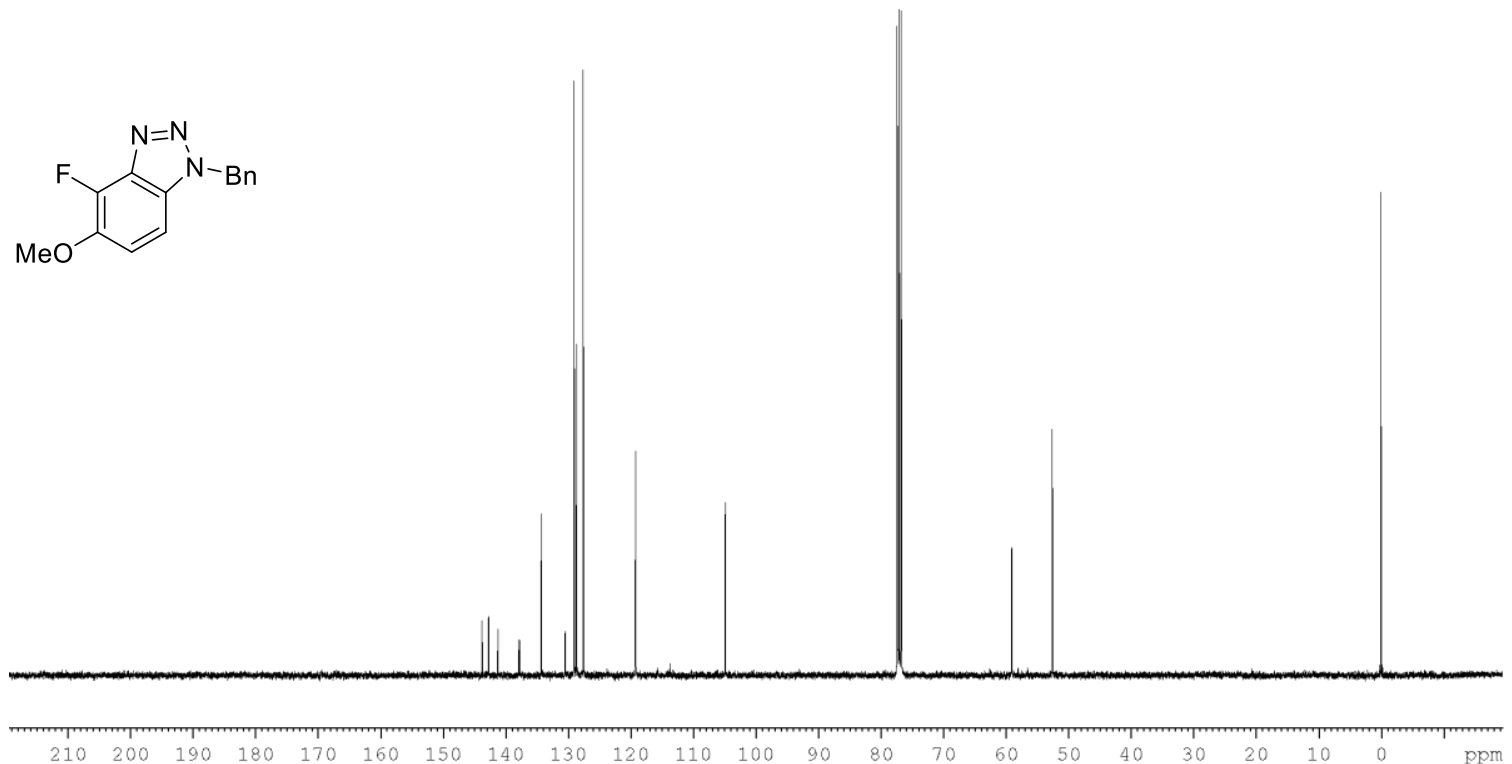

Figure 105. ${ }^{13} \mathrm{C}\left\{{ }^{1} \mathrm{H}\right\} \mathrm{NMR}$ of 8 ge $\mathrm{CDCl}_{3}$ with $1 \% \mathrm{v} / \mathrm{v}$ TMS at $101 \mathrm{MHz}$. 

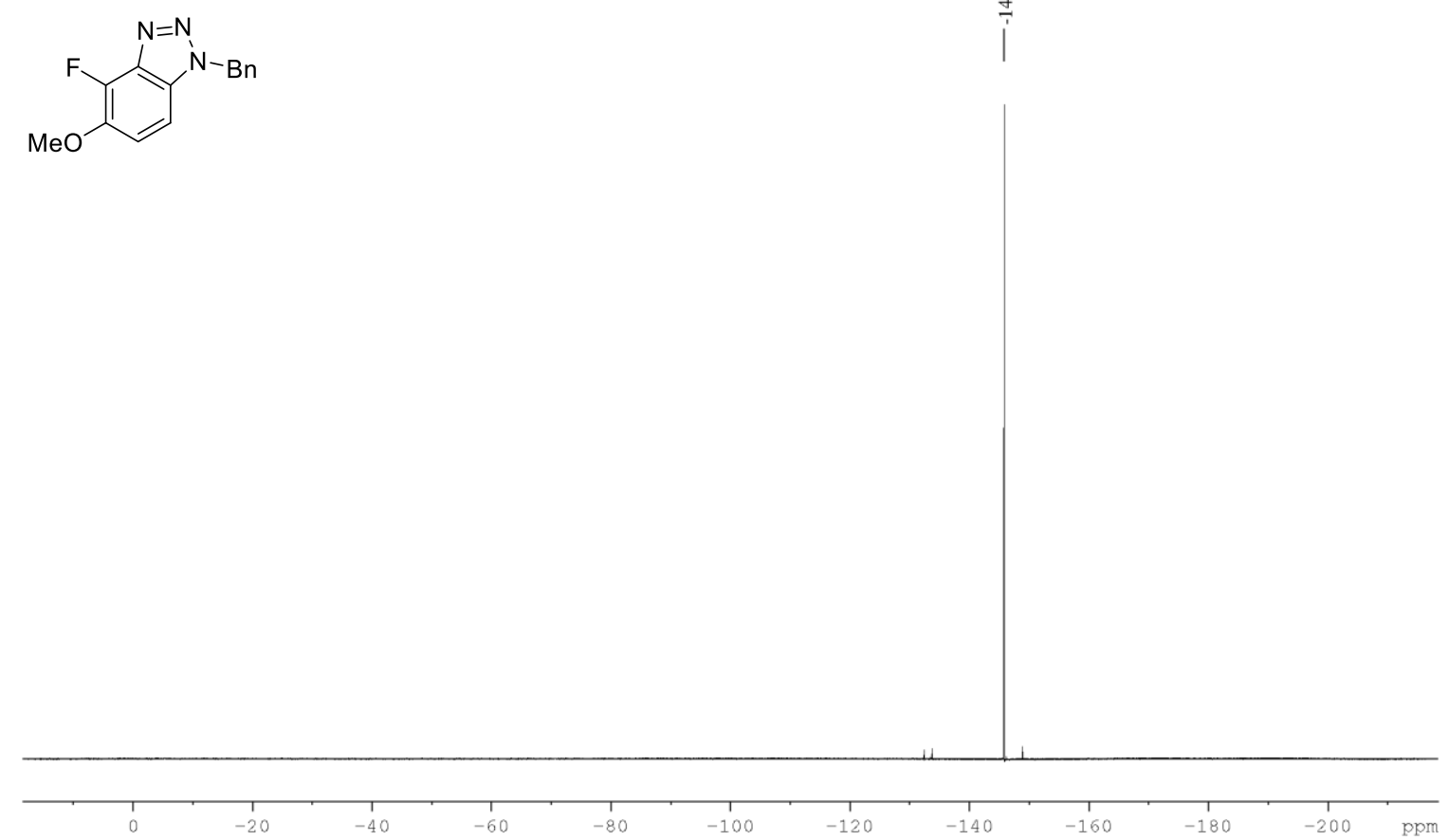

Figure $106 .{ }^{19} \mathrm{~F}\left\{{ }^{1} \mathrm{H}\right\} \mathrm{NMR}$ of 8 ge in $\mathrm{CDCl}_{3}$ with $1 \% \mathrm{v} / \mathrm{v}$ TMS at $376 \mathrm{MHz}$.

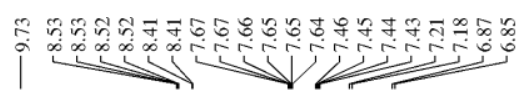<smiles>Cc1ccc(O)c(-c2cccnc2)c1Cl</smiles>

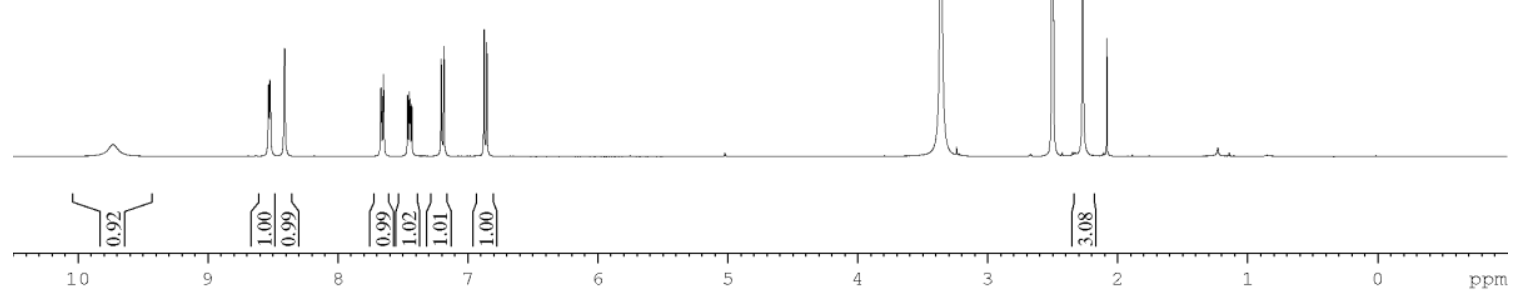

Figure 107. ${ }^{1} \mathrm{H}$ NMR of 8 af in DMSO-d 6 at $400 \mathrm{MHz}$. 


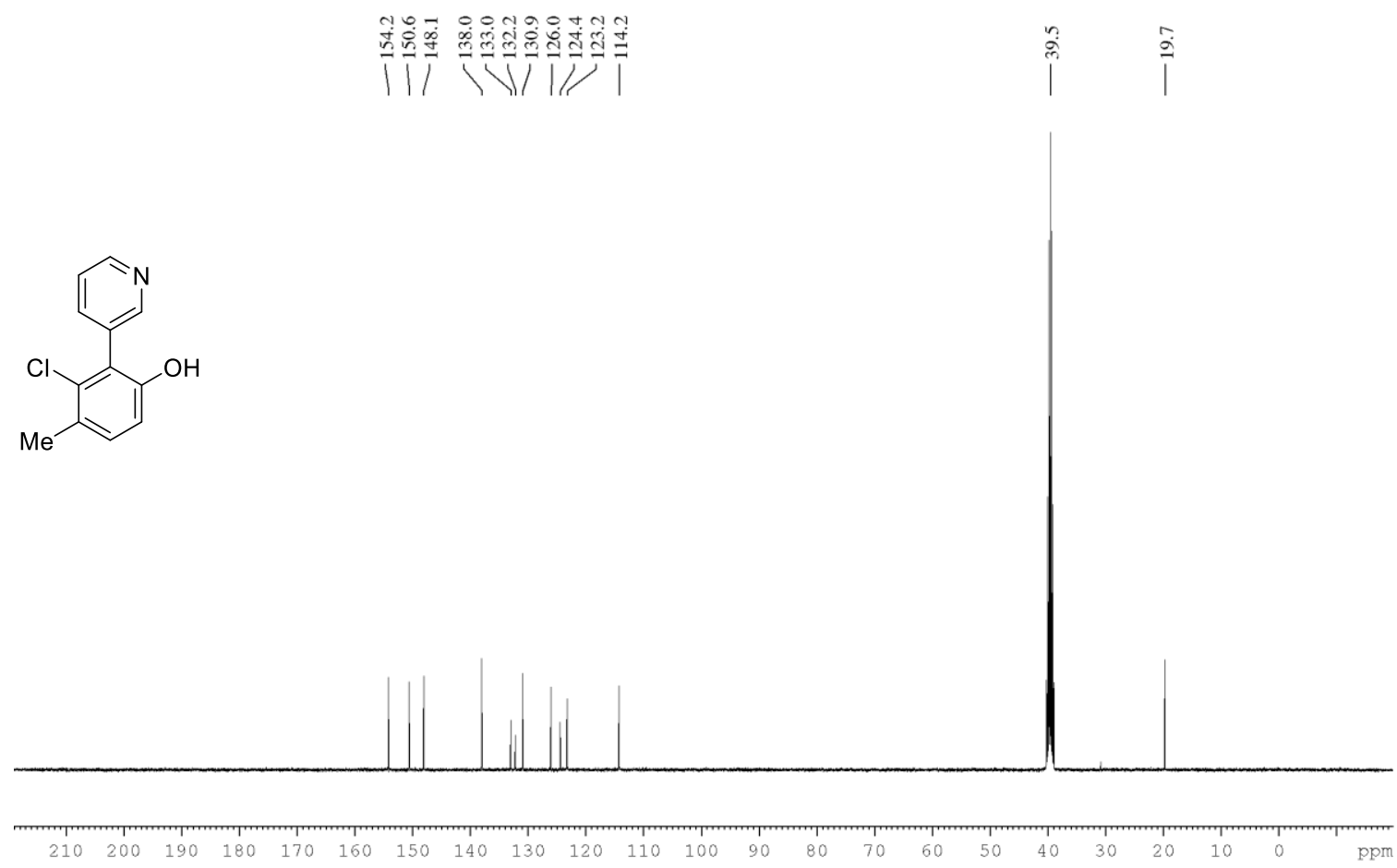

Figure $108 .{ }^{13} \mathrm{C}\left\{{ }^{1} \mathrm{H}\right\}$ NMR of 8af DMSO-d $\mathrm{d}_{6}$ at $101 \mathrm{MHz}$.

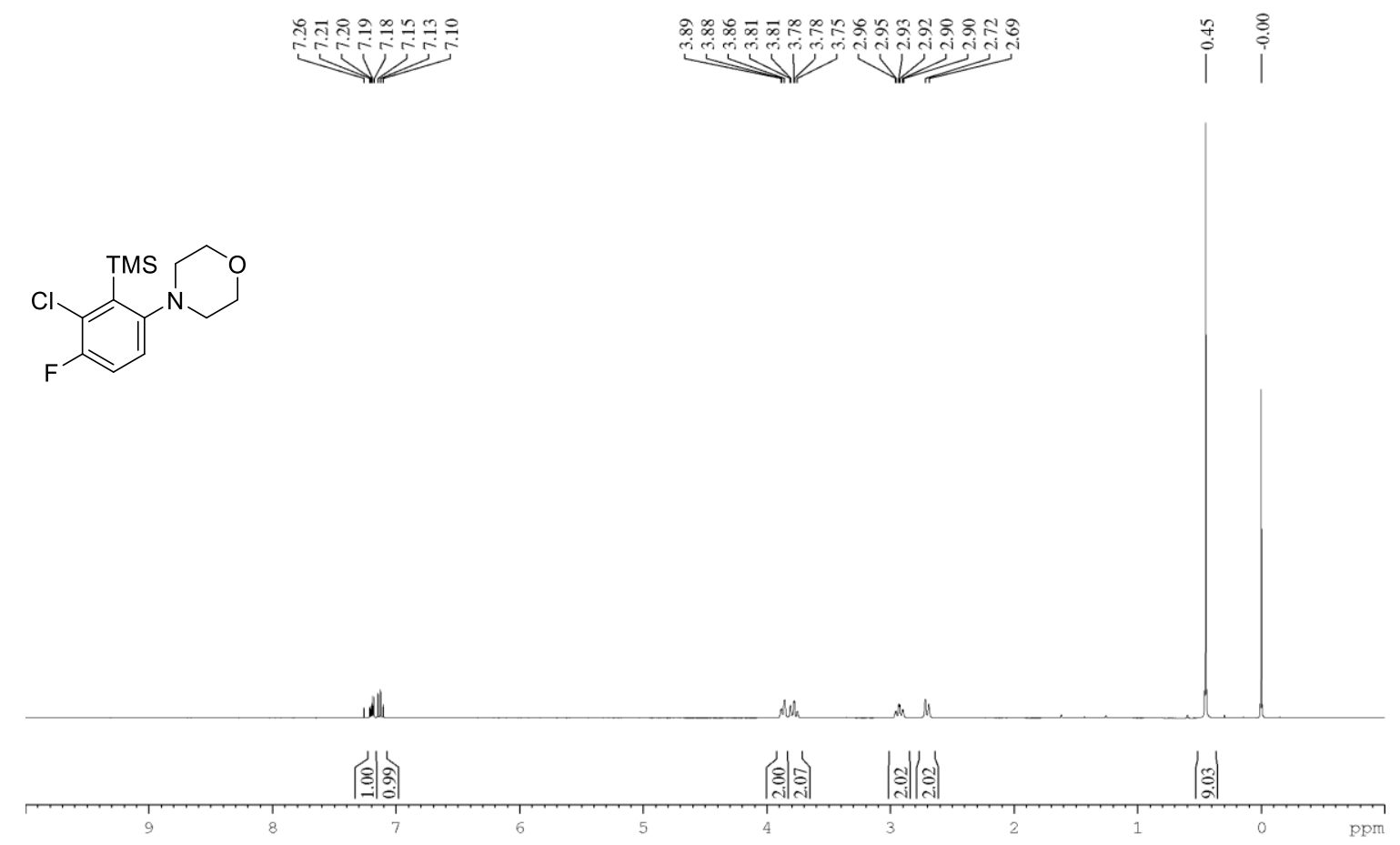

Figure 109. ${ }^{1} \mathrm{H} \mathrm{NMR}$ of $8 \mathrm{dg}$ in $\mathrm{CDCl}_{3}$ with $1 \% \mathrm{v} / \mathrm{v}$ TMS at $400 \mathrm{MHz}$. 


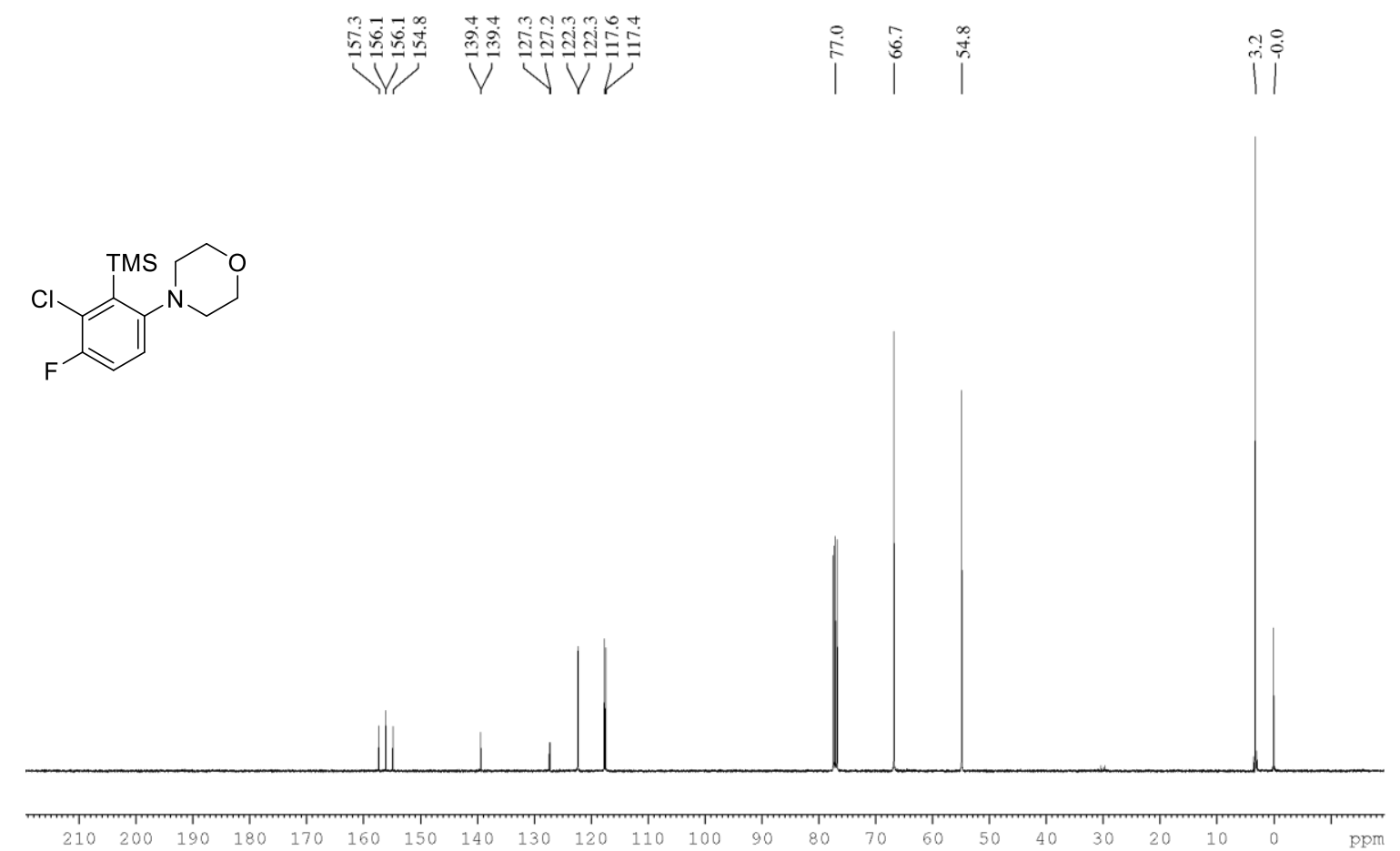

Figure $110 .{ }^{13} \mathrm{C}\left\{{ }^{1} \mathrm{H}\right\} \mathrm{NMR}$ of $8 \mathrm{dg} \mathrm{CDCl}_{3}$ with $1 \% \mathrm{v} / \mathrm{v}$ TMS at $101 \mathrm{MHz}$.

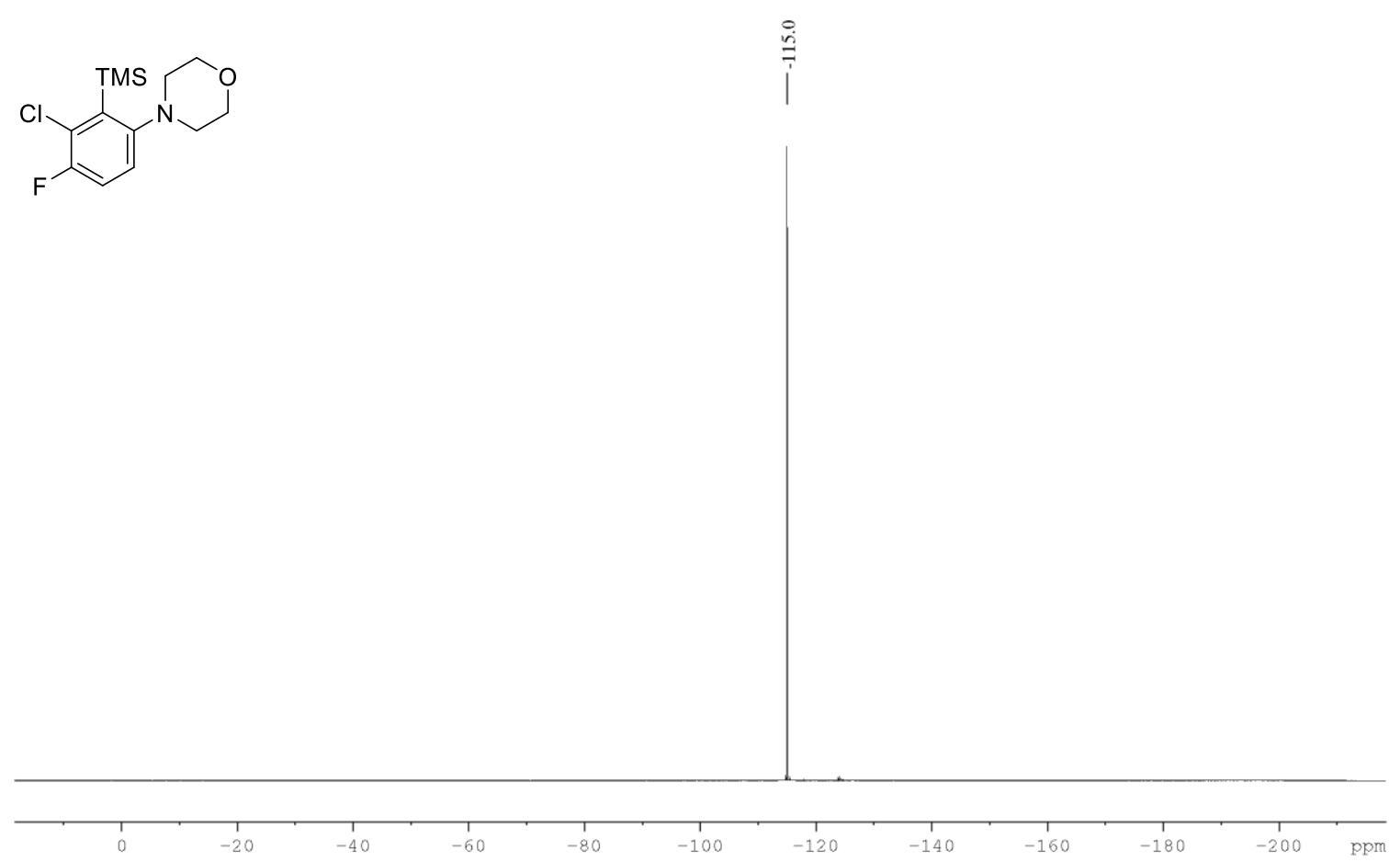

Figure $111 .{ }^{19} \mathrm{~F}\left\{{ }^{1} \mathrm{H}\right\} \mathrm{NMR}$ of $8 \mathrm{dg}$ in $\mathrm{CDCl}_{3}$ with $1 \% \mathrm{v} / \mathrm{v}$ TMS at $376 \mathrm{MHz}$. 


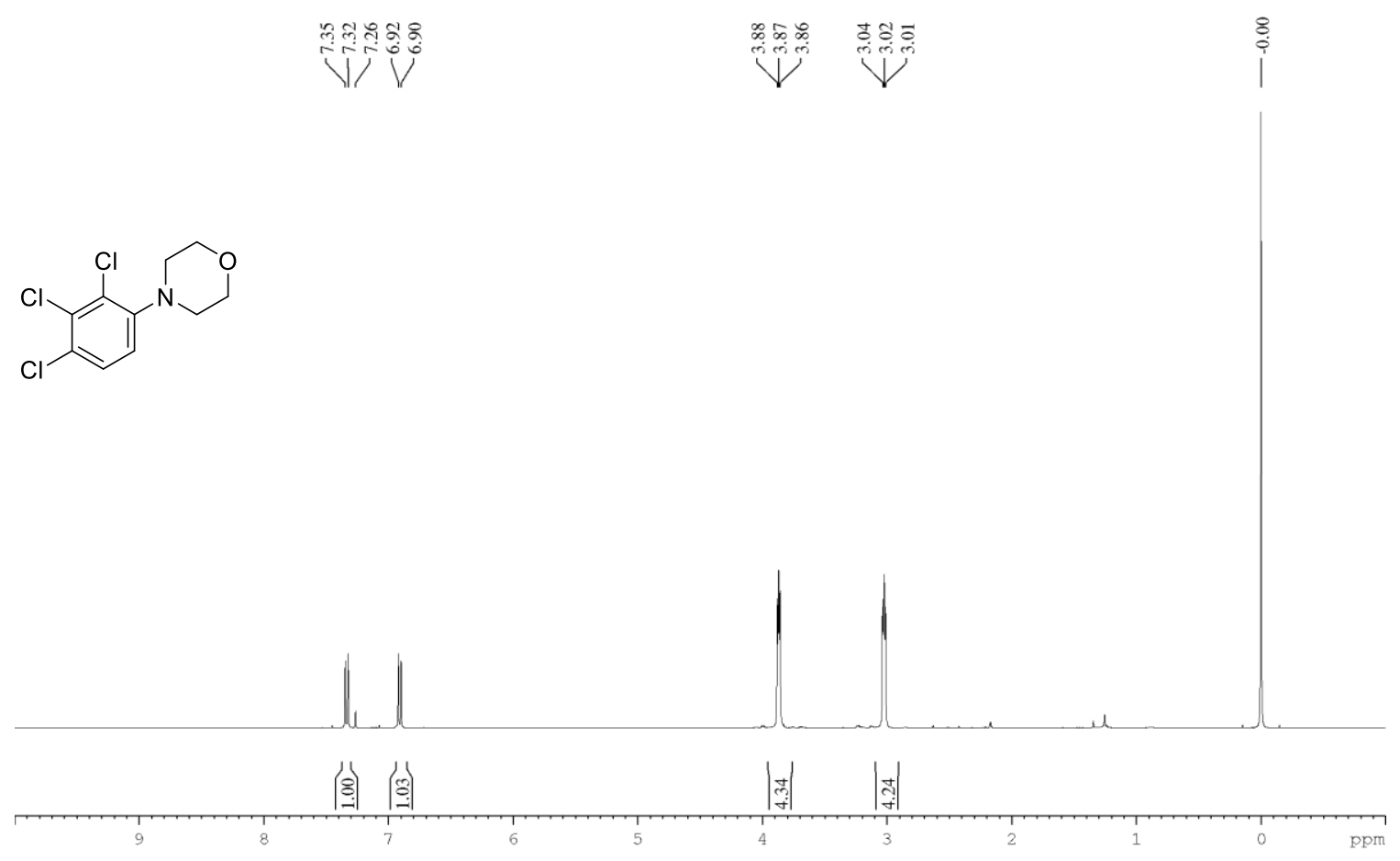

Figure $112 .{ }^{1} \mathrm{H}$ NMR of $8 \mathbf{b h}$ in $\mathrm{CDCl}_{3}$ with $1 \% \mathrm{v} / \mathrm{v}$ TMS at $400 \mathrm{MHz}$.

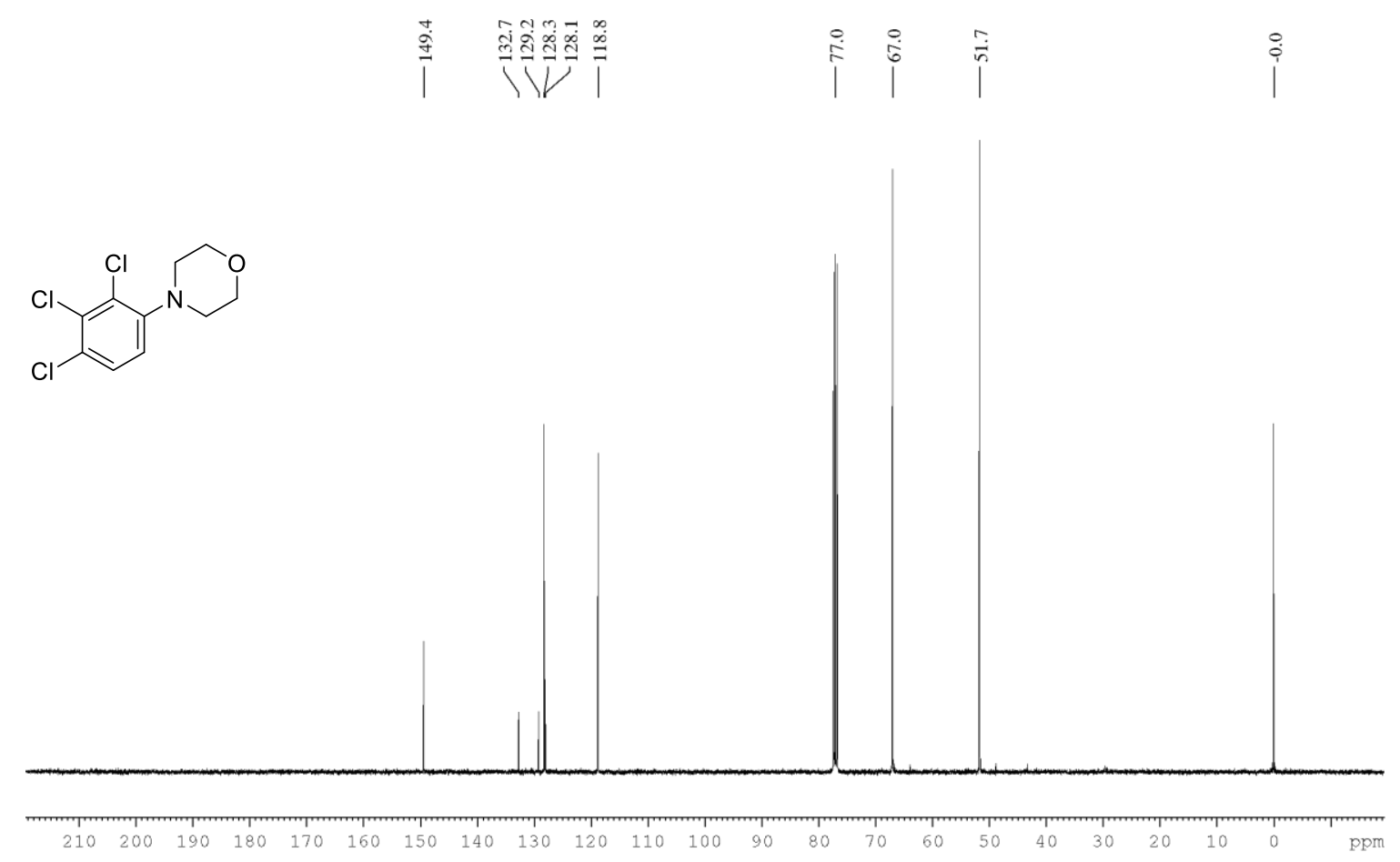

Figure $113 .{ }^{13} \mathrm{C}\left\{{ }^{1} \mathrm{H}\right\} \mathrm{NMR}$ of $8 \mathbf{b h ~ C D C l} 3$ with $1 \% \mathrm{v} / \mathrm{v}$ TMS at $101 \mathrm{MHz}$. 


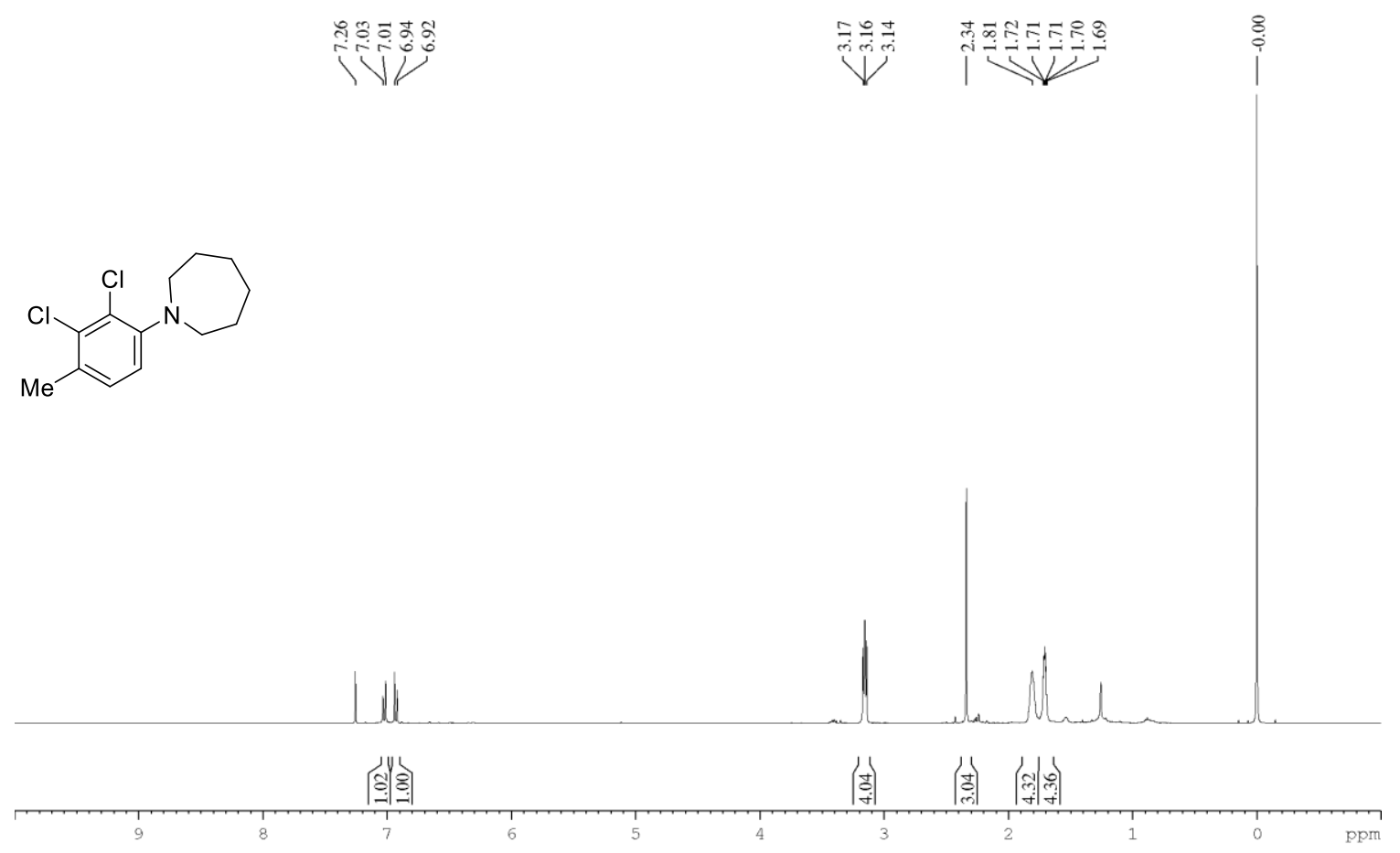

Figure 114. ${ }^{1} \mathrm{H}$ NMR of 8 ai in $\mathrm{CDCl}_{3}$ with $1 \% \mathrm{v} / \mathrm{v}$ TMS at $400 \mathrm{MHz}$.
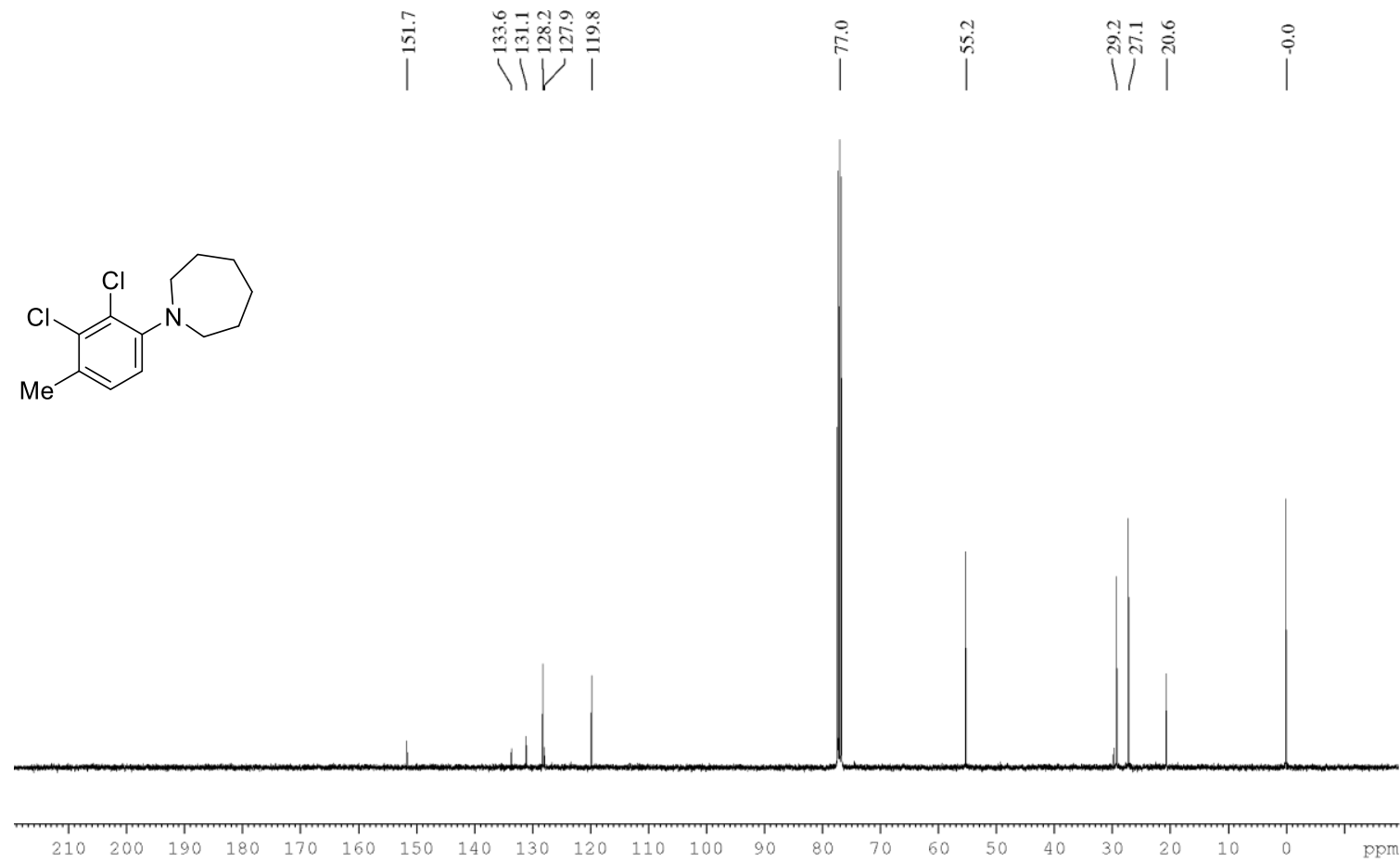

Figure $115 .{ }^{13} \mathrm{C}\left\{{ }^{1} \mathrm{H}\right\}$ NMR of 8 ai $\mathrm{CDCl}_{3}$ with $1 \% \mathrm{v} / \mathrm{v}$ TMS at $101 \mathrm{MHz}$. 


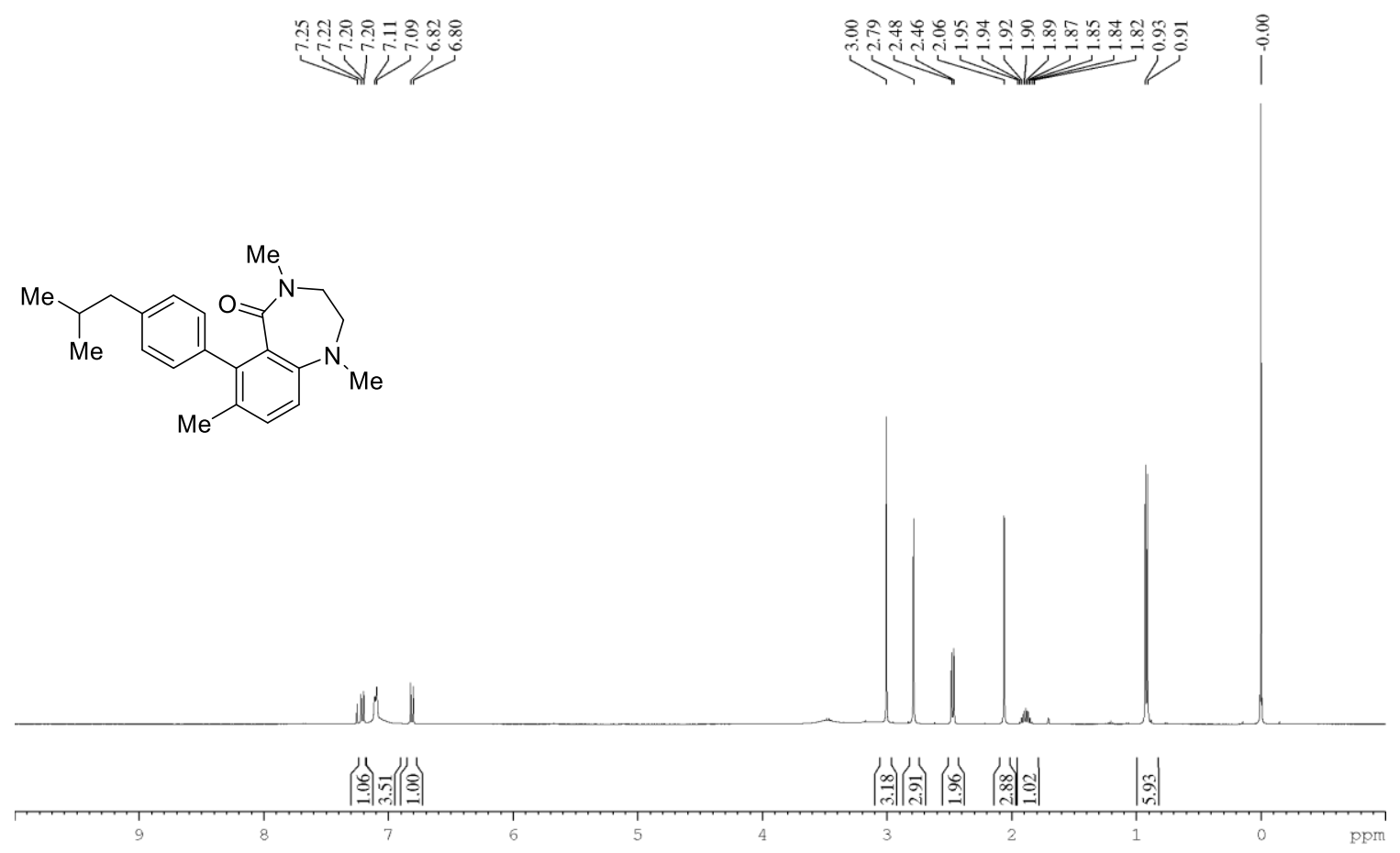

Figure 116. ${ }^{1} \mathrm{H}$ NMR of $9 a$ in $\mathrm{CDCl}_{3}$ with $1 \% \mathrm{v} / \mathrm{v}$ TMS at $400 \mathrm{MHz}$.
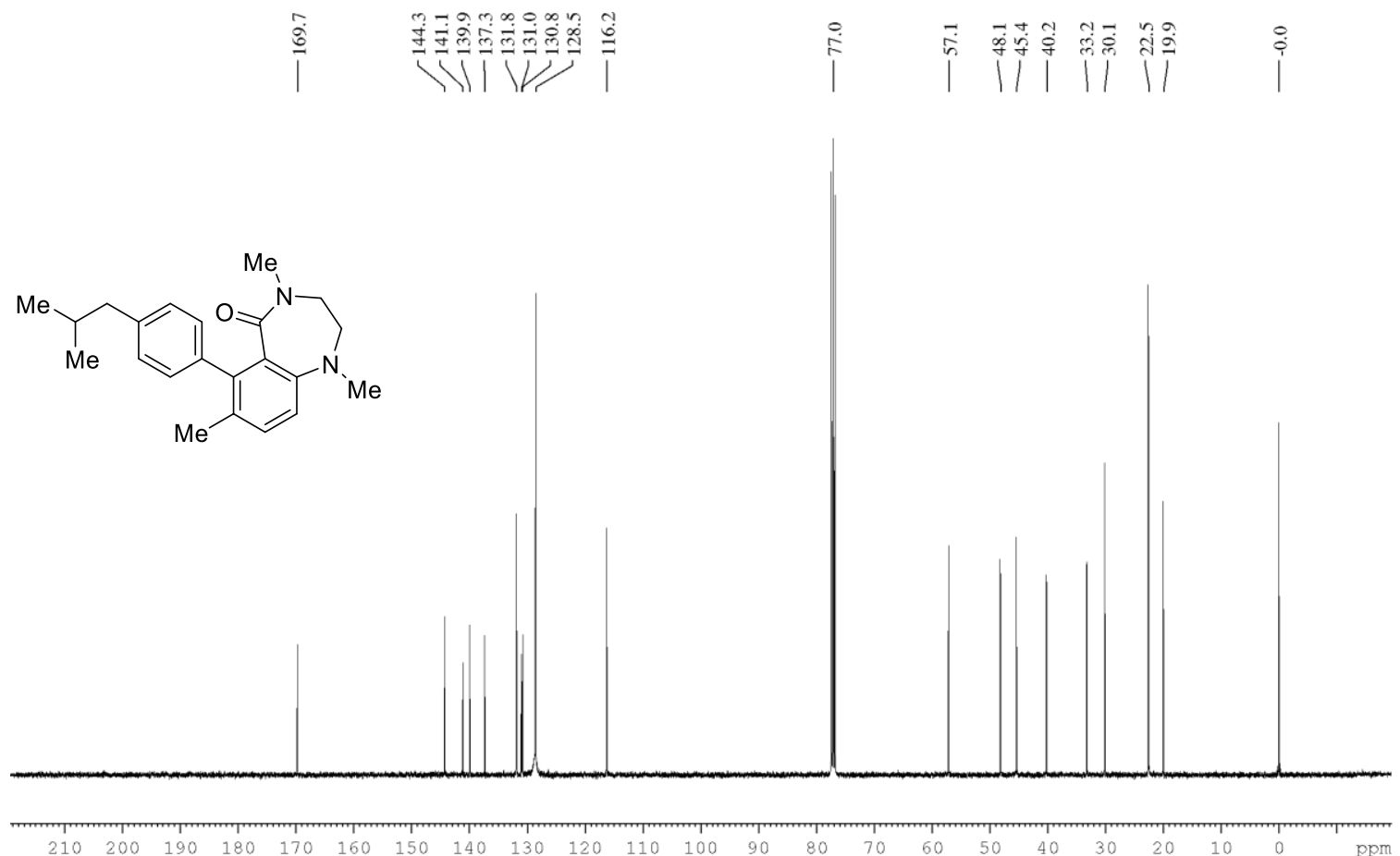

Figure 117. ${ }^{13} \mathrm{C}\left\{{ }^{1} \mathrm{H}\right\} \mathrm{NMR}$ of $9 \mathrm{a} \mathrm{CDCl}_{3}$ with $1 \% \mathrm{v} / \mathrm{v}$ TMS at $101 \mathrm{MHz}$. 


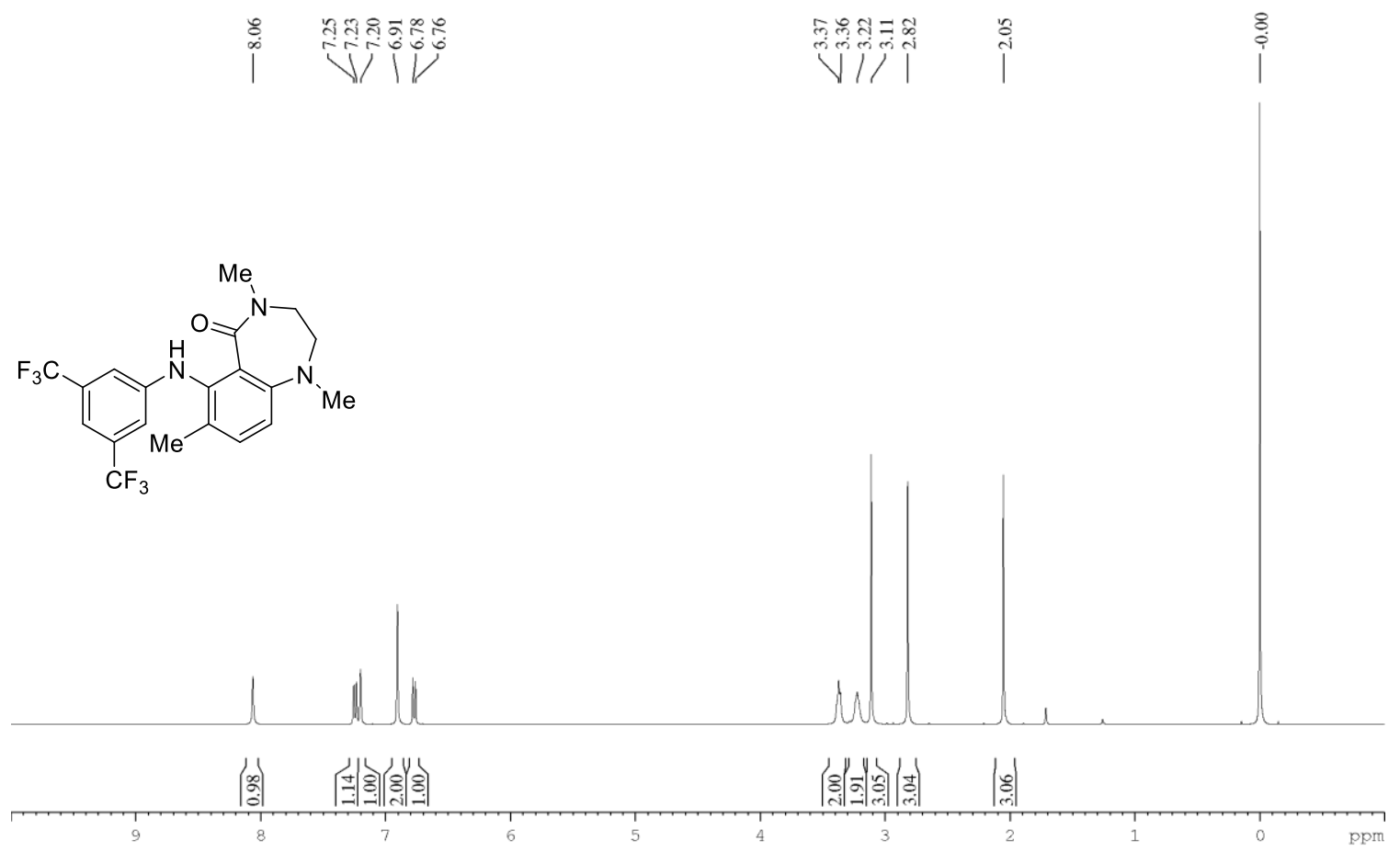

Figure $118 .{ }^{1} \mathrm{H}$ NMR of $9 b$ in $\mathrm{CDCl}_{3}$ with $1 \% \mathrm{v} / \mathrm{v}$ TMS at $400 \mathrm{MHz}$.

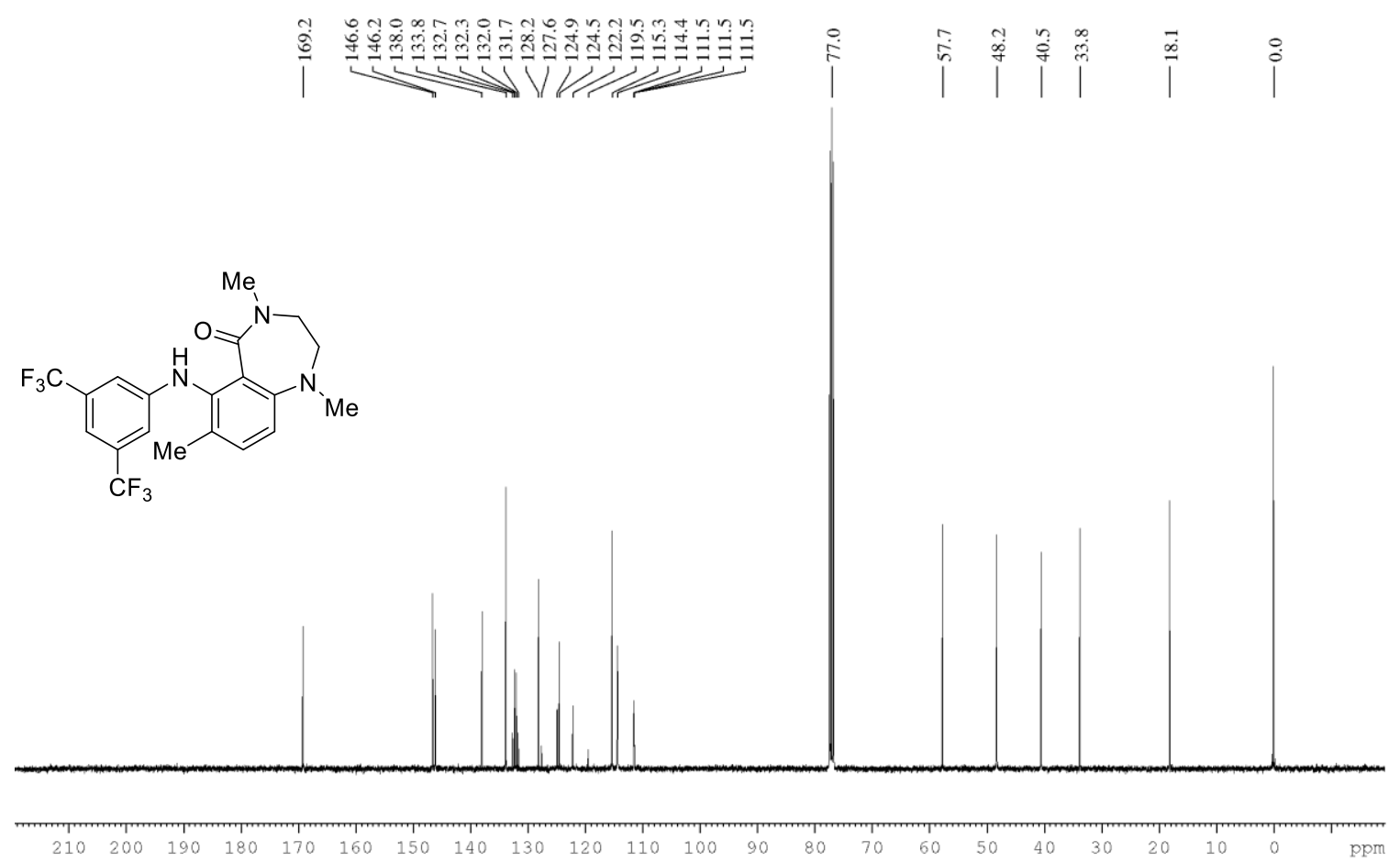

Figure 119. ${ }^{13} \mathrm{C}\left\{{ }^{1} \mathrm{H}\right\} \mathrm{NMR}$ of $9 \mathrm{~b} \mathrm{CDCl}_{3}$ with $1 \% \mathrm{v} / \mathrm{v}$ TMS at $101 \mathrm{MHz}$. 


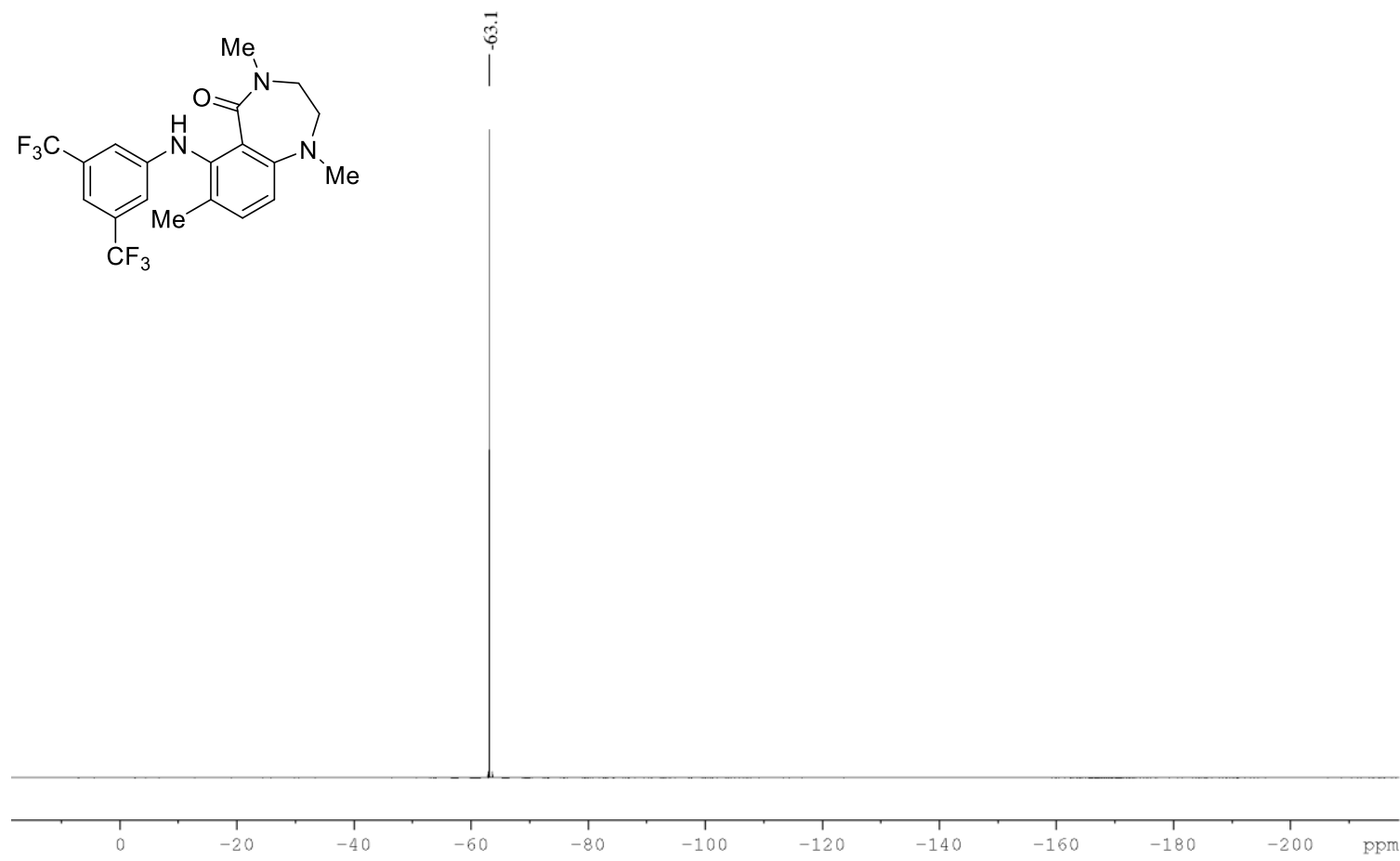

Figure $120 .{ }^{19} \mathrm{~F}\left\{{ }^{1} \mathrm{H}\right\} \mathrm{NMR}$ of $9 \mathrm{~b}$ in $\mathrm{CDCl}_{3}$ with $1 \% \mathrm{v} / \mathrm{v}$ TMS at $376 \mathrm{MHz}$.
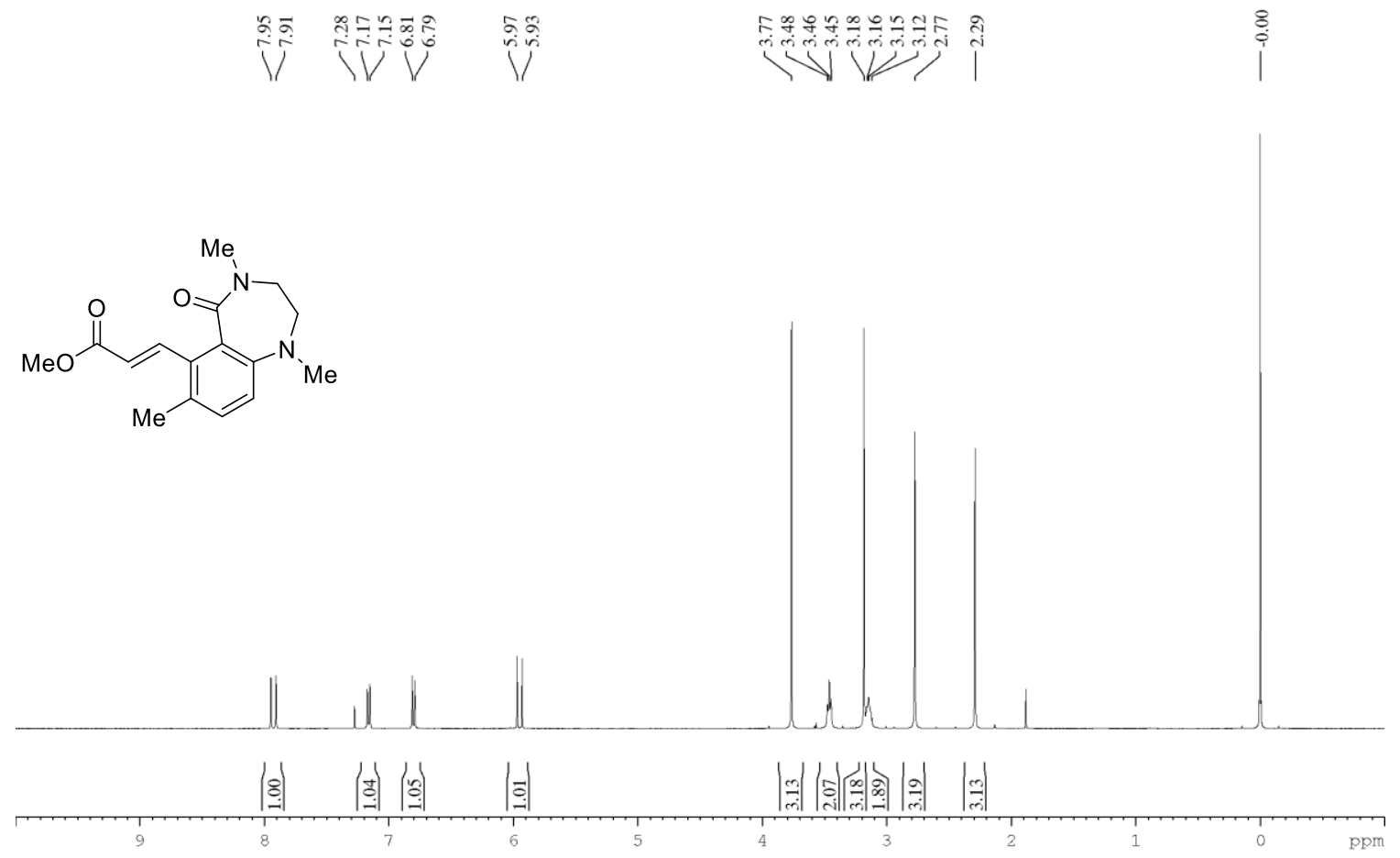

Figure $121 .{ }^{1} \mathrm{H} \mathrm{NMR}$ of $9 \mathrm{c}$ in $\mathrm{CDCl}_{3}$ with $1 \% \mathrm{v} / \mathrm{v}$ TMS at $400 \mathrm{MHz}$. 


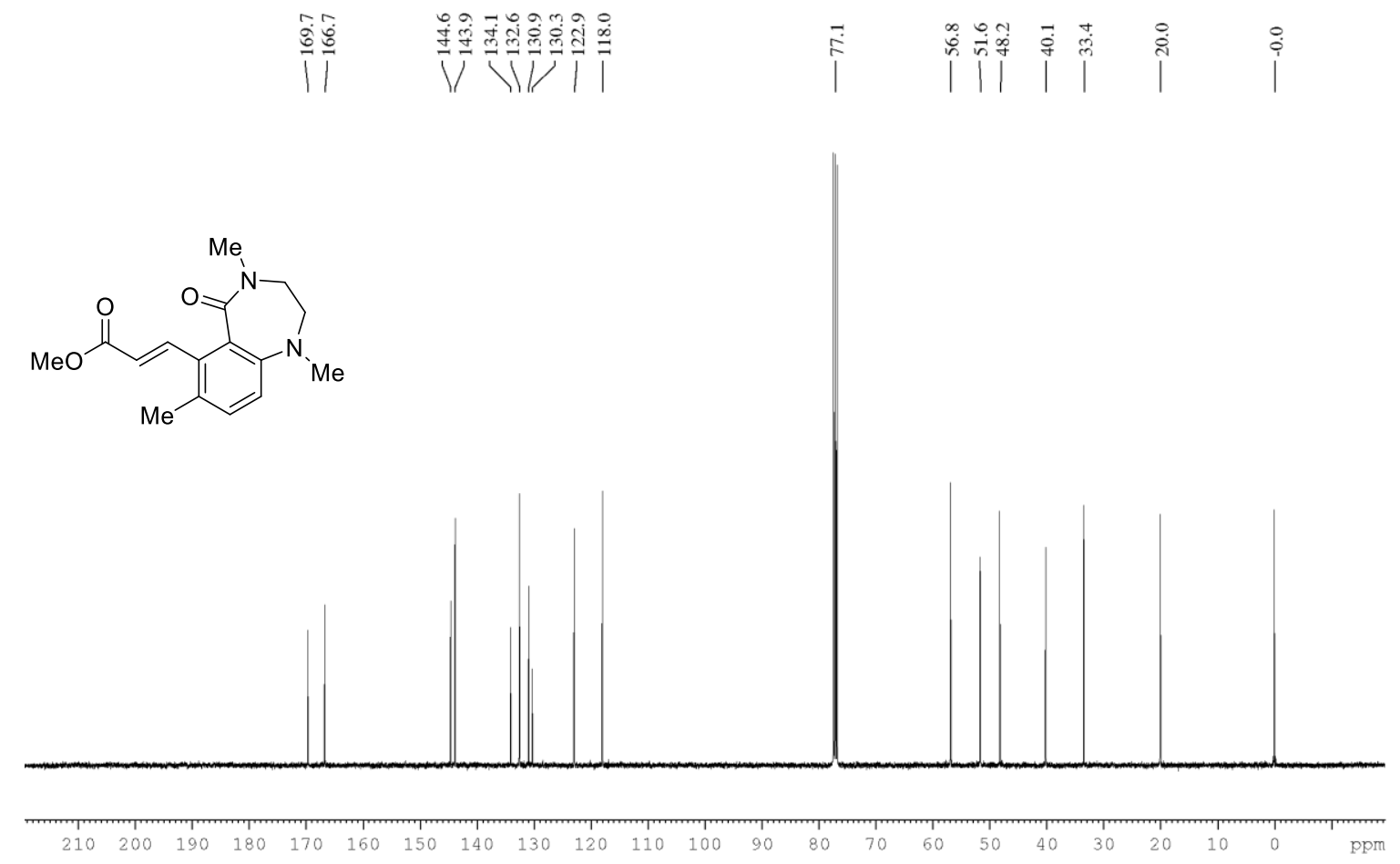

Figure $122 .{ }^{13} \mathrm{C}\left\{{ }^{1} \mathrm{H}\right\} \mathrm{NMR}$ of $9 \mathrm{c} \mathrm{CDCl} 3$ with $1 \% \mathrm{v} / \mathrm{v}$ TMS at $101 \mathrm{MHz}$.

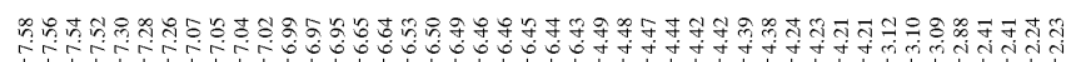

$\Rightarrow N \mathrm{VIN}$

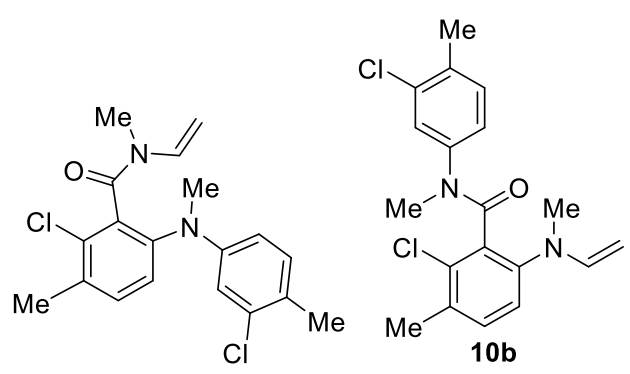

$10 \mathbf{a}$

Wh

ul

1

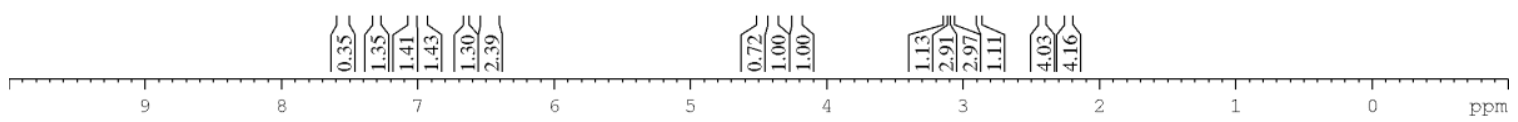

Figure 123. ${ }^{1} \mathrm{H}$ NMR of $10 a$ and $10 \mathrm{~b}$ in $\mathrm{CDCl}_{3}$ with $1 \% \mathrm{v} / \mathrm{v}$ TMS at $400 \mathrm{MHz}$. 


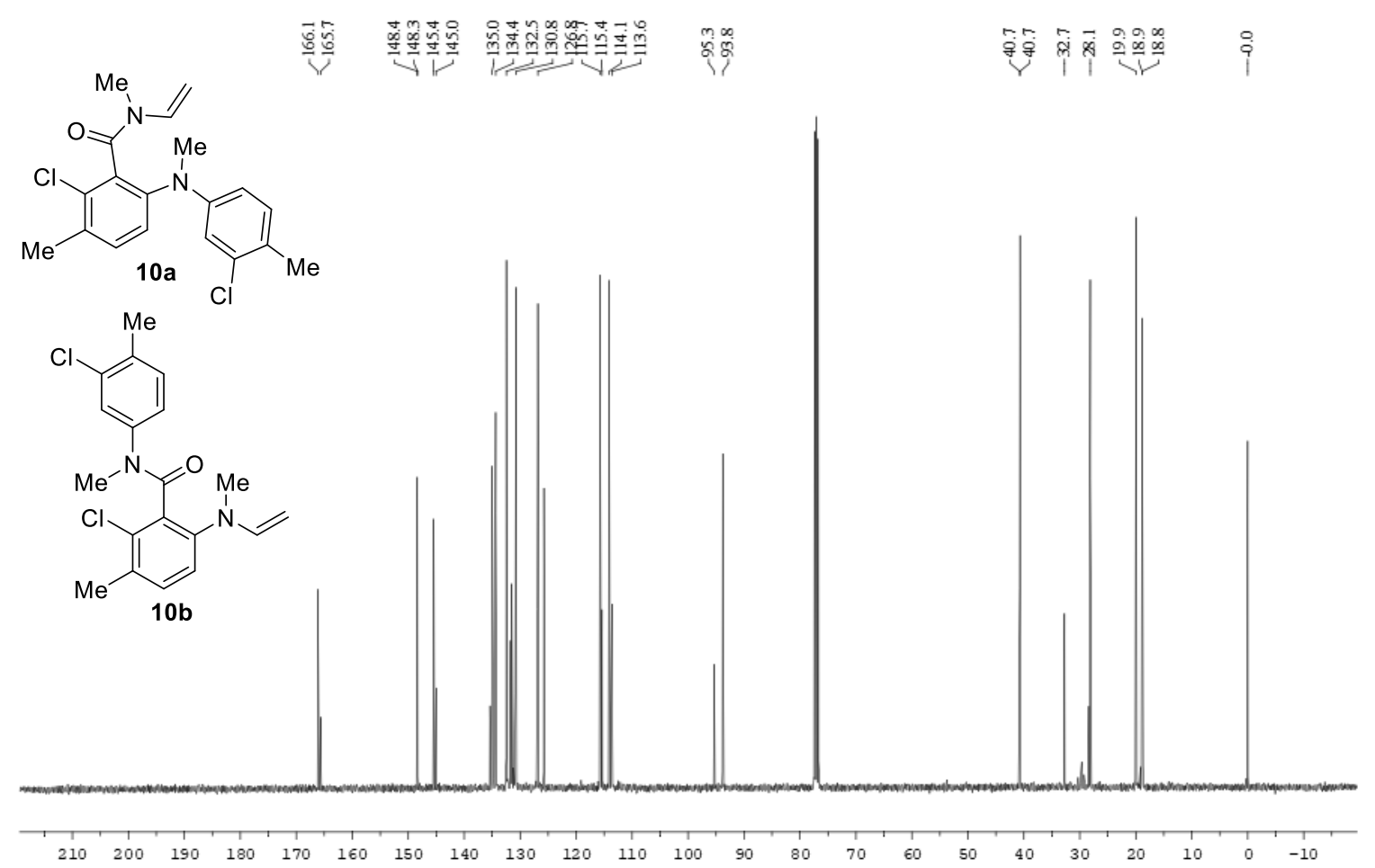

Figure 124. ${ }^{13} \mathrm{C}\left\{{ }^{1} \mathrm{H}\right\}$ NMR of $10 \mathrm{a}$ and $10 \mathrm{~b} \mathrm{CDCl}_{3}$ with $1 \% \mathrm{v} / \mathrm{v}$ TMS at $101 \mathrm{MHz}$.

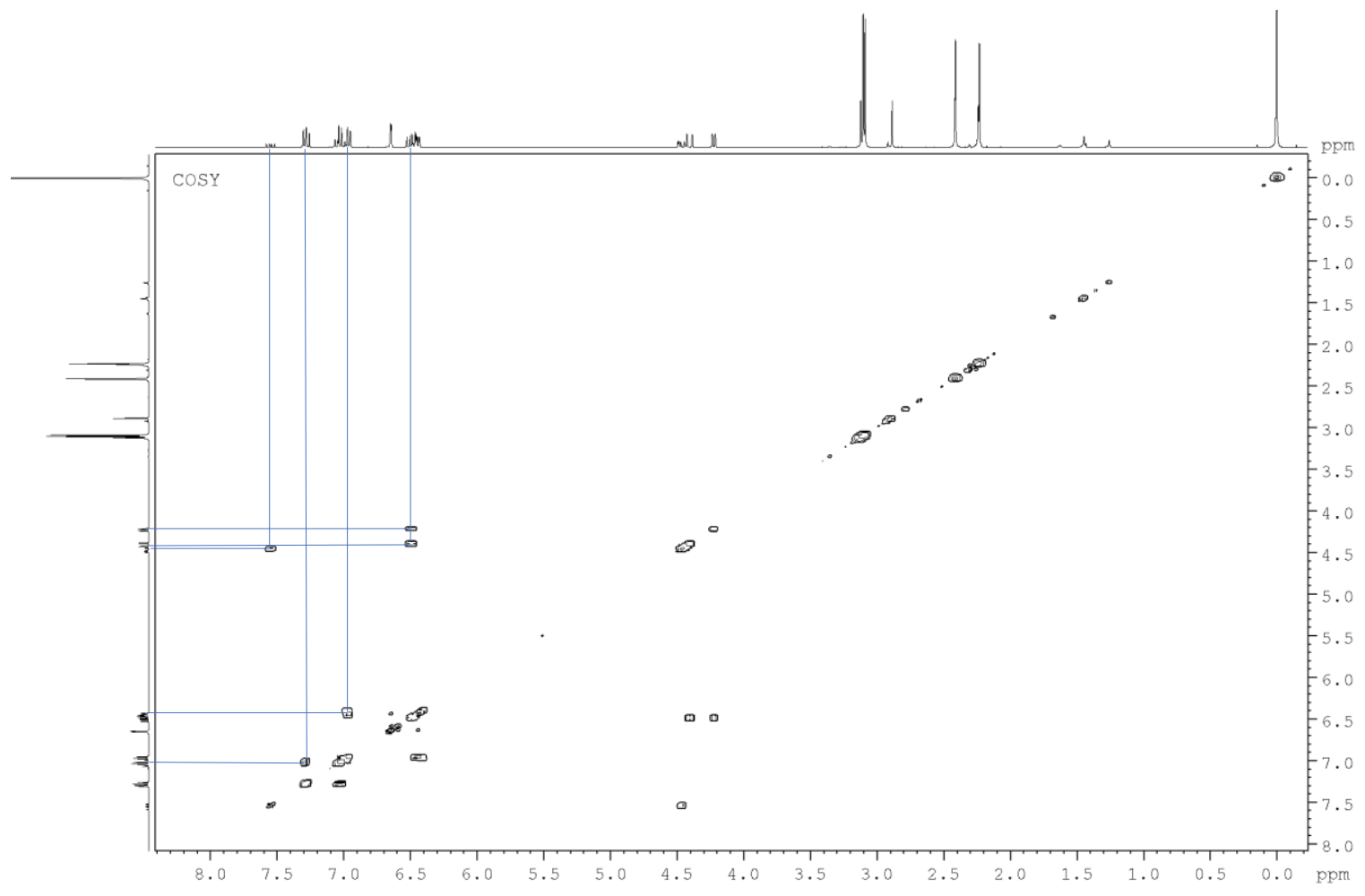

Figure 125. COSY of 10a and $\mathbf{1 0 b}$ in $\mathrm{CDCl}_{3}$ with $1 \% \mathrm{v} / \mathrm{v}$ TMS at $600 \mathrm{MHz}$. 


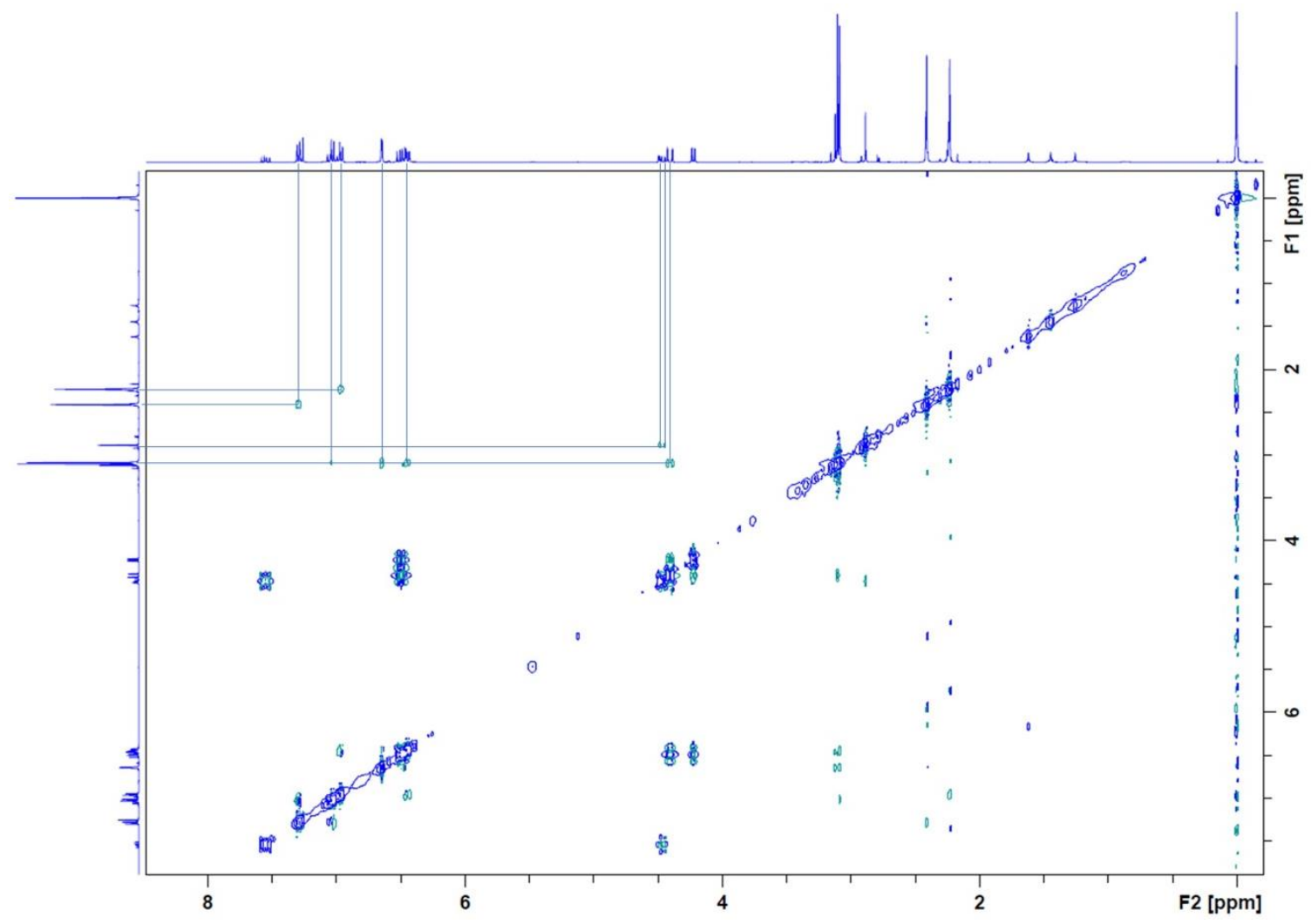

Figure 126. NOESY of $10 \mathrm{a}$ and $10 \mathrm{~b}$ in $\mathrm{CDCl}_{3}$ with $1 \% \mathrm{v} / \mathrm{v}$ TMS at $400 \mathrm{MHz}$.

DEPT 135
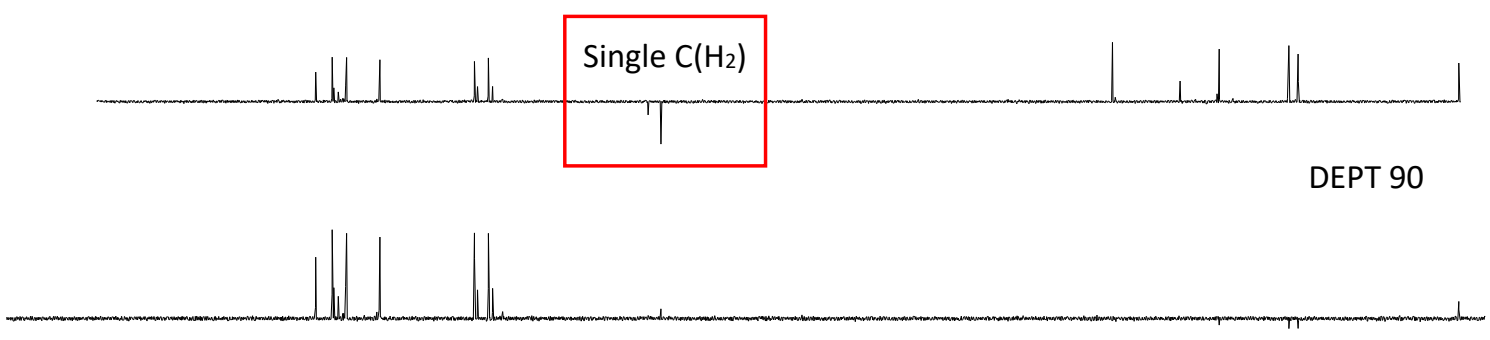

DEPT 45

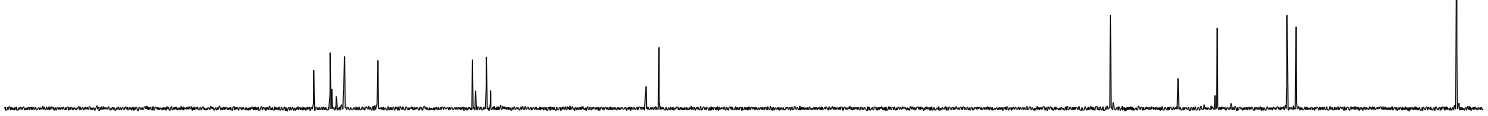

${ }^{13} \mathrm{C}$
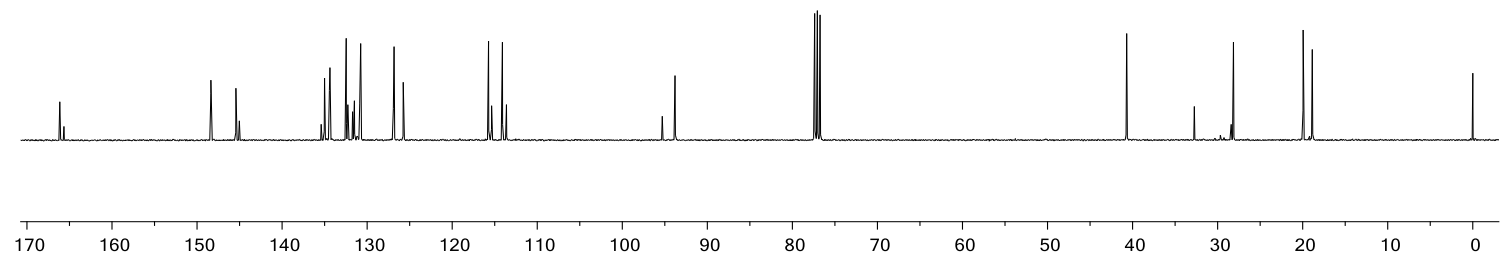

Figure 127. Stacked ${ }^{13} \mathrm{C}$ NMR spectra of $10 \mathrm{a}$ and $10 \mathrm{~b}$. 


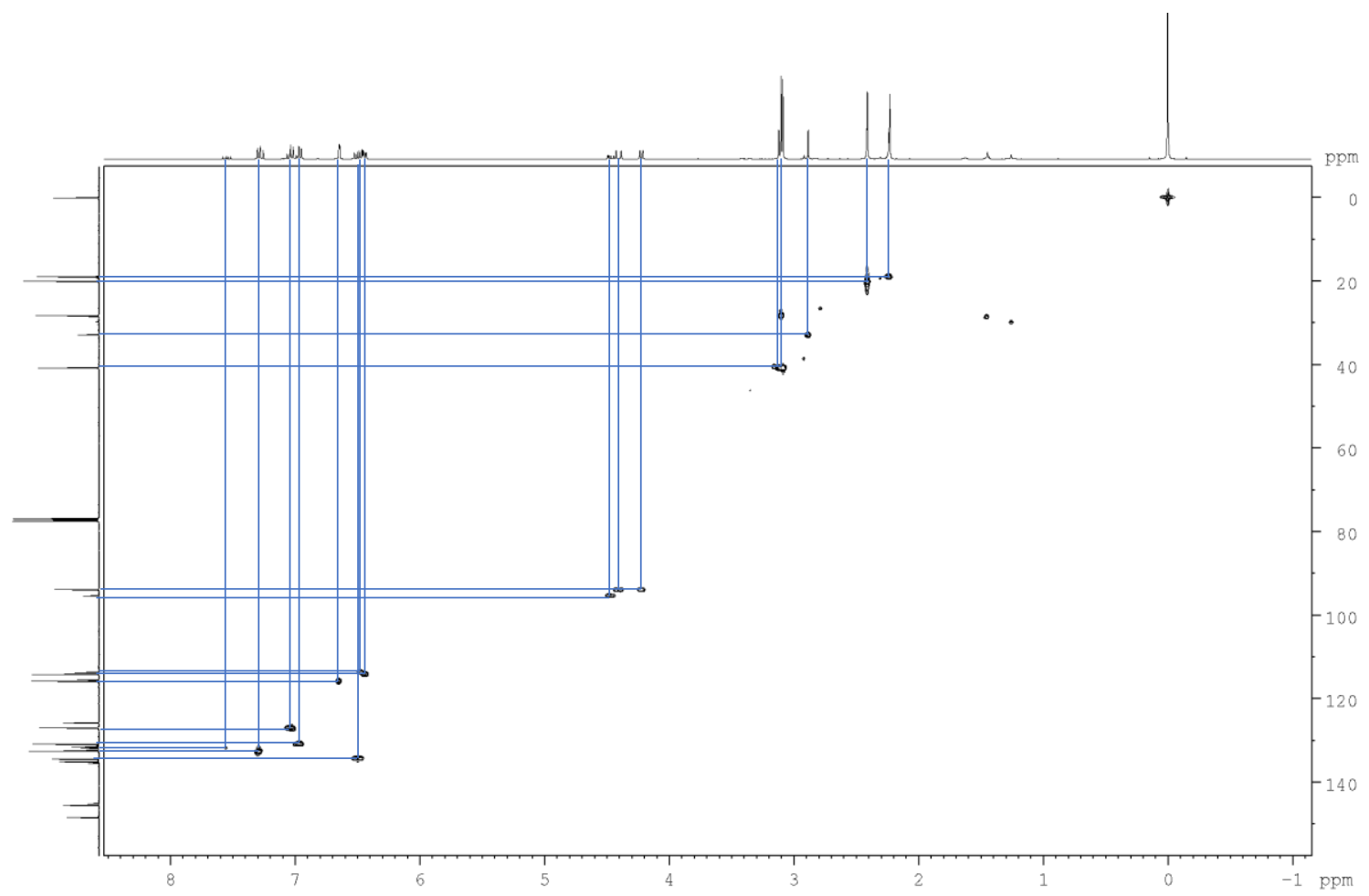

Figure 128. HSQC of $10 \mathrm{a}$ and $10 \mathrm{~b}$ in $\mathrm{CDCl}_{3}$ with $1 \% \mathrm{v} / \mathrm{v} \mathrm{TMS}$ at $400 \mathrm{MHz}$.

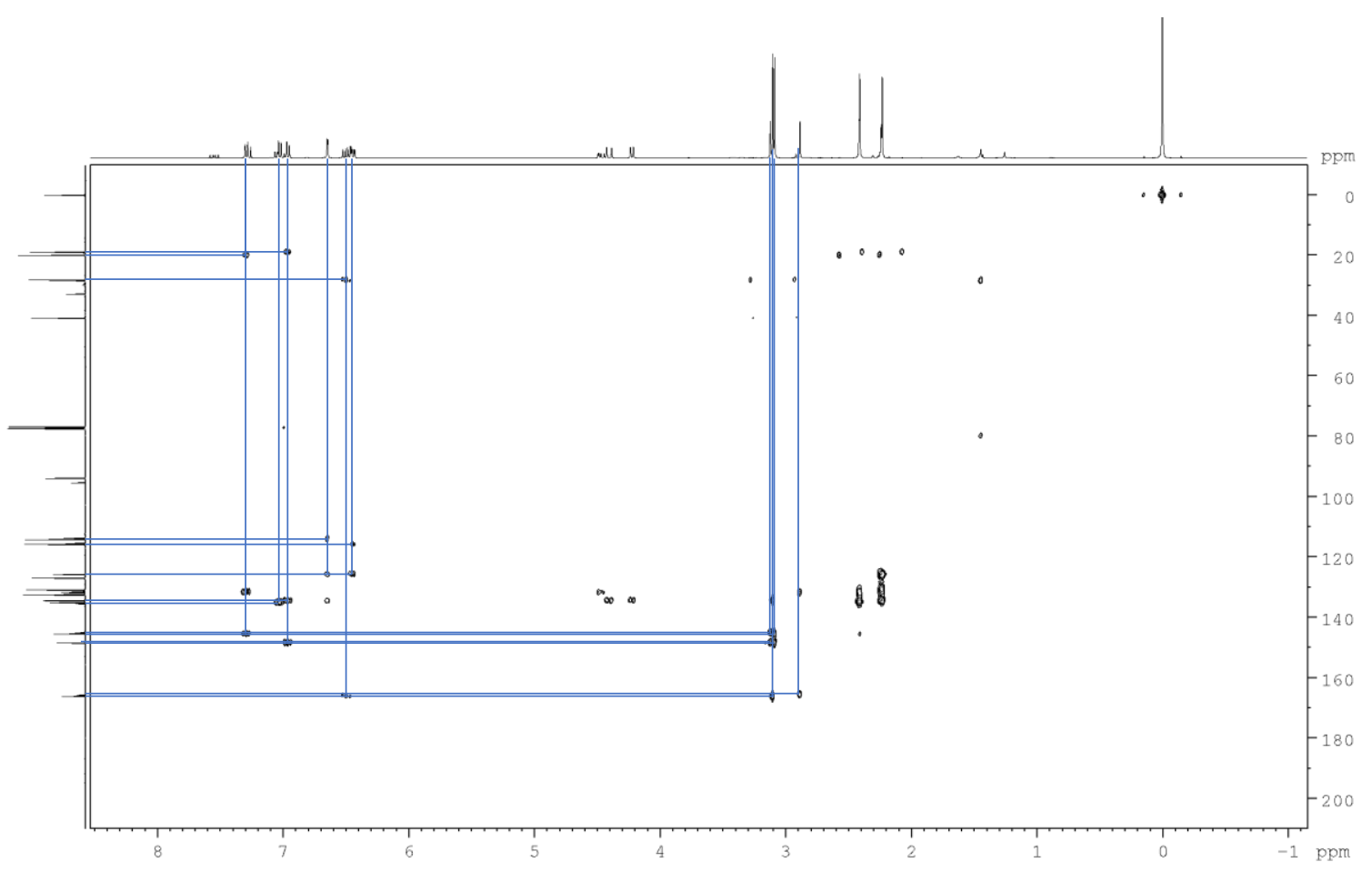

Figure 129. $\mathrm{HMBC}$ of $10 \mathrm{a}$ and $10 \mathrm{~b}$ in $\mathrm{CDCl}_{3}$ with $1 \% \mathrm{v} / \mathrm{v} \mathrm{TMS}$ at $400 \mathrm{MHz}$ (unambiguous correlations shown). 
<smiles>C=CN(C)C(=O)c1c(N(C)c2ccc(C(F)(F)F)c(F)c2)ccc(C)c1Cl</smiles>

10c<smiles>C=CN(C)c1cc(O)c(C)c(Cl)c1C(=O)N(C)c1ccc(F)c(C(F)(F)F)c1</smiles>

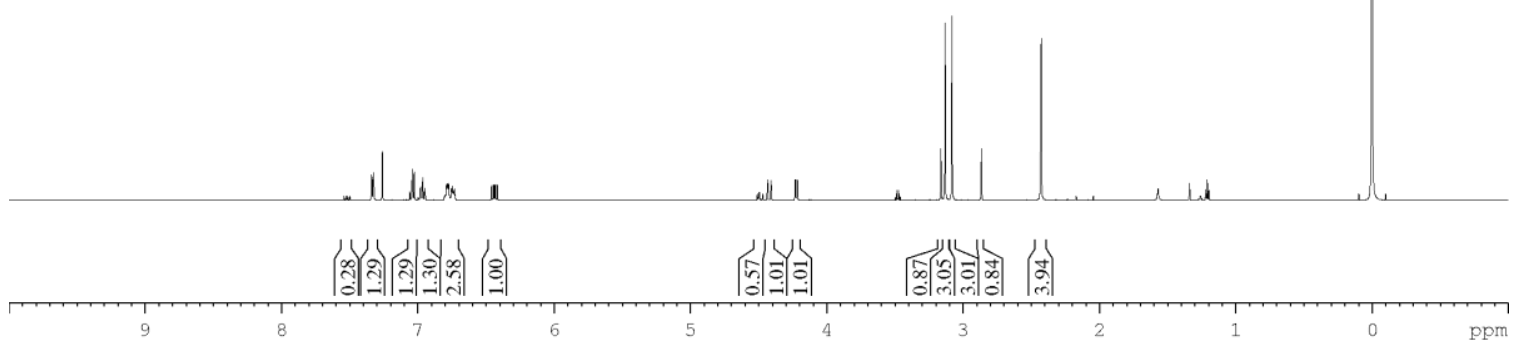

Figure $130 .{ }^{1} \mathrm{H} \mathrm{NMR}$ of $10 \mathrm{c}$ and $10 \mathrm{~d}$ in $\mathrm{CDCl}_{3}$ with $1 \% \mathrm{v} / \mathrm{v} \mathrm{TMS}$ at $600 \mathrm{MHz}$.
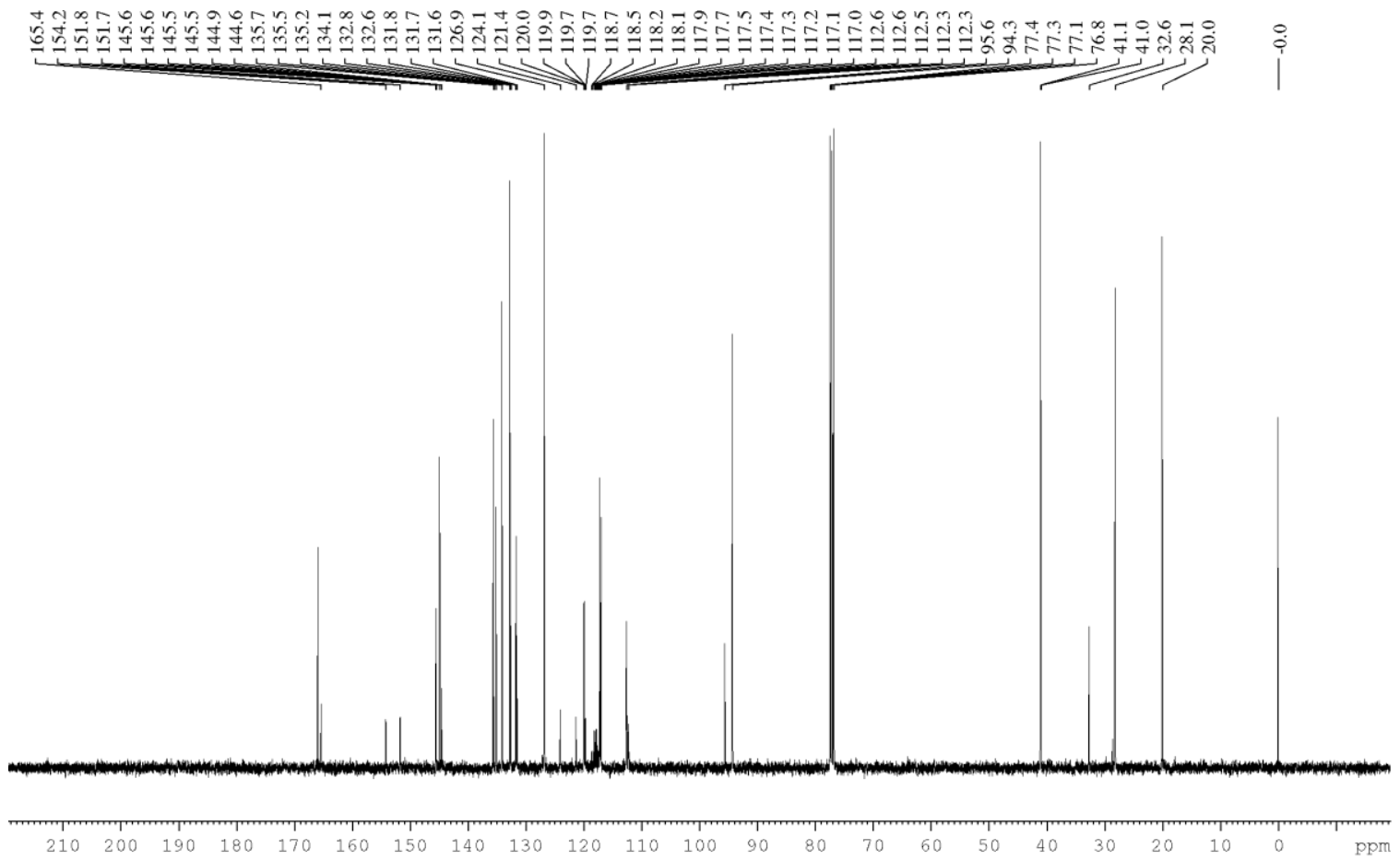

Figure $131 .{ }^{13} \mathrm{C}\left\{{ }^{1} \mathrm{H}\right\} \mathrm{NMR}$ of $\mathbf{1 0 c}$ and $10 \mathrm{~d} \mathrm{CDCl}_{3}$ with $1 \% \mathrm{v} / \mathrm{v}$ TMS at $101 \mathrm{MHz}$. 


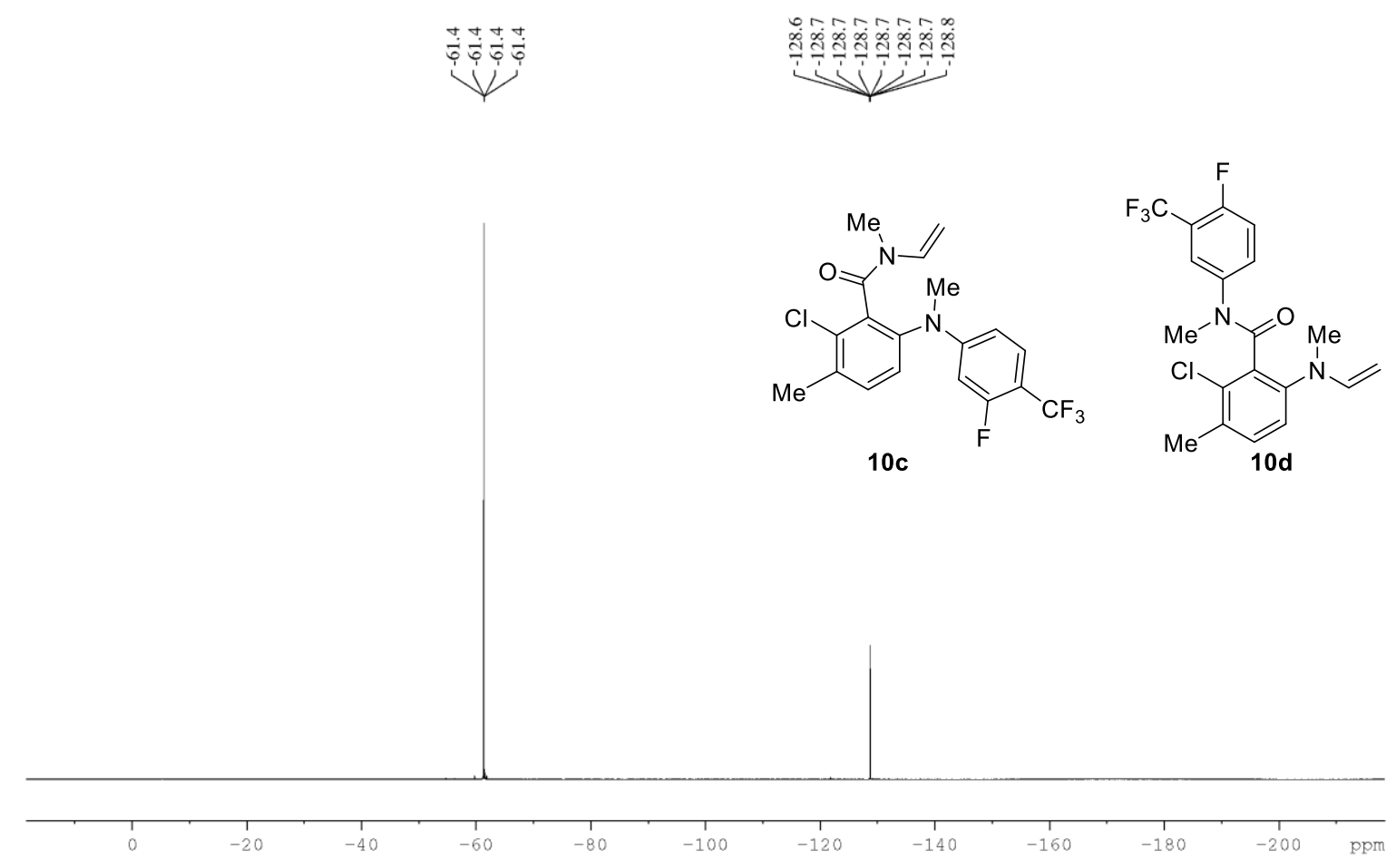

Figure $132 .{ }^{19} \mathrm{~F}\left\{{ }^{1} \mathrm{H}\right\} \mathrm{NMR}$ of $10 \mathrm{c}$ and $10 \mathrm{~d}$ in $\mathrm{CDCl}_{3}$ with $1 \% \mathrm{v} / \mathrm{v}$ TMS at $376 \mathrm{MHz}$.

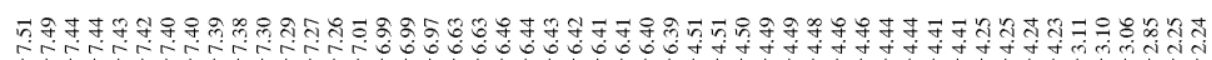

等
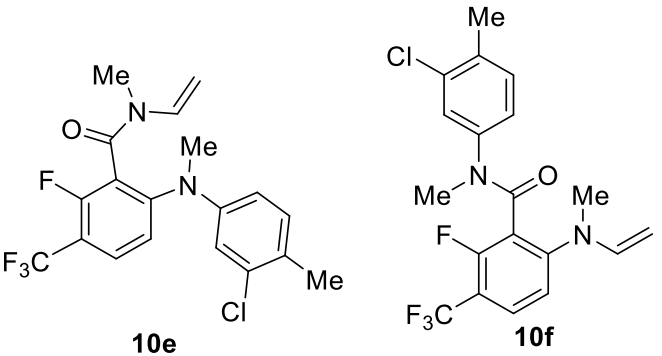

will

光
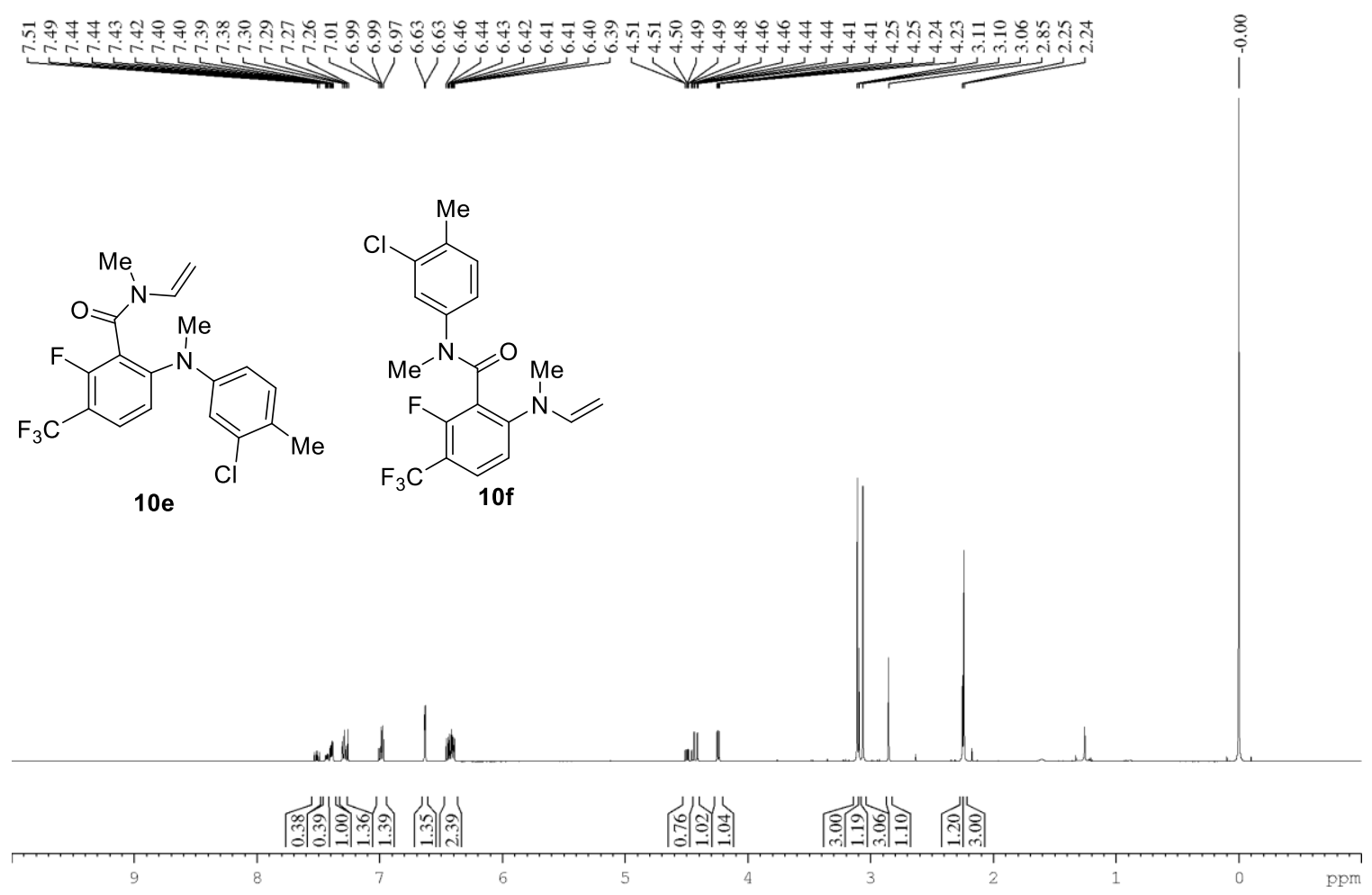

Figure 133. ${ }^{1} \mathrm{H}$ NMR of $10 e$ and 10 in $\mathrm{CDCl}_{3}$ with $1 \% \mathrm{v} / \mathrm{v}$ TMS at $400 \mathrm{MHz}$. 

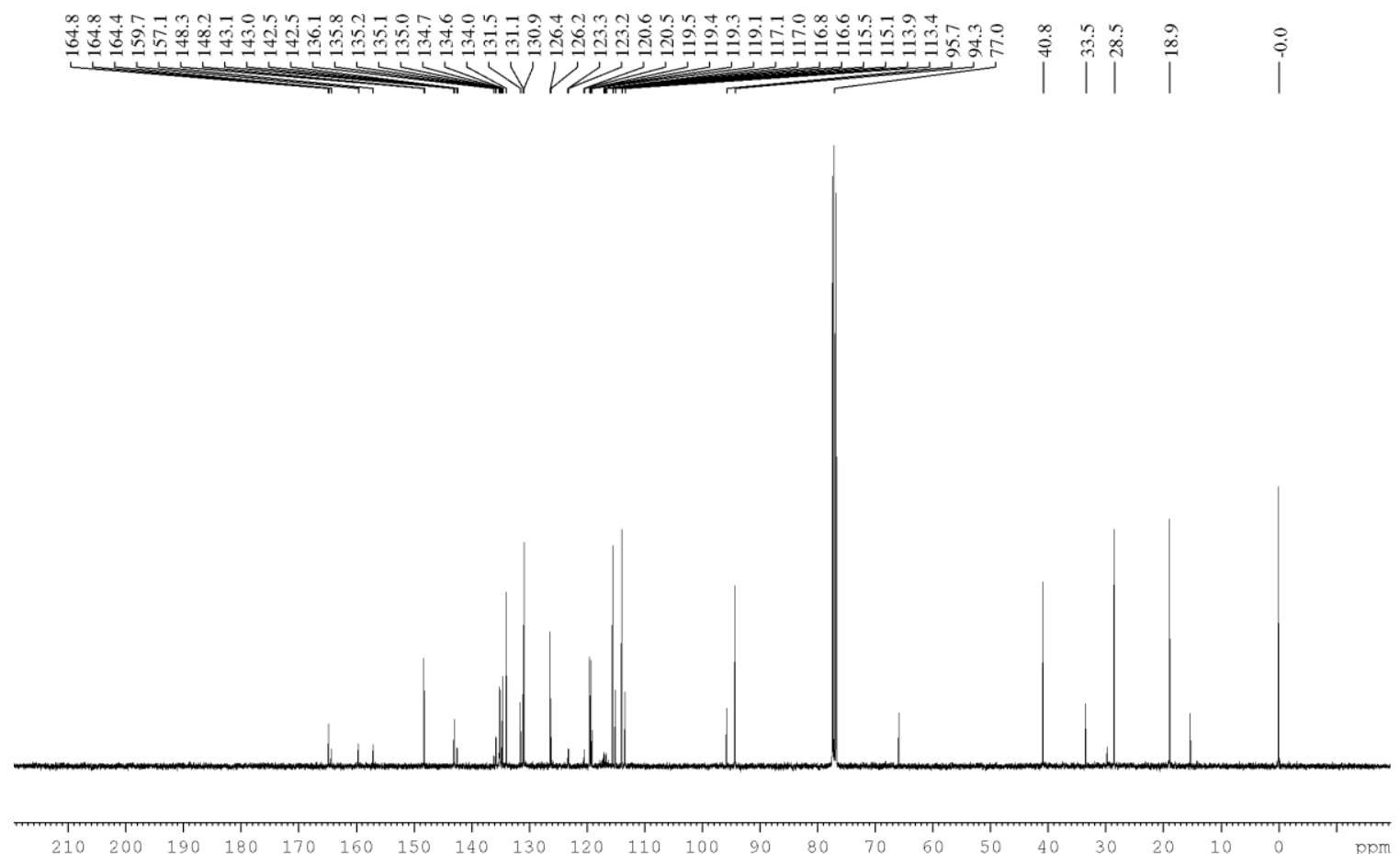

Figure 134. ${ }^{13} \mathrm{C}\left\{{ }^{1} \mathrm{H}\right\}$ NMR of $10 \mathrm{e}$ and $10 \mathrm{fDCl} \mathrm{CD}_{3}$ with $1 \% \mathrm{v} / \mathrm{v}$ TMS at $101 \mathrm{MHz}$.

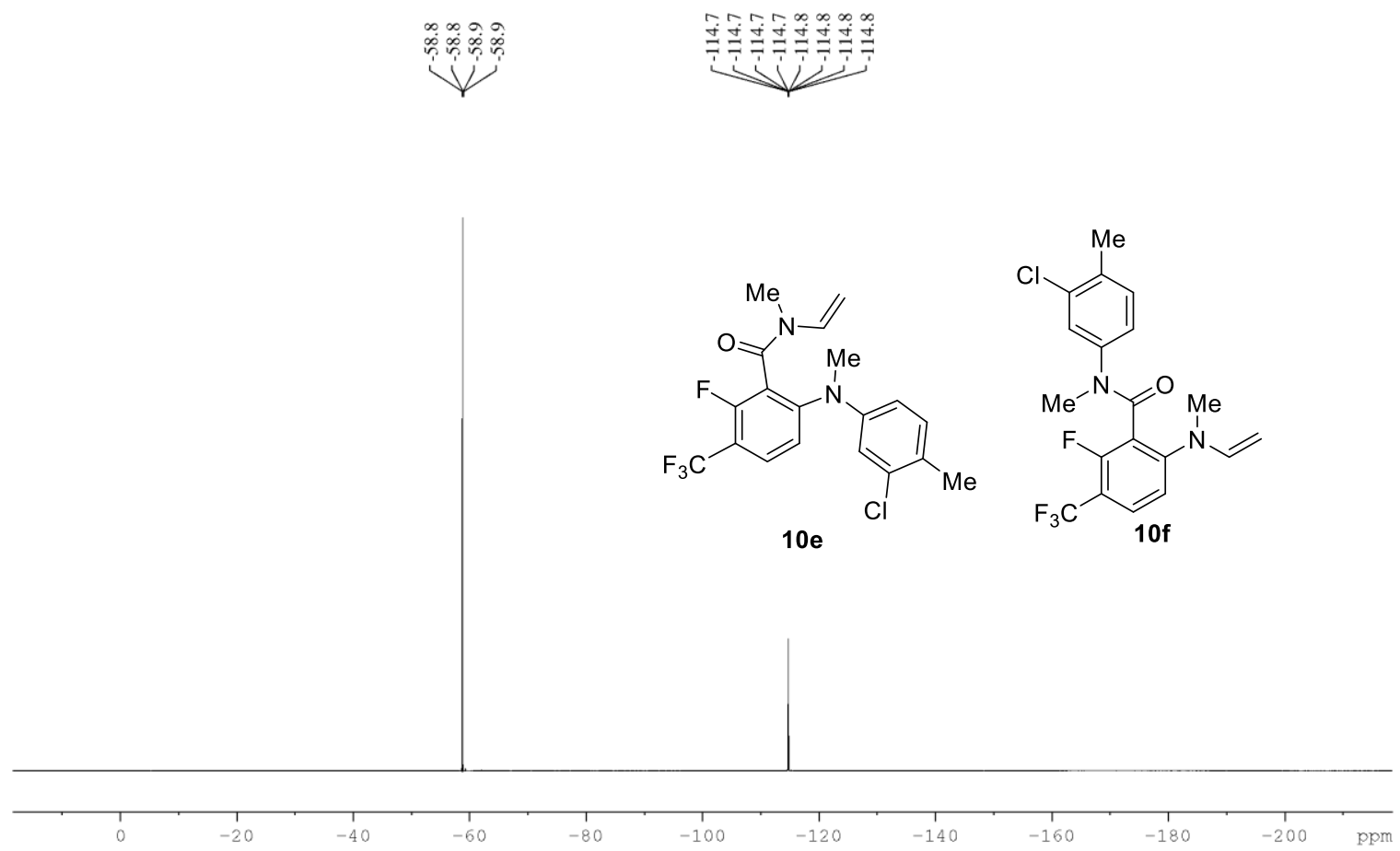

Figure $135 .{ }^{19} \mathrm{~F}\left\{{ }^{1} \mathrm{H}\right\}$ NMR of $\mathbf{1 0 e}$ and $\mathbf{1 0 f}$ in acetone- $d_{6}$ with $1 \% \mathrm{v} / \mathrm{v}$ TMS at $376 \mathrm{MHz}$. 
<smiles>C=COCCN(c1ccccc1)c1ccc(C)c(Cl)c1</smiles>

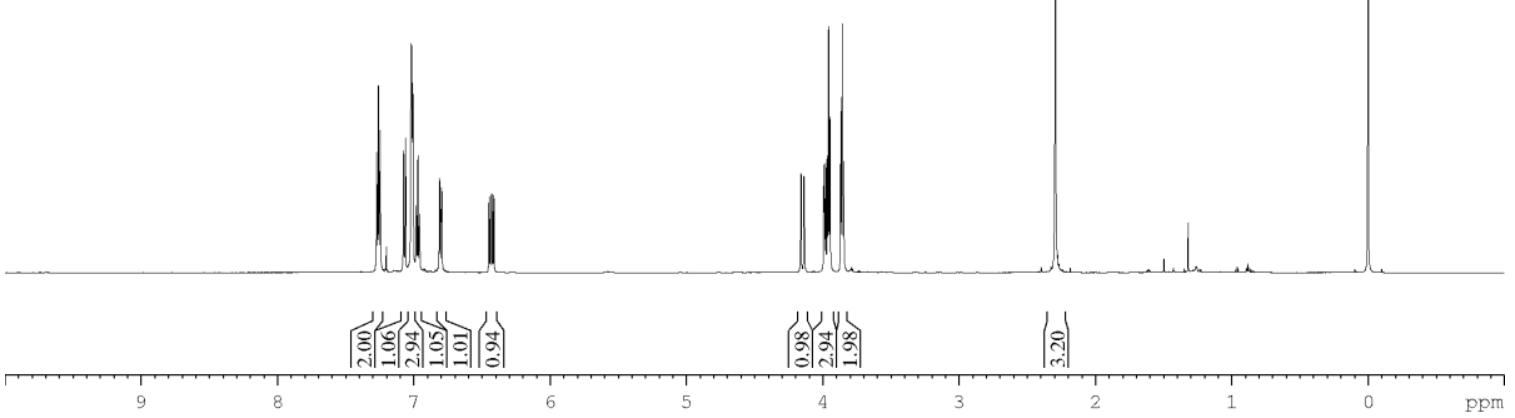

Figure 136. ${ }^{1} \mathrm{H}$ NMR of 8 ah in $\mathrm{CDCl}_{3}$ with $1 \% \mathrm{v} / \mathrm{v} \mathrm{TMS}$ at $600 \mathrm{MHz}$.

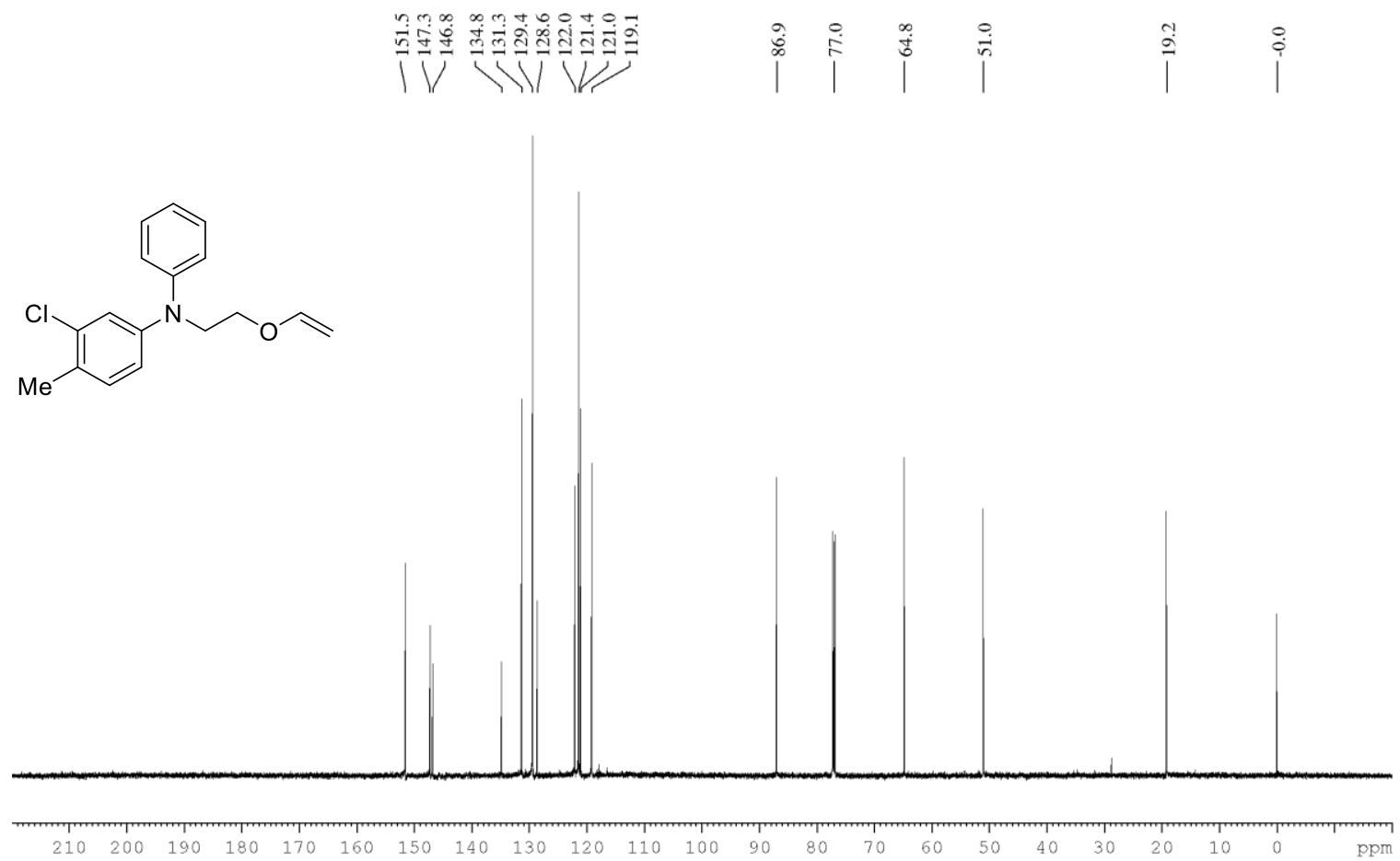

Figure 137. ${ }^{13} \mathrm{C}\left\{{ }^{1} \mathrm{H}\right\} \mathrm{NMR}$ of 8 ah $\mathrm{CDCl}_{3}$ with $1 \% \mathrm{v} / \mathrm{v}$ TMS at $151 \mathrm{MHz}$. 

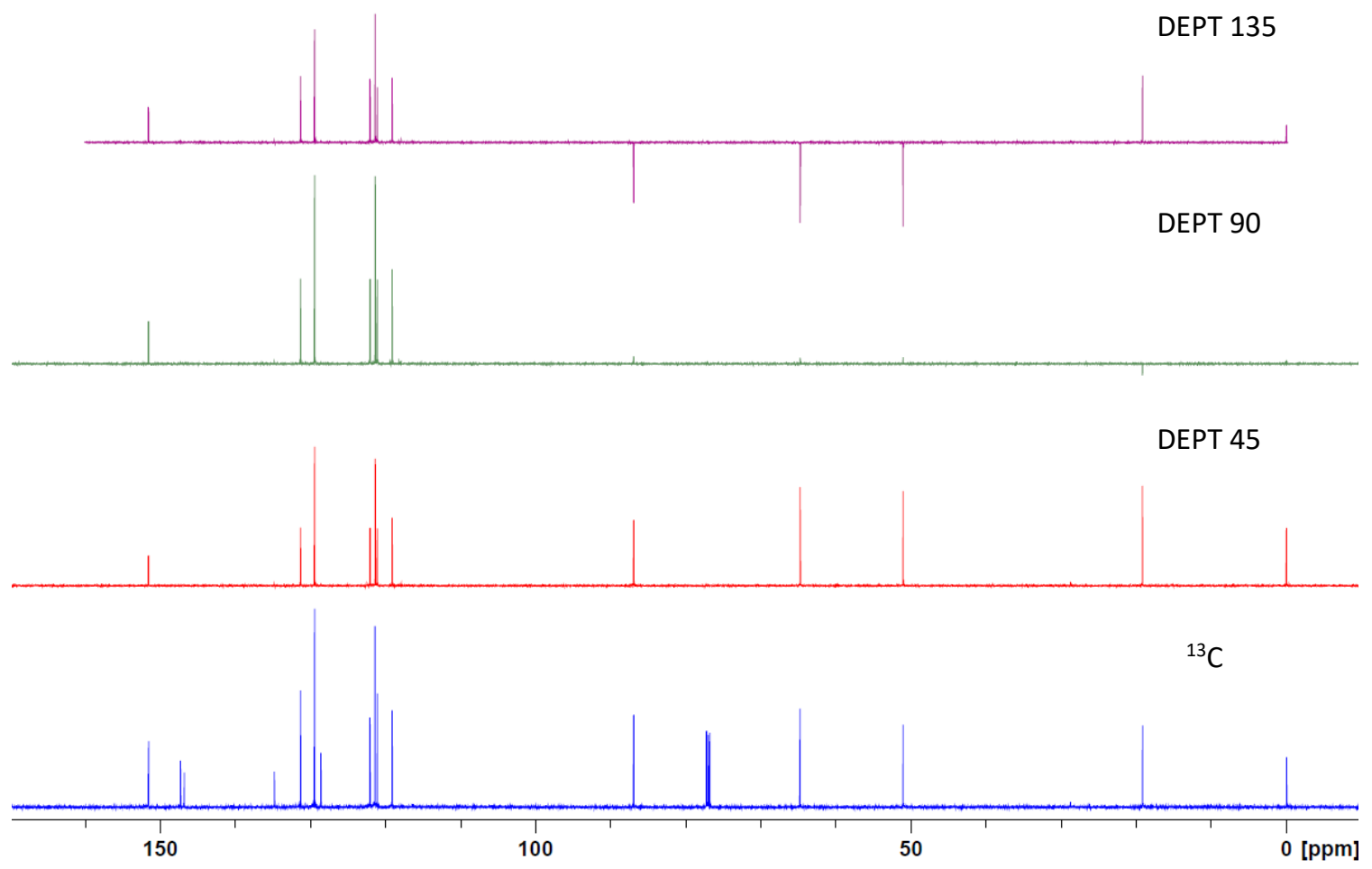

Figure 138. Stacked ${ }^{13} \mathrm{C}$ NMR spectra of 8 ah.

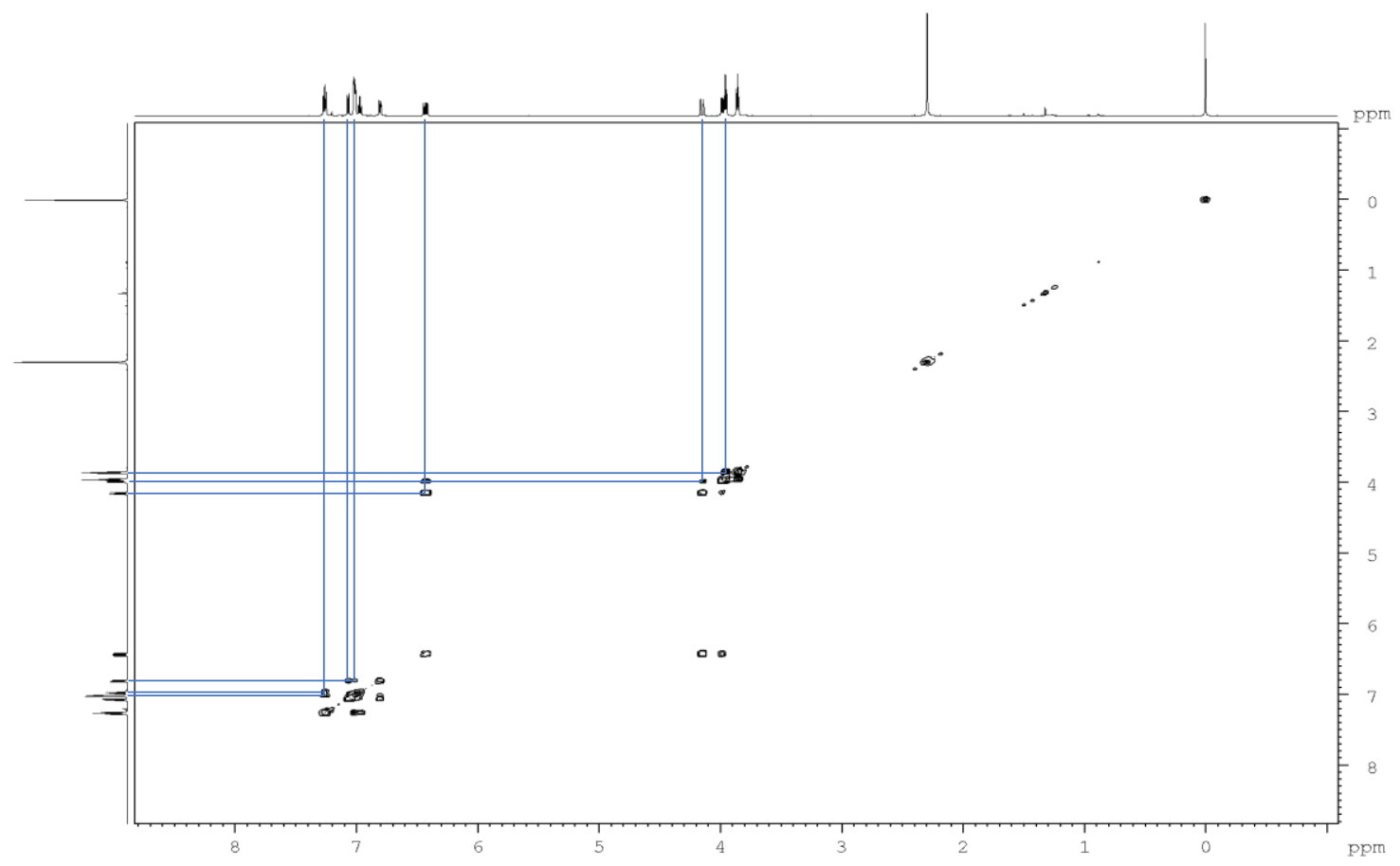

Figure 139. COSY of $8 \mathrm{ah}$ in $\mathrm{CDCl}_{3}$ with $1 \% \mathrm{v} / \mathrm{v}$ TMS at $600 \mathrm{MHz}$. 


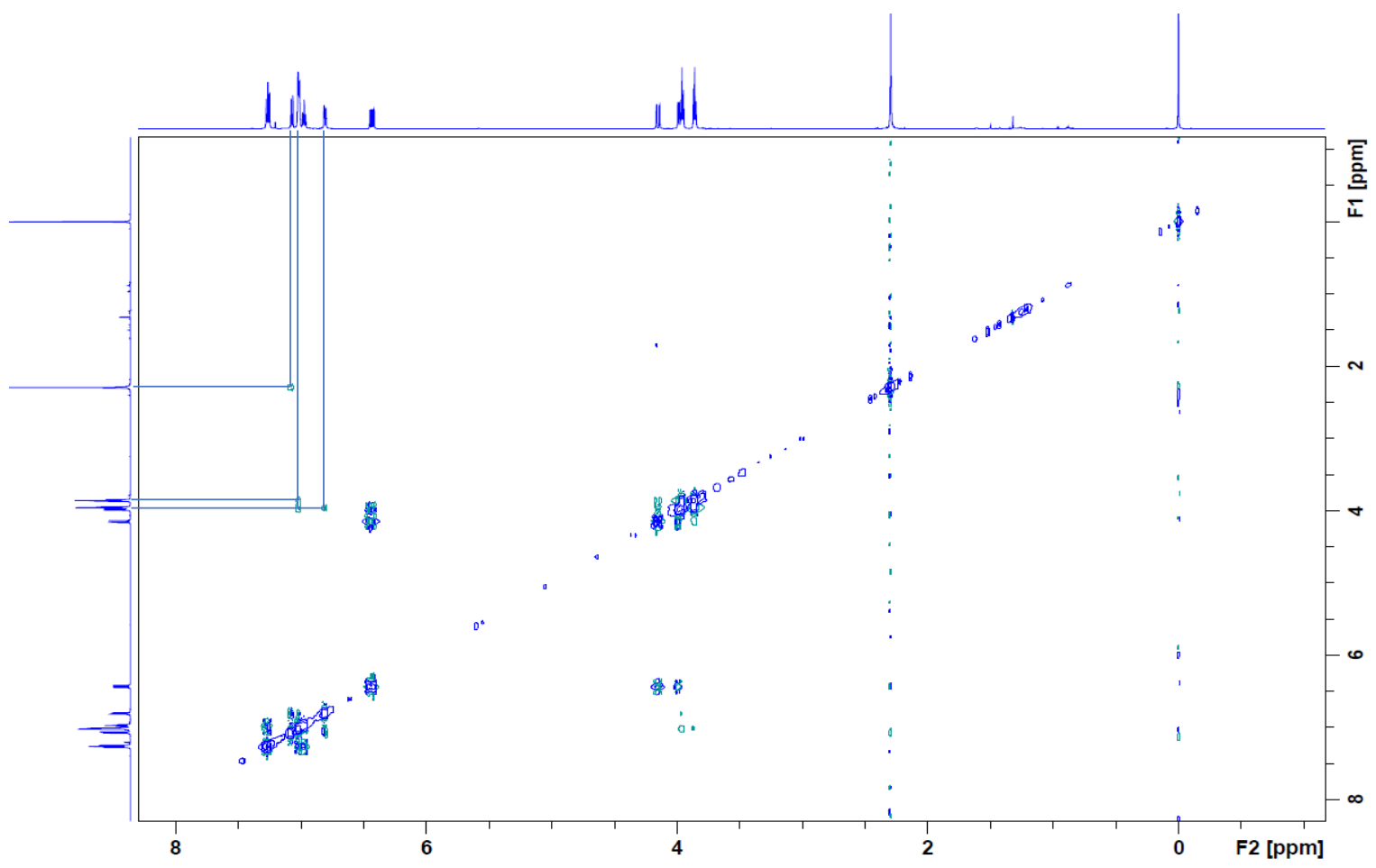

Figure 140. NOESY of 8 ah in $\mathrm{CDCl}_{3}$ with $1 \% \mathrm{v} / \mathrm{v} \mathrm{TMS}$ at $400 \mathrm{MHz}$. 


\subsection{Supporting information for Chapter 4}

\subsubsection{Preparration of aryl(TMP)iodonium tosylates}

\subsubsection{General procedure G}

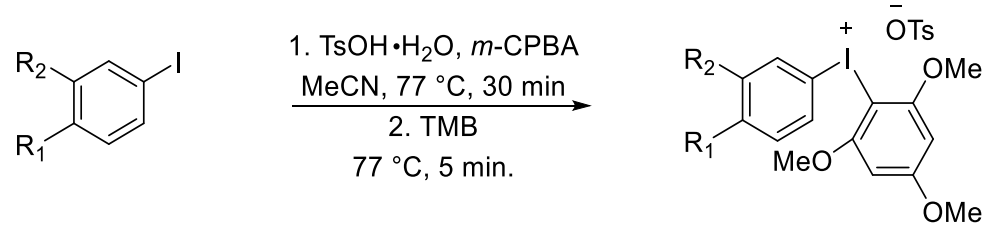

Scheme 25. Synthesis of aryl(TMP)iodonium salts from aryl iodides.

Prepared according to the literature procedure. ${ }^{59}$ Aryl iodide (1.0 equiv.) and acetonitrile $(1 \mathrm{~mL} / \mathrm{mmol})$ were added to a round bottom flask, equipped with a magnetic stir bar. Toluenesulfonic acid monohydrate (1.01 equiv.) was added in one portion, followed by one portion of m-CPBA (1.01 equiv.). The flask was lowered into an oil bath set to $77^{\circ} \mathrm{C}$ and stirred vigorously. After 30 min 1,3,5-trimethoxybenzene (1.01 equiv.) was added in one portion and stirring was continued at $77^{\circ} \mathrm{C}$ for 5 minutes. The reaction was removed from heat and concentrated under reduced pressure. The resulting crude residue was triturated with diethyl ether. The precipitate was isolated by vacuum filtration and washed by slurry filtration with diethyl ether to give analytically pure $\operatorname{aryl}(2,4,6$-trimethoxyphenyl)iodonium tosylate.

\subsubsection{General procedure H}

Prepared according to the literature procedure. ${ }^{66}$ Aryl iodide (1.0 equiv.) and dichloromethane $(7 \mathrm{~mL} / \mathrm{mmol})$ were added to a round bottom flask, equipped with a magnetic stir bar followed by the addition of $m$-CPBA (1.1 equiv.) at stirring. After the mixture was stirred at room temperature for 4 hours, toluenesulfonic acid monohydrate 
(1.1 equiv.) was added followed by 1,3,5-trimethoxybenzene (1.1 equiv.). The reaction mixture was stirred at room temperature for $30 \mathrm{~min}$, and solvent was evaporated under reduced pressure. The resulting crude residue was triturated with diethyl ether. The precipitate was isolated by vacuum filtration and washed by slurry filtration with diethyl ether to give analytically pure aryl(2,4,6-trimethoxyphenyl)iodonium tosylate.

\subsubsection{Characterization of aryl(TMP)iodonium tosylates}

Compound 11c<smiles></smiles>

Prepared according to the general procedure $\mathrm{G}$ on $3.0 \mathrm{mmol}$ and obtained in $87 \%$ yield $(1.56 \mathrm{~g}, 2.6 \mathrm{mmol})$ as a white powder.

${ }^{1} \mathbf{H}$ NMR (DMSO- $\left.d_{6}, 400 \mathrm{MHz}\right) \delta=8.43$ (dd, appears as triplet, $J=1.6 \mathrm{~Hz} 1 \mathrm{H}$ ), 8.13 (dd, $J=$ 7.9, $1.7 \mathrm{~Hz}, 2 \mathrm{H}), 7.62(\mathrm{dd}$, appears as triplet, $J=7.9 \mathrm{~Hz}, 1 \mathrm{H}), 7.47(\mathrm{~d}, J=8.0,2 \mathrm{H}), 7.10(\mathrm{~d}$, $J=7.8,2 \mathrm{H}), 6.48(\mathrm{~s}, 2 \mathrm{H}), 3.95(\mathrm{~s}, 6 \mathrm{H}), 3.88(\mathrm{~s}$, overlaps with singlet at $3.87,3 \mathrm{H}), 3.87(\mathrm{~s}$, overlaps with singlet at $3.88,3 \mathrm{H}), 2.28(\mathrm{~s}, 3 \mathrm{H})$.

${ }^{13} \mathrm{C}\left\{{ }^{1} \mathrm{H}\right\}$ NMR (DMSO-d $\left.6,101 \mathrm{MHz}\right) \delta=166.3,164.4,159.3,145.8,138.4,137.5,134.4$, 132.1, 131.9, 131.8, 128.0, 125.5, 116.1, 92.2, 87.0, 57.4, 56.2, 52.8, 20.8.

FT-IR: 2943, 1725, 1578, 1344, 1158, 1100, 1031, 814, $677 \mathrm{~cm}^{-1}$.

HRMS: Calculated for $\mathrm{C}_{17} \mathrm{H}_{18} \mathrm{O}_{5} \mathrm{I}^{+}[\mathrm{M}-\mathrm{OTs}]^{+}$: 429.0193; Found: 429.0179.

Melting point: $195.4-199.5^{\circ} \mathrm{C}$.

Compound 11g

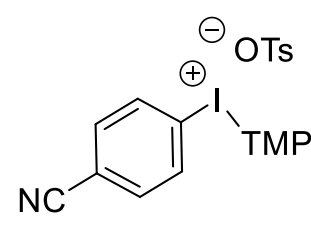


Prepared according to the general procedure $\mathrm{G}$ on a $3 \mathrm{mmol}$ scale and obtained in $81 \%$ yield $(1.38 \mathrm{~g}, 2.4 \mathrm{mmol})$ as a white powder. Spectral data are consistent with those previously reported. ${ }^{87}$

${ }^{1} \mathrm{H}$ NMR (DMSO- $\left.d_{6}, 400 \mathrm{MHz}\right) \delta=8.06(\mathrm{~d}, J=8.4 \mathrm{~Hz}, 2 \mathrm{H}), 7.91(\mathrm{~d}, J=8.4 \mathrm{~Hz}, 2 \mathrm{H}), 7.46(\mathrm{~d}$, $J=8.0 \mathrm{~Hz}, 2 \mathrm{H}), 7.10(\mathrm{~d}, J=7.9 \mathrm{~Hz}, 2 \mathrm{H}), 6.49(\mathrm{~s}, 2 \mathrm{H}), 3.93(\mathrm{~s}, 6 \mathrm{H}), 3.87(\mathrm{~s}, 3 \mathrm{H}), 2.28(\mathrm{~s}, 3 \mathrm{H})$.

${ }^{13} \mathrm{C}$ NMR (DMSO-d $\left.d_{6}, 101 \mathrm{MHz}\right) \delta=166.5,159.4,145.7,137.6,134.8,134.8,128.0,125.5$, 121.0, 117.5, $114.192 .2,87.0,57.4,56.2,20.8$.

Compound 111

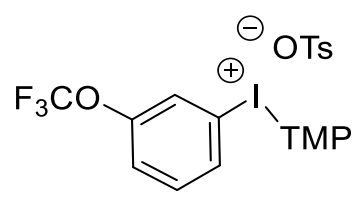

Prepared according to the general procedure $\mathrm{G}$ on a $1 \mathrm{mmol}$ scale and obtained in $79 \%$ yield $(0.496 \mathrm{~g}, 0.79 \mathrm{mmol})$ as a white powder.

${ }^{1} \mathrm{H}$ NMR (DMSO- $\left.\boldsymbol{d}_{6}, 400 \mathrm{MHz}\right) \delta=8.00(\mathrm{~s}, 1 \mathrm{H}), 7.89(\mathrm{~d}, J=7.2 \mathrm{~Hz}, 1 \mathrm{H}), 7.63-7.61(\mathrm{~m}, 2 \mathrm{H})$, $7.47(\mathrm{~d}, J=7.7 \mathrm{~Hz}, 2 \mathrm{H}), 7.10(\mathrm{~d}, J=7.7 \mathrm{~Hz}, 2 \mathrm{H}), 6.48(\mathrm{~s}, 3 \mathrm{H}), 3.94(\mathrm{~s}, 6 \mathrm{H}) 3.88(\mathrm{~s}, 3 \mathrm{H}), 2.28$ $(\mathrm{s}, 3 \mathrm{H})$.

$.01(\mathrm{~s}, 1 \mathrm{H}), 7.89$ (d, J = 7.4 Hz, 1H), 7.66-7.59 (m, 2H), 7.47 (d, J = 7.9 Hz, 2H), 7.12 (d, J=7.8 $\mathrm{Hz}, 2 \mathrm{H}), 6.48(\mathrm{~s}, 2 \mathrm{H}), 3.94(\mathrm{~s}, 6 \mathrm{H}), 3.87(\mathrm{~s}, 3 \mathrm{H}), 2.29(\mathrm{~s}, 3 \mathrm{H})$.

${ }^{13}$ C NMR (DMSO- $\left.d_{6}, 101 \mathrm{MHz}\right) \delta=166.3,159.3,148.4(\mathrm{~m}), 145.6,137.5,137.5,133.2$, $133.1,127.9,126.7,125.4,124.3,115.9,119.7$ (q, JC-F $=257.9$ ), 92.0, 87.1, 57.2, 56.1, 20.7.

${ }^{19} \mathrm{~F}\left\{{ }^{1} \mathrm{H}\right\}$ NMR (DMSO- $\left.d_{6}, 376 \mathrm{MHz}\right) \delta=-57.1$.

FTIR: 3056, 2963, 2925, 2902, 2846, 1572, 1161, 1114, 1029, 744, $704 \mathrm{~cm}^{-1}$.

HRMS: Calculated for $\mathrm{C}_{16} \mathrm{H}_{15} \mathrm{O}_{4} \mathrm{~F}_{3} I^{+}[\mathrm{M}-\mathrm{OTs}]^{+}$: 454.9962; Found: 454.9951.

Melting Point: $173.7-175.0^{\circ} \mathrm{C}$.

Compound 110<smiles>O=[N+]([O-])c1ccc([N+](=O)[O-])c([18OH])c1</smiles> 
Prepared according to the general procedure $\mathrm{G}$ on a $2.0 \mathrm{mmol}$ scale and obtained in $68 \%$ yield $(0.830 \mathrm{~g}, 1.38 \mathrm{mmol})$ as an off-white powder.

${ }^{1} \mathrm{H}$ NMR (DMSO-d $\left.6,400 \mathrm{MHz}\right) \delta=8.81(\mathrm{~d}, J=1.3 \mathrm{~Hz}, 1 \mathrm{H}), 8.33(\mathrm{dd}, J=8.4,1.3 \mathrm{~Hz}, 1 \mathrm{H}$ ), $7.78(\mathrm{~d}, J=8.5 \mathrm{~Hz}, 1 \mathrm{H}), 7.46(\mathrm{~d}, J=7.7 \mathrm{~Hz}, 1 \mathrm{H}), 7.10(\mathrm{~d}, J=7.8 \mathrm{~Hz}, 1 \mathrm{H}), 6.46(\mathrm{~s}, 2 \mathrm{H}), 3.97$ $(\mathrm{s}, 6 \mathrm{H}), 3.85(\mathrm{~s}, 3 \mathrm{H}), 2.71(\mathrm{~s}, 3 \mathrm{H}), 2.28(\mathrm{~s}, 3 \mathrm{H})$.

${ }^{13} \mathrm{C}\left\{{ }^{1} \mathrm{H}\right\}$ NMR (DMSO-d $\left.d_{6}, 101 \mathrm{MHz}\right) \delta=165.6,158.6,147.6,145.4,144.9,137.0,131.1$, $130.7,127.4,126.0,124.8,120.2,91.6,86.7,56.6,55.5,24.2,20.1$.

FTIR: $3100,2923,2856,1601,1511,1342,1012,727,680 \mathrm{~cm}^{-1}$.

HRMS: Calculated for $\mathrm{C}_{16} \mathrm{H}_{17} \mathrm{NO}_{5} \mathrm{I}^{+}[\mathrm{M}-\mathrm{OTs}]^{+}:$: 430.0146 ; Found: 430.0133.

Melting point: $216.9-217.9^{\circ} \mathrm{C}$

Compound 11p<smiles>Cc1c(F)cc(Br)cc1[I-][IH]([O-])=[W]</smiles>

Prepared according to the general procedure $\mathrm{G}$ on $2.0 \mathrm{mmol}$ and obtained in $85 \%$ yield $(1.11 \mathrm{~g}, 1.7 \mathrm{mmol})$ as a white powder.

${ }^{1} \mathrm{H}$ NMR (DMSO-d $\left.6,400 \mathrm{MHz}\right) \delta=8.39(\mathrm{~d}, J=6.7 \mathrm{~Hz}, 1 \mathrm{H}), 7.61(\mathrm{~d}, J=9.5 \mathrm{~Hz}, 1 \mathrm{H}), 7.47$ (d, $J=7.5 \mathrm{~Hz}, 2 \mathrm{H}), 7.11(\mathrm{~d}, J=7.7 \mathrm{~Hz}, 2 \mathrm{H}), 6.45(\mathrm{~s}, 2 \mathrm{H}), 3.96(\mathrm{~s}, 6 \mathrm{H}), 3.86(\mathrm{~s}, 3 \mathrm{H}), 2.55(\mathrm{~s}, 3 \mathrm{H})$, $2.29(\mathrm{~s}, 3 \mathrm{H})$

${ }^{13} \mathrm{C}\left\{{ }^{1} \mathrm{H}\right\}$ NMR (DMSO- $\left.d_{6}, 101 \mathrm{MHz}\right) \delta=166.0,160.0\left(\mathrm{~d}, J_{\mathrm{C}-\mathrm{F}}=248.4 \mathrm{~Hz}\right), 159.15,145.6$, $143.3\left(\mathrm{~d}, J_{\mathrm{C}-\mathrm{F}}=8.6 \mathrm{~Hz}\right), 140.8,137.4,127.8,125.3,118.8\left(\mathrm{~d}, J_{\mathrm{C}-\mathrm{F}}=23.4 \mathrm{~Hz}\right), 115.9,106.6(\mathrm{~d}$, $\left.J_{C-F}=22.1 \mathrm{~Hz}\right), 92.0,86.9,57.0,56.0,24.2,20.5$

${ }^{19} \mathrm{~F}\left\{{ }^{1} \mathrm{H}\right\}$ NMR (DMSO-d, $\left.376 \mathrm{MHz}\right) \delta=-102.86$.

FTIR: 3021, 2980, 2844, 1584, 1177,1117, 1030, 1007, 875, $678 \mathrm{~cm}^{-1}$.

HRMS: Calculated for $\mathrm{C}_{16} \mathrm{H}_{16} \mathrm{BrFO}_{3} \mathrm{I}^{+}[\mathrm{M}-\mathrm{OTs}]^{+}:$: 480.9306 ; Found: 480.9298

Melting Point: $195.0-197.0^{\circ} \mathrm{C}$.

Compound 11r 
<smiles>Cc1ccc([I-]([O-])[18OH])cc1Br</smiles>

Prepared according to the general procedure $\mathrm{G}$ on a $3 \mathrm{mmol}$ scale and obtained in $83 \%$ yield ( $1.58 \mathrm{~g}, 2.5 \mathrm{mmol})$ as a white powder.

${ }^{1} \mathrm{H}$ NMR (DMSO-d $\left.{ }_{6}, 400 \mathrm{MHz}\right) \delta=8.12(\mathrm{~d}, J=1.5 \mathrm{~Hz}, 1 \mathrm{H}), 7.77$ (dd, $J=8.1,1.5 \mathrm{~Hz}, 1 \mathrm{H}$ ), 7.47-7.42 (m, 3H), $7.10(\mathrm{~d}, J=7.9 \mathrm{~Hz}, 2 \mathrm{H}), 6.47(\mathrm{~s}, 2 \mathrm{H}), 3.94(\mathrm{~s}, 6 \mathrm{H}), 3.87(\mathrm{~s}, 3 \mathrm{H}), 2.35(\mathrm{~s}$, $3 \mathrm{H}), 2.28(\mathrm{~s}, 3 \mathrm{H})$.

${ }^{13} \mathrm{C}\left\{{ }^{1} \mathrm{H}\right\}$ NMR (DMSO-d $\left.\boldsymbol{d}_{6}, 101 \mathrm{MHz}\right) \delta=166.2,159.3,145.7,141.6,137.6,136.6,133.7$, 133.3, 128.0, 125.5, 125.5 (overlapping peak), 113.1, 92.1, 87.2, 57.3, 56.2, 22.3, 20.8.

FTIR: 3091, 2936, 1578, 1160, 1116, 1031, $1008 \mathrm{~cm}^{-1}$.

HRMS: Calculated for $\left.\mathrm{C}_{16} \mathrm{H}_{17} \mathrm{BrO}_{3}\right|^{+}$462.9400; Found: 462.9392.

Melting point: $223.5-226^{\circ} \mathrm{C}$.

Compound 11s

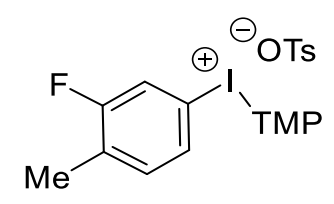

Prepared according to the general procedure $\mathrm{G}$ on a $3 \mathrm{mmol}$ scale and obtained in $90 \%$ yield ( $1.55 \mathrm{~g}, 2.7 \mathrm{mmol}$ ) as a white powder.

${ }^{1} \mathrm{H}$ NMR (DMSO-d $\left.6,400 \mathrm{MHz}\right) \delta=7.89(\mathrm{dd}, J=6.8,1.6 \mathrm{~Hz}, 1 \mathrm{H}), 7.80-7.76(\mathrm{~m}, 1 \mathrm{H}), 7.46(\mathrm{~d}$, $J=7.99 \mathrm{~Hz}, 2 \mathrm{H}), 7.25(\mathrm{t}, J=9.2 \mathrm{~Hz}, 1 \mathrm{H}), 7.10(\mathrm{~d}, J=7.9 \mathrm{~Hz}, 2 \mathrm{H}), 6.45(\mathrm{~s}, 2 \mathrm{H}), 3.94(\mathrm{~s}, 6 \mathrm{H})$, $3.88(\mathrm{~s}, 3 \mathrm{H}), 2.28(\mathrm{~s}, 3 \mathrm{H}), 2.24(\mathrm{~s}, 3 \mathrm{H})$.

${ }^{13} \mathrm{C}\left\{{ }^{1} \mathrm{H}\right\}$ NMR (DMSO- $\left.d_{6}, 101 \mathrm{MHz}\right) \delta=166.2,160.3$ (d, $J_{C-F}=250.9 \mathrm{~Hz}$ ), 159.3, 145.7, 137.6, $134.2\left(\mathrm{~d} J_{\mathrm{C}-\mathrm{F}}=4.7 \mathrm{~Hz}\right), 130.2\left(\mathrm{~d}, J_{\mathrm{C}-\mathrm{F}}=3.3 \mathrm{~Hz}\right.$ ), $128.9\left(\mathrm{~d}, J_{\mathrm{C}-\mathrm{F}}=16.7 \mathrm{~Hz}\right), 128.0,125.5,120.9$ $\left(d, J_{C-F}=25.4 \mathrm{~Hz}\right), 112.1\left(\mathrm{~d}, J_{\mathrm{C}-\mathrm{F}}=7.2 \mathrm{~Hz}\right), 92.0,87.3,57.3,56.2,20.7,14.1$ (d, $\left.J_{\mathrm{C}-\mathrm{F}}=2.9 \mathrm{~Hz}\right)$.

${ }^{19} \mathrm{~F}\left\{{ }^{1} \mathrm{H}\right\}$ NMR (DMSO-d, $\left.376 \mathrm{MHz}\right) \delta=-111.4$.

FTIR: 3090, 2941, 1580, 1175, 1117, 1031, $1008 \mathrm{~cm}^{-1}$.

HRMS: Calculated for $\mathrm{C}_{16} \mathrm{H}_{17} \mathrm{FO}_{3} \mathrm{I}^{+}[\mathrm{M}-\mathrm{OTs}]^{+}:$403.0201; Found: 403.0191. 
Melting point: $207.0-209.2^{\circ} \mathrm{C}$.

\section{Compound 11w}<smiles>COc1ccc(Cl)cc1I(O)O[Na]</smiles>

Prepared according to the general procedure $\mathrm{H}$ on $2.0 \mathrm{mmol}$ and obtained in $84 \%$ yield $(1.02 \mathrm{~g}, 1.7 \mathrm{mmol})$ as a white powder. Spectral data are consistent with those previously reported. ${ }^{97}$

${ }^{1} \mathrm{H}$ NMR (DMSO-d $\left.{ }_{6}, 400 \mathrm{MHz}\right) \delta=8.03(\mathrm{~d}, J=2.3 \mathrm{~Hz}, 1 \mathrm{H}), 7.65(\mathrm{dd}, J=8.9,2.3 \mathrm{~Hz}, 1 \mathrm{H}$ ), $7.47(\mathrm{~d}, J=7.9 \mathrm{~Hz}, 2 \mathrm{H}), 7.27$ (d, J= $7.9 \mathrm{~Hz}, 1 \mathrm{H}), 7.10$ (d, J=7.8 Hz, 2H), $6.42(\mathrm{~s}, 2 \mathrm{H}), 3.93$ $(\mathrm{s}, 6 \mathrm{H}), 3.87(\mathrm{~s}, 3 \mathrm{H}), 3.84(\mathrm{~s}, 3 \mathrm{H}), 2.28(\mathrm{~s}, 3 \mathrm{H})$.

${ }^{13} \mathrm{C}\left\{{ }^{1} \mathrm{H}\right\}$ NMR (DMSO-d $\left.\boldsymbol{d}_{6}, 101 \mathrm{MHz}\right) \delta=165.4,158.9,155.1,145.2,136.9,135.1,133.0$, $127.4,124.9,124.6,113.4,106.2,91.4,86.0,56.7,56.6,55.5,20.2$.

\section{Compound 11w'}<smiles>COc1ccc(Cl)c([Al-][O-])c1</smiles>

Prepared according to the general procedure $\mathrm{H}$ on $2.0 \mathrm{mmol}$ with the following modifications: the reaction was conducted at $30{ }^{\circ} \mathrm{C}$ in the presence of toluenesulfonic acid. The product was obtained in $60 \%$ yield $(0.727 \mathrm{~g}, 1.2 \mathrm{mmol}$ ) as a white powder.

${ }^{1} \mathrm{H}$ NMR (DMSO-d $\left.{ }_{6}, 400 \mathrm{MHz}\right) \delta=7.71(\mathrm{~d}, J=2.9 \mathrm{~Hz}, 1 \mathrm{H}), 7.66(\mathrm{~d}, J=8.9 \mathrm{~Hz}, 1 \mathrm{H}), 7.47$ (d, $J=8.0 \mathrm{~Hz}, 2 \mathrm{H}), 7.20(\mathrm{dd}, J=8.9,2.9 \mathrm{~Hz}, 1 \mathrm{H}), 7.10(\mathrm{~d}, J=7.8 \mathrm{~Hz}, 2 \mathrm{H}), 6.44(\mathrm{~s}, 2 \mathrm{H}), 3.94(\mathrm{~s}$, $6 \mathrm{H}), 3.86(\mathrm{~s}, 3 \mathrm{H}), 3.80(\mathrm{~s}, 3 \mathrm{H}), 2.28(\mathrm{~s}, 3 \mathrm{H})$.

${ }^{13} \mathrm{C}\left\{{ }^{1} \mathrm{H}\right\}$ NMR (DMSO-d $\left.\boldsymbol{d}_{6}, 101 \mathrm{MHz}\right) \delta=165.59,158.87,157.96,145.18,136.93,129.66$, $127.41,126.24,124.87,122.85,119.01,118.35,91.42,86.81,56.52,55.59,55.54,20.16$.

FTIR: 3082, 2943, 2834, 1576, 157, 1117, 1030, 1005, $677 \mathrm{~cm}^{-1}$.

HRMS: Calculated for $\left.\mathrm{C}_{16} \mathrm{H}_{17} \mathrm{ClO}_{4}\right|^{+}[\mathrm{M}-\mathrm{OTs}]^{+}:$: 434.9855; Found: 434.9845. 
Melting Point: $214.1-216.0^{\circ} \mathrm{C}$

Compound 11x<smiles>OI(c1ccccc1)c1cc(Br)ccc1F</smiles>

Prepared according to the general procedure $\mathrm{G}$ on $3.0 \mathrm{mmol}$ and obtained an isolated yield of $82 \%$ ( $1.57 \mathrm{~g}, 2.5 \mathrm{mmol})$ as a white powder.

${ }^{1} \mathrm{H}$ NMR (DMSO- $\left.d_{6}, 400 \mathrm{MHz}\right) \delta=8.31-8.29(\mathrm{~m}, 1 \mathrm{H}), 7.90-7.84(\mathrm{~m}, 1 \mathrm{H}), 7.56-7.45(\mathrm{~m}, 3 \mathrm{H})$, $7.10(\mathrm{~d}, J=7.8 \mathrm{~Hz}, 2 \mathrm{H}), 6.45(\mathrm{~s}, 2 \mathrm{H}), 3.94(\mathrm{~s}, 6 \mathrm{H}), 3.85(\mathrm{~s}, 3 \mathrm{H}), 2.28(\mathrm{~s}, 3 \mathrm{H})$.

${ }^{13} \mathrm{C}\left\{{ }^{1} \mathrm{H}\right\}$ NMR (DMSO- $\left.d_{6}, 101 \mathrm{MHz}\right) \delta=166.3,159.3,158.8\left(\mathrm{~d}, J_{\mathrm{C}-\mathrm{F}}=250.0 \mathrm{~Hz}\right.$ ), 145.7, 138.6, 137.6, 137.5, 128.0, 125.5, $118.6\left(d, J_{C-F}=24.3 \mathrm{~Hz}\right), 117.5\left(d, J_{C-F}=3.4 \mathrm{~Hz}\right), 105.0$ (d, J J-F $=$ $26.4 \mathrm{~Hz}), 92.1,87.4,57.2,56.2,20.8$.

${ }^{19} \mathrm{~F}\left\{{ }^{1} \mathrm{H}\right\}$ NMR (DMSO-d $\left.6,376 \mathrm{MHz}\right) \delta=-100.0$.

FTIR: 3094, 2992, 2873, 1577, 1157, 1118, 1030, 835, $681 \mathrm{~cm}^{-1}$.

HRMS: Calculated for $\mathrm{C}_{15} \mathrm{H}_{14} \mathrm{BrFO}_{3} \mathrm{I}^{+}[\mathrm{M}-\mathrm{OTs}]^{+}$: 466.9150; Found: 466.9142.

Melting Point: $222.0-223.0{ }^{\circ} \mathrm{C}$.

Compound 11x'

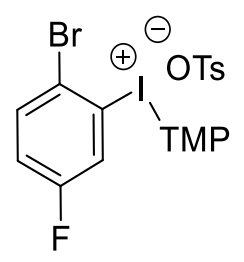

Prepared according to the general procedure $\mathrm{G}$ on $1.0 \mathrm{mmol}$ and obtained in $87 \%$ yield ( $0.556 \mathrm{~g}, 0.87 \mathrm{mmol}$ ) as a white powder.

${ }^{1} \mathrm{H}$ NMR (DMSO-d $\left.6,400 \mathrm{MHz}\right) \delta=8.12(\mathrm{dd}, J=7.5,3.0 \mathrm{~Hz}, 1 \mathrm{H}), 7.95(\mathrm{dd}, J=8.9,5.1 \mathrm{~Hz}$, $1 \mathrm{H}), 7.47-7.44(\mathrm{~m}, 3 \mathrm{H}), 7.10(\mathrm{~d}, J=7.8 \mathrm{~Hz}, 2 \mathrm{H}), 6.44(\mathrm{~s}, 2 \mathrm{H}), 3.94(\mathrm{~s}, 6 \mathrm{H}), 3.86(3 \mathrm{H}), 2.28$ $(\mathrm{s}, 3 \mathrm{H})$. 
${ }^{13} \mathrm{C}\left\{{ }^{1} \mathrm{H}\right\}$ NMR (DMSO- $\left.d_{6}, 101 \mathrm{MHz}\right) \delta=166.2,160.3\left(\mathrm{~d}, J_{\mathrm{C}-\mathrm{F}}=252.2\right), 159.3,145.6,137.4$, $134.4\left(d, J_{C-F}=7.7\right), 127.9,125.8\left(d, J_{C-F}=25.2\right), 125.3,121.9\left(d, J_{C-F}=7.2\right), 121.6\left(d, J_{C-F}=\right.$ 3.2), $121.1\left(d, J_{C-F}=22.3\right), 91.9,87.4,57.0,56.0,20.6$.

${ }^{19} \mathrm{~F}\left\{{ }^{1} \mathrm{H}\right\}$ NMR (DMSO-d, $\left.376 \mathrm{MHz}\right) \delta=-111.09$

FTIR: 3089, 2972, 2864, 1577, 1155, 1117, 1030, 805, $677 \mathrm{~cm}^{-1}$.

HRMS: Calculated for $\mathrm{C}_{15} \mathrm{H}_{14} \mathrm{BrFO}_{3} \mathrm{I}^{+}[\mathrm{M}-\mathrm{OTs}]^{+}:$466.9150; Found: 466.9140.

Melting Point: $200.3-203.0^{\circ} \mathrm{C}$.

\section{Compound 11y}<smiles>Cc1ccc(Br)cc1I(O)c1ccccc1</smiles>

Prepared according to the general procedure $\mathrm{G}$ on $1.0 \mathrm{mmol}$ and obtained in $89 \%$ yield $(0.568 \mathrm{~g}, 0.89 \mathrm{mmol})$ as a white powder.

${ }^{1} \mathrm{H}$ NMR (DMSO-d $\left.{ }_{6}, 400 \mathrm{MHz}\right) \delta=8.22(\mathrm{~d}, J=2.0 \mathrm{~Hz}, 1 \mathrm{H}), 7.73(\mathrm{dd}, J=8.2,2.0 \mathrm{~Hz}, 1 \mathrm{H}$ ), 7.49-7.45 (m, 3H), $7.10(\mathrm{~d}, J=7.8 \mathrm{~Hz}, 2 \mathrm{H}), 6.45(\mathrm{~s}, 2 \mathrm{H}), 3.95(\mathrm{~s}, 6 \mathrm{H}), 3.85(\mathrm{~s}, 3 \mathrm{H}), 2.28(\mathrm{~s}$, $3 \mathrm{H})$.

${ }^{13} \mathrm{C}\left\{{ }^{1} \mathrm{H}\right\}$ NMR (DMSO-d $\left.\boldsymbol{d}_{6}, 101 \mathrm{MHz}\right) \delta=166.1,159.3,145.8,139.8,138.5,137.5,135.0$, $132.7,128.0,125.5,121.8,119.5,92.2,86.8,57.2,56.1,24.2,21.8$.

FTIR: 3078, 2981, 2923, 1591, 1154, 1114, 1031, 1006, 818, $676 \mathrm{~cm}^{-1}$.

HRMS: Calculated for $\mathrm{C}_{16} \mathrm{H}_{17} \mathrm{BrO}_{3} \mathrm{l}^{+}[\mathrm{M}-\mathrm{OTs}]^{+}$: 462.9400; Found: 462.9391.

Melting Point: $211.0-213.1^{\circ} \mathrm{C}$.

Compound $\mathbf{1 1 z}$<smiles>Cc1ccc(Cl)cc1I(O)c1ccccc1</smiles> 
Prepared according to the general procedure $\mathrm{G}$ on $3.0 \mathrm{mmol}$ and obtained in $90 \%$ yield $(1.60 \mathrm{~g}, 2.7 \mathrm{mmol})$ as a white powder.

${ }^{1} \mathrm{H}$ NMR (DMSO- $\left.d_{6}, 600 \mathrm{MHz}\right) \delta=8.1(\mathrm{~d}, J=2.2 \mathrm{~Hz}, 1 \mathrm{H}$ ), $7.61(\mathrm{dd}, J=8.2,2.2 \mathrm{~Hz}, 1 \mathrm{H}$ ), 7.54 (d, J = 8.4 Hz, 1H), 7.46 (d, J = 7.9 Hz, 2H), 7.10 (d, J= $7.9 \mathrm{~Hz}, 2 \mathrm{H}), 6.45(\mathrm{~s}, 2 \mathrm{H}), 3.95(\mathrm{~s}, 6 \mathrm{H})$, $3.86(\mathrm{~s}, 3 \mathrm{H}), 2.57(\mathrm{~s}, 3 \mathrm{H}), 2.28(\mathrm{~s}, 3 \mathrm{H})$.

${ }^{13} \mathrm{C}\left\{{ }^{1} \mathrm{H}\right\}$ NMR (DMSO-d $\left.\boldsymbol{d}_{6}, 101 \mathrm{MHz}\right) \delta=161.1,156.3,142.7,136.5,134.6,132.8,129.2$, $129.1,128.5,125.0,122.5,118.4,89.2,83.8,54.2,53.2,21.1,17.8$.

FTIR: $2981,1577,1219,1203,1155,1115,1007,820,679 \mathrm{~cm}^{-1}$.

HRMS: Calculated for $\mathrm{C}_{15} \mathrm{H}_{14} \mathrm{BrFO}_{3} \mathrm{I}^{+}\left[\mathrm{M}\right.$ - OTs] ${ }^{+}$: 418.9914; Found: 418.9905.

Melting Point: $155.7-166.6^{\circ} \mathrm{C}$.

Compound 11aa<smiles>Cc1ccc(F)cc1I(O[Na])c1ccccc1</smiles>

Prepared according to the general procedure $\mathrm{G}$ on $3.0 \mathrm{mmol}$ and obtained in $89 \%$ yield (1.53 g, $2.7 \mathrm{mmol})$ as a white powder.

${ }^{1} \mathrm{H}$ NMR (DMSO- $\left.d_{6}, 600 \mathrm{MHz}\right) \delta=7.94$ (dd, $\left.J=7.6,2.7 \mathrm{~Hz}, 1 \mathrm{H}\right), 7.57$ (dd, $J=8.5,5.8 \mathrm{~Hz}$, $1 \mathrm{H}), 7.46$ (d, $J=8.0 \mathrm{~Hz}, 2 \mathrm{H}$ ), 7.41 (ddd, $J=8.4,8.4,2.7 \mathrm{~Hz}, 1 \mathrm{H}), 7.10$ (d, J = 7.8 Hz, 2H), 3.95 $(\mathrm{s}, 6 \mathrm{H}), 3.86(\mathrm{~s}, 3 \mathrm{H}), 2.57(\mathrm{~s}, 3 \mathrm{H}), 2.28(\mathrm{~s}, 3 \mathrm{H})$.

${ }^{13} \mathrm{C}\left\{{ }^{1} \mathrm{H}\right\}$ NMR (DMSO-d $\left.d_{6}, 101 \mathrm{MHz}\right) \delta=166.1,159.7$ (d, $\left.J_{\mathrm{C}-\mathrm{F}}=249.5 \mathrm{~Hz}\right), 159.3,145.7,137.6$, $136.8\left(d, J_{C-F}=3.3 \mathrm{~Hz}\right), 132.0\left(\mathrm{~d}, J_{\mathrm{C}-\mathrm{F}}=7.6 \mathrm{~Hz}\right), 128.0,125.5,123.5\left(\mathrm{~d}, J_{\mathrm{C}-\mathrm{F}}=24.1 \mathrm{~Hz}\right), 120.2$ $\left(d, J_{C-F}=7.5 \mathrm{~Hz}\right), 119.3\left(d, J_{C-F}=20.7 \mathrm{~Hz}\right), 92.1,86.8,57.2,56.2,23.8,20.8$.

${ }^{19} \mathrm{~F}\left\{{ }^{1} \mathrm{H}\right\}$ NMR (DMSO-d, $\left.376 \mathrm{MHz}\right) \delta=-113.5\left(\mathrm{dd}, J_{\mathrm{F}-\mathrm{H}}=7.2 \mathrm{~Hz}\right.$ ).

FTIR: $2940,1580,1228,1153,1152,1007,812,687 \mathrm{~cm}^{-1}$.

HRMS: Calculated for $\mathrm{C}_{15} \mathrm{H}_{14} \mathrm{BrFO}_{3} \mathrm{I}^{+}[\mathrm{M}-\mathrm{OTs}]^{+}: 403.0212$; Found: 403.0201.

Melting Point: $186.6-187.5^{\circ} \mathrm{C}$. 


\subsubsection{Synthesis and characterization of aryne trapping products}

\subsubsection{General procedure I}

The iodonium salt ( $0.5 \mathrm{mmol}, 1$ equiv.) was weighed out and placed in a $12 \mathrm{~mL}$ vial containing a magnetic stir bar. TBME $(2.5 \mathrm{~mL})$ and arynophile $7 \mathrm{~g}(0.16 \mathrm{~mL}, 1.5 \mathrm{mmol}, 3$ equiv.) or 7 e $(0.07 \mathrm{~mL}, 0.55 \mathrm{mmol}, 1.1$ equiv.) were added sequentially forming slurry. Ground to fine powder $\mathrm{NaOt}-\mathrm{Bu}(0.0721 \mathrm{~g}, 0.75 \mathrm{mmol}, 1.5$ equiv. or as indicated) was weighed out in air and added to the vial with stirring in one portion. The vial was sealed with a cap, and the reaction mixture was vigorously stirred at the room temperature (with $7 \mathrm{~g}$ ) or at $0{ }^{\circ} \mathrm{C}$ (with $7 \mathrm{e}$ ) for 1 hour. The reaction was quenched with an aqueous solution of ammonium chloride $(7 \mathrm{~mL})$ and extracted with EtOAc $(3 \times 3 \mathrm{~mL})$. The combined organic phases were dried with $\mathrm{MgSO}_{4}$, drying agent was removed by vacuum filtration, and solvent was removed on rotary evaporator. The crude residue was purified by column chromatography on silica gel with diethyl ether/hexanes mixture or ethyl acetate/hexanes mixture as eluent.

\subsubsection{General procedure J: telescoped reaction}

Aryl iodide $(0.5 \mathrm{mmol}, 1$ equiv.) was weighed out and added to a $12 \mathrm{~mL}$ vial containing a stir bar. Acetonitrile $(0.5 \mathrm{~mL})$ was added to the vial followed by $p$ toluenesulfonic acid monohydrate $(0.095 \mathrm{~g}, 0.5 \mathrm{mmol}, 1$ equiv.) and m-CPBA (0.122 g, 0.5 mmol, 1 equiv.). The vial was placed in an aluminum block set to $77^{\circ} \mathrm{C}$, and the mixture was stirred at this temperature for 30 mins. 1,3,5-Trimethoxybenzene $(0.084 \mathrm{~g}, 0.5 \mathrm{mmol}$, 1 equiv.) was added in one portion and the reaction was stirred for 5 mins. The vial was 
removed from heat and allowed to cool down. TBME was added at stirring, and iodonium salt was allowed to precipitate out of the solution until free-flowing powder was observed. The vial was removed from a stir plate and, after the solid settled, the liquid phase was removed with a pipette. Washing with TBME was repeated two more times to remove the majority of contaminants. TBME $(2 \mathrm{~mL})$ was added to the resulted slurry followed by arynophile (3 equiv.). $\mathrm{NaOt}$ - $\mathrm{Bu}$ (1.5 equiv. with $7 \mathrm{~g}$ or 3 equiv. with $7 \mathrm{a}$ ) was added at stirring, and the mixture was allowed to react for 1 hour at room temperature. The reaction was quenched with saline solution $(7 \mathrm{~mL})$ and extracted with EtOAc $(3 \times 3 \mathrm{~mL})$. The combined organic phases were dried with $\mathrm{MgSO}_{4}$, drying agent was removed by vacuum filtration, and solvent was removed on rotary evaporator. The crude residue was purified by column chromatography on silica gel.

\section{Compound 12ag}<smiles>CC(=O)c1ccc2c(c1)C1C=CC2O1</smiles>

Prepared from 11a with furan ( $0.2 \mathrm{~mL}, 2.75 \mathrm{mmol}, 5.5$ equiv.) according to the general procedure I on $0.5 \mathrm{mmol}$ scale with the following modification: reaction was conducted at $0{ }^{\circ} \mathrm{C}$, LiHMDS ( $1 \mathrm{M}$ in toluene, $0.5 \mathrm{~mL}, 1$ equiv.) was used instead of $\mathrm{NaOt}$-Bu. The product was obtained in $69 \%$ yield $(0.0700 \mathrm{~g}, 0.35 \mathrm{mmol})$ as a white solid. Spectral data are consistent with those previously reported. ${ }^{98}$

${ }^{1} \mathrm{H}$ NMR (CDCl 3 with $1 \%$ v/v TMS, $\left.400 \mathrm{MHz}\right) \delta=7.87(\mathrm{~s}, 1 \mathrm{H}), 7.75(\mathrm{~d} \mathrm{~J}=7.4 \mathrm{~Hz}, 1 \mathrm{H}), 7.29$ (d, J= 7.4 Hz, 1H), 7.05-7.00 (m, 2H), 5.75-5.74 (m, 2H), 3.89 (s, 3H).

${ }^{13} \mathrm{C} \mathrm{NMR}_{(\mathrm{CDCl}}$ with $1 \% \mathrm{v} / \mathrm{v}$ TMS, $101 \mathrm{MHz}$ ) $\delta=166.9,154.4,149.5,143.3,142.4,128.1$, 127.3, 120.7, 119.9, 82.1(5), 82.1(2), 52.1.

\section{Compound $12 \mathrm{cg}$}


<smiles>CC(=O)c1cccc2c1C1C=CC2O1</smiles>

major

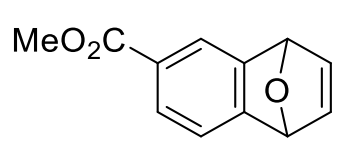

minor (12ag)

Prepared from $11 \mathrm{c}$ with furan $(0.109 \mathrm{~mL}, 1.5 \mathrm{mmol}, 3$ equiv.) according to the general procedure I with the following modification: LiHMDS ( $1 \mathrm{M}$ in toluene, $0.5 \mathrm{~mL}, 1$ equiv.) was used instead of $\mathrm{NaOt}-\mathrm{Bu}$, and the reaction was performed at $0{ }^{\circ} \mathrm{C}$. The product was isolated in $70 \%$ yield $(0.0704 \mathrm{~g}, 0.35 \mathrm{mmol}$ ) as a colorless oil. Structural isomer 12ag resulted from deprotonation of the more sterically accessible position and was isolated in $8 \%$ yield $(0.008 \mathrm{~g}, 0.04 \mathrm{mmol})$. Characterization for the major isomer is shown below.

$\mathrm{R}_{f}=0.18$ in $20 \% \mathrm{Et}_{2} \mathrm{O} /$ hexanes

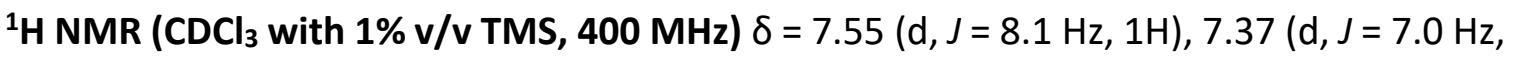
$1 \mathrm{H}), 7.09-7.01(\mathrm{~m}, 3 \mathrm{H}), 6.37(\mathrm{~s}, 1 \mathrm{H}), 5.74(\mathrm{~s}, 1 \mathrm{H}), 3.92(\mathrm{~s}, 3 \mathrm{H})$.

${ }^{13} \mathrm{C}$ NMR ( $\mathrm{CDCl}_{3}$ with 1\% v/v TMS, $\left.101 \mathrm{MHz}\right) \delta=166.4,152.4,150.2,143.7,142.6,125.4$, 125.2, 123.7(3), 123.6(9), 82.7, 82.8, 52.0.

FTIR: 3008, 2950, 2843, 1713, 1274, $1118 \mathrm{~cm}^{-1}$.

HRMS: Calculated for $\mathrm{C}_{12} \mathrm{H}_{11} \mathrm{O}_{3}{ }^{+}[\mathrm{M}+\mathrm{H}]^{+}$: 203.0708; Found: 203.0698.

Compound 12eg<smiles>O=[N+]([O-])c1ccc2c(c1)C1C=CC2O1</smiles>

Prepared from 11e with furan ( $0.2 \mathrm{~mL}, 5.5$ equiv.) according to the general procedure I on $0.5 \mathrm{mmol}$ scale with the following modification: LiHMDS ( $1 \mathrm{M}$ in toluene, $0.5 \mathrm{~mL}, 1$ equiv.) was used instead of $\mathrm{NaOt}$-Bu. The product was obtained in $57 \%$ yield $(0.0539 \mathrm{~g}$, $0.29 \mathrm{mmol}$ ) as a golden solid. Spectral data are consistent with those previously reported. ${ }^{98}$

${ }^{1} \mathbf{H}$ NMR (CDCl 3 with 1\% v/v TMS, 400 MHz) $\delta=8.04(\mathrm{~d}, J=1.8 \mathrm{~Hz}, 1 \mathrm{H}), 7.98(\mathrm{dd}, J=7.8,1.9$ $\mathrm{Hz}, 1 \mathrm{H}), 7.36(\mathrm{~d}, J=7.8 \mathrm{~Hz}, 1 \mathrm{H}), 7.10(\mathrm{dd}, J=5.5,1.8 \mathrm{~Hz}, 1 \mathrm{H}), 7.05(\mathrm{dd}, J=5.5,1.8 \mathrm{~Hz}, 1 \mathrm{H})$, 5.81-5.79 (m, 2H).

${ }^{13} \mathrm{C}$ NMR ( $\mathrm{CDCl}_{3}$ with $1 \%$ v/v TMS, $\left.101 \mathrm{MHz}\right) \delta=156.4,151.3,145.7,143.4,142.3,122.3$, $120.0,115.2,82.0(2), 82.0(1)$.

Compound 12gg 
NC<smiles>C1=CC2OC1c1ccccc12</smiles>

Prepared from $11 \mathrm{~g}$ with furan $(0.2 \mathrm{~mL}, 5.5$ equiv.) according to the general procedure I on $0.5 \mathrm{mmol}$ scale with the following modification: LiHMDS ( $1 \mathrm{M}$ in toluene, $0.5 \mathrm{~mL}, 1$ equiv.) was used instead of $\mathrm{NaOt}$-Bu. The product was obtained in $78 \%$ yield $(0.0663 \mathrm{~g}, 0.39$ $\mathrm{mmol}$ ) as a yellow crystalline solid. Spectral data are consistent with those previously reported. 56

${ }^{1} \mathrm{H}$ NMR ( $\mathrm{CDCl}_{3}$ with $1 \%$ v/v TMS, $\left.400 \mathrm{MHz}\right) \delta=7.46(\mathrm{Br}, 1 \mathrm{H})$, 7.36-7.31 (m, 2H), 7.06-7.02 $(\mathrm{m}, 2 \mathrm{H}), 5.76(\mathrm{t}, \mathrm{J}=1.92,2 \mathrm{H})$

${ }^{13} \mathrm{C}$ NMR ( $\mathrm{CDCl}_{3}$ with 1\% v/v TMS, $\left.101 \mathrm{MHz}\right) \delta=154.6,150.5,143.1,142.5,130.9,122.8$, $120.7,119.1,108.8,82.1,81.9$.

\section{Compound 12ig}<smiles>O=[N+]([O-])c1cccc2c1C1C=CC2O1</smiles>

Prepared from $11 \mathrm{i}$ and furan $(0.109 \mathrm{~mL}, 1.5 \mathrm{mmol}, 3$ equiv.) according to the general procedure I on a $0.5 \mathrm{mmol}$ scale and obtained in $82 \%$ yield $(0.0834 \mathrm{~g}, 0.41 \mathrm{mmol})$ as a yellow solid.

$\mathrm{R}_{f}=0.2$ in $10 \%$ ether/hexanes

${ }^{1} \mathrm{H}$ NMR $\left(\mathrm{CDCl}_{3}\right.$ with $1 \%$ v/v TMS, $\left.400 \mathrm{MHz}\right) \delta=7.72(\mathrm{dd}, J=8.4,0.7 \mathrm{~Hz} 1 \mathrm{H}), 7.48(\mathrm{~d}, J=$ $7.0 \mathrm{~Hz}, 1 \mathrm{H}), 7.17-7.12(\mathrm{~m}, 3 \mathrm{H}), 6.49(\mathrm{~m}, 1 \mathrm{H}), 5.83(\mathrm{~m}, 1 \mathrm{H})$.

${ }^{13} \mathrm{C} \mathrm{NMR}\left(\mathrm{CDCl}_{3}\right.$ with 1\% v/v TMS, $\left.101 \mathrm{MHz}\right) \delta=152.6,146.7,144.3,142.4,142.0,126.7$, $124.9,119.3,82.6,81.9$.

FTIR: 3100, 2922, 2856, 1511, 1342, 1276, $727 \mathrm{~cm}^{-1}$.

HRMS: Calculated for $\mathrm{C}_{10} \mathrm{H}_{7} \mathrm{NO}_{3}{ }^{+}[\mathrm{M}+\mathrm{H}]^{+}:$190.0504; Found: 190.0499 .

Melting point: $120.9-122.6^{\circ} \mathrm{C}$.

Compound 12jg<smiles>Clc1cccc2c1C1C=CC2O1</smiles> 
Prepared from $11 \mathrm{j}$ with furan $(0.109 \mathrm{~mL}, 1.5 \mathrm{mmol}, 3$ equiv.) according to the general procedure I on $0.5 \mathrm{mmol}$ scale and obtained in $78 \%$ yield $(0.0701 \mathrm{~g}, 0.39 \mathrm{mmol})$ as a white solid; prepared according to the general procedure $\mathrm{J}$ and obtained in $67 \%$ yield. Spectral data are consistent with those previously reported. ${ }^{56}$

${ }^{1} \mathrm{H}$ NMR (CDCl 3 with 1\% v/v TMS, $\left.400 \mathrm{MHz}\right) \delta=7.14-7.09(\mathrm{~m}, 1 \mathrm{H}), 7.08-7.04(\mathrm{~m}, 2 \mathrm{H}), 6.91$ $(\mathrm{m}, 2 \mathrm{H}), 5.87(\mathrm{~s}, 1 \mathrm{H}), 5.74(\mathrm{~s}, 1 \mathrm{H})$

${ }^{13} \mathrm{C}$ NMR ( $\mathrm{CDCl}_{3}$ with 1\% v/v TMS, $\left.101 \mathrm{MHz}\right) \delta=151.5$ 147.2, 143.3, 142.4, 126.9, 126.5, $125.7,118.5,82.9,81.2$.

Compound $12 \mathrm{~kg}$<smiles>N#Cc1cccc2c1C1C=CC2O1</smiles>

Prepared from $11 \mathbf{k}$ with furan $(0.109 \mathrm{~mL}, 1.5 \mathrm{mmol}, 3$ equiv.) according to the general procedure I on $0.5 \mathrm{mmol}$ scale and obtained in $81 \%$ yield $(0.0688 \mathrm{~g}, 0.41 \mathrm{mmol})$ as a white solid. Spectral data are consistent with those previously reported. ${ }^{56}$

${ }^{1} \mathrm{H} \mathrm{NMR}\left(\mathrm{CDCl}_{3}\right.$ with $1 \%$ v/v TMS, $\left.400 \mathrm{MHz}\right) \delta=77.42$ (d, $\left.J=7.1 \mathrm{~Hz}, 1 \mathrm{H}\right), 7.19$ (dd, $J=7.9$, $1.0 \mathrm{~Hz}, 1 \mathrm{H}), 7.10-7.05(\mathrm{~m}, 3 \mathrm{H}), 5.9(\mathrm{~s}, 1 \mathrm{H}), 5.7(\mathrm{~s}, 1 \mathrm{H})$.

${ }^{13} \mathrm{C}$ NMR ( $\mathrm{CDCl}_{3}$ with 1\% v/v TMS, $\left.101 \mathrm{MHz}\right) \delta=154.6,150.7,143.7,142.2,127.1,126.1$, $123.8,116.7,105.1,82.4,81.4$.

Compound $12 \mathrm{mg}$<smiles>Clc1cc(Cl)c2c(c1)C1C=CC2O1</smiles>

Prepared from $11 \mathrm{~m}$ with furan $(0.109 \mathrm{~mL}, 1.5 \mathrm{mmol}, 3$ equiv.) according to the general procedure I on $0.5 \mathrm{mmol}$ scale and obtained in $87 \%$ yield $(0.0926 \mathrm{~g}, 0.44 \mathrm{mmol})$ as a white solid.

$\mathrm{R}_{f}=0.47$ in $10 \%$ ether/hexanes

${ }^{1} \mathrm{H} \mathrm{NMR}\left(\mathrm{CDCl}_{3}\right.$ with 1\% v/v TMS, $\left.400 \mathrm{MHz}\right) \delta=7.11(\mathrm{~s}, 1 \mathrm{H}), 7.07(\mathrm{~d}, J=5.51 \mathrm{H}), 7.02(\mathrm{~d}, J$ $=5.5,1 \mathrm{H}) 6.94(\mathrm{~s}, 1 \mathrm{H}), 5.84(\mathrm{~s}, 1 \mathrm{H}), 5.71(\mathrm{~s}, 1 \mathrm{H})$

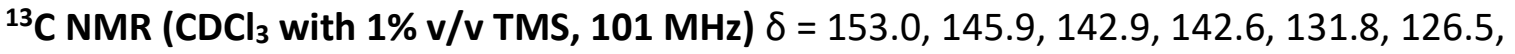
$125.1,119.7,82.6,81.0$. 
FTIR: 3069, 3030, 2958, 1580, 1276, $817 \mathrm{~cm}^{-1}$.

HRMS: Calculated for $\mathrm{C}_{10} \mathrm{H}_{6} \mathrm{OCl}_{2}{ }^{+}[\mathrm{M}+\mathrm{H}]^{+}:$212.9874; Found: 203.0698.

Melting point: $36.0-39.1^{\circ} \mathrm{C}$.

Compound 12ng<smiles>FC(F)(F)c1ccc(Cl)c2c1C1C=CC2O1</smiles>

Prepared from $11 \mathrm{n}$ with furan $(0.109 \mathrm{~mL}, 2.75 \mathrm{mmol}, 5.5$ equiv) according to the general procedure I on $0.5 \mathrm{mmol}$ scale and obtained in $54 \%$ yield $(0.27 \mathrm{mmol}, 0.066 \mathrm{~g})$ as a yellow oil.

$\mathrm{R}_{f}=0.656 \% \mathrm{EtOAc} /$ hexanes

${ }^{1} \mathrm{H} \mathrm{NMR}\left(\mathrm{CDCl}_{3}\right.$ with 1\% v/v TMS, $\left.400 \mathrm{MHz}\right) \delta=7.15-7.04(\mathrm{~m}, 4 \mathrm{H}), 6.03(\mathrm{~s}, 1 \mathrm{H}), 5.92(\mathrm{~s}, 1 \mathrm{H})$

${ }^{13} \mathrm{C}$ NMR ( $\mathrm{CDCl}_{3}$ with 1\% v/v TMS, $\left.101 \mathrm{MHz}\right) \delta=150.5\left(\mathrm{q}, J_{\mathrm{C}-\mathrm{F}}=2.7 \mathrm{~Hz}\right), 148.8,143.1$, $142.9,129.8,126.6,123.7\left(q, J_{C-F}=272.5 \mathrm{~Hz}\right.$ ), $123.2\left(q, J_{C-F}=3.9 \mathrm{~Hz}\right), 122.3\left(q, J_{C-F}=34.0\right.$ $\mathrm{Hz}), 82.3\left(\mathrm{q}, J_{\mathrm{C}-\mathrm{F}}=1.62 \mathrm{~Hz}\right), 81.1$.

FTIR: 1603, 1314, 1280, 1162, 1093, $875 \mathrm{~cm}^{-1}$.

HRMS: Calculated for $\mathrm{C}_{11} \mathrm{H}_{6} \mathrm{OClF}_{3}{ }^{+}[\mathrm{M}+\mathrm{H}]^{+}:$247.0132; Found: 247.0128 .

Compound 12 og<smiles>Cc1ccc([N+](=O)[O-])c2c1C1C=CC2O1</smiles>

Prepared from 110 with furan $(0.109 \mathrm{~mL}, 1.5 \mathrm{mmol}, 3$ equiv.) according to the general procedure I on $0.5 \mathrm{mmol}$ scale with the following modification: LiHMDS (1 M in toluene, $0.5 \mathrm{~mL}, 1$ equiv.) was used instead of $\mathrm{NaOt}$-Bu. The product was obtained in $72 \%$ yield $(0.36 \mathrm{mmol}, 0.073 \mathrm{~g})$ as an orange crystalline solid.

$\mathrm{R}_{f}=0.20$ in $10 \% \mathrm{Et}_{2} \mathrm{O} /$ hexanes

${ }^{1} \mathrm{H}$ NMR (CDCl 3 with 1\% v/v TMS, $\left.400 \mathrm{MHz}\right) \delta=7.63(\mathrm{~d}, J=8.5 \mathrm{~Hz}, 1 \mathrm{H}), 7.14(\mathrm{~m}, 1 \mathrm{H}), 6.9$ $(\mathrm{d}, J=8.5 \mathrm{~Hz}, 1 \mathrm{H}), 6.4(\mathrm{~s}, 1 \mathrm{H}), 5.4(\mathrm{~s}, 1 \mathrm{H}), 2.3(\mathrm{~s}, 3 \mathrm{H})$. 
${ }^{13} \mathrm{C}$ NMR ( $\mathrm{CDCl}_{3}$ with $1 \%$ v/v TMS, $\left.101 \mathrm{MHz}\right) \delta=150.6,146.4,143.8,142.2,140.8,135.9$, $128.3,119.5,82.9,80.5,18.2$.

FTIR: 3100, 2922, 2856, 1511, 1342, $794 \mathrm{~cm}^{-1}$.

HRMS: Calculated for $\mathrm{C}_{11} \mathrm{H}_{9} \mathrm{ON}_{3}{ }^{+}[\mathrm{M}+\mathrm{H}]^{+}:$204.0665; Found: 204.0654.

Melting point: $148.0-150.5^{\circ} \mathrm{C}$.

Compound $12 \mathrm{pg}$<smiles>Cc1c(F)cc(Br)c2c1C1C=CC2O1</smiles>

Prepared from $11 \mathrm{p}$ with furan $(0.109 \mathrm{~mL}, 1.5 \mathrm{mmol}, 3$ equiv.) according to the general procedure I on $0.5 \mathrm{mmol}$ and obtained in $76 \%$ yield $(0.0969 \mathrm{~g}, 0.38 \mathrm{mmol})$ as a white solid. $\mathrm{R}_{f}=0.39$ in $10 \%$ ether/hexanes

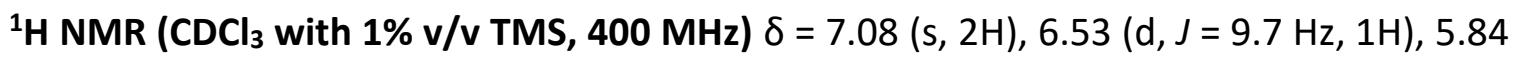
$(\mathrm{s}, 1 \mathrm{H}), 5.78(\mathrm{~s}, 1 \mathrm{H}), 2.25(\mathrm{~s}, 3 \mathrm{H})$.

${ }^{13} \mathrm{C}$ NMR ( $\mathrm{CDCl}_{3}$ with 1\% v/v TMS, $\left.101 \mathrm{MHz}\right) \delta=156.3$ (d, $J_{\mathrm{C}-\mathrm{F}}=246.5 \mathrm{~Hz}$ ), 152.1 (d, JC- $=$ $1.3 \mathrm{~Hz}$ ), 144.7 (d, $J_{\mathrm{C}-\mathrm{F}}=2.2 \mathrm{~Hz}$ ), 143.8, 142.2, 130.0 (d, $J_{\mathrm{C}-\mathrm{F}}=7.4 \mathrm{~Hz}$ ), 113.5 (d, $J_{\mathrm{C}-\mathrm{F}}=23.4$ $\mathrm{Hz}), 100.1\left(\mathrm{~d}, J_{\mathrm{C}-\mathrm{F}}=25.0 \mathrm{~Hz}\right), 83.0\left(\mathrm{~d}, J_{\mathrm{C}-\mathrm{F}}=2.9 \mathrm{~Hz}\right), 81.7,17.5\left(\mathrm{~d}, J_{\mathrm{C}-\mathrm{F}}=1.0 \mathrm{~Hz}\right)$.

FTIR: $3019,2925,2849,1455,1275,1126,879 \mathrm{~cm}^{-1}$.

HRMS: Calculated for $\mathrm{C}_{11} \mathrm{H}_{9} \mathrm{OBrF}^{+}\left[\mathrm{M}+\mathrm{H}^{+}:\right.$254.9815; Found: 254.9811.

Melting point: $59.6-61.5^{\circ} \mathrm{C}$.

Compound 12qg<smiles>Cc1ccc2c(c1[N+](=O)[O-])C1C=CC2O1</smiles>

Prepared from $11 q$ with furan $(0.109 \mathrm{~mL}, 1.5 \mathrm{mmol}, 3$ equiv.) according to the general procedure I on $0.5 \mathrm{mmol}$ scale and obtained in $70 \%$ yield $(0.0747 \mathrm{~g}, 0.37 \mathrm{mmol})$ contaminated with $3 \%$ of 2,4,6-trimethoxyphenyl iodide, as a dark yellow solid. Spectral data are consistent with those previously reported. ${ }^{56}$ 
${ }^{1} \mathrm{H}$ NMR (CDCl 3 with $1 \%$ v/v TMS, $\left.400 \mathrm{MHz}\right) \delta=7.26(\mathrm{~d}, J=7.1 \mathrm{~Hz}, 1 \mathrm{H}), 7.16(\mathrm{dd}, J=5.5$, $1.6 \mathrm{~Hz}, 1 \mathrm{H}), 7.10(\mathrm{dd}, J=5.5,1.6 \mathrm{~Hz}, 1 \mathrm{H}), 6.95(\mathrm{~d}, J=7.2 \mathrm{~Hz}, 1 \mathrm{H}), 6.11(\mathrm{~s}, 1 \mathrm{H}), 5.77(\mathrm{~s}, 1 \mathrm{H})$, $2.5(\mathrm{~s}, 3 \mathrm{H})$.

${ }^{13} \mathrm{C}$ NMR ( $\mathrm{CDCl}_{3}$ with 1\% v/v TMS, $\left.101 \mathrm{MHz}\right) \delta=150.0,147.2,144.1,143.7,142.1,129.3$, $129.1,123.4,82.7,82.0,19.7$.

Compound 12rg<smiles>Cc1ccc2c(c1Br)C1C=CC2O1</smiles>

Prepared from $11 \mathrm{r}$ with furan $(0.109 \mathrm{~mL}, 1.5 \mathrm{mmol}, 3$ equiv.) according to the general procedure I on $0.5 \mathrm{mmol}$ scale and obtained in $87 \%$ yield $(0.103 \mathrm{~g}, 0.44 \mathrm{mmol})$ as an offwhite solid. Spectral data are consistent with those previously reported. ${ }^{56}$

${ }^{1} \mathrm{H}$ NMR $\left(\mathrm{CDCl}_{3}\right.$ with $1 \% \mathrm{v} / \mathrm{v}$ TMS, $\left.400 \mathrm{MHz}\right) \delta=7.08-7.02(\mathrm{~m}, 3 \mathrm{H}), 6.82(\mathrm{dd}, J=7.0,0.5$ $\mathrm{Hz}, 1 \mathrm{H}), 5.78(\mathrm{~s}, 1 \mathrm{H}), 5.75(\mathrm{~s}, 1 \mathrm{H}), 2.3(\mathrm{~s}, 3 \mathrm{H})$.

${ }^{13} \mathrm{C}$ NMR ( $\mathrm{CDCl}_{3}$ with $1 \%$ v/v TMS, $\left.101 \mathrm{MHz}\right) \delta=150.5,148.7,143.7,142.2,134.6,127.1$, $118.7,117.4,83.3,83.2,23.0$

Compound 12sg<smiles>Cc1ccc2c(c1F)C1C=CC2O1</smiles>

Prepared from $11 \mathrm{~s}$ with furan $(0.109 \mathrm{~mL}, 1.5 \mathrm{mmol}, 3$ equiv.) according to the general procedure I on $0.5 \mathrm{mmol}$ scale and obtained in $77 \%$ yield $(0.0680 \mathrm{~g}, 0.385 \mathrm{mmol})$ as a white solid.

$\mathrm{R}_{f}=0.24$ in $20 \% \mathrm{Et}_{2} \mathrm{O} /$ hexanes

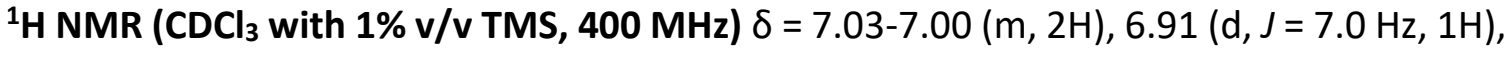
$6.77(\mathrm{dd}$, appears as triplet, $J=6.8 \mathrm{~Hz}, 1 \mathrm{H}), 5.9(\mathrm{~s}, 1 \mathrm{H}), 5.69-5.68(\mathrm{~m}, 1 \mathrm{H}), 2.20(\mathrm{~d}, J=1.6$ $\mathrm{Hz}, 3 \mathrm{H})$.

${ }^{13} \mathrm{C}$ NMR ( $\mathrm{CDCl}_{3}$ with 1\% v/v TMS, $\left.101 \mathrm{MHz}\right) \delta=154.8\left(\mathrm{~d}, \mathrm{~J}_{\mathrm{C}-\mathrm{F}}=245.8 \mathrm{~Hz}\right.$ ), 150.0 (d, $J_{\mathrm{C}-\mathrm{F}}=$ $4.4 \mathrm{~Hz}$ ), 143.3, 142.3, 133.4 (d, $J_{\mathrm{C}-\mathrm{F}}=21.4 \mathrm{~Hz}$ ), 128.2 (d, $\left.J_{\mathrm{C}-\mathrm{F}}=3.5 \mathrm{~Hz}\right), 123.3$ (d, $J_{\mathrm{C}-\mathrm{F}}=17.8$ $\mathrm{Hz}), 115.9\left(\mathrm{~d}, J_{\mathrm{C}-\mathrm{F}}=3.1 \mathrm{~Hz}\right), 82.4,79.5,14.4\left(\mathrm{~d}, J_{\mathrm{C}-\mathrm{F}}=3.4 \mathrm{~Hz}\right)$.

${ }^{19} \mathrm{~F}\{1 \mathrm{H}\} \mathrm{NMR}\left(\mathrm{CDCl}_{3}\right.$ with $1 \% \mathrm{v} / \mathrm{v}$ TMS, $\left.376 \mathrm{MHz}\right) \delta=-125.4$.

FTIR: 3032, 2952, 2860, 1472, 1235, $823 \mathrm{~cm}^{-1}$. 
HRMS: Calculated for $\mathrm{C}_{11} \mathrm{H}_{10} \mathrm{OF}^{+}[\mathrm{M}+\mathrm{H}]^{+}:$: 177.0710; Found: 177.0706 .

Melting point: $28.3-30.9^{\circ} \mathrm{C}$.

Compound 12 tg<smiles>Cc1ccc2c(c1Cl)C1C=CC2O1</smiles>

Prepared from 11t with furan $(0.109 \mathrm{~mL}, 1.5 \mathrm{mmol}, 3$ equiv.) according to the general procedure I on $0.5 \mathrm{mmol}$ scale and obtained in $81 \%$ yield $(0.078 \mathrm{~g}, 0.405 \mathrm{mmol})$ contaminated with a $2 \%$ of 2,4,6-trimethoxyphenyl iodide, as a white solid.

$\mathrm{R}_{f}=0.66$ in $16 \%$ EtOAc/hexanes

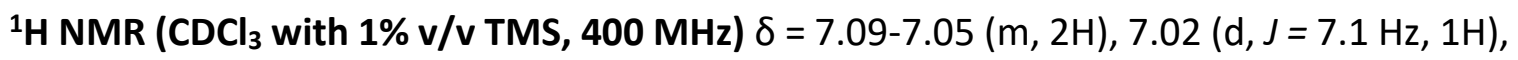
$6.84(\mathrm{dd}, J=7.1,0.7 \mathrm{~Hz}, 1 \mathrm{H}), 5.87(\mathrm{~s}, 1 \mathrm{H}), 5.72(\mathrm{~s}, 1 \mathrm{H}), 2.30(\mathrm{~s}, 3 \mathrm{H})$.

${ }^{13} \mathrm{C}$ NMR $\left(\mathrm{CDCl}_{3}\right.$ with $1 \% \mathrm{v} / \mathrm{v}$ TMS, $\left.101 \mathrm{MHz}\right) \delta=148.8,147.7,143.6,142.2,133.1,127.3$, $127.2,118.1,82.9,81.5,19.4$.

FTIR: $3032,2943,2850,1488,1279,835 \mathrm{~cm}^{-1}$.

HRMS: Calculated for $\mathrm{C}_{11} \mathrm{H}_{10} \mathrm{OCl}{ }^{+}[\mathrm{M}+\mathrm{H}]^{+}$: 193.0415; Found: 193.0413 .

Melting point: $66.3-68.5^{\circ} \mathrm{C}$.

Compound 12vg<smiles>Brc1cccc2c1C1C=CC2O1</smiles>

Prepared from $11 \mathrm{v}$ with furan $(0.109 \mathrm{~mL}, 1.5 \mathrm{mmol}, 3$ equiv.) according to the general procedure J on $0.5 \mathrm{mmol}$ scale and obtained in $78 \%$ yield $(0.0876 \mathrm{~g}, 0.39 \mathrm{mmol})$ as a white solid. Spectral data are consistent with those previously reported. ${ }^{99}$

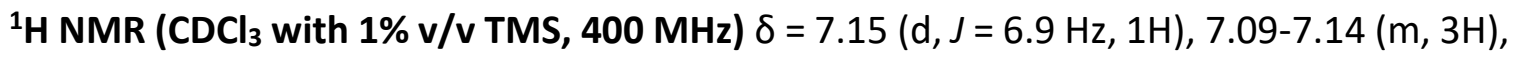
$6.84(\mathrm{dd}$, appears as triplet, $J=7.6 \mathrm{~Hz}, 1 \mathrm{H}), 5.79(\mathrm{~s}, 1 \mathrm{H}), 5.77(\mathrm{~s}, 1 \mathrm{H})$,

${ }^{13} \mathrm{C} \mathrm{NMR}$ (CDCl 3 with 1\% v/v TMS, $101 \mathrm{MHz}$ ) $\delta=151.6,149.8,143.4,142.4,128.4,127.1$, 119.0, 114.5,83.2, 82.8.

Compound 12de 
<smiles>COc1cccc2c1nnn2Cc1ccccc1</smiles>

Prepared from 11d and benzyl azide according to the general procedure I on $0.5 \mathrm{mmol}$ and obtained in $97 \%$ yield $(0.116 \mathrm{~g}, 0.49 \mathrm{mmol})$ as an off-white solid. Spectral data are consistent with those previously reported. ${ }^{100}$

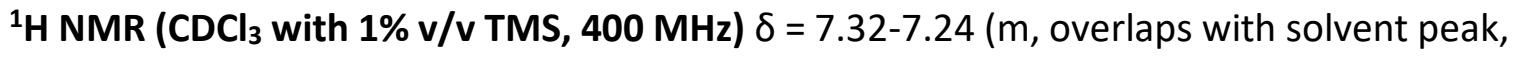
$6 \mathrm{H}), 6.89(\mathrm{~d}, J=8.3 \mathrm{~Hz}, 1 \mathrm{H}), 6.66(\mathrm{~d}, J=7.7 \mathrm{~Hz}, 1 \mathrm{H}), 5.81(\mathrm{~s}, 2 \mathrm{H}), 4.10(\mathrm{~s}, 3 \mathrm{H})$.

${ }^{13} \mathrm{C} \mathrm{NMR}$ (CDCl 3 with 1\% v/v TMS, 101 MHz) $\delta=151.7,138.3,134.7(9)$ ) 134.7(5), 128.9, 128.6, 128.4, 127.5, 103.3, 101.8, 56.2, 52.2.

Compound $12 \mathrm{he}$<smiles>Fc1cccc2c1nnn2Cc1ccccc1</smiles>

Prepared from $11 \mathrm{~h}$ and benzyl azide according to the general procedure I on $0.5 \mathrm{mmol}$ and obtained in $59 \%$ yield $(0.0636 \mathrm{~g}, 0.28 \mathrm{mmol})$ as an off-white solid. Spectral data are consistent with those previously reported. ${ }^{101}$

$\mathrm{R}_{f}=0.29$ in $16 \%$ EtOAc/Hexanes

${ }^{1} \mathrm{H}$ NMR ( $\mathrm{CDCl}_{3}$ with $1 \%$ v/v TMS, $\left.400 \mathrm{MHz}\right) \delta=7.3-7.37(\mathrm{~m}$, overlaps with solvent peak, $4 \mathrm{H}), 7.26-7.28(\mathrm{~m}, 2 \mathrm{H}), 7.13(\mathrm{~d}, J=8.4 \mathrm{~Hz}, 1 \mathrm{H}), 6.99$ (dd, J=10.0, $7.8 \mathrm{~Hz}, 1 \mathrm{H}), 5.85(\mathrm{~s}, 2 \mathrm{H})$.

${ }^{13} \mathrm{C} \mathrm{NMR}\left(\mathrm{CDCl}_{3}\right.$ with 1\% v/v TMS, $\left.101 \mathrm{MHz}\right) \delta=153.4\left(\mathrm{~d}, J_{\mathrm{C}-\mathrm{F}}=259.4\right), 136.5\left(\mathrm{~d}, J_{\mathrm{C}-\mathrm{F}}=\right.$ 18.9), $135.6\left(d, J_{C-F}=6.5\right), 134.2,129.0,128.9,128.2\left(d, J_{C-F}=6.8\right), 127.5,108.5\left(d, J_{C-F}=\right.$ 16.9), $105.8\left(d, J_{C-F}=5.0\right), 52.5$.

Compound 12le<smiles>FC(F)(F)Oc1cccc2c1nnn2Cc1ccccc1</smiles>

Prepared from 11l and benzyl azide according to the general procedure I on $0.5 \mathrm{mmol}$ and obtained in $66 \%$ yield $(0.0967 \mathrm{~g}, 0.33 \mathrm{mmol})$ as an orange solid.

$\mathrm{R}_{f}=0.31$ in $16 \%$ EtOAc/Hexanes

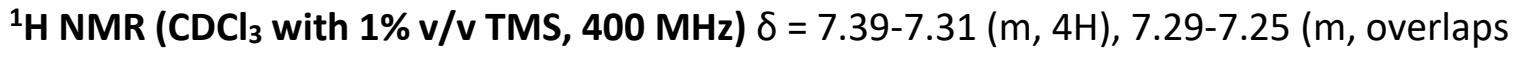
with solvent signal, $3 \mathrm{H}$ ), $7.18(\mathrm{dd}, J=7.7,1.1 \mathrm{~Hz}, 1 \mathrm{H}), 5.86(\mathrm{~s}, 2 \mathrm{H})$. 
${ }^{13} \mathrm{C}$ NMR (CDCl 3 with 1\% v/v TMS, $101 \mathrm{MHz} \delta=140.1$ (q, $J_{\mathrm{C}-\mathrm{F}}=1.94 \mathrm{~Hz}$ ), 139.4, 135.1, $134.2,129.1,128.7,127.8,127.7,120.7\left(q, J_{C-F}=259.81 \mathrm{~Hz}\right), 114.3\left(d, J_{C-F}=0.94 \mathrm{~Hz}\right), 108.5$, 52.6 .

${ }^{19} \mathrm{~F}\{1 \mathrm{H}\} \mathrm{NMR}\left(\mathrm{CDCl}_{3}\right.$ with $\left.1 \% \mathrm{v} / \mathrm{v} \mathrm{TMS}, 376 \mathrm{MHz}\right) \delta=-57.7$.

FTIR: 3090, 2918, 2850, 1626, 1508, 1216, 1143, 721, $693 \mathrm{~cm}^{-1}$.

HRMS: Calculated for $\mathrm{C}_{14} \mathrm{H}_{11} \mathrm{~F}_{3} \mathrm{~N}_{3} \mathrm{O}^{+}[\mathrm{M}+\mathrm{H}]^{+}$: 294.0849; Found: 294.0839.

Melting point: $73.7-75.1^{\circ} \mathrm{C}$.

Compound 12ue<smiles>Fc1ccc2c(nnn2Cc2ccccc2)c1C(F)(F)F</smiles>

Prepared from 11s and benzyl azide according to the general procedure I on $0.5 \mathrm{mmol}$ and obtained in $60 \%$ yield $(0.0884 \mathrm{~g}, 0.30 \mathrm{mmol})$ as an orange crystalline solid.

$\mathrm{R}_{f}=0.32$ in $29 \%$ EtOAc/hexanes

${ }^{1} \mathrm{H}$ NMR $\left(\mathrm{CDCl}_{3}\right.$ with $1 \% \mathrm{v} / \mathrm{v}$ TMS, $\left.400 \mathrm{MHz}\right) \delta=7.48(\mathrm{~m}, 1 \mathrm{H}), 7.38-7.31(\mathrm{~m}, 3 \mathrm{H})$, 7.28-7.24 (m, overlaps with solvent peak, $3 \mathrm{H}), 5.88(\mathrm{~s}, 2 \mathrm{H})$.

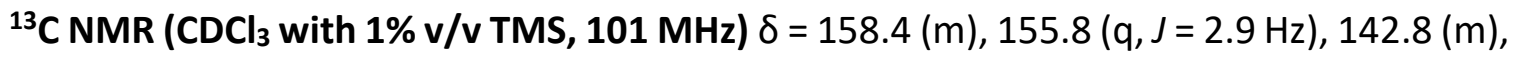
133.8, 130.1, 129.3, 129.0, 127.6, 124.12 (dq, $J=274.9,1.5 \mathrm{~Hz}), 118.0$ (d, JC-F $=27.9 \mathrm{~Hz}$ ), $114.9\left(\mathrm{~d}, J_{\mathrm{C}-\mathrm{F}}=11.0 \mathrm{~Hz}\right), 52.9$.

${ }^{19} \mathrm{~F}\{1 \mathrm{H}\}$ NMR $\left(\mathrm{CDCl}_{3}\right.$ with $\left.1 \% \mathrm{v} / \mathrm{v} \mathrm{TMS}, 376 \mathrm{MHz}\right) \delta=-56.4(\mathrm{~d}, J=19.1 \mathrm{~Hz}),-117.1(\mathrm{q}, J=$ $19.1 \mathrm{~Hz})$.

FTIR: 3093, 2923, 1602, 1428, 1319, 1263, 780, $710 \mathrm{~cm}^{-1}$.

HRMS: Calculated for $\mathrm{C}_{14} \mathrm{H}_{10} \mathrm{~F}_{4} \mathrm{~N}_{3}{ }^{+}[\mathrm{M}+\mathrm{H}]^{+}:$296.0805; Found: 296.0796.

Melting point: $149.0-152.0^{\circ} \mathrm{C}$.

Compound 12ia<smiles>CN1CCN(C)c2cccc([N+](=O)[O-])c2C1=O</smiles>

Prepared from 3-nitrophenyl iodide according to the general procedure $\mathrm{J}$ and obtained in $55 \%$ yield $(0.0646 \mathrm{~g}, 0.27 \mathrm{mmol})$ as a yellow solid. 
$\mathrm{R}_{f}=0.20$ in $30 \%$ acetone/hexanes

${ }^{1} \mathrm{H}$ NMR $\left(\mathrm{CDCl}_{3}\right.$ with 1\% v/v TMS, $\left.400 \mathrm{MHz}\right) \delta=7.44-7.38(\mathrm{~m}, 2 \mathrm{H}), 7.07(\mathrm{dd}, J=7.1,2.2$ $\mathrm{Hz}, 1 \mathrm{H}), 3.60(\mathrm{t}, J=5.7,2 \mathrm{H}), 3.33(\mathrm{t}, J=5.7,2 \mathrm{H}), 3.21(\mathrm{~s}, 3 \mathrm{H}), 2.86(\mathrm{~s}, 3 \mathrm{H})$.

${ }^{13} \mathrm{C}$ NMR ( $\mathrm{CDCl}_{3}$ with $1 \%$ v/v TMS, $\left.101 \mathrm{MHz}\right) \delta=166.3,150.1,147.1,130.9,124.7,121.9$, $116.7,56.8,47.9,40.2,33.6$.

FTIR: 3089, 2906, 2827, 1663, 1522, 1487, 1430, 1353, $849 \mathrm{~cm}^{-1}$.

HRMS: Calculated for $\mathrm{C}_{11} \mathrm{H}_{13} \mathrm{~N}_{3} \mathrm{O}_{3}{ }^{+}[\mathrm{M}+\mathrm{H}]^{+}$: 236.1030; Found: 236.1021.

Melting Point: $155.0-156.4^{\circ} \mathrm{C}$.

\subsubsection{Selectivity study}

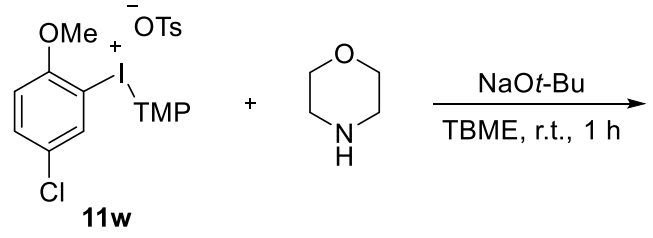<smiles>COc1ccc(Cl)c(N2CCOCC2)c1</smiles><smiles>COc1ccc(Cl)cc1N1CCOCC1</smiles>

Scheme 26. Regioselectivity of trapping aryne formed from $\mathbf{1 1 w}$.

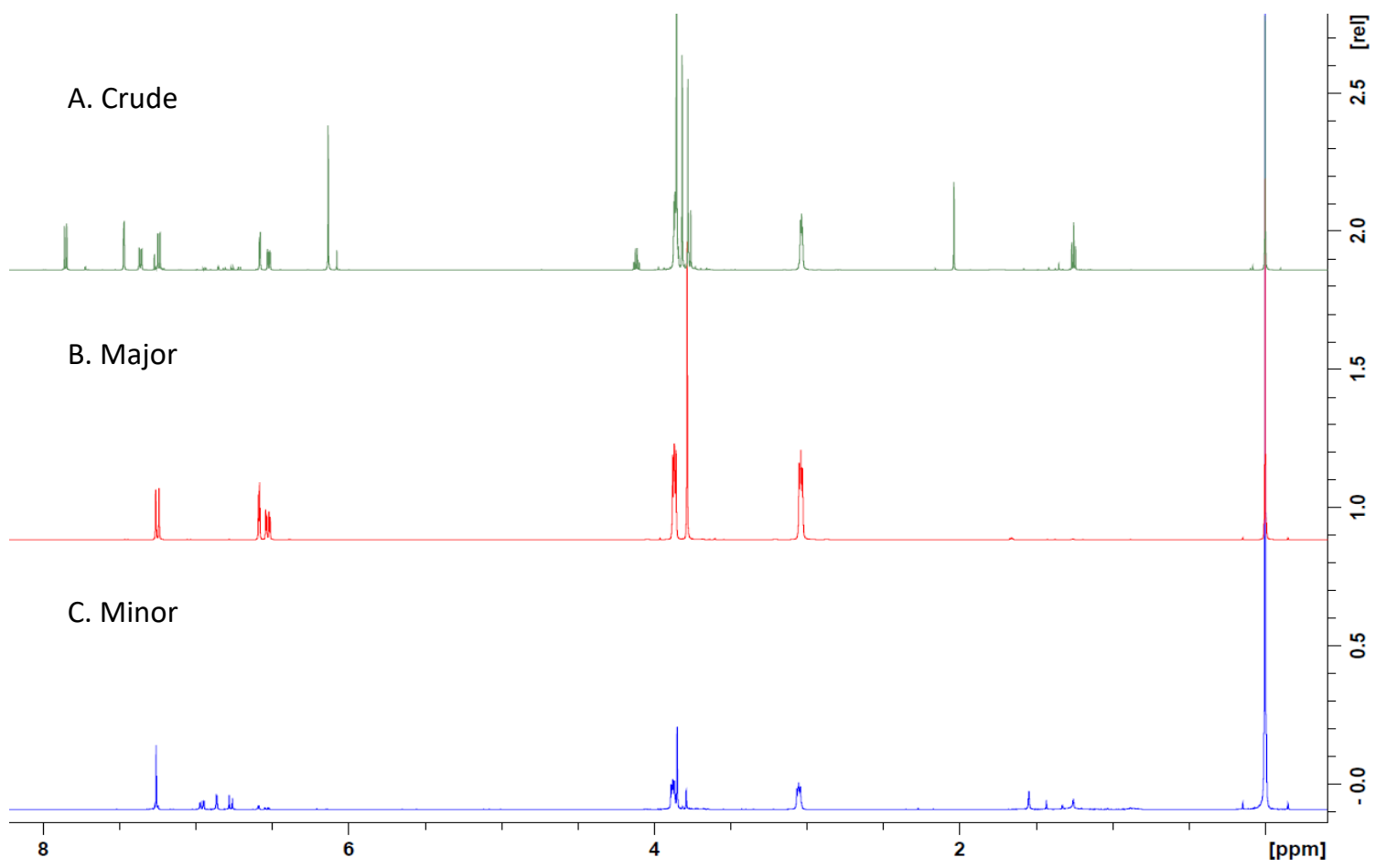

Figure 141. A. ${ }^{1} \mathrm{H}$ NMR spectrum of crude reaction mixture of $11 \mathrm{w}$ with morpholine recorded at $400 \mathrm{MHz}$ in $\mathrm{CDCl}_{3} ; \mathrm{B} .{ }^{1} \mathrm{H} \mathrm{NMR}$ spectrum of the major product recorded at $400 \mathrm{MHz}$ in $\mathrm{CDCl}_{3} ; \mathrm{C} .{ }^{1} \mathrm{H} \mathrm{NMR}$ spectrum of the minor product recorded at $400 \mathrm{MHz}$ in $\mathrm{CDCl}_{3}$. 

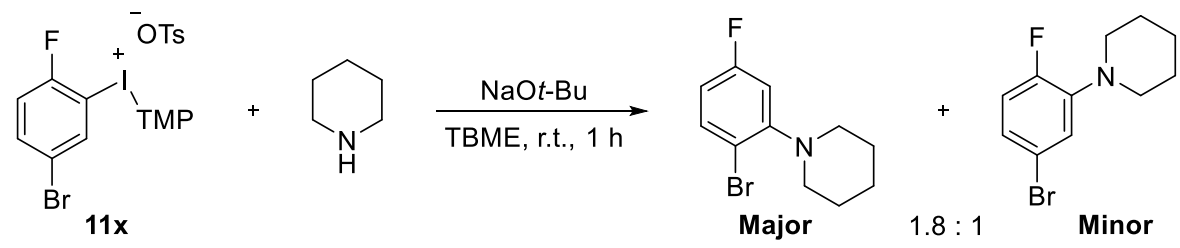

Scheme 27. Regioselectivity of trapping aryne formed from 11x.

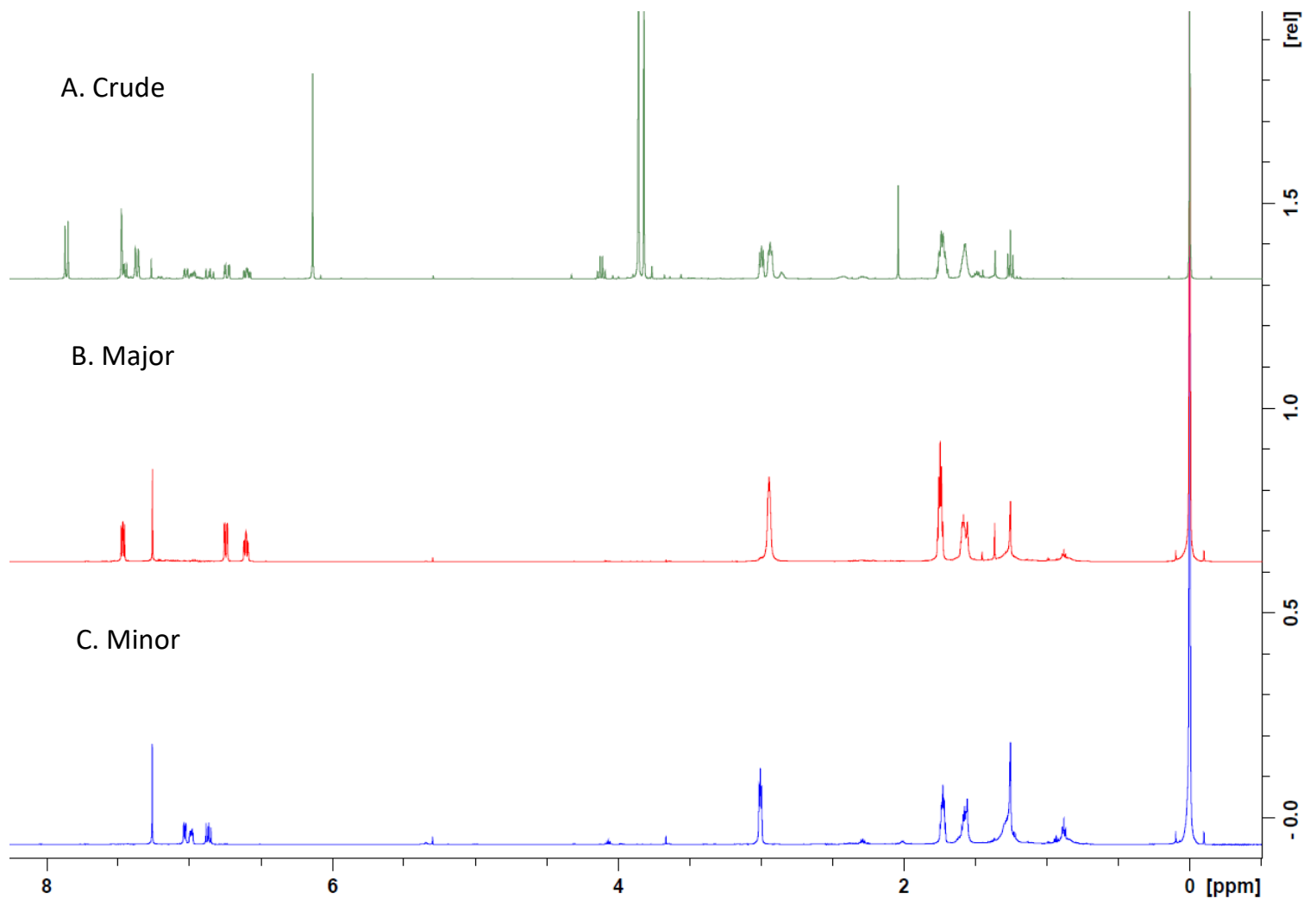

Figure 142. A. ${ }^{1} \mathrm{H}$ NMR spectrum of crude reaction mixture of $11 \mathrm{x}$ with piperidine recorded at $400 \mathrm{MHz}$ in $\mathrm{CDCl}_{3} ; \mathrm{B} .{ }^{1} \mathrm{H}$ NMR spectrum of the major product recorded at $400 \mathrm{MHz}$ in $\mathrm{CDCl}_{3} ; \mathrm{C} .{ }^{1} \mathrm{H}$ NMR spectrum of the minor product recorded at $400 \mathrm{MHz}$ in $\mathrm{CDCl}_{3}$.<smiles>Cc1ccc(Br)cc1I(O)NC(=O)O</smiles><smiles>C1COCCN1</smiles>

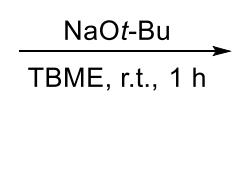<smiles>Cc1ccc(Br)cc1N1CCOCC1</smiles><smiles>[M]C1COCCN1c1cc(C)ccc1Br</smiles>

Scheme 28. Regioselectivity of trapping aryne formed from 11y. 


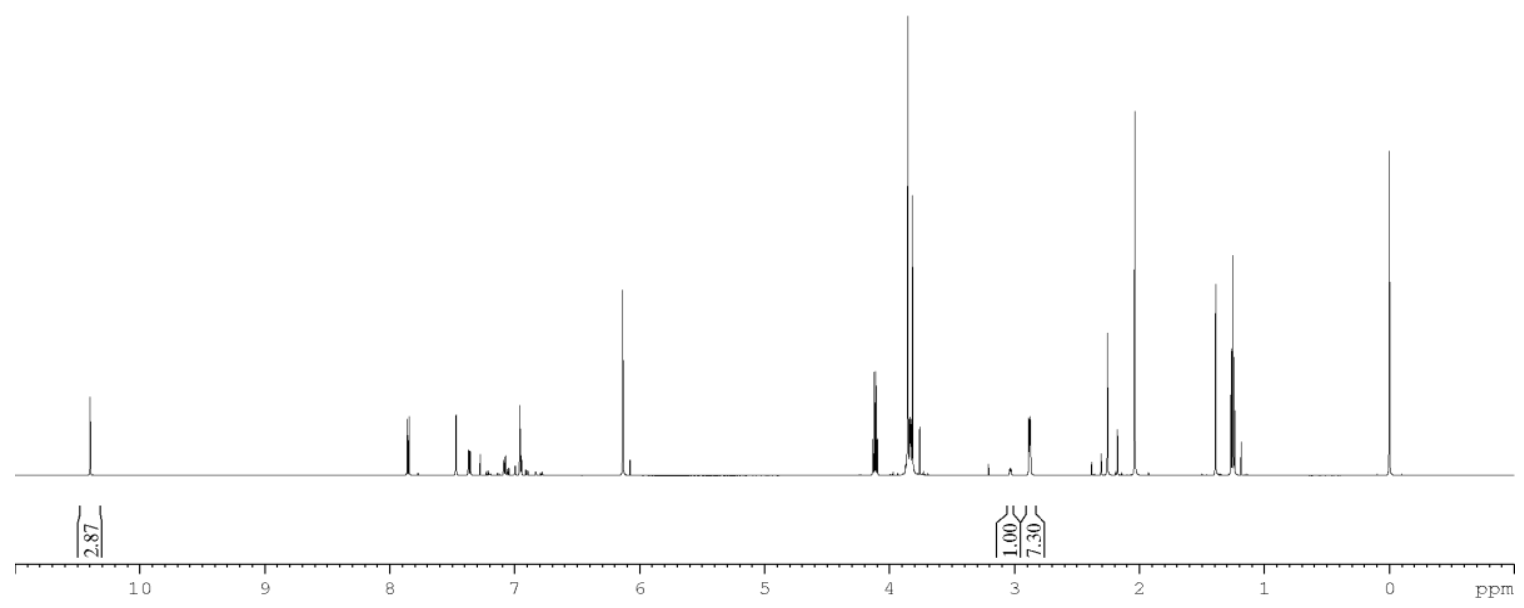

Figure 143. ${ }^{1} \mathrm{H}$ NMR spectrum of crude reaction mixture of 11y with morpholine recorded at $400 \mathrm{MHz}$ in $\mathrm{CDCl}_{3}$.

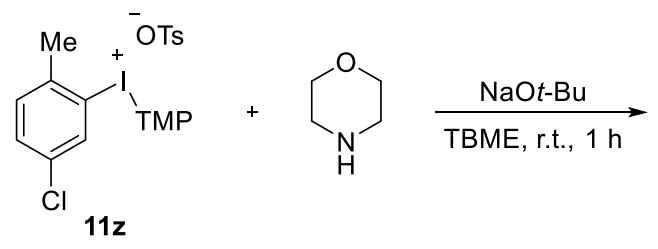<smiles>COC1CN(c2cc(C)ccc2Cl)CCO1</smiles>

Scheme 29. Regioselectivity of trapping aryne formed from $\mathbf{1 1 z .}$

1ㅇํㅇ

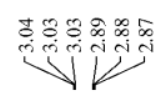

$\stackrel{8}{i}$

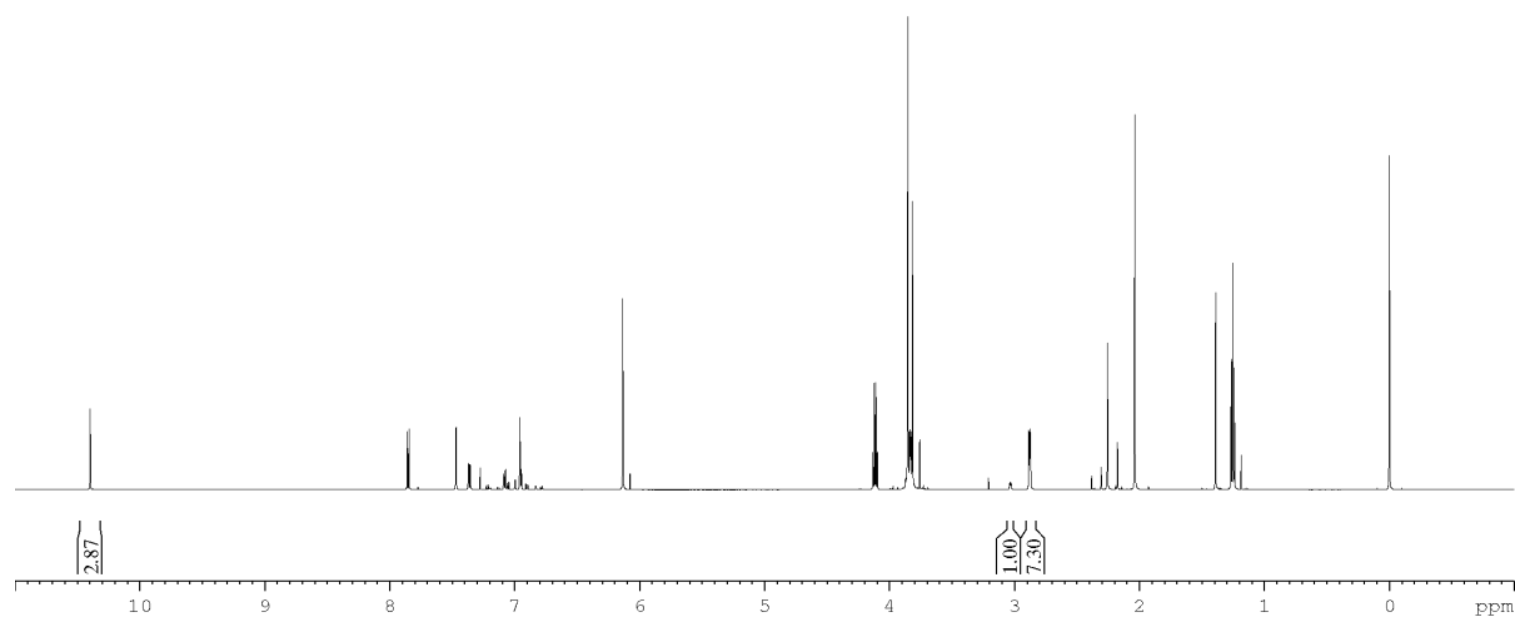

Figure 144. ${ }^{1} \mathrm{H}$ NMR spectrum of crude reaction mixture of $11 z$ with morpholine recorded at $400 \mathrm{MHz}$ in $\mathrm{CDCl}_{3}$. 


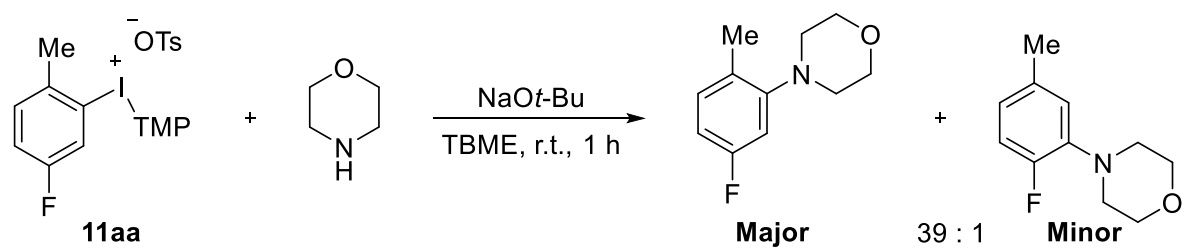

Scheme 30. Regioselectivity of trapping aryne formed from 11aa.

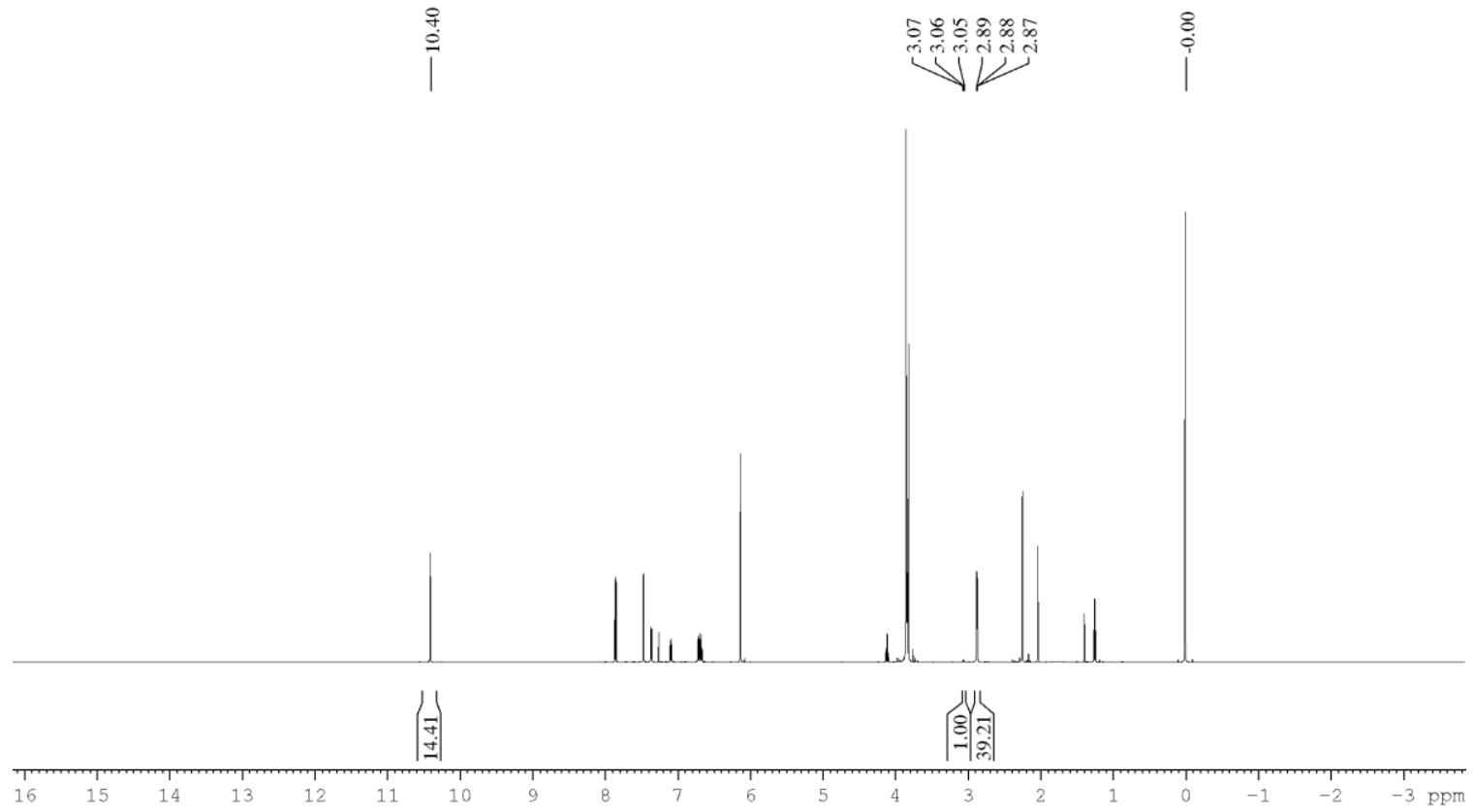

Figure 145. ${ }^{1} \mathrm{H}$ NMR spectrum of crude reaction mixture of 11aa with morpholine recorded at $400 \mathrm{MHz}$ in $\mathrm{CDCl}_{3}$. 


\subsubsection{Spectral data}

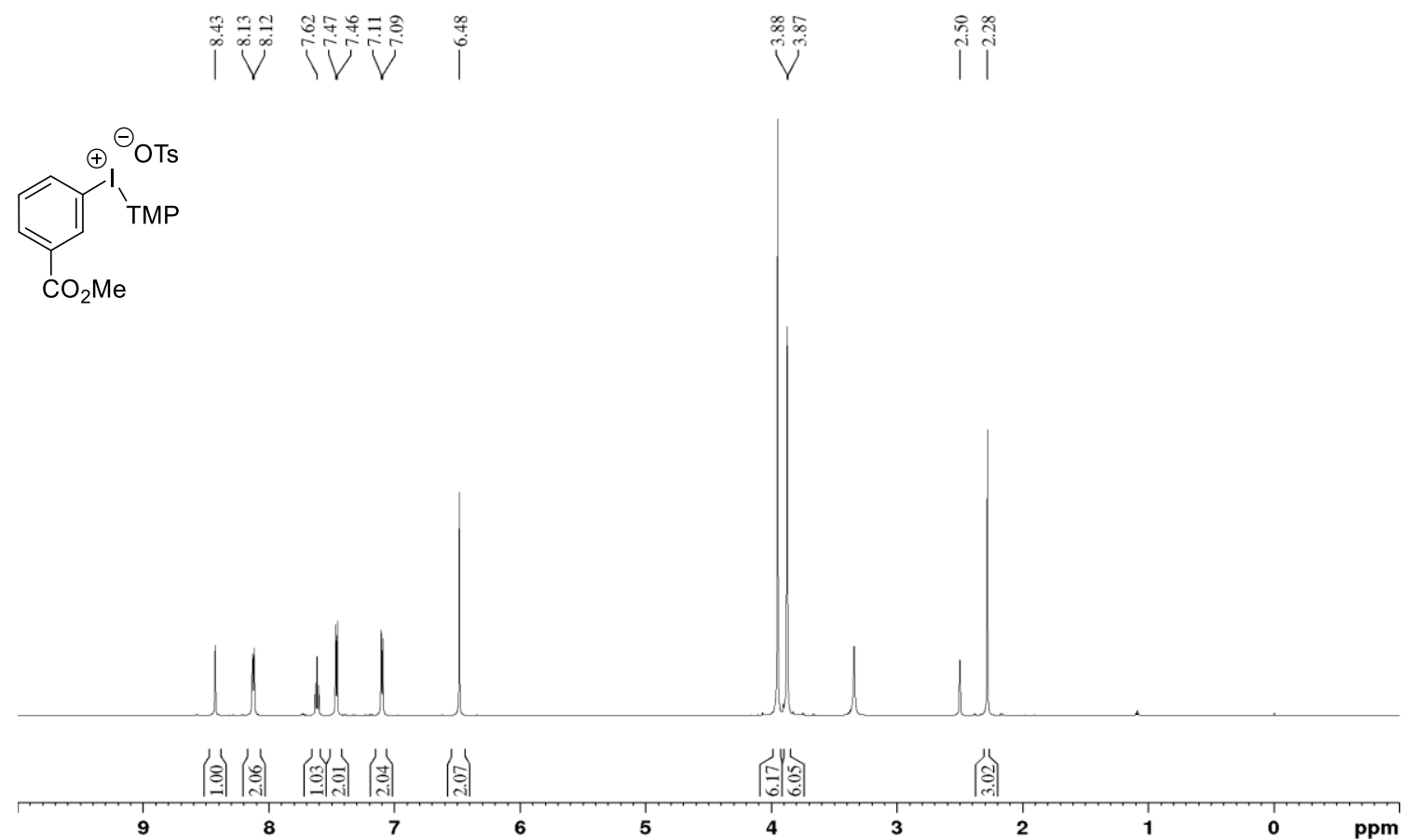

Figure 146. ${ }^{1} \mathrm{H}$ NMR of $11 \mathrm{c}$ in DMSO at $400 \mathrm{MHz}$.
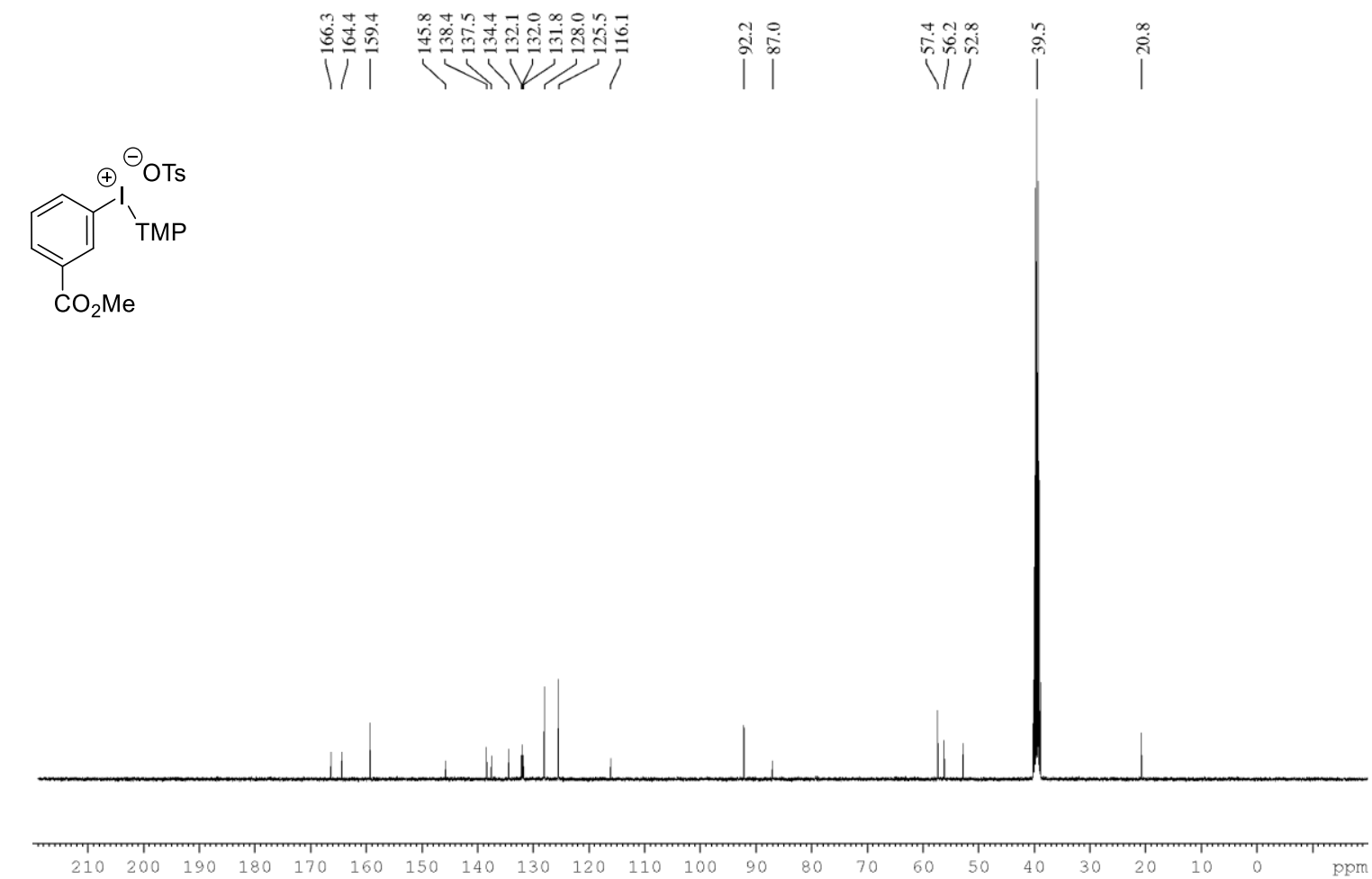

Figure 147. ${ }^{13} \mathrm{C}\left\{{ }^{1} \mathrm{H}\right\}$ NMR of $11 \mathrm{c}$ in DMSO-d 6 at $101 \mathrm{MHz}$. 


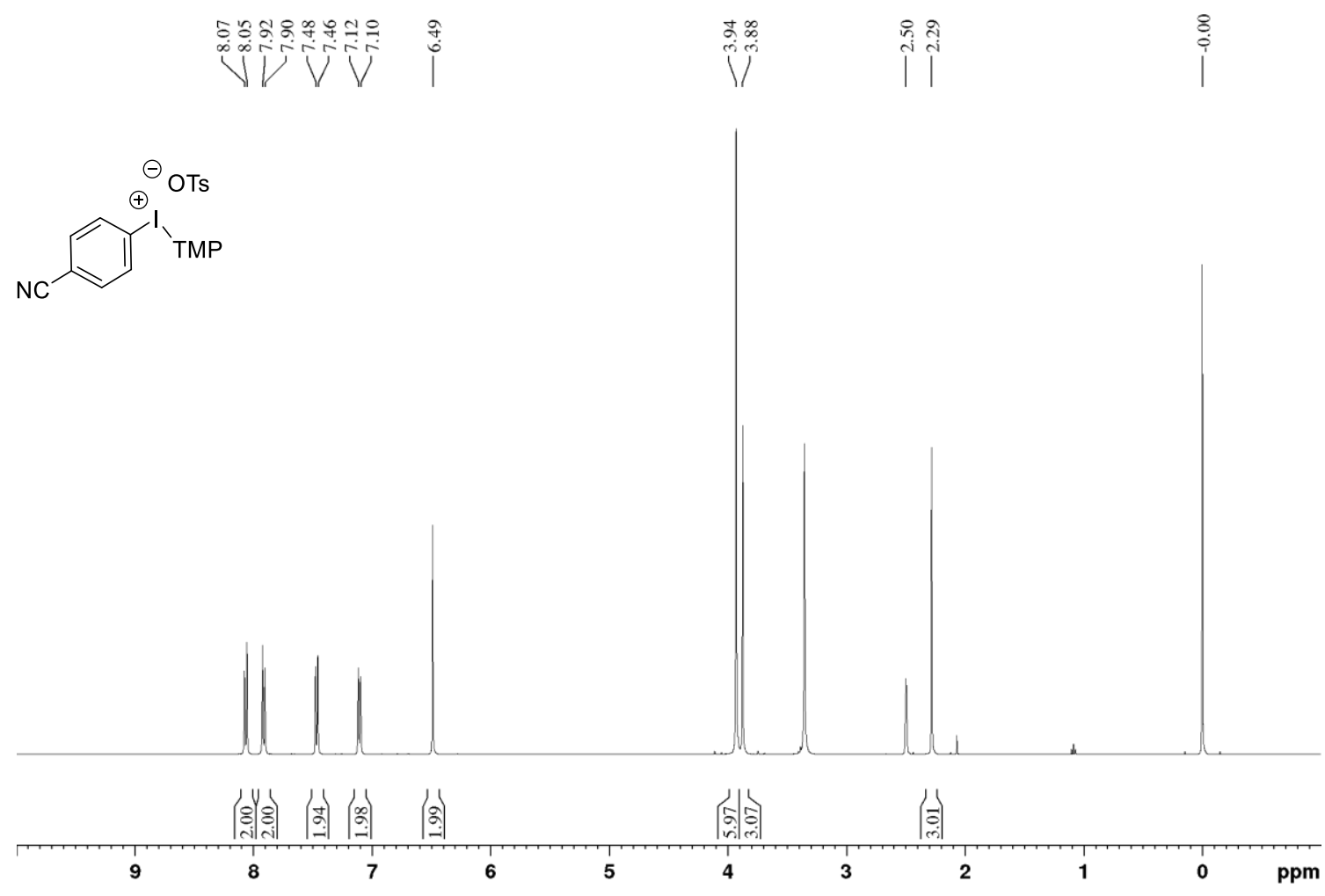

Figure $148 .{ }^{1} \mathrm{H}$ NMR of $\mathbf{1 1 g}$ in DMSO-d 6 with $1 \% \mathrm{v} / \mathrm{v}$ TMS at $400 \mathrm{MHz}$.

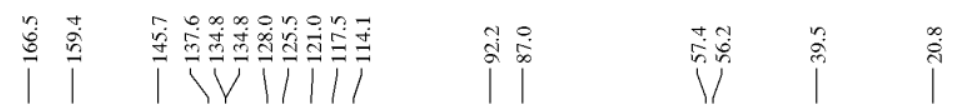

TMP
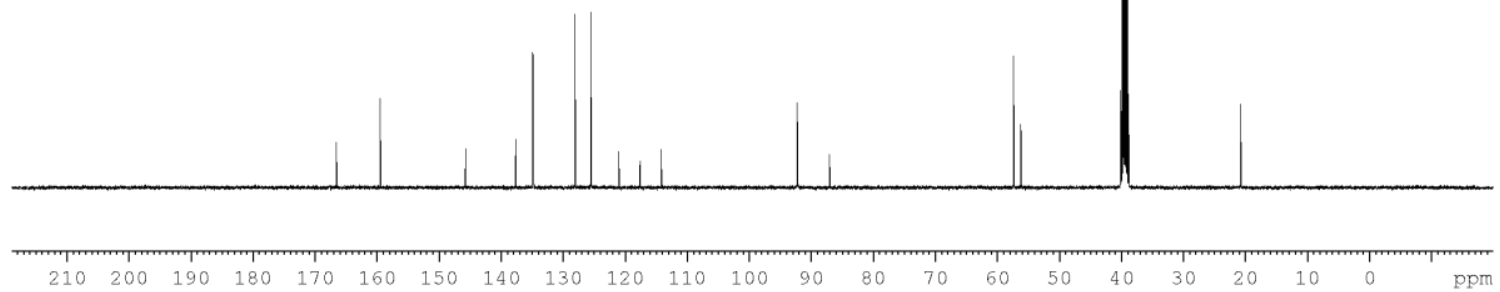

Figure $149 .{ }^{13} \mathrm{C}\left\{{ }^{1} \mathrm{H}\right\}$ NMR of $\mathbf{1 1 g}$ in DMSO-d $\mathrm{d}_{6}$ at $101 \mathrm{MHz}$. 


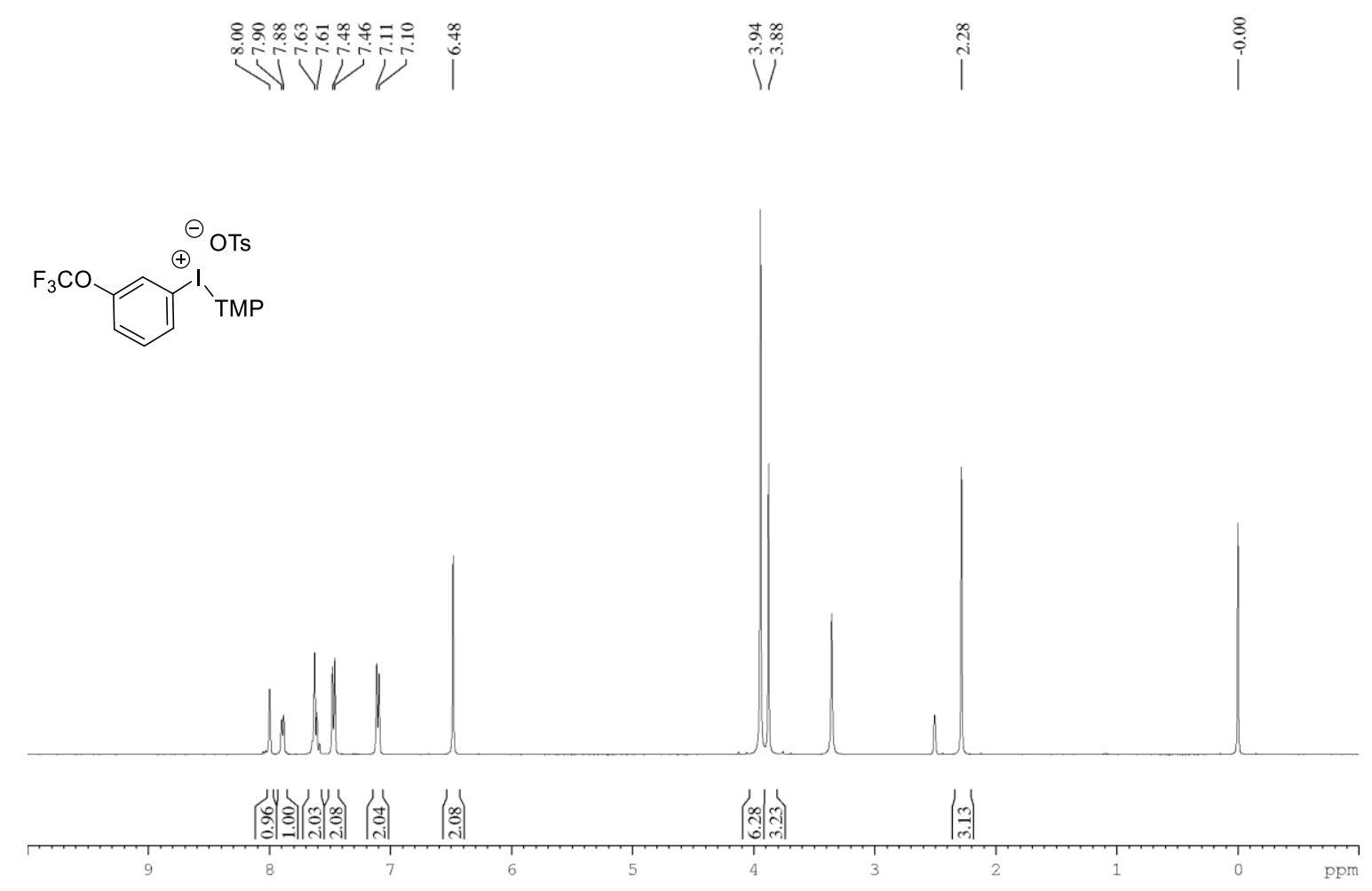

Figure 150. ${ }^{1} \mathrm{H}$ NMR of $\mathbf{1 1 l}$ in DMSO- $\mathrm{d}_{6}$ with $1 \% \mathrm{v} / \mathrm{v}$ TMS at $400 \mathrm{MHz}$.

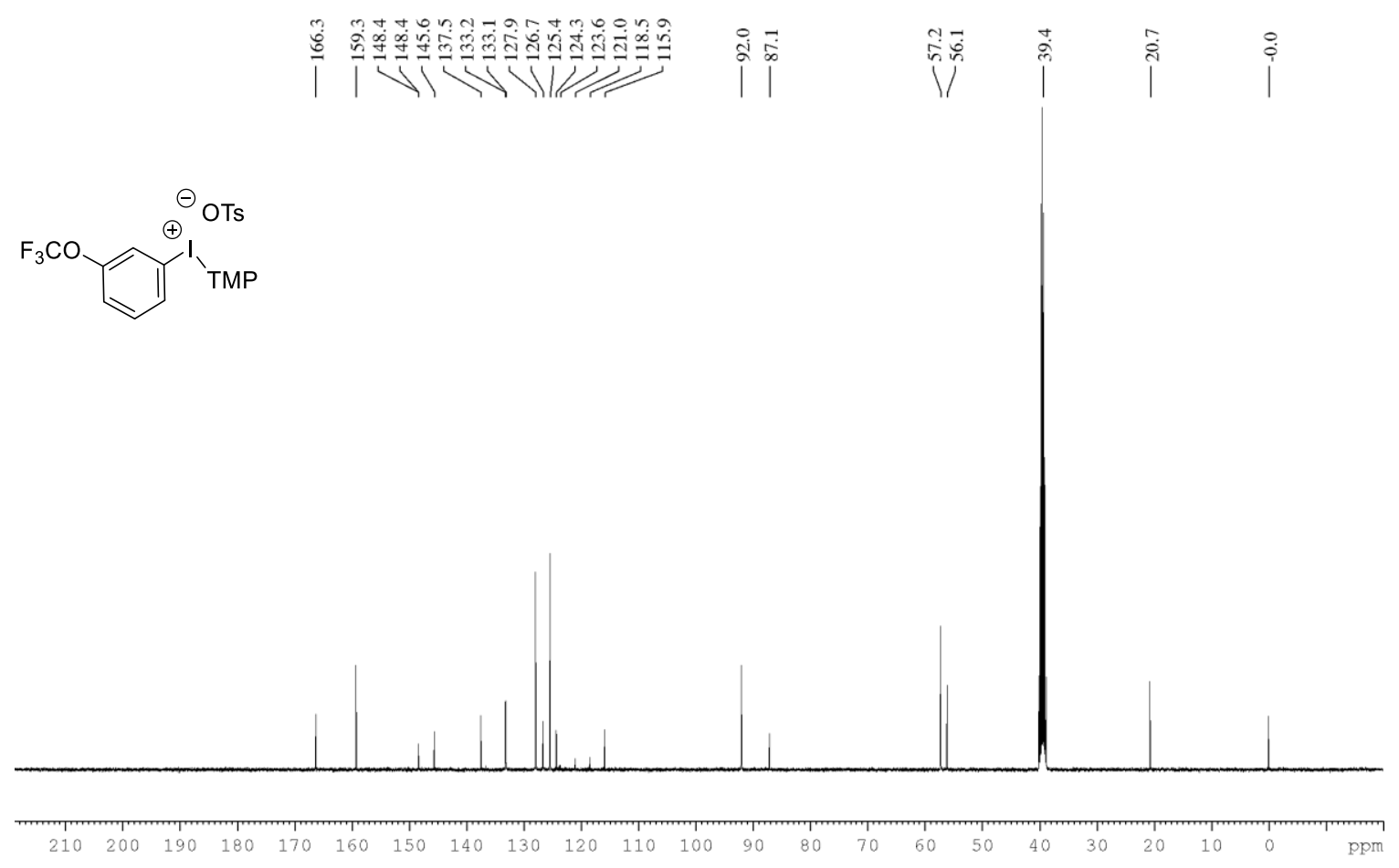

Figure $151 .{ }^{13} \mathrm{C}\left\{{ }^{1} \mathrm{H}\right\} \mathrm{NMR}$ of $11 \mathrm{c}$ in DMSO-d 6 with $1 \% \mathrm{v} / \mathrm{v}$ TMS at $101 \mathrm{MHz}$. 


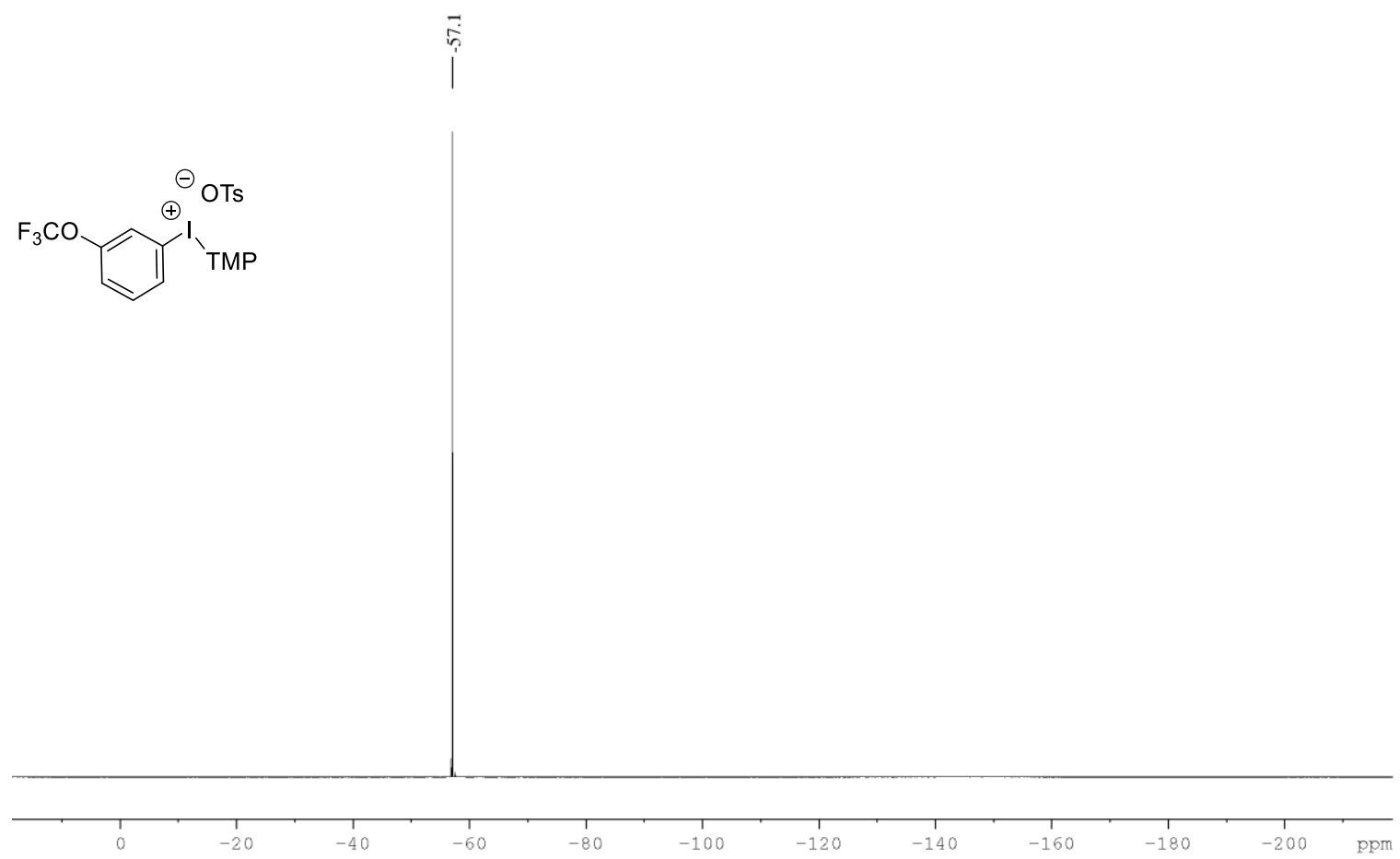

Figure $152 .{ }^{19} \mathrm{~F}\left\{{ }^{1} \mathrm{H}\right\}$ NMR of $11 \mathrm{c}$ in DMSO- $\mathrm{d}_{6}$ with $1 \% \mathrm{v} / \mathrm{v}$ TMS at $376 \mathrm{MHz}$.

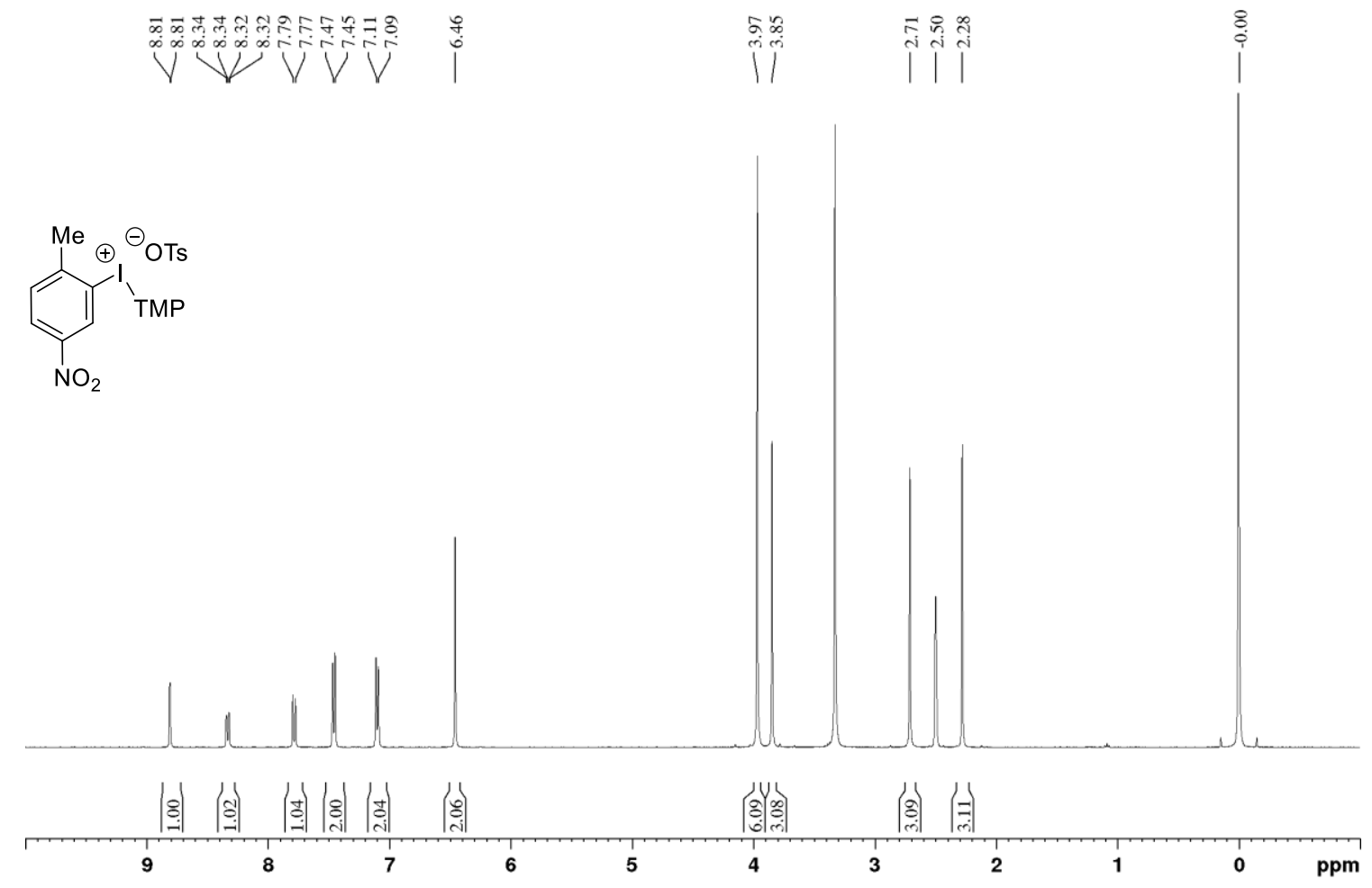

Figure 153. ${ }^{1} \mathrm{H}$ NMR of $\mathbf{1 1 0}$ in DMSO-d 6 with $1 \% \mathrm{v} / \mathrm{v}$ TMS at $400 \mathrm{MHz}$. 


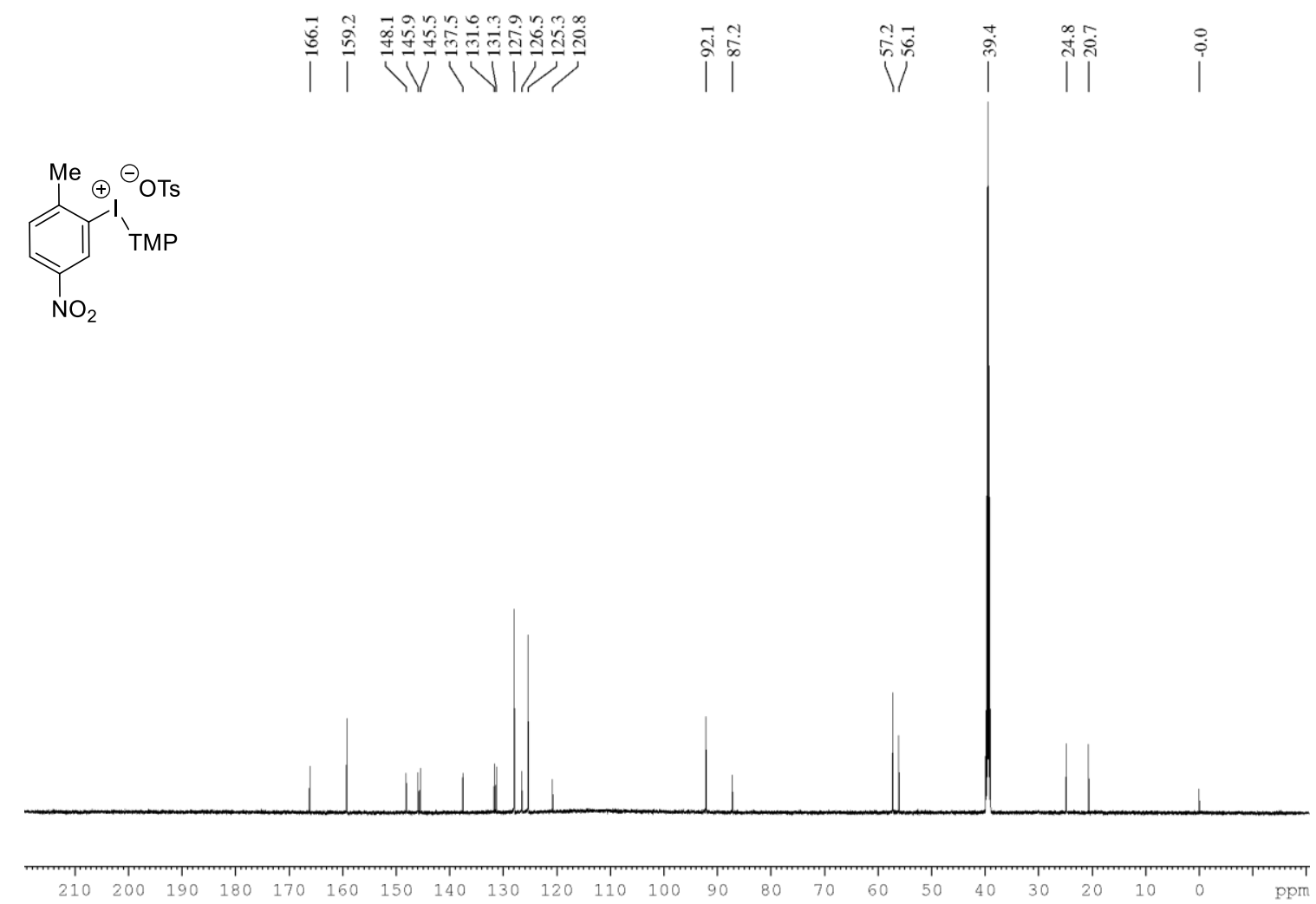

Figure $154 .{ }^{13} \mathrm{C}\left\{{ }^{1} \mathrm{H}\right\}$ NMR of $\mathbf{1 1 0}$ in DMSO-d 6 with $1 \% \mathrm{v} / \mathrm{v}$ TMS at $101 \mathrm{MHz}$.

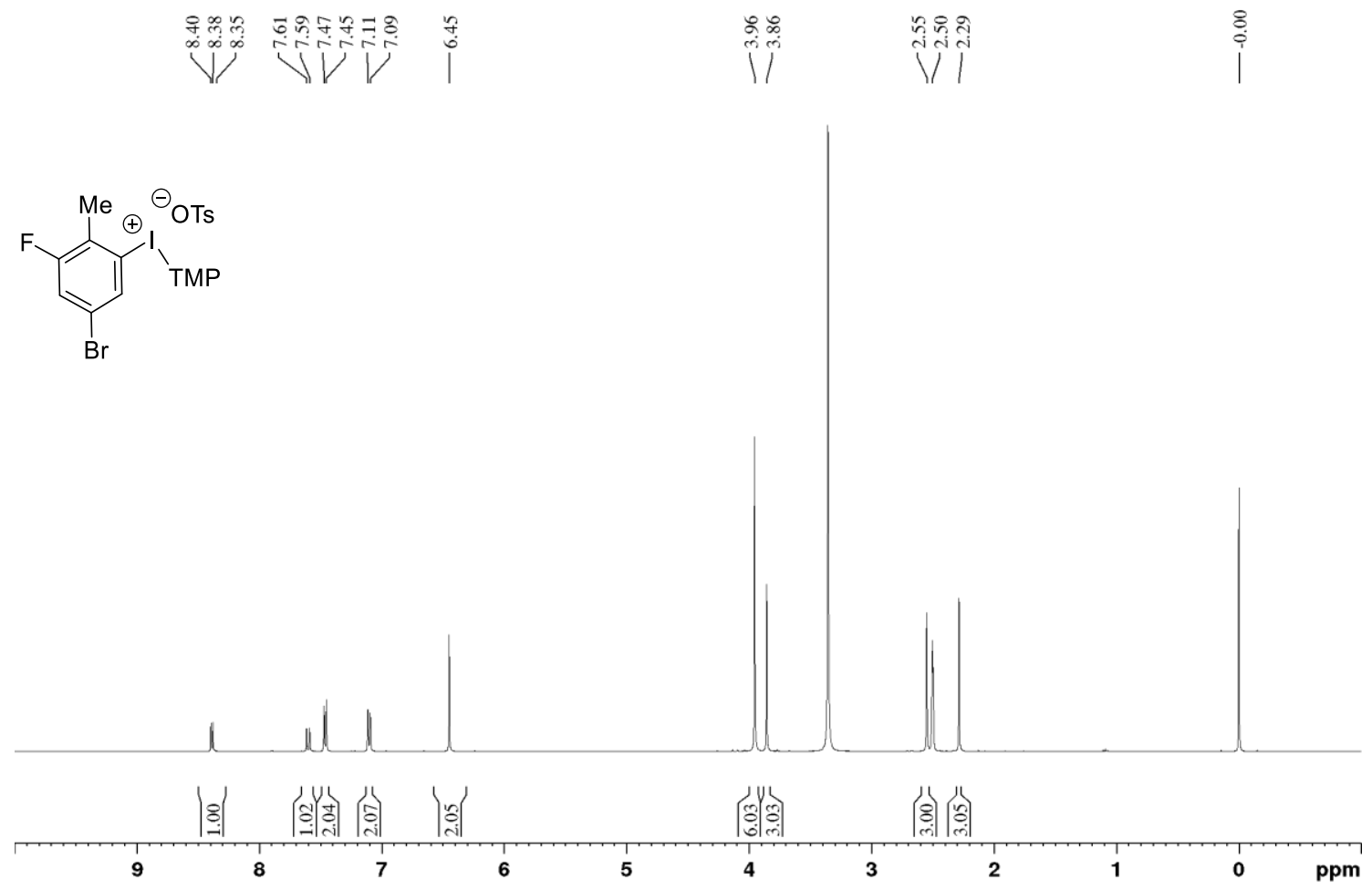

Figure 155. ${ }^{1} \mathrm{H}$ NMR of $11 \mathrm{p}$ in DMSO-d 6 with $1 \% \mathrm{v} / \mathrm{v}$ TMS at $400 \mathrm{MHz}$. 


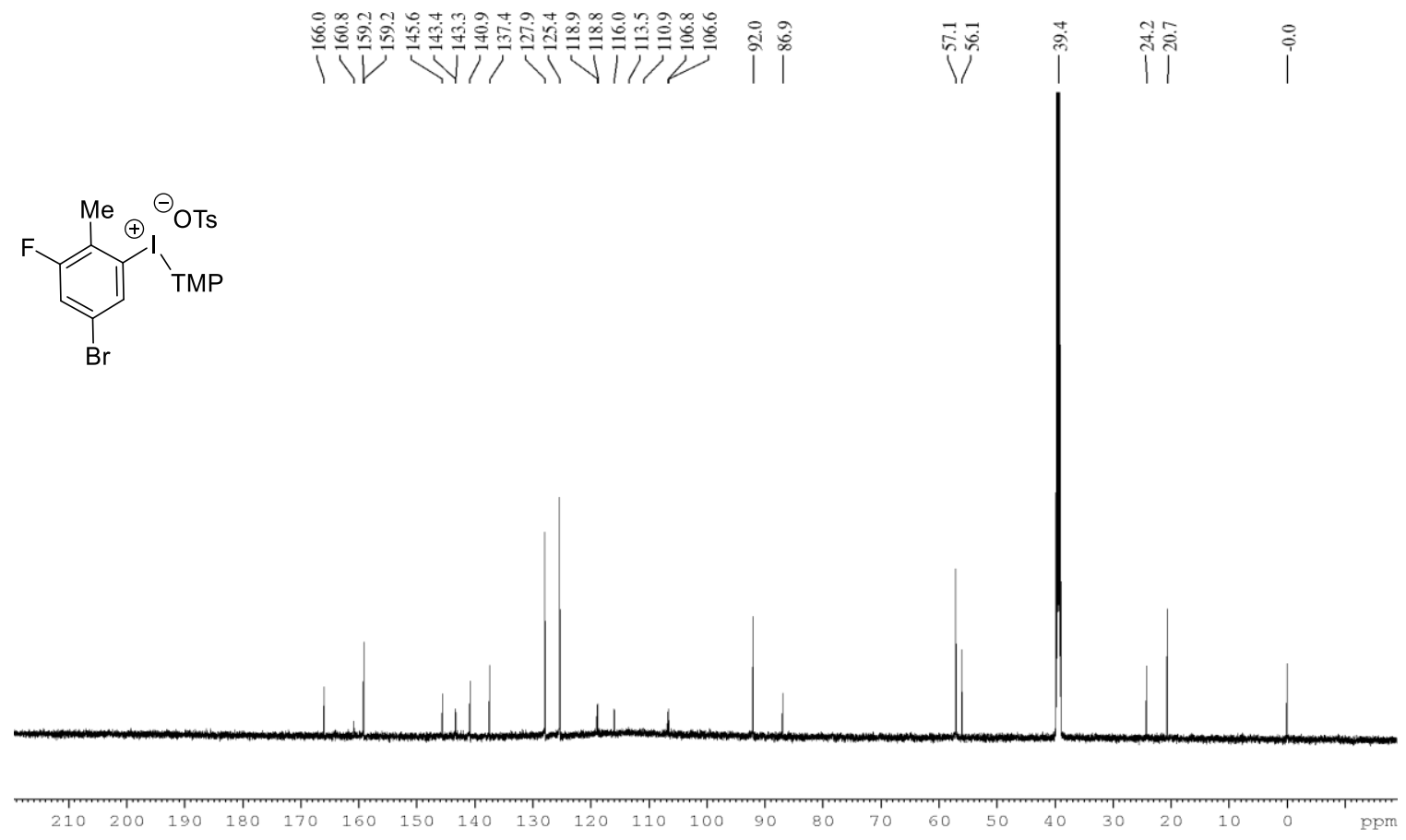

Figure $156 .{ }^{13} \mathrm{C}\left\{{ }^{1} \mathrm{H}\right\}$ NMR of $11 p$ in DMSO-d 6 with $1 \% \mathrm{v} / \mathrm{v}$ TMS at $101 \mathrm{MHz}$.

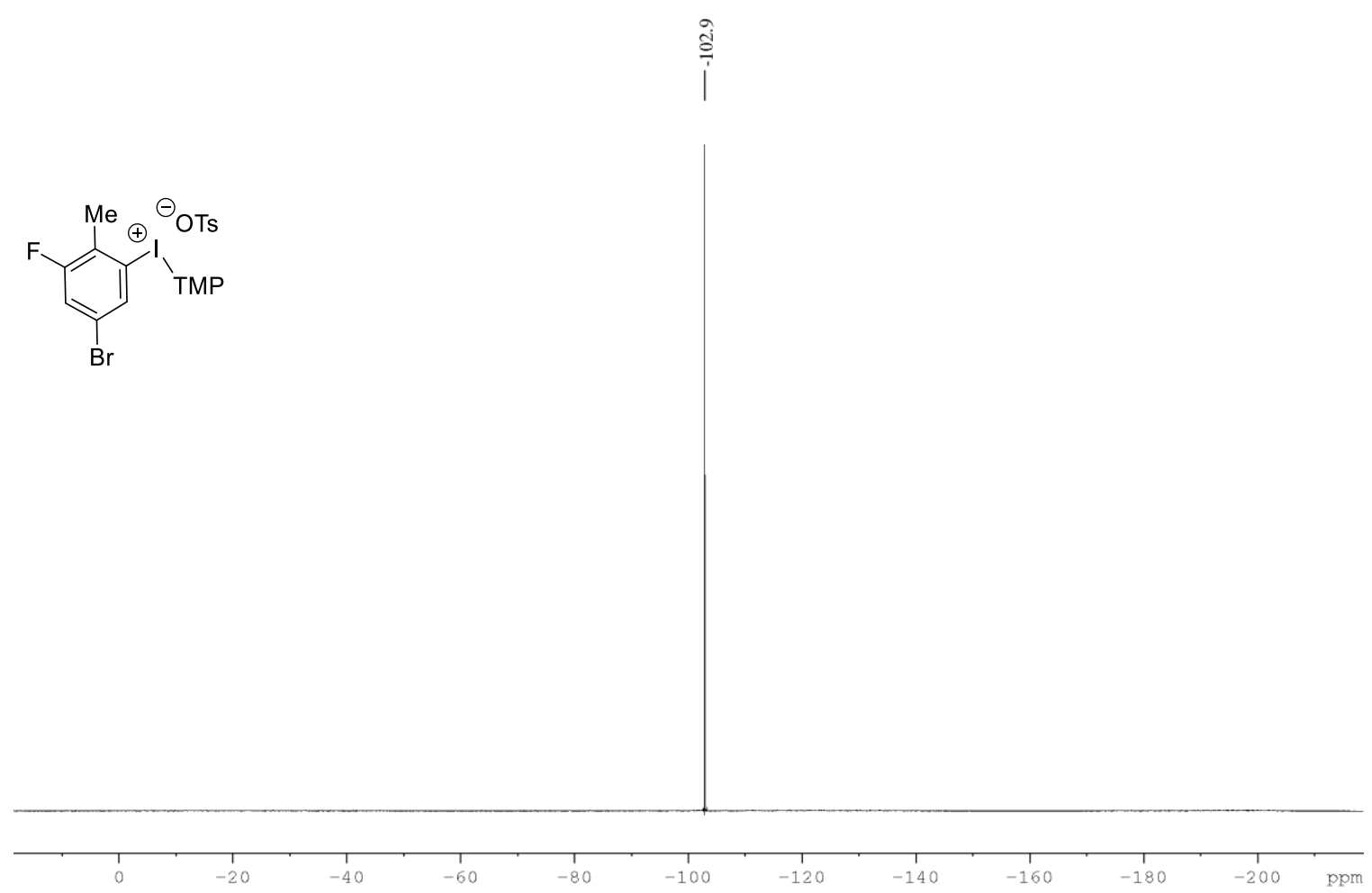

Figure 157. ${ }^{19} \mathrm{~F}\left\{{ }^{1} \mathrm{H}\right\}$ NMR of $11 p$ in DMSO-d 6 with $1 \% \mathrm{v} / \mathrm{v}$ TMS at $376 \mathrm{MHz}$. 


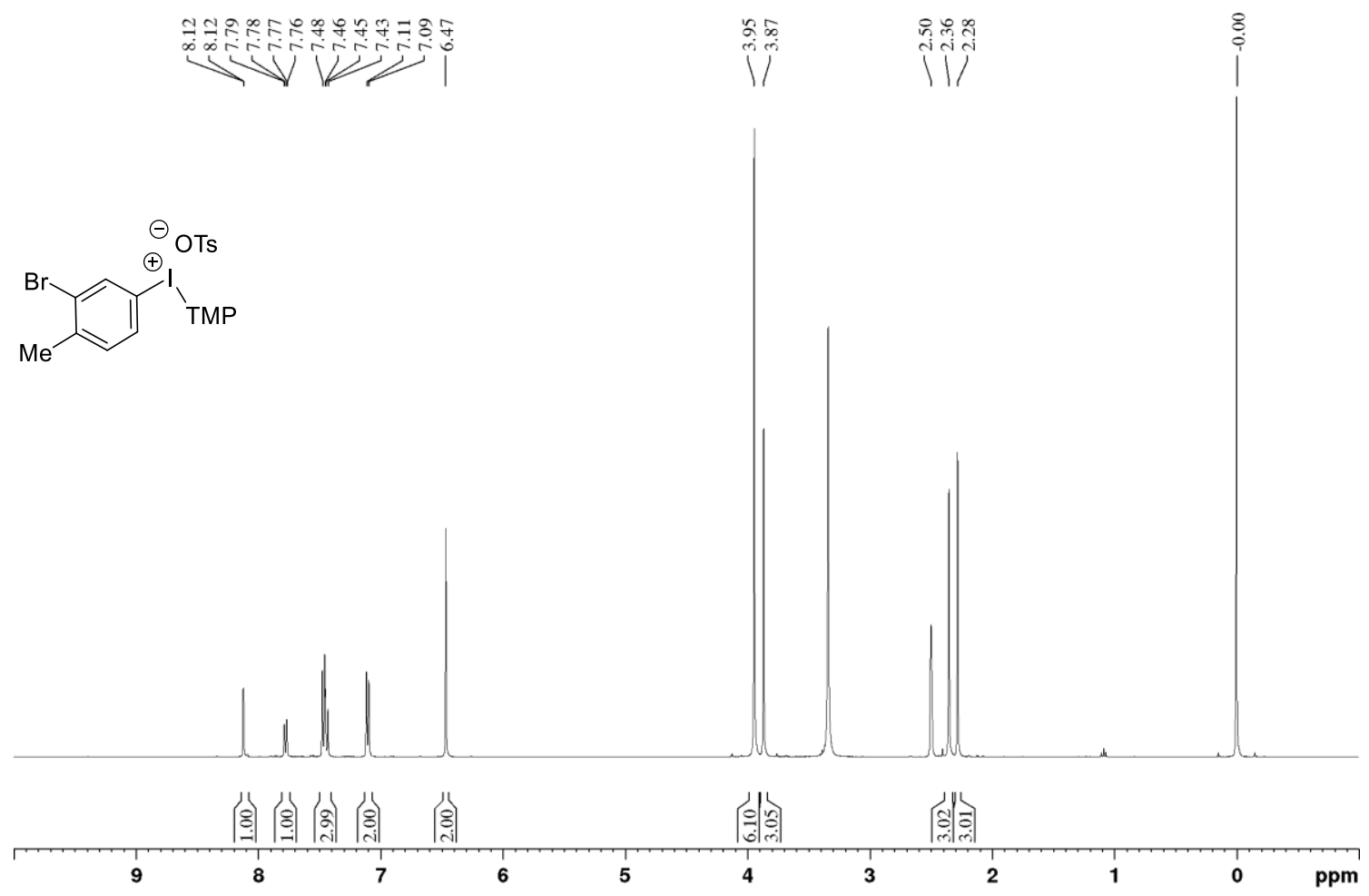

Figure $158 .{ }^{1} \mathrm{H}$ NMR of $11 \mathrm{r}$ in DMSO-d 6 with $1 \% \mathrm{v} / \mathrm{v}$ TMS at $400 \mathrm{MHz}$.
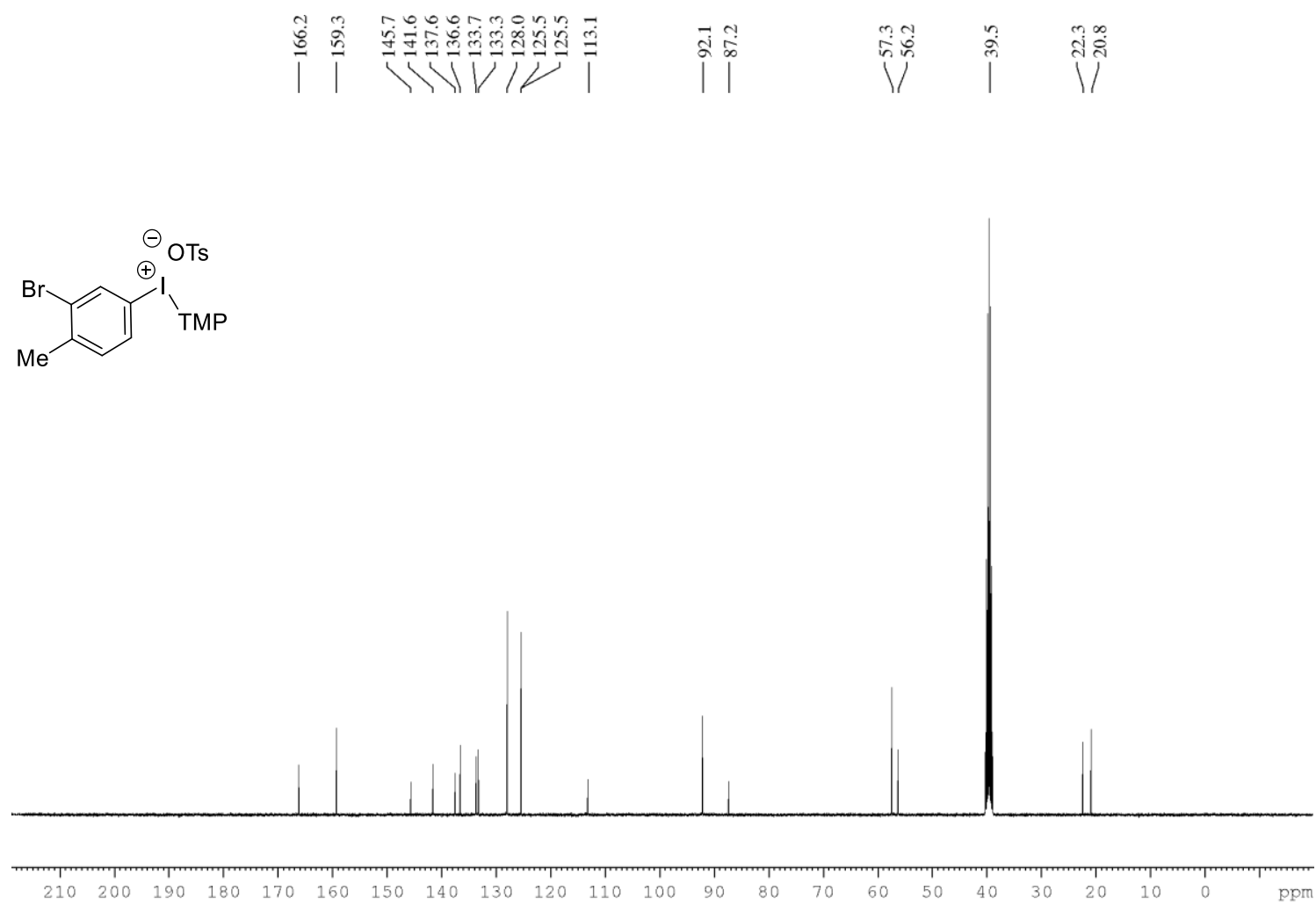

Figure 159. ${ }^{13} \mathrm{C}\left\{{ }^{1} \mathrm{H}\right\}$ NMR of $11 \mathrm{r}$ in DMSO-d 6 at $101 \mathrm{MHz}$. 


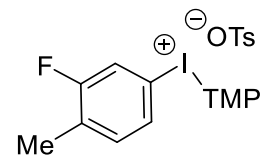

in

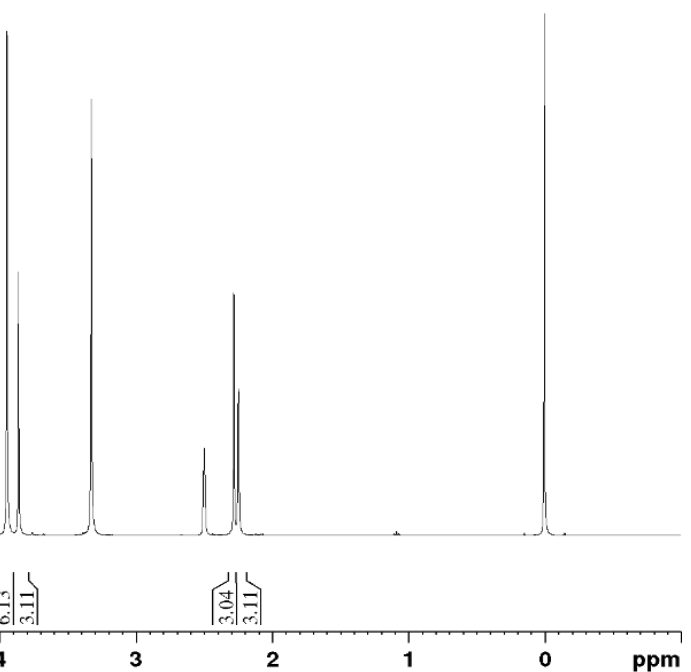

Figure $160 .{ }^{1} \mathrm{H}$ NMR of $11 \mathrm{~s}$ in DMSO-d 6 with $1 \% \mathrm{v} / \mathrm{v}$ TMS at $400 \mathrm{MHz}$.
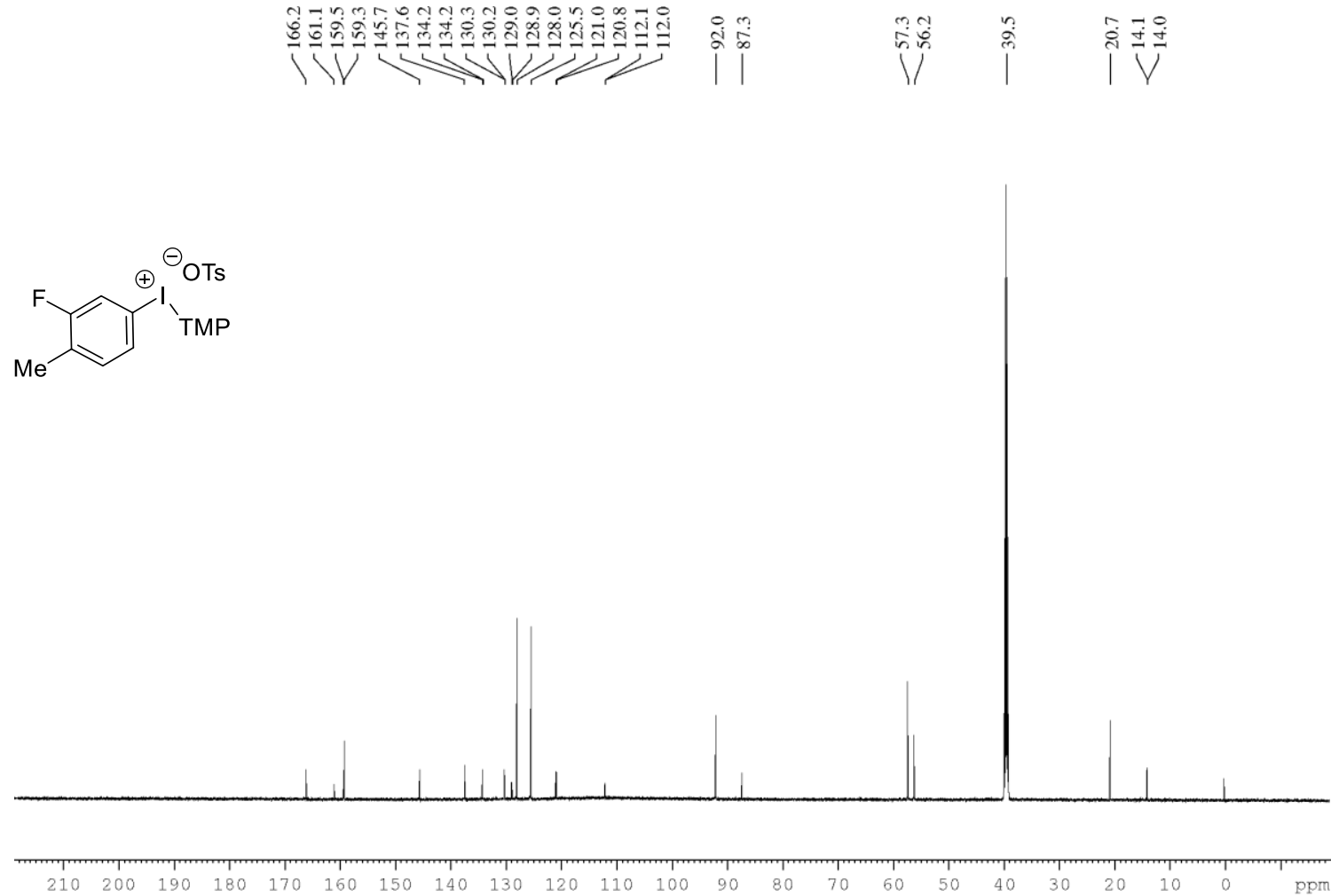

Figure $161 .{ }^{13} \mathrm{C}\left\{{ }^{1} \mathrm{H}\right\}$ NMR of $11 \mathrm{~s}$ in DMSO-d 6 with $1 \% \mathrm{v} / \mathrm{v}$ TMS at $101 \mathrm{MHz}$. 


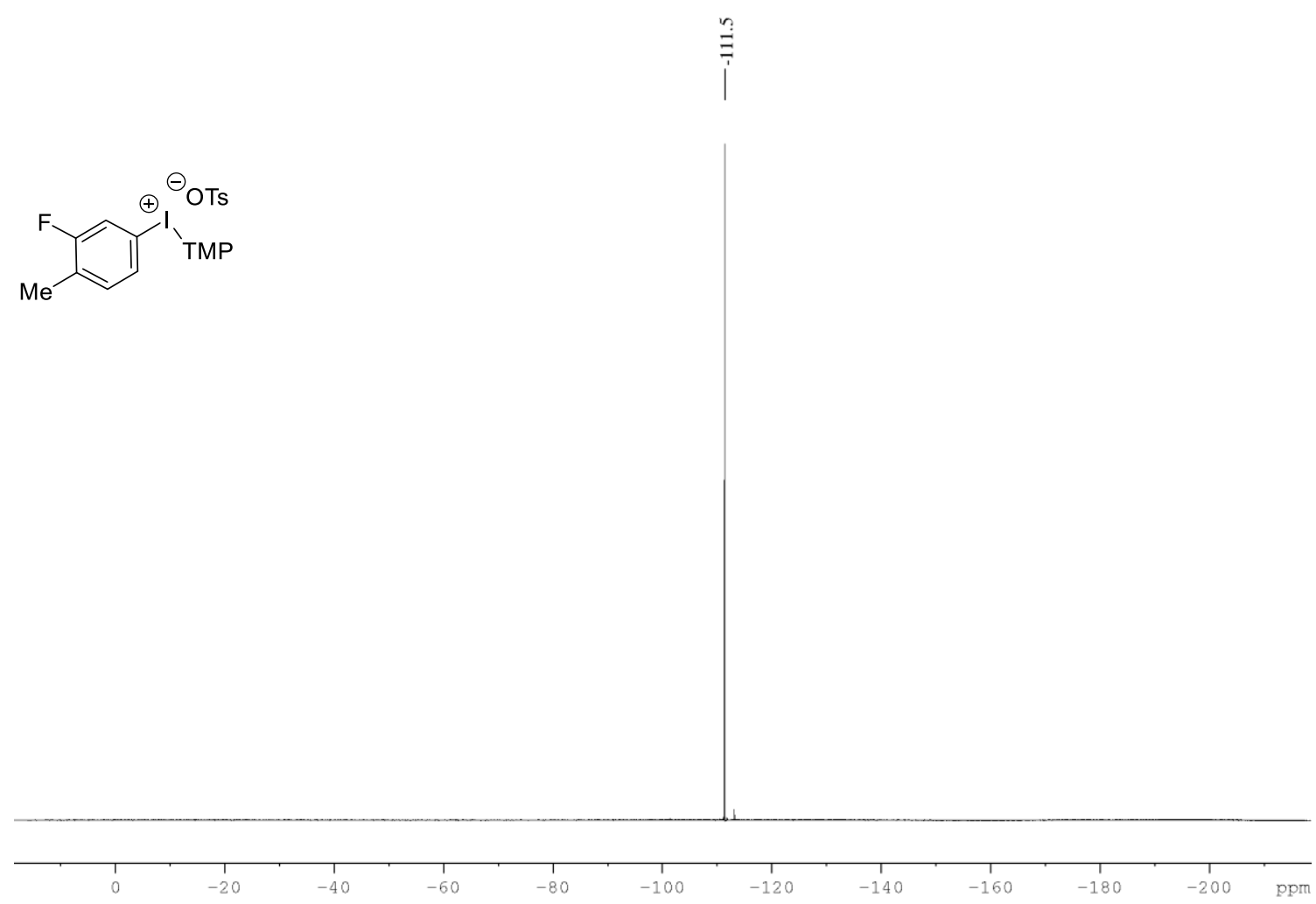

Figure 162. ${ }^{19} \mathrm{~F}\left\{{ }^{1} \mathrm{H}\right\}$ NMR of $11 \mathrm{~s}$ in DMSO- $\mathrm{d}_{6}$ with $1 \% \mathrm{v} / \mathrm{v}$ TMS at $376 \mathrm{MHz}$.
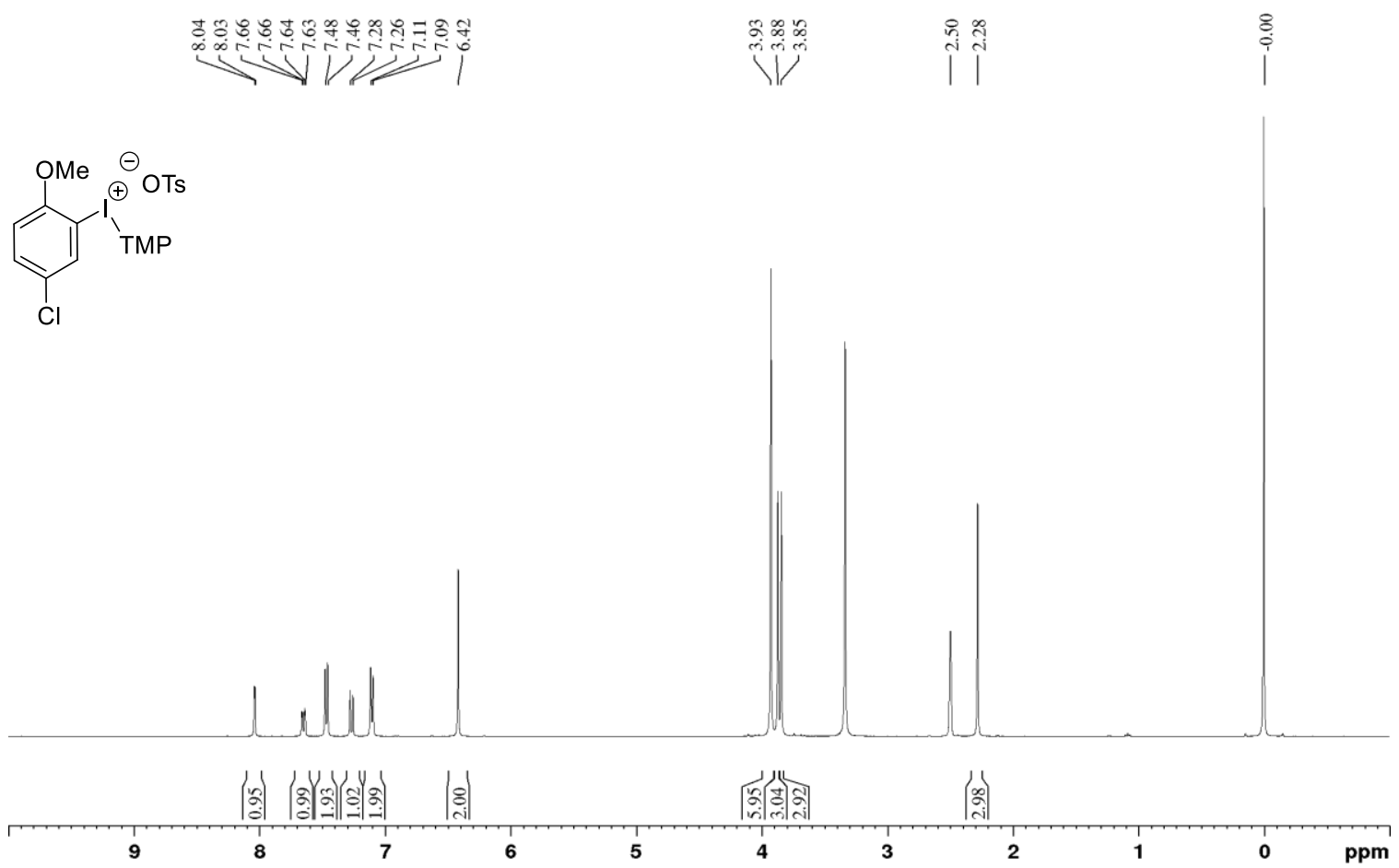

Figure $163 .{ }^{1} \mathrm{H}$ NMR of $\mathbf{1 1 w}$ in DMSO- $\mathrm{d}_{6}$ with $1 \% \mathrm{v} / \mathrm{v}$ TMS at $400 \mathrm{MHz}$. 
<smiles>[3H][Te][I-]c1cc(Cl)ccc1OC</smiles>

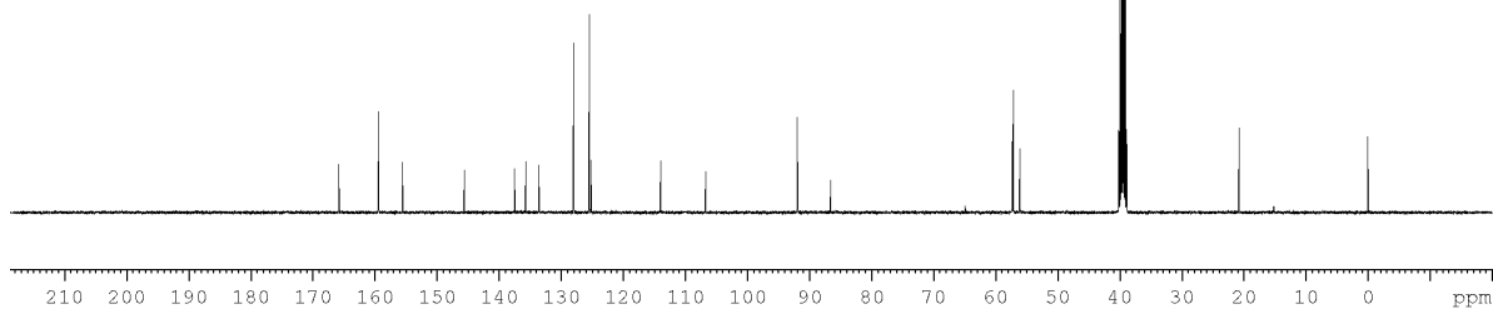

Figure 164. ${ }^{13} \mathrm{C}\left\{{ }^{1} \mathrm{H}\right\}$ NMR of 11 w in DMSO- $\mathrm{d}_{6}$ with $1 \% \mathrm{v} / \mathrm{v}$ TMS at $101 \mathrm{MHz}$.
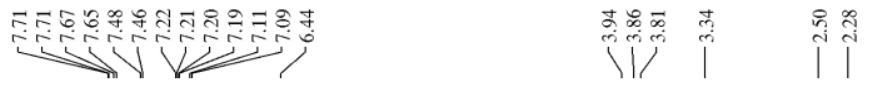

$\underbrace{\mathrm{Cl}}_{\mathrm{OMe}}{ }_{\mathrm{TMP}}^{\Theta_{\mathrm{OTS}}}$

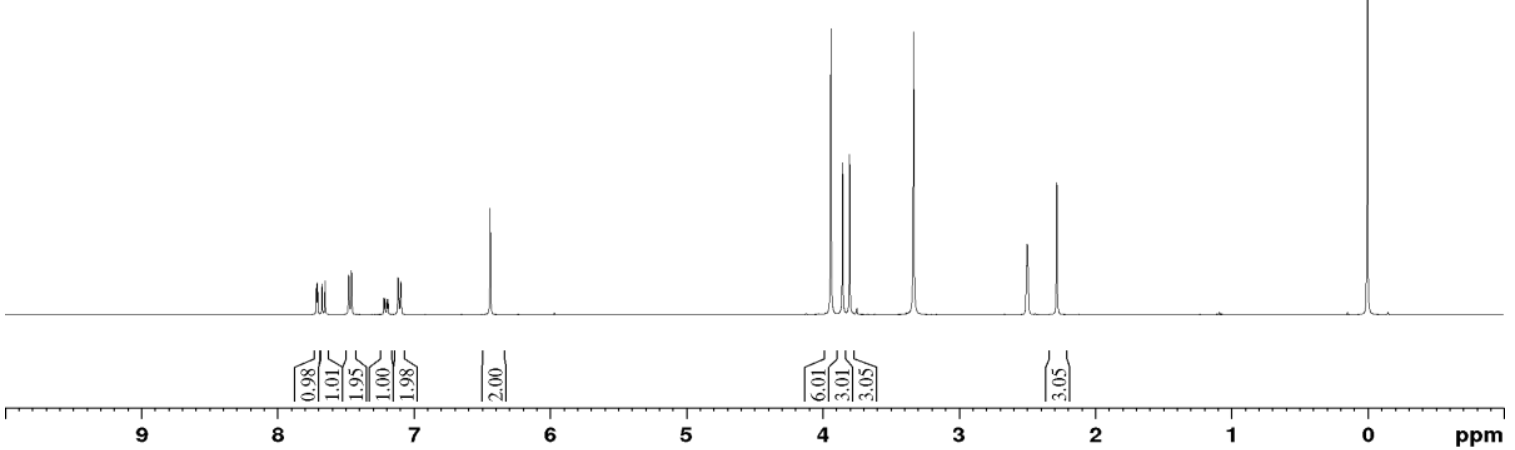

Figure $165 .{ }^{1} \mathrm{H}$ NMR of $11 w^{\prime}$ in DMSO-d 6 with $1 \%$ v/v TMS at $400 \mathrm{MHz}$. 


\section{li}<smiles>COc1ccc(Cl)c([18O][Na])c1</smiles>
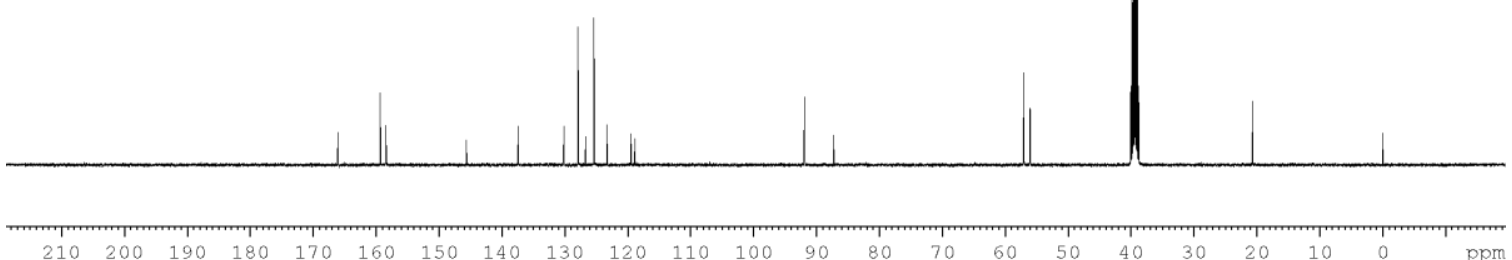

Figure 166. ${ }^{13} \mathrm{C}\left\{{ }^{1} \mathrm{H}\right\}$ NMR of $\mathbf{1 1} \mathbf{w}^{\prime}$ in DMSO-d 6 with $1 \% \mathrm{v} / \mathrm{v}$ TMS at $101 \mathrm{MHz}$.
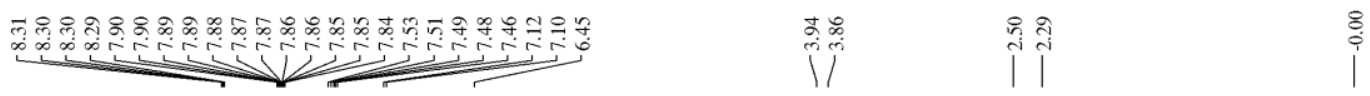

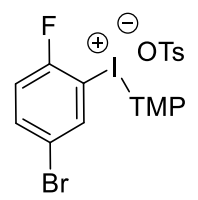

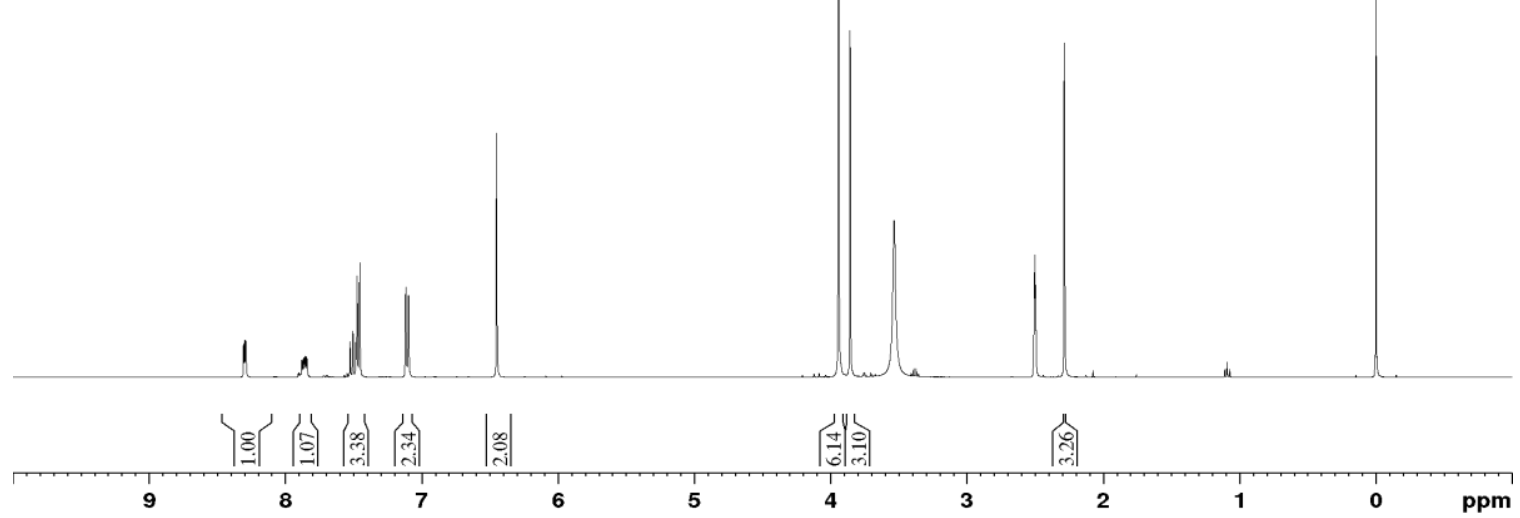

Figure 167. ${ }^{1} \mathrm{H}$ NMR of $11 x$ in DMSO- $\mathrm{d}_{6}$ with $1 \% \mathrm{v} / \mathrm{v}$ TMS at $400 \mathrm{MHz}$. 

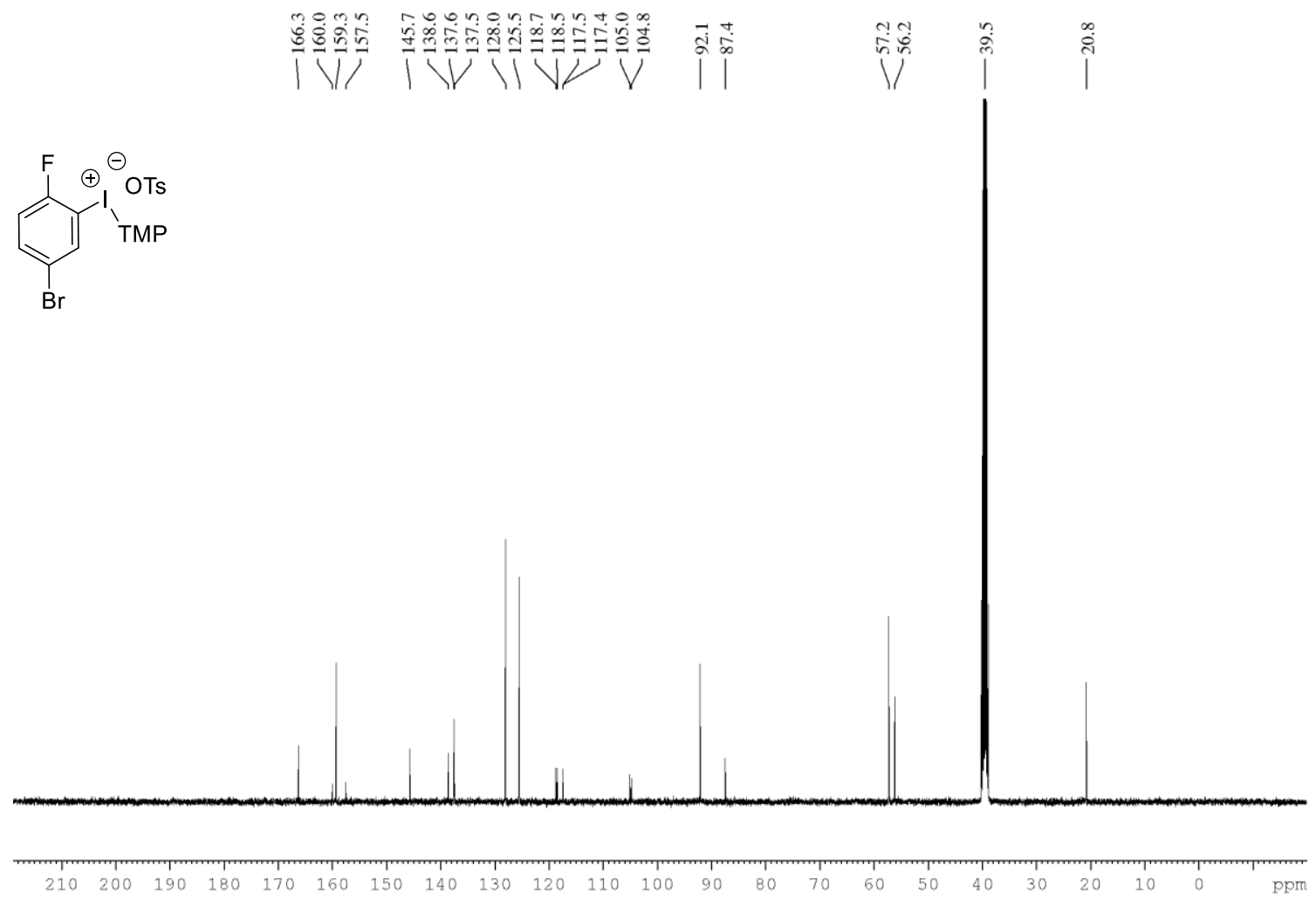

Figure $168 .{ }^{13} \mathrm{C}\left\{{ }^{1} \mathrm{H}\right\}$ NMR of $\mathbf{1 1 x}$ in DMSO-d 6 at $101 \mathrm{MHz}$.

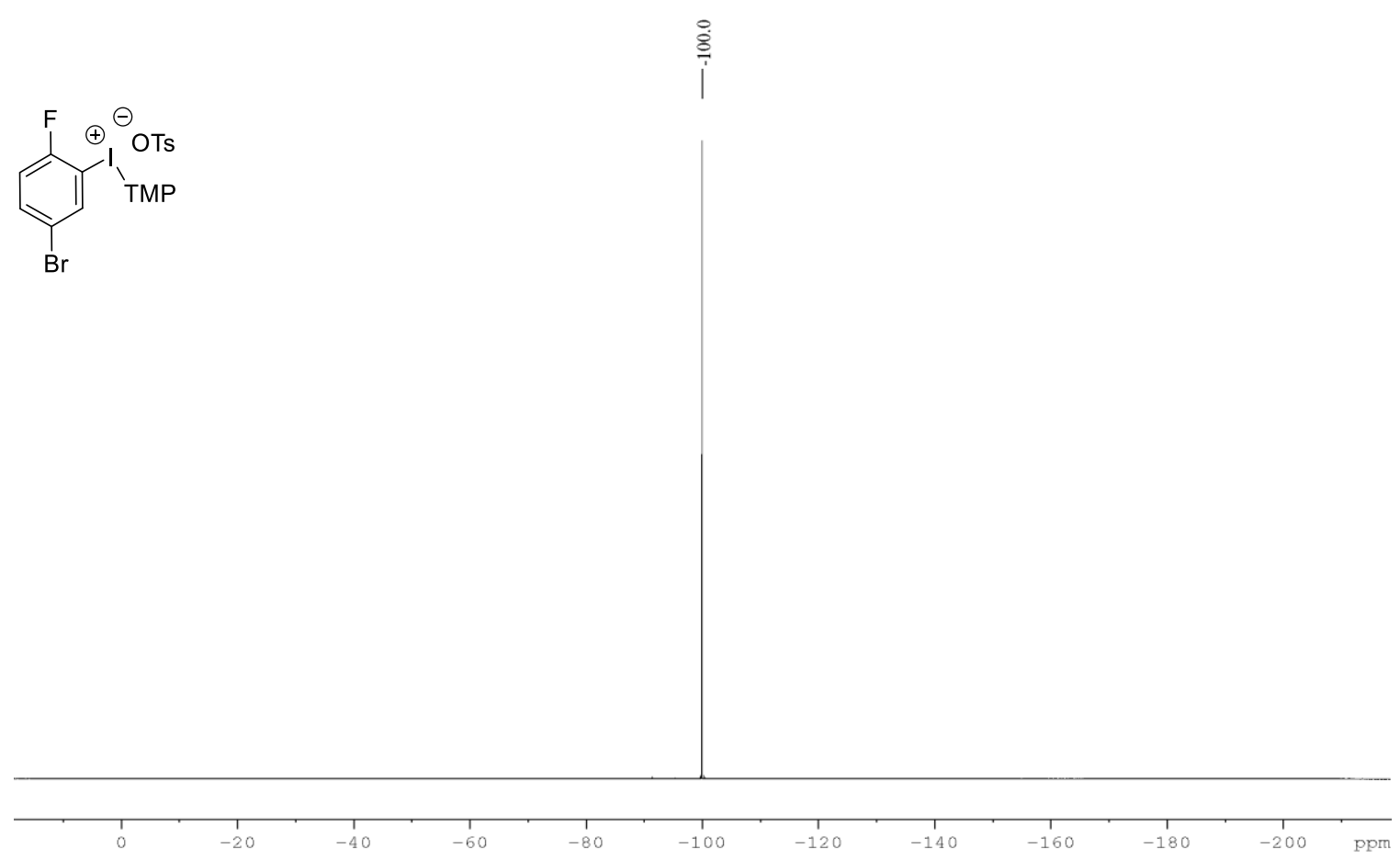

Figure 169. ${ }^{19} \mathrm{~F}\left\{{ }^{1} \mathrm{H}\right\}$ NMR of $11 x$ in DMSO-d 6 with $1 \% \mathrm{v} / \mathrm{v}$ TMS at $376 \mathrm{MHz}$. 


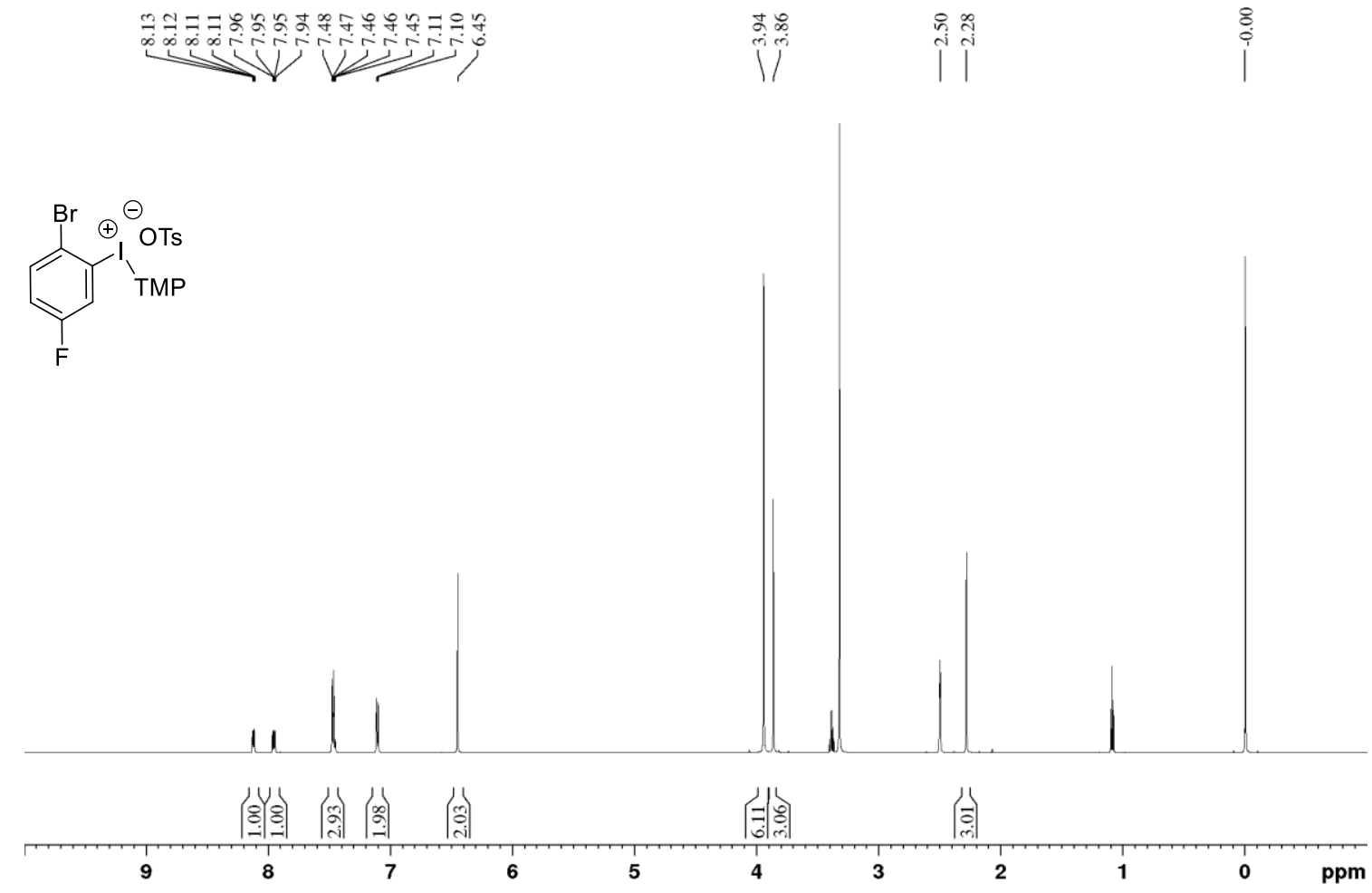

Figure $170 .{ }^{1} \mathrm{H}$ NMR of $\mathbf{1 1} \mathbf{x}^{\prime}$ in DMSO-d 6 with $1 \% \mathrm{v} / \mathrm{v}$ TMS at $400 \mathrm{MHz}$.

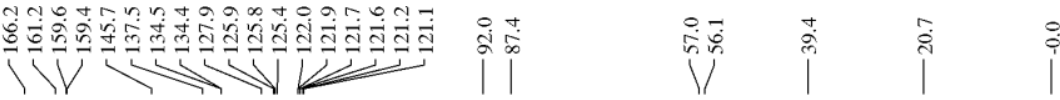

$\underbrace{\overbrace{T M P}^{O}}_{F}$
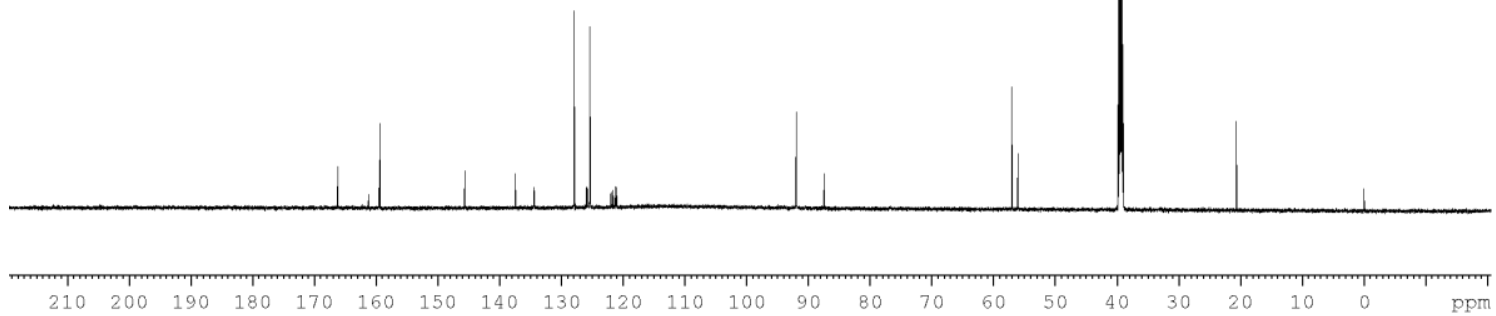

Figure $171 .{ }^{13} \mathrm{C}\left\{{ }^{1} \mathrm{H}\right\}$ NMR of $11 \mathbf{x}^{\prime}$ in DMSO-d 6 with $1 \% \mathrm{v} / \mathrm{v}$ TMS at $101 \mathrm{MHz}$. 


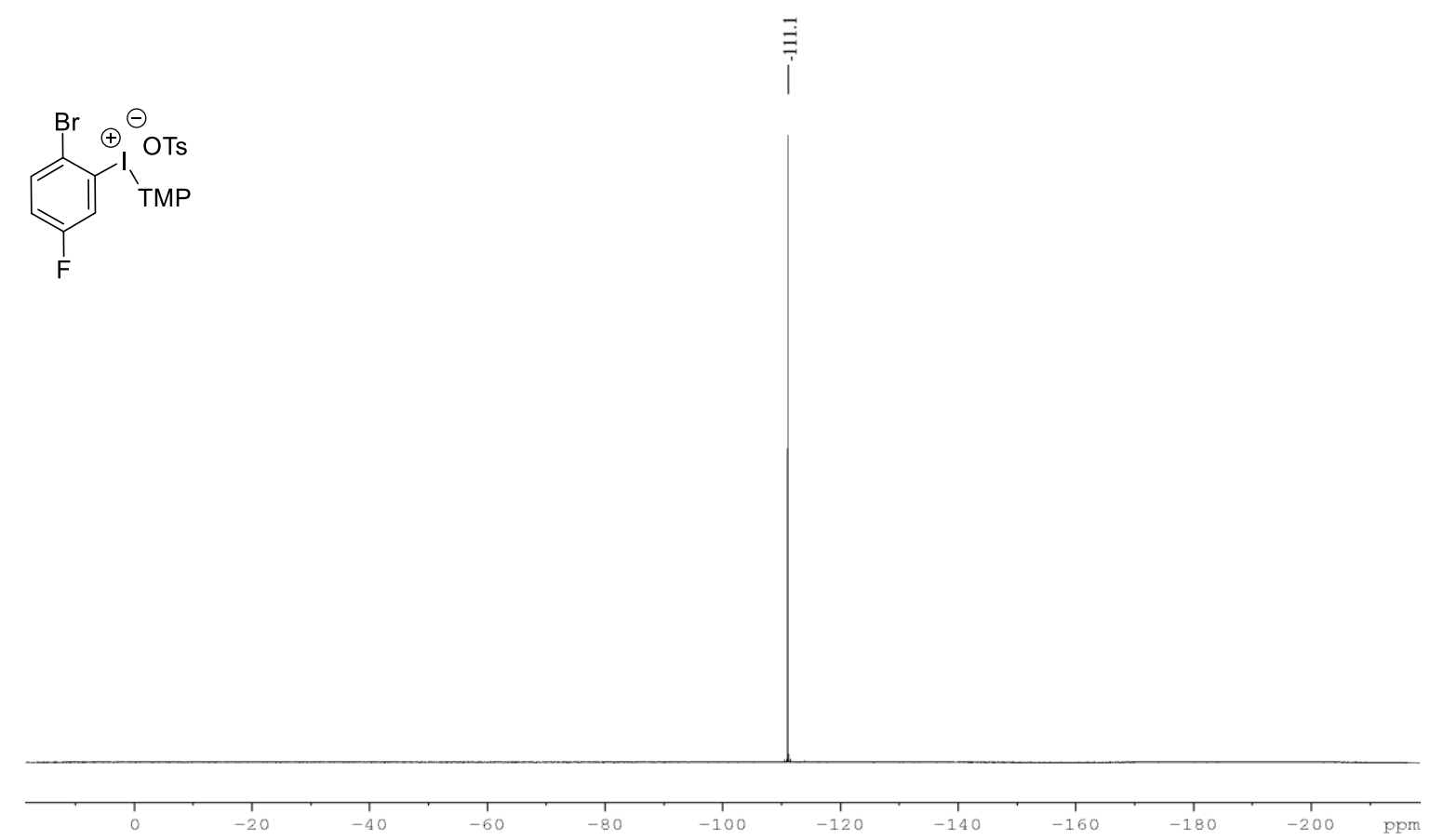

Figure $172 .{ }^{19} \mathrm{~F}\left\{{ }^{1} \mathrm{H}\right\}$ NMR of $11 \mathbf{x}^{\prime}$ in DMSO-d 6 with $1 \% \mathrm{v} / \mathrm{v}$ TMS at $376 \mathrm{MHz}$.

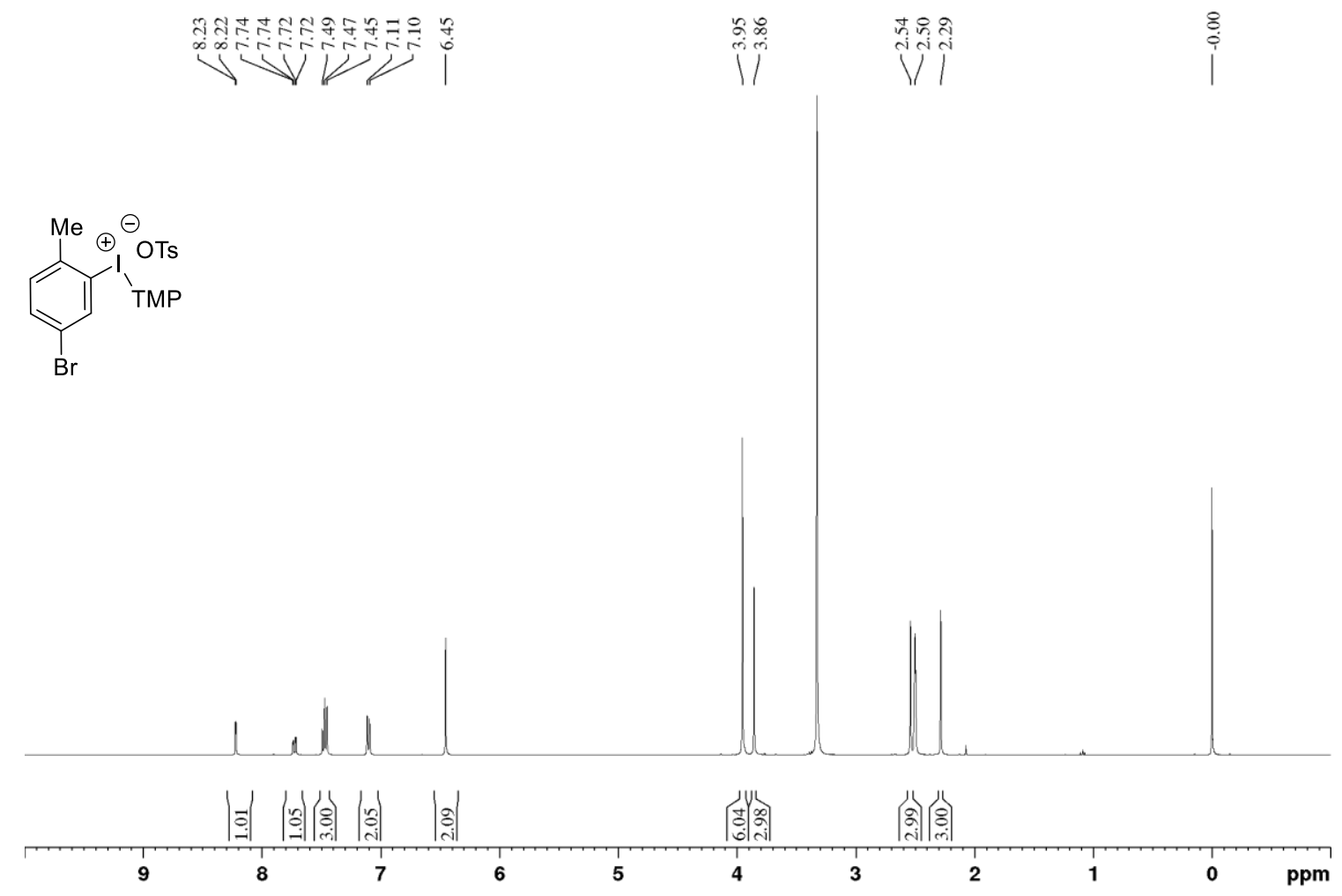

Figure 173. ${ }^{1} \mathrm{H}$ NMR of $11 y$ in DMSO- $\mathrm{d}_{6}$ with $1 \% \mathrm{v} / \mathrm{v}$ TMS at $400 \mathrm{MHz}$. 
<smiles>Cc1ccc(Br)cc1I([O-])O[Na]</smiles>

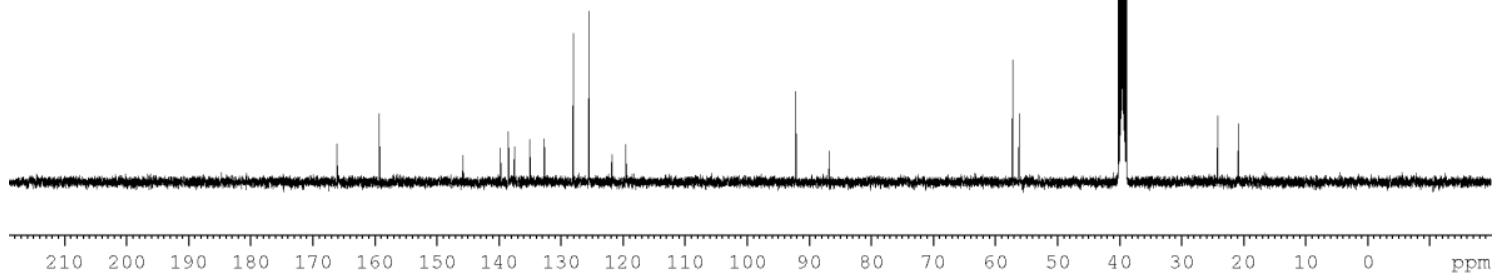

Figure $174 .{ }^{13} \mathrm{C}\left\{{ }^{1} \mathrm{H}\right\}$ NMR of $\mathbf{1 1 y}$ in DMSO-d 6 at $101 \mathrm{MHz}$.
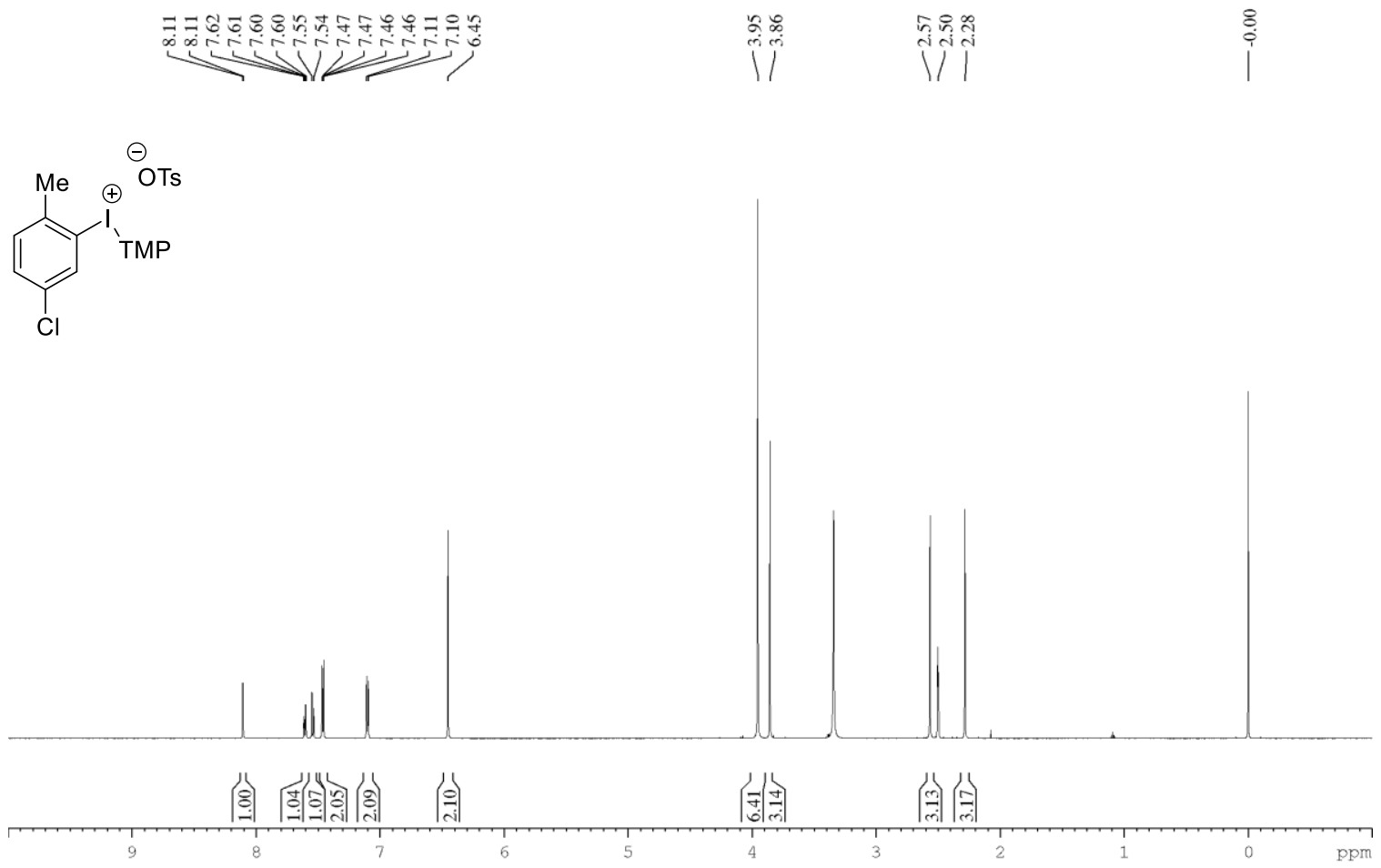

Figure $175 .{ }^{1} \mathrm{H}$ NMR of $\mathbf{1 1 z}$ in DMSO-d 6 with $1 \% \mathrm{v} / \mathrm{v}$ TMS at $600 \mathrm{MHz}$. 


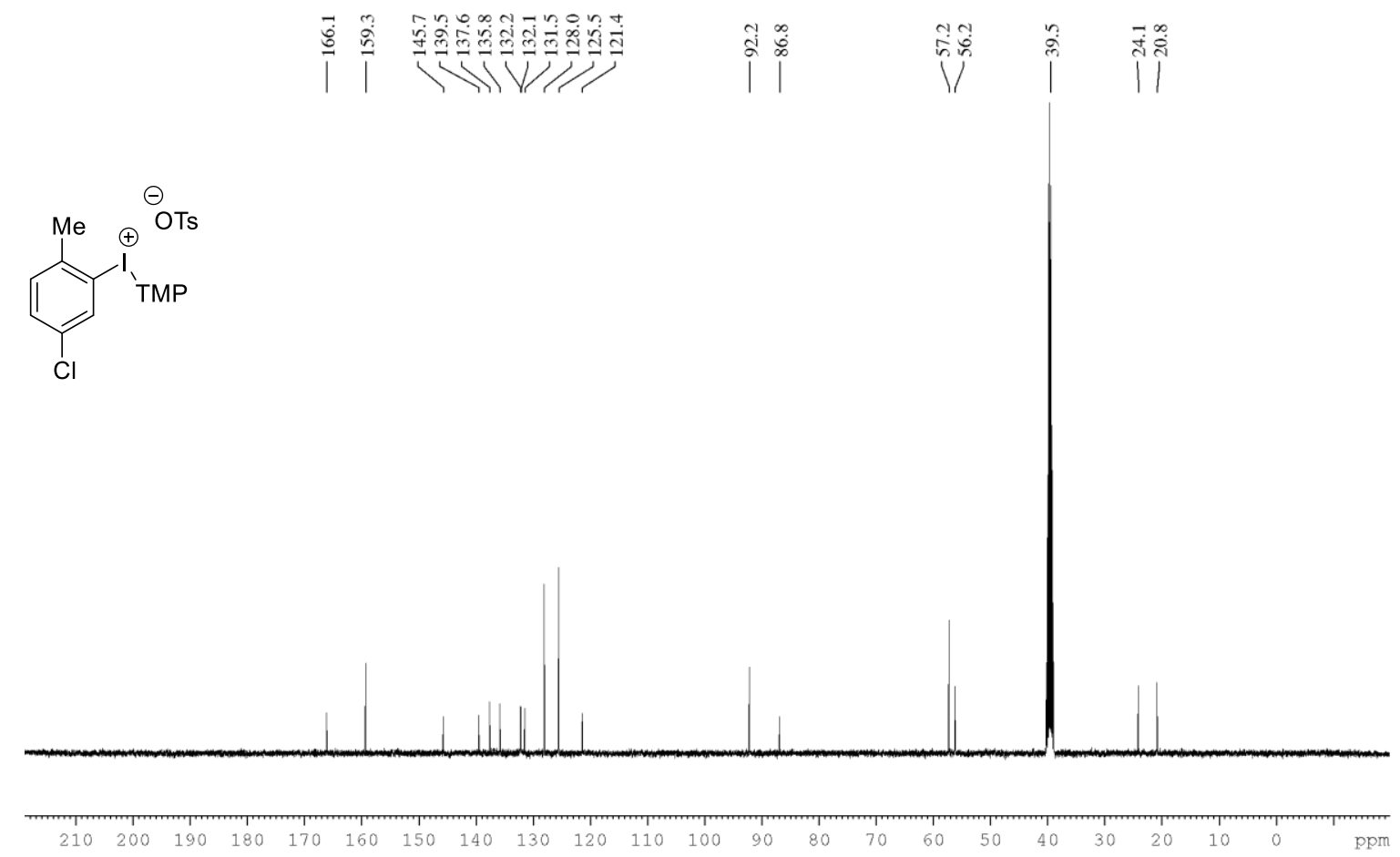

Figure $176 .{ }^{13} \mathrm{C}\left\{{ }^{1} \mathrm{H}\right\}$ NMR of $\mathbf{1 1 z}$ in DMSO-d 6 at $101 \mathrm{MHz}$.

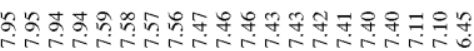

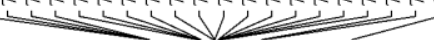
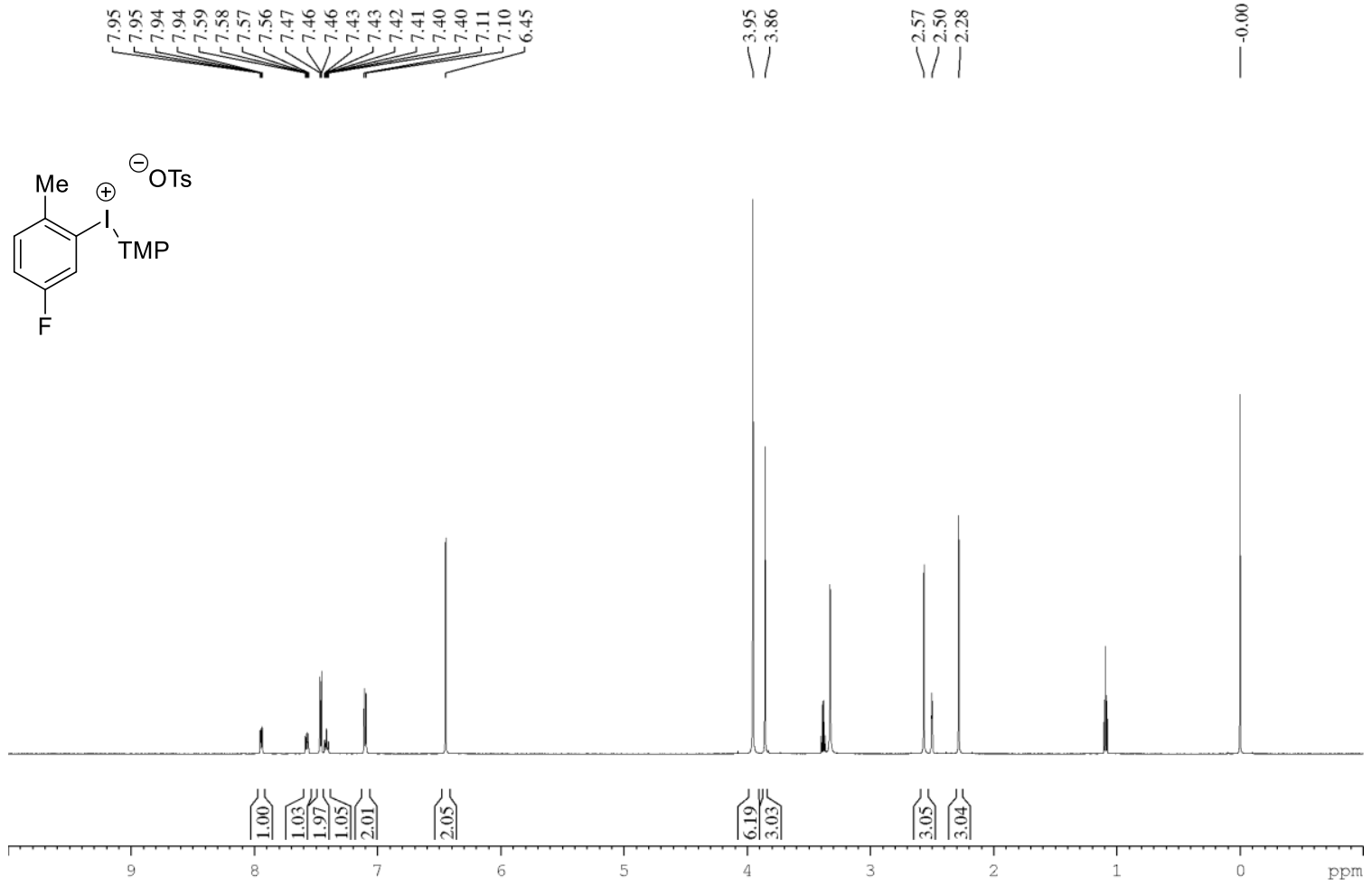

Figure 177. ${ }^{1} \mathrm{H}$ NMR of 11aa in DMSO-d 6 with $1 \% \mathrm{v} / \mathrm{v}$ TMS at $600 \mathrm{MHz}$. 

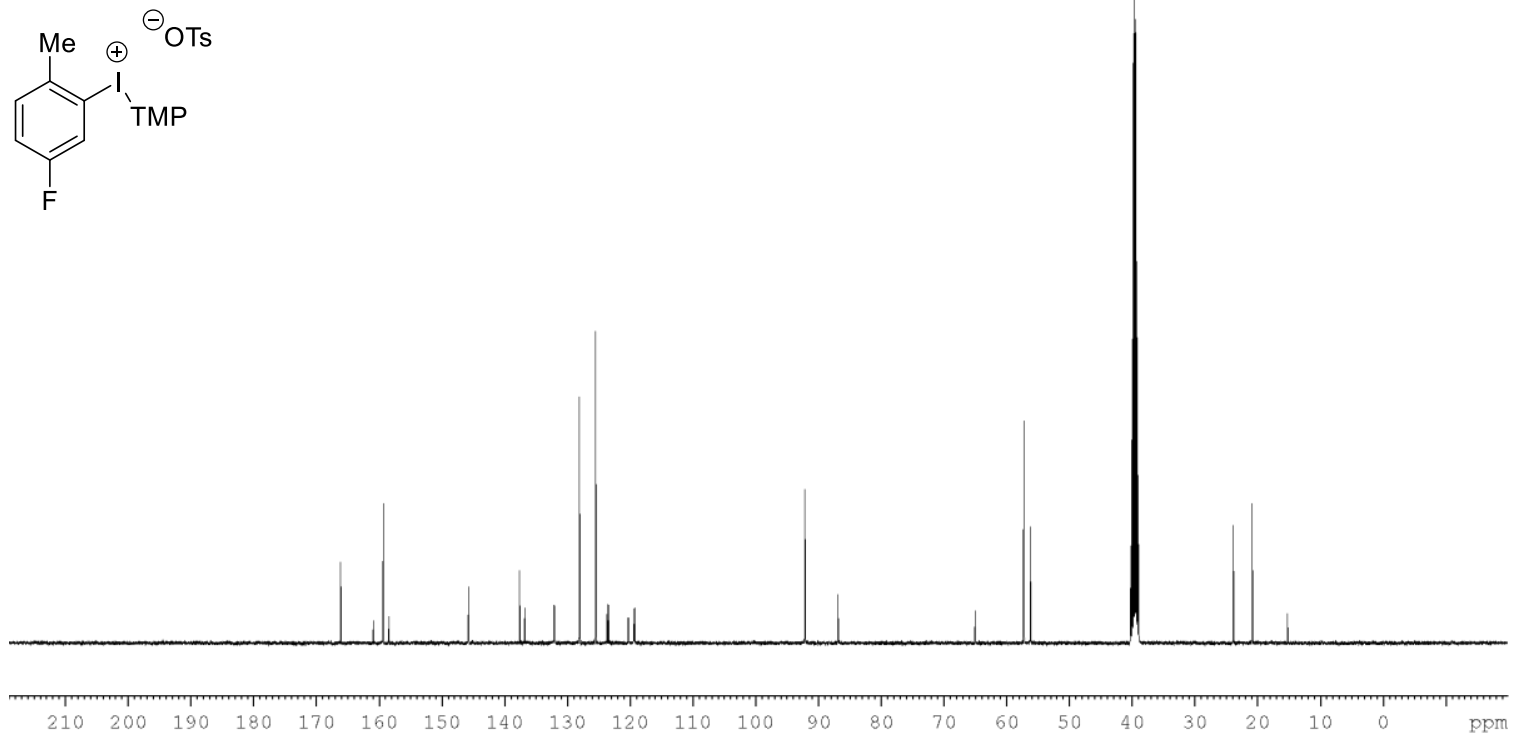

Figure $178 .{ }^{13} \mathrm{C}\left\{{ }^{1} \mathrm{H}\right\}$ NMR of 11aa in DMSO-d $\mathrm{d}_{6}$ at $101 \mathrm{MHz}$.

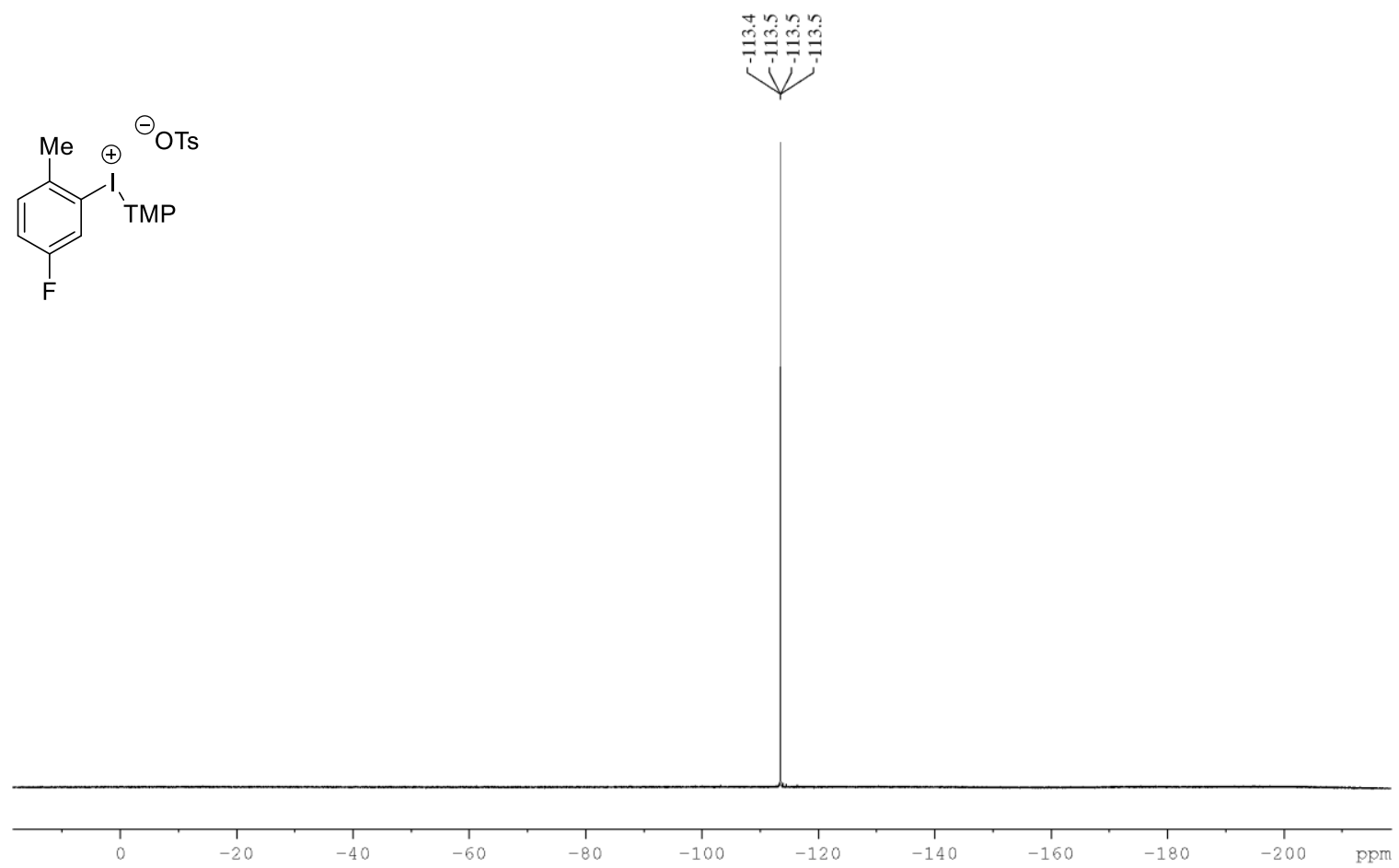

Figure 179. ${ }^{19} \mathrm{~F}\left\{{ }^{1} \mathrm{H}\right\}$ NMR of 11aa in DMSO- $\mathrm{d}_{6}$ at $376 \mathrm{MHz}$. 


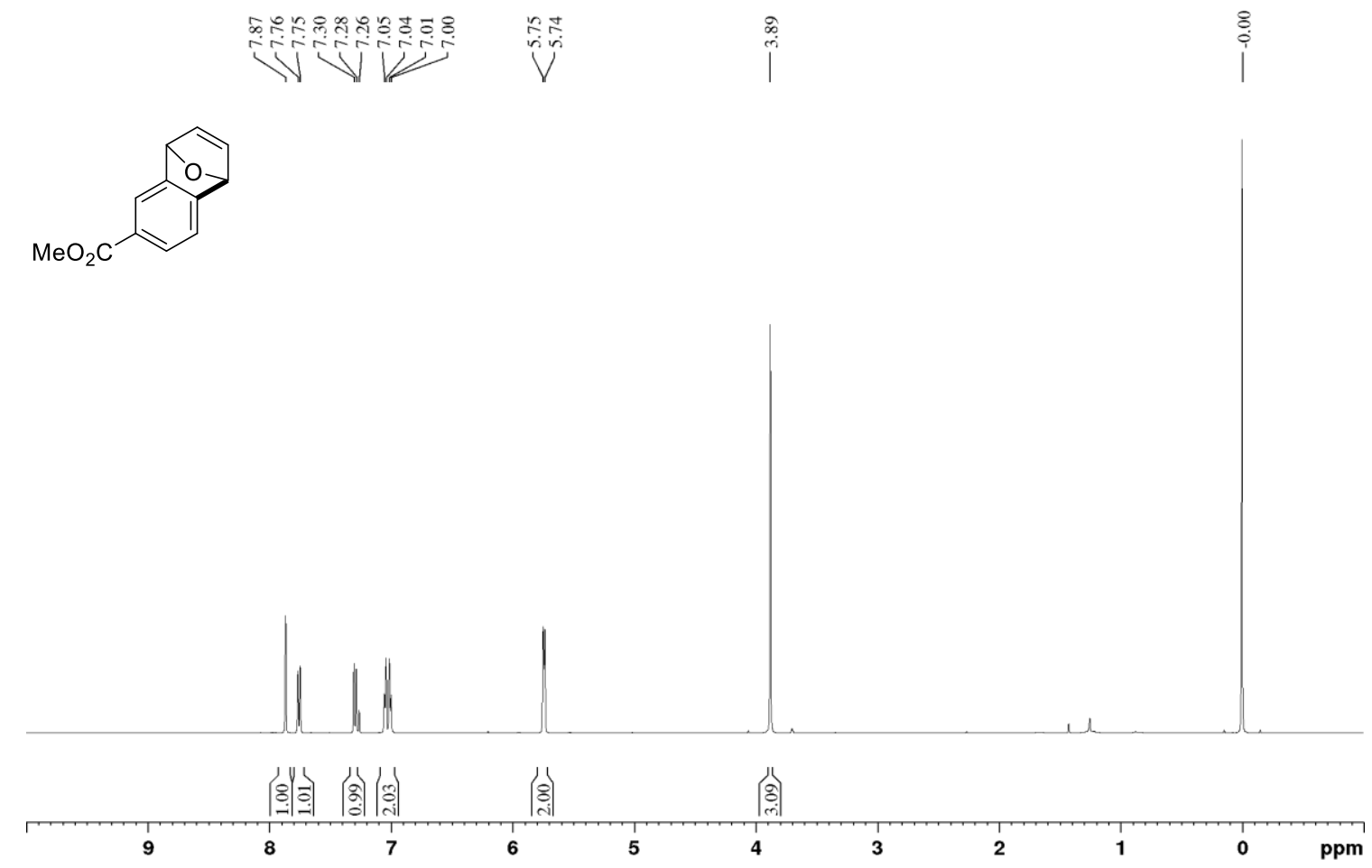

Figure $180 .{ }^{1} \mathrm{H}$ NMR of $12 \mathrm{ag}$ in $\mathrm{CDCl}_{3}$ with $1 \% \mathrm{v} / \mathrm{v}$ TMS at $400 \mathrm{MHz}$.
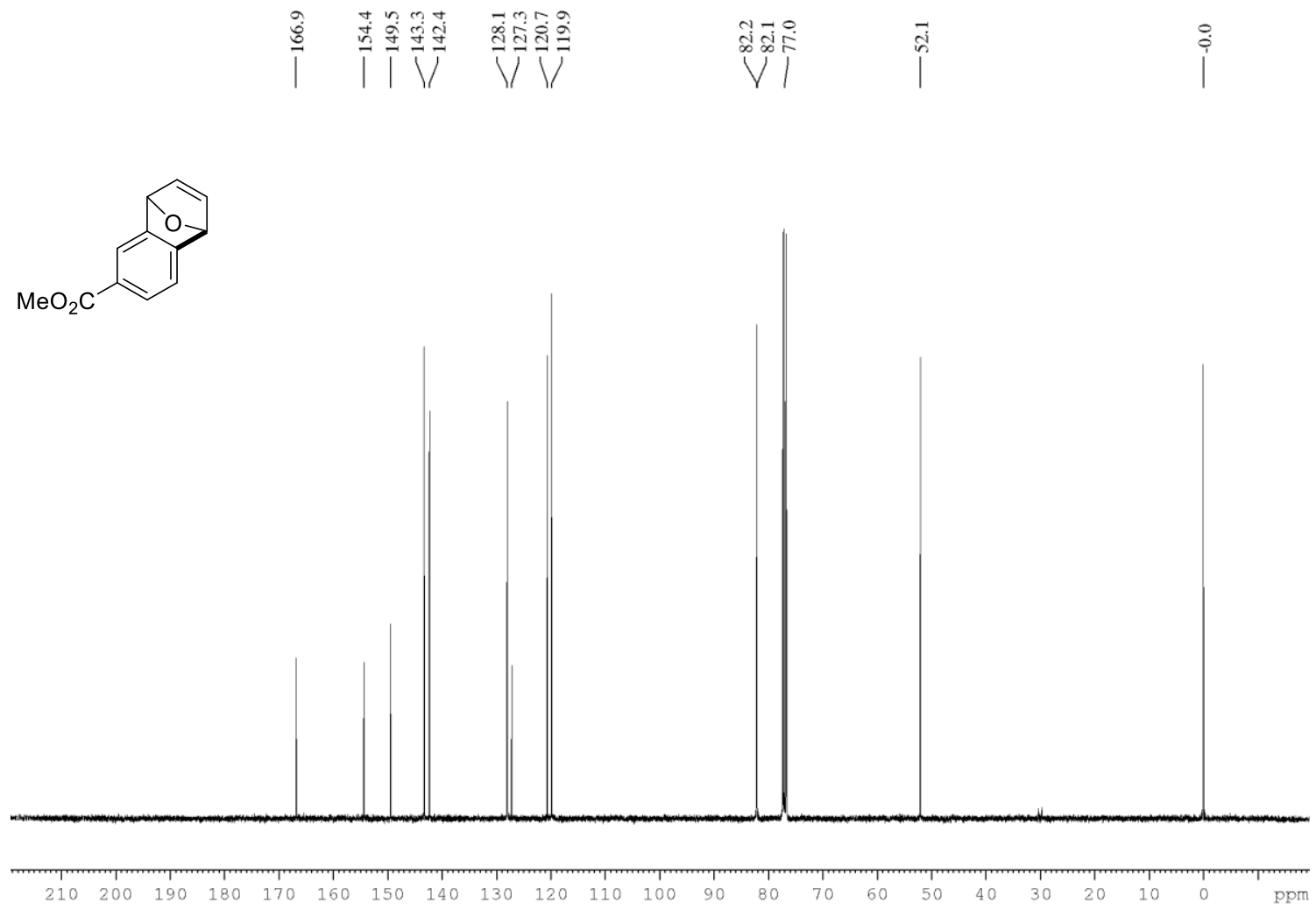

Figure $181 .{ }^{13} \mathrm{C}\left\{{ }^{1} \mathrm{H}\right\}$ NMR of 12 ag in $\mathrm{CDCl}_{3}$ with $1 \% \mathrm{v} / \mathrm{v}$ TMS at $101 \mathrm{MHz}$. 


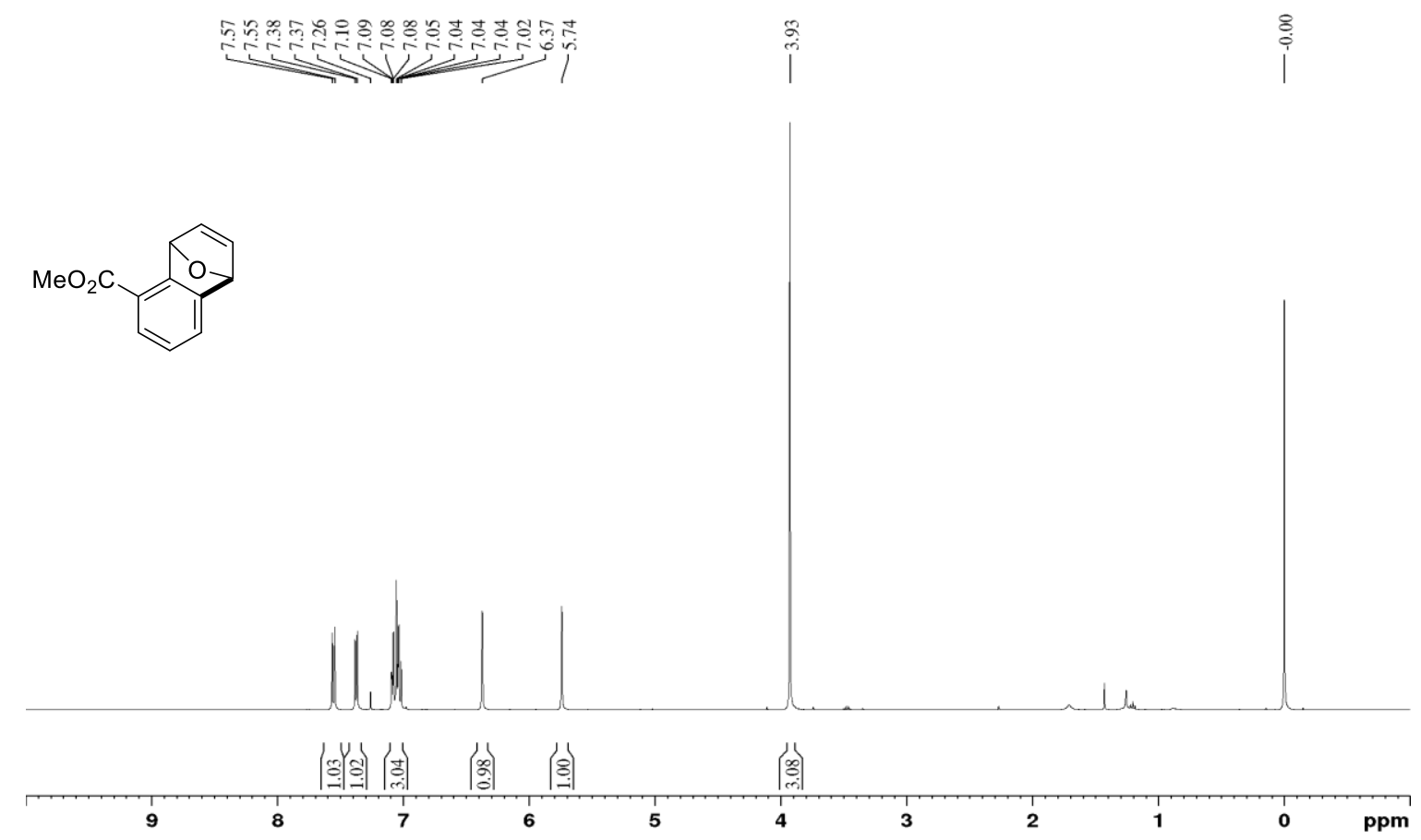

Figure 182. ${ }^{1} \mathrm{H} \mathrm{NMR}$ of $\mathbf{1 2} \mathrm{cg}$ in $\mathrm{CDCl}_{3}$ with $1 \% \mathrm{v} / \mathrm{v}$ TMS at $400 \mathrm{MHz}$.

l

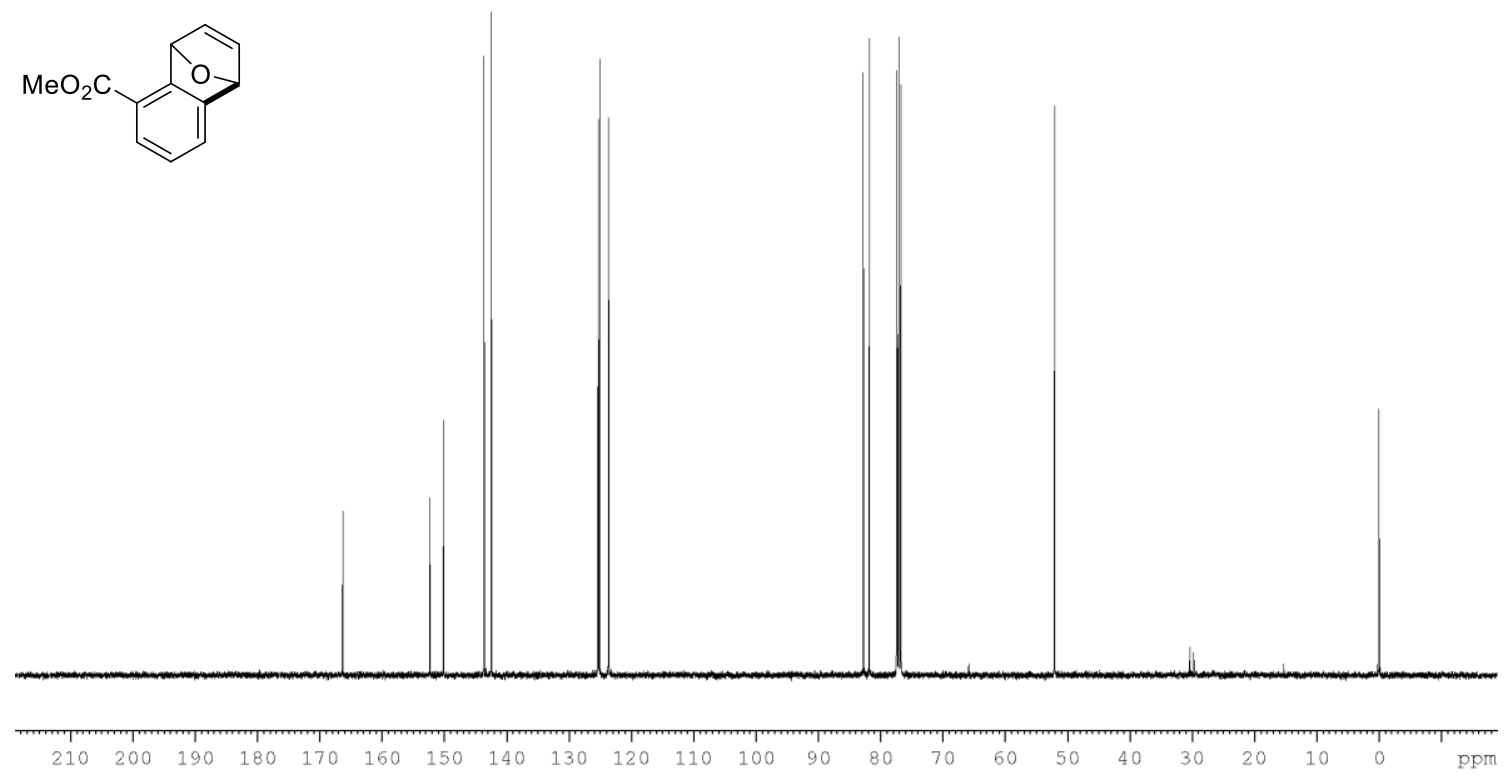

Figure $183 .{ }^{13} \mathrm{C}\left\{{ }^{1} \mathrm{H}\right\} \mathrm{NMR}$ of $\mathbf{1 2} \mathrm{cg}$ in $\mathrm{CDCl}_{3}$ with $1 \% \mathrm{v} / \mathrm{v}$ TMS at $101 \mathrm{MHz}$. 

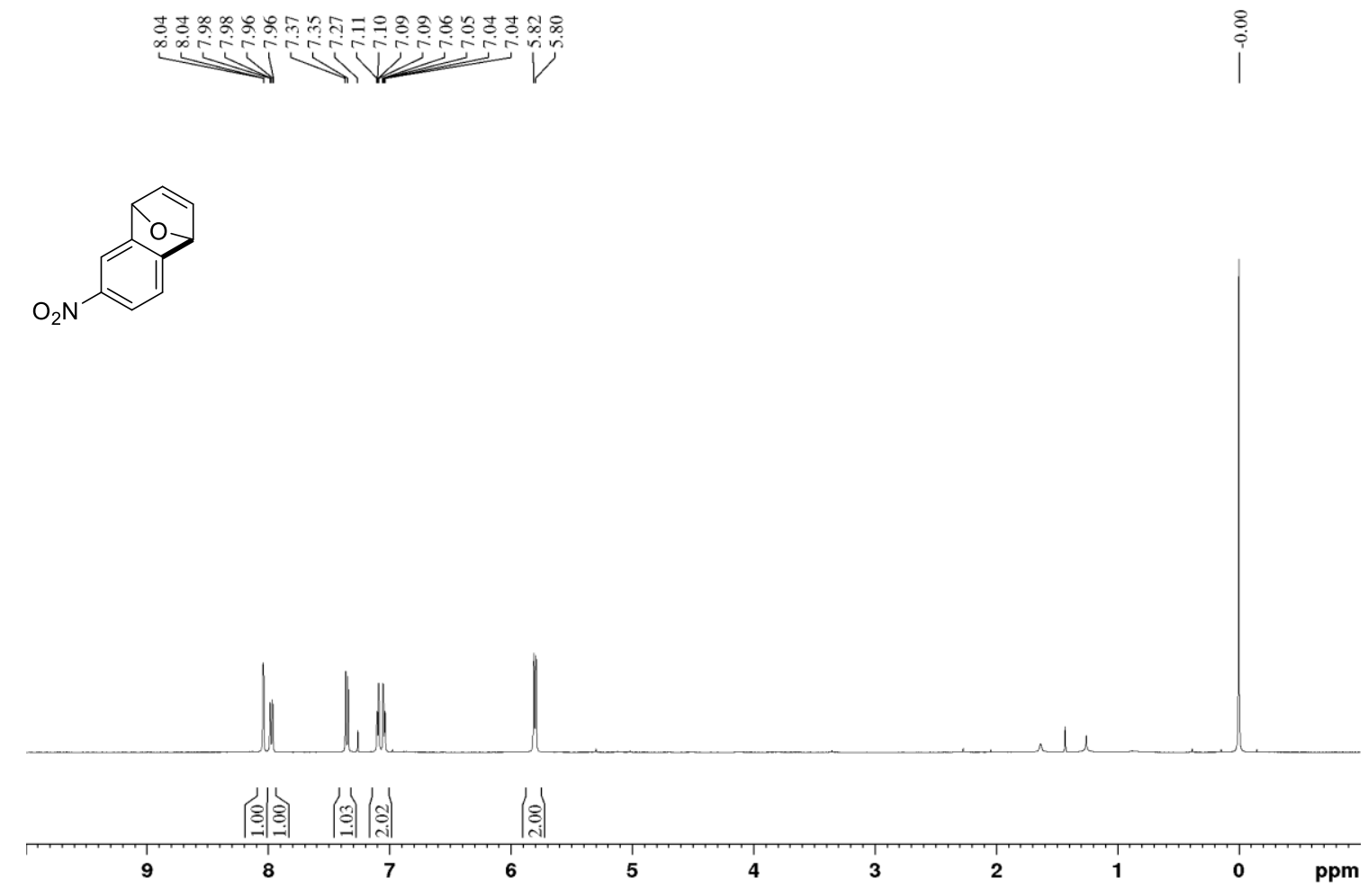

Figure 184. ${ }^{1} \mathrm{H}$ NMR of $12 \mathrm{eg}$ in $\mathrm{CDCl}_{3}$ with $1 \% \mathrm{v} / \mathrm{v}$ TMS at $400 \mathrm{MHz}$.
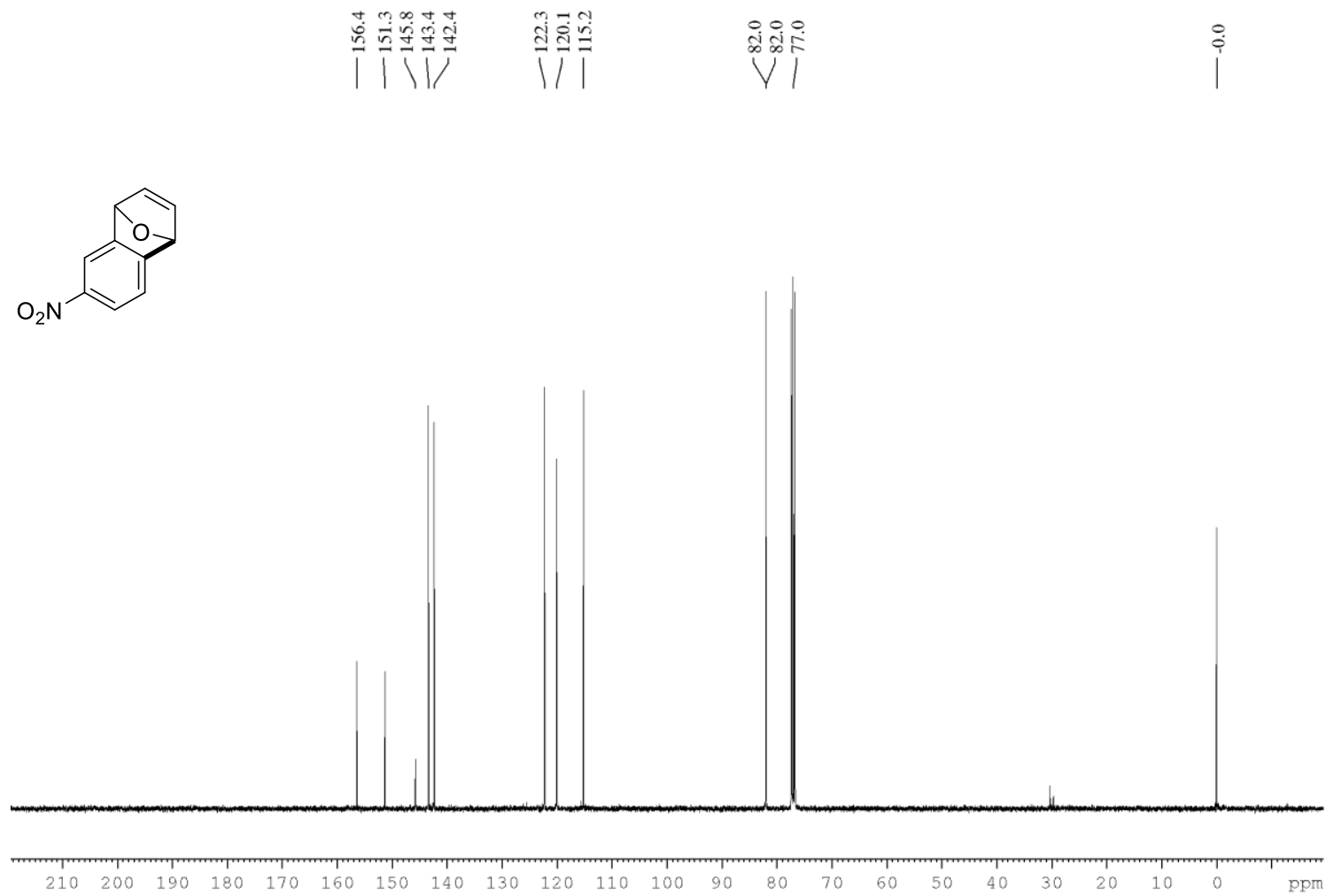

Figure $185 .{ }^{13} \mathrm{C}\left\{{ }^{1} \mathrm{H}\right\}$ NMR of $12 \mathrm{eg}$ in $\mathrm{CDCl}_{3}$ with $1 \% \mathrm{v} / \mathrm{v}$ TMS at $101 \mathrm{MHz}$. 


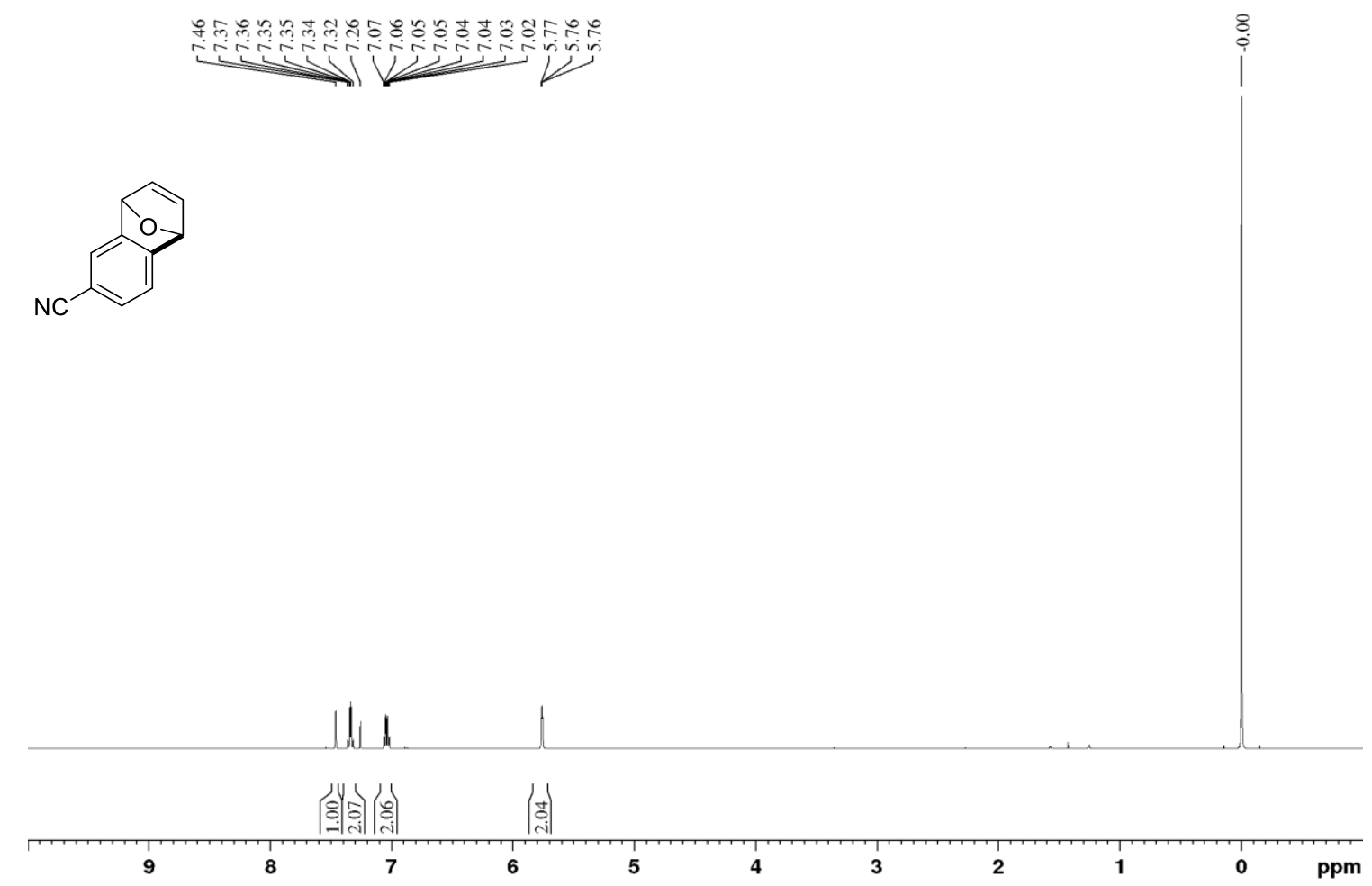

Figure $186 .{ }^{1} \mathrm{H}$ NMR of $12 \mathrm{gg}$ in $\mathrm{CDCl}_{3}$ with $1 \% \mathrm{v} / \mathrm{v}$ TMS at $400 \mathrm{MHz}$.
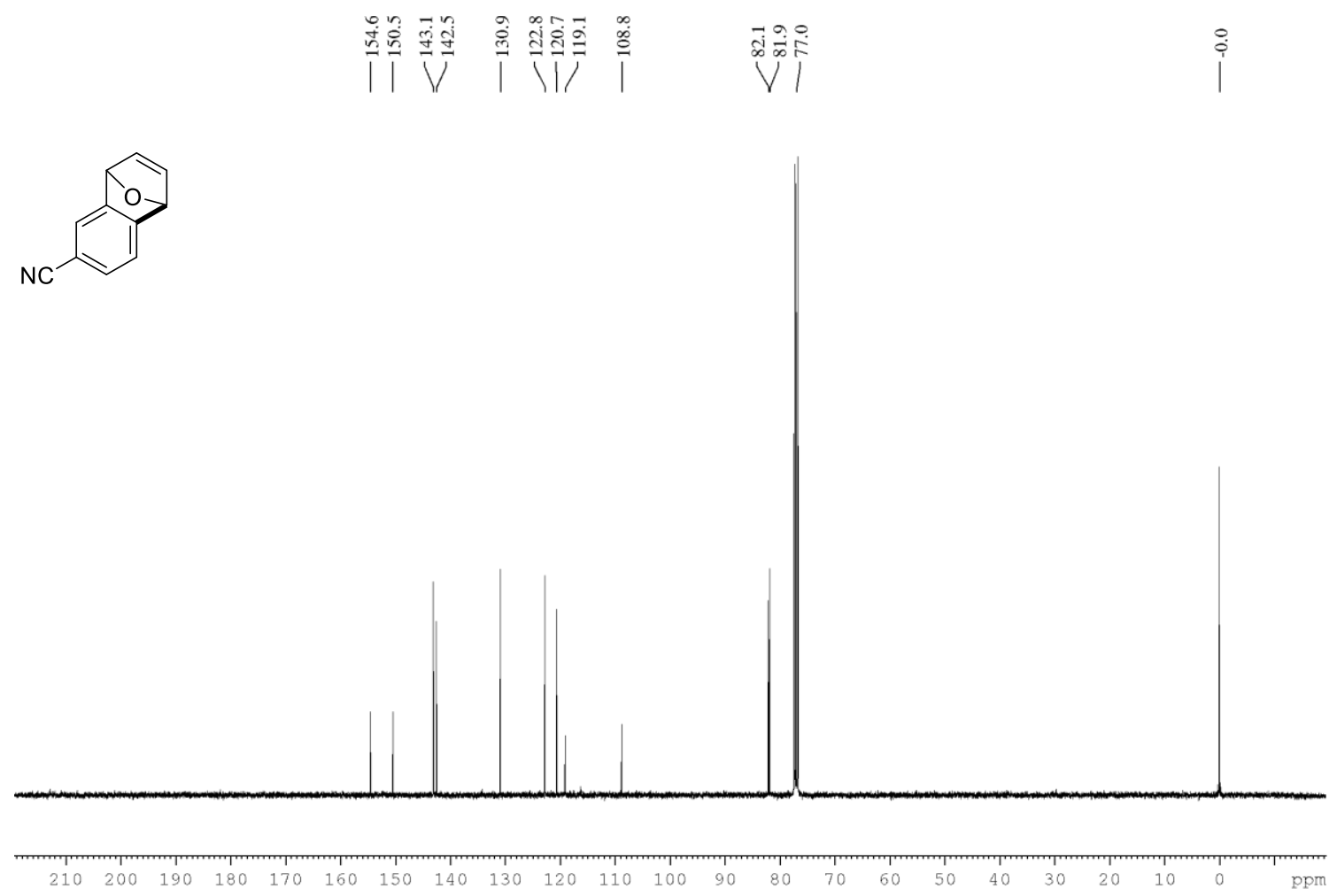

Figure 187. ${ }^{13} \mathrm{C}\left\{{ }^{1} \mathrm{H}\right\} \mathrm{NMR}$ of $\mathbf{1 2 g g}$ in $\mathrm{CDCl}_{3}$ with $1 \% \mathrm{v} / \mathrm{v}$ TMS at $101 \mathrm{MHz}$. 


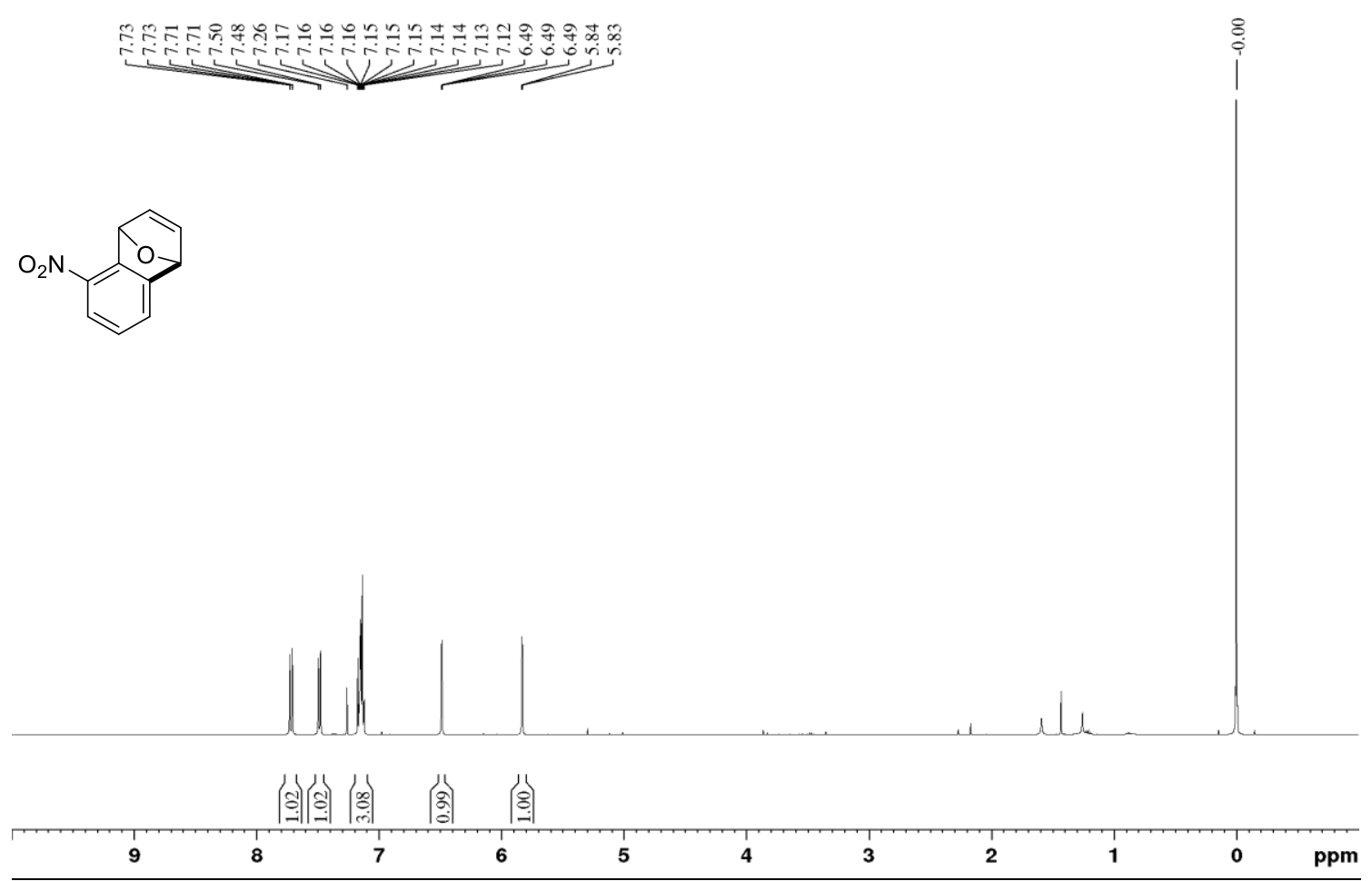

Figure 188. ${ }^{1} \mathrm{H}$ NMR of 12 ig in $\mathrm{CDCl}_{3}$ with $1 \% \mathrm{v} / \mathrm{v}$ TMS at $400 \mathrm{MHz}$.

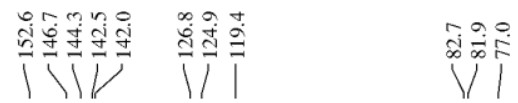

$\mathrm{O}_{2} \mathrm{~N}$
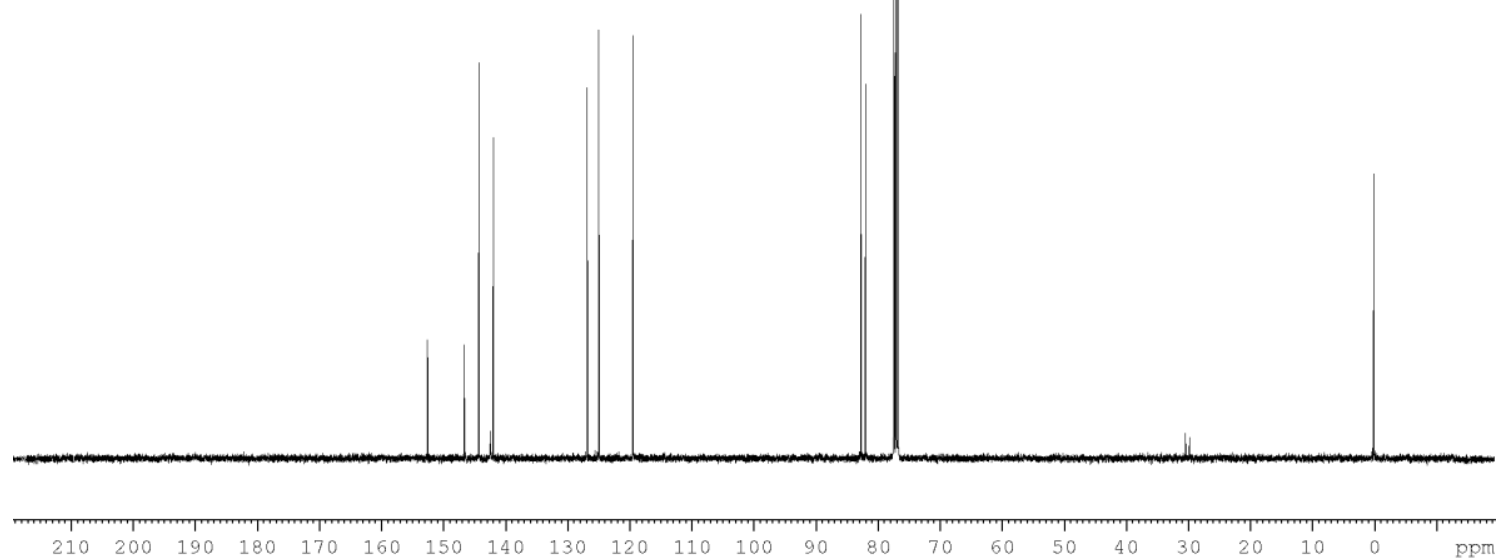

Figure 189. ${ }^{13} \mathrm{C}\left\{{ }^{1} \mathrm{H}\right\}$ NMR of 12 ig in $\mathrm{CDCl}_{3}$ with $1 \% \mathrm{v} / \mathrm{v}$ TMS at $101 \mathrm{MHz}$. 


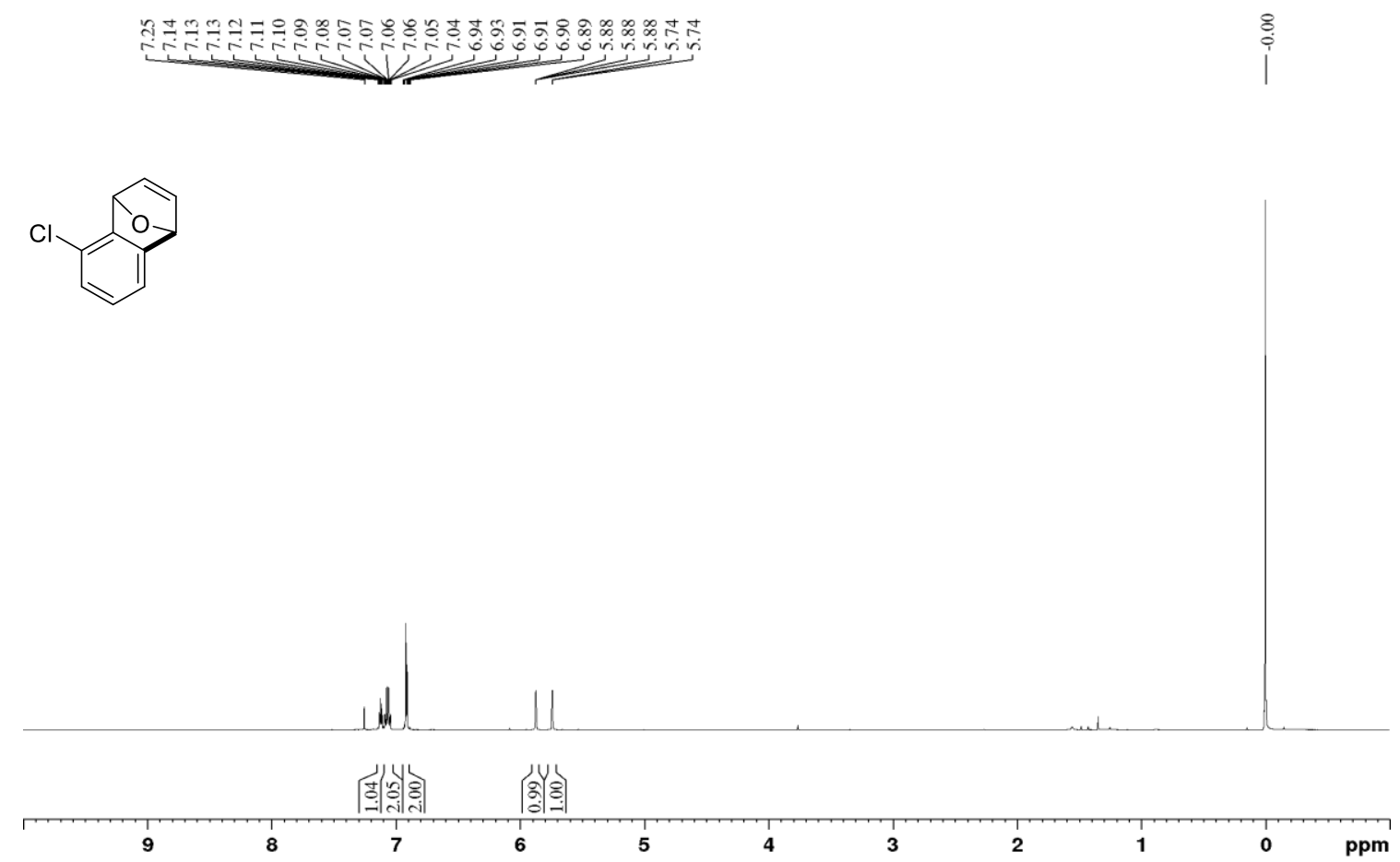

Figure $190 .{ }^{1} \mathrm{H}$ NMR of $12 \mathrm{jg}$ in $\mathrm{CDCl}_{3}$ with $1 \% \mathrm{v} / \mathrm{v}$ TMS at $400 \mathrm{MHz}$.

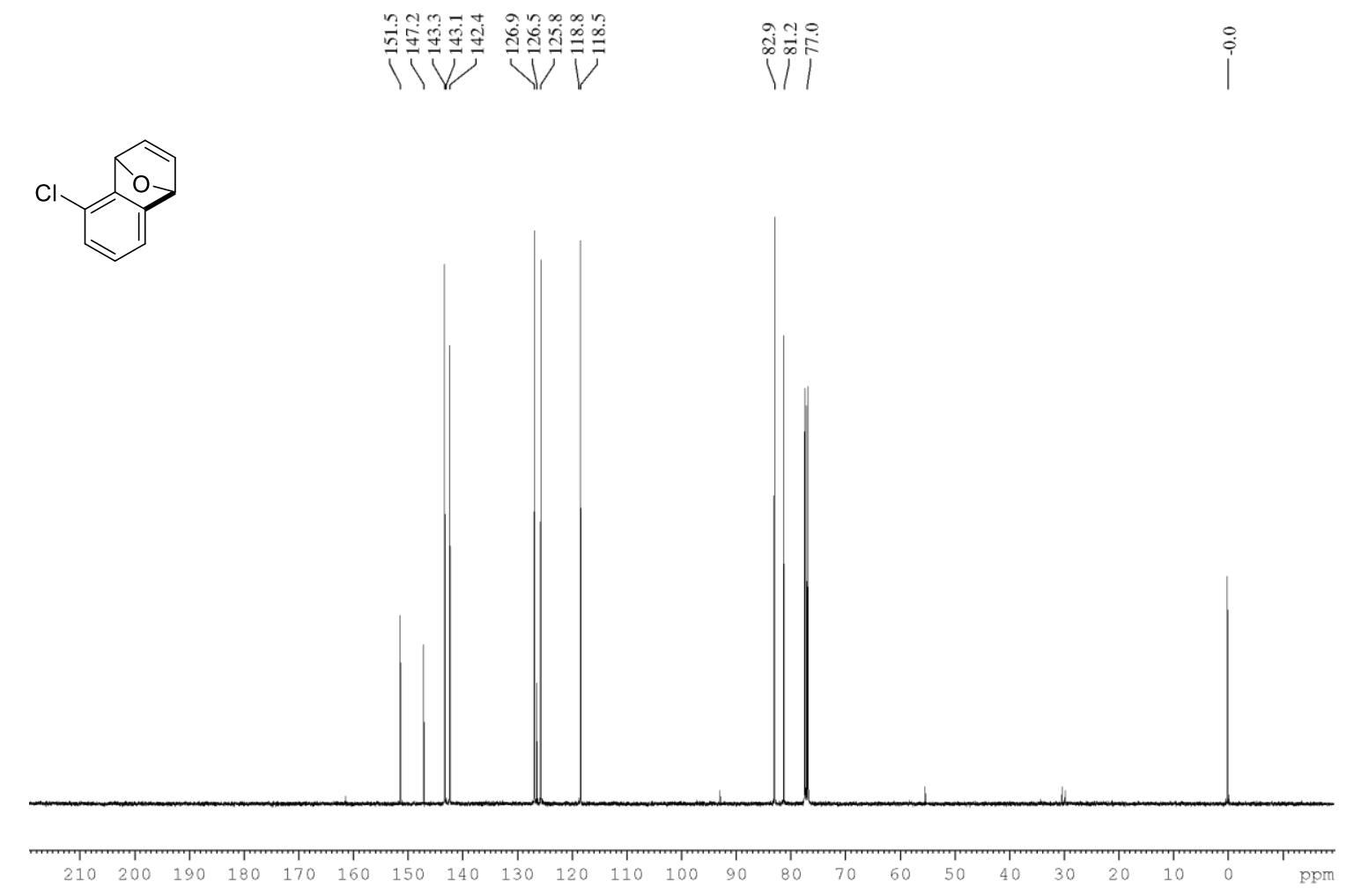

Figure $191 .{ }^{13} \mathrm{C}\left\{{ }^{1} \mathrm{H}\right\}$ NMR of $\mathbf{1 2}$ jg in $\mathrm{CDCl}_{3}$ with $1 \% \mathrm{v} / \mathrm{v}$ TMS at $101 \mathrm{MHz}$. 


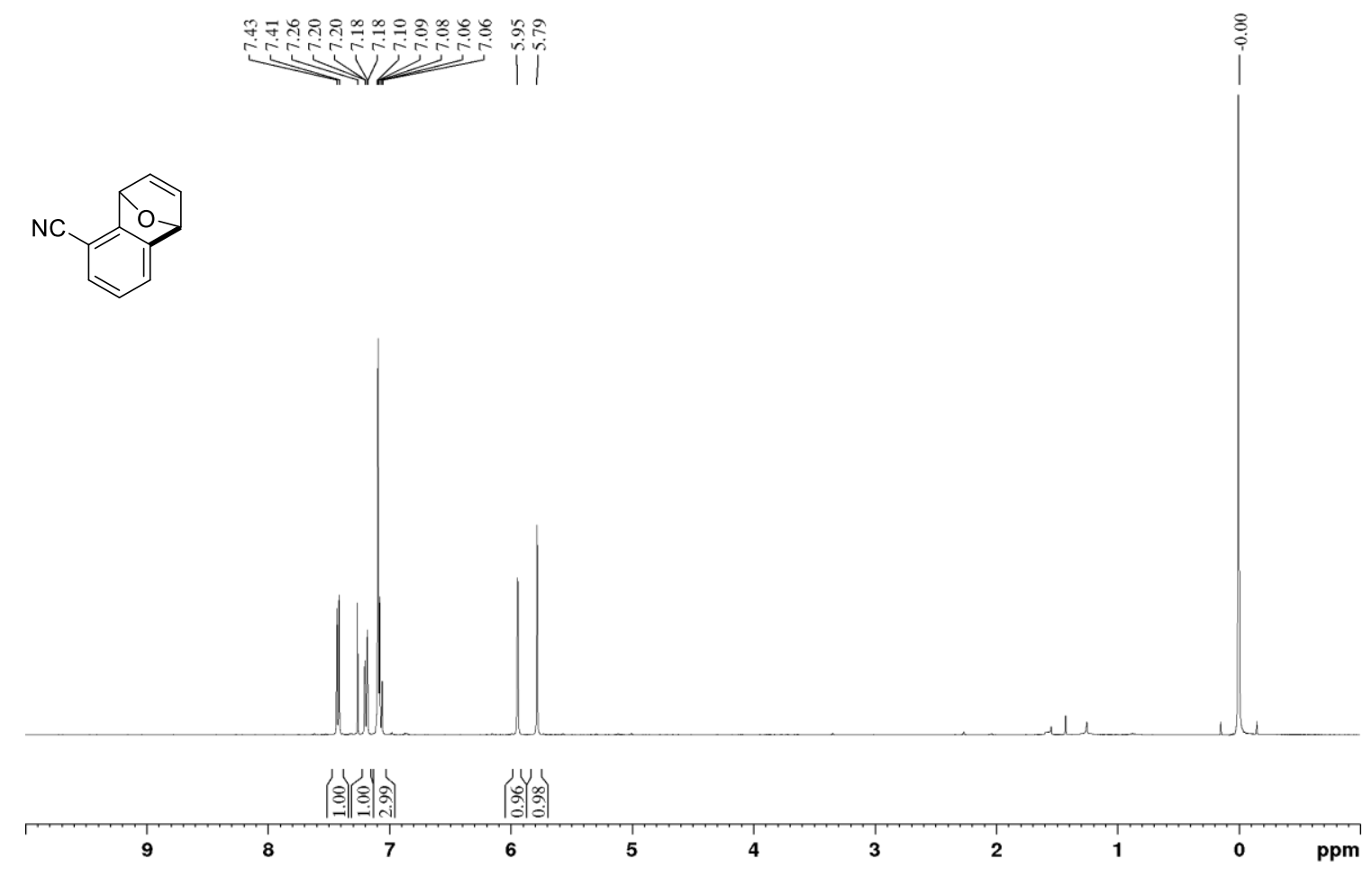

Figure 192. ${ }^{1} \mathrm{H}$ NMR of $\mathbf{1 2} \mathbf{k g}$ in $\mathrm{CDCl}_{3}$ with $1 \% \mathrm{v} / \mathrm{v}$ TMS at $400 \mathrm{MHz}$.
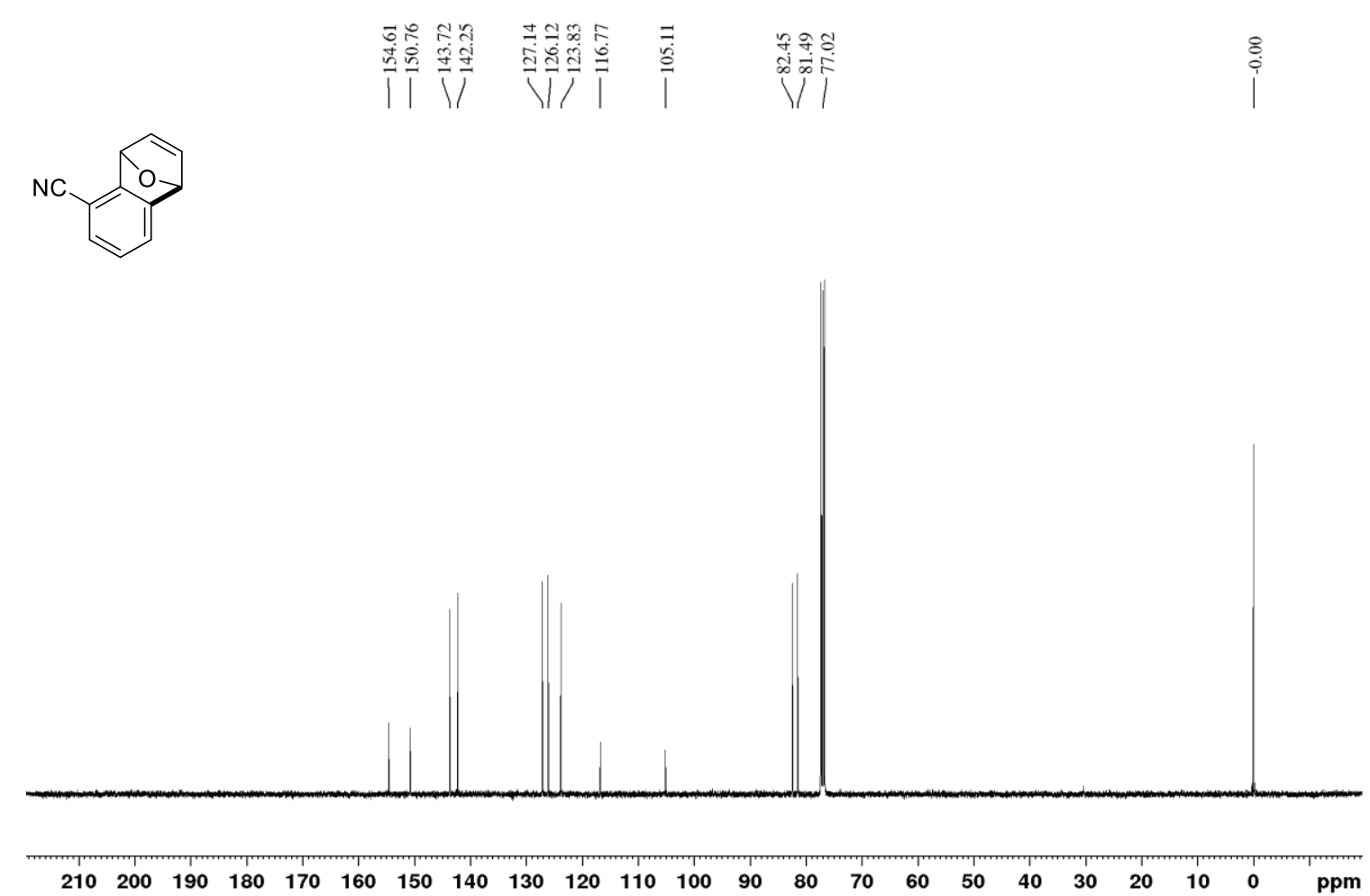

Figure 193. ${ }^{13} \mathrm{C}\left\{{ }^{1} \mathrm{H}\right\}$ NMR of $\mathbf{1 2} \mathbf{k g}$ in $\mathrm{CDCl}_{3}$ with $1 \% \mathrm{v} / \mathrm{v}$ TMS at $101 \mathrm{MHz}$. 


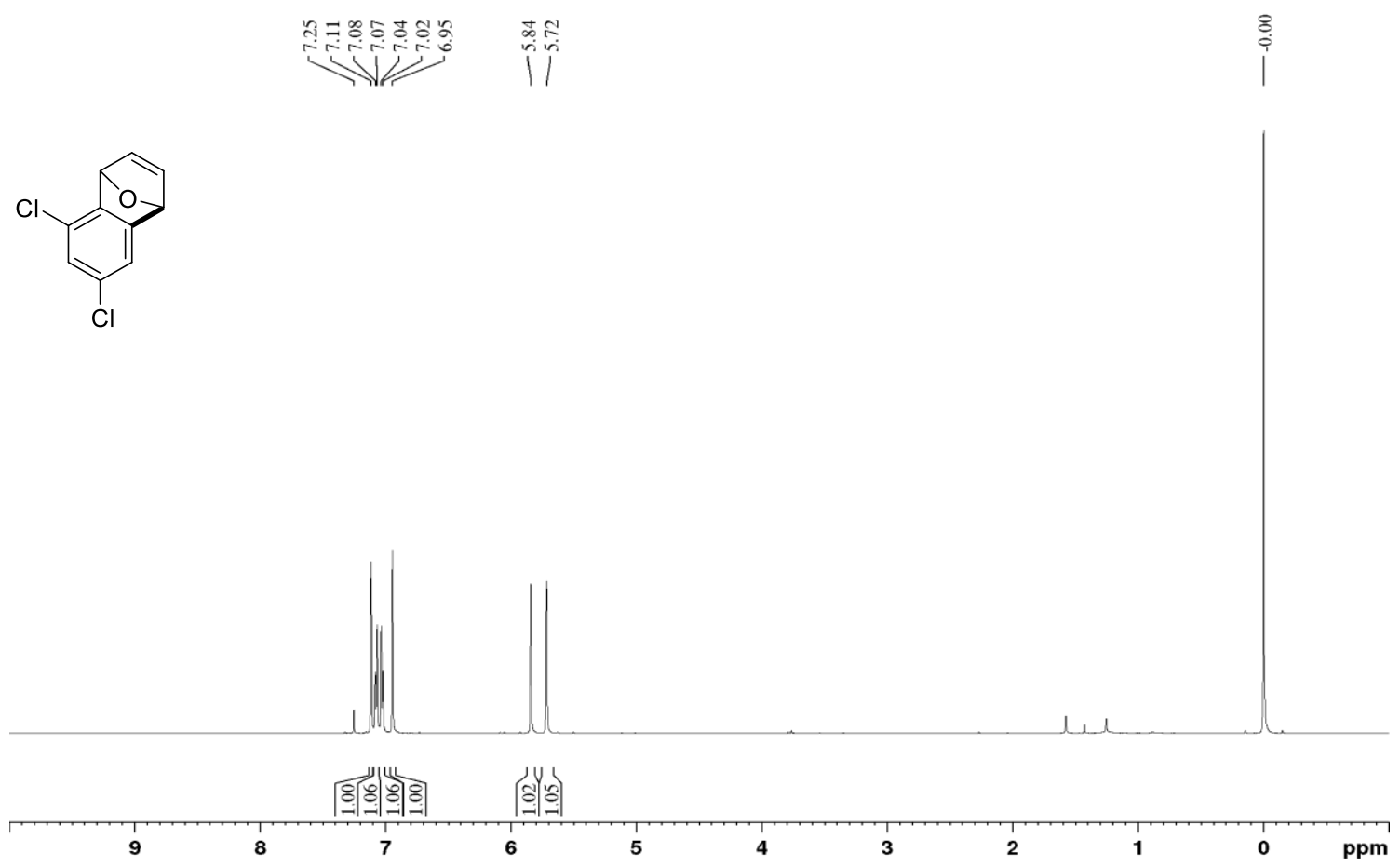

Figure 194. ${ }^{1} \mathrm{H}$ NMR of $12 \mathrm{mg}$ in $\mathrm{CDCl}_{3}$ with $1 \% \mathrm{v} / \mathrm{v}$ TMS at $400 \mathrm{MHz}$.
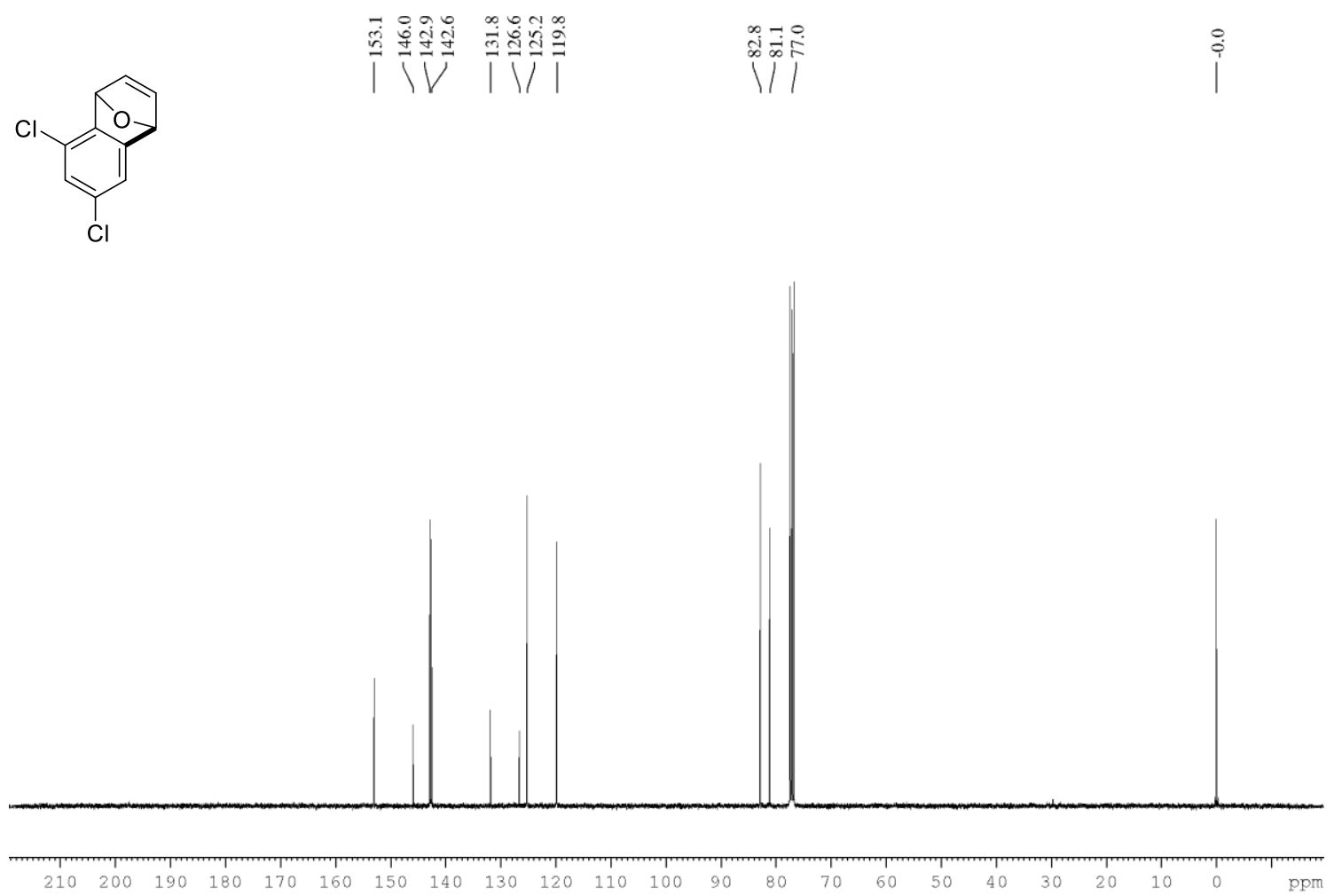

Figure $195 .{ }^{13} \mathrm{C}\left\{{ }^{1} \mathrm{H}\right\} \mathrm{NMR}$ of $\mathbf{1 2} \mathbf{m g}$ in $\mathrm{CDCl}_{3}$ with $1 \% \mathrm{v} / \mathrm{v}$ TMS at $101 \mathrm{MHz}$. 


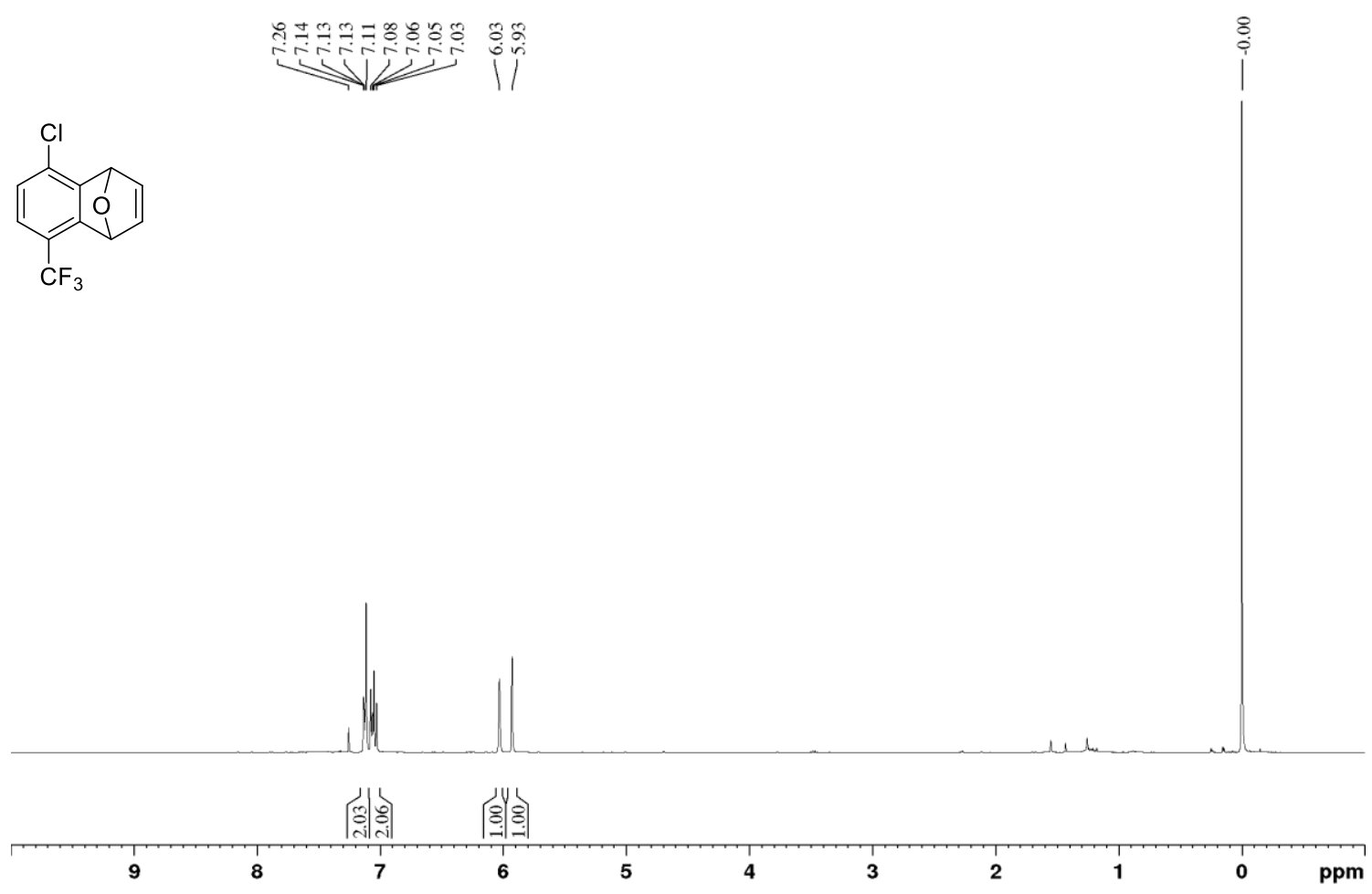

Figure 196. ${ }^{1} \mathrm{H}$ NMR of $12 \mathrm{ng}$ in $\mathrm{CDCl}_{3}$ with $1 \% \mathrm{v} / \mathrm{v}$ TMS at $400 \mathrm{MHz}$.

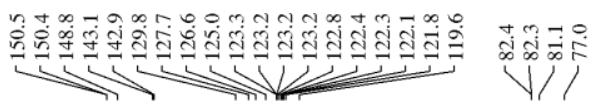<smiles>FC(F)(F)c1ccc(Cl)c2c1C1C=CC2O1</smiles>
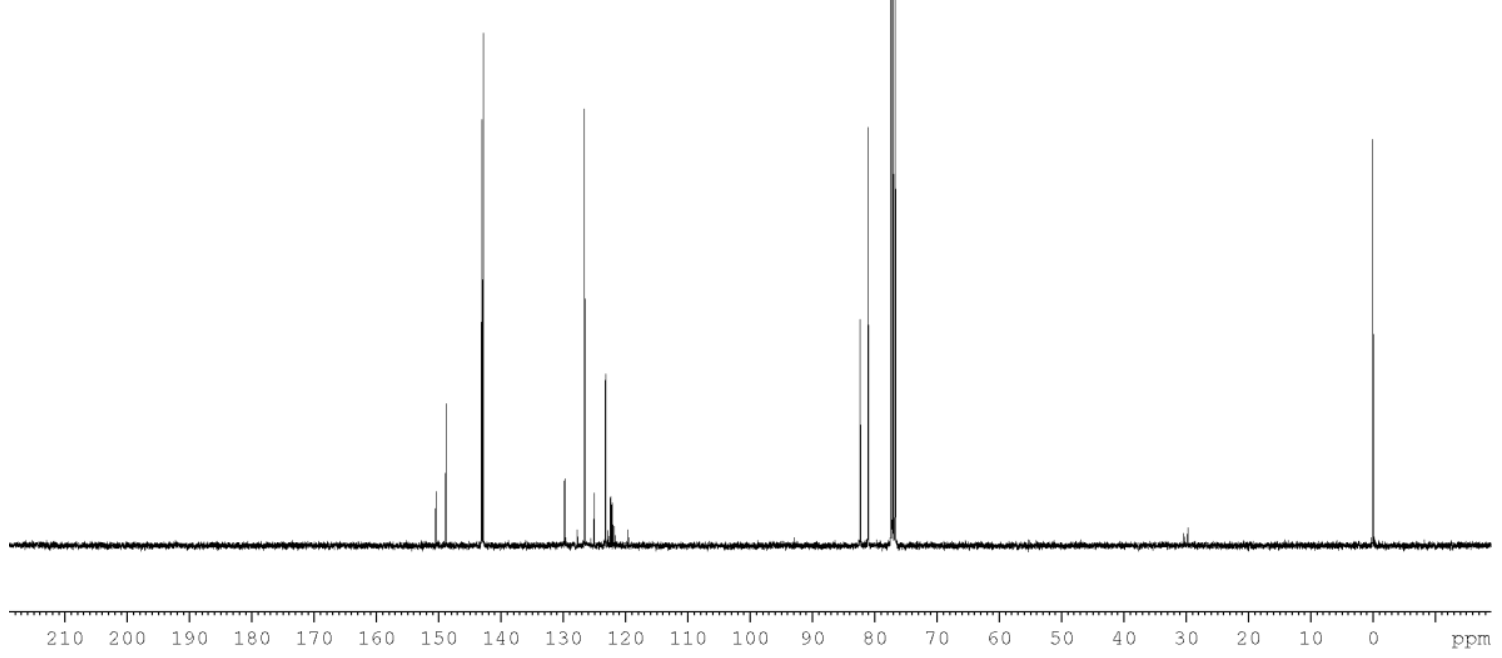

Figure 197. ${ }^{13} \mathrm{C}\left\{{ }^{1} \mathrm{H}\right\} \mathrm{NMR}$ of $\mathbf{1 2 n g}$ in $\mathrm{CDCl}_{3}$ with $1 \% \mathrm{v} / \mathrm{v}$ TMS at $101 \mathrm{MHz}$. 


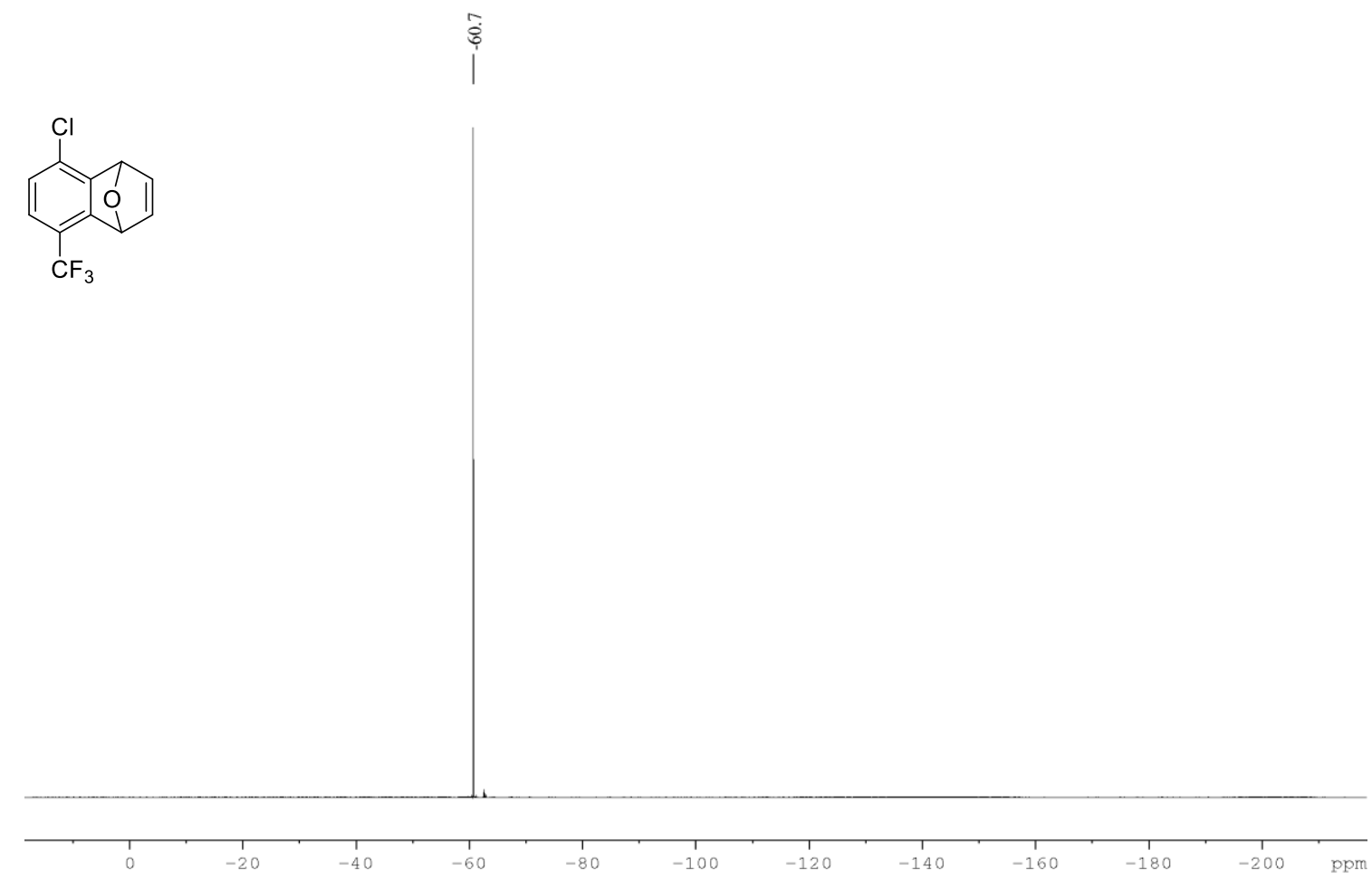

Figure 198. ${ }^{19} \mathrm{~F}\left\{{ }^{1} \mathrm{H}\right\}$ NMR of $\mathbf{1 2 n g}$ in $\mathrm{CDCl}_{3}$ with $1 \% \mathrm{v} / \mathrm{v}$ TMS at $376 \mathrm{MHz}$.
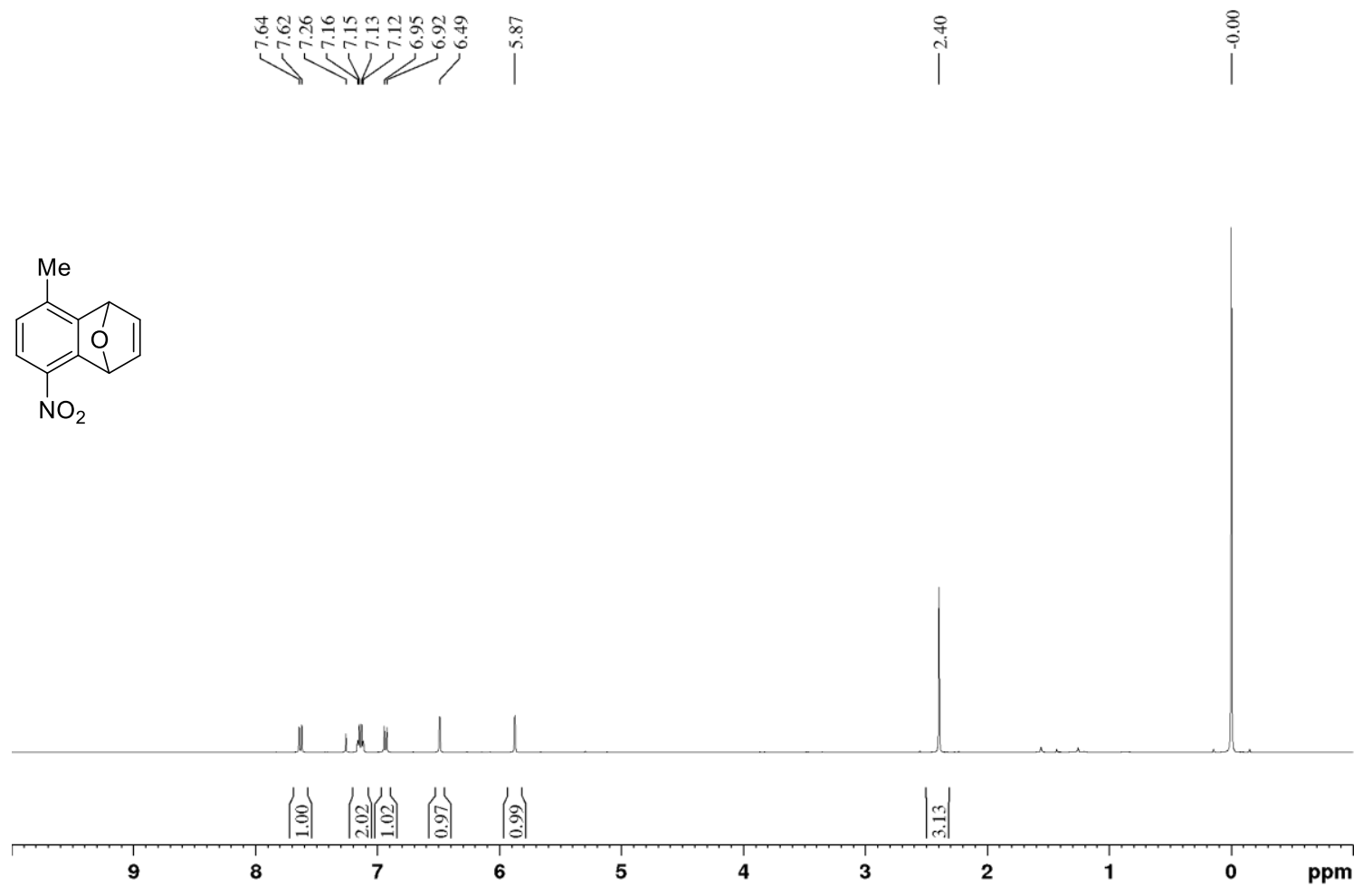

Figure 199. ${ }^{1} \mathrm{H}$ NMR of 120 in $\mathrm{CDCl}_{3}$ with $1 \% \mathrm{v} / \mathrm{v}$ TMS at $400 \mathrm{MHz}$. 
<smiles>Cc1ccc([N+](=O)[O-])c2c1C1C=CC2O1</smiles>

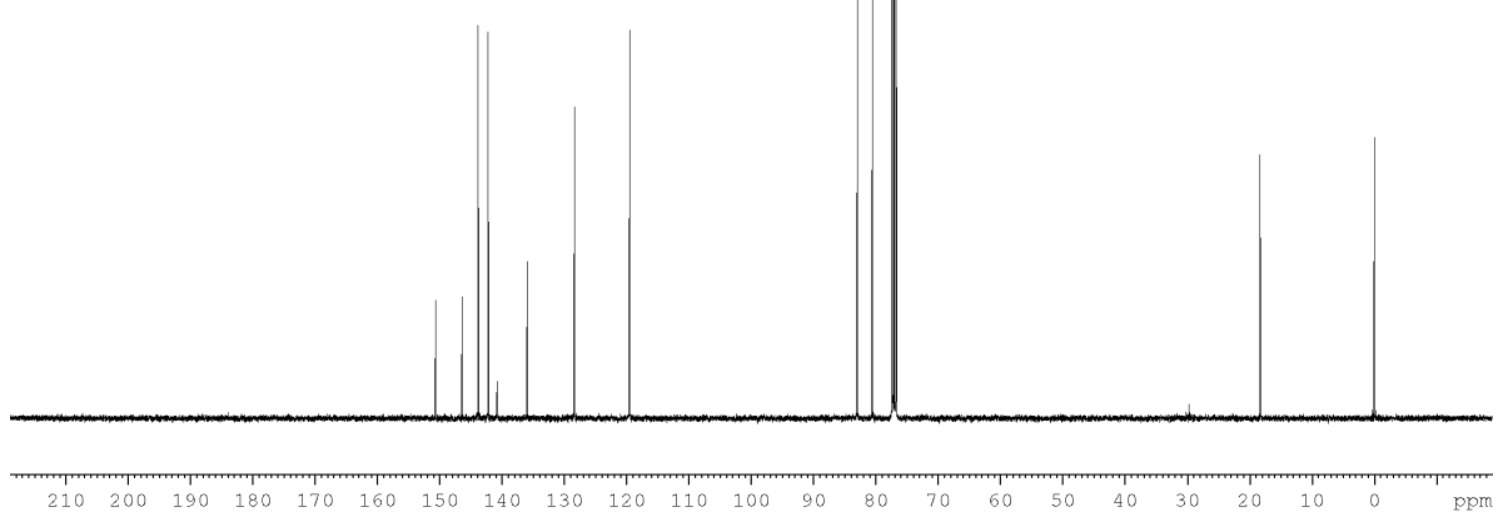

Figure 200. ${ }^{13} \mathrm{C}\left\{{ }^{1} \mathrm{H}\right\}$ NMR of 120 in $\mathrm{CDCl}_{3}$ with $1 \% \mathrm{v} / \mathrm{v}$ TMS at $101 \mathrm{MHz}$.
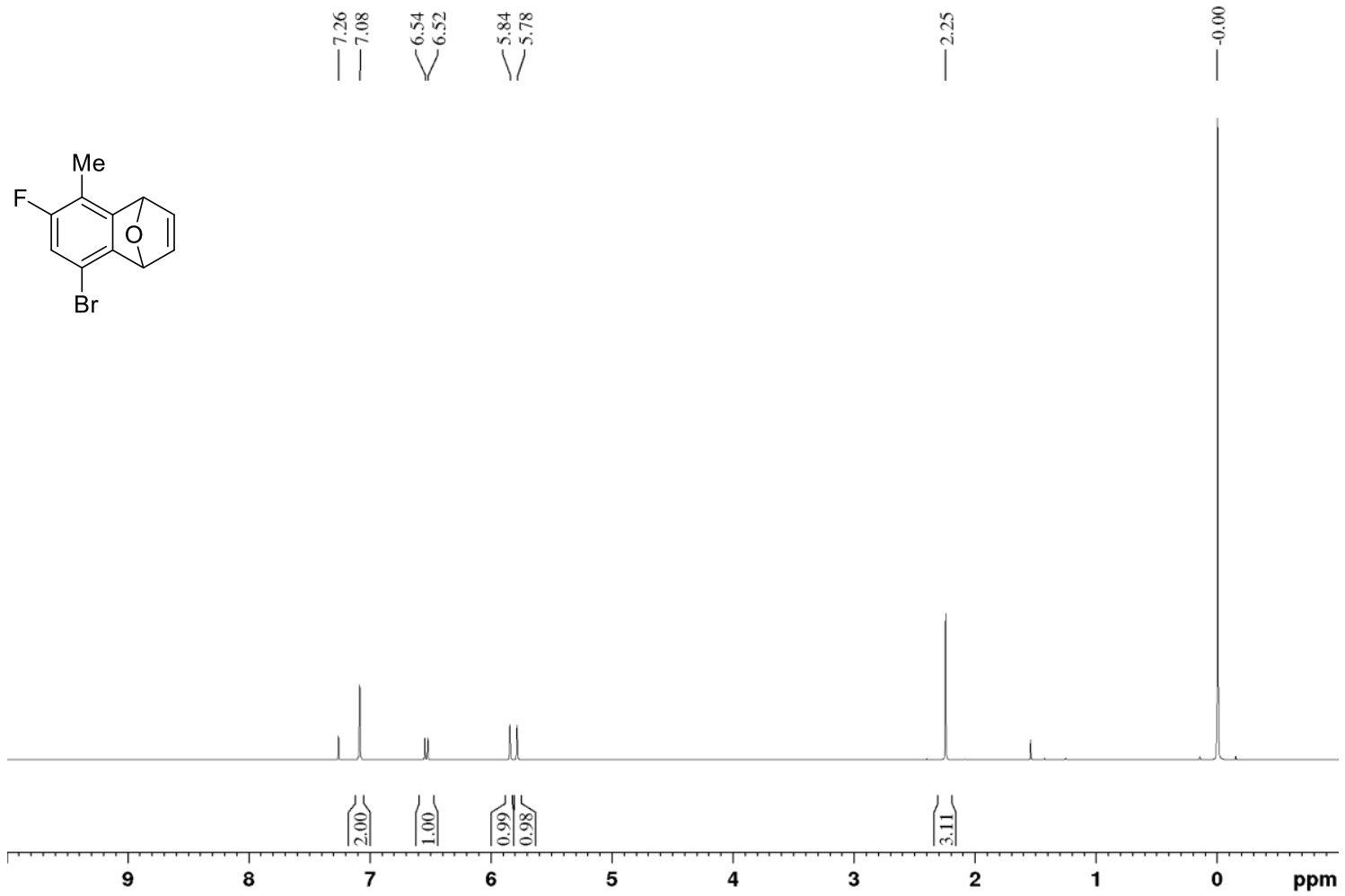

Figure 201. ${ }^{1} \mathrm{H}$ NMR of $12 \mathrm{pg}$ in $\mathrm{CDCl}_{3}$ with $1 \% \mathrm{v} / \mathrm{v}$ TMS at $400 \mathrm{MHz}$. 

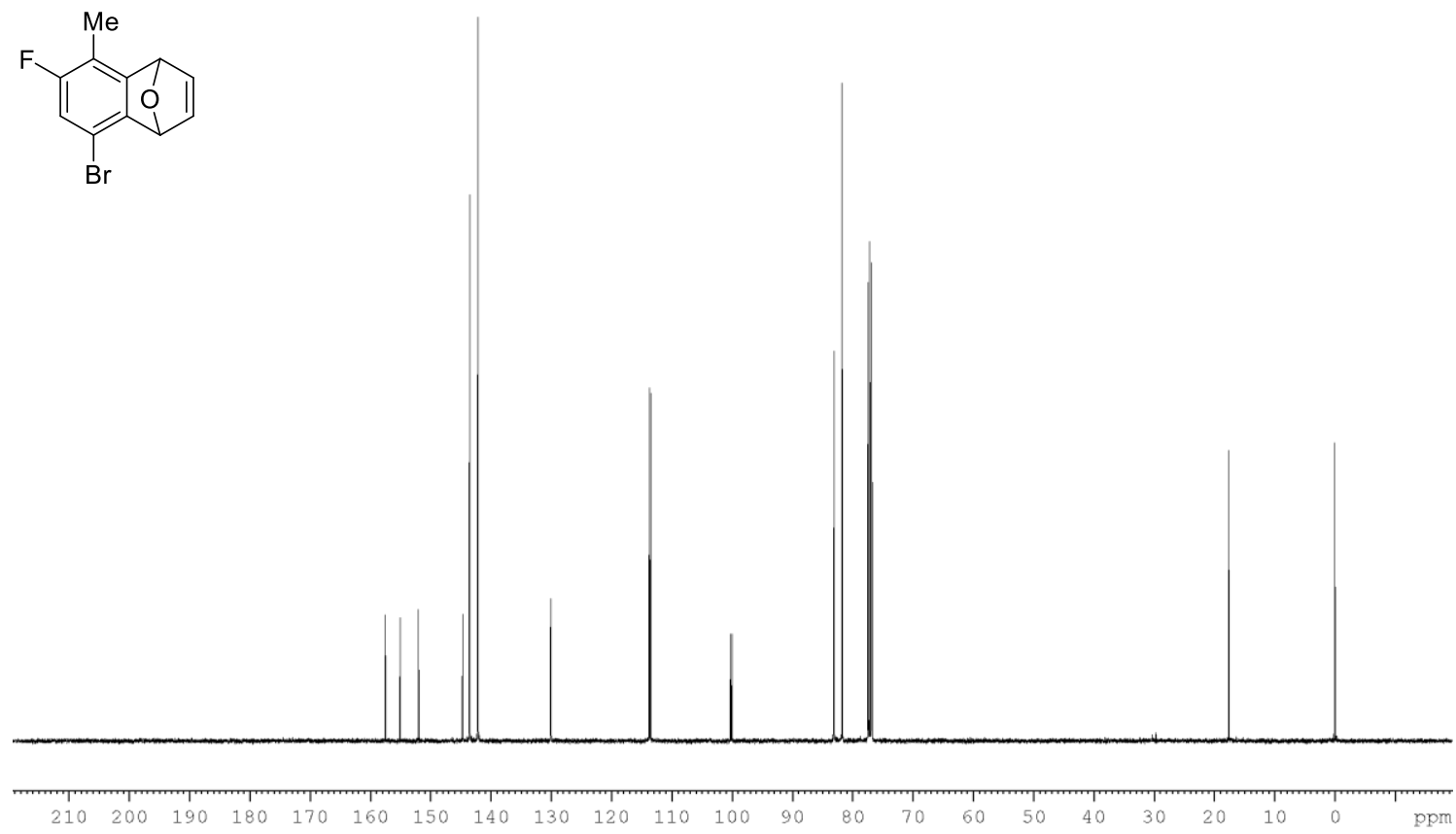

Figure 202. ${ }^{13} \mathrm{C}\left\{{ }^{1} \mathrm{H}\right\}$ NMR of $12 \mathrm{pg}$ in $\mathrm{CDCl}_{3}$ with $1 \% \mathrm{v} / \mathrm{v}$ TMS at $101 \mathrm{MHz}$.<smiles>Cc1c(F)cc(Br)c2c1C1C=CC2O1</smiles>

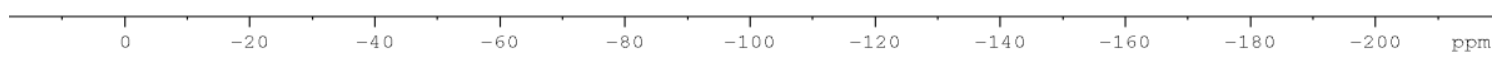

Figure 203. ${ }^{19} \mathrm{~F}\left\{{ }^{1} \mathrm{H}\right\} \mathrm{NMR}$ of $12 \mathrm{pg}$ in $\mathrm{CDCl}_{3}$ with $1 \% \mathrm{v} / \mathrm{v}$ TMS at $376 \mathrm{MHz}$. 


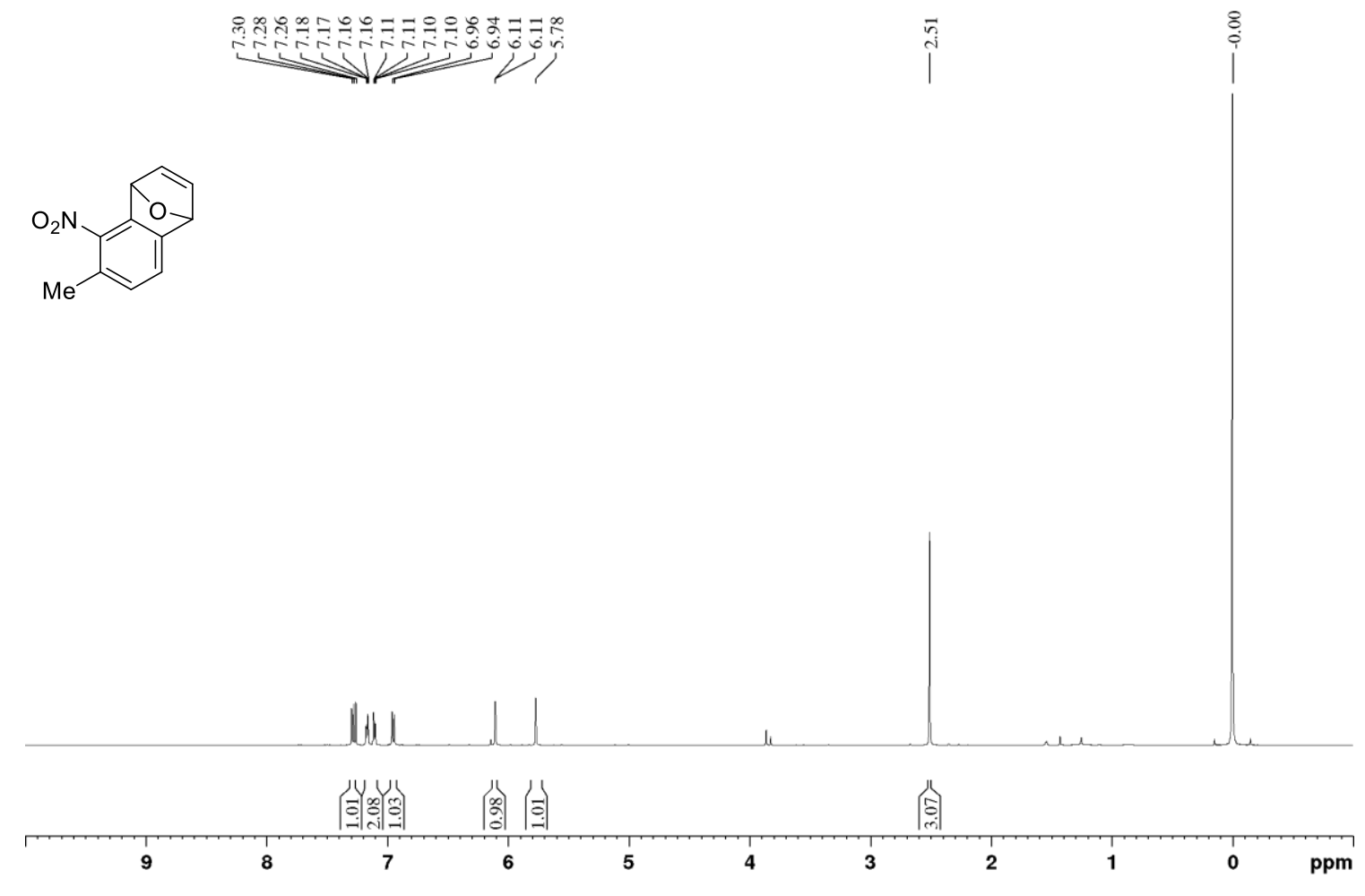

Figure 204. ${ }^{1} \mathrm{H}$ NMR of $12 q g$ in $\mathrm{CDCl}_{3}$ with $1 \% \mathrm{v} / \mathrm{v}$ TMS at $400 \mathrm{MHz}$.
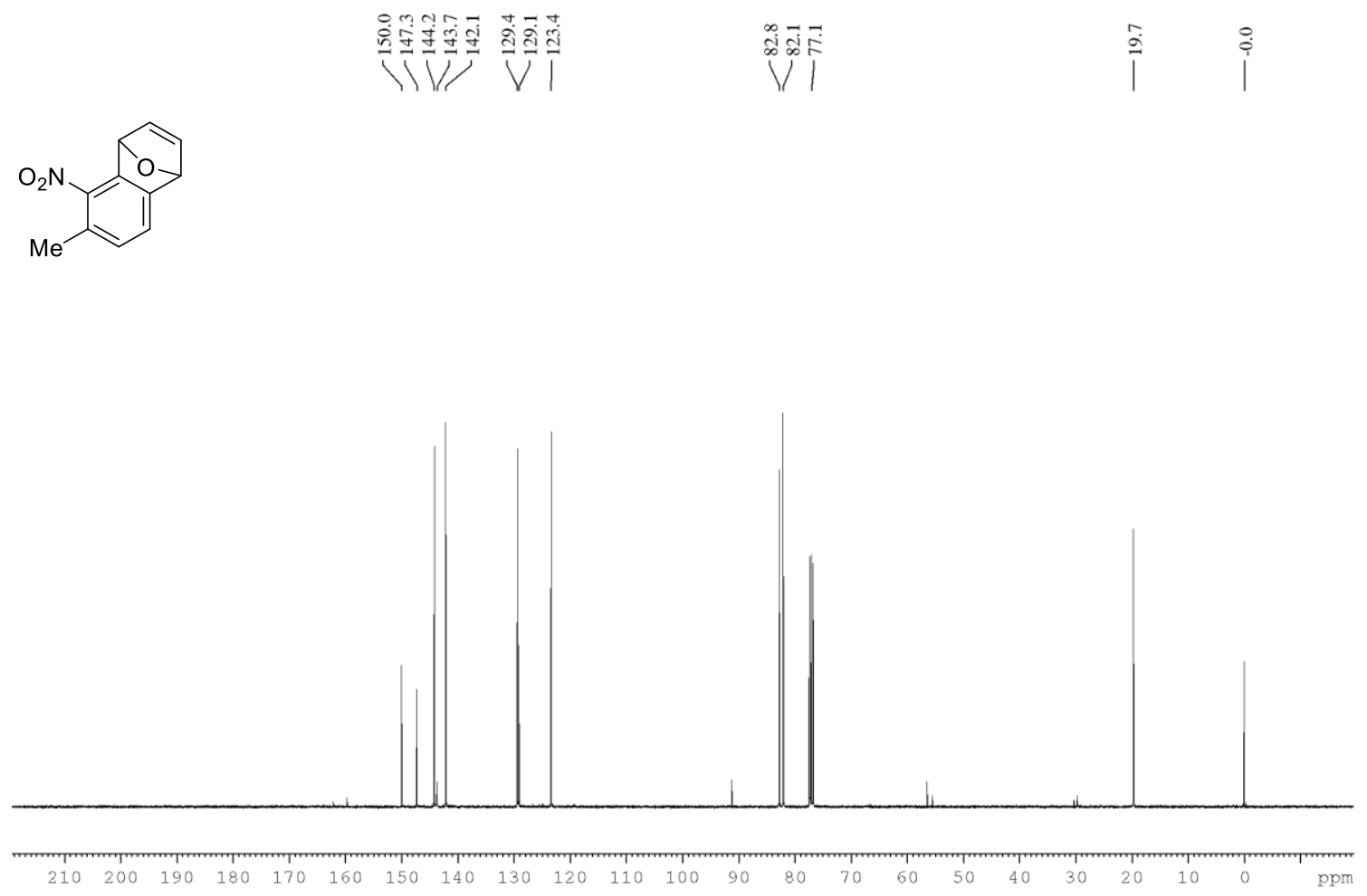

Figure 205. ${ }^{13} \mathrm{C}\left\{{ }^{1} \mathrm{H}\right\} \mathrm{NMR}$ of $\mathbf{1 2 q g}$ in $\mathrm{CDCl}_{3}$ with $1 \% \mathrm{v} / \mathrm{v}$ TMS at $101 \mathrm{MHz}$. 

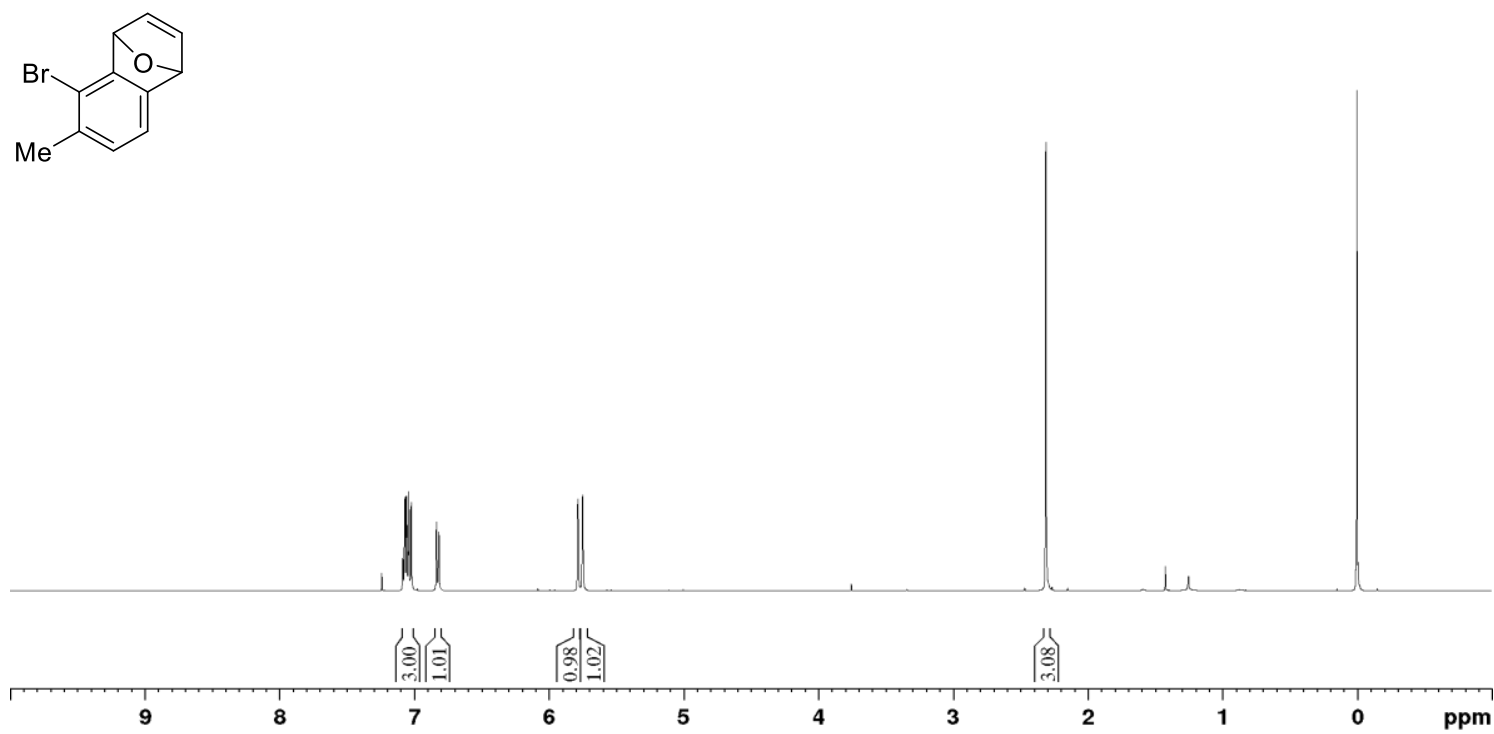

Figure 206. ${ }^{1} \mathrm{H} \mathrm{NMR}$ of $12 \mathrm{rg}$ in $\mathrm{CDCl}_{3}$ with $1 \% \mathrm{v} / \mathrm{v}$ TMS at $400 \mathrm{MHz}$.

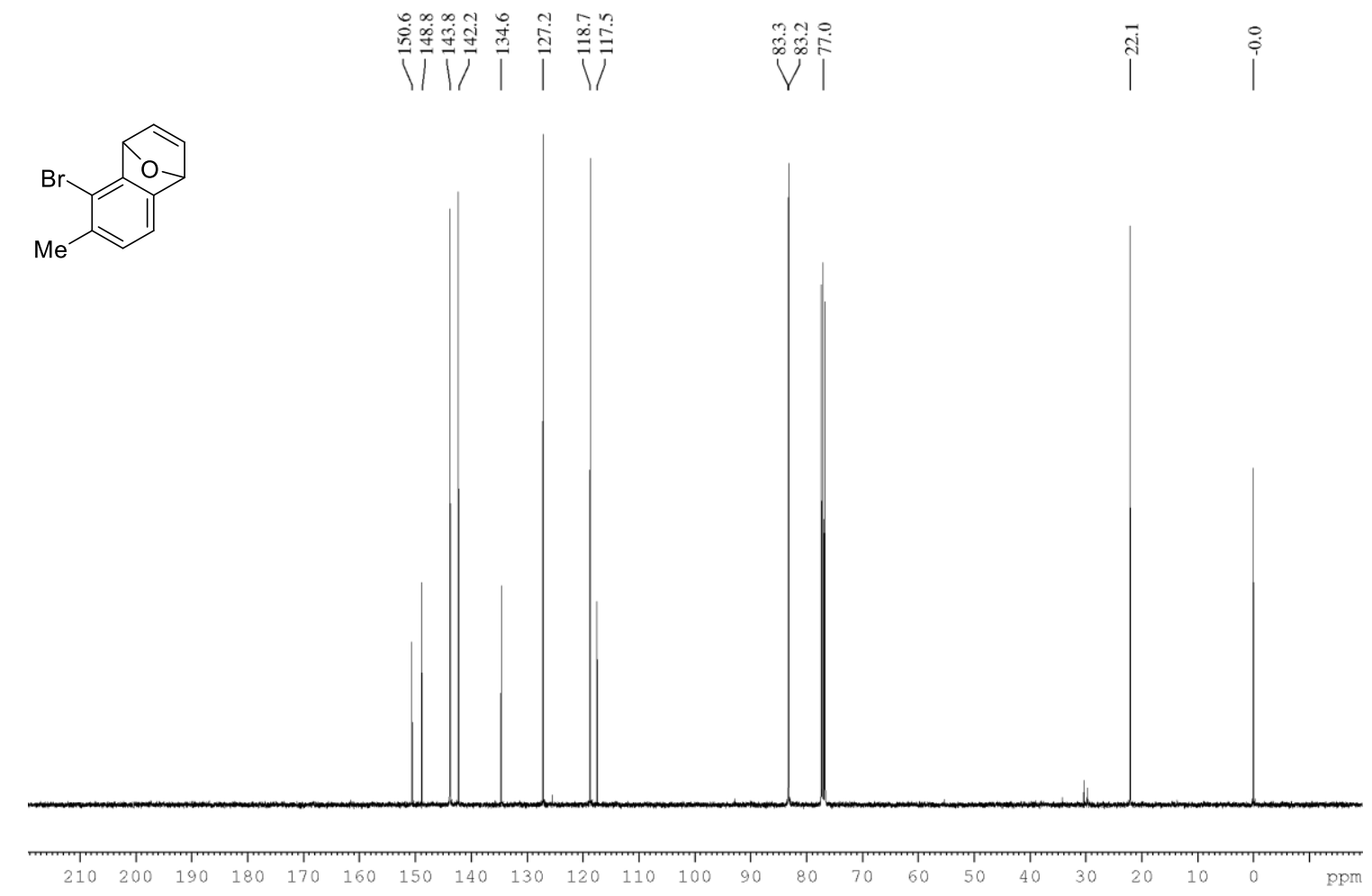

Figure 207. ${ }^{13} \mathrm{C}\left\{{ }^{1} \mathrm{H}\right\}$ NMR of $12 \mathrm{rg}$ in $\mathrm{CDCl}_{3}$ with $1 \% \mathrm{v} / \mathrm{v}$ TMS at $101 \mathrm{MHz}$. 


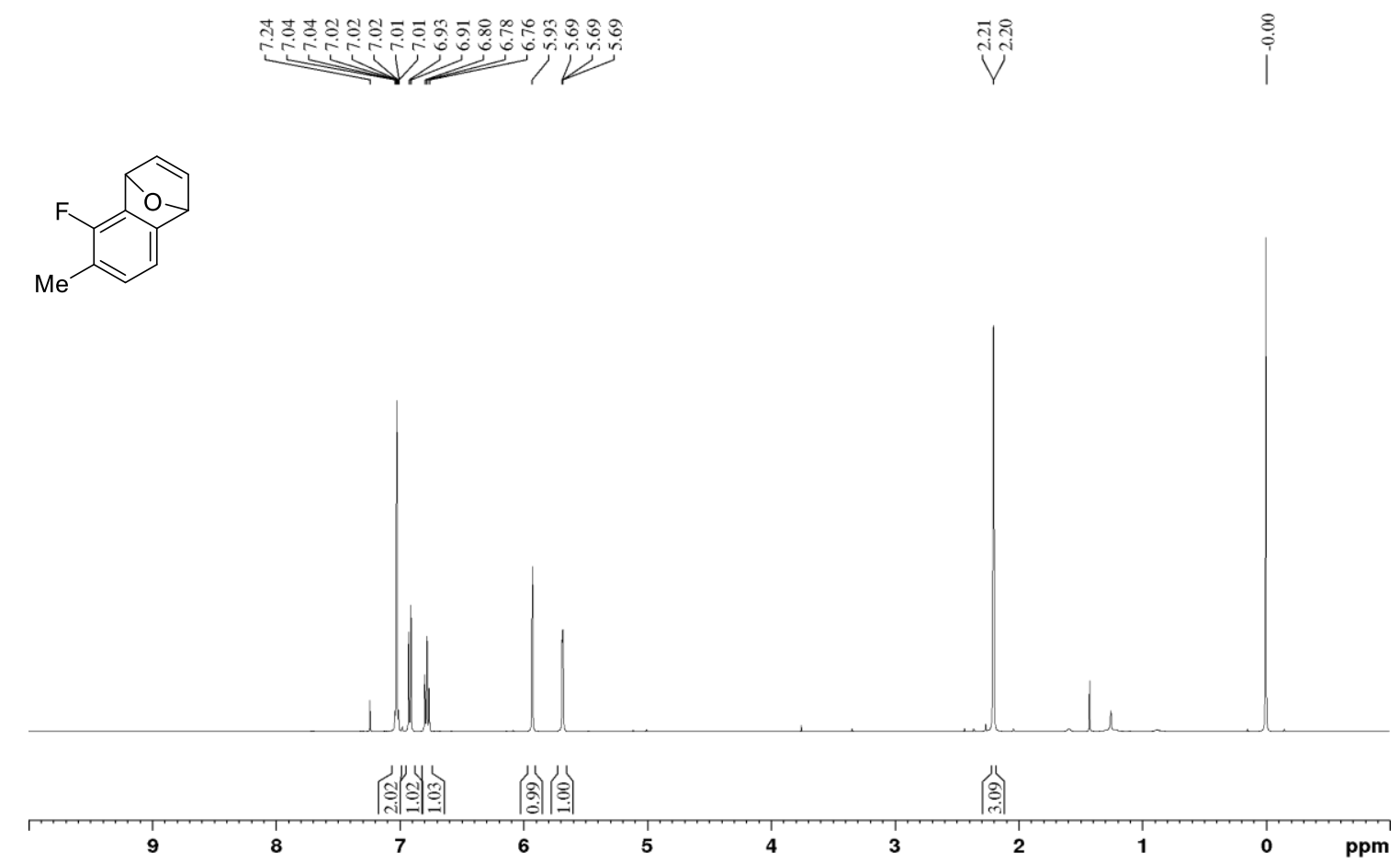

Figure 208. ${ }^{1} \mathrm{H}$ NMR of $12 \mathrm{sg}$ in $\mathrm{CDCl}_{3}$ with $1 \% \mathrm{v} / \mathrm{v}$ TMS at $400 \mathrm{MHz}$.
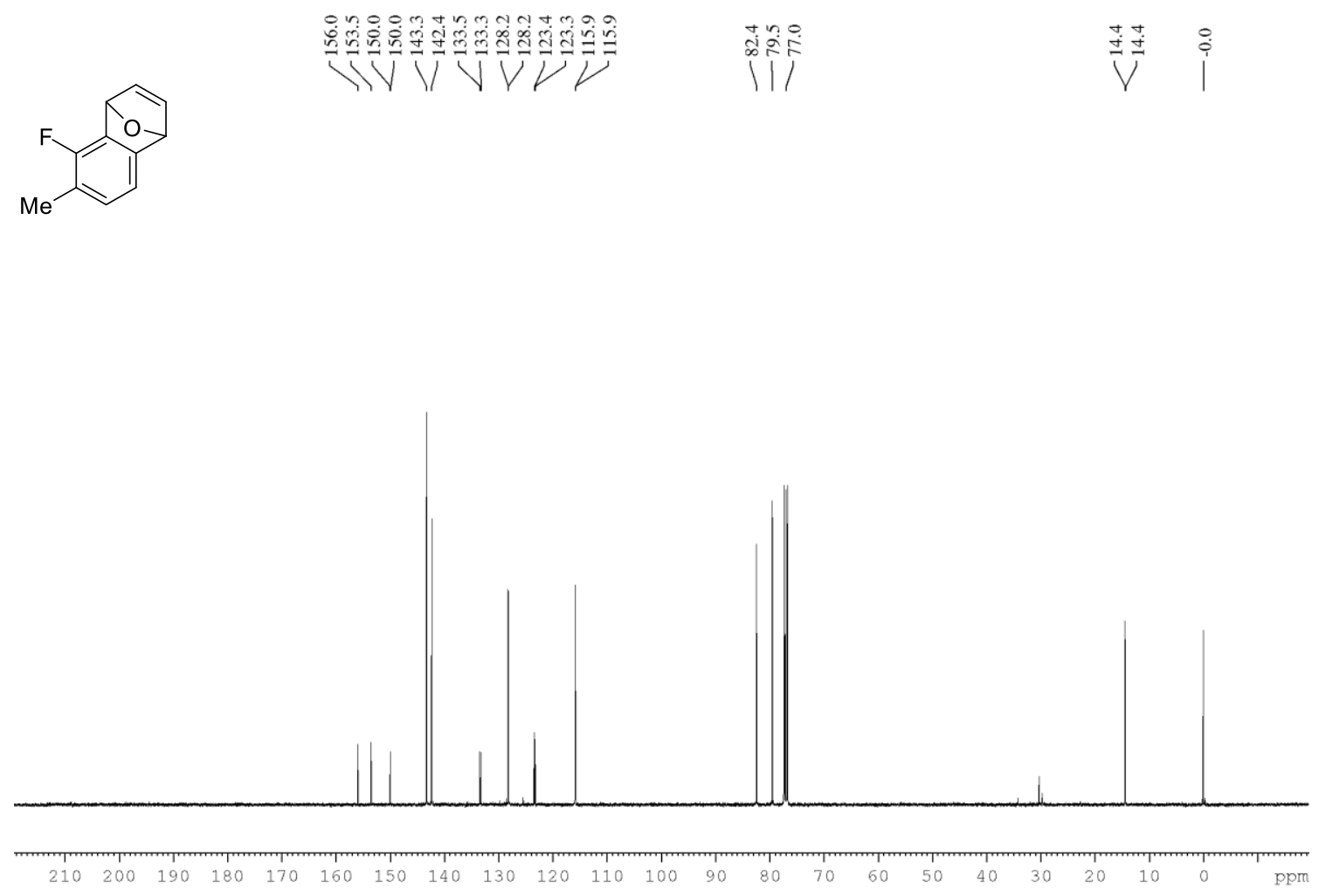

Figure 209. ${ }^{13} \mathrm{C}\left\{{ }^{1} \mathrm{H}\right\} \mathrm{NMR}$ of $12 \mathrm{sg}$ in $\mathrm{CDCl}_{3}$ with $1 \% \mathrm{v} / \mathrm{v}$ TMS at $101 \mathrm{MHz}$. 


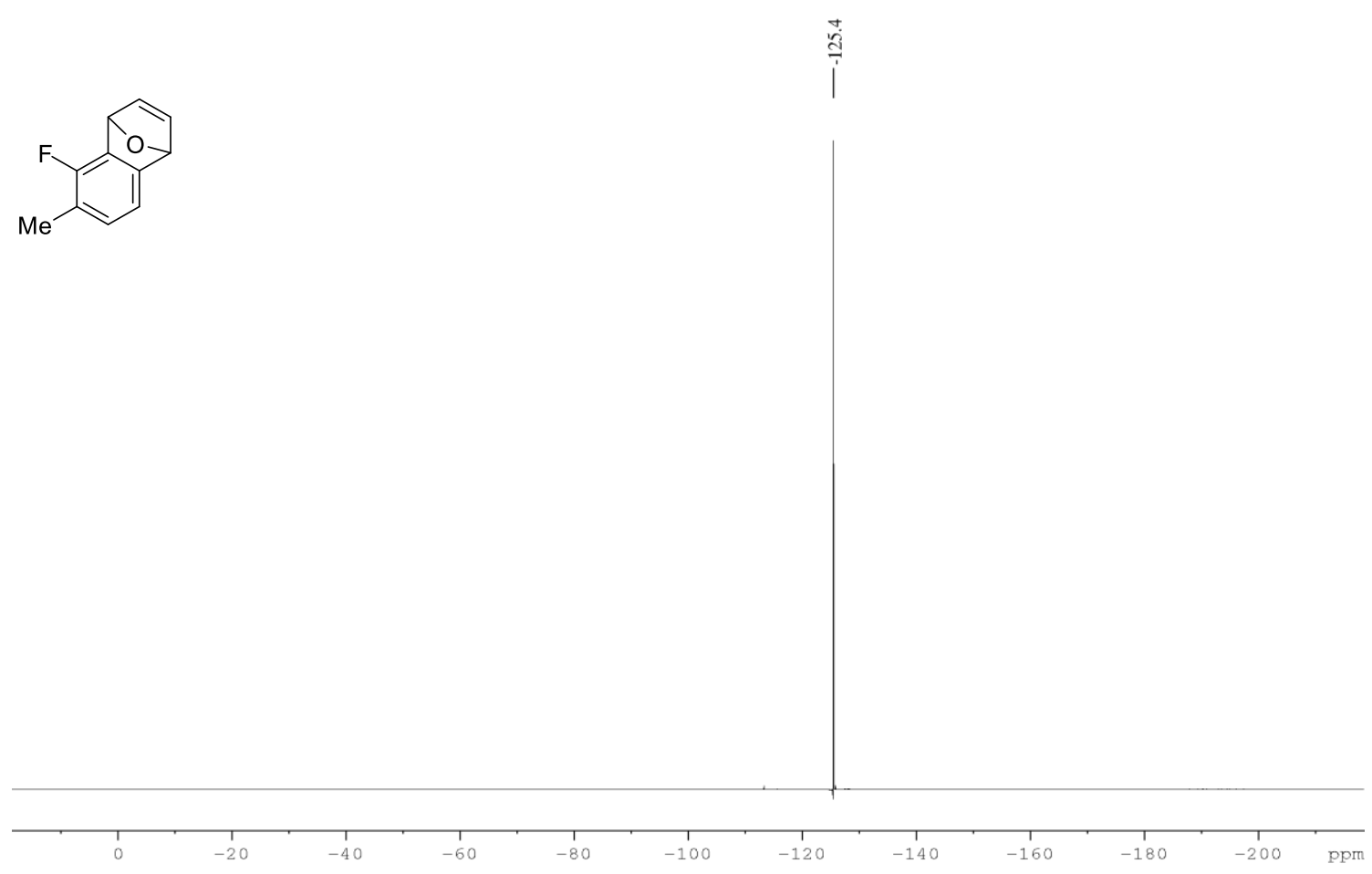

Figure 210. ${ }^{19} \mathrm{~F}\left\{{ }^{1} \mathrm{H}\right\} \mathrm{NMR}$ of $\mathbf{1 2 s g}$ in $\mathrm{CDCl}_{3}$ with $1 \% \mathrm{v} / \mathrm{v}$ TMS at $376 \mathrm{MHz}$.
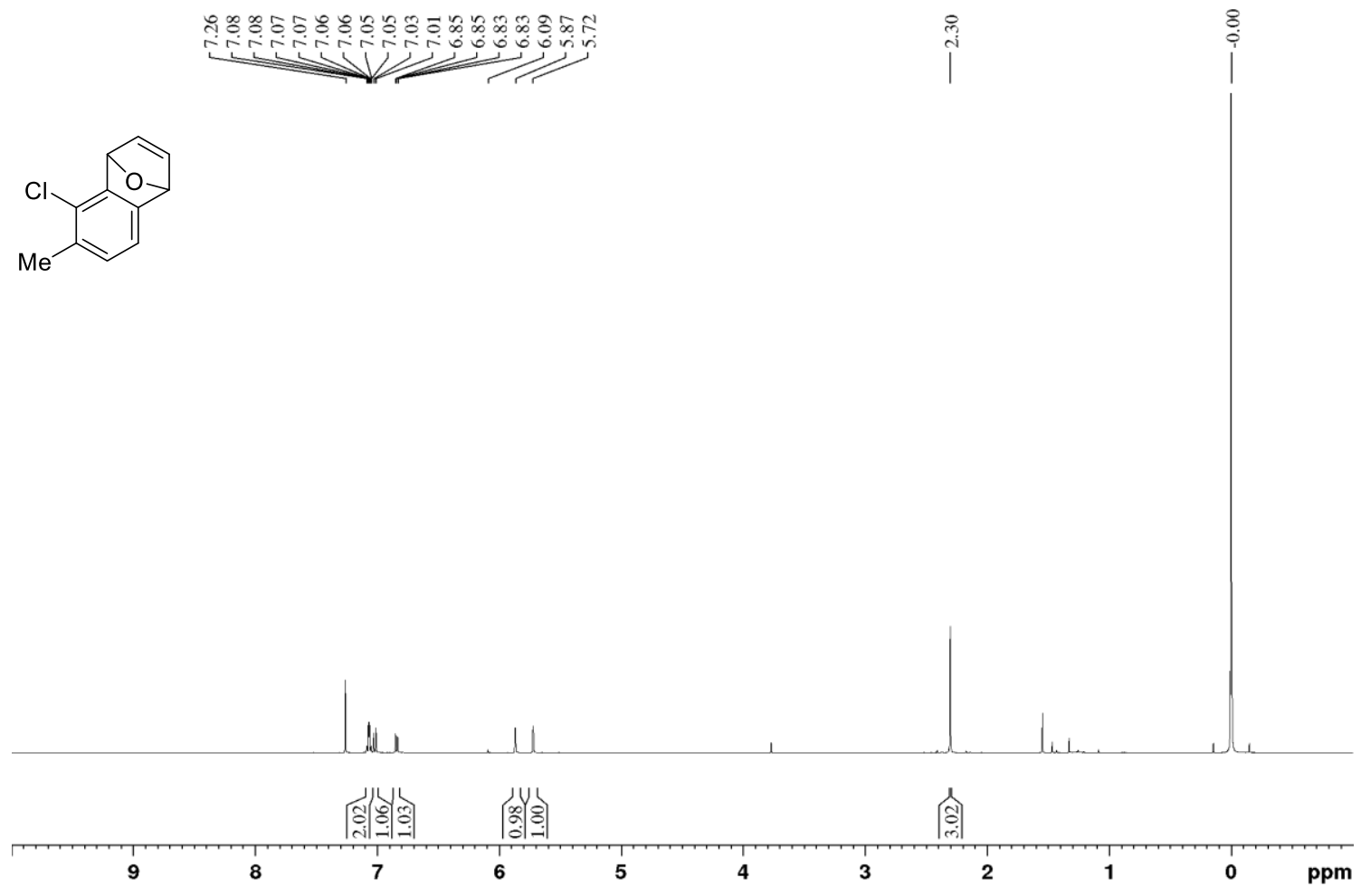

Figure 211. ${ }^{1} \mathrm{H}$ NMR of $12 \operatorname{tg}$ in $\mathrm{CDCl}_{3}$ with $1 \% \mathrm{v} / \mathrm{v}$ TMS at $400 \mathrm{MHz}$. 
<smiles>COc1ccc2c(c1Cl)C1C=CC2O1</smiles>

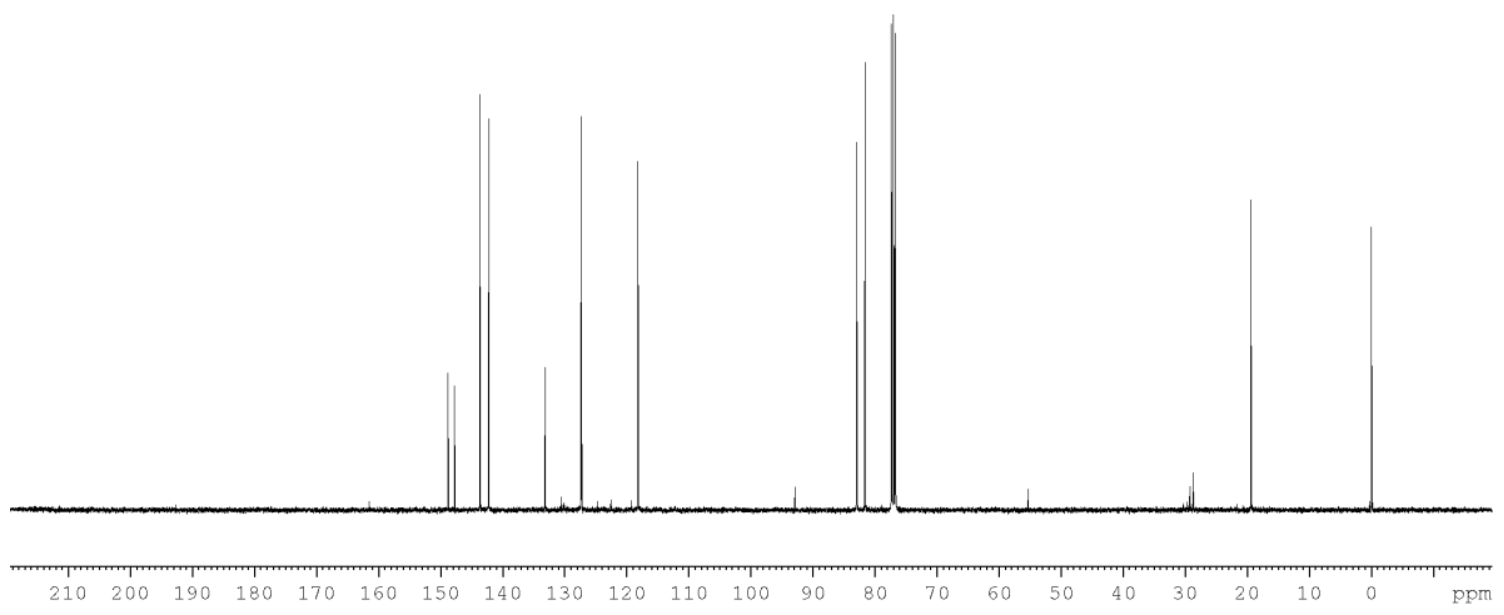

Figure 212. ${ }^{13} \mathrm{C}\left\{{ }^{1} \mathrm{H}\right\}$ NMR of $12 \operatorname{tg}$ in $\mathrm{CDCl}_{3}$ with $1 \% \mathrm{v} / \mathrm{v}$ TMS at $101 \mathrm{MHz}$.
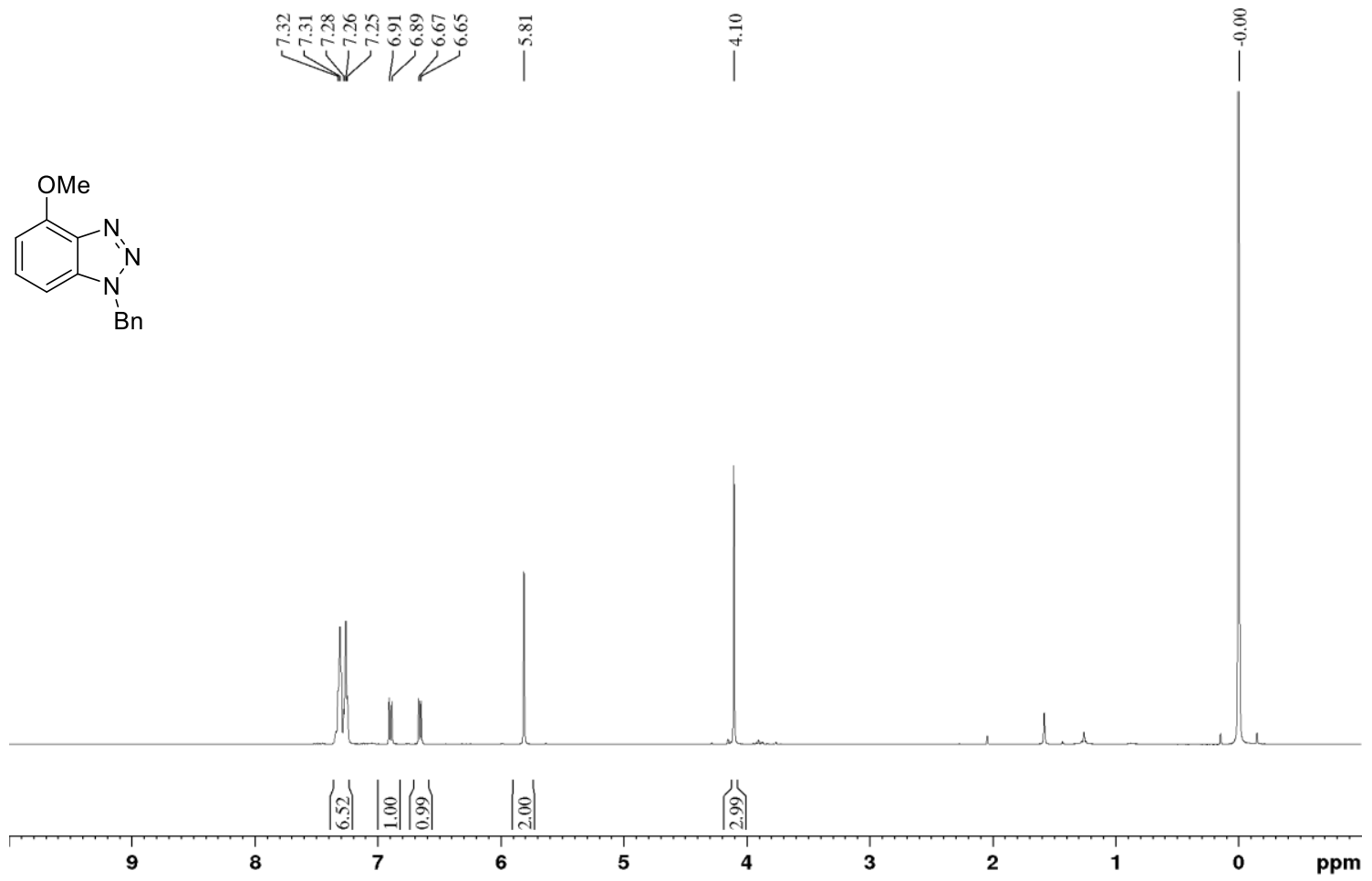

Figure 213. ${ }^{1} \mathrm{H}$ NMR of 12 de in $\mathrm{CDCl}_{3}$ with $1 \% \mathrm{v} / \mathrm{v}$ TMS at $400 \mathrm{MHz}$. 


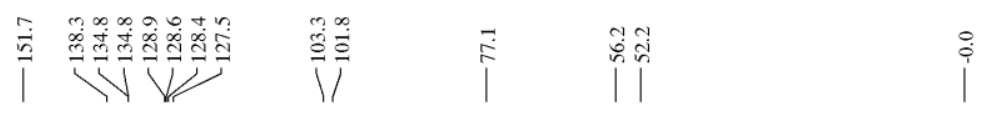<smiles>COc1cccc2c1nnn2Cc1ccccc1</smiles>

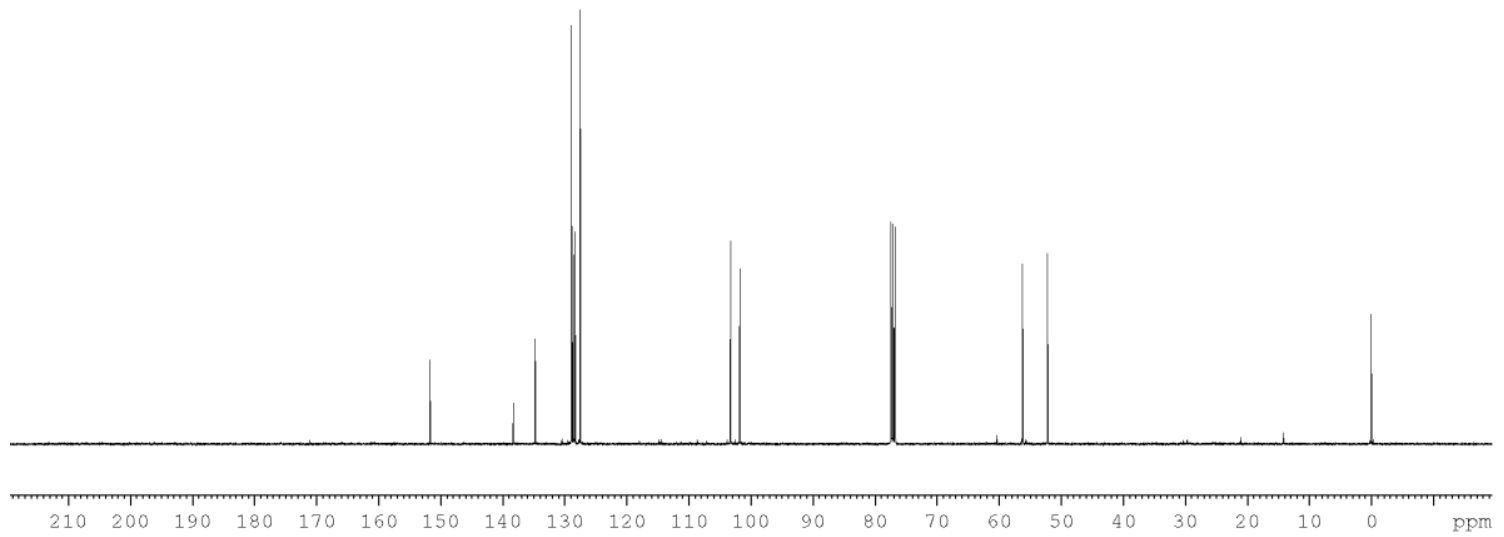

Figure 214. ${ }^{13} \mathrm{C}\left\{{ }^{1} \mathrm{H}\right\}$ NMR of $\mathbf{1 2 d e}$ in $\mathrm{CDCl}_{3}$ with $1 \% \mathrm{v} / \mathrm{v}$ TMS at $101 \mathrm{MHz}$.
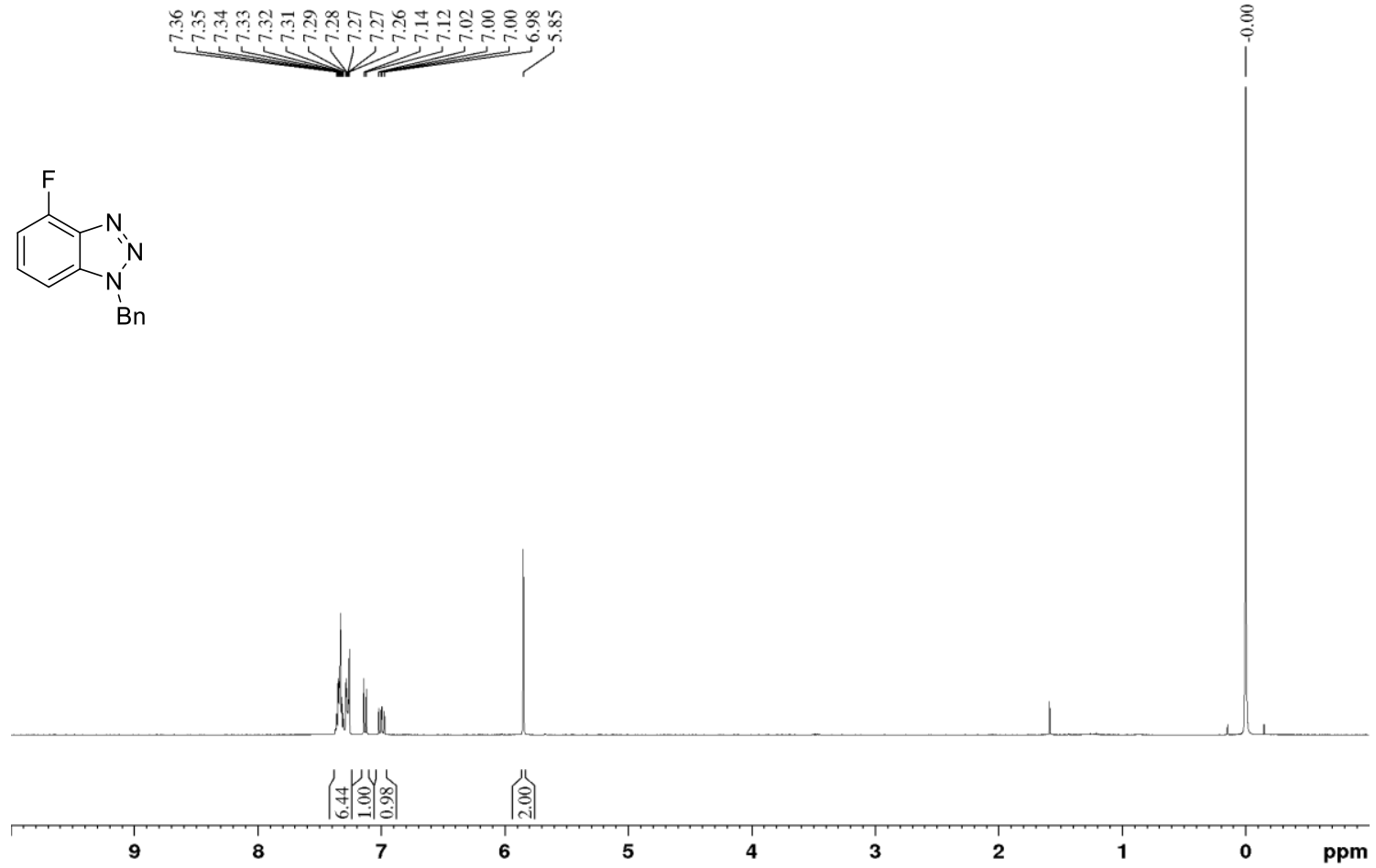

Figure 215. ${ }^{1} \mathrm{H} \mathrm{NMR}$ of $12 \mathrm{he}$ in $\mathrm{CDCl}_{3}$ with $1 \% \mathrm{v} / \mathrm{v} \mathrm{TMS}$ at $400 \mathrm{MHz}$. 


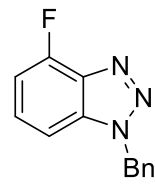

$\mathrm{Bn}$

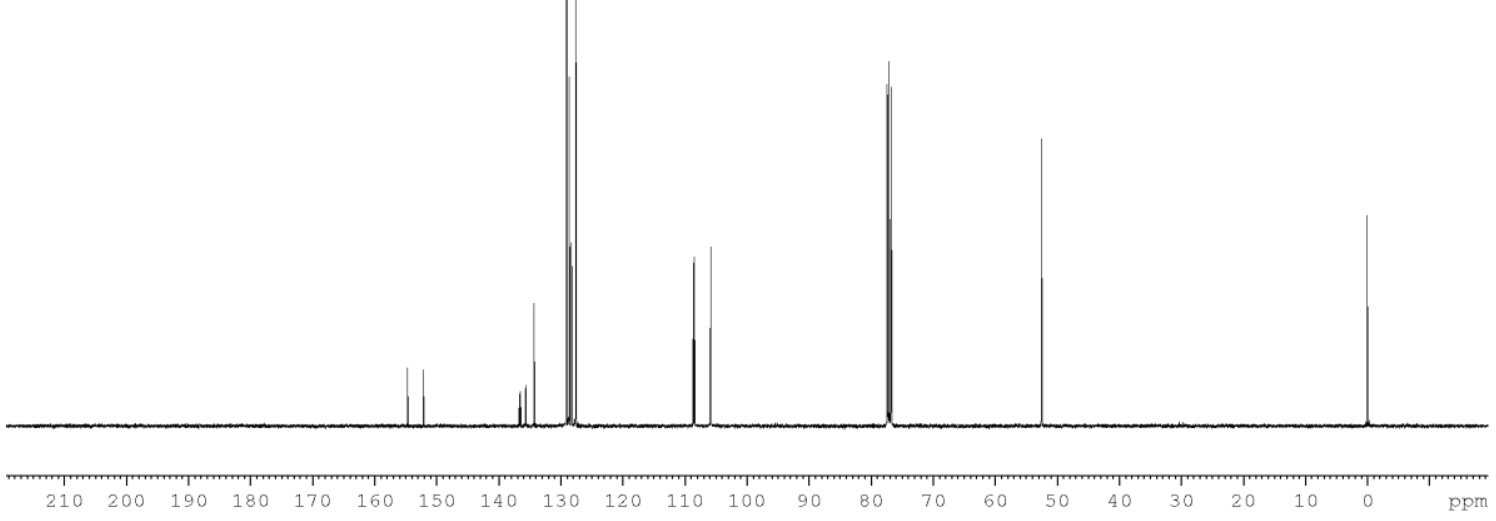

Figure 216. ${ }^{13} \mathrm{C}\left\{{ }^{1} \mathrm{H}\right\}$ NMR of $12 \mathrm{he}$ in $\mathrm{CDCl}_{3}$ with $1 \%$ v/v TMS at $101 \mathrm{MHz}$.

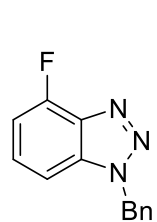

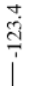
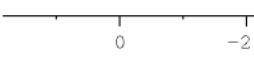

$20-40$

40

$-60$

$-100$

$-120$

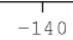

$-160$

ppm

Figure 217. ${ }^{19} \mathrm{~F}\left\{{ }^{1} \mathrm{H}\right\}$ NMR of 12 he in $\mathrm{CDCl}_{3}$ with $1 \% \mathrm{v} / \mathrm{v}$ TMS at $376 \mathrm{MHz}$. 


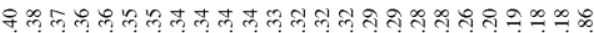

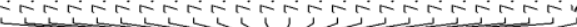

$\mathrm{OCF}_{3}$

$\overbrace{B n}^{N}$

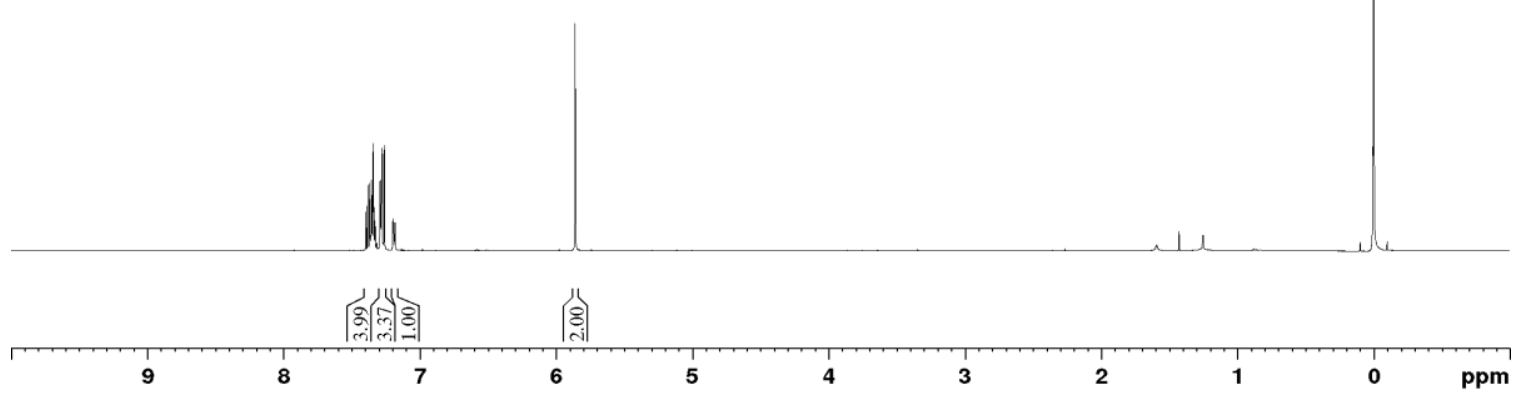

Figure 218. ${ }^{1} \mathrm{H}$ NMR of 12 le in $\mathrm{CDCl}_{3}$ with $1 \% \mathrm{v} / \mathrm{v}$ TMS at $400 \mathrm{MHz}$.

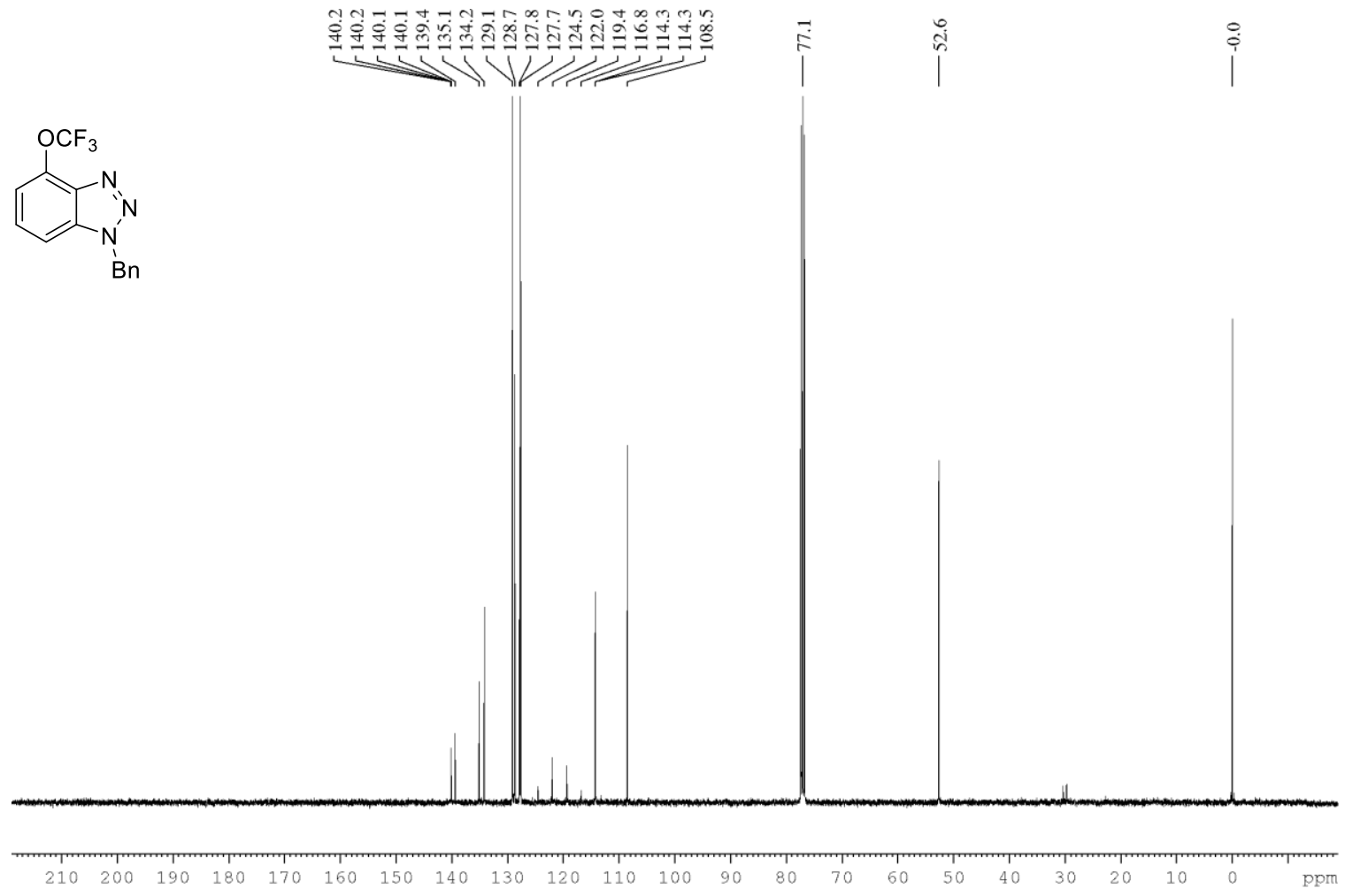

Figure 219. ${ }^{13} \mathrm{C}\left\{{ }^{1} \mathrm{H}\right\}$ NMR of 12 le in $\mathrm{CDCl}_{3}$ with $1 \% \mathrm{v} / \mathrm{v}$ TMS at $101 \mathrm{MHz}$. 


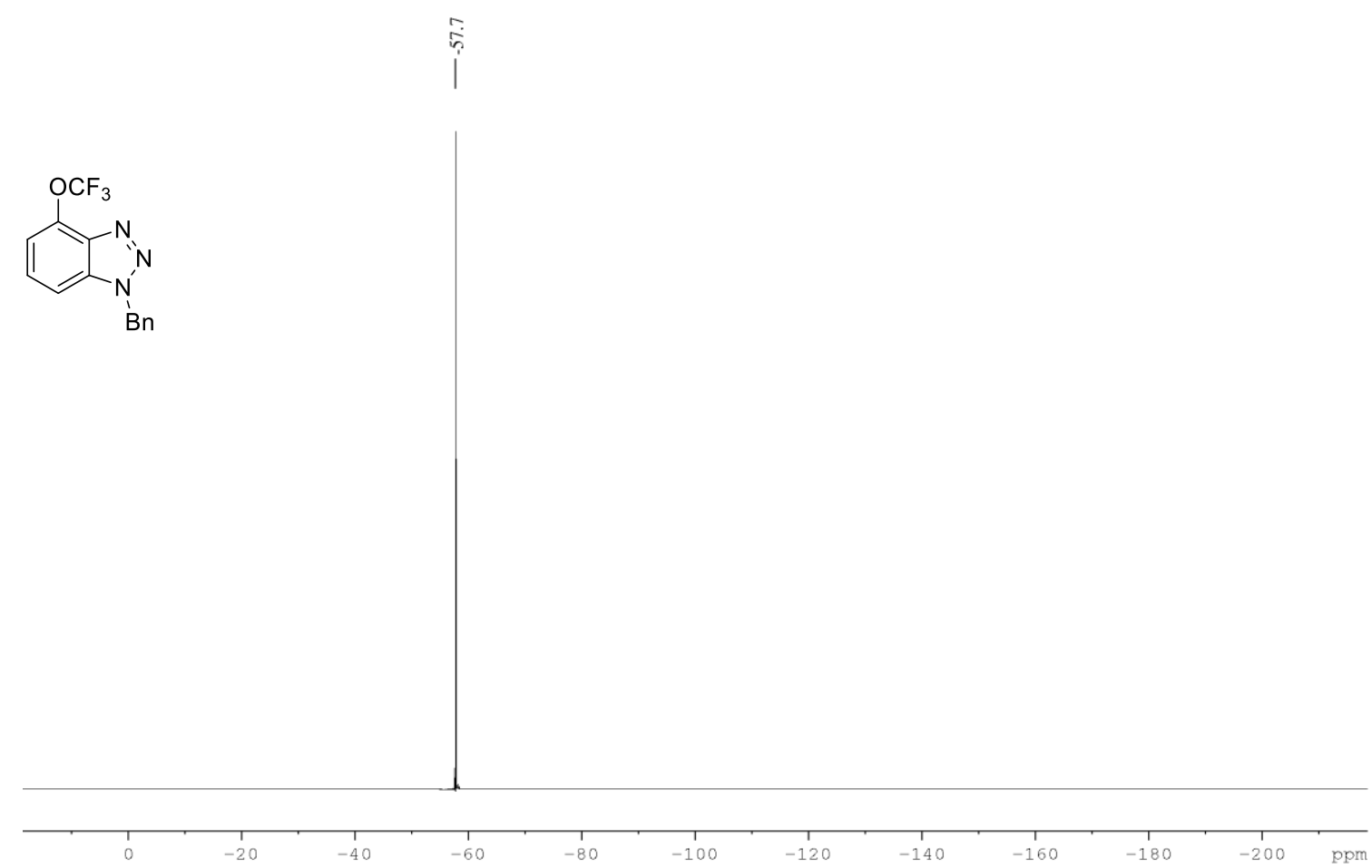

Figure $220 .{ }^{19} \mathrm{~F}\left\{{ }^{1} \mathrm{H}\right\} \mathrm{NMR}$ of $12 \mathrm{le}$ in $\mathrm{CDCl}_{3}$ with $1 \% \mathrm{v} / \mathrm{v}$ TMS at $376 \mathrm{MHz}$.

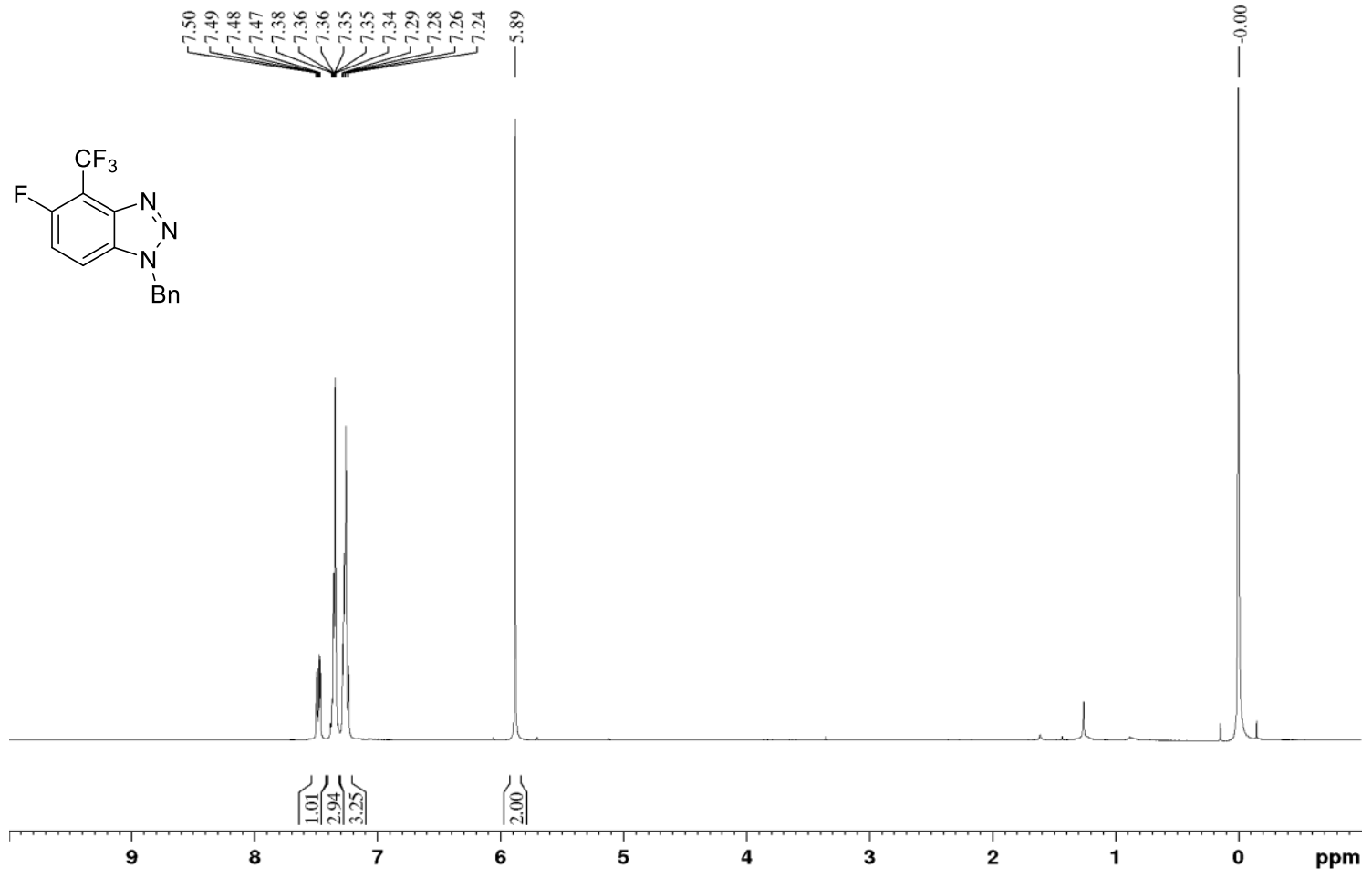

Figure 221. ${ }^{1} \mathrm{H}$ NMR of 12 ue in $\mathrm{CDCl}_{3}$ with $1 \% \mathrm{v} / \mathrm{v}$ TMS at $400 \mathrm{MHz}$. 


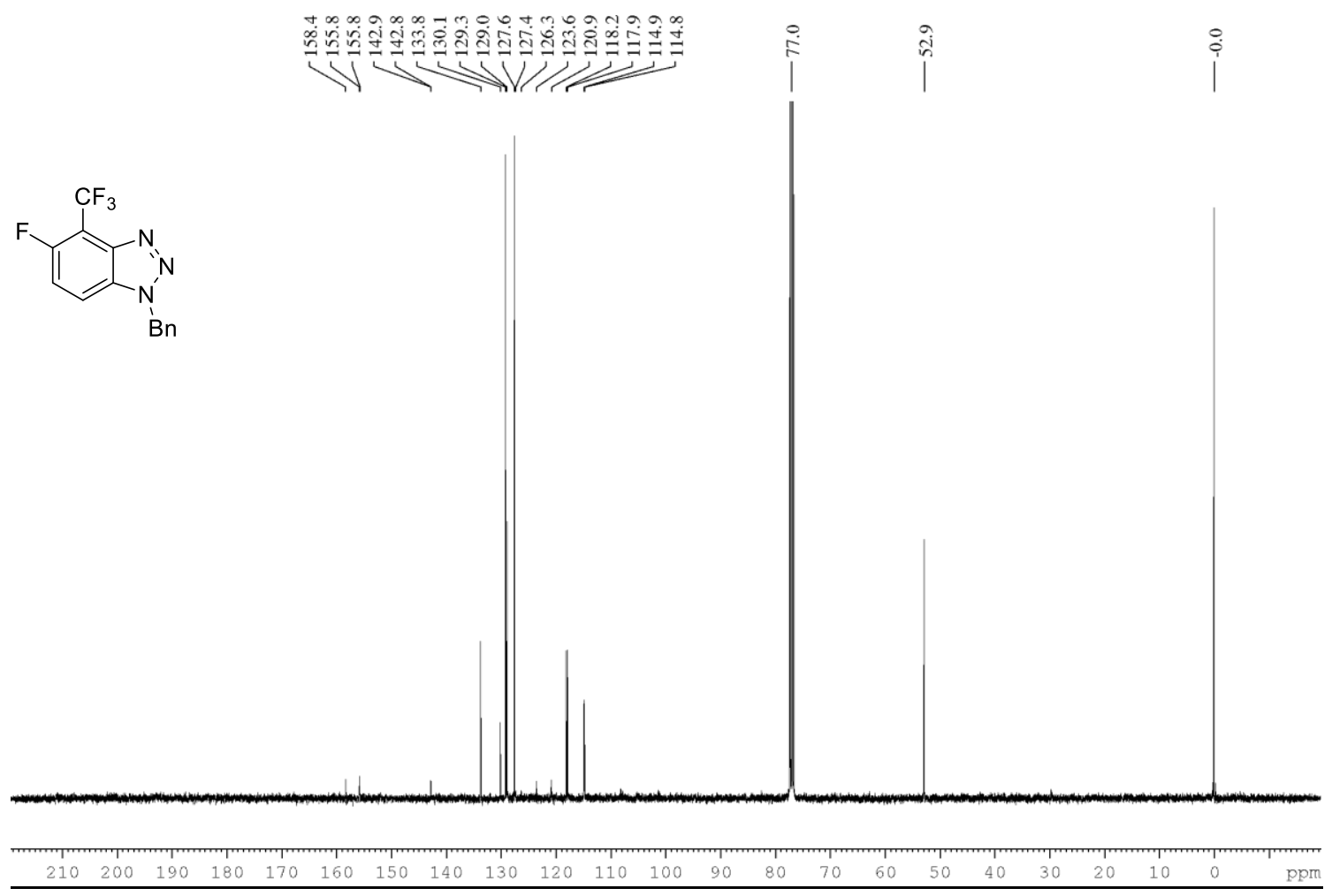

Figure 222. ${ }^{13} \mathrm{C}\left\{{ }^{1} \mathrm{H}\right\} \mathrm{NMR}$ of 12ue in $\mathrm{CDCl}_{3}$ with $1 \% \mathrm{v} / \mathrm{v}$ TMS at $101 \mathrm{MHz}$.

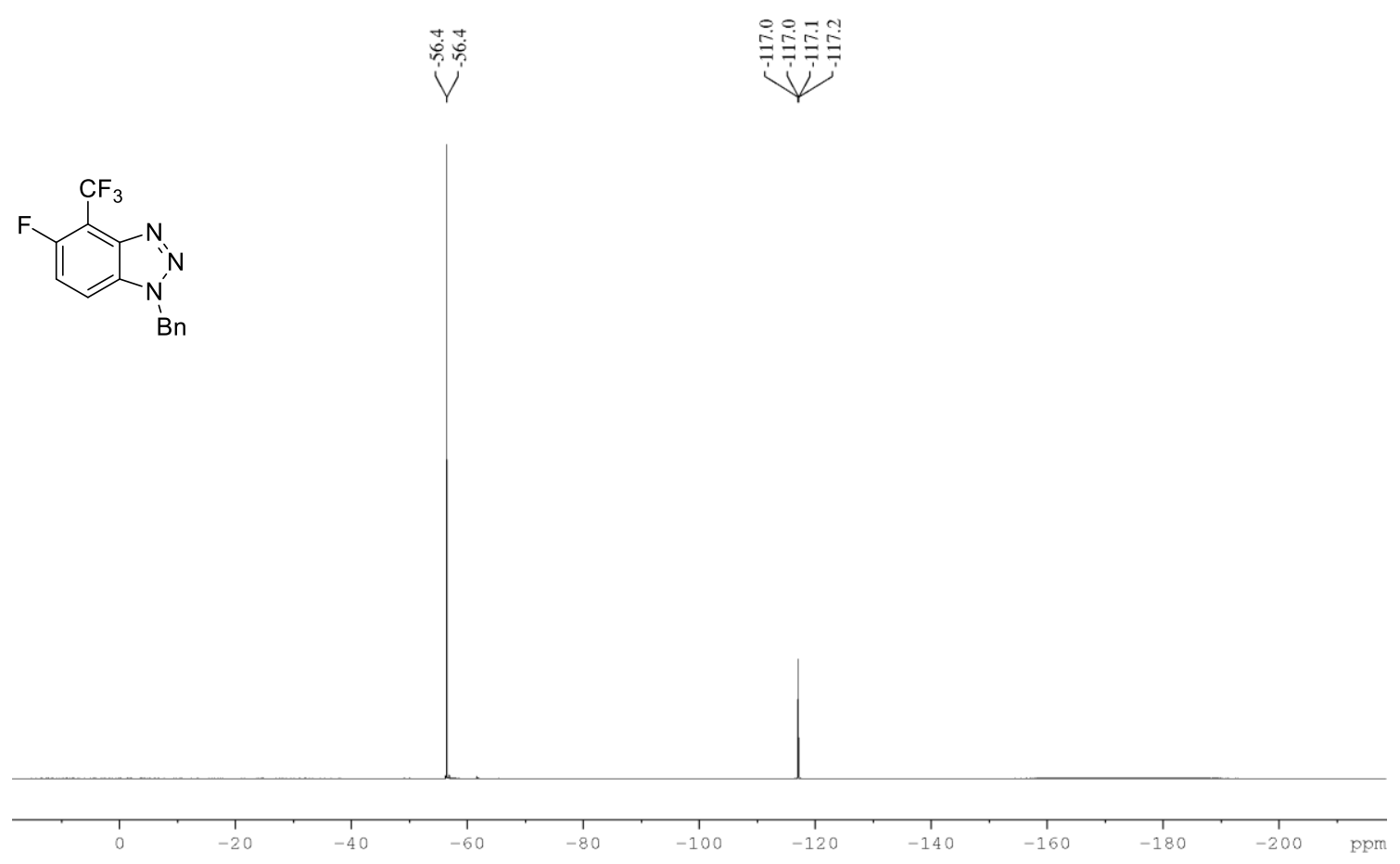

Figure 223. ${ }^{19} \mathrm{~F}\left\{{ }^{1} \mathrm{H}\right\}$ NMR of 12 ue in $\mathrm{CDCl}_{3}$ with $1 \% \mathrm{v} / \mathrm{v}$ TMS at $376 \mathrm{MHz}$. 
References

(1) Ritchie, T. J.; Macdonald, S. J. F. The Impact of Aromatic Ring Count on Compound Developability - Are Too Many Aromatic Rings a Liability in Drug Design? Drug Discov. Today 2009, 14 (21-22), 1011-1020.

https://doi.org/10.1016/j.drudis.2009.07.014.

(2) Roughley, S. D.; Jordan, A. M. The Medicinal Chemist's Toolbox: An Analysis of Reactions Used in the Pursuit of Drug Candidates. J. Med. Chem. 2011, 54 (10), 3451-3479. https://doi.org/10.1021/jm200187y.

(3) Taylor, R. D.; Maccoss, M.; Lawson, A. D. G. Rings in Drugs. J. Med. Chem. 2014, 57 (14), 5845-5859. https://doi.org/10.1021/jm4017625.

(4) Leeson, P. D.; Springthorpe, B. The Influence of Drug-like Concepts on DecisionMaking in Medicinal Chemistry. Nat. Rev. Drug Discov. 2007, 6 (11), 881-890. https://doi.org/10.1038/nrd2445.

(5) Lovering, F.; Bikker, J.; Humblet, C. Escape from Flatland: Increasing Saturation as an Approach to Improving Clinical Success. J. Med. Chem. 2009, 52 (21), 67526756. https://doi.org/10.1021/jm901241e.

(6) Bemis, G. W.; Murcko, M. A. The Properties of Known Drugs. 1. Molecular Frameworks. J. Med. Chem. 1996, 39 (15), 2887-2893. https://doi.org/10.1021/jm9602928.

(7) Brown, D. G.; Gagnon, M. M.; Boström, J. Understanding Our Love Affair with PChlorophenyl: Present Day Implications from Historical Biases of Reagent Selection. J. Med. Chem. 2015, 58 (5), 2390-2405. https://doi.org/10.1021/jm501894t.

(8) Brown, D. G.; Boström, J. Analysis of Past and Present Synthetic Methodologies on Medicinal Chemistry: Where Have All the New Reactions Gone? J. Med. Chem. 2016, 59 (10), 4443-4458. https://doi.org/10.1021/acs.jmedchem.5b01409.

(9) Carey, J. S.; Laffan, D.; Thomson, C.; Williams, M. T. Analysis of the Reactions Used for the Preparation of Drug Candidate Molecules. Org. Biomol. Chem. 2006, 4 (12), 2337-2347. https://doi.org/10.1039/b602413k.

(10) Walters, W. P.; Green, J.; Weiss, J. R.; Murcko, M. A. What Do Medicinal Chemists Actually Make? A 50-Year Retrospective. J. Med. Chem. 2011, 54 (19), 6405-6416. https://doi.org/10.1021/jm200504p.

(11) Galabov, B.; Nalbantova, D.; Schleyer, P. V. R.; Schaefer, H. F. Electrophilic Aromatic Substitution: New Insights into an Old Class of Reactions. Acc. Chem. Res. 2016, 49 (6), 1191-1199. https://doi.org/10.1021/acs.accounts.6b00120.

(12) Rodriguez, R. A.; Pan, C. M.; Yabe, Y.; Kawamata, Y.; Eastgate, M. D.; Baran, P. S. 
Palauchlor: A Practical and Reactive Chlorinating Reagent. J. Am. Chem. Soc. 2014, 136 (19), 6908-6911. https://doi.org/10.1021/ja5031744.

(13) Bartoli, G.; Todesco, P. E. Nucleophilic Substitution. Linear Free Energy Relations between Reactivity and Physical Properties of Leaving Groups and Substrates. Acc. Chem. Res. 1977, 10 (4), 125-132. https://doi.org/10.1021/ar50112a004.

(14) Meisenheimer, J. Ueber Reactionen Aromatischer Nitrokörper. Justus Liebig's Ann. der Chemie 1902, 323 (2), 205-246. https://doi.org/10.1002/jlac.19023230205.

(15) Artamkina, G. A.; Egorov, M. P.; Beletskaya, I. P. Some Aspects of Anionic .Sigma.Complexes. Chem. Rev. 1982, 82 (4), 427-459.

https://doi.org/10.1021/cr00050a004.

(16) Suzuki, A. Cross-Coupling Reactions of Organoboranes: An Easy Way to Construct C-C Bonds (Nobel Lecture). Angew. Chemie - Int. Ed. 2011, 50 (30), 6722-6737. https://doi.org/10.1002/anie.201101379.

(17) Orendt, A. M.; Facelli, J. C.; Radziszewski, J. G.; Horton, W. J.; Grant, D. M.; Michl, J. 13 C Dipolar NMR Spectrum of Matrix-Isolated o-Benzyne- 1, 2 - 13 C 2. J. Am. Chem. Soc. 1996, 118 (4), 846-852. https://doi.org/10.1021/ja953417r.

(18) Bachmann, W. E.; Clarke, H. T. THE MECHANISM OF THE WURTZ-FITTIG REACTION 1. J. Am. Chem. Soc. 1927, 49 (8), 2089-2098.

https://doi.org/10.1021/ja01407a038.

(19) Roberts, J. D.; Simmons, H. E.; Carlsmith, L. A.; Vaughan, C. W. REARRANGEMENT IN THE REACTION OF CHLOROBENZENE-1-C 14 WITH POTASSIUM AMIDE 1. J. Am. Chem. Soc. 1953, 75 (13), 3290-3291. https://doi.org/10.1021/ja01109a523.

(20) Tadross, P. M.; Stoltz, B. M. A Comprehensive History of Arynes in Natural Product Total Synthesis. Chem. Rev. 2012, 112 (6), 3550-3577. https://doi.org/10.1021/cr200478h.

(21) Bhunia, A.; Yetra, S. R.; Biju, A. T. Recent Advances in Transition-Metal-Free Carbon-Carbon and Carbon-Heteroatom Bond-Forming Reactions Using Arynes. Chem. Soc. Rev. 2012, 41 (8), 3140. https://doi.org/10.1039/c2cs15310f.

(22) Kitamura, T.; Yamane, M.; Inoue, K.; Todaka, M.; Fukatsu, N.; Meng, Z.; Fujiwara, Y. A New and Efficient Hypervalent lodine-Benzyne Precursor, (Phenyl)[o(Trimethylsilyl)Phenyl]lodonium Triflate: Generation, Trapping Reaction, and Nature of Benzyne. J. Am. Chem. Soc. 1999, 121 (50), 11674-11679. https://doi.org/10.1021/ja992324x.

(23) Yedulla, V. R.; Pradhan, P.; Yang, L.; Lakshman, M. K. Cycloaddition of Arynes and Cyclic Enol Ethers as a Platform for Access to Stereochemically Defined 1,2Disubstituted Benzocyclobutenes. European J. Org. Chem. 2015, 2015 (4), 750- 
764. https://doi.org/10.1002/ejoc.201403250.

(24) Kitamura, T.; Todaka, M.; Shin-machi, I.; Fujiwara, Y. A Convenient and Efficient Synthesis of Benzotriazoles and Benzisoxazolines Using Anew Hypervalent lodineBenzyne Precursor. Heterocycl. Commun. 1998, 4 (3), 205-216. https://doi.org/10.1515/HC.1998.4.3.205.

(25) Mesgar, M.; Nguyen-Le, J.; Daugulis, O. New Hindered Amide Base for Aryne Insertion into Si-P, Si-S, Si-N, and C-C Bonds. J. Am. Chem. Soc. 2018, 140 (42), 13703-13710. https://doi.org/10.1021/jacs.8b07064.

(26) Yoshida, H.; Mimura, Y.; Ohshita, J.; Kunai, A. Insertion of Arynes into CarbonHalogen Sigma-Bonds: Regioselective Acylation of Aromatic Rings. Chem. Commun. (Camb). 2007, 2 (23), 2405-2407. https://doi.org/10.1039/b701581j.

(27) Yoshida, H.; Watanabe, M.; Ohshita, J.; Kunai, A. Aryne Insertion into $\alpha$ Cyanocarbonyl Compounds: Direct Introduction of Carbonyl and Cyanomethyl Moieties into the Aromatic Skeletons. Tetrahedron Lett. 2005, 46 (39), 67296731. https://doi.org/10.1016/j.tetlet.2005.07.119.

(28) Pintori, D. G.; Greaney, M. F. Insertion of Benzene Rings into the Amide Bond: One-Step Synthesis of Acridines and Acridones from Aryl Amides. Org. Lett. 2010, 12 (1), 168-171. https://doi.org/10.1021/ol902568x.

(29) Hendrick, C. E.; McDonald, S. L.; Wang, Q. Insertion of Arynes into N-Halo Bonds: A Direct Approach to O -Haloaminoarenes. Org. Lett. 2013, 15 (13), 3444-3447. https://doi.org/10.1021/ol401518c.

(30) Truong, T.; Daugulis, O. Divergent Reaction Pathways for Phenol Arylation by Arynes: Synthesis of Helicenes and 2-Arylphenols. Chem. Sci. 2013, 4 (1), 531535. https://doi.org/10.1039/c2sc21288a.

(31) Wang, M.; Huang, Z. Transition Metal-Free N-Arylation of Secondary Amides through lodonium Salts as Aryne Precursors. Org. Biomol. Chem. 2016, 14 (43), 10185-10188. https://doi.org/10.1039/С6OB01649A.

(32) Bergstrom, F. W.; Sturz, H. G.; Tracy, H. W. The Use of the Fused Eutectic of Sodium Amide and Potassium Amide in Organic Syntheses. J. Org. Chem. 1946, 11 (3), 239-246. https://doi.org/10.1021/jo01173a005.

(33) Bunnett, J. F.; Kearley, F. J. Comparative Mobility of Halogens in Reactions of Dihalobenzenes with Potassium Amide in Ammonia. J. Org. Chem. 1971, 36 (1), 184-186. https://doi.org/10.1021/jo00800a036.

(34) Truong, T.; Mesgar, M.; Le, K. K. A.; Daugulis, O. General Method for Functionalized Polyaryl Synthesis via Aryne Intermediates. J. Am. Chem. Soc. 2014, 136 (24), 8568-8576. https://doi.org/10.1021/ja504886x. 
(35) Cho, S.; Wang, Q. Ortho-Difunctionalization of Arynes by LiZnEt2(TMP)-Mediated Deprotonative Zincation/Elimination of Aryl Triflates. Tetrahedron 2018, 74 (26), 3325-3328. https://doi.org/10.1016/j.tet.2018.03.044.

(36) Cho, S.; Wang, Q. 1,2-Difunctionalization of Aryl Triflates: A Direct and Modular Access to Diversely Functionalized Anilines. Org. Lett. 2020, 22 (4), 1670-1674. https://doi.org/10.1021/acs.orglett.0c00320.

(37) Matsumoto, T.; Hosoya, T.; Katsuki, M.; Suzuki, K. New Efficient Protocol for Aryne Generation. Selective Synthesis of Differentially Protected 1,4,5-

Naphthalenetriols. Tetrahedron Lett. 1991, 32 (46), 6735-6736.

https://doi.org/10.1016/S0040-4039(00)93589-5.

(38) Tochtermann, W.; Stubenrauch, G.; Re, K. Darstellung von HexahydrochrysenDerivaten. 1974, 3352, 3340-3352.

(39) Gilman, H.; Gaj, B. J. Coupling Reactions with Some Organolithium Compounds in Tetrahydrofuran. J. Org. Chem. 1957, 22 (4), 447-449. https://doi.org/10.1021/jo01355a606.

(40) Wittig, G.; Pohmer, L. Über Das Intermediäre Auftreten von Dehydrobenzol. Chem. Ber. 1956, 89 (5), 1334-1351. https://doi.org/10.1002/cber.19560890539.

(41) Stiles, M.; Miller, R. G. Decomposition of Benzenediazonium-2-Carboxylate. J. Am. Chem. Soc. 1960, 82 (14), 3802. https://doi.org/10.1021/ja01499a094.

(42) Reynolds, G. A. The Reaction of Organic Azides with Benzyne. J. Org. Chem. 1964, 29 (12), 3733-3734. https://doi.org/10.1021/jo01035a531.

(43) Himeshima, Y.; Sonoda, T.; Kobayashi, H. FLUORIDE-INDUCED 1,2-ELIMINATION OF O -TRIMETHYLSILYLPHENYL TRIFLATE TO BENZYNE UNDER MILD CONDITIONS. Chem. Lett. 1983, 12 (8), 1211-1214. https://doi.org/10.1246/cl.1983.1211.

(44) Kitamura, T.; Yamane, M. (Phenyl)[o-(Trimethylsilyl)Phenyl]lodonium Triflate. A New and Efficient Precursor of Benzyne. J. Chem. Soc. Chem. Commun. 1995, 983 (9), 983. https://doi.org/10.1039/c39950000983.

(45) Takikawa, H.; Nishii, A.; Sakai, T.; Suzuki, K. Aryne-Based Strategy in the Total Synthesis of Naturally Occurring Polycyclic Compounds. Chem. Soc. Rev. 2018, 47 (21), 8030-8056. https://doi.org/10.1039/C8CS00350E.

(46) Dubrovskiy, A. V.; Markina, N. A.; Larock, R. C. Use of Benzynes for the Synthesis of Heterocycles. Org. Biomol. Chem. 2013, 11 (2), 191-218. https://doi.org/10.1039/C2OB26673C.

(47) Atkinson, D.; Sperry, J.; Brimble, M. Improved Synthesis of the Benzyne Precursor 2-(Trimethylsilyl)Phenyl Trifluoromethanesulfonate. Synthesis (Stuttg). 2010, 6, 911-913. https://doi.org/10.1055/s-0029-1218631. 
(48) Medina, J. M.; Mackey, J. L.; Garg, N. K.; Houk, K. N. The Role of Aryne Distortions, Steric Effects, and Charges in Regioselectivities of Aryne Reactions. J. Am. Chem. Soc. 2014, 136 (44), 15798-15805. https://doi.org/10.1021/ja5099935.

(49) Bronner, S. M.; Garg, N. K. Efficient Synthesis of 2-(Trimethylsilyl)Phenyl Trifluoromethanesulfonate: A Versatile Precursor to o -Benzyne. J. Org. Chem. 2009, 74 (22), 8842-8843. https://doi.org/10.1021/jo9020166.

(50) Bartholomäus, R.; Bachmann, J.; Mang, C.; Haustedt, L. O.; Harms, K.; Koert, U. Synthesis of the AB-Ring Pyranolactone Substructure of Granaticin A. European J. Org. Chem. 2013, 2013 (1), 180-190. https://doi.org/10.1002/ejoc.201201279.

(51) Oshiyama, T.; Satoh, T.; Okano, K.; Tokuyama, H. Total Synthesis of Batzelline C and Isobatzelline C. RSC Adv. 2012, 2 (12), 5147-5149. https://doi.org/10.1039/c2ra20604h.

(52) Oshiyama, T.; Satoh, T.; Okano, K.; Tokuyama, H. Total Synthesis of Makaluvamine $A / D$, Damirone B, Batzelline C, Makaluvone, and Isobatzelline C Featuring OnePot Benzyne-Mediated Cyclization-Functionalization. Tetrahedron 2012, 68 (46), 9376-9383. https://doi.org/10.1016/j.tet.2012.09.034.

(53) Akiyama, T.; Imasaki, Y.; Kawmisi, M. Arylation of Tetrazolide With Diaryliodonium Halides: Evidence for Intermediacy of Benzyne. Chem. Lett. 1974, 3 (3), 229-230. https://doi.org/10.1246/cl.1974.229.

(54) Cadogan, J.I.G., Rowley, A.G., Sharp, J.T., Sledzinski, B., Wilson, N. . 1072 J.C.S. Perkin. J. Chem. Soc., Perkin Trans. 1975, 1, 1072-1074.

(55) Graskemper, J. W.; Wang, B.; Qin, L.; Neumann, K. D.; Dimagno, S. G. Unprecedented Directing Group Ability of Cyclophanes in Arene Fluorinations with Diaryliodonium Salts. Org. Lett. 2011, 13 (12), 3158-3161. https://doi.org/10.1021/ol201080c.

(56) Sundalam, S. K.; Nilova, A.; Seidl, T. L.; Stuart, D. R. A Selective C-H Deprotonation Strategy to Access Functionalized Arynes by Using Hypervalent lodine. Angew. Chemie Int. Ed. 2016, 55 (29), 8431-8434. https://doi.org/10.1002/anie.201603222.

(57) Merritt, E. A.; Olofsson, B. Diaryliodonium Salts: A Journey from Obscurity to Fame. Angew. Chemie - Int. Ed. 2009, 48 (48), 9052-9070. https://doi.org/10.1002/anie.200904689.

(58) Zhdankin, V. V.; Stang, P. J. Chemistry of Polyvalent lodine. Chem. Rev. 2008, 108 (12), 5299-5358. https://doi.org/10.1021/cr800332c.

(59) Seidl, T. L.; Sundalam, S. K.; McCullough, B.; Stuart, D. R. Unsymmetrical Aryl(2,4,6-Trimethoxyphenyl)Iodonium Salts: One-Pot Synthesis, Scope, Stability, and Synthetic Studies. J. Org. Chem. 2016, 81 (5), 1998-2009. 
https://doi.org/10.1021/acs.joc.5b02833.

(60) Chun, J. H.; Pike, V. W. Regiospecific Syntheses of Functionalized Diaryliodonium Tosylates via [Hydroxy(Tosyloxy)lodo]Arenes Generated in Situ from

(Diacetoxyiodo)Arenes. J. Org. Chem. 2012, 77 (4), 1931-1938.

https://doi.org/10.1021/jo202517v.

(61) Dohi, T.; Yamaoka, N.; Kita, Y. Fluoroalcohols: Versatile Solvents in Hypervalent lodine Chemistry and Syntheses of Diaryliodonium(III) Salts. Tetrahedron 2010, 66 (31), 5775-5785. https://doi.org/10.1016/j.tet.2010.04.116.

(62) Seidl, T. L.; Stuart, D. R. An Admix Approach to Determine Counter Anion Effects on Metal-Free Arylation Reactions with Diaryliodonium Salts. J. Org. Chem. 2017, 82 (22), 11765-11771. https://doi.org/10.1021/acs.joc.7b01599.

(63) Basu, S.; Sandtorv, A. H.; Stuart, D. R. Imide Arylation with Aryl(TMP)lodonium Tosylates. Beilstein J. Org. Chem. 2018, 14, 1034-1038. https://doi.org/10.3762/BJOC.14.90.

(64) Sandtorv, A. H.; Stuart, D. R. Metal-Free Synthesis of Aryl Amines: Beyond Nucleophilic Aromatic Substitution. Angew. Chemie - Int. Ed. 2016, 55 (51), 15812-15815. https://doi.org/10.1002/anie.201610086.

(65) Gallagher, R. T.; Basu, S.; Stuart, D. R. Trimethoxyphenyl (TMP) as a Useful Auxiliary for in Situ Formation and Reaction of Aryl(TMP)lodonium Salts: Synthesis of Diaryl Ethers. Adv. Synth. Catal. 2020, 362 (2), 320-325. https://doi.org/10.1002/adsc.201901187.

(66) Kwon, Y. Do; Son, J.; Chun, J. H. Chemoselective Radiosyntheses of Electron-Rich [18F]Fluoroarenes from $\operatorname{Aryl}(2,4,6$-Trimethoxyphenyl)Iodonium Tosylates. J. Org. Chem. 2019, 84 (6), 3678-3686. https://doi.org/10.1021/acs.joc.9b00019.

(67) Koseki, D.; Aoto, E.; Shoji, T.; Watanabe, K.; In, Y.; Kita, Y.; Dohi, T. Efficient NArylation of Azole Compounds Utilizing Selective Aryl-Transfer TMP-Iodonium(III) Reagents. Tetrahedron Lett. 2019, 60 (18), 1281-1286.

https://doi.org/10.1016/j.tetlet.2019.04.012.

(68) Neerbye Berntsen, L.; Nova, A.; Wragg, D. S.; Sandtorv, A. H. Cu-Catalyzed N-3Arylation of Hydantoins Using Diaryliodonium Salts. Org. Lett. 2020, 22 (7), 26872691. https://doi.org/10.1021/acs.orglett.0c00642.

(69) Dohi, T.; Ueda, S.; Hirai, A.; Kojima, Y.; Morimoto, K.; Kita, Y. Selective Aryl Radical Transfers into N-Heteroaromatics from Diaryliodonoium Salts with Trimethoxybenzene Auxiliary. Heterocycles 2017, 95 (2), 1272-1284. https://doi.org/10.3987/COM-16-S(S)90.

(70) Sun, D.; Yin, K.; Zhang, R. Visible-Light-Induced Multicomponent Cascade Cycloaddition Involving: N -Propargyl Aromatic Amines, Diaryliodonium Salts and 
Sulfur Dioxide: Rapid Access to 3-Arylsulfonylquinolines. Chem. Commun. 2018, 54 (11), 1335-1338. https://doi.org/10.1039/c7cc09410h.

(71) Wishart, D. S.; Feunang, Y. D.; Guo, A. C.; Lo, E. J.; Marcu, A.; Grant, J. R.; Sajed, T.; Johnson, D.; Li, C.; Sayeeda, Z.; et al. DrugBank 5.0: A Major Update to the DrugBank Database for 2018. Nucleic Acids Res. 2018, 46 (D1), D1074-D1082. https://doi.org/10.1093/nar/gkx1037.

(72) Novel Drug Approvals for 2019 | FDA https://www.fda.gov/drugs/new-drugs-fdacders-new-molecular-entities-and-new-therapeutic-biological-products/noveldrug-approvals-2019 (accessed Jan 11, 2020).

(73) Kim, S.; Chen, J.; Cheng, T.; Gindulyte, A.; He, J.; He, S.; Li, Q.; Shoemaker, B. A.; Thiessen, P. A.; Yu, B.; et al. PubChem 2019 Update: Improved Access to Chemical Data. Nucleic Acids Res. 2019, 47. https://doi.org/10.1093/nar/gky1033.

(74) Sheridan, R. P.; Zorn, N.; Sherer, E. C.; Campeau, L. C.; Chang, C.; Cumming, J.; Maddess, M. L.; Nantermet, P. G.; Sinz, C. J.; O’Shea, P. D. Modeling a Crowdsourced Definition of Molecular Complexity. J. Chem. Inf. Model. 2014, 54 (6), 1604-1616. https://doi.org/10.1021/ci5001778.

(75) Lipinski, C. A.; Lombardo, F.; Dominy, B. W.; Feeney, P. J. Experimental and Computational Approaches to Estimate Solubility and Permeability in Drug Discovery and Development Settings. Adv. Drug Deliv. Rev. 1997, 23 (1-3), 3-25. https://doi.org/10.1016/S0169-409X(96)00423-1.

(76) Sheridan, R. P.; Maiorov, V. N.; Holloway, M. K.; Cornell, W. D.; Gao, Y. D. Druglike Density: A Method of Quantifying the "Bindability" of a Protein Target Based on a Very Large Set of Pockets and Drug-like Ligands from the Protein Data Bank. J. Chem. Inf. Model. 2010, 50 (11), 2029-2040. https://doi.org/10.1021/ci100312t.

(77) Sheridan, R. P. The Centroid Approximation for Mixtures: Calculating Similarity and Deriving Structure-Activity Relationships. J. Chem. Inf. Comput. Sci. 2000, 40 (6), 1456-1469. https://doi.org/10.1021/ci000045j.

(78) Zhang, Z.; Wu, X.; Han, J.; Wu, W.; Wang, L. Direct Arylation of Tertiary Amines via Aryne Intermediates Using Diaryliodonium Salts. Tetrahedron Lett. 2018, 59 (18), 1737-1741. https://doi.org/10.1016/j.tetlet.2018.03.067.

(79) Chen, H.; Han, J.; Wang, L. Diels-Alder Cycloadditions of N -Arylpyrroles via Aryne Intermediates Using Diaryliodonium Salts. Beilstein J. Org. Chem. 2018, 14, 354363. https://doi.org/10.3762/bjoc.14.23.

(80) Yoshida, H.; Shirakawa, E.; Honda, Y.; Hiyama, T. Addition of Ureas to Arynes: Straightforward Synthesis of Benzodiazepine and Benzodiazepine Derivatives. Angew. Chemie - Int. Ed. 2002, 41 (17), 3247-3249. 
https://doi.org/10.1002/1521-3773(20020902)41:17<3247::AID-

ANIE3247>3.0.CO;2-P.

(81) Safety Issues in the Scale-up of Chemical Reactions. 2013.

(82) Ochiai, M.; Sato, K.; Takino, T. Association and Dissociation of ( Z ) - ( -

Bromoalkenyl ) - ( Phenyl ) lodonium Bromide in Chloroform Solution : Detection of Vinyl- 3-Iodane Dimer in Solution. Tetrahedron Lett. 1999, 40, 1559-1562.

(83) Ghosh, R.; Lindstedt, E.; Jalalian, N.; Olofsson, B. Room Temperature, Metal-Free Arylation of Aliphatic Alcohols. ChemistryOpen 2014, 3 (2), 54-57.

https://doi.org/10.1002/open.201402006.

(84) Lindstedt, E.; Stridfeldt, E.; Olofsson, B. Mild Synthesis of Sterically Congested Alkyl Aryl Ethers. Org. Lett. 2016, 18 (17), 4234-4237. https://doi.org/10.1021/acs.orglett.6b01975.

(85) Ahmed, G.; Breslin, H. J. .; Burke, J.; Curry, M. A.; Diebold, J. L.; Dorsey, B. D.; Dugan, B. J.; Feng, D.; Gingrich, D. E.; Guo, T.; et al. US008552186B2, 2013.

(86) Picazo, E.; Houk, K. N.; Garg, N. K. Computational Predictions of Substituted Benzyne and Indolyne Regioselectivities. Tetrahedron Lett. 2015, 56 (23), 35113514. https://doi.org/10.1016/j.tetlet.2015.01.022.

(87) Meng, H.; Wen, L.; Xu, Z.; Li, Y.; Hao, J.; Zhao, Y. Nonafluoro- Tert-Butoxylation of Diaryliodonium Salts. Org. Lett. 2019, 21 (13), 5206-5210.

https://doi.org/10.1021/acs.orglett.9b01813.

(88) Miura, T.; Morimoto, M.; Murakami, M. Copper-Catalyzed Amination of Silyl Ketene Acetals with N-Chloroamines. Org. Lett. 2012, 14 (20), 5214-5217. https://doi.org/10.1021/ol302331k.

(89) Sirois, J. J.; DeBoef, B. Transition-Metal Free Umpolung Carbon-Nitrogen versus Carbon-Chlorine Bond Formation. Tetrahedron Lett. 2015, 56 (41), 5610-5612. https://doi.org/10.1016/J.TETLET.2015.08.053.

(90) Fulmer, G. R.; Miller, A. J. M.; Sherden, N. H.; Gottlieb, H. E.; Nudelman, A.; Stoltz, B. M.; Bercaw, J. E.; Goldberg, K. I. NMR Chemical Shifts of Trace Impurities: Common Laboratory Solvents, Organics, and Gases in Deuterated Solvents Relevant to the Organometallic Chemist. Organometallics 2010, 29 (9), 21762179. https://doi.org/10.1021/om100106e.

(91) Sokolovs, I.; Lubriks, D.; Suna, E. Copper-Catalyzed Intermolecular C-H Amination of (Hetero)Arenes via Transient Unsymmetrical ^3-lodanes. J. Am. Chem. Soc. 2014, 136 (19), 6920-6928. https://doi.org/10.1021/ja502174d.

(92) A. Merritt, E.; M. T. Carneiro, V.; F. Silva, L.; Olofsson, B. Facile Synthesis of Koser's Reagent and Derivatives from lodine or Aryl lodides. J. Org. Chem. 2010, 
75 (21), 7416-7419. https://doi.org/10.1021/jo101227j.

(93) Ochiai, M.; Toyonari, M.; Nagaoka, T.; Chen, D. W.; Kida, M. Stereospecific Synthesis of Vinyl(Phenyl)Iodonium Tetrafluoroborates via Boron-lodane Exchange of Vinylboronic Acids and Esters with Hypervalent Phenyliodanes. Tetrahedron Lett. 1997, 38 (38), 6709-6712. https://doi.org/10.1016/S00404039(97)01571-2.

(94) Walker, S. D.; Barder, T. E.; Martinelli, J. R.; Buchwald, S. L. A Rationally Designed Universal Catalyst for Suzuki-Miyaura Coupling Processes. Angew. Chemie - Int. Ed. 2004, 43 (14), 1871-1876. https://doi.org/10.1002/anie.200353615.

(95) Surry, D. S.; Buchwald, S. L. Dialkylbiaryl Phosphines in Pd-Catalyzed Amination: A User's Guide. Chem. Sci. 2011, 2 (1), 27-50. https://doi.org/10.1039/c0sc00331j.

(96) Sheldrick, G. M. A Short History of SHELX. Acta Crystallogr. Sect. A Found. Crystallogr. 2008, 64 (1), 112-122. https://doi.org/10.1107/S0108767307043930.

(97) Lindstedt, E.; Reitti, M.; Olofsson, B. One-Pot Synthesis of Unsymmetric Diaryliodonium Salts from lodine and Arenes. J. Org. Chem. 2017, 82 (22), 1190911914. https://doi.org/10.1021/acs.joc.7b01652.

(98) Sapountzis, I.; Lin, W.; Fischer, M.; Knochel, P. Preparation of Polyfunctional Arynes via 2-Magnesiated Diaryl Sulfonates. Angew. Chemie Int. Ed. 2004, 43 (33), 4364-4366. https://doi.org/10.1002/anie.200460417.

(99) Sarkar, D.; Melkonyan, F. S.; Gulevich, A. V; Gevorgyan, V. Twofold Unsymmetrical C-H Functionalization of PyrDipSi-Substituted Arenes: A General Method for the Synthesis of Substituted meta-Halophenols. Angew. Chemie Int. Ed. 2013, 52 (41), 10800-10804. https://doi.org/10.1002/anie.201304884.

(100) Carolina, A.; Muraca, A.; Raminelli, C. Exploring Possible Surrogates for Kobayashi's Aryne Precursors. 2020. https://doi.org/10.1021/acsomega.9b03989.

(101) Yoshimura, A.; Fuchs, J. M.; Middleton, K. R.; Maskaev, A. V.; Rohde, G. T.; Saito, A.; Postnikov, P. S.; Yusubov, M. S.; Nemykin, V. N.; Zhdankin, V. V. Pseudocyclic Arylbenziodoxaboroles: Efficient Benzyne Precursors Triggered by Water at Room Temperature. Chem. - A Eur. J. 2017, 23 (66), 16738-16742.

https://doi.org/10.1002/chem.201704393. 